\title{
Von der Wirkung zur Wertung
}

Formal-ästhetische Werte in den Diskussionen des Ingeborg-Bachmann-Wettbewerbs 1999-2009

Dissertation zur Erlangung des philosophischen Doktorgrades an der

Philosophischen Fakultät der Georg-August-Universität Göttingen

vorgelegt von Kathrin Rahmann

aus Detmold (Lippe)

Göttingen 2017 



\section{Dank}

Ohne die Unterstützung zahlreicher Helfer hätte diese Arbeit nicht entstehen können. Ihnen möchte ich an dieser Stelle von Herzen danken.

Meine Doktormutter Simone Winko hat dieses Projekt über sieben Jahre hinweg begleitet, mir alle Freiheiten gelassen und an den entscheidenden Stellen wichtige Impulse gegeben. Ich möchte ihr ganz besonders dafür danken, dass sie mir die Möglichkeit gegeben hat, dieses Projekt von allem Anfang an und über den gesamten Zeitraum hinweg eigenständig zu entwickeln und an meinen Aufgaben zu wachsen. Ich danke ihr für dieses Vertrauen, für den konstruktiven Austausch und ihren fachlichen Rat, für die sie immer zur Verfügung stand. Eine bessere Betreuung hätte ich mir nicht wünschen können. Danken möchte ich in diesem Zusammenhang auch meiner Zweitbetreuerin Claudia Stockinger, die von Anfang an vorbehaltlos für das Projekt zur Verfügung stand.

Unverzichtbar für diese Arbeit war der sachkundige und geduldige technische Support von Arnd Tretbar, der mir viele Arbeitsgänge erleichtert hat.

Für ihre schier unendliche Geduld beim Korrekturlesen der Arbeit und des Korpus danke ich: Petra Balzer, Sandra Debot, Wiebke Rahmann und Arnd Tretbar.

Diese Arbeit ist durch ein Promotionsstipendium der Konrad-Adenauer-Stiftung gefördert worden. Für diese Förderung bin ich der Stiftung sehr dankbar. Ich danke auch Addy Balzer und Arnd Tretbar für ihre großzügige Unterstützung und dafür, dass sie die Hoffnung nicht aufgegeben haben.

Bettina Bock und Sandra Debot standen mir mit fachlichem und nicht fachlichem Rat immer zur Seite. Danke! 



\section{Inhalt}

I Kontexte 1

1 Einleitung 1

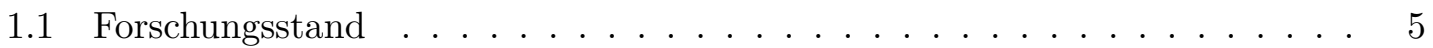

1.2 Vorhaben und Erkenntnisziele . . . . . . . . . . . . . . . . 16

1.3 Leseleitfaden . . . . . . . . . . . . . . . . . . . . . . . . 18

2 Anlage der Arbeit und Vorgehensweise 20

2.1 Auswahl und Eigenschaften des Textkorpus . . . . . . . . . . . . . . . 20

2.2 Korpuserfassung und Analysemethode . . . . . . . . . . . . . . . . 21

2.2 .1 Transkription . . . . . . . . . . . . . . . 24

2.2 .2 Analyse eines einzelnen Jahrgangs . . . . . . . . . . . . . . . 25

2.2.3 Erfassung und Analyse von Problemkategorien . . . . . . . . . . 26

2.2.4 Stichwortgeleitete Analyse des Korpus . . . . . . . . . . . . . 26

2.2.5 Detailanalysen von Einzeldiskussionen . . . . . . . . . . . . . 27

2.2 .6 Überprüfung . . . . . . . . . . . . . . . . . . . . . . . 27

2.3 Schwachstellen der Vorgehensweise . . . . . . . . . . . . . . . . . . 28

3 Über den Ingeborg-Bachmann-Wettbewerb 29

3.1 Literaturpreise als Wertungs- und Kanonisierungsinstanzen . . . . . . . . 30

3.2 Der Ingeborg-Bachmann-Wettbewerb . . . . . . . . . . . . . . . . . . 32

3.2.1 Weitere verliehene Preise . . . . . . . . . . . . . . . 34

$3.2 .2 \quad$ Die Jury . . . . . . . . . . . . . . . . . . . . . . . . . . 35

3.2 .3 Die Autoren . . . . . . . . . . . . . . . . . . . . . . 36

3.3 Zusammenfassung . . . . . . . . . . . . . . . . . . 37 
4.1 Werte . . . . . . . . . . . . . . . . . . . 39

4.2 Konstruktivistisches Wertverständnis . . . . . . . . . . . . . . . . . . 41

4.3 Wertungen und die Feldtheorie Pierre Bourdieus . . . . . . . . . . . . . . 42

4.4 Der kognitionspsychologische Ansatz von Benno Belke und Helmut Leder . 48

4.5 Leselust als „blinder Fleck" der Wertungsforschung . . . . . . . . . . . . . 51

4.6 Die Spielarten von „Lust" am literarischen Text bei Thomas Anz . . . . . . 55

4.7 Subjektivität, Intersubjektivität und Objektivität von Wertungen . . . . 58

4.8 Wertungstheorien der Literaturwissenschaft . . . . . . . . . . . . . . . . . 61

4.8.1 Wertungen ausdrücken. Verbale und motivationale Wertungen . . . 61

4.8.2 Drei Modelle der Bewertung von Literatur . . . . . . . . . . . . . . 62

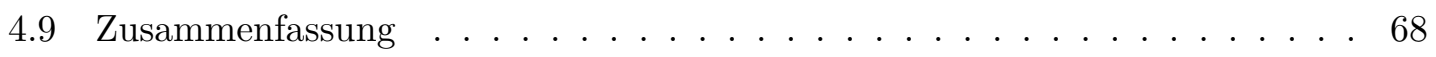

5 Die Kommunikationssituation beim Ingeborg-Bachmann-Wettbewerb 70

5.1 Diskursaspekte . . . . . . . . . . . . . . . . . . 70

5.2 Rahmenbedingungen der Kommunikation . . . . . . . . . . . . . 70

5.2.1 Vorbereitungsmöglichkeiten und Diskussionsimpuls . . . . . . . . 71

5.2 .2 Öffentlichkeit und Mehrfachadressiertheit . . . . . . . . . . . 72

5.2 .3 Interaktion und Feedback . . . . . . . . . . . . . . . 73

5.2 .4 Redezeit und Rederecht . . . . . . . . . . . . . . . . . . . 74

5.2.5 Intention und Zielgerichtetheit . . . . . . . . . . . . 75

5.3 Mündlichkeit . . . . . . . . . . . . . . . . . . . . . 75

5.3.1 Konstitutivität und Prozessualität . . . . . . . . . . 77

5.3 .2 Interaktivität . . . . . . . . . . . . . . . 78

5.3 .3 Methodizität und Pragmatizität . . . . . . . . . . 78

5.4 Aspekte der besonderen Intention . . . . . . . . . . . . . . . . . 80

5.5 Zusammenfassung . . . . . . . . . . . . . . . . 81 
6 Autor, Leser, literarischer Text und Literaturkritik aus Sicht der Juroren

6.1 Aussagen der Juroren über Maßstäbe der Kritik . . . . . . . . . . . . . . . . 84

6.2 Der Literarischer Text aus Sicht der Jury . . . . . . . . . . . . . . . 86

6.3 Der Autor als Bürge für die Textqualität und das „richtige“ Verhältnis zur Wirklichkeit . . . . . . . . . . . . . . . . . . 88

6.4 Die Rolle des Lesers aus Perspektive der Jury . . . . . . . . . . . . . . . . . 92

6.5 Zusammenfassung . . . . . . . . . . . . . . . . . . 94

$\begin{array}{lll}7 & \text { Gute Texte aus der Perspektive des Creative Writing } & 97\end{array}$

7.1 Die Normativität des Creative Writing . . . . . . . . . . . . . . . . 97

7.2 Auswahl der Creative-Writing-Handbücher . . . . . . . . . . . . . . . . . 99

7.3 Zielgruppe der Creative-Writing-Handbücher f . . . . . . . . . . . . . 99

7.4 Ziele der Creative-Writing-Anleitungen . . . . . . . . . . . . . . . . . 101

7.5 Aufbau der Creative-Writing-Handbücher . . . . . . . . . . . . . . . . 102

7.6 Ratschläge und Anweisungen für erzählende Literatur . . . . . . . . . . . 103

7.7 Universelle Eigenschaften von guten Texten . . . . . . . . . . . . . . . 106

8 Exkurs: Textqualität in Textlinguistik und linguistischer Leseforschung109

8.1 Textualität nach R. de Beaugrande und W. U. Dressler . . . . . . . . . . 109

8.2 Leserpsychologie . . . . . . . . . . . . . . . . . . . . . . . . 112

8.3 Zusammenfassung . . . . . . . . . . . . . . . . . . . . 113

$\begin{array}{lr}\text { II Stichwortgeleitete Analyse } & 115\end{array}$

9 Wertungen und Werte in den stichwortgeleiteten Analysen 115

9.1 Ausgangslage . . . . . . . . . . . . . . . . . . . . . . . 115

9.2 Vorgehen bei der Analyse . . . . . . . . . . . . . . . . . . . . 118

9.3 Die verdeckte Ordnung: Textwirkungen im Spiegel formal-ästhetischer Werte121 
10.1 Orientierung als Textwirkung . . . . . . . . . . . . . . . . . 124

10.2 Kohärenz . . . . . . . . . . . . . . . . . . . . . . . . . 124

10.2.1 Explizite Formulierungen des Wunsches nach Verstehen . . . . . . . 130

10.2.2 Passungsverhältnisse - Stimmigkeit und Angemessenheit . . . . . . . 133

10.2 .3 Zusammenfassung . . . . . . . . . . . . . . . . 146

10.3 Sprache und Form . . . . . . . . . . . . . . . . . . 147

10.3 .1 Gestaltetheit . . . . . . . . . . . . . . . 147

10.3 .2 Präzision . . . . . . . . . . . . . . . 163

10.3 .3 Dichte . . . . . . . . . . . . . . . . 170

$\begin{array}{lr}11 \text { Aktivierung } & 176\end{array}$

11.1 Aktivierung als Textwirkung . . . . . . . . . . . . . 176

11.2 Offenheit . . . . . . . . . . . . . . . . . . . . 182

11.2.1 Offenheit als Angebot an den Leser . . . . . . . . . . . . . . . . . 183

11.2.2 Der Erzählmodus des Showing . . . . . . . . . . . . . . . . 187

11.2.3 Überdeterminiertheit . . . . . . . . . . . . . . . . . . . . . . . . . 191

11.2.4 Zusammenfassung . . . . . . . . . . . . . . . . . 194

11.3 Lebendigkeit, Anschaulichkeit und Akzeptanz (Figur, Erzähler, Perspektive) 195

11.3.1 Die Bedeutung von Figuren und Erzähler für die Textwirkung . . . . 195

11.3.2 Lebendigkeit und Plastizität als Bewertungskriterien für literarische Figuren . . . . . . . . . . . . . . . 200

11.3.3 Erzähler und Erzählperspektive . . . . . . . . . . . . . . . . 204

11.3.4 Die Wohlwollende Neutralität des Erzählers . . . . . . . . . . 206

11.3.5 Zusammenfassung . . . . . . . . . . . . . . . . 210

12 Originalität

12.1 Der Wert Originalität . . . . . . . . . . . . . . . . . . . . . 214

12.1.1 Originalität als Innovation . . . . . . . . . . . . . . . . . 217 
12.1.2 Originalität im Konflikt mit Lesegenuss . . . . . . . . . . . . . 221

12.1.3 Der „eigene Ton“ . . . . . . . . . . . . . . . . . . . 222

12.1.4 "Mut" und "Risiko" . . . . . . . . . . . . . . 225

12.1.5 Konventionalität . . . . . . . . . . . . . . . 228

12.1.6 Nachahmung erfolgreicher Muster . . . . . . . . . . . . 233

12.1.7 Originalität als Selbstzweck . . . . . . . . . . . . 235

12.1.8 Zusammenfassung . . . . . . . . . . . . . . . . . 237

$\begin{array}{ll}\text { III Detailanalysen } & 239\end{array}$

13 Ute-Christine Krupp: „Köln-Tokio“ (2001) 239

13.1 Transkript der Diskussion . . . . . . . . . . . . . . . 239

13.2 Analyse der Diskussion . . . . . . . . . . . . . . . . . . 244

13.3 Zusammenfassung . . . . . . . . . . . . . . . . 250

14 Kathrin Passig: „Sie befinden sich hier“ (2006) 252

14.1 Transkript der Diskussion . . . . . . . . . . . . . . . . . . 252

14.2 Analyse der Diskussion . . . . . . . . . . . . . . . 257

14.3 Zusammenfassung . . . . . . . . . . . . . . . . 263

15 Katrin de Vries: „Die Lust am Walde“ (2003) 265

15.1 Transkript der Diskussion . . . . . . . . . . . . . . . 265

15.2 Analyse der Diskussion . . . . . . . . . . . . . . . . 270

15.3 Zusammenfassung . . . . . . . . . . . . . . . . . . . . . 279

16 Nikolai Vogel: „Plug in“ (2005) 282

16.1 Transkript der Diskussion . . . . . . . . . . . . . . . . . 282

16.2 Analyse der Diskussion . . . . . . . . . . . . . . . . . . 288

16.3 Zusammenfassung . . . . . . . . . . . . . . . . . 297 
17 Inka Parei (2003)

17.1 Transkript der Diskussion . . . . . . . . . . . . . . . . . 299

17.2 Analyse der Diskussion . . . . . . . . . . . . . . . . . . . . . . . . 304

17.3 Zusammenfassung . . . . . . . . . . . . . . . . . . 313

18 Björn Kern: „Eine halbe Stunde noch“ (2007) 314

18.1 Transkript der Diskussion . . . . . . . . . . . . . . . . . . . 314

18.2 Analyse der Diskussion . . . . . . . . . . . . . . . . . . . . 321

18.3 Zusammenfassung . . . . . . . . . . . . . . . . . 330

19 Andera Winkler: „Aus dem Gras“ (2009) 332

19.1 Transkript der Diskussion . . . . . . . . . . . . . . . . 332

19.2 Analyse der Diskussion . . . . . . . . . . . . . . . . 336

19.3 Zusammenfassung . . . . . . . . . . . . . . . . . . . . . 342

20 Fazit

344 


\title{
Teil I
}

\section{Kontexte}

\section{$1 \quad$ Einleitung}

\begin{abstract}
Und es kann ja auch nicht sein, dass wir dann zu einer Literatur kommen, die, weil sie strukturell richtig ist, unendlich langweilt, und zwar alle. [...] Das ist keine Geschmacksangelegenheit. (2001 Krupp, 18:22 Schindel)

Also „langweilig“ ist immer ein Kriterium von Reich-Ranicki und „langweilig“ ist einfach kein Kriterium für Literatur. Das ist kein Kriterium! [Heiterkeit] (1999 Seidenauer, 22:22 Bachmann)
\end{abstract}

So unterschiedlich können Werte eingeschätzt werden. Warum werden manche Texte sehr geschätzt, andere schnell vergessen, wiederum andere verachtet? Und welche Rolle spielt der Text selbst in der Bewertung? Welche Rolle spielt seine spezifisch künstlerische, formale Beschaffenheit? Ist die Form des Textes überhaupt ein Kriterium? Ist Langeweile ein Kriterium? Ist die Form des Textes das Kriterium schlechthin? Ist Langeweile „nur“ ein Geschmacksurteil? Ist Langeweile unprofessionell?

Die Literaturwissenschaft muss sich solche Fragen nicht nur gefallen lassen, sie sollte sie sich stellen, sich den wissenschaftlichen Herausforderungen stellen, die mit ihnen verbunden sind. Wenn von Interessierten die Frage gestellt wird, warum Bob Dylan der Nobelpreis zugesprochen wurde, sollte ein Literaturwissenschaftler, mindestens einer, der sich mit der Literatur des 20. und 21. Jahrhunderts befasst, Antworten geben können. Nicht unbedingt die eine gültige Antwort, aber wenigstens doch Ansätze zu einer Antwort. Aus ihrem aktuellen Selbstverständnis als einer Wissenschaft heraus, die Kriterien wie „Systematik, Methodik, Objektivität und intersubjektive Nachprüfbarkeit“ (Allkemper/Eke 2007, 15) genügen möchte, braucht sich die Literaturwissenschaft nicht veranlasst zu fühlen, Normen für die Bewertung von Literatur aufzustellen. Es handelt sich schließlich um Ansprüche einer deskriptiven Forschung. Es ist aber ihre Aufgabe, Auskunft darüber zu geben, wie die Bewertung von Literatur funktioniert. Es ist ihre Aufgabe, alles zu beschreiben, was mit Literatur und dem Umgang mit ihr zu tun hat, in den Worten S. J. Schmidts (1980, 19), „Texte im Gesamtzusammenhang von auf sie bezogenen Handlungen, Handlungsketten, Objekten, Sachverhalten usw. [zu] erforschen“. Dabei steht sie vor einer schwierigen Aufgabe, denn die Bewertung von Literatur lässt sich nicht mit dem Sammeln von möglichen oder nötigen Wertmaßstäben und Textqualitäten abhandeln, und das nicht nur, weil solche Wertmaßstäbe nirgends verzeichnet sind und weil kaum eine Wertung idealtypisch 
formuliert wird. „Auf der Grundlage des Maßstabs Originalität bewerte ich diesen Text als nicht geglückt“", ist eine Formulierung, die man kaum finden wird. Das liegt nicht nur daran, dass Bewertungen von Literatur neben der wertenden Funktion auch noch ganz andere Funktionen haben: unterhalten, informieren, überzeugen (vgl. Anz 2007, 196; Anz 1990, 425). Literarische Texte stehen darüber hinaus immer auch in einem sozialen Raum. Schon bevor der Leser ein Buch überhaupt zu lesen beginnt, wird er mit Einschätzungen dieses Textes konfrontiert; oft ist eine Bewertung durch eine andere Person sogar der Auslöser für die Lektüre, sei es die Empfehlung eines Freundes, sei es eine Besprechung in den Medien. Und sogar bevor ein Buch überhaupt erscheint, durchläuft es Bewertungsprozesse. Es wird vom Lektor begutachtet und mit Blick auf eine „Verbesserung“ im Sinne des Verlages überarbeitet. Es wird für den Verkauf mit Metatexten versehen, u.a. mit dem Klappentext, mit Ankündigungen in Verlagsprogrammen, mit einer Präsentation des Autors. Der literarische Text wird so in einen konventionalisierten Verarbeitungs- und Vermittlungsprozess überführt. Er wird „,gesellschaftsfähig“ gemacht. Ein großer Teil der Wertungen in diesem Prozess ist dem späteren Rezipienten gar nicht zugänglich (vgl. Heydebrand/Winko 2008, 225).

Aber auch der Leser selbst bringt ein je spezifisches Voraussetzungssystem mit: eine Biografie und eine persönliche wie auch schichtgeprägte Lesebiografie (vgl. Schneider 2009). Ob er Mann oder Frau, Banker, Lehrer oder Müllmann ist, kann das Lektüreverhalten ebenso beeinflussen wie Erfahrungen, die er zuvor mit Texten gemacht hat, welche Texte er gelesen hat und wie seine Lektüre in seinem sozialen Umfeld aufgenommen wurde. Jeder Leser ist geprägt von gesellschaftlichen Normen, Konventionen und sozialen Leitbildern, derer er sich während seiner Lektüre und durch seine Lektüre möglicherweise vergewissern möchte, ohne sich dessen bewusst zu sein. Auch seine Wahrnehmung ist in einer spezifischen Weise geschult. Was dem einen Leser mühselig zu lesen erscheint, erfüllt einen anderen mit Freude, weil es sich ihm mühelos erschließt. Und nicht zuletzt sind auch die Bewertungen selbst Teil eines kommunikativen Prozesses, in dem etwas erreicht werden soll. Die Reaktion oder antizipierte Reaktion desjenigen, demgegenüber die Wertung geäußert wird, wirkt zurück auf das Wertungsverhalten, denn der Wertende sucht möglicherweise Anerkennung, Komplizenschaft oder einen sozialen Vorteil. Kurz gesagt, Leser ist nicht gleich Leser.

Und der Text selbst? Der Text steht inmitten dieses Gefüges aus individuellen, gesellschaftlichen, kognitiven und kommunikativen Faktoren, und man kann zu Recht fragen, welche Rolle der Text überhaupt spielen kann, sind sich Leseforschung wie Literaturwissenschaft 
doch weitgehend einig darüber, dass der „Text im Kopf“ (Fix 2003, 80 f.), der bei jedem Leser im Verlauf der Lektüre als „mentales Modell“ (Christmann/Groeben 1999, 170) entsteht, keine eins zu eins Übertragung eines Codes, sondern eine Konstruktion ist, die von vielen Kontextfaktoren abhängt. Diese Erkenntnis, ergänzt um die Annahme, dass Wissen - Werte eingeschlossen - „nicht Erkenntnissicherung zeitloser, ontologischer Fakten, sondern ein sozial verhandeltes Gut der Vergesellschaftung, das Resultat von Vereinbarungen auf der Grundlage historischer, gegenseitiger Zusagen [ist]" (Spitzmüller/Warnke 2011, 41), lassen zunächst einmal darauf schließen, dass der Text als Bezugsgröße eher kaleidoskopische Qualität hat. Der Text ist in dieser Perspektive reiner Stimulus. Wahrnehmungsapparat und soziale Interaktion machen aus diesem Stimulus das ausfransende, komplexe, wandelbare Konstrukt Text, das sich unter neuen Bedingungen ganz neu zusammensetzen kann. Insbesondere für die Literaturwissenschaft, deren Status als Wissenschaft davon abhängt, dass literarische Texte besondere Texte sind, die nach eigenen Regeln funktionieren, ist die formale Beschaffenheit des literarischen Textes als eine an ihm feststellbare Größe allerdings von existenzieller Bedeutung (vgl. Engel 2007, 32). Gerade deswegen bildet die Rolle der (künstlerischen) Form des Textes, seiner spezifischen Beschaffenheit als (künstlerischer) Text, einen Knackpunkt in der Wertungsforschung. Der Text ist zunächst Ausgangspunkt der Lektüre und Bezugspunkt aller Aussagen, die über ihn getroffen werden. Was immer über ihn gesagt wird, sollte in einem nachvollziehbaren Verhältnis zum Text stehen. „Faktisch scheinen wir uns einig zu sein“, bemerkt Ricarda Schmidt (2007, 21), "daß ein Werturteil auch auf analytisch festgehaltenen, empirisch nachprüfbaren Textmerkmalen beruhen muss“. Gerade Literaturwissenschaftler dringen darauf, dass „[d]er Akt der Wertung, sofern er denn nachvollziehbar und mehr als rein subjektive Geschmacksäußerung sein soll“ (Blatnik 2003, 26), begründet werden muss. Als unstrittig darf wohl gelten, dass der literarische Text den Ausgangspunkt für die Lektüre bildet und dass dieser Text zunächst einmal schwarz auf weiß für alle Leser dasselbe Verarbeitungsangebot macht (vgl. Fix 2003). Es gibt den Text, und obwohl er rezipientenbezogen, offen, prozessual und vage ist, muss das nicht dazu führen, dass die Beschaffenheit des Textes als Forschungsgegenstand ihre Bedeutung verliert (Fix 2003, 80). Damit soll nicht geleugnet werden, dass die Interpretation und Bewertung von literarischen Texten auch von den „unwritten rules of the literary game“ (Fish 1980, 343) abhängt. Sowohl das Lesen als auch die begleitenden Handlungen wie Interpretieren, Bewerten und Einordnen sind ungeheuer vielschichtige Prozesse. Je nachdem, mit welcher Fragestellung diesen Prozessen begegnet wird, fallen die Befunde unterschiedlich aus. Im Rahmen die- 
ser Arbeit wird davon ausgegangen, dass sowohl textuelle als auch kognitive und soziale Aspekte in der Wahrnehmung von Literatur eine Rolle spielen. Gegenüber Haltungen wie der, „dass es letztlich keine wirklich festzumachenden Merkmale literarischer Qualität in der Literatur gibt" (Grube 2014, 9, Fußnote 8), soll aber immerhin die Position stark gemacht werden, dass literarische Texte, auch kanonische, deswegen noch lange keine willkürlich zusammengewürfelten Schriftstücke sein müssen. Mag es keine „festzumachenden Merkmale literarischer Qualität" geben, so könnte es immerhin Merkmale geben, die die Attraktivität fördern. Im Rahmen dieser Arbeit wird die These vertreten, dass die Beschaffenheit literarischer Texte nicht vollkommen bedeutungslos ist. Die Frage nach den tatsächlich vorhandenen Eigenschaften will diese Arbeit allerdings gar nicht stellen, sondern vielmehr die Frage nach den wahrgenommenen Eigenschaften. Vorausgesetzt werden soll jedoch, dass Wahrnehmungen nicht willkürlich sind, sondern dass sie sich in der Regel in einem nachvollziehbaren Verhältnis zum Stimulus Text befinden. Gibt es also formale und sprachliche Eigenschaften eines Textes, die ihn im Auge des Lesers geeigneter machen, einen Leseeindruck hervorzurufen, der zu einer positiven Bewertung führt? Gibt es Eigenschaften, die für eine Textbewertung argumentativ wichtig sind oder ist es so, dass zwar die Textwahrnehmung durch die formale Beschaffenheit gesteuert wird, diese Eigenschaften aber für die Argumentation einer Wertung unerheblich bleiben?

Die Antworten der Literaturwissenschaftler, die sich mit diesen Fragen beschäftigt haben, könnten kontroverser nicht sein. Studien, die zu belegen versuchen, dass als wertvoll eingestufte Texte formale Eigenschaften teilen (Neuhaus 2002; van Peer 1998; Bloom 1994), stehen solchen gegenüber, die argumentieren, dass formal-ästhetische Eigenschaften unbedeutend seien, weil letztlich in der Bewertung von Literatur gesellschaftliche Positionen ausgehandelt würden, die eher mit Macht, Konventionen und Tabus zu tun hätten, als mit der Beschaffenheit der Texte selber (Grube 2014; Bourdieu 2001; Hassan 2001; Guillory 1995). Dazwischen gibt es solche Stimmen, die auch diese Arbeit inspiriert haben, die die Vermutung aussprechen, es sei wahrscheinlich, dass formal-ästhetischen Eigenschaften einer unter mehreren Bezugspunkten für Wertungen seien, es sei die Aufgabe der Literaturwissenschaft, normative „Altlasten“ abzuwerfen und deskriptive Verfahren zu entwickeln, um herauszufinden, welche Eigenschaften dies sind (Buck 2011; Bortolussi et al. 2008; van Peer 2008; Winko 2002). Buck (2011, 33), die grundsätzlich der konstruktivistischen Position anhängt, bemerkt, dass daraus ,selbstverständlich nicht folgen [darf], dass Texte im Bewertungsprozess keine Rolle spielen“.

Die große Spannbreite an Aussagen über die mögliche Rolle von Texteigenschaften bei 
der und für die Bewertung liegt auch in einem methodischen Problem begründet. Was Spitzmüller/Warnke $(2011,26)$ für die Diskurslinguistik beobachten, gibt es auch in der Literaturwissenschaft: eine große Tradition der Introspektion und Hermeneutik, die auf neuere Ansprüche wissenschaftlicher Arbeit trifft:

Dass man wissenschaftliche Aussagen datenorientiert trifft, scheint eine Selbstverständlichkeit zu sein, ist es aber in der Linguistik gerade nicht, was einerseits mit der philologisch-interpretativen Tradition des Faches zu tun hat und andererseits und vor allem mit dem so genannten „Introspektionsprinzip“ der Generativen Grammatik, wonach Urteile über die Grammatikalität durch Befragung der eigenen Sprachkompetenz hinreichend möglich sind.

Aus der Perspektive der Selbstbeobachtung liegt es nahe, dass auch formale textuelle Eigenschaften die Wertung mit bedingen. Eine solche Selbstbeobachtung gibt wichtige Hinweise, sie weist vielfach in die richtige Richtung und ist doch, wie alltägliche Erfahrungen zeigen, mitunter als subjektiv zu relativieren. Angesichts des wachsenden Ansehens der empirischen Wissenschaft außerhalb wie innerhalb der Wissenschaftsgemeinde, ist es ratsam, das Prinzip der Introspektion durch empirische Daten zu ergänzen. Was für die Linguistik gilt, gilt für die Literaturwissenschaft erst recht. Breit angelegte, korpusbasierte Studien mit einem qualitativen empirischen Fokus wären nötig, um das durch Selbstbeobachtung Erfasste in einer größeren Konstellation zu verorten.

\subsection{Forschungsstand}

Die Wissenschaft, deren Kernbereich es ist, zu erfassen, wie Literatur funktioniert, hat das Thema „Wertung“ bisher wenig zur Kenntnis genommen. Obwohl die Literaturwissenschaft literarische Texte immer auch gewertet hat, indem manche Texte für wertvoller, der Auseinandersetzung wert, andere dagegen für unbedeutend deklariert wurden (vgl. Müller-Seidel 1965), gehört die Wertungsforschung, das heißt eine reflektierte Auseinandersetzung mit den Regeln und Mechanismen der Wertung, bis heute nicht zu ihren Kernbereichen. Wohl aber findet das Thema „Wertung“ seit den Siebzigerjahren, und dann noch einmal in den Neunzigerjahren des 20. Jahrhunderts, vermehrt Aufmerksamkeit. Die meiste Aufmerksamkeit erhielt die Frage nach der Bewertung von Literatur in der Kanonforschung, die sich parallel mit den öffentlichen Kanondebatten entwickelt hat. Seit den Sechzigerjahren des 20. Jahrhunderts oszilliert die Auseinandersetzung mit dem literarischen Kanon ${ }^{1}$ zwischen nivellierend-demokratischen Bestrebungen und Rufen nach

$\overline{1}$ Der Begriff wird im Rahmen dieser Arbeit im Sinne des bildungsbürgerlichen Kanons verwendet. Damit wird eine Vereinfachung vorgenommen, die primär der Verständigung dient. Renate von Heydebrand 
Orientierung im Meer der verfügbaren Bücher. Während heute das Internet sogar literarischen Laien die Möglichkeit gibt, ihre Kritiken öffentlichkeitswirksam zu publizieren, schwelt parallel eine Bildungsdebatte, die mit dem Wunsch nach verbindlichem Wissen einhergeht. Laienrezensionen, Self-Publishing-Plattformen und Publikumspreise florieren ebenso wie Buchreihen mit angeblich besonders wertvollen oder kanonischen Büchern, vielfach herausgegeben von überregionalen Zeitungsverlagen (SZ Bibliothek, Marcel ReichRanickis Kanon, ZEIT-Schülerbibliothek). Die Wertungsforschung, die sich in der zweiten Hälfte des 20. Jahrhunderts langsam herausbildet, spiegelt diese zwei Pole - nivellierenddemokratisch und qualitativ-selektiv - in wissenschaftskonformer Terminologie und Perspektive: Verbindlichkeit und Relativität, Essentialismus und Konstruktivismus sind die Pole, die die Diskussion in der Wissenschaft seit den 1950er Jahren bestimmten. Die Literaturwissenschaft kann sich seit den 1970er Jahren den Impulsen aus der Soziologie, die mit so großen Namen wie Foucault, Barthes, Bourdieu und Assmann verbunden sind, und die trotz aller Unterschiede eine gemeinsame Stoßrichtung haben, nämlich auf die gesellschaftliche Bedingtheit der Bewertung kultureller Phänomene aufmerksam zu machen, nicht mehr verschließen. Wertungen werden heute primär als soziale Praktiken begriffen, gesteuert durch soziale Organisationsformen, durch kommunikative Codes, durch Bestrebungen, den Status quo zu stabilisieren oder zu destabilisieren.

Bourdieu (2001) begreift Wertungsprozesse als einen Kampf um kulturelles Kapital, das den Wertenden in Abgrenzung zur Ökonomie erlaubt, Literatur zu „handeln“. Das literarische Feld bildet dabei einen gesellschaftlichen Teilbereich, der nach eigenen Regeln und, ganz essentiell, in Abgrenzung zum ökonomischen und politischen Feld funktioniert. Die Stellung des Wertenden und seine argumentative Positionierung in der Debatte entscheiden über den Rang eines Textes; der Text selber bleibt zweitrangig.

Eine Entthronisierung des Autors und damit eine Verschiebung des Blickwinkels auf den literarischen Text stoßen Foucault und Barthes in den späten Sechzigerjahren an. Foucault ([1969] 2000) begreift den „Autor“ und das „Werk“ als Ordnungseinheiten, die im Wesentlichen die Funktion haben, eine Orientierung im Umgang mit Literatur zu ermöglichen. Sowohl der Autor als auch das Werk dienen als Ordnungskategorien, die Texte als zusammengehörig und in vielen Fällen auch als qualitativ einheitlich, ausweisen. Barthes ([1968] 2000), der den Autor ebenfalls als Ordnungsgröße begreift, plädiert für dessen Verbannung, um den Blick auf die „Schrift“ freizugeben. Mit der Abwendung nicht nur vom Autor, sondern auch vom Text als geschlossenem Ganzen macht Barthes auf Konventionen

(1996) und Hermann Korte (2002) bieten eine differenzierte und problemorientierte Darstellung des Begriffs. 
im Umgang mit Texten aufmerksam, die bis dahin auch ihre Bewertung prägten, nämlich die Konzentration auf Autoren, mit denen sich bereits eine Wertung verband und auf einen bestimmten Umgang mit Texten, der sie als intentionale, künstlerische Gebilde, und nicht als Produkte ihres Kommentars begriff. Barthes und Foucault befassen sich nicht eigentlich mit der Textbewertung, sondern mit der Frage, wie Praktiken im Umgang mit Texten, die kulturell und sozial geprägt sind, das Verständnis von Texten prägen. Dieses Verständnis von Texten betrifft nur zum Teil ihre Wertigkeit. Wichtig an diesen Ansätzen für die Wertungstheorie ist ihr allgemeiner Trend weg von der Betrachtung einzelner Texte unter dem Schirm einer verbürgten Wertigkeit, hin zu einer Betrachtung von Texten als Ausdruck gesellschaftlicher Zusammenhänge. Die Gedächtnistheorie von Jan Assmann (2005) lenkt den Blick auf Techniken der Verwaltung und Weitergabe von Wissen über Generationen hinweg. Er sieht Texte als Möglichkeit der Fixierung von Wissen im weitesten Sinne. Texte können, um ins kulturelle Gedächtnis einzugehen, archiviert oder kanonisiert werden. Während archivierte Texte zugänglich gehalten werden, sind mit kanonisierten Texten Praktiken verbunden, die darauf zielen, sie im Bewusstsein präsent zu halten. Auch die Theorie des kulturellen Gedächtnisses lenkt den Blick weg von den Texten selber, hin zu den gesellschaftlichen Funktionen, die Texte haben.

Dennoch wird auch die Frage nach der Rolle des Textes als Bezugspunkt von Wertungen immer wieder aufgeworfen. So geht Rita Schober $(1982,250)$ von einer „besondere[n] Rolle des ,Gestaltwerts' für die schöne Literatur" aus, der bei Wertungsfragen auch zu berücksichtigen sei. Obwohl „Werte [... ] keine den Objekten an sich zukommenden Attribute oder natürliche Eigenschaften, sondern ihrem Wesen nach soziale, speziell ideologische Phänomene [sind]" (Schober 1982, 242), werde Literatur in erster Linie in einem Modus der „ästhetischen Wertung“ bewertet, also nicht politisch-ideologisch oder moralisch-ethisch (Schober 1982, 245). Willie van Peer $(2008,3)$ hat darauf aufmerksam gemacht, dass es keinen Grund gebe, warum textuelle Faktoren (neben kontextuellen Faktoren) nicht auch eine Rolle in der Bewertung von Literatur spielen sollten. Der Sammelband „The Quality of Literature. Linguistic studies in literary evaluation“, herausgegeben von van Peer (2008), versammelt Arbeiten, die alle der Frage gewidmet sind, welche Rolle formal-ästhetische Eigenschaften in der Bewertung von Texten spielen.

Die 1950er Jahre markieren den Anfang einer Entwicklung, in der vermehrt Arbeiten entstehen, die sich mit dem Problem der Wertung aus literaturwissenschaftlicher Perspektive beschäftigen. Wie Walter Erhardt (1998, 102 ff.) gezeigt hat, sind die 1950er Jahre, die heute primär als eine Phase der Stabilisierung des Kanons gesehen werden, auch eine Pha- 
se der Kanonerweiterung unter dem Vorzeichen der werkimmanenten Interpretation. Nach der Hitler-Diktatur bestand zunächst die Notwendigkeit, Autoren des 20. Jahrhunderts in den Kanon aufzunehmen, insbesondere Autoren, die von den Nationalsozialisten als unwürdige Vertreter der deutschen Literatur, milde gesagt, aus dem Kanon ausgesondert wurden. Weitgehend unstrittig war in den 1950er Jahren jedoch, dass der Wert eines Textes in diesem selbst veranlagt ist und von aufmerksamen und geschulten Lesern mittels einer textnahen Interpretation aufgespürt werden kann. Aufsätze aus den späten Fünfziger- und frühen Sechzigerjahren sind dabei geradezu mystisch geprägt. Herbert Wutz ([1957] 1980, 164 f.) stellt sich Werte als „letzte einfache Qualitäten“ vor, die nicht gedacht, sondern „gefühlt“ werden. Es gebe „grundsätzlich keine andere Evidenz dieses Werts als die des Wertgefühls“ (ebd.). Entsprechend ist das Werten auch keine lernbare Tätigkeit, sondern ein Talent, das „den Einsatz der ganzen und innersten Persönlichkeit [fordert]. Und das um so mehr, je höher die Werte stehen, die es zu erfassen gilt“ (ebd., 167). Der Glaube, dass „ganz bestimmte feststellbare Eigenschaften eines Gedichts für seine Schönheit notwendig sind“ (ebd., 168), ist bei ihm ungebrochen. Trotz dieser „feststellbaren Eigenschaften eines Gedichts“, die seine Schönheit ausmachen, weist Wutz die Idee zurück, es könne einen Wertekatalog geben, anhand dessen literarische Werke bewertet werden können (ebd., 186). Wenn aber „,[d]er große Dichter [...] den großen Leser und Kritiker [fordert]“ (ebd., 185), heißt das letztendlich, dass Wert - so paradox es klingen mag - von der Autorität des Wertenden abhängt. Wert wird zwar als dem Kunstwerk innewohnend und faktisch gegeben angesehen, fassbar wird der Wert aber nur durch einen „großen Geist“. Emrich ([1961] 1980, 192) spricht vom „Bewußtseinsstand des Kritikers“, der auf demselben Niveau sein müsse wie der „Bewußtseinsgrad des Schaffenden“. Wodurch aber ist verbürgt, dass der jeweils Wertende den entsprechenden „Bewußtseinsstand“ hat? Diese Frage wird nicht beantwortet; sie lässt sich nur aus dem elitären Selbstverständnis des Bildungsbürgertums heraus klären. Aus der Perspektive der späten 1950er Jahre beantwortet sie sich offenbar von selbst. Diskussionen über Werte erübrigen sich, weil sich Wert auf der Grundlage eines okkulten Wissens entweder erschließt oder nicht. Kriterien können zwar durchaus benannt werden - Stimmigkeit, Ganzheit, Offenheit, Polyvalenz-, die Praxis des Wertens unterliegt aber keinen formulierbaren Regeln. Das Wertungswissen ist in dieser Sichtweise zwar dokumentierbar, dadurch aber noch lange nicht anwendbar. Selbst das Wissen, dass Stimmigkeit, um nur ein mögliches Beispiel zu nennen, ein hoher Wert ist, befähigt einen Kritiker ohne entsprechendes Einfühlungsvermögen nicht dazu, diesen Wert in einem Text „richtig“ aufzuspüren. 
Dieses zunächst etwas verworrene Bild der „Wertungsforschung“ der späten Fünfziger- und frühen Sechzigerjahre - eine „dringliche Aufgabe theoretischer Reflexion“ sei die Bewertung von Literatur erst seit Anfang der Siebzigerjahre (Schober 1980, 241) - zeigt doch sehr deutlich den Status, der dem Text, dem Rezipienten/Kritiker und dem Wertungskriterium zugewiesen wird. Die Einschätzung eines Textes spielt sich zwischen dem Kritiker und dem Text - stellvertretend für den Autor - allein ab. Sie setzt voraus, dass beide einen gemeinsamen ästhetischen Horizont haben. Die positive Bewertung eines künstlerischen Textes hat mehr mit einem gelungenen Dialog zwischen Text und Leser zu tun als mit der Anwendung bestimmter Kriterien. Zusammengehalten wird das Wertungswissen der Zeit durch eine gemeinsame Methode im Umgang mit Texten: die werkimmanente Interpretation (vgl. Erhardt 1998). Essentialismus und Elitarismus des Wertungsverhaltens und Kanonglaubens, wie sie in den 1950er Jahren die Auseinandersetzung mit Literatur dominierten, bilden in aktuellen Diskussionen meist einen argumentativen Kontrapunkt, von dem sich viele Literaturwissenschaftler deutlich distanzieren (Grube 2014; Rippl/Winko 2013; Freise 2013).

In den folgenden Jahrzehnten verschiebt sich die Vorstellung von literarischer Wertung radikal, und dennoch bleiben grundlegende Vorstellungen der Fünfzigerjahre aktuell. Das mystische Ergriffensein des Lesers in einem geglückten Dialog mit einem großartigen Text Staigers vielfach zitiertes „begreifen, was uns ergreift“ - fällt dem neuen naturwissenschaftlichen Paradigma zum Opfer. Gesucht wird in der Folgezeit nach beweisbaren Kriterien. An die Stelle des einfühlenden Kritikers mit dem passenden „Bewußtseinsstand“ tritt ein Kritiker mit Sozialstatus, Biografie, Herkunft, beruflichen Zielen. Die gesellschaftliche Dimension von Werten und des Wertens wird entdeckt. Dass aber eine gelungene Lektüre auf der Grundlage eines Angebotes, das der Text macht, auch eine Rolle bei der Bewertung spielen könnte und dass der Leser irgendwie in den Bann des Textes gezogen werden muss, bleibt stets ein Gedanke, der die Arbeit der Kanon- und Wertungsforschung begleitet. So bemerkt Neuhaus $(2002,18)$, alle Leser läsen aus hedonistischen Gründen. Weil eine solche Auffassung aber quer zum methodischen Mainstream steht, findet sie wenig Beachtung.

Die gesellschaftliche Aufbruchstimmung der späten 1960er und 1970er Jahre mit dem verstärkten Bewusstsein für soziale Machtverhältnisse und den aufblühenden Befreiungsbewegungen - Gleichstellung der Frau, Befreiung von Kolonialherrschaft, Anerkennung gleichgeschlechtlicher Partnerschaften, Distanzierung von christlich geprägten Moralvorstellungen - bringt auch eine Hinterfragung des literarischen Kanons und mit ihm verbundenen literarischen Wertungen mit sich (Rippl/Straub 2013, 110). Insbesondere in den 
USA wird eine erbitterte Kanondebatte ausgetragen (vgl. Böhler 1998). Aus der Perspektive der Kanongegner stellt sich der Kanon nicht als eine Auswahl der besten Texte, sondern viel mehr als eine Auswahl von Autoren einer herrschenden gesellschaftlichen Gruppe der Dead White European Males - dar und seine Öffnung u. a. für Frauen, Schwarze und zeitgenössische Autoren wird gefordert (vgl. Beilein 2013, 68).

Erst mit diesem Versuch, den bis dahin unangefochtenen Kanon in Frage zu stellen und gezielt zu öffnen oder sogar abzuschaffen, entsteht die Notwendigkeit, sich wissenschaftlich mit dem Kanon - und damit auch mit der Bewertung von Literatur - auseinanderzusetzen, um die Kritik gegenüber den Vertretern eines festen Kanons zu fundieren (Beilein 2013, $67)$.

Die Wertungsforschung ist von der Kanonforschung kaum loszulösen. Die Notwendigkeit, Bewertungskriterien für Literatur zu begründen oder überhaupt erst zu erforschen, entwickelt sich parallel zum gesteigerten Bewusstsein für die gesellschaftliche Bedingtheit von Werten, das heißt mit der Vorstellung, dass literarische Güte nichts Gegebenes ist, sondern dass Werte die Machtstellung gesellschaftlicher Gruppen oder einzelner Personen stützen. Prominente Beispiele sind die Theorien von Bourdieu (2001) und Guillory (1995).

Primär, aber nicht ausschließlich, aus der Kanondebatte heraus entsteht die Forderung nach einer Empirisierung aufgestellter Behauptungen und Theorien (u. a. Beilein et al. 2012, 4; Bortolussi et al. 2008; Schmidt 2007, 21; Winko 2002, 21 f.; S.J. Schmidt 1980). Eine solche Empirisierung sollte das Hauptanliegen der Wertungsforschung sein. Begreift man nämlich Kanon, wie beispielsweise von Simone Winko (2002) beschrieben, als das Ergebnis eines komplexen Zusammenspiels unterschiedlicher Wertungshandlungen - intentionaler und nicht-intentionaler, verbaler und non-verbaler - dann ist es Aufgabe der Wertungsforschung, belastbare Theorien anzubieten, wie diese Wertungen als gewissermaßen kleinste Einheiten funktionieren. Bisher jedoch ist die Wertungsforschung hinter der Kanonforschung zurückgeblieben (Rippl/Winko 2013, 2).

Das große Problem der Kanon- und Wertungsdebatte seit den Sechzigerjahren ist, dass sie emotional geführt wird. Henry L. Gates (1992) stellt Kanonisierung in „Canon Confidential. A Sam Slade Caper" - einer ironischen Agenten-Geschichte - gar als Geheimorganisation dar, hart umkämpft und undurchschaubar. Die Vertreter des Kanons - sei es nun der bildungsbürgerliche oder ein für Arbeits- oder Bildungsziele zweckmäßiger verteidigen den Kanon als Menge entweder ästhetisch besserer oder aber kulturell und gesellschaftlich anerkannter Werke (Bloom 1994; Engel 2007; Reich-Ranicki 2003), die radikalen Demokraten und Konstruktivisten unter den Kritikern fordern die Loslösung von 
Kanones generell oder wenigstens vom bildungsbürgerlichen Kanon (vgl. z. B. Marx 2004, Hassan 2001, Madsen 1999), weil sie nicht nur Auswahl, sondern auch Zensur bedeuten (vgl. Heydebrand 1998; Assmann 1987). Veröffentlichungen zum Thema „Kanon“ sind vielfach von dem Wunsch geprägt, das eine oder das andere - Befreiung vom Kanon oder Erhaltung des Kanons - herbeizuführen. Insbesondere Verfechter der Auffassung, es gebe durchaus textuelle Kriterien, die eine Rolle spielen, wenn es um die Bewertung von Texten geht „,[halten] es nicht für nötig, die Belastbarkeit der jeweiligen Urteilsgrundlage zu demonstrieren“ (Freise 2013, 50). In anderen Worten: Das Vorhandensein solcher textuellen Merkmale wird behauptet, aber nicht nachgewiesen.

Ein weiteres Problem der Literaturwissenschaft besteht in dem Legitimationsproblem, mit dem das Wissen um die Bewertung von Literatur einhergeht. Zu wissen, was gut ist und warum, ist auch eine Anforderung von außen, mit der die Literaturwissenschaft sich auseinanderzusetzen hat (Winko 2007, 251). Normative Setzungen aus dem Selbstverständnis als Experten heraus werden von manchen Literaturwissenschaftlern - zumeist implizit angestrebt (Neuhaus 2002; Andreotti 2009). Wer, wenn nicht die Literaturwissenschaftler, kann überhaupt literarische Werte festlegen und überprüfen, lautet dann die Frage. Eine solche normative Herangehensweise steht jedoch quer zum wissenschaftlichen Selbstverständnis, das auf Neutralität und Deskriptivität ausgelegt ist (Allkemper/Eke 2007, 15; Schmidt 1980).

Verschiedene Forscher haben versucht, die Kanonfähigkeit oder die Textqualität anhand von textuellen Kriterien zu überprüfen (Barney 2008; Olsen 2008; van Peer 2008; Neuhaus 2002). In der Regel fällt diese Prüfung wertungskonform aus, das heißt, die Autoren kommen zu dem Ergebnis, die untersuchten Texte seien formal und stilistisch überlegen, wenn es sich um kanonische Texte handelt, oder formal und stilistisch unterlegen, wenn es sich um nicht kanonisierte Texte handelt, und daher zu Recht Bestandteil des Kanons oder eben nicht. ${ }^{2} \mathrm{Zu}$ bedenken ist dabei, dass die Wertmaßstäbe, mit denen diese Überprüfung vorgenommen wird, von den Autoren selbst angesetzt und als gültig vorausgesetzt werden. Dass es eine Reihe von formal-ästhetischen Wertmaßstäben gibt, die in der Literaturwissenschaft anerkannt sind, steht dabei jenseits aller Diskussion. Dazu ähneln sich die Vorschläge für entsprechende Maßstäbe zu stark. Die Zusammenstellung der formal-ästhetischen Wertmaßstäbe von Heydebrand/Winko (1996, 113 ff.) bietet einen guten Überblick über häufig verwendete Werte: Selbstreferenz, Polyvalenz, Offenheit,

2 Neuhaus (2002) kommt gemäß dem Ziel seiner Studie zu dem Ergebnis, dass viele nicht kanonisierte Texte die literarischen Kriterien, die für die Kanonisierung vielfach angenommen werden, durchaus erfüllen. 
Schönheit, Stimmigkeit, Ganzheit, Komplexität, Dichte/Intensität. ${ }^{3}$ Dass diese Maßstäbe auch auf die Entstehung eines Kanons - des Kanons der Literaturwissenschaft - einwirken, ist wahrscheinlich. Ob es allerdings diese, und nur diese, formal-ästhetischen Maßstäbe sind, die die Genese eines Kanons bedingen, an dem schließlich nicht nur Literaturwissenschaftler als Expertenleser beteiligt sind, und ob es weiterhin diese Maßstäbe sein werden, die den Kanon bestimmen, das ist eine Frage, deren Beantwortung noch zu leisten ist. Und nicht nur nach dem $O b$, sondern auch nach dem Wie-Sehr sollte gefragt werden. Die an der Diskussion beteiligten Literaturwissenschaftler neigen - nicht ganz zu Unrecht - dazu, ihren eigenen Verstehenshorizont als allgemeingültig oder wenigstens exemplarisch zu betrachten. Die Bewertung von Literatur mit der daraus resultierenden Kanonbildung ist jedoch ein Prozess, der weitaus mehr Menschen betrifft als nur Literaturwissenschaftler.

Die literaturwissenschaftliche Wertungsforschung jongliert zwar munter mit Annahmen über (formal-ästhetische) Wertungskriterien, konnte diese aber bisher entweder nur introspektiv oder aus ihrem grundsätzlichen Literaturverständnis heraus begründen. Wertungskriterien hatten also entweder persönlichen Erfahrungswert oder formulierten einen, meistens aus den Grundannahmen der Autonomieästhetik begründeten, Sollzustand. Solche hypothetischen Kriterien wurden vielfach in Studien implementiert, die eine Aussage über den Ist-Zustand zum Ziel hatten. Wenn etwa van Peer und Fricke (1999) ein Gedicht Ulla Hahns in einer bestimmten Weise manipulieren, um dann ihre Probanden - allesamt aus dem literaturwissenschaftlichen Bereich - zu fragen, welche Version besser sei, das Original oder die manipulierte Fassung, setzen schon die Manipulationen Annahmen über die Wirksamkeit und damit indirekt über Bewertung voraus. Das Ergebnis läuft Gefahr, zur Selffulfilling Prophecy zu werden: Textstellen werden so manipuliert, dass sie ihre vom Forscher erkannte Mehrdeutigkeit verlieren und aus seiner Perspektive eindeutig werden. Wenn der Text in der Folge als ästhetisch schlechter eingestuft wird, wird das auf dessen Eindeutigkeit zurückgeführt. Methodisch ließen sich jene Vorannahmen, die van Peer/Fricke intuitiv aus ihrem literaturwissenschaftlichen Expertenwissen heraus machen, besser begründen, wenn sich die angesetzten formal-ästhetischen Wertmaßstäbe auf einer breiten Materialbasis als verbreitet nachweisen ließen.

Sehr deutlich wird diese Schwierigkeit bei Stefan Neuhaus (2002), der den umgekehrten Weg gegangen ist und Texte begutachtet hat, die nicht kanonisiert sind, um herauszufinden, ob sie den in der Literaturwissenschaft angesetzten Maßstäben möglicherweise doch

3 Heydebrand/Winko selbst gehen nicht davon aus, dass diese Liste abgeschlossen oder allgemeingültig wäre. Sie stellt eine Bestandsaufnahme wichtiger formal-ästhetischer Werte dar und wurde im Rahmen dieser Arbeit als Orientierung verwendet. 
entsprechen. Sein erklärtes Ziel bestand darin, die Selbstverständlichkeit, mit der manche Texte ausgeschlossen werden, aufzubrechen (Neuhaus 2002, 9). Er skizziert die Vision eines nachvollziehbaren Kanons, der auf der Grundlage von Expertenwertungen nach bestimmten Kriterien gewonnen wird, einen Kanon „der nicht an die Auflistung bestimmter Titel gebunden ist, sondern aus der professionellen Bewertung von Texten gewonnen wird; einer Bewertung, die keine Dichterfürsten krönt, sondern sich darum bemüht, Texte nach ihren eigenen Voraussetzungen zu beurteilen, und zwar so, dass die Bewertungen für jeden anderen transparent sind“ (Neuhaus 2002, 10). Mit diesem Versuch, dem Ergebnis der Kanondebatten, dass der Kanon keineswegs ein Kanon der Besten sei, Rechnung zu tragen, geht Neuhaus gleichzeitig hinter die Befunde der 1970er Jahre zurück, indem er zum einen dem Expertenleser als fähigen Interpreten und Kritiker wieder ins Amt hebt und gleichzeitig voraussetzt, Texte könnten „nach ihren eigenen Voraussetzungen“ bewertet werden. Jedoch macht er darauf aufmerksam, dass es ein Irrtum sei, dass „ein Text [.. ] unabhängig von subjektiver Betrachtung bestimmte Eigenschaften [habe], die seine literarische Qualität ausmachen. So wie der Text nur in der Rezeption existiert, gibt es diese Eigenschaften nur in der Zuschreibung durch den Leser." (Neuhaus 2002, 11). Obwohl Neuhaus Werte als Konstrukte betrachtet, bedeutet das keine Veränderung des argumentativen Umgangs mit ihnen. Die Unterscheidung zwischen essentialistischen und konstruierten Werten ist rein perspektivisch. In seinen Beispielanalysen setzt Neuhaus dann die von Heydebrand/Winko (1996) als prägend herausgearbeiteten formal-ästhetischen Werte normativ an, um die ausgewählten, nicht kanonisierten Texte auf Kanonfähigkeit zu überprüfen. So sehr die Stoßrichtung dieses Experiments zu begrüßen ist, kann es doch nicht darüber hinwegtäuschen, dass der Kanon erstens nicht ausschließlich von Expertenlesern gemacht wird, sondern vielmehr ein komplexes Zusammenspiel intentionaler, vor allem aber auch nicht intentionaler Aktionen ist (vgl. Winko 2002). Neuhaus diskreditiert alle Wertungen, die nicht durch „Experten“ - unklar, wer das überhaupt sein darf - verbürgt sind. Zweitens setzt Neuhaus Werte an, die viele Literaturwissenschaftler anerkannt haben, aber kaum wirklich überprüft wurden, und zwar ausschließlich formal-ästhetische Werte, die Neuhaus zufolge dazu beitragen, dass das Lesen angenehm ist:

Eine Ergänzung scheint angebracht. Alle Leser lesen Literatur aus hedonistischen Gründen oder, anders gesagt, weil sie Gratifikationen davon erwarten. Polyvalenz/ Offenheit ermöglicht es ihnen erst, den Text aus sich selbst zu beziehen und die Voraussetzung für eine hedonistische Lektüre zu schaffen; Stimmigkeit bezeichnet die formale und inhaltliche Schönheit des Textes, die wie die Schönheit eines anderen Kunstwerks genossen werden kann. Originalität hebt den Text von anderen Texten ab und schafft so erst die Unterscheidbarkeit, ohne die der Text langweilig wirken würde; Selbstreferenz bezeichnet das spielerische Moment des Textes, der die Beziehung zwischen sich 
und dem Leser auf eine neue Ebene hebt, die - besonders für professionelle Leser zusätzliche Gratifikationen bereithält. (Neuhaus 2002, 18)

Neuhaus gelingt es dann auch, in den von ihm herangezogenen Beispieltexten nachzuweisen, dass die genannten Kriterien zutreffen, obwohl sie nicht kanonisiert sind. Unter den von ihm gewählten Texten sind sowohl Texte von heute kaum bekannten Autoren als auch unbekannte Texte von kanonisierten Autoren. Neuhaus' Experiment lässt viele Fragen offen: Inwieweit hängt das Zuschreiben der genannten Werte von der Wahrnehmung dieses einzelnen Kritikers ab? Inwieweit hängt seine Wertzuschreibung von den Zielen seiner Arbeit ab? Wie stehen die gewählten formal-ästhetischen Kriterien im Verhältnis zu anderen Kriterien, z. B. inhaltlichen und wirkungsbezogenen? Lässt sich der Kanonisierungsgrad vielleicht durch andere Wertmaßstäbe erklären? Und nicht zuletzt: Wie stehen die Textstellen, an denen Neuhaus bestimmte formal-ästhetische Werteigenschaften nachweisen kann, zu Textstellen, die diese Kriterien nicht erfüllen? Kurz: Neuhaus unternimmt ein vielversprechendes Experiment auf der Grundlage seines Expertenstatus. Zu prüfen wäre jedoch, wie groß die Schnittmenge dieses Expertenwissens mit anderen Kritikern ist.

Michaela Köhler (1999) hat Zeitungsrezensionen in den überregionalen deutschen Zeitungen (ZEIT, Süddeutsche Zeitung und Frankfurter Allgemeine Zeitung) auf verwendete Werte und ihre sprachliche Umsetzung hin untersucht. Sie geht dabei von den zur Bewertung verwendeten Wörtern, Wortgruppen und sprachlichen Bildern aus und ordnet sie Wertmaßstäben zu. Die Werte, die sie herausarbeitet, bilden eine bunte Mischung verschiedener Maßstabskategorien. Sie kommt zu dem Ergebnis, dass

die subjektive Bewertungshandlung des Rezensenten immer auf der Basis von Kriterien vollzogen wird, die nicht allgemein bekannt oder anerkannt sind, auch wenn die Rezension diesen Anschein erweckt. Dabei zielt der Rezensent auf ein implizites Einverständnis mit dem Leser ab. (Köhler 1999, 322)

Obwohl Köhler mit ihrem ergebnisoffenen Forschungsansatz wichtige Pionierarbeit geleistet hat, bleiben auch bei ihr viele Fragen offen. Wenn Wertungen letztlich subjektiv sind, die Kriterien „nicht allgemein bekannt oder anerkennt“, bleibt die Frage, warum Köhler nicht ein viel breiteres Maßstabsrepertoire vorfindet. Denn letztlich gelingt es ihr trotzdem, die gefundenen Textstellen auf nicht einmal zehn Kategorien herunterzubrechen. Es bleibt auch die Frage, wie es gelingen kann, dass der Rezensent das „implizite Einverständnis“ aufbaut. Welches Gewicht unterschiedlichen Wertaspekten zukommt, bleibt ebenso ungeklärt wie die Frage, wie einzelne Maßstäbe zusammenhängen.

Sabine Buck (2011) hat eine der umfassendsten empirischen Werte-Studien in der aktuellen germanistischen Literaturwissenschaft umgesetzt. Sie hat ebenfalls Zeitungsrezen- 
sionen aus den überregionalen Tageszeitungen mit Blick auf den Konflikt zwischen ethischen und ästhetischen Wertungen untersucht. Zusätzlich zu ihrem Rezensionskorpus hat Buck medienwirksame Literaturskandale der Neunziger- und Zweitausenderjahre untersucht und Kritiker zu ihrem Werteverständnis befragt. Sie kommt zu dem Ergebnis, dass in den programmatischen Aussagen der Kritiker über Wertung formal-ästhetische Wertungen dominieren, ethische Maßstäbe dagegen abgelehnt werden. In der literaturkritischen Praxis beobachtet sie jedoch, dass in Literaturskandalen explizit mit moralischen Maßstäben gewertet wird und dass in ,gewöhnlichen“ Rezensionen vielfach implizit moralisch gewertet wird (Buck 2011, 384 ff.). Sie erbringt damit den Nachweis am Material, dass die Bewertung von Literatur kein „moralfreier Raum“ ist (Buck 2011, 379). Ihre Rezensionsanalysen und Kritikerbefragungen machen aber auch deutlich, dass Literaturkritik ihrem eigenen Selbstverständnis nach formorientiert arbeitet, was sich in Rezensionen spiegelt, die nicht Teil eines Literaturskandals sind. Dort nämlich wird der „Code, der autonomieästhetisch geprägt ist“ (Buck 2011, 385), eingehalten. Wie Köhler verweist auch Buck dabei auf die Schwierigkeit, konkrete Wertmaßstäbe aus den Rezensionen zu gewinnen (Buck 2011, 384). Warum aber ist die Einhaltung des formal-ästhetischen Codes so bedeutend? Und wie genau funktioniert dieser Code?

Mit den Arbeiten von Kienecker (1989), Heydebrand/Winko (1996) und Worthmann (2004) sind seit den 1990er Jahren eine Reihe von theoretischen Arbeiten auf dem Gebiet der Wertungsforschung entstanden, die dieser einen theoretischen Rahmen und eine Terminologie zur Verfügung stellen. Insbesondere die „Einführung in die Wertung von Literatur" von Heydebrand/Winko hat Ordnung in das Wissen über Werte und Wertungen gebracht. Friederike Worthmann (2004) hat dieses Modell um wichtige kognitionspsychologische Einsichten ergänzt. Sie hat den Blick dabei auf die Wechselwirkung von textseitigen und leserseitigen Faktoren gelenkt, aber auch darauf aufmerksam gemacht, dass das Werten kein rein rationaler Vorgang ist, sondern, je nachdem, welchen „Anspruch“ die Wertung hat, ob sie nach der Erfüllung von Wünschen fragt oder nach der Erfüllung eines Ideals, unterschiedliche Aspekte der Textbewertung in den Vordergrund stellen kann. Auf theoretischer Ebene hat sich seit Mitte der 1990er Jahre viel getan.

Dennoch fehlen in der Wertungsforschung nach wie vor Arbeiten, die statt nach dem SollZustand nach dem Ist-Zustand fragen und dabei nicht in erster Linie das im Sozialisationsprozess, speziell an Schulen und Universitäten, erlernte Wertungswissen reproduzieren, indem konventionalisierte Maßstäbe an Texte herangetragen und überprüft werden, sondern Arbeiten, die sich einem breiteren Spektrum von Wertenden und tatsächlichen 
Wertaussagen zuwenden. Einen besonderen Knackpunkt bilden dabei weiterhin die formalästhetischen Werte, denn diese sorgen nach wie vor für Spannungen in der Wertungsforschung. Simone Winko $(2002,21)$ hat darauf hingewiesen, dass die Frage nach Texteigenschaften der „blinde Fleck“ der Kanontheorien sei. Daran hat sich auch fünfzehn Jahre später kaum etwas geändert. Formal-ästhetische Werte fügen sich schwer in das aktuelle Selbstverständnis der Disziplin und gängige Methoden der wissenschaftlichen Auseinandersetzung mit Literatur ein. Sie sind schwer greifbar. Gleichzeitig wirken sie etwas angestaubt. Dennoch sind formal-ästhetische Werte oft dort präsent, wo es nicht mehr um eine Begutachtung unter wissenschaftlichem Aspekt geht (vgl. Winko 2002; Buck 2011). Es gilt also, diesen introspektiven Erkenntnissen mit Mitteln nahezukommen, die die Literaturwissenschaft als eine primär wissenschaftliche Disziplin zur Verfügung stellt.

\subsection{Vorhaben und Erkenntnisziele}

Die vorliegende Arbeit möchte genau an diesem Punkt ansetzen. Um der Frage nach der Rolle von formal-ästhetischen Werten in der Bewertung von Literatur nachzugehen, sollten nicht Texte, deren Gesamtbewertung und Kanonstatus schon geklärt ist, auf der Grundlage von vorausgesetzten Wertmaßstäben betrachtet werden. Es wird stattdessen der Versuch unternommen, auf der Grundlage von Expertenwertungen über Texte mit ungeklärtem Bewertungsstatus herauszuarbeiten, welche formal-ästhetischen Werte überhaupt in „echten“ Wertungssituationen, das heißt jenseits von programmatischen Diskussionen, in Wertungen verwendet werden und welchen Stellenwert sie in diesen haben. Werte werden dabei als diskursives Wissen aufgefasst, ein Wissen, das erst durch Handlungen, insbesondere auch sprachliche Handlungen hervorgebracht und in verbalen Wertungen immer neu verhandelt wird (vgl. Spitzmüller/Warnke 2011). Als soziale und kognitive Konstrukte sind Werte nur als Handlungen fassbar und daher gut mittels einer inhaltlich ausgerichteten (linguistischen) Diskursanalyse, die danach fragt „warum zu einer bestimmten Zeit bestimmte Aussagen getroffen werden - vor allem auch, warum nicht - und wie durch diese Praxis des Aussagens die Gegenstände des Sagens und Schreibens zu Wirklichkeit werden“ (Spitzmüller/Warnke, 2011, 40), fassbar. Nicht als gegebene Größe werden Werte betrachtet, weder die axiologischen, noch die attributiven (vgl. Kapitel 4.8), sondern als ausgehandeltes Wissen, das sich aber, und hier liegt das spezifische Interesse, in einer besonderen Weise auf den Gegenstand, dessen Wert verhandelt wird, den literarischen Text, bezieht. Mit den mündlichen Diskussionen des Ingeborg-Bachmann-Wettbewerbs 1999-2009 wurde ein

Korpus gewählt, das verhältnismäßig spontane Bewertungen von Literaturexperten aus 
verschiedenen Bereichen über Texte und Autoren, deren Gesamtstatus noch ungeklärt ist, enthält. Ziel der Arbeit ist es, eine Vorstellung von der Art, dem Spektrum und der Wichtigkeit formal-ästhetischer Werte auf einer breiten Materialbasis zu erlangen. Da bisher in der Wertungsforschung besonders die Begründung von Wertmaßstäben methodisch problematisch war, weil diese letztendlich den Anschein entweder des Subjektiven oder des Programmatischen hatten, kann auf diesem Wege ein längst überfälliger Einblick in das Wertungsverhalten außerhalb der wissenschaftlichen Praxis und außerhalb der Feuilletons großer deutschsprachiger Zeitungen gewährt werden. ${ }^{4}$ Die gewonnenen Einsichten geben nicht nur Aufschluss über den Status quo des Wertgefüges am Anfang des 21. Jahrhunderts, sondern können als ein Wegweiser für weitere Untersuchungen in der literaturwissenschaftlichen Wertungsforschung dienen. Die Arbeit schließt eine Untersuchung der bewerteten Texte aus. Eine Untersuchung der literarischen Texte daraufhin, welche Eigenschaften sie haben und wie sich diese zu den dann geäußerten Wertungen verhalten, würde bedeuten, die Beobachterposition, die in dieser Arbeit eingenommen wird, zu verlassen und selbst analytisch und interpretativ mit den Texten umzugehen. Darüber hinaus hätte eine solche Untersuchung auch den zeitlichen Rahmen der Arbeit gesprengt.

Der Schwerpunkt der Arbeit lag daher auf der Analyse von Wertungshandlungen: den Ingeborg-Bachmann-Preis-Diskussionen der Jahre 1999-2009. Den methodischen Ansätzen der Grounded Theory folgend wurde der Arbeit am Material ein hoher Stellenwert eingeräumt, eine „theoretische Vorbelastung“ und Thesenbildung wurde bewusst vermieden. Zu diesem weitgehenden Verzicht auf Vorannahmen gehörte auch, dass die Wertungen der Juroren und ihre Expertenposition niemals in Frage gestellt wurden. Es wurde stets angenommen, dass die Urteile der Juroren begründet sind und in einem sinnvollen Verhältnis zum Text stehen. Am Anfang stand die Frage: Welches Wertungsverhalten mit Bezug auf formal-ästhetische Werte kann man in den Diskussionen beobachten? Nach einer orientierenden Einarbeitung in die literaturwissenschaftliche Wertungstheorie entstand die Arbeit in einem Dialog aus Arbeit am Korpus und Auseinandersetzung mit (literaturwissenschaftlichen) Theorien sowie Impulsen aus anderen Disziplinen. Was sich in der schriftlichen Darbietung der Arbeit als zwei Teile - Kontext und Analyse - spaltet, hat es während der Arbeit an diesem Projekt nie gegeben. Die Auseinandersetzung mit der Theorie entsprach stets dem Kenntnisstand aus der Analyse. So verschob sich aufgrund der Ergebnisse der Analysen der Fokus immer mehr von diskurslinguistischen Fragestel-

$4 \quad$ Zwar sind viele der Jurymitglieder des Ingeborg-Bachmann-Wettbewerbs auch als Feuilletonisten bekannt, im Rahmen des Wettbewerbs agieren sie allerdings in einem anderen literaturkritischen Kontext, der sich deutlich vom Feuilleton unterscheidet. 
lungen in Richtung solcher der literaturwissenschaftlichen Kognitionsforschung und der empirischen Wirkungsforschung. Die Analyse des Korpus und die Ergebnisse der theoretischen Literatur- und Sozialwissenschaften standen in einer fruchtbaren Wechselwirkung. Dabei wurden viele Anleihen aus angrenzenden Disziplinen gemacht, deren Positionen als Anregungen in der Auseinandersetzung mit den Analyseergebnissen aufgegriffen wurden. Sie hatten für die Arbeit vorwiegend Inspirationswert und wurden weder in ihrer ganzen Tragweite betrachtet, noch wurden sie umfassend in ihrem wissenschaftlichen Entstehungskontext verortet. Auf ein umfassendes theoretisches Panorama wurde aufgrund des gewählten Ansatzes verzichtet. Die Grundhaltung, die die Arbeit an diesem Projekt geprägt hat, war eine Haltung der Neugier in Bezug auf das Material und der Offenheit in Bezug auf Impulse aus den verschiedensten Bereichen. Diese Grundhaltung hat einen frischen Blick auf Wertungsvorgänge möglich gemacht. Im Sinne dieser Idee versteht sich die Arbeit selbst nicht als ein Abschluss, sondern vielmehr als ein Impulsgeber für weitere Arbeiten auf dem Gebiet der literaturwissenschaftlichen Wertungsforschung.

\subsection{Leseleitfaden}

Um einen möglichst guten Lesefluss zu ermöglichen, sollen einige Stolpersteine schon an dieser Stelle aus dem Weg geräumt werden.

In der gesamten Arbeit wird der besseren Lesbarkeit halber das generische Maskulinum verwendet. Selbstverständlich sind mit „Juroren“, „Lesern“, „Autoren“, „Kritikern“ und so weiter stets auch die Jurorinnen, Leserinnen, Autorinnen etc. gemeint.

Anstatt des Wortes „Form“ werden im Rahmen dieser Arbeit häufig die Begriffe „Machart“ und „Gestaltung“ als Synonyme verwendet. Der Begriff „Machart" entstammt dabei der Wertsprache der Juroren und bietet den Vorteil, dass er weniger vorbelastet ist als der Begriff der Form, aber auch angemessener für den Bereich der erzählenden Literatur. Während der Begriff „Form“ die Vorstellung einer Reihe klar definierter Merkmale evoziert, in die der Inhalt gefasst wird, verweist der Ausdruck „Machart“ (aber auch „Gestaltung“) auf die Art und Weise, wie Autoren Informationen in Texten präsentieren und arrangieren. Damit sind die griffigen und flexibleren Ausdrücke „Machart" und „Gestaltung" besser geeignet, um das zu erfassen, was die Juroren an erzählenden Texten auf der Ebene der „Form" wahrnehmen.

Die Arbeit gliedert sich in drei große Teile. Im ersten Teil werden einige Kontexte präsentiert, die für das Verständnis des Wettbewerbsgeschehens und den Umgang mit den 
Diskussionen in der Analyse wichtig sind. Im zweiten Teil werden die Analyseergebnisse der stichwortgeleiteten Korpusanalyse (vgl. Kapitel 2.2.4) präsentiert. Diese Analysen bildeten das Kernstückt der Korpusanalyse. Es wurde Wert darauf gelegt, die Analyseergebnisse durch Zitate zu belegen und auf diese Weise nachvollziehbar zu machen. Dennoch können die Zitate nur punktuelle Einblicke gewähren. Illustrativen Charakter haben die Detailanalysen, die den dritten Teil der Arbeit bilden. Sie gewähren einen detaillierten und besser nachvollziehbaren Einblick in die Mechanismen der formal-ästhetischen Literaturbewertung im Rahmen des Ingeborg-Bachmann-Wettbewerbs.

Es soll an dieser Stelle auch noch einmal betont werden, dass diese Arbeit sehr stark in ihrem Material verankert ist. Am Anfang der Auseinandersetzung mit den BachmannPreis-Diskussionen stand nur die eine Leitfrage: Wie beziehen sich die Juroren auf die Form des Textes und wie lässt sich das erklären? Es folgte eine langwierige Auseinandersetzung mit dem Korpus und eine Suche nach Erklärungen, im Rahmen derer verschiedene Zugänge ausprobiert und verworfen wurden. Dieser Prozess konnte in der Präsentation der Ergebnisse nur punktuell sichtbar gemacht werden.

Das Reizwort „formale-ästhetische Werte“ mag dazu verleiten, anzunehmen, diese Arbeit stehe in der Tradition eines Werteessentialismus. Dem sei entgegnet, dass es mir weder darum geht und ging, zu beweisen, dass die Wertung von Texten einzig von deren Form abhängt, noch darum, zu zeigen, dass sie auf keinen Fall von ihr abhängen kann. Vielmehr wurde angenommen, dass Bewertungen äußerst komplexe Handlungen sind, die sich sowohl auf die Wahrnehmung des Textes (wahrgenommene Texteigenschaften) stützen, als auch kommunikative - und damit soziale - Akte, sind. Über diese Grundannahme hinaus war die Haltung immer eine fragende. 


\section{Anlage der Arbeit und Vorgehensweise}

\subsection{Auswahl und Eigenschaften des Textkorpus}

Das Textkorpus, das dieser Arbeit zugrunde liegt, besteht aus den Jurydiskussionen, die im Rahmen des Ingeborg-Bachmann-Wettbewerbs der Jahre 1999 bis 2009 stattfanden, sofern sie über das Archiv der Webseite des Preises http://bachmannpreis.orf.at/stories/archiv/ zum Beginn der Arbeit im Jahr 2010 verfügbar waren.

Prinzipiell standen m. E. für die anvisierte Fragestellung zwei Möglichkeiten zur Auswahl, ein Textkorpus zu bilden. Man hätte zum einen aus einem existierenden Konvolut von Texten das auswählen können, was für den zu untersuchenden Aspekt von Belang ist oder auf den ersten Blick zu sein scheint. Eine solche Wahl hätte vorausgesetzt, dass sich bereits klar umreißen lässt, was für die Fragestellung interessant ist und was nicht.

Da es bisher kaum korpusbasierende Studien über formal-ästhetische Wertungen im Wertungsalltag professioneller Leser gibt und die wenigen Arbeiten, die es gibt (z. B. Köhler 2000; Buck 2011), Korpora verwenden, deren einzelne Texte - in der Regel Rezensionen - nach Eignung ausgewählt wurden, wurde für diese Arbeit ein Korpus der zweiten Variante gewählt: ein Textkorpus, dessen Texte dieselben Rahmenbedingungen haben, ohne dass dabei nach Repräsentativität und Aussagekraft der einzelnen Texte unterschieden wird. In einem solchen Korpus sind die Texte zwar durch die Rahmenbedingungen geeint, intern aber nicht thematisch geordnet. Es eignet sich besonders gut für Studien, die auf wenig Vorarbeit anderer Wissenschaftler zurückgreifen können. Zwar ist dann ein klarer kontextueller Rahmen vorgegeben, das Material an sich muss aber nicht nach bestimmten Vorannahmen ausgewählt werden. Subjektive Einflussfaktoren werden so begrenzt.

Die Auswahl des Korpus erfolgte bewusst mit Blick auf eine ausreichende Breite des Materials. Die Bachmann-Preis-Diskussionen bieten den Vorteil, dass eine relativ konstante Sprechergruppe $^{5}$ unter ähnlichen Bedingungen und mit ähnlichen soziologischen Voraussetzungen sich relativ spontan, immer aber wertend, zu einem gemeinsamen Gegenstand äußert. Während die Verfasser von Rezensionen unabhängig voneinander ein Buch bewerten und dabei ggf. auch auf die Erfordernisse des jeweiligen Mediums, für das sie rezensieren, eingehen müssen, beziehen sich die Juroren im selben Medium auf einen Text, der zusätzlich zur individuellen, stillen Lektüre vorgetragen wird, sodass die unmittelbarere „Lektüreerfahrung“ eine gemeinsame ist, sich auf die gleiche „Darbietung“ des Textes

5 Über die Jahre hinweg ändert sich zwar die Besetzung der Jury, einige Juroren wie Burkhard Spinnen, Iris Radisch, Ursula März und Robert Schindel (u. a.) sind aber über viele Jahre hinweg vertreten. Innerhalb eines Jahrgangs ist die Sprechergruppe konstant. 
bezieht (vgl. Kapitel 5.2.1).

Darüber hinaus bietet das Korpus der Ingeborg-Bachmann-Wettbewerb-Diskussionen den Vorteil, dass es aus mündlichen Äußerungen besteht und in dieser Hinsicht auch eine Ergänzung zu Studien darstellt, die auf schrifliche Wertungsäußerungen wie Zeitungsrezensionen zurückgreifen, wie etwa die Untersuchungen von Köhler (2000) und Buck (2011). Mündlichkeit ist auch deswegen ein wichtiges Kriterium, weil es die Spontaneität und Prozessualität der Kommunikation offenlegt und dadurch Aussagen über Wertungsprozesse im Gegensatz zu Wertungsaussagen getroffen werden können (vgl. Kapitel 5.3). Verzichtet wurde durch diese Entscheidung auf eine Repräsentation verschiedener Medien und verschiedener sozialer Gruppen bzw. Schichten. Verzichtet wurde außerdem auf eine diachrone Perspektive. Die Ergebnisse der Analyse geben Aufschluss über das Wertungsverhalten professioneller Leser zu Beginn des dritten Jahrtausends und regen dadurch Vergleiche mit anderen Lesergruppen und Epochen an; sie sind keinesfalls universell.

Empirische Studien auf breiter Materialbasis sind in der Literaturwissenschaft nicht die Standardform des wissenschaftlichen Vorgehens. Zwar gibt es spätestens seit S.J. Schmidts „Grundriss der Empirischen Literaturwissenschaft“ (1980) eine Hinwendung zu empirischen Fragestellungen und Methoden, dennoch bleibt die Literaturwissenschaft eine Wissenschaft, zu deren Repertoire sowohl hermeneutische als auch empirische Arbeitstechniken zählen (vgl. Grübel et al. 2001). In dieser Arbeit wurde bewusst ein empirisches und induktives Forschungsdesign gewählt, das nicht von vorformulierten Annahmen über die Bedeutung und Art formal-ästhetischer Werte ausgeht, sondern diese aus authentischem Wertungsmaterial abzuleiten versucht.

Die Auswahlkriterien für das Korpus - Umfang, Mündlichkeit, Repräsentativität für den Bereich der professionellen Leser und Aktualität - bestimmen auch weitestgehend die Methode, die für die Analyse ausgewählt wurde. Für das vorliegende Material und das Erkenntnisziel der Arbeit werden Methoden der qualitativen Sozialforschung adaptiert (s.u.).

\subsection{Korpuserfassung und Analysemethode}

Für die Analyse der Transkripte musste ein Weg gewählt werden, der sowohl dem Umfang des Materials, über 1000 DIN A4 Seiten Text, als auch der Art der Daten - mündlich, relativ spontan, in der Öffentlichkeit, von Experten geäußert - gerecht wird. Es war nicht möglich, teilweise aber auch nicht sinnvoll, alle angefertigten Transkripte detailliert, nach Vorbild der philologischen Methode zu analysieren. 
Gleichzeitig war ein textnahes, interpretierendes Vorgehen notwendig, um den Kern der Argumentationen herauszuarbeiten.

Eine quantitative Untersuchung, bei der die Häufigkeit des Auftretens bestimmter Signalwörter Hinweise auf die Bedeutung eines Phänomens gegeben hätte, wurde zwar in Betracht gezogen, um die durch qualitative Analysen gewonnenen Einsichten zu ergänzen, im Verlauf der Analyse jedoch verworfen. Die Häufigkeit des Auftretens bestimmter Signalwörter gibt zwar möglicherweise Aufschluss darüber, wie feststehend und konstant bestimmte Formulierungen sind, um Werte auszudrücken, sie gibt aber keinen Aufschluss über die Häufigkeit, mit der Argumentationen auf einen bestimmten Wert abzielen. Darüber hinaus werden durch eine quantitative Analyse Zusammenhänge ausgeblendet, die in Hinblick auf die Frage nach formal-ästhetischen Werten besonders aufschlussreich sind. So kommt beispielsweise das Wort „Spaß“ insgesamt nur 31 Mal im Korpus vor. Dabei ist noch nicht überprüft, ob diese Treffer tatsächlich relevant sind, ob sie sich also in Aussagen wie „dieser Text hat mir Spaß gemacht“ überhaupt auf den Text oder gar auf formal-ästhetische Werte beziehen. Nimmt man ausschließlich die Anzahl der Treffer für das Suchwort „Spaß“ als Ausgangspunkt, könnte man also annehmen, dass die positive Wirkung „Spaß“, die ein Text auslöst, keine gewichtige Rolle spielt. Bei genauerem Hinsehen - und hier ist ein philologisches, interpretierendes Vorgehen dann unumgänglich stellte sich aber heraus, dass die Kategorie „Spaß“ durchaus eine bedeutende Rolle spielt, dass aber häufig indirekt auf sie Bezug genommen wird, indem sie eng mit Aussagen über Form des Textes verwoben wird. Die Frage nach dem Warum, die sich an dieser Stelle aufdrängt, lässt sich aus quantitativen Daten nicht beantworten, sondern nur durch eine genaue Betrachtung der diskursiven Kontexte. Auf genau dieses Phänomen im Umgang mit quantitativen Daten weisen auch die Begründer der Grounded Theory A. Strauss und J. Corbin (1996) bzw. A. Strauss und B.G. Glaser (2010) hin. Sie machen einen bedeutenden Vorteil qualitativer Sozialforschung deutlich. Im Gegensatz zu quantitativen Daten können qualitative Daten Aufschlüsse darüber geben, warum sich bestimmte Dinge so verhalten, wie sie sich verhalten. Sie können außerdem Aufschlüsse darüber geben, wie die Involvierten ihre eigene Situation wahrnehmen. Die Stärke qualitativer Forschung besteht darin, Zusammenhänge herzustellen. Am Untersuchungsphänomen Beteiligte werden immer als Experten dieses Phänomens aufgefasst. Prototypische Untersuchungsgegenstände der qualitativen Sozialforschung sind für Strauss/Corbin (1996) das Interview und die Feldforschung mit teilnehmender Beobachtung und Interviews. Sie weisen aber auch darauf hin, dass sich die Methode auf andere Bereiche und auch anderes Datenmaterial übertra- 
gen lässt. Kerngedanke der Grounded Theory ist, dass sich qualitative Forschung genauso wie quantitative Forschung nach klaren Regeln und Qualitätsstandards durchführen lässt. Ihr Anspruch ist, dass jede Theorie in ihrem Material geerdet - daher der Name Grounded Theory - ist, das heißt, durch das Material, durch qualitative Daten abgesichert sein muss. Vermieden wird dadurch, dass materialfremde Theorien auf das Material appliziert werden und es auf diese Weise „passend gemacht" wird bzw. dass wichtige Bestandteile des Materials übersehen werden, weil in der implementierten, aus einem anderen Zusammenhang übernommenen Theorie bestimmte theoretische Bausteine nicht vorhanden sind. Zentral für die Methode ist ein ständiges Oszillieren zwischen bottom-up und top-down Vorgängen bei der Genese von Theorie aus dem Material:

Eine „Grounded“ Theory ist eine gegenstandsverankerte Theorie, die induktiv aus der Untersuchung des Phänomens abgeleitet wird, welches sie abbildet. Sie wird durch systematisches Erheben und Analysieren von Daten, die sich auf das untersuchte Phänomen beziehen, entdeckt, ausgearbeitet und vorläufig bestätigt. Folglich stehen Datensammlung, Analyse und die Theorie in einer wechselseitigen Beziehung zueinander. Am Anfang steht nicht eine Theorie, die anschließend bewiesen werden soll. Am Anfang steht viel mehr ein Untersuchungsbereich - was in diesem Bereich relevant ist, wird sich erst im Forschungsprozeß herausstellen. (Strauss/Corbin 1996, 7 f.)

Konkret heißt das, dass sich der Forscher seinem Untersuchungsgegenstand mit einem grundlegendem Vorwissen nähert, das ihm hilft, erste Daten zu erheben. Er begegnet den Daten mit größtmöglicher Offenheit und kodiert sie. Beim Kodieren werden Auffälligkeiten im Text in abstraktere Kategorien übertragen, die Kategorien gebündelt und in Beziehung gesetzt. Mit den so gewonnenen Kategorien kann der Forscher dann wieder an sein Material gehen, ggf. neues Material sammeln und überprüfen, ob die Kategorien und ihre Beziehungen dem Material standhalten. ${ }^{6}$ Dieses Prozedere wird so lange wiederholt, bis ein Zustand der theoretischen Sättigung (Strauss/Corbin 1996, 159) eintritt. An diesem Punkt ist die Theorie dicht, weist nach Möglichkeit keine Lücken mehr auf, und die Überprüfung am Material bringt keine neuen Erkenntnisse. Eine Theorie ist dann wissenschaftlich gut, wenn sie sieben Punkte erfüllt: 1. Signifikanz; 2. Vereinbarkeit von Theorie und Beobachtung; 3. Verallgemeinerbarkeit; 4. Reproduzierbarkeit; 5. Präzision; 6. Regelgeleitetheit; 7. Verifizierbarkeit (Strauß/Corbin 1996, 18).

Für die Arbeit am Ingeborg-Bachmann-Wettbewerb-Korpus wurde das Vorgehen der Grounded Theory so weit übertragen, wie es für das Erkenntnisziel und den Umfang der Arbeit sowie in Anbetracht der Beschaffenheit des Korpus angemessen war. Wichtig war dabei

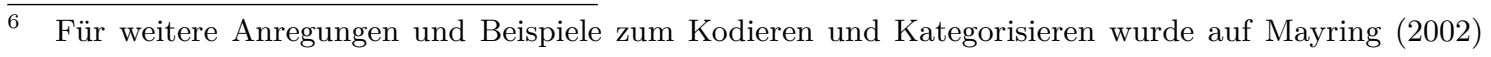
zurückgegriffen. 
zunächst die offene, das heißt möglichst nicht durch bekannte Theorien oder Annahmen geleitete Auseinandersetzung mit den Diskussionen. Die Diskussionen wurden in mehreren Durchgängen analysiert, wobei sie zunächst in der Breite und dann zunehmend in der Tiefe erfasst wurden. Kodiert wurde jeweils nach Wertmaßstäben, die mit zunehmender Kenntnis des Korpus immer mehr zu Komplexen gebündelt werden konnten. Da die Grounded Theory großen Wert auf Nachvollziehbarkeit des Vorgehens legt, sollen im Folgenden die einzelnen Analyseschritte, die vorgenommen wurden, dargestellt werden.

\subsubsection{Transkription}

An erster Stelle der Auseinandersetzung mit dem Korpus stand die Transkription. Um das mündliche Material überschaubar und vor allem bearbeitbar zu machen, wurden von den als Videomaterial auf der Webseite http://bachmannpreis.orf.at/stories/archiv/ verfügbaren Diskussionen Transkripte für die Jahrgänge 1999-2009 angefertigt. ${ }^{7}$ Bei der Transkription wurde keine Vorauswahl getroffen, da die Kategorien zur Strukturierung des Materials aus dem Material (bottom-up) erarbeitet werden sollten. Es wurde prinzipiell angenommen, dass jede Information eine potentiell wichtige Information ist. Entsprechend wurden alle verfügbaren Diskussionen vollständig transkribiert.

Da die Diskussionen sehr stark strukturiert sind und es nur selten schnelle Sprecherwechsel, Überschneidungen, Unterbrechungen etc. gibt, wurde auf eine Zeilentranskription verzichtet. Die Redebeiträge sind oft monologisch und etwa zwei bis drei Minuten lang. Sie wurden daher im Block transkribiert und mit der Zeitmarke des Beginns des Redebeitrags versehen, die bei der späteren Zuordnung von Zitaten ähnlich funktioniert wie die Seitenangabe im Buch. Die Redebeiträge wurden außerdem ihrem Sprecher zugeordnet. Die Angabe „2000 Draesner, 14:03 Radisch“ bedeutet also, dass es sich um den Redebeitrag handelt, den Iris Radisch nach 14 Minuten und 3 Sekunden des vom ORF auf der genannten Webseite zur Verfügung gestellten Mitschnitts der Diskussion zur Autorin Draesner im Jahr 2000 beginnt. Darauf folgt die Transkription des Redebeitrags. Im Großen und Ganzen wurde orthographisch transkribiert. Zugrunde gelegt wurden die Transkriptionsregeln aus dem „Praxisbuch Transkription“ (Drehsing/Pehl 2013). Die Syntax wurde dabei nicht verändert. Versprecher, Wortfindungsschwierigkeiten, grammatische Fehler, Wiederholungen und Unstimmigkeiten im Satzbau wurden nicht berichtigt. Lautliche Besonderheiten wurden dagegen nicht in die Transkription aufgenommen, da sie keinen Mehrwert für den

7 Die von den Autoren vorgetragenen literarischen Texte stehen ebenfalls über das Archiv auf der Webseite des Bachmann-Preises zur Verfügung. 
Gegenstand der Arbeit versprachen. Dafür wurden Besonderheiten der Prosodie (Lautstärke, undeutliches Sprechen, Ironie, Imitation, Betonung) und auch Lachen und Applaus in Klammern angemerkt, wenn sie auffällig waren.

Die Interpunktion wurde, soweit wie möglich, der Standardinterpunktion des Deutschen angeglichen und zugunsten guter Lesbarkeit angepasst, das heißt, es wurden Punkte statt Kommas gesetzt, wenn dies möglich war. Aufgrund der Mündlichkeit des Materials konnten viele Satzkonstruktionen nicht eindeutig bestimmt werden. Es wurde die Variante gewählt, die als sinngemäß passend verstanden wurde. Abgebrochene Sätze wurden mit Schrägstrich (/) beendet, ebenso Abbrüche im Wort. Sofern kontextuelle oder gesprächsbegleitende Faktoren, zum Beispiel Gestik, die eine Reaktion in der Jury auslöst, oder Vorfälle im Publikum (Handyklingeln etc.) - eine Rolle spielten, wurden sie angemerkt. Wenn Redebruchstücke nicht verständlich waren, entweder weil sie undeutlich gesprochen oder die Tonqualität der Aufnahme schlecht war, wurde dies in Klammern als [unv.] vermerkt; ebenso wenn Anfänge fehlten: [Anfang fehlt]. Für die Kommentierung des Gesprochenen wurden stets eckige Klammern gewählt.

Gelegentlich zitieren Jurymitglieder aus den vorgelesenen Texten. Wenn das Zitat vom Juror abgelesen wird, wurde es aus dem Text des Autors in die Transkription übernommen. Wenn der Juror frei zitiert, wurde die Wortwahl des Jurors in das Transkript übernommen und vermerkt, dass der Juror frei zitiert: [zitiert frei KR].

\subsubsection{Analyse eines einzelnen Jahrgangs}

Während des Transkribierens wurde in Notizen mit dem offenen Kodieren begonnen. Im zweiten Schritt wurde ein Jahrgang, der Jahrgang 2000, für eine intensive Analyse ausgewählt. Der Jahrgang 2000 schien für die erste detaillierte Auseinandersetzung am geeignetsten, weil er, so der Eindruck während und nach der Transkription, ein Spektrum an Beispielen enthielt, die typisch für die Art sind, wie in Klagenfurt gewertet wird. Aus diesem Jahrgang wurde ein erstes Kategoriensystem erarbeitet und die Kategorien in Beziehung gesetzt. Die Erarbeitung des Kategoriensystems umfasste mehrere Lektüren des Jahrgangs 2000, bei denen die beobachteten Phänomene so lange abstrahiert, geordnet und überprüft wurden, bis der Eindruck entstanden war, ein für diesen Ausschnitt des Korpus befriedigendes Kategoriensystem erarbeitet zu haben. Als Orientierung für die Einordnung der Wertungen dienten die Wertetypen von Heydebrand/Winko (1996). Dieses Schema bot während der gesamten Arbeit eine Orientierung. In diesem ersten Durchgang entstand ein erstes umfassendes Bild vom Wertungsverhalten und den Werten der Jury, das in der wei- 
teren Bearbeitung verfeinert und erweitert werden konnte. Kernbeobachtung dieses ersten Durchgangs war, dass es einen Zusammenhang zwischen gelungenem Leseprozess - einer möglichst weitreichenden „Simulation“ des Textes (vgl. Oatley 1994) - und der Bewertung gibt.

\subsubsection{Erfassung und Analyse von Problemkategorien}

In einem dritten Schritt wurden weitere Jahrgänge des Wettbewerbs in Hinblick darauf durchgesehen, ob sich der erarbeitete Zusammenhang zwischen erfolgreicher „Simulation“ und Grad der Anerkennung bestätigen und differenzieren lässt. Im Zuge dieser Analysen wurden Argumentationsweisen identifiziert, die einer intensiveren Auseinandersetzung bedurften. Dies betraf insbesondere drei Bereiche: 1. die spezifische Balance von Kohärenz und Offenheit, die zu einer positiven Bewertung führt, 2. Aussagen der Juroren über ihr Selbstverständnis und ihr Literaturverständnis und 3. Wertungen, die ihren Ursprung offensichtlich darin hatten, dass der Text mit „Lust" gelesen wurde.

\subsubsection{Stichwortgeleitete Analyse des Korpus}

Bearbeitungsschritte 4 (stichwortgeleitete Analyse) und 5 (Detailanalyse, siehe unten) wurden teilweise parallel durchgeführt, um eine gegenseitige Überprüfung der punktuellen, das heißt textstellenbasierenden, stichwortgeleiteten Analyse und der kontextualisierten Analyse einzelner Diskussionen im Detail zu erzielen. In der stichwortgeleiteten Analyse wurden zunächst auf Grundlage der Kenntnis der Diskussionen typische Formulierungen gesucht, die dazu geeignet waren, relevante Korpusstellen aufzuspüren. Mit einem einfachen Suchlauf (Microsoft Word) wurden die Textstellen im Korpus markiert, auf Relevanz überprüft und mit ihrem näheren sprachlichen Umfeld isoliert. Als relevant wurden die Textstellen immer dann eingestuft, wenn in ihnen eine im weitesten Sinne form- oder sprachbezogene Aussage über den Text gemacht wurde. Ergab das Suchwort „Sprache“ beispielsweise den Treffer „zur Sprache kommen“, wurde diese Textstelle nicht berücksichtigt. Zufallsfunde, die zwar nicht unmittelbar zum erwarteten Sinn des Suchworts passten, allerdings in anderer Weise für das Thema relevant waren, wurden dagegen berücksichtigt. Wenn also das Suchwort „Form“ den Treffer „das habe ich in dieser Form noch nie gelesen. Diese minutiöse Art der Darstellung“ ergeben hätte, wäre die Textstelle aufgenommen worden, obwohl „Form“ nicht im Sinne von „formale Gestaltung“ verwendet wird, denn statt dessen wird der Maßstab Originalität sprachlich begründet, wie sich aus 
dem unmittelbaren sprachlichen Kontext ergibt.

Die als relevant eingestuften Textstellen - alle mit einem Bezug auf Sprache und Form - wurden nach Wertmaßstäben kategorisiert. Nicht immer war dabei die Zuordnung zu einem Maßstab möglich. In solchen Fällen wurden alle in Frage kommenden Maßstäbe notiert. Im Anschluss wurden die Textstellen nach Zugehörigkeit zu den Maßstäben sortiert und alle Textstellen daraufhin analysiert, wie sie sich zu dem Maßstab verhalten. Modifikationen der Kategorisierung aufgrund von Fehleinschätzung wurden vorgenommen.

\subsubsection{Detailanalysen von Einzeldiskussionen}

Die teilweise parallel, teilweise in Anschluss an die stichwortgeleitete Analyse durchgeführten Detailanalysen sollen zeigen, wie sich das Zusammenspiel der Werte im Kontext einer ganzen Diskussion verhält. Damit wird der Tatsache Rechnung getragen, dass Wertungen im Rahmen des Ingeborg-Bachmann-Wettbewerbs nicht als einzelne Wertaussagen geäußert werden, sondern Teil eines dynamischen Wertungsprozesses sind, in dem nicht, wie etwa in einer Rezension, ein einzelnes wertendes Subjekt seine Meinung über einen $\mathrm{zu}$ bewertenden Gegenstand äußert, sondern in dem die Meinungen verschiedener Wertender direkt aufeinandertreffen und sich so gegenseitig bedingen. Auswahlkriterium für die Detailanalyse war deshalb auch der Eindruck der Repräsentativität für bestimmte Wertekonstellationen. Insgesamt wurden sieben Detailanalysen durchgeführt.

\subsection{6 Überprüfung}

Im Rahmen des Korrekturprozesses der Arbeit wurden auch die Diskussions-Transkripte noch einmal vollständig korrekturgelesen. Diese Gelegenheit wurde genutzt, um die Ergebnisse noch einmal mit dem gesamten Material rückzukoppeln und zu überprüfen, ob die Ergebnisse ergänzt, in Einzelheiten verworfen oder differenziert werden müssen. Diese Überprüfung ergab, dass die Ergebnisse im Wesentlichen vollständig, zutreffend und nachvollziehbar waren. Die wenigen Modifikationen und Ergänzungen, die angebracht waren, ließen sich mit geringem Aufwand integrieren. ${ }^{8}$

\footnotetext{
$\overline{8}$ Das Korpus böte darüber hinaus allerdings eine Vielzahl weiterer Analysemöglichkeiten, die im Rahmen
} dieser Arbeit nicht verfolgt wurden. 


\subsection{Schwachstellen der Vorgehensweise}

Neben den klaren Vorteilen eines umfassenden, ursprünglich mündlichen Korpus gibt es klare Nachteile desselben. Den Vorzügen der Spontaneität und vergleichsweise größeren Unmittelbarkeit mündlicher Aussagen steht eine gewichtige Schwierigkeit im Umgang mit ihr gegenüber, nämlich die Vagheit und die relative Ungeschliffenheit mündlicher Sprache. Dem kann entgegnet werden, dass gerade das germanistische Studium eine solide Grundlage für das Verständnis wertender Aussagen anderer professioneller Leser bildet, und dass die Analyse von Wertungsprozessen daher angemessene und plausible Interpretationen liefern kann. Die Größe des Korpus, die dabei helfen kann, einzelne Fehlinterpretationen durch die Menge vorhandener Aussagen zu relativieren, führte gleichzeitig zu Unübersichtlichkeit und - nicht zuletzt - zu Schwierigkeiten der Darstellbarkeit. Vor allem in den stichwortgeleiteten Analysen konnte nur punktuell für den Leser nachvollziehbar gemacht werden, dass und wie ein Wertmaßstab eingesetzt wird. Diesem Eindruck der Zufälligkeit, sollen die Detailanalysen entgegenwirken. Gerade weil es sich bei der vorliegenden Arbeit um eine Grundlagenstudie handelt, aber auch aufgrund der Menge der analysierten Wertungen, wurden Entscheidungen, welche Aspekte aufzunehmen wären, zugunsten der Übersichtlichkeit getroffen. Jeder der vorgefundenen Wertmaßstäbe ließe sich im Einzelnen noch differenzieren. Im Rahmen dieser Arbeit wurde dem Gesamtbild gegenüber der detaillierten Differenzierung der Vorzug gegeben. Hier bleibt viel Potential für weitere Studien.

Indem die formal-ästhetischen Wertmaßstäbe von Heydebrand/Winko (1996) bei der Kategorisierung als Stütze verwendet wurden, hat sich vor allem in der frühen Analysephase eine Einschränkung des Blicks auf diese Wertmaßstäbe ergeben. Zwar waren diese eine Stütze in der (Selbst-)Verständigung, verstellten aber teilweise auch den Blick auf die konkrete Ausprägung der Maßstäbe. Im weiteren Verlauf der Analyse konnten die dadurch entstandenen Vereinfachungen und Verschiebungen jedoch korrigiert werden. In der verwendeten Terminologie ist der Wertekatalog von Heydebrand/Winko allerdings weitgehend erhalten geblieben. 


\section{3 Über den Ingeborg-Bachmann-Wettbewerb}

Bevor Wertungen und Werte im Rahmen des Ingeborg-Bachmann-Wettbewerbs in den Blick genommen werden, ist es notwendig zu verstehen, wie der Wettbewerb organisiert ist. Eine ausführliche Auseinandersetzung mit der Geschichte des Ingeborg-Bachmann-Wettbewerbs, seiner spezifischen soziologischen Struktur, seiner Funktionsweise als Wettbewerb und seiner medialen Präsenz hat Doris Moser in ihrem Buch „Der Ingeborg-BachmannPreis: Börse, Show, Event“ (2004) dargestellt. Moser beschreibt den Wettbewerb als einen Börsenplatz, auf dem, im Sinne Bourdieus (2001), verschiedene Kapitalsorten (vgl. Kapitel 4.3) gehandelt werden. Neben dem Ziel, ,gute“ literarische Texte und ihre Autoren auszuzeichnen, das man jedem Literaturpreis unterstellen kann, gehe es auch darum, Kontakte zu knüpfen, die Aufmerksamkeit der Öffentlichkeit auf sich zu ziehen und sein Prestige zu verbessern, letztlich also darum, aus der Zusammenkunft in Klagenfurt finanziellen Gewinn zu ziehen (Moser 2004, 424). Obwohl nicht von der Hand zu weisen ist, dass der Wettbewerb eine ökonomische Komponente hat, werden in ihm nicht zuerst ökonomische, sondern kulturelle Werte verhandelt. Gleichzeitig ist der Wettbewerb ein Event, zu dem Akteure der unterschiedlichen Bereiche des Literaturbetriebs anwesend sind, und das dadurch erlaubt, Kontakte zu knüpfen und in einen gemeinsamen Diskurs über Literatur einzutreten. Insofern stellt der Ingeborg-Bachmann-Wettbewerb eine Veranstaltung dar, bei der, trotz der Hoffnung auf finanziellen Gewinn - sei er unmittelbar oder langfristig die wohl alle Beteiligten teilen, vor allem kulturelles Kapital gehandelt wird. Insbesondere für die Juroren, die als Wertende den Mittelpunkt der vorliegenden Arbeit bilden, ist der finanzielle Gewinn kaum unmittelbar; ${ }^{9}$ der potentielle Gewinn an kulturellem Kapital dürfte jedoch hoch sein. Der Ingeborg-Bachmann-Wettbewerb muss als eine Veranstaltung gesehen werden, in deren Rahmen 1. Aufmerksamkeit auf den Literaturbetrieb als Ganzes und auf die teilnehmenden Autoren und Juroren gelenkt wird; 2. Kontakte unter den verschiedenen Akteuren des Literaturbetriebs geknüpft werden und 3. Meinungen über die Wertigkeit der dort vorgestellten literarischen Texte ausgetauscht werden. In der langsam beginnenden Auseinandersetzung mit Literaturpreisen (Dahnke 2016; Dücker 2013; Dücker 2005; Moser 2004) ist das Interesse primär auf die Frage gelenkt worden, was Literaturpreise welcher Interessensgruppe einbringen. Die Grundfragen sind: Warum werden überhaupt Preise gestiftet und warum machen Autoren mit? Die genaue Umsetzung der vordergründigen Absicht der Preise, nach bestimmten oder unbestimmten Kriterien

9 Die Juroren erhalten auch eine finanzielle Entschädigung (Honorar). Das geht u. a. aus den Diskussionen selbst hervor. Über die Höhe des Honorars macht der Veranstalter, auch auf Anfrage, keine Angaben. 
„gute“ Literatur auszuzeichnen, hat bisher weniger Beachtung gefunden. Dennoch ist die Beurteilung von Literatur vordergründig stets das Kernanliegen der Preise, und ist gerade deshalb ein interessanter Gegenstand für die Wertungsforschung. Die folgende Übersicht über die Organisation und Funktionsweise des Ingeborg-Bachmann-Wettbewerbs soll einen kurzen Blick auf den Kontext der Wertungsanalysen ermöglichen und gleichzeitig jene Facetten hervorheben, die für den Ingeborg-Bachmann-Preis besonders prägend sind. Die Geschichte des Preises wird dabei nicht beachtet, sondern nur jene Eigenschaften, die für den Untersuchungszeitraum 1999 bis 2009 von Bedeutung sind. Für ausführlichere Informationen sei noch einmal auf Doris Mosers Arbeit verwiesen.

\subsection{Literaturpreise als Wertungs- und Kanonisierungsinstanzen}

Literaturpreise wirken als Institutionen intentional - wenn auch nicht explizit - an der Bildung von Kanones mit (zu Kanonisierungsprozessen: Winko 2002). Indem Werke ausgezeichnet werden, die im Sinne der Satzung des Preises als gelungen gelten, wird der Anspruch öffentlich gemacht, dass das entsprechende Werk wertvoll ist. Aufgrund dieser Eigenschaft von Literaturpreisen müssen alle Handlungen, die im Rahmen eines Literaturpreises bzw. -wettbewerbs in Bezug auf den ausgezeichneten oder auch auf die zur Auswahl stehenden Texte ausgeführt werden, als wertende Handlungen verstanden werden. Mit der Vergabe des Preises verbinden sich neben der wertenden Funktion (Auszeichnung eines als bedeutend eingeschätzten Autors, Textes oder Werkes) weitere Funktionen: Die Vergabe eines Literaturpreises bringt der verleihenden Institution sowie ggf. dem Verleihungsort Aufmerksamkeit und Prestige. Dahnke (2016, 214) geht davon aus, dass „der erste und zentrale Beweggrund zur Gründung eines Literaturpreises [...] für viele Akteure die Beachtung inner- und außerhalb des literarischen Feldes [ist]". Ebenso verschafft die Zuerkennung eines Preises dem Autor Aufmerksamkeit und Prestige in der Öffentlichkeit, damit verbunden einen ökonomischen Gewinn durch das Preisgeld und möglicherweise bessere Absatzzahlen. Literaturpreise wirken insgesamt daran mit, das literarische Feld zu strukturieren und der Literatur punktuell breitere Aufmerksamkeit zu verschaffen. Sie sind untereinander nicht gleichwertig, sondern haben ein unterschiedliches Gewicht, das sich u. a. in der medialen Präsenz wiederspiegelt (zur Funktionen von Literaturpreisen: Dücker 2013; Dücker 2005; Dahnke 2016).

Dücker $(2005,18)$ begreift die Vergabe von Literaturpreisen als Gabentausch. Der Autor erhält den Preis. Als Gegengabe erhält die verleihende Institution „einen Text, der es der

Institution erlaubt, ihre kulturpolitischen Ziele öffentlich zu vertreten“. Über den Umweg 
des Textes als einem kulturell bedeutenden Objekt, versuchen sich die Institutionen auf diesem Weg in die Literaturgeschichte „einzuschleichen“. Nimmt man diese Dimension von Literaturpreisen ernst, müsste in Klagenfurt eine Jury sitzen, die die „kulturpolitischen Ziele" der Stadt Klagenfurt, sowie ganz nebenbei auch noch mehrerer anderer preisstiftender Institutionen vertritt. Denn anlässlich der Tage der deutschsprachigen Literatur in Klagenfurt werden neben dem Hauptpreis eine ganze Reihe anderer Preise verliehen (vgl. Abschnitt 3.2.1). Schon allein wenn man annähme, es ginge nur um die kulturelle Repräsentation der Stadt Klagenfurt, wäre es schwierig, die kulturpolitischen Ziele genau zu bestimmen. Klagenfurt als einer Stadt, die nicht unbedingt als ein kulturelles Zentrum in Europa gilt, mag es darum gehen, mit einem kulturellen Event dieser Größenordnung zu signalisieren, dass Klagenfurt ein Ort der Kultur, der Literatur, ist (Moser 2004, 118 ff.). Nähme man an, die Jury bezöge diese Dimension bewusst in ihre Wertungshandlungen ein, müsste es ihr um kulturelle Repräsentativität gehen. Die Jury steht aber als eine öffentlich wertende Jury auch vor einer ganz anderen Herausforderung: Sie muss das literarisch interessierte Publikum und das Fachpublikum aus dem Literaturbetrieb überzeugen (vgl. Kapitel 5). Mit einer allzu starken Abweichung vom Knowing How der Literaturbewertung gäbe sie sich der Lächerlichkeit preis, würde Prestige verlieren. Faktisch spielen diese hypothetischen Überlegungen für die Juroren selbst wohl kaum eine Rolle. Zum einen sind alle möglichen Referenzrahmen - kulturelle Repräsentativität und literarische Qualität äußerst flexible Kategorien, die individuell gefüllt werden können. Zum anderen erfolgen die Bewertungen, insbesondere auch, weil sie mündlich, spontan geäußert werden, intuitiv. Es ist für den Klagenfurter Wettbewerb davon auszugehen, dass die Funktion für die Stadt Klagenfurt allein dadurch erfüllt wird, dass ein Literaturpreis vergeben wird, dessen Jury hochkarätig besetzt ist und der große mediale Präsenz hat. Die Urteilsbegründung, das macht den Wettbewerb so interessant für die Untersuchung von Wertungen, muss auf der literarischen Ebene erfolgen.

Für Autoren bedeutet die Zusprechung eines Preises neben ökonomischen Gewinn und medialer Aufmerksamkeit (zur Rolle von Aufmerksamkeit für den Autor vgl. Kampmann 2013 und Anz 2013) außerdem einen Gewinn an kulturellem Kapital. Dass erhaltene Literaturpreise, zum Teil sogar die Nominierung für Preise oder die Teilnahme an Wettbewerben wie dem Ingeborg-Bachmann-Wettbewerb, als Auszeichnung verstanden und auch eingesetzt werden, wird deutlich, wenn man bedenkt, dass sie fester Bestandteil der öffentlichen Lebensläufe von Autoren sind und daher beispielsweise in Klappentexten genannt werden. Literaturpreise sind sehr vielfältig in ihrem Anliegen und ihren Absichten (vgl. Dücker 
2013; Dücker 2005). Zentrale Unterschiede liegen darin, ob das Gesamtwerk eines Autors ausgezeichnet und damit ein bereits vorhandenes Prestige weiter gefördert wird (z. B. Georg-Büchner-Preis), oder ob ein einzelner Text eines Autors aufgrund seiner Qualität geehrt wird (z. B. Deutscher Buchpreis). Bei den einzeltextwertenden Preisen können solche unterschieden werden, die von einem Text eine bestimmte Grundvoraussetzung fordern Zugehörigkeit zu einem Genre, intellektuelle Nähe zum Namensgeber des Preises, Alter des Autors, Ausrichtung des Textes (engagiert, experimentell) - oder ob es keine Einschränkung gibt und somit, so jedenfalls kann man annehmen, ausschließlich das Gelungensein des Textes in Bezug auf nicht konkretisierte Maßstäbe ausschlaggebend für seine Bewertung ist. Der Ingeborg-Bachmann-Preis zeichnet einen einzelnen Text aus, genaugenommen sogar eine konkrete Performanz eines Textes. ${ }^{10}$ Kriterium ist offenbar das literarische „Gelungensein“. Die Richtlinien des Preises lassen keine Rückschlüsse auf Urteilskriterien zu. Die Diskussionen lassen allerdings vermuten, dass keine Maßstäbe vorausgesetzt werden. Beschränkt ist der Ingeborg-Bachmann-Wettbewerb allein auf erzählende Texte, die sich in 25-30 Minuten vortragen lassen.

Im deutschsprachigen Raum gibt es nur wenige Literaturpreise derselben Größenordnung, die mit dem Ingeborg-Bachmann-Preis die charakteristische Wettbewerbsstruktur teilen. Der Leonce-und-Lena-Preis in Darmstadt ist ein vergleichbarer Wettbewerb für Lyrik, ebenfalls mit öffentlichen Diskussionen (Literarischer März „Wettbewerb“). Beim Open Mike in Berlin lesen die Autoren zwar auch öffentlich, die Jury entscheidet aber hinter geschlossenen Türen. Außerdem besteht die Jury aus nur drei Mitgliedern, die allesamt Autoren sind (Haus für Poesie „Statuten“).

\subsection{Der Ingeborg-Bachmann-Wettbewerb}

Der Ingeborg-Bachmann-Preis ist mit einem Preisgeld von 25.000 Euro seit 2006 (davor 22.500 Euro (2003-2005), 21.800 Euro (2002), 250.000 ÖS (1999-2000), 300.000 ÖS (2001)) einer der bedeutenderen Literaturpreise im deutschsprachigen Raum. Seit seiner Gründung 1977 ist das Verleihungsverfahren mehrfach leicht geändert worden, der Gesamtcharakter hat sich jedoch kaum verändert: Über die Jahre wurde die Jury verkleinert und dadurch weniger Autoren eingeladen, die Sendezeiten im Fernsehen haben sich mehrfach verschoben, die Anzahl und Dotierung der verliehenen Preise hat sich mit den jeweiligen

$\overline{10}$ Es gilt allerdings als ungeschriebenes Gesetz unter den Juroren, dass die Bewertung sich in erster Linie auf den gedruckten und nicht auf den gelesenen Text beziehen sollte. Das betonen die Juroren in den Diskussionen immer wieder explizit. Dennoch entspricht es der Logik der Veranstaltung, dass der vorgetragene Text die aktuellste Variante ist und sich dem Publikum unmittelbar als Gegenstand der Bewertung darstellt (vgl. Kapitel 5). 
Sponsoren geändert, die Rolle und Rechte des Moderators haben sich verschoben und durch das Internet hat sich der Wettbewerb neue Präsentationsformen erschlossen. Gleich geblieben ist seit 1977 die Präsentation als Wettbewerb, die den Preis, neben dem Anspruch auf Transparenz, wesentlich prägt. Die Organisation als Wettbewerb erlaubt es, die Bewertung als ein Event aufzubauen und ihm größere mediale Präsenz zu verschaffen. Im Gegensatz zu anderen Literaturpreisen, bei denen lediglich das Resultat der Juryentscheidung präsentiert wird, bietet der Ingeborg-Bachmann-Wettbewerb Einblicke in den Prozess der Urteilsfindung. Diese Prozessualität verschafft dem Verleihungsverfahren eine Dynamik, die das literaturinteressierte Publikum dazu einlädt, dem Preis über längere Zeit Aufmerksamkeit zu schenken, mit einem Favoriten mitzufiebern oder, seit der Möglichkeit im Internet für den Publikumspreis eine Stimme abzugeben, die Preisvergabe teilweise mitzubestimmen. Mit dem Anspruch der Transparenz geht die vielfältige mediale Aufbereitung einher. Indem der gesamte Prozess der Bewertung offengelegt wird, suggeriert der Wettbewerb eine größere Glaubwürdigkeit. Wettbewerbscharakter, Anspruch auf Transparenz und Glaubwürdigkeit sowie Prozessualität sind also jene Eigenschaften, die den Ingeborg-Bachmann-Wettbewerb kennzeichnen, und die in der Auseinandersetzung mit den Bewertungen immer auch in den Blick genommen werden müssen.

Seine mediale Präsenz schafft sich der Preis primär durch seine Anlage als Wettbewerb: Die von den einzelnen Jurymitgliedern eingeladenen Autoren - jeder Juror hat das Recht, zwei Autoren einzuladen - lesen ihren Text vor; direkt im Anschluss erfolgt die Bewertung durch die Jurymitglieder. Die Bewertung durch die Jury erfolgt zum einen vor einem vor-Ort-Publikum im ORF Theater in Klagenfurt und wird zum anderen live auf dem Fernsehsender 3sat übertragen, sodass Interessierte das Geschehen verfolgen können. Zudem gibt die Webseite des Wettbewerbs seit 1998 ausführliche Informationen. Zunächst wurden die Lesungen und Diskussionen als Audio-Dateien zur Verfügung gestellt (1998), in den darauffolgenden Jahren wurden Videos zur Verfügung gestellt. Die Webseite bietet außerdem die gelesenen Texte online und zum Download, Hintergrundinformationen zu den Autoren und Zusammenfassungen der Diskussionen sowie der Preisverleihung. Darüber hinaus wurden seit Gründung des Preises 1977 im Anschluss an den Wettbewerb zunächst alle Texte als Buch unter dem Titel „Klagenfurter Texte“ veröffentlicht und seit 1990 die Siegertexte mit zugehörigen Diskussionstranskripten und Voten der Jurymitglieder während der Preisverleihung mit der jeweiligen Jahreszahl unter dem Titel „Die Besten [1990] - Klagenfurter Texte“. Es wird also Wert darauf gelegt, die Transparenz des Wettbewerbs in diversen Medien zu kommunizieren. Der Ingeborg-Bachmann-Wettbewerb 
wird durch die überregionale Presse in Deutschland interessiert, wenn auch häufig kritisch, wahrgenommen.

Die Autoren stehen während des Wettbewerbs in einem direkten Konkurrenzverhältnis zueinander, das heißt, ihre Texte werden gegeneinander abgewogen. Der Wettbewerb ist auf erzählende Texte beschränkt, darüber hinaus gibt es allerdings keine Einschränkungen, sodass davon ausgegangen werden muss, dass das übergeordnete Kriterium eine - nicht näher spezifizierte - Güte, ein Gelungensein, des Textes ist. Das literarisch Gelungene ist unter den Voraussetzungen des aktuellen Wertungsdiskurses, das muss man unterstellen, auch das kulturell Hochwertige.

\subsubsection{Weitere verliehene Preise}

Es wird oft vergessen, dass im Rahmen des Ingeborg-Bachmann-Wettbewerbs nicht nur der Ingeborg-Bachmann-Preis, sondern auch mehrere, dem Preisgeld und der medialen Bedeutung nach kleinere Preise verliehen werden. Die Anzahl und Zusammensetzung der anderen, ,kleineren“ Preise variiert. Zwischen 1999 und 2009 wurden folgende Preise zusätzlich zum Ingeborg-Bachmann-Preis verliehen:

- Preis des Landes Kärnten (1999), (120.000 ÖS)

- Stipendien der Plattform kulturinteressierter Kärntnerinnen und Kärntner (2000), (50.000 ÖS)

- Preis der Jury (2000 - 2005), (10.000 Euro)

- Ernst-Willner-Preis (1999 - 2009), (6.000 - 8.500 Euro)

- 3sat-Stipendium (1999), (6.000 DM)

- 3sat Preis (2000 - 2009), (7.500 Euro)

- Telekom-Stipendium (1999), (50.000 ÖS)

- Telekom Austria-Preis (2006 - 2008), (10.000 Euro)

- Kelag-Publikumspreis (2002 - 2008), (5.000 - 6.000 Euro)

- Kelag-Preis (2009), (10.000 Euro)

- Hypo-Group-Publikumspreis (2009), (7000 Euro) (Wikipedia „Ingeborg-BachmannPreis")

Auch die unbedeutenderen Preise sind mit Preisgeldern dotiert, die zwar mit den „großen“ Preisen mit Preisgeldern über 20.000 Euro nicht mithalten können, mit Preisgeldern zwischen 5000 und 10.000 Euro im Vergleich zu vielen anderen Literaturpreisen jedoch gar 
nicht so unbedeutend sind. Allerdings verbindet sich mit diesen Preisen deutlich weniger Prestige. Bei einer Teilnehmerzahl von 14 Autoren im Jahr 2009 und insgesamt fünf zu verleihenden Preisen, um nur ein Beispiel zu nennen, war die Chance der Autoren, mit einer Auszeichnung aus dem Wettbewerb zu gehen, weitaus höher als bei anderen Literaturpreisen.

\subsubsection{Die Jury}

Die Jury besteht zwischen 1999 und 2009 aus sieben bis neun Juroren. In der Regel stammen zwei Juroren aus der Schweiz, zwei Juroren aus Österreich und die restlichen Juroren aus Deutschland. Alle Juroren haben einen großen Bekanntheitsgrad im Literaturbetrieb. Sie repräsentieren neben den Nationen auch unterschiedliche Berufe: „PublizistInnen, KritikerInnen, WissenschaftlerInnen und SchriftstellerInnen“ (ORF „Richtlinien“). Viele Juroren sind dabei in verschiedenen Bereichen tätig, die mit Literatur zu tun haben, sind also gleichzeitig Literaturwissenschaftler und Autor, Literaturkritiker und Übersetzter etc. Literaturkritiker und Kulturjournalisten sind unter den Juroren stärker repräsentiert als Literaturwissenschaftler und Autoren. Die Übersicht zeigt alle Juroren, die zwischen 1999 und 2009 in der Jury tätig waren - manche von ihnen in mehreren Jahrgängen -, ihre Herkunft und ihren Beruf. Manche Juroren sind in mehreren Rollen im Literaturbetrieb tätig. Es wurde jeweils versucht, ihre Hauptrolle anzugeben. 


\begin{tabular}{l|l|l} 
Literaturkritiker, Publizisten & Literaturwissenschaftler & Autoren \\
\hline Karin Fleischanderl (A) & Ulrike Längle (A) & Robert Schindel (A) \\
Paul Jandl (A) & Konstanze Fliedl (A) & Josef Haslinger (A) \\
Klaus Nüchtern (A) & Daniela Strigl (A) & Alain Claude Sulzer (CH) \\
Pia Reinacher (CH) & Ilma Rakusa (CH) & Burkhard Spinnen (DE) \\
Thomas Widmer (CH) & Hildegard E. Keller (CH) \\
Martin Ebel (CH) & Silvia Bovenschen (DE) & Firgit Vanderbeke (DE) \\
Dieter Bachmann (CH) & Elisabeth Bronfen (DE) \\
Hardy Ruoss (CH) & Norbert Miller (DE) & \\
Iris Radisch (DE) & Heinrich Detering (DE) & \\
Ursula März (DE) & & \\
Thomas Steinfeld (DE) & \\
Ijoma Mangold (DE) & \\
Meike Feßmann (DE) & & \\
Karl Corino (DE) &
\end{tabular}

Es ist davon auszugehen, dass bei der Auswahl der Jurymitglieder neben den genannten Kriterien (ausgewiesenes Prestige im Kulturbetrieb, Nationalität, Beruf) auch ihre mediale Kompetenz eine Rolle spielt. Der Ingeborg-Bachmann-Wettbewerb ist für den Literaturbetrieb ein Event, das, wie bereits gezeigt, medial sehr präsent ist, und daher darauf angewiesen ist, dass die Jurymitglieder wissen, wie man sich vor der Kamera geschickt präsentiert.

\subsubsection{Die Autoren}

Autoren, die beim Ingeborg-Bachmann-Wettbewerb lesen, gehören mit durchschnittlich 36 Jahren (Moser 2004, 192) ${ }^{11}$ eher der jüngeren Autorengeneration an. Die meisten von ihnen haben bereits Texte publiziert und sind von der Literaturkritik wahrgenommen worden. Zugleich handelt es sich in der Regel nicht um etablierte Autoren, deren Prestige bereits gesichert ist. Eine ganze Reihe von Preisträgern ist in den Jahren nach der Teilnahme am Wettbewerb bekannter geworden: Uwe Tellkamp, Juli Zeh, Julia Franck, Jenny Erpenbeck, Wolfgang Herrndorf, Saša Stanišić, Tilman Rammstedt und Clemens J. Setz sind mittlerweile bekannte Autoren mit größeren oder gar großen Erfolgen geworden.

$\overline{11}$ Dieses Durchschnittsalter wurde für die untersuchten Jahrgänge stichprobenartig bestätigt. 
Autoren können sich nicht für den Preis bewerben, sondern müssen von einem Jurymitglied zum Wettbewerb eingeladen werden. ${ }^{12}$ Allerdings besteht dabei die Möglichkeit, einem Jurymitglied einen unpublizierten Text, in jüngeren Jahren unter Vermittlung durch einen Verlag oder eine Literaturzeitschrift (ORF „Ausschreibung“, 2015), zuzusenden, um möglicherweise ausgewählt zu werden.

Für die Autoren bedeutet die Teilnahme neben der Chance auf einen Preis vor allem einen Gewinn an Aufmerksamkeit. In der Befragung von Doris Moser $(2004,320)$ gaben $32 \%$ der Autoren an, die Teilnahme habe ihnen zu finanziellen Gewinnen verholfen, und 38\% der Autoren gaben an, die Teilnahme hätte für sie zu einem Prestigegewinn geführt. Negative Auswirkungen beobachteten nur 4\% (finanzieller Gewinn) und 8\% (Prestige) (ebd.).

Die mediale Präsenz des Wettbewerbs fordert auch von den Autoren in zunehmendem Maße die Bereitschaft, aber auch das Geschick, sich vor laufender Kamera zu inszenieren. Da die Texte von den Autoren vorgetragen werden, spielt der Vortrag für die Einschätzung eine wichtige Rolle. Im untersuchten Zeitraum lässt sich beobachten, dass Autoren zunehmend auch an der Qualität ihres Vortrags gemessen werden. Es ist anzunehmen, dass Autoren, die zu dieser Art von Inszenierung ihrer Texte nicht bereit sind, sich nicht für die Teilnahme am Wettbewerb bewerben würden. Die Bereitschaft, sich medial zu inszenieren, ist also nicht nur ein Kriterium, das die Jurorenwahl beeinflusst, sondern das auch die Autoren betrifft.

Die teilnehmenden Autoren können nur punktuell oder nach Aufforderung in die Diskussion eingreifen. Dass Autoren auf Lob oder Kritik der Jury reagieren und sich dazu positionieren, ist nicht vorgesehen. Jenseits der Lesung seines Textes ist der Autor also ein weitgehend passiver Teilnehmer.

\subsection{Zusammenfassung}

Der Ingeborg-Bachmann-Wettbewerb mit dem Ingeborg-Bachmann-Preis als Hauptpreis zeichnet sich gegenüber anderen Preisen durch sein hohes Preisgeld, seine Transparenz und breite mediale Inszenierung sowie seine Ausrichtung auf überwiegend junge, nicht etablierte aber dennoch bereits bekannte Autoren und künstlerische literarische Erzähltexte aus. Es werden durch die Richtlinien zur Preisvergabe keine Qualitätsmerkmale vorgegeben, auf Grundlage derer Texte bemessen werden sollten (vgl. ORF „Richtlinien“). Da keine Kriterien angegeben werden, kann man davon ausgehen, dass es primär um die Beurteilung der Texte in Bezug auf ihr Gelungensein als literarischer Text, das

$\overline{12}$ Es ist auch möglich, bei mehreren Juroren gleichzeitig einen Text einzureichen. 
heißt als künstlerischer Text geht. Dafür spricht auch, dass die Stadt Klagenfurt, die den Preis stiftet, sich mithilfe dieses Preises auf der kulturellen Bühne präsentieren möchte (vgl. Moser 2004). Wenn literarisches Gelungensein Gegenstand der Wertung ist, bringt das auch mit sich, dass die Juroren sich bei der Urteilsfindung auf jenes Wissen berufen, das ihnen persönlich angemessen erscheint. Neben den bereits genannten Vorteilen des Korpus (Mündlichkeit, gemischte Gruppe von Expertenlesern, Umfang, Prozessualität) ist auch diese Unbestimmtheit der Preisrichtlinien in Hinblick auf Bewertungskriterien, die die Juroren auf ihr erlerntes Wertungswissen zurückwirft, eine günstige Voraussetzung für das Erkenntnisziel der Arbeit. 


\section{Wert und Wertung}

\subsection{Werte}

Bis hierhin sind die Begriffe „Wert“ und „Wertung“ in ihrer alltagssprachlichen Bedeutung verwendet worden. Es ist aber auch schon angeklungen, dass es sich bei Wertungen trotz oder gerade wegen ihrer Alltäglichkeit um ein äußerst komplexes, facettenreiches Phänomen handelt, das zu intensiven Debatten Anlass gegeben hat (vgl. Kapitel 1). Obwohl diese Arbeit nicht anstrebt, einen Beitrag zur theoretischen Bestimmung des Wertbegriffs zu leisten, ist es zweifelsohne notwendig, sich in den literaturwissenschaftlichen Wertungstheorien zu positionieren, denn Wertvorstellungen unterscheiden sich nicht nur inhaltlich - wie Kanondebatten eindrucksvoll illustrieren - sondern auch konzeptuell: Was ist überhaupt ein Wert? Was eine Wertung? Schwierig zu beantworten ist diese Frage vor allem auch deswegen, weil das Wort „Wert“ kein ausschließlich wissenschaftlicher Terminus ist, sondern Bestandteil der Alltagssprache; aber auch weil das Werten eine Tätigkeit ist, die viele alltägliche Handlungen begleitet: Jede alltägliche Entscheidung ist ein Resultat des Abwägens und Auswertens verschiedener Faktoren. Dieser Alltäglichkeit zum Trotz scheinen Werte selbst gerade dort für wertvoll gehalten zu werden, wo sie zum Gegenstand der Auseinandersetzung werden. Sogenannte „Wertedebatten“ verstehen sich von selbst als Debatten, die an die Wurzeln des kulturellen Selbstverständnisses gehen. Diverse Wissenschaften, die sich mit menschlichem Handeln und den Produkten menschlichen Handelns auseinandersetzen, haben sich daher auch mit Werten und Wertungen beschäftigt - neben der Ökonomie auch die Soziologie, die Psychologie, die Ethnologie und die Ethik - und jede Disziplin ist gemäß ihrem Interessensgegenstand und ihrem Untersuchungsziel zu einem Wertbegriff gekommen, der sich von den anderen manchmal stärker, manchmal weniger stark, unterscheidet. Dieses Bedeutungsspektrum von „Wert“, das mit dem der verschiedenen gesellschaftswissenschaftlichen Zweige korreliert, spiegelt sich in den Synonymen, die Duden online für den Begriff „Wert" angibt. Die Synonyme reichen von wirtschaftlichen Begriffen wie „Aktie“, „Sachwert“, „Gegenwert“, „Geldwert“, „Marktwert“, „Tauschwert“ über Wörter, die Zweckmäßigkeit und Wichtigkeit ausdrücken (u. a. „Bedeutung“, „Belang“, „Einfluss“, „Geltung“, „Nutzen“, „Rang“, „Stellenwert“, „Würde“, „Zweck“), den gesellschaftlichen Wert als „Grundsatz“, „Ideal“, „Leitbild“, „Maßstab“, „Wertvorstellung“ bis hin zum mathematischen Zahlenwert (u. a. „Ergebnis“, „Marke“, „Messwert“).

Neben jenen Unterschieden, die aus den Voraussetzungen der jeweiligen Disziplin hervorgehen, beziehen die verschiedenen Wertbegriffe zumindest in den geistes- und sozialwis- 
senschaftlichen Disziplinen dieselben Grundfragen ein, die auch hier als Leitfaden für die Auseinandersetzung dienen sollen. Das Werten von Literatur mag ein Spezialbereich der Wertung sein, der in Bezug auf seinen Gegenstand eine spezifische Ausprägung hat, als Teil eines sozialen Handlungs- und Kommunikationssystems gehört es einem größeren gesellschaftlichen Zusammenhang an; und als Teil einer individuellen Rezeptionspraxis ist es geprägt von individuellen Verstehens- und Ordnungsstrategien, die helfen, zu selegieren und Komplexität zu reduzieren. Die Grundfragen, die Beiträge zur Wertungsforschung zu beantworten versuchen, betreffen:

1. die Verankerung der Werte (konstruktivistisch vs. essentialistisch),

2. die Genese der Werte (individuelle psychische Bedürfnisse vs. gesellschaftliche Funktion),

3. die Stabilität der Werte (stabil vs. wandelbar),

4. die Gültigkeit der Werte (Einzelner, soziale Gruppe, Gesellschaft),

5. den Anspruch der Wertung (Gefallensurteil oder Anerkennungsurteil),

6. die Modi von Wertungen (Wunsch, Ziel, Ideal etc.). ${ }^{13}$

Bereits aus diesen Fragen wird ersichtlich, dass Werte in der aktuellen Forschungslandschaft fast ausschließlich als Zuweisungen von außen gesehen werden. Alle genannten Grundfragen sind aus der konstruktivistischen Annahme, dass Werte nicht den Gegenständen innewohnen, sondern ihnen durch gesellschaftliche Konventionen zugewiesen werden, abzuleiten. Die Punkte 5 und 6 beziehen sich nicht auf Werte, sondern auf Wertungen. Auch hier wird allerdings ein Werterelativismus mitreflektiert, denn wären Werte den Dingen innewohnende Eigenschaften, bestünde die Aufgabe des Wertenden einzig darin, diese Werte aufzuspüren und dingfest zu machen. Wie in der Literaturwissenschaft bis in die Sechzigerjahre des 20. Jahrhunderts hinein üblich, wäre dann das Werten ein Prozess der Eingeweihten, die durch lang geschultes Betrachten des Objekts dessen in ihm angelegten Wert bestimmen können (vgl. Wehrli [1965] 1980; Wutz [1957] 1980; Emrich [1961] 1980; Staiger 1971). „Wahre“ Experten müssten dann immer in der Lage sein, zu einem eindeutigen und übereinstimmenden Urteil zu kommen. Während der Wert von Texten aus dieser Sicht unzweifelhaft ist, kann der Status des Experten stets bezweifelt werden. Auseinandersetzungen können daher eigentlich nur die Legitimität des Expertenstatus betreffen. Im

$\overline{13}$ vgl. zu den Modi des Wertens Worthmann (2004). 
Zuge der Hinwendung zu den gesellschaftlichen Bedingungen des Wertens seit den 1960er Jahren rücken neben der gesellschaftlichen Bedingtheit von Werten die kommunikativen Funktionen von Wertungen stärker ins Blickfeld.

Im Rahmen dieser Arbeit wird eine gemäßigt konstruktivistische Position vertreten: Zwar wird grundsätzlich davon ausgegangen, dass Werte eine kommunikative Funktion haben und dazu beitragen, das literarische Feld zu strukturieren, gleichzeitig wird davon ausgegangen, dass die Zuweisung von bestimmten Werten an einen Text nicht beliebig ist, sondern auch eine Reaktion auf Angebote des Textes darstellt. Ein solches gemäßigt konstruktivistisches Werteverständnis ist am ehesten mit kognitionspsychologischen Befunden über Leseprozesse als eine Mischung aus Top-down- und Bottom-up-Prozessen in Einklang zu bringen. Während grundsätzlich davon ausgegangen werden muss, dass Leser sich durch Wertungen sozial positionieren, bildet die Lektüre des Textes einen Stimulus, der nicht beliebig verändert werden kann. Werte werden zwar zugeschrieben - und das nicht zuletzt als Produkt sozialen Handelns - sie werden aber dennoch in einer Weise auf den Text bezogen, die dem Wertenden durch die Beschaffenheit des Textes gerechtfertigt scheint.

\subsection{Konstruktivistisches Wertverständnis}

Dass Gegenstände oder auch Konzepte nichts besitzen, was sie an und für sich wertvoll macht, sondern dass ihr Wert gesellschaftlich „ausgehandelt“ wird, darf mittlerweile als Konsens der literaturwissenschaftlichen Wertungsforschung vorausgesetzt werden. Die Ansätze sind vielfältig; viele setzen die Legitimität ihres konstruktivistischen Wertverständnisses als selbstverständlich voraus. Angefangen beim Problem der (Nicht-)Repräsentation verschiedener Ethnien im Kanon postkolonialer Gesellschaften (u. a. Gates 1992; Hassan 2001; Madsen 1999; Marx 2004) über Ansätze, die von der Theorie des kulturellen Gedächtnisses ausgehen, wie sie in dem Aufsatzband „Kanon und Zensur“ (Assmann 1987) zusammengefasst sind, bis hin zu systemtheoretischen Überlegungen (beispielhaft Berlemann 2011) gibt es eine ganze Bandbreite von konstruktivistisch geprägten Annäherungen, vor allem an das Phänomen Kanon, damit verbunden aber auch an literarische Wertungen. Dagegen, dass Texte an sich wertvoll sind, spricht unter anderem, dass Werte sich im Laufe der Geschichte verändert haben und dass verschiedene Kulturen, oft sogar verschiedene soziale Gruppen innerhalb einer Gesellschaft, unterschiedliche Werte vertreten und zu unterschiedlichen Wertungsergebnissen kommen (vgl. Rippl/Winko 2014; Heydebrand 1998, 1).

Mit der Annahme eines Wertekonstruktivismus (vgl. Buck 2013, 10; Neuhaus 2013, 40; 
Winko 2007, 444) werden allerdings neue Fragen aufgeworfen: Wie intersubjektiv sind Werte überhaupt? Wie wird ein Wertekonsens gesellschaftlich „ausgehandelt“? Warum überhaupt gibt es gemeinsame Werte? Wie stabil sind Werte? Und, angenommen Wertmaßstäbe werden gesellschaftlich „ausgehandelt“, gibt es nicht trotzdem, gerade bei künstlerischen Objekten, Eigenschaften, die eine positive Bewertung wenigstens begünstigen? Immerhin gibt es neben Verschiebungen im Kanon (De-und Rekanonisierungen), neben zeitlichen und gesellschaftlichen Unterschieden, auch Kunstprodukte, die die Zeiten überdauern und in unterschiedlichen Kulturen geschätzt werden. Neben sehr viel Dissens gibt es auch Konsens, und zwar nicht nur über Inhalte, sondern auch darüber, dass manche Texte gelungen sind.

Zwei Varianten des konstruktivistischen Wertmodells sollen hier in den Mittelpunkt gestellt werden, weil sie zwei unterschiedliche Zugänge illustrieren, wie man sich die Genese von Werten vorstellen kann: der soziologische Ansatz von Pierre Bourdieu und die kognitionspsychologischen Ansätze von Worthmann sowie Belke und Leder. Bourdieu illustriert dabei eine radikal konstruktivistische, soziologische Perspektive; die kognitionspsychologischen Ansätze zeigen auf, wie Input und Verarbeitung bei Bewertungsprozessen zusammenwirken. Auf einen großen Überblick über die Wertbegriffe der verschiedenen Disziplinen soll bewusst verzichtet werden, um den Blick auf die für diese Arbeit wichtigen Ansätze zum Thema Wertung frei zu halten. Eine möglichst präzise Bestimmung des theoretischen Wertbegriffs ist nicht Teil des Erkenntnisziels dieser Arbeit, die in erster Linie nach der Beschaffenheit von auf die Form des Textes bezogenen Wertungen fragt. Das konstruktivistische Wertmodell gibt zwar eine Antwort auf die Frage, wie Wertzuweisungen in der Verständigung über Werte funktionieren, es vernachlässigt aber einen Bestandteil der Rezeption literarischer Texte, der entscheidenden Einfluss auf die Bewertung hat: die unmittelbare Wirkung des Textes während der Lektüre. Die Lust am Text ist ein Faktor, dessen Relevanz zwar sofort intuitiv einleuchtet, der aber aus verschiedenen Gründen keinen festen Platz in Wertungstheorien gefunden hat. Auch dieser Aspekt soll angesprochen werden. Abschließend sollen drei literaturwissenschaftliche Wertungsmodelle, die Aufschluss darüber geben, wie genau Werte und Wertungen in literaturwissenschaftlichen Kontexten funktionieren, vorgestellt werden.

\subsection{Wertungen und die Feldtheorie Pierre Bourdieus}

Die Theorie des literarischen Feldes des Soziologen Pierre Bourdieu (2001) ist deswegen für die Auseinandersetzung mit literarischen Werten so interessant, weil sie nicht das Objekt 
der Wertung selbst, den Text, in den Vordergrund rückt, sondern einen Erklärungsansatz dafür liefern kann, warum überhaupt Akteure des Literaturbetriebs ein Interesse haben, an einer Veranstaltung wie dem Klagenfurter Wettbewerb teilzunehmen. ${ }^{14}$ Obwohl Bourdieu keine Wertungstheorie per se intendiert hat, lässt sich seine Idee des literarischen Feldes als ein Machtgefüge, in dem es darum geht, kulturelle Leistungen in Prestige umzusetzen, gut auf den Bereich der Wertung anwenden. Wertungen bilden jedoch nur einen Teil jener Handlungen, die das literarische Feld strukturieren.

Bereits Doris Moser beschreibt den Wettbewerb in Klagenfurt als einen Börsenplatz, auf dem verschiedenerlei Kapital gehandelt wird:

Die Veranstaltung ist der Versuch, die Dichotomie von Kunst und Ökonomie aufzuheben, indem das andere [Ökonomie] in den Dienst des einen [Kunst] gestellt wird, das es ermöglichen soll: Preisgeld, Kontakte, Publikationsmöglichkeiten, öffentliche Aufmerksamkeit, Ehre. (Moser 2004, 424)

Indem sie den Wettbewerb analog zur Börse als ökonomischer Einrichtung beschreibt, knüpft sie an Bourdieus Theorie an. Neben ökonomischem Kapital kann Bourdieu (2001) zufolge auch kulturelles und soziales Kapital gehandelt werden. Folgt man dieser Theorie, ist der Wettbewerb in Klagenfurt, so sieht es auch Doris Moser, eine Institution, die den Handel mit den verschiedenen Kapitalsorten, die die unterschiedlichen Repräsentanten einbringen, ermöglicht. Autoren bringen kulturelles, je nach Bekanntheitsgrad auch soziales, Kapital ein. Die im Publikum anwesenden Verlagsvertreter bringen ökonomisches Kapital ein. Jurymitglieder setzen als bekannte Experten ihr soziales Kapital ein, um das kulturelle Kapital, das Texte für Autoren bedeuten, zu erhöhen - nicht selbstlos, versteht sich, sondern um den eigenen Expertenstatus zu untermauern, wenn der Autor einen Preis erhält. Die Autoren wiederum dürfen darauf hoffen, dass der erhöhte kulturelle Wert ihrer Texte dazu führt, dass sie nicht nur an kulturellem, sondern auch an sozialem und ökonomischem Kapital gewinnen (vgl. Neuhaus 2014, 39). Verbalisiert wird dabei freilich nur der Handel mit kulturellem Kapital. Nur auf dieser Ebene ist Bourdieu zufolge das Feilschen um Werte dem Diskurs über den Gegenstand „Literatur“ angemessen.

Die Feldtheorie Bourdieus, von Moser (2004) auf den Ingeborg-Bachmann-Wettbewerb übertragen, bildet einen plausiblen theoretischen Rahmen, um zu verstehen, warum ein Wettbewerb wie der in Klagenfurt stattfindet, warum Autoren an ihm teilnehmen und Juroren ihre Arbeitszeit dafür zu Verfügung stellen. Dennoch ist sie, darauf wird später

14 Die Juroren bekommen für ihre Teilnahme auch ein Honorar. Insofern spielen möglicherweise auch wirtschaftliche Interessen eine Rolle. Über die Honorare und deren Höhe gibt der Veranstalter jedoch auf Anfrage keine Auskunft. 
einzugehen sein, nicht ausreichend, um zu verstehen, wie genau die Interaktion zwischen Leser und Text bei der Textbewertung funktioniert.

Die soziologische Theorie des literarischen Feldes gibt Hinweise darauf, was Wertungshandlungen für den gesellschaftlichen Teilbereich - das literarische Feld - leisten: Werte leiten die Kommunikation. Sie bieten Eckpunkte der Orientierung. Als (kommunikative) Handlungen tragen sie dazu bei, das Feld zu strukturieren, Macht und Kapital zu stabilisieren und umzuverteilen. Damit ist eine Komponente erfasst, die aus soziologischer, zum Teil auch aus psychologischer Sicht, grundsätzlich mit Werten verbunden ist: die Orientierungs- und Identifikationsfunktion für eine Gruppe von Menschen. So geht etwa der Soziologe Kluckhohn (1951) davon aus, Werte seien etwas allgemein Wünschenswertes. Der Psychologe Bilsky $(2009,47)$ hebt ebenso hervor, Werte seien u. a. „kognitive Repräsentationen [...] interaktiver Erfordernisse für die Abstimmung interpersonalen Verhaltens und gesellschaftlicher Erfordernisse für die Sicherung sozialen Wohlergehens und Überlebens".

Bourdieus Theorie kann jedoch nur bedingt erklären, wie der Diskurs über den Wert von Texten im Detail abläuft, warum er genau so abläuft und warum die Kommunikation und die Entscheidungen so ausfallen, wie sie ausfallen, und nicht anders. Auch die Rolle, die der bewertete Text für den Ausgang der Wertung hat, ist weitestgehend unklar. Konkretes Wertungsverhalten lässt sich mittels Bourdieus Theorie ebenso wenig voraussagen wie mithilfe des formal-ästhetischen Wertewissens.

Bourdieu (2001) stützt sich in „Die Regeln der Kunst“ auf Analysen der Literaturlandschaft des ausgehenden 19. und beginnenden 20. Jahrhunderts. Als prägend sieht er für diese Zeit einen Wechsel von Epochen des experimentellen Schreibens und Epochen, die mit bereits bekannten Formen spielen, wobei es immer den Experten überlassen bleibt, neue Spielarten zu entdecken und ihnen Anerkennung zu verschaffen. Gelungene neue Literatur zu finden, ist damit zunächst Expertensache. Erst „,[w]enn sich, nach einer Vermittlungstätigkeit der Experten ein größeres Publikum an die ,neue ${ }^{6}$ Kunst und Literatur gewöhnt hat, dann setzt auch der ökonomische Erfolg ein“ (Neuhaus 2014, 39). Die soziale Stellung des Publikums ist dieser Theorie zufolge entscheidend für den Status des Werkes. Das heißt, wer viele Expertenleser überzeugt, gewinnt an kulturellem Kapital; wer dagegen eine breite Leserschaft zu überzeugen vermag, verliert daran. In Bourdieus Worten nimmt der Wert der Anerkennung ab „wenn die besondere Kompetenz, die dem Konsumenten zuerkannt wird, abnimmt“ (Bourdieu 2001, 190). „Als Prinzip ,guter Literatur gilt also zunächst Verknappung des Angebots - statt des für andere Waren üblichen Ziels der 
Massenproduktion“ (Neuhaus 2014, 39). Weil Bourdieu Autonomie als konstituierendes Merkmal des literarischen Feldes sieht und das Ziel, ein Buch zu verkaufen, diese Autonomie durchbräche, ist das Gute prinzipiell nicht das Breitenwirksame und viel Verkaufte. Bourdieu beschreibt die Ordnung des literarischen Feldes als „spiegelverkehrtes Gegenbild der ökonomischen Welt" (Bourdieu 2001, 342).

Gerade weil Bourdieu sich in seiner Theorie primär auf vergangene Epochen stützt, ist zu fragen, ob die genannten Aspekte, die elitäre Position des Experten einerseits und das Grundprinzip der Verknappung „guter“ literarischer Produkte andererseits, noch zutreffend sind.

Dass Experten über ein Wissen verfügen, das sich nicht jeder angeeignet hat, liegt in der Natur der Sache, nicht nur im literarischen Feld. Allerdings gehörte es lange zum Habitus der Literaturexperten, ihren Zugang zur Literatur als einzigartig zu verstehen. Die in einem 1980 von Peter Gebhardt herausgegebenen Sammelband zur Wertung von Literatur zusammengetragenen Aufsätze zeugen beispielsweise von einer Haltung, die für die Einschätzung von Literatur ganz besondere geistige Vorausetzungen annimmt: Durch Einfühlung in die Literatur, die sehr viel Übung und Empathie verlangt, können Literaturexperten die inneren Regeln des Kunstwerks erfassen und ihren Schönheitswert beurteilen. Autoren sind Genies, Literaturwissenschaftler ihre lesenden Pendants. Nun haben aber soziologische Ansätze wie die Feldtheorie Bourdieus die Literaturwissenschaft längst erreicht, prägen diese und greifen so in jene Bereiche über, in denen an Universitäten ausgebildete Literaturexperten arbeiten. Das Bewusstsein für die Funktionsweise des literarischen Feldes hat also Eingang in die Arbeit der Experten außerhalb der Universitäten gefunden. Parallel zu dieser Veränderung in der Literaturwissenschaft (Cultural Turn) mit ihren Folgen für Literaturexperten mit literaturwissenschaftlichem Vorwissen, die nicht (nur) an den Universitäten arbeiten, vollzieht sich die Veränderung der Medienlandschaft mit der Verbreitung der Massenmedien und ihrem Potential, viele Menschen mit denselben Informationen auszustatten: Radio, Fernsehen und besonders das Internet. Die Entwicklung und Verbreitung des Internets ermöglicht zusätzlich die breite Teilnahme an der Gestaltung von Informationen. Während also einerseits das Bewusstsein steigt, dass viele literarische Entwicklungen nicht aus künstlerischen Gründen stattfinden, sondern aufgrund von Machtverschiebungen innerhalb des Feldes oder möglicherweise sogar als Reflex größerer sozialer Veränderungen (vgl. zum Beispiel Grube 2014; Marx 2004; Hassan 2001; Guillory 1995), kann man gleichzeitig beobachten, dass eine „Demokratisierung“ von Informationen stattfindet, die mit einer neuen „demokratischen“ Rhetorik einhergeht. Insbesondere das Internet nährt 
die Illusion, dass jeder mitmachen könne und solle, dass es neben den anerkannten Experten aus Wissenschaft und Kulturbetrieb Laien geben könne, die eine Wertungsexpertise für einen bestimmten Bereich der Literatur oder eine bestimmte Leserschaft entwickelt haben. Diese Entwicklung wirkt der Vorstellung vom ausgebildeten Experten mit singulärem Zugriff auf den Gegenstand, der ihm eine einzigartige (mächtige) Stellung verleiht, entgegen. Dem durch Ausbildung legitimierten Experten tritt also ein Laien-Experte an die Seite, dessen Status sich auf Kennerschaft und Repräsentativität für eine bestimmte Lesergruppe stützt. Auf Produzentenseite eröffnen die elektronische Veröffentlichung (EBook) und der kostengünstige Digitaldruck Möglichkeiten, sich den Auswahlmechanismen der Verlage zu entziehen. ${ }^{15}$ Professionelle Leser müssen sich unter diesen Voraussetzungen neu positionieren. Dass es einen Literaturbetrieb ohne Machtverhältnisse geben wird, in dem jeder publizieren kann, was er will und in dem Lesern - in den Worten dieser Rhetorik - nichts „,vorenthalten“ wird, ist nicht zu erwarten. Die Auswahl und Orientierung, wie sie Verlage und Literaturkritiker bieten, sind notwendige Bestandteile des Umgangs mit Literatur. Allerdings ist davon auszugehen, dass die Konkurrenz zu Laien-Kritikern, die durch ihre starke Präsenz auf Blogs, in entsprechenden Communities wie beispielsweise www.vorablesen.de oder als Kundenbewertungen bei großen Online-Versandhändlern Einfluss auf die Landschaft der Literaturkritik nehmen, eine andere Selbstpräsentation der Experten fordert. Ein Experte kann unter diesen Voraussetzungen nur derjenige sein, der das finden kann, was einer möglichst großen Anzahl von „Laien-Kritikern“ mit literarischem Interesse auch gefällt. ${ }^{16}$ „Guter“ Literatur muss es gelingen, neben den professionellen Lesern mit viel Leseerfahrung auch ein breiteres Publikum zu erreichen. Der Vermittlerstatus von Literaturexperten (vgl. Schmidt 1982, 164 f.) spiegelt sich auch in den Vorstellungen vom Berufsbild wieder. Redakteuren und Lektoren wird in Berufsbeschreibungen heute eine Rolle als Manager, Kommunikator, Organisator und Vermittler zugeschrieben - die Rolle des Gutachters wird dabei explizit als veraltet dargestellt (vgl. Neuhaus 2009). Diese Gesamtentwicklung findet sich auch in den Creative-Writing-Anleitungen (vgl. Kapitel 7) wieder, die der Vorstellung vom regellos schreibenden Genie, die des handwerklich geschickten und geübten Autors gegenüberstellen, der keine Minderheitenliteratur verfasst,

15 Einen ausführlichen Einblick in die Entwicklung des „Kommunikationsraums Buchmarkt“ nach der Jahrtausendwende bietet die Dissertation von Anke Vogel (2011). Sie zeigt die diversen Möglichkeiten auf, wie Leser über verschiedene mediale Kanäle an Bücher und Informationen über Bücher kommen. Insbesondere der online Buchhandel und digitale Formate spielen dabei eine entscheidende Rolle.

16 Vorausgesetzt wird dabei eine Überschneidung der Leseinteressen. Es gibt Zweige der Literatur, die von der professionellen Literaturkritik fast vollständig ausgespart werden, etwa Liebesromane, Western, Science Fiction Serien und Heftchenromane. In diesen Bereichen kommt es auch zu keiner Konkurrenz. Die Konkurrenz zwischen Laien-Kritikern und professionellen Kritikern betrifft vorwiegend den Bereich der (gehobenen) Unterhaltung. 
sondern eine Literatur, die ein breites Publikum - im Idealfall inklusive der geübten Leser - überzeugen kann. Bourdieus Theorie vom literarischen Feld als einem gesellschaftlichen Raum, in dem Experten darum ringen, Prestige zu erlangen, indem sie origineller, neuer Literatur zum Durchbruch verhelfen, hilft zu verstehen, warum den Auseinandersetzungen über den Wert literarischer Texte überhaupt Aufmerksamkeit zukommt und warum verschiedene Akteure ein Interesse haben, sich aktiv daran zu beteiligen. Die Bewertung literarischer Texte wird so als ein Prozess erkennbar, in dem der Wertende nicht nur auf einen Text reagiert, sondern mit seinen Wertaussagen darüber hinaus auch seine soziale Stellung zu beeinflussen versucht. Insbesondere der Blick auf die Entwicklung der Medienlandschaft, ganz besonders das Internet, sollte dazu anhalten, die konkreten Aussagen, die Bourdieu über die Gesetzmäßigkeiten des literarischen Feldes trifft, auf den Prüfstand zu stellen. Einiges spricht dafür, dass ökonomischer Erfolg und kultureller Wert nicht mehr zwei sich komplementär ausschließende Faktoren sind.

So plausibel die Theorie Bourdieus den gesellschaftlichen Aspekt der Bewertung von Literatur zu erfassen vermag, so sehr vernachlässigt sie, dass Wertungen immer auch den konkreten Bezug auf das Wertobjekt haben und dass Wertende, wenn sie überzeugen wollen, angehalten sind, intersubjektiv nachvollziehbar über das Objekt zu urteilen. Insofern kann die Theorie des literarischen Feldes einen Rahmen für die Beantwortung der Grundfrage dieser Arbeit bereitstellen. Dieser Rahmen ist wichtig. Dennoch wird in der Bewertung von Literatur über den Gegenstand „Literatur“ gesprochen und dieses Sprechen über Text verlangt eine Bezugnahme auf den Text, die nach den Regeln der Kommunikation, wie sie beispielsweise Grice (1991) u. a. mit der Maxime der Qualität formuliert hat, nicht willkürlich sein sollte. Welche Eigenschaften an einem Text gesehen oder übergangen werden, welche im Rahmen einer Bewertung des Textes wie argumentativ eingesetzt werden, richtet sich nicht nur nach der Produktivität kommunikativer Positionen für die Akkumulierung von kulturellem Kapital; es richtet sich auch nach Potentialen, die der Text anzubieten hat. Anders ist Kommunikation nicht denkbar. Nimmt man die Feldtheorie Bourdieus als Ausgangspunkt, kann man die Grundfrage dieser Arbeit, welche Rolle formal-ästhetische Werte in der Bewertung der Texte spielen, in zwei Richtungen präzisieren. Man kann fragen, welche Positionen ein hohes, prestigesteigerndes Potential haben. Daneben kann man aber auch fragen, welche formal-ästhetischen Eigenschaften von Texten herausgegriffen werden, um derartige Positionen kommunikativ zu verankern.

Die kognitionspsychologischen Ansätze, die im Folgenden erläutert werden, bieten einen Blick auf die verschiedenen kognitiven Komponenten und Prozesse, die die Bewertung äs- 
thetischer Objekte bedingen. Sie können dafür die Frage, welche Bedeutung Wertungen für die Wertenden in ihrem sozialen Gefüge haben, nicht beantworten.

\title{
4.4 Der kognitionspsychologische Ansatz von Benno Belke und Helmut Leder
}

Die psychologische Forschung sieht neben der kommunikativen und identifikatorischen Leistung auch einen individuellen Nutzen von Werten auf der Ebene der Bedürfnisse:

\begin{abstract}
Werte sind (a) Konzepte oder Überzeugungen, die sich (b) auf wünschenswerte Zielzustände oder Verhaltensweisen beziehen, (c) situationsübergreifend sind, (d) die Wahl und die Bewertung von Verhalten und Ereignissen leiten und (e) in Hinblick auf ihre relative Bedeutung geordnet sind. Sie sind kognitive Repräsentationen individueller (biologischer) Bedürfnisse (Motive), interaktiver Erfordernisse für die Abstimmung interpersonalen Verhaltens und gesellschaftlicher Erfordernisse für die Sicherung sozialen Wohlergehens und Überlebens. (Bilsky 2009, 47)
\end{abstract}

Gegenüber der soziologischen Herangehensweise Bourdieus, in der Handlungen im Umgang mit Literatur stets in der Funktion gesehen werden, soziales oder kulturelles Kapital (Prestige) anzusammeln - somit eine distinguierende Funktion von Werten -, stellt Bilsky als Psychologe die integrative Funktion von Werten in den Vordergrund: Sie sind „situationsübergreifend" und dienen „interaktive[n] Erfordernisse[n]" und „der Sicherung des Wohlergehens". Werte haben hier eine Ordnungs- und Orientierungsfunktion. Nun ist die Definition Bilskys eine Handbuchdefinition, die sich ganz allgemein auf Werte in der Psychologie bezieht und daher zum einen überhaupt nicht auf den Bezug des Individuums zu (literarischen) Kunstwerken gemünzt ist, zum anderen versuchen muss, eine ganze Bandbreite von Positionen in der Psychologie zusammenzufassen.

Der Frage, wie ästhetische Wahrnehmung, und Wertung als Teil ästhetischer Erfahrung, aus kognitionspsychologischer Sicht zu beschreiben wäre, ist die Arbeit von Belke und Leder (2006) gewidmet. Die Autoren sehen das Bewerten als einen integralen Bestandteil der Auseinandersetzung mit Kunstwerken. Als bewusstes Urteilen findet es allerdings erst relativ spät im Rezeptionsprozess statt. Das Modell von Belke und Leder bietet Ansätze zu Antworten auf genau jene Fragen, die das soziologische Feldmodell nicht geben konnte: Selbst wenn es bei Wertungen letztendlich darum geht, sich im literarischen Feld zu distinguieren und Prestige zu sammeln, ist Wertung nicht willkürlich, sondern orientiert sich am Gegenstand der Wertung. Es werden zwar keine ihm innewohnenden Eigenschaften zutage gefördert, jedoch wird das Kunstwerk wahrgenommen - der Text „gelesen“ - und bildet als Wahrgenommenes die Grundlage für die konkrete Auseinandersetzung. Sobald 
eine Wertung nicht mehr nur eine persönliche Klassifikation bedeutet, sondern nach außen möglicherweise sogar mit dem Ziel zu überzeugen, kommuniziert wird, ist eine konkrete Bezugnahme auf den Gegenstand unabdingbar.

Das Modell der ästhetischen Wahrnehmung leistet neben der genauen Abbildung einzelner Rezeptionsschritte auch eine Integration affektiver Reaktionen auf Kunstwerke. Literaturwissenschaftliche Wertungstheorien (vgl. Kapitel 4.8) erwecken leicht den Eindruck, Wertungen, insbesondere Expertenwertungen, seien ein rationales Vorgehen, bei dem ein Wertender ,in einer konkreten Situation aufgrund von Wertmaßstäben (axiologischen Werten) und bestimmten Zuordnungsvoraussetzungen einem Objekt Werteigenschaften (attributive Werte) zuschreibt“ (Heydebrand/Winko 1996, 39). Wertungen werden in Gefallenswertungen und Anerkennungswertungen unterschieden (vgl. Worthmann 2004, 228), ${ }^{17}$ wobei Gefallenswertungen dem Bereich des Gefühls zugeordnet werden und bisher wenig Beachtung fanden, wohingegen Anerkennungswertungen den eigentlichen Gegenstand der Wertungsforschung bilden und dem rationalen Bereich zugeordnet werden (ebd., 220 ff.). Auch Belke und Leder $(2006,9)$ sind der Ansicht, dass „sich das Urteil des Gefallens eher auf den affektiven Zustand [bezieht], während ein Urteil über die ästhetische Qualität eher als kognitives Resultat der ästhetischen Verarbeitung interpretiert werden kann“. Sie legen jedoch Wert darauf, dass sich das kognitive ästhetische Urteil und die ästhetische Emotion im Wahrnehmungsprozess gegenseitig bedingen, und zwar in jedem Stadium des Rezeptionsprozesses. Damit leisten sie etwas, was der literaturwissenschaftlichen Forschung bisher nicht gelungen ist: die Zusammenführung von intuitiver, affektiver Wahrnehmung des Textes und seiner durch Diskursregeln gesteuerten verbalen Bewertung. Wie sich in der Analyse der Klagenfurter Diskussionen zeigen wird, sind Wertungsprozesse, auch unter Experten, von genau dieser Wechselwirkung geprägt.

Im Modell der ästhetischen Erfahrung („Model of aesthetic experience“) von Belke und Leder (2006) steht an erster Stelle die optische Wahrnehmung des Kunstwerks. Bezogen auf Literatur entspricht diese Stufe dem Leseprozess. Zwar gibt es Komponenten der Wahrnehmung von Literatur, die sich ausschließlich auf das äußere Erscheinungsbild beziehen - Gedichte werden zunächst rein optisch von Prosa unterschieden, die Dicke eines Buches oder sein Druckbild können es attraktiver oder unattraktiver machen - die Auseinandersetzung mit dem Text an sich beginnt allerdings erst mit dem Lesen. In mehreren kognitiven Verarbeitungsschritten wird das Kunstwerk analysiert und mit vorherigen Wahrnehmungserfahrungen sowie allgemeinen und kunstspezifischen Wissensbeständen in

$\overline{17}$ Kienecker (1989) macht eine ähnliche Unterscheidung. 
Beziehung gesetzt. Analyse darf in diesem Zusammenhang nicht gleichgesetzt werden mit der intentionalen, intensiven Auseinandersetzung mit einem Text wie sie Literaturwissenschaftler betreiben. Analyse bedeutet hier zunächst, die Informationen auf der Wahrnehmungsebene zu filtern und zu ordnen, sodass der Gegenstand „verständlich“ wird. Bei Texten heißt das zunächst einen „Text im Kopf“ (Fix 2003, 80 f.) entstehen zu lassen oder sich die „Textwelt“ (Schwarz-Friesel 2006, 67) zugänglich zu machen. Gleichzeitig läuft eine affektive Auseinandersetzung mit dem Gegenstand der Betrachtung ab: „Die ,ästhetische Emotion', auch übersetzbar mit ästhetischer Lust, beruht aus Sicht des Modells auf dem subjektiven Erfolg der Verarbeitung des ästhetischen Objektes und dessen affektiven Begleiterscheinungen“ (Belke/Leder 2006, 9). Je erfolgreicher also der Analyseprozess auf der kognitiven Ebene subjektiv wahrgenommen wird, desto größer auch die ästhetische Lust.

Am Ende des Auswertungsprozesses steht auf kognitiver Ebene ein ästhetisches Urteil, auf der emotionalen Ebene eine „aesthetic emotion“. Diese beiden „Endprodukte“ müssen laut Belke/Leder (2006) nicht gleich ausfallen: Insbesondere Experten können ein ästhetisches Erlebnis, das mit positiven ästhetischen Emotionen einherging auf der kognitiven Ebene trotzdem mit einem negativen ästhetischen Urteil belegen und umgekehrt, meistens jedoch weisen ästhetische Emotion und ästhetisches Urteil in dieselbe Richtung (Belke/Leder 2006, 10).

Belke/Leder $(2006,3)$ gehen außerdem davon aus - und das ist der zweite Punkt, der die Wertungsmodelle u. a. der Literaturwissenschaft um eine entscheidende Nuance ergänzt -, dass die ästhetische Erfahrung von ,,affektiv positiven, selbst verstärkenden und belohnenden Momenten“ geprägt ist, u. z. umso mehr, je mehr der kognitive Verarbeitungsprozess als erfolgreich eingestuft wird:

In dem Modell wird angenommen, daß die erfolgreiche Klassifikation (hinsichtlich Stil und dargestelltem Inhalt) an sich eine selbstbelohnende, affektiv positive Erfahrung ist, die eine ästhetische Evaluation des Objektes positiv beeinflussen kann. Aufgrund der oftmals starken semantischen Mehrdeutigkeit und dem Fehlen klarer referentieller Verweise sind zum einen interindividuell sehr verschiedene Klassifikationen auf dieser Stufe zu erwarten und anderseits eine starke Tendenz mit zunehmender Expertise stilspezifisch zu klassifizieren. Vermutlich stellt gerade diese Bedeutungsvielfalt eine kognitive Herausforderung dar und macht die erfolgreiche Zuordnung hinsichtlich Stil oder Inhalt zu einem nicht trivialen, affektiv bedeutsamen Ereignis. (Belke/Leder 2006, 7)

Der Eindruck, ein Kunstwerk zu verstehen, leitet also selbstbelohnende, affektiv positive Prozesse ein, die wiederum die weitere Auseinandersetzung mit dem Gegenstand motivieren und das abschließende Urteil bedingen. Gerade die Hindernisse, die Kunstwerke dem 
Verstehen in den Weg stellen, können diese Empfindungen positiv steigern. Belke/Leder $(2006,8)$ gehen dabei davon aus, dass „es [vermutlich] sogar ein konstituierendes Merkmal der ästhetischen Erfahrung [ist], daß eine eindeutige Auflösung nicht möglich ist und vom Rezipienten auch akzeptiert wird“. Diese Annahmen geben auch einen Hinweis darauf, warum Wertungen gruppenspezifisch sehr unterschiedlich ausfallen. Mit wachsender Übung können Leser komplexere Texte als (be-)lohnend empfinden. Unterschiedliche Urteile über Texte können also offenbar nicht nur dadurch erklärt werden, dass Leser sich im literarischen Feld unterschiedlich zu positionieren versuchen - ohnehin ist eine distinktive Haltung nur für professionelle Kritiker bedeutend -, sondern auch dadurch, dass unterschiedlich ausgeprägte Leseerfahrung und eine andere Lesesozialisation dazu führen, dass andere Texte als in einem angemessenen Maße zugänglich empfunden werden. Neben der Integration emotionaler Aspekte bietet das Modell der ästhetischen Erfahrung also einen Ansatz, der universell ist, insofern als er keine soziologischen Einschränkungen enthält.

\subsection{Leselust als „blinder Fleck“ der Wertungsforschung}

Das Modell ästhetischer Erfahrung macht auf einen Aspekt aufmerksam, der in der Wertungsforschung mit Bezug auf die sogenannte hohe Literatur bisher wenig beachtet wurde, die Tatsache nämlich, dass es einen lustvollen Umgang mit Literatur gibt, der möglicherweise die Bewertung beeinflusst. Literaturwissenschaftliche Arbeiten zum Thema Wertung leugnen emotionale Reaktionen auf literarische Texte zwar nicht, weil aber emotionale Reaktionen nicht als legitimer Bestandteil wissenschaftlicher Praxis gelten (vgl. z. B. Irsigler et al. 2008), sind sie eher ein vernachlässigter Bestandteil der wissenschaftlichen Auseinandersetzung mit Texten. Kienecker (1989, 69 ff.) geht beispielsweise davon aus, dass jedes literarische Urteil in einem „Appetenzurteil“ (Geschmacksurteil) wurzelt. Er merkt aber auch an, jedes Werturteil sei „begründungspflichtig und -fähig“ (Kienecker 1980, 80). Begründungen setzen stets auf intersubjektive Nachvollziehbarkeit und Beweiskraft. Subjektive Gefallensurteile, als die Wirkungen stets gelten, können diesem Anspruch ihrem Wesen nach nicht gerecht werden.

So müssen literaturwissenschaftliche Arbeiten, die die Ausprägung formal-ästhetischer Werte in kanonischen und nicht kanonischen Texten überprüfen wollen, wie etwa die Arbeiten von Neuhaus (2002), Olsen (2008), Barney (2008), Lerner (2008), auf intersubjektiv fassbare Texteigenschaften eingehen. Die wissenschaftliche Praxis, die intersubjektive Nachvollziehbarkeit zum Ziel hat, lenkt in textorientierten Arbeiten also den Blick weg von der Wirkung hin auf Eigenschaften, die materiell greifbar sind. 
Dass Leselust und Textwirkungen in der Wertungsforschung bisher eine geringe Rolle gespielt haben, ist strukturell in den Positionen der Wertungsforschung angelegt. Lenken Arbeiten, die sich mit der gesellschaftlichen Bedingtheit von Wertungen befassen, den Blick weg vom lesenden Individuum und hin zu den gesellschaftlichen Bedingungen seines Urteils (z. B.Guillory 1995; Grube 2014), sehen sich Arbeiten, die die Bedingungen einer positiven Rezeption im Text selber sehen, verpflichtet, diese Bedingungen am Text selber nachzuweisen (u. a. Neuhaus 2002; Fricke/van Peer 1999). Textwirkungen sind in beiden Perspektiven keine legitime Grundlage der Begründung.

Leselust und Lektürewirkung finden zwar in der Wertungsforschung bisher kaum Beachtung, jedoch gibt es sowohl eine theoretische als auch eine empirische Auseinandersetzung damit, wie Literatur ihre Wirkung beim Leser erzielt. Impulse kommen dabei beispielsweise aus der Medienwissenschaft und der Auseinandersetzung mit Film und Fernsehen, die weniger stark durch den Anspruch des kulturell Wertvollen vorbelastet sind, sodass ihre Wirkungspotentiale mehr Aufmerksamkeit erhielten (z. B. Vorderer et al. 2004), aber auch aus der literaturwissenschaftlichen Evolutionsforschung (z. B. die Arbeiten von Katja Mellmann und Karl Eibl) und der Erforschung literarischer Wirkung wie etwa in den Arbeiten von David S. Miall (2007; 1998), Kneepken/Zwaan (1994) und Oatley (1994), um nur einige zu nennen.

Seit den Neunzigerjahren wird „Leselust“ in Literaturkritik und Literaturwissenschaft wieder stärker diskutiert. Verschiedene Buchtitel von Literaturkritikern, aber auch aus der Literaturwissenschaft, weisen darauf hin, dass das Thema an Präsenz gewinnt. So etwa Uwe Wittstocks „Leselust. Wie unterhaltsam ist die neue deutsche Literatur ¿“ (1995), in dem der Autor die Ansicht vertritt, die deutsche Literatur sei sowohl bei den Deutschen als auch international so unbeliebt, weil sie in Sachen Unterhaltsamkeit weit hinter anderen Nationalliteraturen - der amerikanischen, der britischen, der französischen, der lateinamerikanischen - zurückbleibe. Wittstock führt dieses Defizit darauf zurück, dass die Literaturkritik unterhaltsamen Texten keine Qualitäten zutraue. Die Lösung liegt für ihn in einer Literatur, die Unterhaltsamkeit mit inhaltlichem und formalem Anspruch vereint. Auch Ulrich Greiners „Leseverführer“ (2005) - der Titel deutet es bereits an - stößt in eine ähnliche Richtung. Unter dem Titel „Leseglück. Eine vergessene Erfahrungð“ (1996) veröffentlichten Alfred Bellebaum und Ludwig Muth einen Sammelband, der sich ebenfalls, allerdings unter pädagogischen Vorzeichen, der Frage widmet, worin „Leseglück“ besteht und wie man es pädagogisch in der Leseförderung nutzen kann. Auch Hans-Dieter Gelfert, der an eine klare Unterscheidbarkeit von guter und schlechter Literatur anhand von 
spezifischen, im Übrigen altbekannten, Maßstäben glaubt, ist in seinem eher populärwissenschaftlichen Werk „Was ist gute Literatur ¿“ (2006), bemüht, diese Werte vom Manko der kulturellen und zeitlichen Relativität zu befreien, indem er sie mit psychologisch angelegten Wahrnehmungskonstanten in Verbindung bringt. Gute Texte, so die These, erzeugen mittels ihrer spezifischen Gestaltungsweise ästhetische Lust. Mit Thomas Anz“ „Literatur und Lust. Glück und Unglück beim Lesen" $(2002)^{18}$ erscheint schließlich auch ein literaturtheoretisches Buch zum Thema, das verschiedene Varianten von Leseglück theoretisch zu erfassen sucht.

Die freiwillige Lektüre zur puren Unterhaltung (ohne Bildungs- oder Informationsintention) nennt Nell (1988) in seiner empirischen Studie Ludic Reading. Ludic Reading verlangt dem Leser keine Anstrengung ab („effortlessness“). Obwohl es enorm viel Aufmerksamkeit erfordert, wird es als erholsam empfunden. Die Funktion des Lesens für den Leser ist rein psychologisch. Je nach psychologischer Disposition kann die Lektüre entweder dazu dienen, unangenehme Stimuli (Sorgen, Ängste) zu dämpfen oder Stimuli kontrolliert zu ergänzen. In beiden Fällen wird ein Grundzustand der maßvollen Erregung („arousal“) hergestellt, der, so die Annahme bei Nell, als angenehm empfunden wird. Lektüre ist also genau dann lustvoll, wenn sie ein psychisches Gleichgewicht herstellen kann. Nell ist bemüht, mittels neuropsychologischer Studien und empirisch gewonnener Daten verschiedener Art (EEG, Gruppendiskussion, Fragebogen, Interview) offenzulegen, was die lustvolle Lektüre ausmacht.

Ludwig Muth (1996) stellt die Frage nach dem Leseglück in einen Zusammenhang mit der psychologischen Glücksforschung. Er greift dabei auf die Forschung von Mihaly Csikszentmihalyi (2008) zurück, der Glück als Flow-Effekt beschreibt. Muth $(1996,61)$ fasst die Voraussetzung des Flow-Effekts in sieben Punkten zusammen, die sich in der Tat mit vielen Überlegungen zur Freude am Lesen, die er zusammenträgt, decken: Erstens muss die Tätigkeit herausfordernd sein und dabei den Fähigkeiten des Ausführenden entsprechen. Sie muss zweitens eine klares Ziel mit konkreten Rückmeldungen haben. Drittens muss mit der Tätigkeit völlige Konzentration und Hingabe einhergehen. Die Tätigkeit wird viertens von einer völligen Veränderung des Zeitgefühls begleitet. Sie ermöglicht fünftens eine spielerische Autonomie und sechstens die Überwindung von Ich-Grenzen. Sie wird damit siebtens zu einer autotelischen Erfahrung, das heißt, sie ist eine Tätigkeit, die nur um ihrer selbst willen ausgeführt wird. Der siebte Punkt „autotelische Erfahrung“ fasst

$\overline{18}$ Bemerkenswert ist auch die nicht nur bei Anz anzutreffende Korrelation von Lust und Glück, die keineswegs selbstverständlich ist. 
das Besondere des Flow-Erlebnisses zusammen. Dass ausgerechnet Selbstgenügsamkeit als zentraler Aspekt des Flow-Effekts genannt wird, erinnert stark an Vorstellungen von der Selbstgenügsamkeit (Autonomie) der Literatur, die, wie auch immer man Autonomie letztendlich expliziert, darauf zielt, dass die Literatur nicht auf einen pragmatischen Nutzen gerichtet sein sollte. Das Kennzeichen Konzentration deckt sich mit Nells Beobachtung, dass lustvolles Lesen eine hohe Konzentration erfordert. Auch der Hinweis darauf, dass die Tätigkeit sowohl herausfordernd als auch bewältigbar sein sollte, ist eine bekannte Annahme der literaturwissenschaftlichen Auseinandersetzung (Nell 1988; Anz 2002). Sie findet sich aber auch im Modell der ästhetischen Wahrnehmung (Belke/Leder 2006) wieder. Die Analysen, die im Rahmen dieser Arbeit durchgeführt wurden, weisen mit den zwei großen Wertekomplexen Orientierung und Aktivierung ebenfalls in diese Richtung. Vor allem aus empirischer Sicht spricht also einiges dafür, dass es wesentlich für die lustvolle Rezeption und positive Bewertung eines Textes ist, dass dieser sowohl zugänglich ist als auch eine kreative Leistung des Rezipienten erfordert.

Eine positive Wirkung von literarischen Texten scheint unweigerlich gekoppelt an eine Fokussierung der Aufmerksamkeit (Baisch et al. 2013, 8) und damit einhergehend mit einem Verlust des Zeitgefühls. Wer „gebannt“ (ebd.) liest, vergisst, dass er liest und vergisst auch, was um ihn herum geschieht. Wenn diese Aufmerksamkeitsfokussierung gelingt, wird der Text zu einem Erlebnis; er wird als unterhaltsam wahrgenommen. Als einige bekannte Mittel der Aufmerksamkeitsbindung nennt Hakemulder (2013, 160) die Identifikation mit einer Figur der erzählten Welt (Identifikationsfigur), die Erzählperspektive und den Aufbau von Spannung ,by manipulating the level of knowledge that the characters have and the level of knowledge of recipients“. Damit führt Hakemulder gestalterische Elemente auf, die auch als Kernelemente des Creative Writing (vgl. Kapitel 7) fungieren und die, wie die Analysen gezeigt haben, auch in den Bachmann-Preis-Diskussionen immer wieder aufgegriffen werden. Was aus diesen Darbietungsstrategien für den Leser folgt, ist im Idealfall Lust. Vorderer et al. (2004) sehen Lust (pleasure) als Kern jeder Unterhaltung, zeigen aber gleichzeitig, wie unterschiedliche Personen, je nach Herkunft und Anspruch, einen anderen Unterhaltungswert aus Filmen ziehen. Kneepken/Zwaan (1994) stellen Emotionen als Teil des Textverstehens dar. Dabei gehen sie davon aus, dass interessiertes Lesen, das wenig aktiver Aufmerksamkeitsfokussierung bedarf, weniger geistige Ressourcen benötigt und daher positive Emotionen hervorruft (ebd., 128). Sie unterscheiden zwei unterschiedliche Emotionen: F-Emotionen, die sich auf die fiktionale Entwicklung der Geschichte beziehen und A-Emotionen, die sich auf die Wahrnehmung des Textes als ästhetisches Produkt be- 
ziehen. Während F-Emotionen dazu führen, dass der Text besser im Gedächtnis bleibt, führen A-Emotionen dazu, dass der Text strukturell besser erfasst wird. Die F-Emotionen stehen dabei in Zusammenhang mit eben jenen Textbausteinen, die Hakemulder (2013) als bedeutend für die Konstitution von Aufmerksamkeitsbindung sieht: Empathie mit der Figur und Aufbau von Spannung. Ob F-Emotionen empfunden werden, meinen Kneepken/Zwaan (1994, 132), hänge davon ab, inwieweit Leser bereit seien, sich in die Ereignisse und Situationen der Geschichte zu vertiefen und von ihrer Bereitschaft, sich in die Reaktionen der Charaktere hineinzuversetzen.

Alle diese Studien, so unterschiedlich ihre Interessen auch sein mögen, weisen darauf hin, dass eine positive Textwirkung durch zwei Faktoren bedingt ist: Den Grad, in dem es dem Text gelingt, die Aufmerksamkeit des Lesers zu binden und den Grad der emotionalen Anteilnahme am Text, wobei diese Emotionen ein breites Spektrum umfassen, angefangen von Empathie für die Figuren, über gespanntes Miterleben der Handlung bis hin zu freudigem Erkennen von ästhetischen Gestaltungstechniken.

\subsection{Die Spielarten von „Lust“ am literarischen Text bei Thomas Anz}

Auch Thomas Anz (2002) sucht in seiner theoretischen Arbeit „Literatur und Lust. Glück und Unglück beim Lesen“ den Grund, aus dem so viele Menschen so gerne lesen, nicht in Bildung, sozialem Prestige oder moralischem Gewinn, sondern in der Lust, die das Lesen von Literatur verursacht, wenn der Leser einen ihm adäquaten Text zur Verfügung hat. Auch er geht primär davon aus, dass es die Befriedigung psychischer Bedürfnisse ist, die das Lesen attraktiv macht. Im Gegensatz zu Nell, der auch aufgrund seines empirischen Ansatzes die Anzahl der Hypothesen gering hält, stellt Anz eine Reihe von Möglichkeiten vor, wie Literatur Bedürfnisse des Menschen befriedigt.

Lust und Unlust sind in erster Linie Begriffe der Psychologie und so verortet auch Anz, der die Spielarten der Lust an der Literatur zusammenträgt, viele dieser Spielarten im Psychologischen, in Grundbedürfnissen des Menschen. Literatur ist, so seine nicht neuen Überlegungen, vergleichbar mit dem Spiel. Zuerst formuliert bekanntlich Friedrich Schiller die Idee, dass Spielen ein Grundbedürfnis und das Verspielte ein Charakterzug des Menschen schlechthin sei. Karl Eibl (2009) begreift Literatur in seiner bioanthropologischen Herangehensweise ebenfalls als eine Art Spiel. Spielen ist demnach Teil des „Organisationsmodus“, in den jedes komplexe Lebewesen nach der Geburt eintritt. Beim Menschen hält sich dieser Organisationsmodus ein Leben lang:

Damit bekommt der obskure „Spieltrieb“ eine funktionale Begründung im Organisati- 
onsmodus. Jeder komplexe Organismus muss sich nach seiner Geburt überhaupt erst einmal fertig bauen, und dieses Fertigbauen geschieht im Organisationsmodus. Beim Menschen hält sich dieser Organisationsmodus offenbar bis ans Lebensende durch, weil er wegen der höchst komplexen und heterogenen Struktur des menschlichen Gehirns auch nach der Fertigstellung zu Instandhaltungs- und Reparaturaufgaben benötigt wird. Betätigung im Organisationsmodus kostet Energie, bringt aber im Augenblick der Betätigung nichts ein. [...] Zum Organisationsmodus gehört deshalb unabdingbar die intrinsische Belohnung des momentanen Verhaltens - das ist die Lust. (Eibl 2009, 282)

Die Lust, die mit Literatur einhergeht, hat in dieser Sichtweise wenig mit der Art zu tun, wie Literatur gemacht ist; sie ist vielmehr automatisch an das Eintreten in einem SpielRaum gekoppelt, um das zwar nützliche, aber nicht unmittelbar überlebensnotwendige und in dieser Hinsicht „unattraktive“ Spielen, attraktiv zu machen. Wo der Spielstatus verfehlt wird, kann keine Lust erzeugt werden.

Anz (2002) versucht den Mechanismen auf die Spur zu kommen, die es erlauben, in das Spiel Literatur einzutreten und es als lustvoll zu empfinden. Er wendet sich dabei verschiedenen Erscheinungsformen der Lust zu: der Lust am Schönen, am Erhabenen, am Schrecklichen, am Lachen, am Sexuellen. Die möglichen Begründungen für die verschiedenen Arten der Lust sind divers und ein abschließendes Urteil über den Grund für das Lustempfinden lässt sich nicht fällen. Jedoch kehrt auch hier ein Muster immer wieder. Eine spezielles Gleichgewicht von Bekanntheit (Bestätigung) und Neuem (Stimulation). Im Kapitel zu „Literatur und Spiel“ heißt es:

Wer von dem Komplexitätsgrad einer Reizkonfiguration in seiner Kompetenz überfordert oder unterfordert wird, reagiert auf die Schwierigkeiten mit Unlust. Nur wenn das Schwierigkeitsniveau eines Spieles den Fähigkeiten des Spielers entspricht, ist es für ihn lustvoll. Ist es zu hoch, reagiert der Spieler mit Unlustgefühlen der Angst oder des Ärgers, ist es zu tief angesetzt mit der Unlust der Langeweile. (Anz 2002, 70)

Ganz ähnlich im Kapitel über die Lust an der Schönheit, wo es um formale Eigenschaften des Textes geht: „Gleichförmigkeit, Ordnung, Regelmäßigkeit oder Einheitlichkeit allein“ würden noch nicht als angenehm empfunden, „sondern nur in der Kombination mit Differenzen, Ordnungswidrigkeiten, Regelabweichungen oder Mannigfaltigkeit“ (ebd., 88). Wiedererkennen allein, das Durchschauen der Ordnung, führt zu Langeweile. Die Wahrnehmung des Schönen spiegelt also die Grundvoraussetzung der Freude an einem Spiel: Durchsicht ohne Voraussehbarkeit. Mit Fechner spricht Anz $(2002,108)$ vom Prinzip der einheitlichen Verknüpfung des Mannigfaltigen:

Das ästhetische Prinzip der einheitlichen Verknüpfung des Mannigfaltigen beschreibt eine Art Kompromißlösung zur Befriedigung zweier verschiedener, miteinander in Konflikt stehender Bedürfnisse: eines Bedürfnisses nach Gleichförmigkeit, Orientierung, 
Zusammenhang und Widerspruchslosigkeit auf der einen Seite und eines Bedürfnisses nach Abwechslung, der Vermeidung von Monotonie und Langeweile auf der anderen.

Damit ist auch noch einmal darin erinnert, dass die Ursache für die Lust am Text nicht ausschließlich in der bewussten oder automatisierten Anwendung erlernter Werte zu suchen ist, sondern auch in Bedürfnissen des Lesers bei der Verarbeitung des Textes. Es ist dabei wichtig, dass die Ordnung sich dem Leser nicht gleich erschließt, sondern dass ihr Erkennen mit geistiger Aktivität verbunden ist (ebd., 109).

Wie Victor Nell (1988) geht Anz davon aus, dass der Mensch ein Bedürfnis nach einem Grundmaß an Erregung (,arousal“) hat. Auch bei Anz' „Spannungslust“ funktioniert dieses Prinzip:

Literarische Texte erzeugen also Spannung, indem sie im Leser, oft über die Identifikation mit einer Figur des Textes, die Erfahrung eines Mangels stimulieren, die wiederum das Begehren hervorbringt, den Mangel zu beseitigen. (Anz 2002, 168)

Spannungslust verhält sich also ganz ähnlich wie die Lust am Schrecklichen. Ein Mangel, eine unbefriedigendes Gefühl, wird erzeugt und im Verlauf des Textes wieder abgebaut. Leser wissen, dass es zu einer Auflösung kommen wird, wie sie auch wissen, dass die Gefahr, die in einem Buch dargestellt wird, ihnen nichts anhaben kann.

Auch Komik und Erotik leben vom Aufbau einer Spannung, die dann befriedigt wird. Ein Grundprinzip der Lust an Literatur ist also, nimmt man Anz' verschiedene Überlegungen zusammen, dass der Leser mit einem starken Stimulus konfrontiert wird, den er vermittels seiner geistigen Aktivität, seiner Teilnahme am Geschehen durch die Lektüre, in eine Ordnung, in Bekanntes aufzulösen versucht. Gelingt ihm das, empfindet er Lust, andernfalls Unlust. Erregung und Bestätigung stehen in einer Wechselwirkung, die als befriedigend empfunden wird, weil sie in einem Spiel stattfindet. Literatur wird dann nicht mehr als lustvoll empfunden, wenn eine dieser Komponenten nicht mehr funktioniert. Gründe können Überforderung oder Unterforderung sein, wenn der Text nicht ausreichend stimulierend ist oder seine Stimuli nicht (an)erkannt werden; oder aber, wenn die dargebotenen Stimuli aufgrund von Überkomplexität, moralischen Vorbehalten oder mangelnden Bewältigungsstrategien (z. B. im Umgang mit Angst) nicht verarbeitet werden können.

Inwieweit sind diese Überlegungen zur Bedeutung von Leselust und Textwirkung von Bedeutung für die Bewertungen im Rahmen des Ingeborg-Bachmann-Wettbewerbs? Ob ein Text lustvoll rezipiert wird, ob er also in der Lage ist, die Aufmerksamkeit des Lesers zu binden, ohne dass er dabei den Eindruck hat, eine Anstrengung zu unternehmen, geht der eigentlichen Bewertung voraus und ist, so darf man aus eigener Leseerfahrung schließen, 
schwer beeinflussbar. Gleichzeitig ist „Lust“ als Wertungsmaßstab im deutschsprachigen Raum nicht angesehen. Die immer noch vorhandene, mittlerweile aber etwas abgeschwächte, Trennung der Literatur in unterhaltend und „ernst“ zeugt davon. Am Beginn jeder Diskussion steht aber ein entweder lustvolles oder unangenehmes, häufig auch ein ambigues Lektüreerlebnis. Die Juroren müssen den Erwartungen gerecht werden, dieses Erlebnis durch intersubjektiv nachvollziehbare Kriterien zu begründen. In den Bewertungen werden daher - es lässt sich nicht vermeiden, an dieser Stelle ein wenig auf die Ergebnisse der Analysen vorauszugreifen - Urteile, die ihren Ursprung in der Lust am Text/am Lesen haben, mit anderen Bewertungsmaßstäben maskiert.

Nun sind die Leser, die beim Ingeborg-Bachmann-Wettbewerb werten, das genaue Gegenteil von Freizeitlesern, die auf nichts zu achten haben als auf ihren persönlichen Lustgewinn. Dennoch spielt auch für sie, das lässt sich an den Diskussionen deutlich zeigen, der Lustgewinn, den ein Text hervorzurufen vermag, eine entscheidende Rolle. Als Kritiker, Autoren, Redakteure, Übersetzer strukturieren die Juroren in ihrem Berufsleben den Buchmarkt mit. Ihr beruflicher Erfolg hängt u. a. davon ab, wie erfolgreich sie in ihren Prognosen und Einschätzungen sind. Und Erfolg bemisst sich unter anderem an ihrer Fähigkeit, mit ihrer Auswahl den Geschmack des entsprechenden Lesepublikums an künstlerischer Literatur interessierte Leser - zu treffen. Die große Menge des Lesepublikums liest allerdings zur eigenen Unterhaltung. Auch anspruchsvolle Lektüre ist nicht mehr unbedingt ein Bildungsnachweis - kann es aber nach wie vor sein - und bemisst sich zunehmend am Unterhaltungswert. Es kann also davon ausgegangen werden, dass die Juroren a) die allgemeinen psychischen Voraussetzungen teilen, die Menschen dazu bringen, Bücher zu lesen und dass sie b) immer auch mit Blick auf die Akzeptanz ihrer Wertung im breiteren Publikum werten (müssen). Aus diesem Grund darf auch den Juroren unterstellt werden, dass in ihren Wertungen, das Lustpotential eines Textes von Bedeutung ist, mindestens unbewusst, mitunter aber auch ganz bewusst. Die Analysen der Diskussionen werden das deutlich zeigen.

\subsection{Subjektivität, Intersubjektivität und Objektivität von Wertungen}

In Anbetracht der Kenntnis der Regeln des literarischen Feldes einerseits und des Wissens über den ästhetischen Erfahrungsprozess aus kognitionspsychologischer Sicht andererseits stellt sich die Frage nach dem Grad der Subjektivität von Wertungen, insbesondere von Wertungen, wie sie im Rahmen des Ingeborg-Bahmann-Wettbewerbs geäußert werden. Unstreitig ist, dass Werte als Bestandteile einer diskursiven Praxis konstruiert sind. Den 
Rahmen des literarischen Diskurses bildet das literarische Feld, dessen Akteure um Prestige konkurrieren und auch daran interessiert sind, dieses Prestige in ökonomisches Kapital umzusetzen. Dass das literarische Feld entgegen seiner Selbstinszenierung letztlich auch Regeln der Macht und der Ökonomie gehorcht und dass diese auch Auswirkungen darauf haben, wie gewertet wird, kann nicht von der Hand gewiesen werden. Zu fragen bleibt indes zum einen, wie die Kommunikation des literarischen Feldes genau funktioniert, zum anderen, wie sie auf Subjektseite mit der Wahrnehmung des Objektes der Wertung zu verbinden ist.

Mit Sabine Buck $(2011,50)$ gehe ich davon aus, dass der Umgang mit Literatur eine soziale Praxis im Sinne Schatzkis (1996) ist. Schatzkis Beschreibung einer integrative social practice enthält kondensiert eine Reihe von Annahmen, die sich auf den Bereich der Literatur übertragen lassen.

The understanding, rules, and teleoaffective structure that organize a practice specify how actions (including speech acts) ought to be carried out, understood, prompted, and responded to; what specifically and equivocally should be done or said (when, where...); and which ends should be pursued, which projects, tasks, and actions carried out for that end, and which emotions possessed - when, that is, one is engaged in the practice. (Schatzki 1996, 101)

Auf den speziellen Bereich der Literatur übertragen heißt das, dass „der Umgang mit Literatur auf einem sozial geteilten Fundus von Regeln beruht und insbesondere Experten im Umgang mit Literatur starke Intuitionen darüber teilen, was in der Auseinandersetzung mit Literatur erwartet wird“ (Buck 2011, 46). Für die Wertung von Literatur steht ein Fundus an zulässigen und akzeptablen Positionen bereit. Dieser Fundus ist, ungleich einem Regelsystem, nicht fixiert, sondern wird im Umgang mit dem Gegenstand Literatur erlernt. Positionen aus dem Fundus können auf unterschiedliche Weise in der Argumentation eingesetzt werden. Es gibt Positionen, deren Bedeutung und Einsatzmöglichkeiten relativ stabil sind, andere sind variabel einsetzbar. Die Regeln der Anwendbarkeit bestimmter Wertungen oder Wertungsmuster sind nicht unbedingt bewusst. Sie sind im Sinne Ryles (1992) Teil eines Knowing-How, einer Fähigkeit also, die zwar mittels eines Regelsystems, jedoch auch auf dem Wege der Beobachtung, angelernt werden kann, und deren Regeln sich der Inhaber der Fähigkeit nicht mehr bewusst machen muss. Sein Können (KnowingHow) besteht eben darin, die Fähigkeit ohne mentale Planung ausführen zu können. Das ist auch der Grund dafür, warum in vielen Wertungen keine Explikation der Wertungskriterien vorgenommen wird (vgl. Kienecker 1989, 71). Ein Verständnis der Wertung kann für all diejenigen, die mit der sozialen Praxis der Bewertung von Literatur vertraut sind, 
vorausgesetzt werden. Aus diesem Grund ist es auch legitim, als Literaturwissenschaftler die nicht explizierten Wertungsbestandteile literaturkritischer Wertungen auszuformulieren, sofern der Wertende ebenfalls zur Gruppe der Expertenleser gehört. Obwohl also Lesesozialisationen unterschiedlich verlaufen und jeder Leser potentiell andere Wahrnehmungen von literarischen Texten und andere Anforderungen an sie hat, beinhaltet jede literarische Sozialisation, ganz besonders aber vermutlich jene, die an den Universitäten stattfindet und über die Schulen an Jugendliche weitergegeben wird, auch eine Einübung in soziale Praktiken im Umgang mit Literatur, und somit in, wenn auch nicht genormte, so doch konventionalisierte, Umgangsformen mit dem Gegenstand. Genau in diesem Sinne sind Wertungen also nicht rein subjektiv, sondern auch intersubjektiv verstehbar. Auseinandersetzungen über Werte können in ihren Argumentationen stark divergieren, sie bewegen sich aber dennoch in ein und demselben Koordinatensystem. Die Achsen dieses Systems sind bekannt, wenn sie auch selten expliziert werden. Das geteilte Wissen über literaturbezogene Wertung ist ein Wissen über Handlungsmöglichkeiten, nicht ein Wissen über faktische Werteinheiten. Subjektiv sind Wertungen insofern, als die Spezifika einer individuellen (Lese-)Sozialisation dazu führen, dass bestimmte Argumentationstypen aus dem Fundus und damit bestimmte Typen von literarischen Texten bevorzugt werden.

Die Konzepte der sozialen Praxis (Schatzki) und des Knowing-How (Ryle) machen fassbar, wie Bourdieus Feldtheorie auf der kommunikativen Ebene konkret funktionieren kann.

Letztlich bleibt zu klären, welche Rolle der literarische Text selber in der Bewertung spielt. Inwiefern sind literarische Wertungen objektiv, oder, anders gesagt, durch Eigenschaften des bewerteten Objekts bedingt? Die Textwahrnehmung ist bedingt durch verschiedene Faktoren: die Lesefähigkeit des Lesers (vgl. Nell 1988; Christmann/Groeben 1999), seine literarische Vorbildung, sein Weltwissen, seine aktuelle Verfassung, die Umstände des Lesens (ist hohe Konzentration möglich oder nicht?), die Erwartungen des Lesers an den Text oder den Autor (Kenntnis des Klappentexts und anderer Texte desselben Autors), von moralischen Ansprüchen und auch von literarischen (ästhetischen, inhaltlichen, wirkungsbezogenen). Tatsächlich sehen diese Faktoren bei jedem Leser und bei jeder Lektüre anders aus. Bis zu einem gewissen Grad ist die Textwahrnehmung also immer unkalkulierbar. Auf der anderen Seite ist der literarische Text trotzdem fassbar, nicht vollkommen flüssig. Eine Verständigung über ihn ist in der Regel möglich und obwohl über bestimmte Details seiner Beschaffenheit und Auslegung gestritten werden kann, können mit dem Handwerkszeug der Literaturwissenschaft durchaus auch Texteigenschaften ausgemacht werden, die intersubjektiv „vorhanden“ und nachvollziehbar sind. Texte haben eine Grundveranlagung, die 
Wertungen bestimmter Art fördern, aber nicht zwingend auslösen. Mit Worthmann (2014, 399) gehe ich davon aus, dass die Zuweisung von Werten, sowohl axiologischen als auch attributiven, nicht beliebig erfolgt. Wertende orientieren sich in ihren Wertungen auch an der wahrgenommenen Textgrundlage. Auch kommunikativ sind Wertungen nur dann erfolgsversprechend, wenn eine geteilte Wahrnehmungsgrundlage und eine Art Verständigungsschema existiert.

Wie subjektiv, intersubjektiv oder objektiv Wertungen sind, ist im Einzelfall verschieden. Verschiedene Faktoren beeinflussen den Grad, in dem Intersubjektivität bzw. Objektivität angestrebt oder auch abgelehnt wird. Als kommunikativer Prozess (vgl. auch Kapitel 5) sind sprachliche Wertungen, auch dann, wenn sie einen Dissens über das Gelungensein eines Textes zum Gegenstand haben, ein Akt der Verständigung, in dem kommunikative Konventionen, wie sie etwa Grice (1991) formuliert hat, und erlernte soziale Praktiken, wie sie Ryle (1992) und Schatzki (1996) beschrieben haben, angewendet werden. Wie über Literatur im Rahmen des Ingeborg-Bachmann-Wettbewerbs gesprochen wird, ist also durch ein ungeschriebenes Regelsystem geleitet. Die Regeln kommunikativen Handelns sehen vor, dass das Kommunizierte für den Gesprächspartner zugänglich und nachvollziehbar sein sollte. In diesem Sinne sind Wertungen nach Möglichkeit intersubjektiv. Um Wertungen plausibel zu machen, müssen sie am Objekt, dem Text, orientiert sein. Darüber hinaus bildet aber auch der Rezeptionsprozess als kognitiver Vorgang die erste Grundlage der Wertung. Dass auch der Rezeptionsprozess bereits durch erlernte Praktiken im Umgang mit Literatur gesteuert ist (vgl. z. B. Guillory 1995), spricht nicht dagegen, dass jede Rezeption im Text verankert ist. Es ist aus kognitionspsychologischer Sicht (vgl. Belke/Leder 2006) sogar plausibel, dass Wertungen im Rezeptionsprozess verankert sind und bereits während der Lektüre in einen Dialog mit anderen Wissensbeständen treten: mit Wissen über Literatur, Wissen über Moral, Wissen über Konventionen der Bewertung, Wissen über andere Texte und ihre Bewertung und vieles mehr.

\subsection{Wertungstheorien der Literaturwissenschaft}

\subsubsection{Wertungen ausdrücken. Verbale und motivationale Wertungen}

Wertungen können auf sehr unterschiedliche Art zum Ausdruck kommen oder zum Ausdruck gebracht werden. Simone Winko (2002) unterscheidet in motivationale und verbale Wertungshandlungen. Damit wird auch jenen Wertungshandlungen Rechnung getragen, die den Erfolg eines Buches durch Kauf, Ausstellung, Beschluss, ein Buch mit einem beson- 
deren Einband zu versehen, und ähnlichem beeinflussen. Motivationale Wertungen geben allerdings selbst keinen Aufschluss darüber, warum ein Buch gekauft oder besonders ausgestattet wird. Die Handlung spricht für sich. Bei den sprachlichen Wertungen wiederum ist schwer zu entscheiden, welche sprachlichen Äußerungen als Wertungen gelten können, welche dagegen nicht. Es gibt eine Reihe von Ausdrücken, die per se als Wertausdrücke gelten können (gut, schlecht, hervorragend, grauenhaft) und andere, die mit entsprechendem Hintergrundwissen als Wertausdrücke eingeordnet werden können (z. B. humorvoll, phantasievoll, sprachlich überzeugend, verquast, langweilig) (vgl. Kienecker 1989). Friederike Worthmann (2004) stellt ein ganzes Spektrum sprachlicher Realisierungsformen von Wertungen zusammen, darunter lexikalische, syntaktische und rhetorische Mittel. Allerdings gibt es auch Ausdrücke, die nur in einem Wertungskontext und dann auch nur in Begleitung anderer wertender Aussagen als Wertungen bestimmt werden können, die aber dennoch als Wertausdrücke gelten müssen. Wenn ein Rezensent schriebe „Dieser Text ist wie frischer Spinat", könnte damit sowohl gemeint sein, dass der Text durch seine „Frische“ (Wertmaßstab Originalität) überzeugt. Es könnte aber, je nach Kontext, ebenso gut gemeint sein, dass der Text wie Spinat bei der Verarbeitung (Rezeption) in sich zusammenfällt (Maßstab Dichte) oder dass man darauf gefasst sein muss, zwischen den Blättern Ungeziefer zu finden (Maßstab beispielsweise Moral). Unter Umständen können - beispielsweise bei einer unentschiedenen Bewertung - auch alle Verständnisvarianten aktiviert werden. Selbst Beschreibungen, die auf den ersten Blick sachlich wirken, können wertenden Charakter haben, nämlich dann, wenn ein Kritiker beispielsweise im Anschluss an ein Statement zur Rolle der Frau in der Gesellschaft, beschreibt, wie eine weibliche Figur in einem Buch inszeniert wird. Letztendlich muss man davon ausgehen, dass jede Formulierung wertenden Charakter haben kann. Gerade in genuin wertenden Textsorten wie der Kritik/Rezension oder auch in den Jurydiskussionen ist davon auszugehen, dass jede Aussage als Bestandteil einer komplexeren Wertung verstanden werden kann. Inwieweit verschiedene Aussagen im Kontext der Jurydiskussionen als wertende Aussagen im engeren Sinne verstanden werden, ist letztlich immer Interpretationssache.

\subsubsection{Drei Modelle der Bewertung von Literatur}

Drei umfassende Modelle literarischer Wertung sind in den letzten drei Jahrzehnten entwickelt worden. Das erste, aus dem Jahre 1989, ist die Arbeit von Michael Kienecker. Es handelt sich noch nicht um ein Wertungsmodell im engeren Sinne, sondern vielmehr um eine Auseinandersetzung mit sprachlichen Realisationsformen von Wertung. Die Arbeit 
Kieneckers ist allerdings kennzeichnend für den Beginn einer deskriptiven Betrachtung von Wertung mit einer Abwendung von elitärem Expertentum und stattdessen einem Versuch, sich dem Gegenstand neugierig und offen zuzuwenden. Einige Grundpositionen, die auch in den späteren Modellen immer wieder aufgenommen werden, sind bei Kienecker vorskizziert. Das zweite Modell aus dem Jahr 1996 stammt von Renate von Heydebrand und Simone Winko, das dritte aus dem Jahr 2004 von Friederike Worthmann. Beide Arbeiten bemühen sich 1. um ein umfassendes deskriptives Modell, 2. um ein Bewusstsein für die historische Wandelbarkeit von Werten und 3. um ein praktisch anwendbares Instrumentarium zur Wertungsanalyse.

\section{Das Modell sprachlicher Wertungen von Michael Kienecker}

Kienecker $(1989,11)$ beobachtet zunächst in der Auseinandersetzung mit der Wertung von Literatur ein „Subjektiv-Objektiv-Dilemma“, also den Streit darüber, ob Wertungen überhaupt mit Eigenschaften des Gegenstandes der Wertung gekoppelt sind oder rein subjektiv, durch Voraussetzungen des Individuums, geprägt sind. In seiner Arbeit untersucht er Wertungen sprachanalytisch, u. z. unter dem Vorzeichen der Objektivität bzw. Subjektivität. Da Kienecker nicht nach Werten, sondern nach der Art und Struktur von Wertungen fragt, fehlt bei ihm noch die Kategorisierung von Werteigenschaft und Wertmaßstab, die in den späteren Arbeiten fester Bestandteil der Theorie ist; er geht aber davon aus, dass jedes Werturteil eine subjektive Komponente hat, bei der der Gegenstand zunächst eingeschätzt wird, und eine objektive Komponente, mit der diese subjektive Einschätzung am Gegenstand festgemacht wird (Kienecker 1989, 69). Literarische Werturteile seien, so Kienecker $(1989,80)$, begründungspflichtig und -fähig. Gleichzeitig unterscheidet Kienecker drei Wertungstypen, die sich in späteren Arbeiten ebenfalls wiederfinden und am ehesten als Wertungsmodi zu erfassen sind. Die Modi zielen letztlich auf den Geltungsanspruch von Wertungen ab. Die drei Wertungstypen Kieneckers $(1989,77)$ sind das Appetenzurteil, das aus der Perspektive des Lesers im Sinne eines Gefallensurteils gefällt wird, das Leistungsurteil, das auf den Text ausgerichtet ist und „eine Auszeichnung des beurteilten Textes [...] aufgrund des für nachweisbar gehaltenen Tatbestandes einer Leistung oder eines bewunderten Könnens des Dichters [ausspricht]“ (Kienecker 1989, 74) und schließlich das Akzeptanzurteil. Dieses nimmt die Perspektive der "Botschaft" ein, wobei der Text „als Exemplar einer bestimmten Vergleichsklasse“ beurteilt wird (Kienecker 1989, 77). Kienecker gibt allerdings zu verstehen, dass diese drei Typen in der Praxis kaum voneinander zu trennen sind. 
Wertende haben Kienecker zufolge immer eine Freiheit, welche Eigenschaften eines Objekts sie in ihrer Bewertung als Begründung einsetzen; sie sind dazu angehalten, ihre Bewertung zu begründen und sind in der Art der Begründung frei; gleichzeitig können Werturteile „in dem Sinne objektiv sein [...], daß sie einen allgemein einsehbaren Tatbestand, den der Leistung, oder aber allgemeiner akzeptierter Kriterien zum Bestimmungsgrund haben“ (Kienecker 1989, 79). Die allgemeine Akzeptanz der Kriterien ergibt sich dabei aus Konventionen der Kommunikationsgemeinschaft. Bemerkenswert klar beobachtet Kienecker allerdings, wie Wertungen in der Literaturkritik tatsächlich in vielen Fällen strukturiert sind:

In der praktischen Literaturkritik ist nun häufig eine „elliptische“ Form des Appetenzurteils zu beobachten. Es werden Werturteile nur unter Bezug auf ein objektives Implikat gefällt ohne den expliziten Hinweis auf das persönliche Gefallen, und diese Tatsache könnte verstellen, daß für die Auswahl der „,gut-machenden“ Eigenschaften das urteilende Subjekt verantwortlich ist. (Kienecker 1989, 71 f.)

Entscheidend ist hier, dass die Urteile der Literaturkritik nicht, wie das implizit häufig getan wird, als Leistungsurteile, sondern vielmehr als Gefallensurteile gesehen werden, die aber als Leistungsurteile maskiert werden.

\section{Das Modell von Renate von Heydebrand und Simone Winko}

Das Wertungsmodell von Heydebrand/Winko (1996) ist der erste umfassende Versuch der letzten Jahrzehnte, die Wertung von Literatur systematisch in einem Modell zu erfassen. Es bietet eine klare Begrifflichkeit, um Wertungen zu beschreiben. Durch die gut handhabbare Terminologie ist das Modell Bezugspunkt für die meisten Forschungsarbeiten zum Thema geworden. Wertungen werden als soziale Handlungen betrachtet. Wertungswissen wird demnach im Verlauf der (literarischen) Sozialisation erworben; der Einsatz bestimmter Werte hängt vom Wissen über die Handlung „Bewerten von Literatur“ ab, aber auch von der Rolle, die der Wertende im Sozialsystem Literatur im Moment der Wertung einnimmt. Wie bewertet wird, hängt demzufolge im Wesentlichen von der Beschaffenheit des Sozialsystems Literatur zum Zeitpunkt - oder in der historischen Epoche - der Wertung ab. Der Blickwinkel des Modells ist also literatursoziologisch geprägt. Kognitionspsychologische Einsichten in die Verarbeitung von Texten spielen nur am Rande eine Rolle. Es wird die Einsicht übernommen, dass es sich bei der Rezeption von Texten um einen interaktiven Prozess zwischen dem Sinnangebot des Textes und den Verarbeitungskapazitäten des Lesers handelt. Neben der klaren Terminologie liegt die Stärke des Modells für die Anwendung darin, dass die Autorinnen eine Reihe von Wertmaßstäben zusammenstellen, die 
sie für prägend für die Auseinandersetzung mit Literatur halten. Weil sich die vorliegende Arbeit an der Terminologie von Heydebrand/Winko orientiert, soll diese kurz vorgestellt werden:

Wertungen bestehen diesem Modell zufolge aus fünf Komponenten:

1. einem wertenden Subjekt,

2. einem zu bewertenden/bewerteten Objekt,

3. einem Wertmaßstab (axiologischer Wert),

4. einer Werteigenschaft des bewerteten Objekts (attributiver Wert),

5. und einer Zuordnungsvoraussetzung.

Der Wertmaßstab (axiologischer Wert) ist eine abstrakte Einheit, an der der Gegenstand ein Text, ein Autor, ein Werk - gemessen wird. Die Wertmaßstäbe lassen sich nach ihrem Bezugspunkt in vier Gruppen unterteilen:

1. wirkungsbezogene Werte,

2. relationale Werte,

3. inhaltsbezogene Werte,

4. und formal-ästhetische Werte (ebd.,111 ff.).

Wirkungsbezogene Wertmaßstäbe (ebd., $124 \mathrm{ff}$.) beziehen sich auf die kognitive und emotionale Wirkung, die der Text beim Leser auslösen kann. Sie umfassen eine ganze Bandbreite von Wirkungen, angefangen von dem Anspruch, durch Literatur mehr über „das Leben“ zu erfahren und Hinweise für die Lebensbewältigung zu erhalten, über die Hoffnung auf ökonomischen Gewinn oder Prestigegewinn bis hin zu affektiven und hedonistischen Wirkungen wie Mitleid, Lust, Betroffenheit und Unterhaltung. Insbesondere die affektiven und hedonistischen Werte werden innerhalb dieser Arbeit immer wieder von Bedeutung sein. Ein typisches Werturteil mit einem hedonistischen wirkungsbezogenen Maßstab wäre: Der Text erzeugt Spannung.

Relationale Wertmaßstäbe (ebd., 121 ff.) ordnen den Text in einen Zusammenhang mit anderen Texten ein und bewerten ihn in Hinblick auf diese Beziehung als gelungen oder nicht gelungen. Ein Maßstab dieser Kategorie ist Originalität. Eine typische Wertung wäre: Dieser Text versucht etwas, was es in der Literatur bisher noch nicht gegeben hat. 
Inhaltsbezogene Wertmaßstäbe (ebd., 119 ff.) beziehen sich auf die inhaltliche und stoffliche Gestaltung des Textes. Moralische Werte wären hier anzusiedeln. Ein typisches Werturteil wäre: Die Art, wie in diesem Text Sexualität dargestellt wird, liegt jenseits des Vorstellbaren.

Die formal-ästhetischen Wertmaßstäbe (ebd., 113 ff.) beziehen sich auf die formale Gestaltung des Textes. Aktuell typische Werte sind Selbstreferenz, Polyvalenz, Offenheit und Schönheit. Dem Letztwert Schönheit werden Stimmigkeit, Ganzheit, Komplexität, Intensität/Dichte und die ästhetische Gestaltung der Sprache untergeordnet. Ein typisches Werturteil könnte sein: Dieser Text schachtelt verschiedene Erzählungen kunstvoll ineinander.

Um eine Wertung vorzunehmen, braucht der Wertende nach Heydebrand/Winko nicht nur einen Wertmaßstab, sondern auch eine Objekteigenschaft, die es rechtfertigt, einen bestimmten Wertmaßstab auf einen konkreten Text zu beziehen: eine Werteigenschaft (attributiver Wert). Wertmaßstab und Werteigenschaft werden vom Wertenden aufeinander bezogen. Die Regeln dieser Verknüpfung von Werteigenschaft und Wertmaßstab werden von Heydebrand/Winko als Zuordnungsvoraussetzungen bezeichnet. In unterschiedlichen Wertungssituationen können die Voraussetzungen, unter denen eine Werteigenschaft einem Wertmaßstab zugeordnet wird (Zuordnungsvoraussetzung), variieren. Ein bestimmtes Medium oder ein bestimmter Adressat erfordern in Hinblick auf ein Bewertungsziel (Überzeugung, Kaufentscheidung, Gruppenkonsolidierung) unterschiedliche Zuordnungen von Wertmaßstab und Werteigenschaft. Beispielsweise kann ein Germanistikstudent vor seiner Freundin über seine „Shades-of-Grey“-Lektüre schwärmen und dabei die lebhafte Figurenzeichnung loben und am nächsten Tag im Seminar das Buch aufgrund der stereotypen Figurenzeichnung ablehnen. Seine Wertungshandlung wäre in beiden Fällen dem jeweiligen sozialen Kontext angemessen und würde sein soziales Prestige (und ggf. seine Gruppenzugehörigkeit) fördern.

Da Texte nach Heydebrand/Winko niemals an sich Träger eines Wertes sind, hängen die Bedingungen für die Zuschreibung eines Wertes aufgrund bestimmter Werteigenschaften vom kulturellen Umfeld des Wertenden und zum Teil auch von persönlichen Erfahrungen ab. Jede Wertungsuntersuchung trifft also immer nur eine Aussage über Wertungen in einer bestimmten historischen Zeitspanne und in einer bestimmten sozialen Konstellation. Werte werden in bestimmten Zeitspannen (geschichtlichen und/oder literaturhistorischen Epochen) und in bestimmten sozialen Gruppen geteilt (vgl. auch Schneider 2009). 


\section{Das Wertungsmodell von Friederike Worthmann}

Friederike Worthmann (2004) knüpft in den Grundzügen an die Wertungstheorie von Heydebrand/Winko (1996) an. Sie sieht zunächst dieselbe Grundstruktur aus Wertmaßstab und Werteigenschaft. Während Heydebrand/Winko mit der Zuordnungsvoraussetzung allerdings eher Konventionen des literarischen Diskurses in den Blick nehmen, fokussiert Worthmann Modi und Funktionen von Wertungen und Werten auf der Subjektebene. Zusätzlich zu ihrer Eigenschaft als Handlungen, die ihre Wurzeln in der Sozialisation des Wertenden haben, sieht Worthmann eine subjektive Komponente, die vor allem in der perzeptiven und verstehenden Einordnung des Textes zum Tragen kommt. Sie knüpft dabei an kognitionspsychologische Erkenntnisse an:

Literarische Wertungen lassen sich dem hier favorisierten kognitionspsychologischen Ansatz entsprechend als psychische Informationsverarbeitungsprozesse beschreiben, die mit literarischen Handlungen einhergehen und insofern interaktiv sind, als sie sich sowohl induktiv auf der Basis von Texteigenschaften (d.h. als Bottom-up-Prozesse) als auch deduktiv auf der Basis vom Leser eingebrachter Voraussetzungen (d. h. Topdown-Prozesse) vollziehen. (Worthmann 2013, 399)

Insbesondere Worthmanns Wertmodi sind als Ergänzung aufzufassen. Worthmann (2004) geht davon aus, dass Wertmaßstäbe eine unterschiedliche „Qualität"19 haben, abhängig davon, in welchem Modus sie geäußert werden. Sie unterscheidet zwei Grundmodi: den Modus des Wertmaßtabs als Ideal, der bei Anerkennungswertungen eingesetzt wird und den Modus des Wunsches, der bei Gefallenswertungen zum Ausdruck kommt (ebd., 250). Dabei zeichnet sich die Anerkennungswertung dadurch aus, dass sie einen allgemeinen Anspruch hat, während die Gefallenswertung lediglich einen persönlichen Anspruch hat. Alle anderen Maßstäbe - hier ist Worthmann zufolge alles möglich - lassen sich diesen zwei Grundmodi unterordnen. Die Abstufungen, an denen Worthmann ihre Theorie durchspielt, sind: Ideal, Wunsch, Ziel, Norm, Konvention und Vorbild.

Die Stärke von Worthmanns Modell liegt in der Fähigkeit, Aspekten des Verstehens und der emotionalen Verarbeitung von Texten einen zentralen Platz zuzuweisen. Durch die Erweiterung des Modells um kognitionspsychologisches Wissen wird beispielsweise die Annahme möglich, dass Texte zunächst auf einer Lust/Unlust-Ebene rezipiert werden und Wertmaßstäbe erst in einem sekundären Vorgang an den Text herangetragen werden (Worthmann 2004, 250). Wie sich zeigen wird, kann genau diese Annahme als Schlüssel zum Verständnis der Ingeborg-Bachmann-Wettbewerb-Wertungen gesehen werden. Die Unterscheidung von Wertungen in Modi ermöglicht eine weitere Differenzierung von Wer-

19 „Qualität“ ist hier nicht wertend gemeint. 
tungen, die nicht auf die Auseinandersetzung mit dem Text selber zu tun hat, sondern viel mehr mit der Äußerungsabsicht des Wertenden, für den es einen Unterschied macht, ob er in Hinblick auf eine Norm, einen Wunsch, ein Ziel oder ein Ideal wertet. Unterschiedliche Äußerungskontexte legen unterschiedliche Bewertungsmodi nahe. Eine Empfehlung wird eher im Modus des Wunsches ausgesprochen; eine Bewertung im Rahmen eines Literaturpreises, so wäre anzunehmen, zielt auf ein Ideal.

Worthmann (2004, 241; 2014, 400) macht außerdem klar, dass auch die Absicht, die mit der Wertung verbunden ist, Einfluss auf die Art ihrer Äußerung hat und unterscheidet dabei drei grundlegende Funktionen: die Darstellungsfunktion, die Ausdrucksfunktion und die Appellfunktion, wobei die Darstellungsfunktion den Text fokussiert, die Ausdrucksfunktion die Wahrnehmung des Textes durch den Rezipienten und die Appellfunktion die Wirkung auf den Rezipienten der Wertung.

\subsection{Zusammenfassung}

In der Auseinandersetzung mit Wertungen spielt das bewertete Objekt ebenso eine Rolle wie die Perspektive des Wertenden, seine Einübung in den Umgang mit dem bewerteten Gegenstand (Knowing-How), seine persönlichen Erfahrungen, seine Stellung im Literaturbetrieb und seine Ambitionen, sich im literarischen Feld zu behaupten, der Kontext, in dem gewertet wird und die kommunikative Absicht, mit der sie geäußert wird. Als (sprachliche) Handlungen weisen Beurteilungen von literarischen Texten alle Facetten sprachlichen Handelns auf. Die Expertenleser des Ingeborg-Bachmann-Wettbewerbs müssen daran interessiert sein, den zur Bewertung stehenden Text als Gesprächsgegenstand zu konstituieren (vgl. Kapitel 5) und sich plausibel zu ihm zu äußern, aber auch, sich selbst als Experten zu legitimieren. Aus diesem Grunde ist zu erwarten, dass sie sich sowohl an die Regeln kommunikativen Handelns als auch an das Knowing-How, die spezifischen Kommunikationsregeln, der Literaturexperten halten. Eigenschaften des Textes, die im Rahmen einer Bewertung als gelungen hervorgehoben werden (attributive Werte), sind ebenso Teil der Wertung wie die ideellen Größen, an denen diese Eigenschaften gemessen werden (axiologische Werte).

Jedoch wird jeder Text auch schon während des ersten Leseprozesses kognitiv verarbeitet. Auf dieser Ebene wirkt der Text als Text auf die spätere Bewertung ein. Die ersten, spontanen „Wertungen“ sind nicht auf einer ideellen Ebene anzusiedeln, sondern äußern sich als Lust oder Abneigung beim Lesen. Ob die Lektüre durch Lust oder Abwehr geprägt war - abhängig vom Erfolg der eingesetzten kognitiven Analysestrategien - wirkt sich auf die 
spätere ideelle Bewertung aus. Allerdings ist auch die kognitive Verarbeitung wenigstens teilweise durch den erlernten Umgang mit Texten vorgeprägt. Was Belke/Leder (2006) als zwei einander bedingende Prozesse der kognitiven Verarbeitung sehen, nämlich der perzeptive Erfolg und die wissensgeleitete Weiterverarbeitung, findet sich in literaturwissenschaftlichen Wertungsmodellen in der Unterscheidung der Gefallenswertung und der Anerkennungswertung. Empirische Studien der Textwirkungsforschung legen nahe, dass die affektive Wirkung des Textes einen erheblichen Einfluss auf die Bewertung des Textes hat (vgl. die Kapitel 10.1 und 11.1). Weil sich diese Kopplung auch in den öffentlichen Bewertungen von professionellen Kritikern in einer Literaturpreis-Jury nachvollziehen lässt, wird sie eine der spannendsten Fragen dieser Arbeit sein.

Heydebrand/Winko (1996, 114 f.) haben eine Reihe von gängigen ideellen Wertmaßstäben herausgefiltert. Zu den wichtigsten formal-ästhetischen Werten zählen sie Mehrdeutigkeit, Offenheit, Stimmigkeit, Komplexität und die ästhetische Gestaltung der Sprache. Für die Analysen wird interessant sein, welche davon und welche zusätzlichen formal-ästhetischen Wertmaßstäbe in den Diskussionen verwendet werden. Häufigkeit, Art und Überzeugungskraft der Verwendung lassen auf die Bedeutung des jeweiligen Maßstabs im Koordinatensystem literarischer Wertungen schließen. Als besonders bedeutend hat sich die Frage erwiesen, welche Rolle die (un-)lustvolle Lektüre für die Bewertung durch die Juroren spielt. Denn den kommunikativen Regeln der öffentlichen Expertenwertung entsprechend müssten die Bewertungen zum einen auf Plausibilität, zum anderen auf Konformität mit den Möglichkeiten des Werterepertoires abzielen. Ein subjektiver Leseeindruck dürfte auf beiden Ebenen als ungenügend eingestuft werden. 


\section{Die Kommunikationssituation beim Ingeborg-Bachmann- Wettbewerb}

\subsection{Diskursaspekte}

Die Klagenfurter Diskussionen werden als Teil eines literaturbezogenen Wertungsdiskurses betrachtet. Diskurs wird dabei sehr breit als Wissen begriffen, das gesellschaftlich durch das Sprechen selber, also durch Kommunikation konstituiert und verhandelt wird (vgl. Spitzmüller/Warnke 2011, 41). Dass also in einer bestimmten Form über etwas gesprochen wird, so und nicht anders, mit eben diesen Worten und nicht mit anderen, wird als bedeutsam aufgefasst. Mitgedacht ist dabei immer die Frage, was möglicherweise nicht gesagt wird bzw. wie etwas nicht gesagt wird. Diskursanalyse ist also eine Wissensanalyse (vgl. Roth/Spiegel 2013, 8 f.). Die Zugriffsebene auf die Diskussionen ist in der vorliegenden Arbeit eine diskursanalytische, in dem Sinne, dass der Versuch unternommen wird ausgehend vom sprachlichen Material der Diskussionen auf ein allgemeines Wertungswissen zuzugreifen. Faktoren wie der Äußerungskontext (Raum, Zeit, Situation) und der Sprecher selber müssen als Bezugsgrößen bei der Analyse beachtet werden (vgl. Spitzmüller/Warnke 2011, 123; Roth/Spiegel 2013, 9). In diesem Kapitel soll gezeigt werden, unter welchen Rahmenbedingungen sprachliches Handeln bei den Diskussionen zum IngeborgBachmann-Wettbewerb stattfindet und welche Besonderheiten mündliche Kommunikation im Gesprächsaufbau mit sich bringt. Denn die Klagenfurter Diskussionen sind, anders als beispielsweise Zeitungsrezensionen, eine mündliche Auseinandersetzung zwischen verschiedenen Gesprächspartnern. Darüber hinaus finden sie in einem ganz besonderen medialen Rahmen statt. Diese Faktoren beeinflussen die Art und Weise, wie in Klagenfurt über Literatur gesprochen wird.

\subsection{Rahmenbedingungen der Kommunikation}

Ohne Zweifel sind es vor allem die Art der Präsentation und die mediale Aufbereitung, die den Ingeborg-Bachmann-Wettbewerb zu etwas Besonderem machen (vgl. Kapitel 3). Die bereits erwähnten Eigenschaften Transparenz, Mündlichkeit und Prozessualität, die den Charakter des Preises bestimmen, bestimmen auch die Art, wie die Juroren während des Wettbewerbs kommunizieren. Eine Auswertung der Diskussionen erfordert auch eine Vertrautheit mit der speziellen Kommunikationssituation beim Ingeborg-BachmannWettbewerb und den Eigenheiten mündlicher Kommunikation, die im Folgenden darge- 
stellt werden sollen. Dabei werde ich zunächst auf die generellen Rahmenbedingungen der Diskussionen eingehen, die für den von mir untersuchten Zeitraum charakteristisch sind, dann auf spezielle sprachliche und strukturelle Aspekte der Diskussionen selbst.

\subsubsection{Vorbereitungsmöglichkeiten und Diskussionsimpuls}

Am Anfang jedes Ingeborg-Bachmann-Wettbewerbs steht die für den späteren Beobachter nicht zugängliche Auswahl der Autoren und Texte. Im untersuchten Zeitraum erfolgt diese Auswahl („Einladung“) durch die Juroren. Jeder Juror hat das Recht, zwei Autoren auszuwählen und zum Wettbewerb einzuladen. Die Einladung erfolgt auf der Grundlage eines unveröffentlichten Texts, den der Autor selbst mit der Empfehlung eines Verlages oder einer Literaturzeitschrift dem Juror zukommen lässt. Welchem Juror ein Autor seinen Text ans Herz legt, bleibt ihm selbst überlassen. ${ }^{20}$

Impuls der Diskussion ist der zu begutachtende Text, der den Juroren zum Zeitpunkt der Diskussion in verschiedenen Formen zugänglich ist. Zum einen liegen seit 1997 die Texte allen Juroren etwa eine Woche vor der Veranstaltung vor (Moser 2004, 426), sodass sie die Texte in Ruhe und für sich lesen können. Dabei ist davon auszugehen, dass die Texte still gelesen werden und die Juroren allein lesen. Auf der Grundlage dieser Lektüre kann der Juror Eckpunkte seiner Argumentation bereits vor der Veranstaltung ausarbeiten oder ganze Plädoyers vorformulieren. Dass, wenigstens in komplizierteren Fällen, auf solche Möglichkeiten der Vorbereitung zurückgegriffen wird, kann aus den Diskussionen geschlossen werden. Wenn etwa Iris Radisch (5:36) in der Diskussion zu Thomas Kapielskis (1999) Text ihren Beitrag mit dem Hinweis beginnt, sie habe fast gehofft „dass einer sagt: Das ist nicht Literatur. Dann hätte ich jetzt irgendwie mich hier aufspielen können“, lässt darauf schließen, dass sie in der Vorbereitung eine bestimmte Reaktion der Jury antizipiert hat und ihre eigene Einschätzung mit Blick auf diese antizipierte Haltung konzipiert hat. Die Juroren greifen außerdem explizit darauf zurück, was sie sich „beim ersten Lesen“ oder beim „Lesen zu Hause“ gedacht haben. Der vorschlagende Juror hat darüber hinaus im Vorfeld die Möglichkeit, mit dem Autor in Kontakt zu treten und mit ihm über den Text zu sprechen. Das Jurymitglied, das einen Autor einlädt, hat daher oftmals einen Wissensvorsprung, der mitunter so weit geht, dass er/sie nicht nur den im Wettbewerb vorgetragenen Textausschnitt kennt, sondern das gesamte dazugehörige Romanmanuskript. ${ }^{21}$

20 Es ist auch möglich, sich bei mehreren Juroren gleichzeitig zu bewerben.

21 Für den Wettbewerb können sowohl abgeschlossene Erzähltexte als auch Ausschnitte aus Romanen vorgeschlagen werden. Bei Romanausschnitten gilt der gelesene Ausschnitt als alleinige Grundlage der Bewertung. Bisweilen versuchen jedoch die vorschlagenden Juroren, ihr Mehrwissen in die Diskussion 
So gibt Norbert Miller (12:13) in der Diskussion zu Ulla Lenzes (2003) Text „Schwester und Bruder", einem Romanauszug, eine kurze Zusammenfassung der Gesamtstruktur des Romans. Iris Radisch (2003 Lenze, 13:17) tadelt seine Praxis als „nicht ganz fair“.

Zum anderen tragen die Autoren ihren Text in Klagenfurt vor. Dabei können die Juroren sich auf das Zuhören konzentrieren oder aber den Text, dessen Manuskript ihnen als Ausdruck vorliegt, noch einmal mitlesen. Im Moment der Diskussion ist die vorgetragene Textvariante die zeitlich aktuellere Rezeptionsetappe und somit die unmittelbarere; die im Vorfeld gelesene Fassung ist demgegenüber stärker reflektiert. Dass beide Rezeptionsetappen von Bedeutung sind, zeigen die Diskussionen. In den Gesprächen werden Bewertungen häufig explizit mit Hinweis auf eine - die gehörte oder gelesene - Fassung des Textes ausgesprochen.

\subsection{2 Öffentlichkeit und Mehrfachadressiertheit}

Die Diskussionen zu den Texten finden im ORF-Theater in Klagenfurt statt. Dabei gibt es ein Publikum vor Ort, das zum Teil aus Presse und Fachleuten besteht, zum Teil aber auch aus interessierten Laien und Schulklassen. Darüber hinaus wird der Wettbewerb seit seinen Anfängen 1977 für das Fernsehen aufgezeichnet und seit 1991 vollständig oder teilweise über den Sender 3sat im Fernsehen übertragen (für Details siehe Moser 2004). Etwa seit Beginn des neuen Jahrtausends wird außerdem die Internetseite des Ingeborg-BachmannWettbewerbs http://bachmannpreis.orf.at/ vermehrt genutzt, um das Geschehen weiteren Kreisen zugänglich zu machen. Neben der Bereitstellung der Video-Aufnahmen seit dem Jahr 2000 gibt es seit 2002 auch die Möglichkeit, via Internet für den Publikumspreis abzustimmen. Das Vor-Ort-Publikum ist allerdings von der aktiven Teilnahme an den Diskussionen genauso ausgeschlossen wie das Fernsehpublikum. Es nimmt, sieht man von der Abstimmung für den Publikumspreis und nonverbalen Äußerungsformen wie Gelächter und Applaus ab, weitestgehend eine Zuhörerrolle ein. Die (sprachliche) Aufmerksamkeit der Juroren ist gleichermaßen durch die Anwesenheit des Publikums als auch durch die anderen Juroren gebunden. Alle Beiträge sind also doppelt adressiert. Sie sind primär an die anderen Jurymitglieder gerichtet, die durch ihren Jurorenstatus die Möglichkeit haben, auf Diskussionsbeiträge zu reagieren, und die Entscheidungsträger sind, wenn es um die Preisabstimmung geht; und sie sind an das breitere Publikum gerichtet, das als Multiplikator funktioniert. Da die Veranstalter an einer großen Breitenwirkung interessiert sind, entsteht keine reine Expertendiskussion. Welche Personenkreise tatsächlich durch die

einzubringen. 
Übertragung erreicht werden, ist schwer zu erfassen. Fragt man im Bekanntenkreis, ob der Wettbewerb bekannt ist, zeigt sich, dass neben Germanisten und Literaturwissenschaftlern auch literaturinteressierte Laien wenigstens von der Fernsehübertragung wissen und gelegentlich zuschalten. Primär dürfte das Publikum aber aus Vertretern des Literaturbetriebs bestehen. Folge dieser Doppeltadressiertheit der Redebeiträge ist ein Oszillieren zwischen verschiedenen Modi der Kommunikation. Die Jurymitglieder - allesamt Experten auf dem Gebiet der Gegenwartsliteratur und wenigstens teilweise miteinander bekannt - könnten auf der Grundlage ihres kommunikativen Fachwissens in eine Fachdiskussion eintreten. Sie müssen aber gleichzeitig für das breitere Publikum, das möglicherweise auch Laien mit einschließt, verständlich und plausibel argumentieren. Diese Doppeltadressiertheit wird von den Juroren gelegentlich explizit reflektiert, etwa wenn Silvia Bovenschen anmerkt, sie benutze jetzt ein „Jurorenfuzziwort“ (1999 Kapielski, 12:25 Bovenschen). Gemeint ist damit das „Selbstreferentielle“ (ebd.). Die Jurorin thematisiert an dieser Stelle ihre eigene Rolle als Expertin ironisch und gibt dem Nichtexpertenpublikum und etwaigen Kritikern unter den Journalisten zu verstehen, dass sie sich ihrer kommunikativen Grenzüberschreitung in Richtung Fachkommunikation bewusst ist. ${ }^{22}$ Dabei ist die Bedeutung der Zuschauer für die Juroren selbst nicht zu unterschätzen, denn die Zustimmung des Publikums vor Ort und vor dem Fernseher sichert den Diskutanten soziales Prestige als Vertreter des Kulturbetriebs und damit nicht zuletzt perspektivisch einen gesteigerten ökonomischen Gewinn. Die Verständlichkeit der Diskussionen ist also nicht nur im Sinne der Veranstalter, sondern auch im Sinne der Juroren.

\subsubsection{Interaktion und Feedback}

Zwar sind die Jurorenwertungen sowohl an die Juroren als auch an das erweiterte Publikum gerichtet, das Vor-Ort-Publikum und das Fernsehpublikum bleiben dabei aber weitestgehend stumme Kommunikationsteilnehmer. Gegenstand der Analysen ist daher ausschließlich die Juroren-Interaktion. Für diese sind die Regeln mündlicher Kommunikation prägend. Mündliche Kommunikation ist dadurch gekennzeichnet, dass mehrere Parteien in einer gemeinsamen Situation, in der sie sich wechselseitig wahrnehmen können, miteinander kommunizieren (Fiehler 2004, 56). Es handelt sich auch dann noch um mündliche Kommunikation, wenn sie aufgezeichnet oder mittels technischer Geräte übertragen wird (ebd., 55 f.). Das ist in Klagenfurt der Fall. Dabei interagieren vor allem die Dis-

$\overline{22}$ Bovenschen nimmt gleichzeitig den Gestus des Textes - einer Satire auf den Literaturbetrieb in Klagenfurt - auf. 
kutanten untereinander, aber auch der zweiten Adressatengruppe, dem Publikum, stehen Möglichkeiten zur Verfügung, der Jury (nicht-sprachliches) Feedback zugeben. So kann das Vor-Ort-Publikum durch Applaus oder Lachen Zustimmung zu einem Redebeitrag signalisieren. Rückmeldung erfährt die Jury auch über die Reaktion der Presse auf den Wettbewerb. Pressevertreter sind fester Bestandteil des Vor-Ort-Publikums. Dass die Urteile der Presse von den Juroren wahrgenommen und auch ernst genommen werden, zeigen gelegentliche direkte Hinweise Presseurteile. So nimmt Ursula März (11:30) in der Diskussion zu Eva von Schirach (2005) Bezug auf die im Rahmenprogramm der Tage der deutschsprachigen Literatur geführten Interviews mit Journalisten und Kritikern, in denen gefragt werde, ob es unter den Einsendungen nicht Texte gebe, die ein bisschen in der Literatur weitergehen. Spinnen (2009 Winkler, 15:43) verteidigt sich vorauseilend gegen den Vorwurf „derer, die mitschreiben und so“: Es dürfe auf gar keinen Fall der Eindruck entstehen, es würde diese literarische Tradition - gemeint ist die Avantgarde - jetzt einfach gewissermaßen weggebürstet. Die Juroren stehen also durchaus in einer indirekten Interaktion mit Teilen des Publikums.

\subsubsection{Redezeit und Rederecht}

Die Klagenfurter Diskussionen unterliegen einer starken Strukturierung, die der beschränkten Redezeit und der Verteilung des Rederechts durch den Moderator geschuldet ist. Typischerweise dauern die Diskussionen rund 25 Minuten. Vereinzelt können sie schon früher abbrechen (15 bis 20 Minuten Dauer) oder länger dauern (bis zu 35 Minuten). In diesen durchschnittlich 25 Minuten müssen alle sieben bzw. acht Juroren ihre Meinung geäußert haben können. Für den einzelnen Juror bleiben also ca. drei Minuten Redezeit, in denen er alle für ihn wichtigen Punkte angesprochen haben sollte. Die Juroren melden ihren Redewunsch durch Handzeichen beim Moderator an, der das Rederecht zuteilt. ${ }^{23}$ „Zwischenrufe“ - also kürzere Beiträge, die sich auf einen vorangegangenen Beitrag beziehen, Antworten, Nachfragen und Richtigstellungen - sind möglich, können aber nur begrenzt zugelassen werden. Der Moderator sorgt dafür, dass eine gewisse Gerechtigkeit in der Menge und Länge der Redebeiträge besteht und dass alle Juroren zum Zug kommen. Diese Steuerung der Diskussion durch den Moderator, der bis ins Jahr 2007, ${ }^{24}$ inhaltlich keinen

23 Bis 2007 moderiert Ernst Grandits den Wettbewerb. 2008 übernimmt zunächst Dieter Moor das Amt. Seit 2009 werden die Diskussionen von Clarissa Stadler moderiert.

24 Mit Dieter Moor und Clarissa Stadler verändert sich der Moderationsstil. Hatte Grandits sich auf die Verteilung des Wortrechts beschränkt und dabei die Wortmeldungen der Juroren respektiert, bemüht sich insbesondere Clarissa Stadler auch um eine inhaltliche Strukturierung. Sie fasst Redebeiträge zusammen oder wendet sich mit Fragen direkt an bestimmte Jurymitglieder. 
Anteil an der Diskussion hat, bestimmt die Anforderungen an die Juroren mit. Wollen sie sich mit ihrer Argumentation durchsetzen, müssen sie in ihrer Redezeit möglichst viele, möglichst relevante, möglichst überzeugende Argumente auf eine verständliche Art und Weise kommunizieren. Diese spezielle Ausprägung der Diskussionen ist ihrer Intention geschuldet.

\subsubsection{Intention und Zielgerichtetheit}

Anders als bei einer privaten Unterhaltung, bei der ein mäandernder Austausch über den Text möglich wäre, verfolgen die Klagenfurter Diskussionen ein klares Ziel, nämlich die Bewertung des jeweiligen Textes in Hinblick auf seine Preiswürdigkeit. Sie sind folglich durch die Bewertungsintention strukturiert. Alle Redebeiträge sind darauf zugeschnitten, den Text zu bewerten und ihn auf einer Skala von preiswürdig bis nicht preiswürdig einzuordnen. Daraus folgt, dass fast alle Aussagen, die in der Diskussion gemacht werden, wertend sind. Gerade dieser Aspekt macht die Diskussionen als Korpus für eine Wertungsanalyse so interessant. Außerdem stehen die Juroren in einem Konkurrenzverhältnis zueinander, denn jeder Juror verfolgt das Interesse, den von ihm favorisierten Text in der Preisabstimmung durchzusetzen. Dabei muss es sich nicht zwangsläufig um den selbst vorgeschlagenen Text handeln. Es geht also in den Diskussionen kaum darum, den Text als solchen möglichst adäquat in Hinblick auf seine inhaltlichen Angebote oder seine künstlerische Gestaltung zu erfassen; es geht auch nicht an und für sich darum, ihn zu verstehen. Aussagen über alle genannten Aspekte erfolgen immer in Hinblick auf ihren Nutzen für die Bewertung. Allerdings ist, so viel kann an dieser Stelle schon vorweggenommen werden, die Bezugnahme auf die Machart des Textes fester Bestandteil des aktuellen Wertungsdiskurses. Da die Juroren in einem Konkurrenzverhältnis stehen und ihre eigenen Werte durchsetzen wollen, setzen sie auch Kommunikationsstrategien ein, die auf Überzeugung der anderen Gesprächsteilnehmer abzielen. Die Gesprächsführung bzw. Beitragsstruktur ist daher nicht unbedingt auf korrekte Beschreibung, sondern vorwiegend auf Überzeugungskraft ausgerichtet.

\subsection{Mündlichkeit}

Obwohl die Juroren die Möglichkeit haben, sich inhaltlich und rhetorisch auf ihren Auftritt vorzubereiten, handelt es sich bei den Klagenfurter Diskussionen auch um mündliche Gespräche, die auch die Eigenschaften mündlicher Kommunikation tragen. Mündliche Kommunikation ist im Gegensatz zur schriftlichen Kommunikation primär durch ihre Pro- 
zessualität (Deppermann 2008, 49) bzw. Zeitlichkeit (Fiehler 2004, 59 f.) gekennzeichnet. Jede Sprachhandlung geht in das Vorwissen der Gesprächspartner ein und bestimmt den Gesprächsverlauf als neue Wirklichkeit mit (Deppermann 2008, 68). Der Gegenstand der Kommunikation wird im Gespräch erst konstituiert und präsentiert sich jedem Gesprächsteilnehmer in einer von seinem Weltwissen und seinem kommunikativen Wissen geprägten Variante:

Die spezifischen kommunikativen Sinnkonstrukte, die sukzessive entstehen [...], sind Teilobjektivierungen der an ihrem Zustandekommen beteiligten individuellen Erfahrungen - also der kognitiven Konzepte der Gesprächspartner. (Brinker/Sager 2001, 127)

Brinker/Sager verstehen Gespräche also als einen Austausch, in dem eben nicht der Sender eine Information für einen Empfänger verpackt, der sie dann nur noch zu entpacken hat (Transfermodell), sondern als einen Prozess, in dem die Gesprächspartner gemeinsam den Gegenstand der Kommunikation aufbauen müssen. Das weist zum einen darauf hin, dass der Gegenstand der Kommunikation - in diesem Fall der literarische Text - keine feste, klar konturierte und für alle Teilnehmer identische Einheit ist, zum anderen, dass eine Sprache, die in der Lage ist, den jeweiligen literarischen Text als Gegenstand zu konstituieren, erst gefunden werden muss. Es ist charakteristisch für mündliche Kommunikation, dass dies nur im zeitlichen Nacheinander geschehen kann. Während sich ein schriftlicher Text vor der Weitergabe an den Kommunikationspartner noch verändern lässt, ohne dass Spuren davon bleiben, können Berichtigungen, sowohl grammatischer als auch inhaltlicher Art, in der mündlichen Sprache nur im Anschluss an die Aussage, und für alle Gesprächsteilnehmer als Reparaturvorgang sichtbar, erfolgen.

Obwohl auch im mündlichen Gespräch Klarheit und Eindeutigkeit angestrebt werden, involviert das Verfahren, mit dem diese Klarheit hergestellt wird, zunächst Redundanz und Vagheit, damit die Aussagen für alle Beteiligten anschlussfähig werden bzw. bleiben. Unterstellt wird dabei immer, dass alle Gesprächspartner sich kooperativ verhalten und zur Bewältigung der Gesprächsaufgabe beitragen wollen. Sie wenden in der Formulierung ihrer Beiträge das „et cetera“-Prinzip (Brinker/Sager 2001, 137) an:

Die Gesprächspartner versuchen in diesem Sinne, stets soviel [sic] zu dem Gesagten oder dem Handlungskontext hinzuzufügen, daß die für sie defizitären und damit möglicherweise unverständlichen oder abweichenden Gesprächsbeiträge [...] wieder ihren gängigen Erwartungen und ihrem Verständnis von der augenblicklichen Situation entsprechen. (Brinker/Sager 2001, 137)

Aus diesem Grund sind die Redebeiträge, die im Rahmen des Ingeborg-Bachmann-Wettbewerbs entstehen, auch immer als Annäherungs- und Verständigungsprozess zu verstehen, 
in dem nicht jedes Wort wohlüberlegt gesetzt und jede Aussage intensiv durchdacht und in ein Argumentationssystem eingepasst ist. Die Juroren müssen in der Lage sein, sehr spontan auf den Gesprächsverlauf zu reagieren. Sie können dabei nicht voraussehen, wie die anderen Juroren argumentieren werden. Diese Spontaneität setzt sowohl große Übung in literaturkritischer Argumentation als auch eine große Medienkompetenz voraus. Die spezifischen Folgen und Anforderungen einer solchen mündlichen Kommunikationssituation müssen genauer betrachtet werden.

Deppermann (2008, 8 f.) nennt fünf Merkmale von Gesprächen, die über alle Gesprächstypen hinweg Gültigkeit haben: Konstitutivität, Prozessualität, Interaktivität, Methodizität und Pragmatizität.

Neben der bereits erwähnten Konstitutivität (Gesprächsereignisse werden durch das Gespräch hergestellt) und Prozessualität (Gespräche bestehen aus einer Abfolge von Aktivitäten), sind Methodizität und Pragmatizität von besonderem Interesse.

\subsubsection{Konstitutivität und Prozessualität}

Die beiden Merkmale Konstitutivität und Prozessualität können hier zusammengefasst werden, da sich beide auf die lineare zeitliche Abfolge des Gesprächs beziehen. Der konstitutive und prozessuale Charakter ist insofern für die hier vorgenommene Analyse von Bedeutung, als größere Bestandteile der Diskussionen den Versuch darstellen, den Text als gemeinsame Bezugsgröße zu fassen und zu konturieren. Um einen Austausch über einen Text möglich zu machen - auch Wertungen fußen, sofern sie im Gespräch vollzogen werden, auf einem Verständigungsprozess -, muss zunächst eine grundlegende Verständigung darüber erfolgen, wie der Gegenstand der Bewertung, der Text, beschaffen ist. Gerade weil es sich um literarische Texte handelt, die über Mehrdeutigkeit und eine nicht alltägliche Sprache verfügen, muss zunächst klar gemacht werden, wie ein Text verstanden wird. Dieser Verständigungsprozess prägt die Diskussionen stark, immer in Abhängigkeit von der Größe des Deutungsangebots des Textes und der Zugänglichkeit der Textwelt (vgl. Kapitel 10.1-10.2). Im Verlauf der Diskussion konstituiert sich also der Text bzw. konstituieren sich die verschiedenen Zugriffe auf den Text. Im Zuge der Beschreibung, die natürlich immer auch schon eine Bewertung enthalten kann, entwickelt sich auch eine Beschreibungssprache. Diese kann für einen einzelnen Text gelten, kann sich aber auch durch den ganzen Wettbewerb ziehen, wenn die Texte mit Verweis auf bestimmte, im Gespräch als Referenzpunkte „erarbeitete“ Kriterien in Beziehung gesetzt werden. Im Verlauf eines Wettbewerbs können Kriterien sprachlich „geschaffen“ werden. Mitunter lässt sich beobachten, wie eine 
konsensuelle Beschreibungssprache im Verlauf einer Diskussion erarbeitet wird.

\subsubsection{Interaktivität}

Deppermann $(2008,8)$ betont, dass Gespräche immer auch das Lösen einer gemeinsamen Aufgabe bedeuten. Die Gesprächsteilnehmer bearbeiten durch ihre Kommunikation ein Problem oder eine Aufgabenstellung und wollen dies möglichst erfolgreich tun. Dabei findet Interaktion statt, sobald sich Äußerungen aufeinander beziehen; sie ist also nicht gleichzusetzen mit gelungener Kooperation. Insofern ist jedes Gespräch per se interaktiv und die Klagenfurter Diskussionen keine Ausnahme.

Auch wenn die Ingeborg-Bachmann-Diskussionen stark strukturiert und Rederechte nicht frei verfügbar sind, auch wenn die Juroren in einem Konkurrenzverhältnis zueinander stehen, arbeiten sie an der gemeinsamen Aufgabe: der Findung würdiger, für möglichst viele Juroren akzeptabler Preisträger. Redebeiträge beziehen sich aufeinander, auch wenn sie auf den ersten Blick wie Monologe der Meinungsäußerung wirken.

\subsubsection{Methodizität und Pragmatizität}

Auch diese beiden Eigenschaften Methodizität und Pragmatizität können zusammengefasst werden. Methodizität zielt darauf, dass

Gesprächsteilnehmer [...] typische, kulturell (mehr oder weniger) verbreitete, d. h. für andere erkennbare und verständliche Methoden, mit denen sie Beiträge konstruieren und interpretieren sowie ihren Austausch miteinander organisieren, [benutzen]. (Deppermann 2008, 8)

Das Kriterium der Pragmatizität dagegen bezieht sich auf die Wahl der Methoden in Hinblick auf „gemeinsame und individuelle Zwecke“ (Deppermann 2008, 9).

In Hinblick auf diese Kriterien lassen sich für den Klagenfurter Wettbewerb verschiedene Beobachtungen machen. Aufgrund der geringen Redezeit und der großen thematischen Fokussiertheit der Diskussionen einerseits, der Zielgruppenorientiertheit andererseits, sind die Juroren gezwungen, ihre Beiträge sowohl prägnant als auch für ein breiteres Publikum verständlich zu gestalten. Die, im Gegensatz zu vielen Alltagsgesprächen, sehr klare Zielsetzung der Diskussionen, einen Preisträger zu finden (gemeinsamer Zweck), sowie den eigenen Kandidaten durchzusetzen bzw. durch erfolgreiche Argumentation Prestigezuwachs zu erlangen (persönlicher Zweck), ${ }^{25}$ erfordern rhetorisches Können, damit Bei-

$\overline{25}$ Welche persönlichen Intentionen einzelne Juroren darüber hinaus haben, kann - das liegt in der Natur der Sache - von außen nicht beurteilt werden. 
träge nachvollziehbar und überzeugend wirken. Es geht also viel mehr um Plausibilität und Überzeugungskraft als um Adäquatheit in Hinblick auf den bearbeiteten Gegenstand, den Text. Entsprechend sind die Methoden, die eingesetzt werden, rhetorisch. Sie müssen fähig sein, komplexe literaturkritische Argumentationen in kürzester Zeit aufzurufen und möglichst allgemeinverständlich zu vermitteln. Die Argumente müssen die anwesenden Literaturexperten überzeugen. Dazu wäre die Fachsprache der Literaturwissenschaft oder der Literaturkritik am angemessensten, da sie entsprechende Termini bereithält. Angesichts der intendierten Breitenwirkung (Fernsehpublikum) können solche Termini aber nur dann verwendet werden, wenn sie z. B. über den Schulunterricht weit verbreitet sind - das ist bei einigen Ausdrücken der Erzähltheorie (z. B. Perspektive, Erzähler) der Fall - oder solche, die weitestgehend selbsterklärend sind oder wirken (z. B. „Schelmenroman“). Um Fachtermini und damit das Abdriften in eine reine Expertendiskussion zu vermeiden, wird auf gemeinsames literaturkritisches und literaturgeschichtliches Wissen zurückgegriffen, das, aufgrund seiner starken Verankerung im Milieu kulturell Interessierter, eher als bekannt vorausgesetzt werden kann, sodass über die einfache Nennung von Topoi und Schlagwörtern damit verbundenes, komplexeres Wissen evoziert werden kann. Topoi zeichnen sich nach Wengeler (2003) gerade dadurch aus, dass sie einer rhetorischen Absicht dienen. Rhetorische Diskussionen sind insofern anders, als sie nicht eine wahre Aussage treffen, sondern plausibel und überzeugend sein wollen. Sie folgen einer Alltagslogik (ebd., 178). Solche alltagslogischen Topoi können auch gruppenspezifisch sein - die Klagenfurter Juroren gehören zur Gruppe der professionellen Leser und Literaturpreisjuroren - und sind für diese Gruppe habituell, d. h. „gewohnheitsmäßig und kollektiv verbreitet“ (ebd., 198). Dass die Juroren über ein solches gemeinsames Wissen verfügen, ist nicht nur deswegen wahrscheinlich, weil sie sich alle beruflich mit Literatur beschäftigen, sondern auch, weil sie ihre literarische Sozialisation im Wesentlichen im selben Zeitraum - ca. zwischen 1965 und 1985 - erfahren haben. Sie dürften also mit ähnlichen Texten und ähnlichen Lehrmeinungen konfrontiert worden sein und können auf diese Konzepte, Perspektiven und Werte zurückgreifen, auch wenn sie sie nicht persönlich vertreten. Zur habituellen Argumentationslogik der Juroren gehört aber auch, dass die Wertung „bewiesen“ werden muss. Die Arbeit am Text gilt, das wird in den Diskussionen deutlich, als Königsweg der Bewertung von Literatur als Kunst. Diese Arbeit am Text, deren Ziel die Begründung einer Wertung ist, geht aber anders vonstatten als literaturwissenschaftlich-hermeneutische Textarbeit. Gerade vorausgesetztes und für die Beteiligten nicht weiter erklärungsbedürftiges Wissen enthält auch kulturell verfestigte Wertmuster, die im Zusammenhang dieser Arbeit beson- 
ders interessant sind. So benötigt die Nennung des Namens „Goethe“ in der Regel keine weitere Einordnung. Mit ihm verbindet sich die Vorstellung von Literatur als Kunst, aber auch die Vorstellung vom klassischen Kunstideal, die Vorstellung des deutschen Nationaldichters, des Dichtergenies oder sogar des Universalgenies u.v.m. Diese Vorstellungen können, je nach Bewertungssituation, zwar positiv (Hochkultur) aber auch negativ (Imitation eines veralteten Stilideals) eingesetzt werden. Grundsätzlich bedarf es jedoch keiner weiteren Erläuterungen, wie Goethe einzuordnen ist. Was hier am Beispiel des Namens „Goethe“ gezeigt wurde, gilt auch für andere Autoren und für bestimmte Schlagwörter. Kafka ist der Vertreter einer hermetischen, modernen Literatur mit grotesken Zügen. Bret Easton Ellis‘ Roman „American Psycho“ wird als Paradebeispiel einer Literatur, die mittels grotesker Übertreibung die Auswüchse des Kapitalismus thematisiert, eingesetzt, ohne dass dabei der Roman genauer beschrieben werden müsste. Dass es in der Literatur um das Wie und nicht um das Was gehe, ist nicht begründungsbedürftig. Auch dass man Form und Inhalt aufeinander beziehen können sollte, gehört zu den Topoi, die keiner Ausformulierung bedürfen. Obwohl solche Topoi im Korpus deutlich ausgemacht werden konnten, wurden sie nicht systematisch verfolgt. ${ }^{26}$ Das Wissen, dass sie angewendet werden, ist allerdings wichtig für die grundsätzliche Einschätzung der Art der Kommunikation über Texte, die in Klagenfurt dominiert. Gerade aus literaturwissenschaftlicher Sicht sind literaturkritische Bewertungen mitunter „fremd“, da der Umgang mit dem literarischen Texten ein anderer ist. Das Wissen um den rhetorischen Charakter vieler Äußerungen kann helfen, die Wertungen besser einzuschätzen.

\subsection{Aspekte der besonderen Intention}

Es ist deutlich geworden, dass die Klagenfurter Diskussionen insofern von alltäglichen Sprechsituationen abweichen als sie eine spezifische, klar definierte und allen bewusste Absicht verfolgen: Es sollen Literaturpreise verliehen werden. Diverse Besonderheiten der Diskussionen sind auf diese Intention zurückzuführen, so etwa die thematische Fokussiertheit und die starke Strukturierung durch Verteilung der Rederechte und Redezeiten.

Damit in Verbindung steht allerdings auch die Konkurrenz der Juroren, die ein Interesse haben, den von ihnen eingeladenen oder favorisierten Autoren eine besonders gute Ausgangsposition für einen Preis zu verschaffen. Das Argumentationsverhalten der Juroren ist also stark von der Absicht geprägt, die anderen Juroren und das Publikum von dem Kan-

26 Die Frage nach konkreten Topoi der Bewertung konnte aus zeitlichen Gründen nicht direkt behandelt werden. Einige Topoi beinhaltet allerdings die Liste der Forderungen an Literatur in Kapitel 6.1. 
didaten zu überzeugen, den sie für den besten halten. Auf der anderen Seite verbindet sich für sie persönlich mit der Überzeugungskraft soziales Prestige. Es ist anzunehmen, dass ein in Klagenfurt besonders erfolgreicher Juror in der Folge als besonders begabter Kenner und Kritiker von Literatur gilt, möglicherweise sogar als Entdecker junger Autoren und er/sie daher zunehmend auch für andere Aufgaben und Veranstaltungen gefragt ist. Das Argumentationsverhalten ist daher - und hier unterscheidet sich der Ingeborg-BachmannWettbewerb deutlich von anderen Preisen, bei denen zum einen hinter verschlossenen Türen über Texte verhandelt wird, zum anderen bereits anerkannte Autoren ausgezeichnet werden - deutlich mehr durch die persönlichen Interessen der Juroren geprägt.

\subsection{Zusammenfassung}

Der Blick auf die Art, wie die Jurorenkommunikation in Klagenfurt grundsätzlich funktioniert, das heißt, wen sie erreichen will, was sie erreichen soll und welche Möglichkeiten dafür zur Verfügung stehen, bestätigt noch ein weiteres Mal, dass zu erwarten ist, dass der verwendete Code sich deutlich von dem anderer bekannter Expertentexte unterscheidet. Im Vergleich zur wohl verbreitetesten öffentlichen Form der Literaturbewertung, der gedruckten Rezension, sind die Diskussionen durch ihre Mündlichkeit geprägt. Die sprachliche Umsetzung der Wertung ist ein Prozess. Es findet eine ständige Annäherung an den Gegenstand der Wertung statt, die sich sowohl in den Bewertungen der einzelnen Juroren als auch im Bezug aufeinander aufbaut. Die Bewertungen sind also im Vergleich zu schriftlich ausgearbeiteten Rezensionstexten viel weniger ein fertiges Produkt. Auch durch die gegenseitige Einflussnahme der Wertungsbeiträge aufeinander sind sie dynamischer als schriftliche Wertungen. Das Konkurrenzverhältnis, das man für die Juroren annehmen darf, ihr Wunsch zu überzeugen und anerkannt zu sein, führt außerdem dazu, dass die Bewertungen eine starke rhetorische Komponente haben. In ihrem Bezug auf den Text, der eine große Rolle spielt, ist die Absicht nicht darauf gerichtet, den Text adäquat in Bezug auf dessen vermutete Intention zu erfassen, sondern Aspekte seiner Machart so zu erfassen, dass sie als Zeugnisse seiner Qualität oder Minderwertigkeit taugen. Gespräche mit Kollegen während der Entstehung dieser Arbeit haben immer wieder gezeigt, dass dieser Umgang mit den Texten auf Literaturwissenschaftler befremdend wirken kann. In dieser Irritation zeigt sich ein deutlicher Unterschied zwischen Literaturwissenschaft und Literaturkritik: Literaturkritik hat häufig nicht den Anspruch, Texte gegenstandsadäquat zu analysieren. Sie will informieren, überzeugen und unterhalten, und zwar mit Bezug auf weitestgehend implizite Wertungskriterien. Dennoch wird auch in den Bachmann-Preis- 
Bewertungen darauf geachtet, dass erkennbar bleibt, wie sich die Wertungen auf die Texte beziehen. Auch im Sinne der gemeinsamen Gegenstandskonstitution ist das notwendig. 


\section{Autor, Leser, literarischer Text und Literaturkritik aus Sicht der Juroren}

Die bisherigen Vorüberlegungen über den Wettbewerb im Allgemeinen, Wertungen und die kommunikative Situation im Klagenfurter Wettbewerb bilden lediglich einen kontextuellen Rahmen. Sie werfen zweifellos die Frage auf, ob und wie die Juroren ihre eigene Position in den Diskussionen reflektieren und wie sie das Dreieck aus Autor, Leser und Text einschätzen. An dieser Stelle muss ein wenig auf das Korpus vorausgegriffen werden. Um dem Selbst- und Literaturverständnis der Juroren auf die Spur zu kommen, wurden programmatische Aussagen der Juroren ausgewertet. Diese Aussagen betreffen sowohl das Selbstverständnis der Juroren, ihre Aufgaben und Vorgehensweisen, als auch das Verständnis ihres Gegenstandes, also die Voraussetzungen, Funktionen, Wirkungen und Eigenschaften von Literatur. Es handelt sich damit um Aussagen, in denen bewusst Werte formuliert werden. Gegenüber den Wertungen, die auf einen konkreten Text bezogen sind und somit auf die Bedingungen reagieren, die dieser Text mit sich bringt, sind die programmatischen Äußerungen Ausdruck eines reflektierten Wertungswissens. ${ }^{27}$ In ihm werden Grundannahmen und Konfliktzonen sichtbar. Programmatische Äußerungen über Werte müssen nicht unbedingt mit den Werten in konkreten Äußerungen übereinstimmen. Wie Sabine Buck (2011) zeigen konnte, geben Kritiker, wenn man sie nach Kriterien fragt, zwar selten an, ethisch zu urteilen, in konkreten Wertungen, insbesondere im Rahmen von Literaturskandalen, sind ethische Bewertungen aber dennoch verbreitet. Um programmatische Äußerungen aufzuspüren, wurden im Korpus die Stichworte: „Kriterium/Kriterien“, „Aufgabe der Kritik/unsere Aufgabe“, „Maßstab“ und „Literatur“ gesucht und anschließend ausgewertet.

Besonders fruchtbar war das Suchwort „Literatur“ (einschließlich Komposita wie Literaturkritiker, Literaturgeschichte, Literaturbetrieb etc.). Für die Analyse wurden nur normative Verwendungsweisen herangezogen, rein deskriptive Verwendungsweisen dagegen ausgeschlossen. Von den 720 Ergebnissen für das Wort „Literatur“ wurden 324, also etwa $45 \%$ der Nennungen, als normativ eingestuft. Darunter fielen sowohl eindeutig normative Formulierungen wie Literatur kann (nicht), muss (nicht), soll(te) (nicht), hat (nicht) die Aufgabe als auch Formulierungen, die generelle Aussagen über Literatur treffen, wie etwa Literatur ist immer/niemals.

$\overline{27}$ Dabei stehen die programmatischen Aussagen trotzdem immer im Kontext des diskutierten Texten. Durch die Art der Formulierung wird allerdings klar, dass es in ihnen um allgemeinere Einschätzungen geht. 
Anders als bei der Bewertung eines konkreten Texts, in der durchaus in vielen Fällen das Bemühen zu beobachten ist, sich plausibel auf den Text zu beziehen, geben diese programmatischen Aussagen Aufschlüsse darüber, wie Literatur prinzipiell verstanden wird und welche literarischen Konzepte in aktuellen Debatten umstritten sind. Axiomatische Aussagen tragen dazu bei, dass die Jurymitglieder sich innerhalb der Jury, aber auch gegenüber dem breiteren Publikum, literaturkritisch profilieren können.

Für die Frage danach, wie die Juroren die Rolle des Autors, des Lesers und der außerliterarischen Wirklichkeit einschätzen, wurden außerdem exemplarische Auszüge aus Diskussionen herangezogen.

\subsection{Aussagen der Juroren über Maßstäbe der Kritik}

Für die Auswertung wurden die Einzelnennungen zunächst paraphrasiert und abstrahiert und schließlich zu Forderungen gebündelt. Die Forderungen wurden ihrer Relevanz nach sortiert. Je öfter die jeweilige Forderung in den Diskussionen besprochen wurde, desto höher wurde die Relevanz der Aussage eingestuft. Es wurde jedoch nicht unterschieden, ob der Text in Hinblick auf die entsprechende Forderung positiv oder negativ beurteilt wurde. Die folgenden sieben Forderungen können als eine Rangliste (nach Häufigkeit des Vorkommens) jener Maßstäbe betrachtet werden, die von den Juroren ganz bewusst als Maßstäbe formuliert werden. ${ }^{28}$

1. Literatur soll für den Leser eine Verführungskraft haben. Sie soll beim Lesen Freude machen. (vgl. Abschnitt 6.4)

2. Literatur hat ein spezifisches Verhältnis zur außerliterarischen Wirklichkeit. Literatur soll nicht das Leben eins zu eins abbilden. Literatur soll sich zur Wirklichkeit in Beziehung setzen. Literatur soll authentisch wirken. (vgl. Abschnitt 6.3)

3. Gute Literatur soll etwas hinzufügen, was es so vorher noch nicht gab. Literatur soll originell sein. (vgl. Kapitel 12)

4. Literatur muss ihrer Zeit angemessen sein. Sie muss Eigenheiten ihrer Zeit reflektieren. Sie muss zeitgenössisch sein.

5. Literatur bezieht sich auf Sprache und zeichnet sich durch Sprache aus. Sie muss sprachlich umsetzen, was sie inhaltlich darstellt. (vgl. Kapitel 10.2.2)

28 Es wurden nur die häufigsten Forderungen aufgenommen. Da sich viele der Forderungen auch in den Ergebnissen der Korpus-Analyse spiegeln, wird an dieser Stelle darauf verzichtet, sie im Einzelnen zu belegen. 
6. Literatur hat eigene Gesetze, die sie befolgen muss. Das betrifft vor allem ihre Gestaltung. Gleichzeitig sind diese Regeln nicht absolut, sondern relativ.

7. Entscheidend ist nicht Was umgesetzt wird, sondern Wie es umgesetzt wird. Die Kritik soll sich damit beschäftigen, Wie ein bestimmtes Thema umgesetzt wurde.

8. Der Text muss primär an seiner eigenen Absicht gemessen werden. Es sollten keine externen Maßstäbe an ihn herangetragen werden.

Die Forderungen betreffen die Funktion von Literatur für den Leser (Forderung 1), ihr spezifisches Verhältnis zur Wirklichkeit (Forderung 2 und 4), ihr Verhältnis zu anderen literarischen Texten (Forderung 3) und ihre spezifische Beschaffenheit als sprachliche Äußerung (Forderung 5, 6, 7 und 8). Damit markieren die Forderungen auch einige der Grenzbereiche von Literatur, die immer wieder Stoff für Auseinandersetzungen bieten: ihr Verhältnis zur Wirklichkeit, ihre Bedeutung für den Leser und ihre spezifische textuelle Beschaffenheit. Dass insbesondere die Forderung 1 nach der Verführungskraft von Literatur einen so hohen Stellenwert in den programmatischen Äußerungen einnimmt, deutet darauf hin, dass dieser Aspekt zwar wichtig, aber umstritten ist. Die Detailanalysen zu Andrea Winkler (2009) (vgl. Kapitel 19) und Ute-Christine Krupp (2001) (vgl. Kapitel 13) werden diese Auseinandersetzung beispielhaft zeigen. In beiden Diskussionen stehen sich zwei Parteien gegenüber: Die eine Partei lobt die gelungene formale und sprachliche Gestaltung des Textes, die andere argumentiert dagegen: Der Text sei zwar grundsätzlich als sprachliches Kunstwerk gestaltet, habe sie aber nicht in den Bann gezogen. Die Positionen, es komme allein auf das Wie an und darauf, für einen Inhalt eine angemessene Sprache zu finden, oder es gehe darum, die Möglichkeiten von Literatur als einem Medium, das von der Gestaltung der Sprache lebt, auszuschöpfen, bilden in den Argumentationen, aber auch in den programmatischen Aussagen einen Gegenpol. In den Diskussionen selbst liegt der quantitative Schwerpunkt auf Argumenten, die sich mit der Gestaltung der Texte auseinandersetzen. Erst, wenn sich ein deutlicher Konflikt zwischen hedonistischer Textwirkung und erkennbar gelungener Gestaltung ergibt, entsteht die Notwendigkeit, die Forderung nach „Verführungskraft“ direkt auszusprechen. Die Forderung 7, dass es auf das WIE ankomme, wird vorwiegend verwendet, um inhaltliche Kritik an Texten abzuschmettern. An der oben präsentierten Liste fällt sofort ins Auge, dass es fast keine Forderung nach bestimmten inhaltlichen Elementen gibt. Bisweilen wird die Forderung 4, Literatur müsse die Gegenwart ihrer Entstehungszeit reflektieren, im inhaltlichen Sinne gebraucht. Sie kann aber gleichermaßen auch als eine Forderung nach Originalität auf der Gestaltungsebene ver- 
standen werden. Für beide Varianten bietet das Korpus Beispiele. Die programmatischen Aussagen, wie sie hier zusammengefasst wurden, weisen auf die Ergebnisse der detaillierteren Korpus-Analyse voraus. Sie deuten an, dass die formale und sprachliche Gestaltung einen hohen ideellen Stellenwert für die Juroren hat, dass Originalität und Zeitgemäßheit eine Rolle spielen werden, aber auch dass der Genuss beim Lesen des Textes eine nicht unerhebliche Rolle spielt. Überrascht hat an dieser Stelle, dass die Verführungskraft der Texte in programmatischen Aussagen einen so hohen Stellenwert einnimmt.

Die folgenden Abschnitte sollen einen Einblick geben, welche Perspektive auf das kommunikative Dreieck aus literarischem Text, Autor und Leser die Juroren haben. Dabei wurden nicht nur die programmatischen Aussagen einbezogen, sondern auch andere Beispiele aus dem Korpus.

\subsection{Der Literarischer Text aus Sicht der Jury}

Während viele Literaturwissenschaftler zunehmend einen Literaturbegriff anstreben, der in der Lage ist, viele verschiedene Arten von Texten deskriptiv in einem Modell zu erfassen und sie in Hinblick auf einen Prototypen abzustufen (Schneider 2007, Winko 2009), verwenden die Juroren einen exklusiven und wertenden Literaturbegriff. Literatur - das sind nicht nur schriftlich fixierte Texte, auch nicht nur fiktionale Texte oder Texte, die im Modus der Fiktionalität rezipiert werden, sondern literarische Texte sind primär künstlerische Texte, die dem vagen Kriterium der Literarizität ${ }^{29}$ entsprechen. ${ }^{30}$ Das heißt, je mehr ein Text den Vorstellungen, die die Juroren von künstlerischen Texten haben, gerecht werden kann, desto literarischer ist er in ihren Augen und desto besser wird er eingestuft. Literatur (literarisch) ist dabei nicht einfach eine Beschreibungskategorie, sondern hat schon an sich einen stark wertenden Charakter. Dabei gehen die Juroren nicht davon aus, dass beispielsweise Thriller nicht dem Bereich der Literatur angehören. Thriller, Krimis, Liebesromane, Science Fiction und andere Genres bilden allerdings eher Randbereiche der Literatur und müssen sich im Wettbewerb als besondere, nämlich künstlerisch aufgewertete Vertreter

29 Was genau Literarizität für die Juroren ausmacht, soll in dieser Arbeit u. a. untersucht werden. Es wird aus den Aussagen der Jury schnell klar, dass „Literarizität“ im Sinne der spezifischen Art der Gestaltung literarischer Texte eine große Rolle spielt. Was das genau bedeutet, lässt sich aber allenfalls aus den konkreten Aussagen rekonstruieren.

30 vgl. Schneider 2007. Schneider entwirft einen deskriptiven Literaturbegriff um die drei Säulen Fixierung, Fiktionalität und Poetizität. Den prototypischen Kernbereich von Literatur bilden dementsprechend Texte, die allen drei Merkmalen entsprechen. Er weist aber auch darauf hin, dass der Begriff "Literatur“ von vielen Akteuren des Literaturbetriebs wertend verwendet. wird (ebd., 4). In der Tat spielen alle drei Merkmale für die Juroren eine Rolle und je besser ein Text diesen Merkmalen entspricht, desto mehr ist er Literatur im wertenden Sinne. Dem Merkmal „Poetizität“ kommt allerdings eine argumentative Sonderrolle zu. Es wird als besonders wichtig eingestuft. 
ihres Genres beweisen. Insofern wenden die Juroren eine Logik der Prototypen an. Es gibt ein Wissen über einen Kernbereich von „echter“ Literatur. Daneben gibt es Textgruppen, die als weniger prototypische Vertreter gesehen werden (beispielsweise Genretexte) und die sich dann durch eine „Literarisierung“ besonders qualifizieren müssen. Das wird sehr deutlich, wenn Spinnen (2006 Passig, 12:26) betont, es gebe auch gutes Genre. Dieser impliziten Annahme, Genre sei normalerweise nicht gut, stellt er eine Beschreibung an die Seite, was die Umsetzung eines Genres im Text, seiner Ansicht nach, gut machen kann: „Es gibt Genrebilder, die dem, was in diesem Genre gemacht wird und möglich ist, durchaus noch etwas hinzufügen, nicht nur Virtuosität, sondern auch so etwas wie Zeitgenossenschaft" (ebd.). Diese Vorstellung vom künstlerisch verfeinerten Genre greift auch Detering (2006 Melle, 0:05) auf, wenn er sich erinnert, er und andere Juroren hätten über Geschichten gesagt, „dass sie innerhalb von Genregrenzen, die sie sich selbst gesetzt ha[ben], sehr gut gemacht [sind], dass sie aber das Problem oder vielleicht auch die Selbstbegrenzung [haben], über diese Genregrenzen des Plots und auch der auf den ersten Blick so realistischen Detailgenauigkeit eigentlich nicht hinaus [zu kommen]". Literatur wird implizit eingeteilt in einen Kernbereich, der künstlerischen Literatur, die als besonders repräsentativ gilt, und Randbereiche wie Genre-Texte oder journalistische Formen wie die Reportage. Wenn Iris Radisch (7:12) Tellkamps (2004) Text mit den Worten „[d]as ist Literatur“ beurteilt, geht es nicht darum, den Text zu klassifizieren. Sie fügt schließlich auch klärend hinzu "große Literatur".

Hochgelobt, und also auch als besonders wertvoll eingeschätzt, werden Texte, die in ihren Grundzügen realistisch sind und Situationen, die sich im weitesten Sinne als Alltagssituationen beschreiben lassen, aus einer neuen Perspektive darbieten. Verfremdende Techniken sind dabei durchaus akzeptiert, nicht jedoch die weniger alltäglichen oder sogar imaginierten Welten der Genreliteratur wie Fantasy, Science Fiction, Thriller. Die Siegertexte von Georg Klein, Kathrin Passig, Clemens J. Setz, Tilman Rammstedt und Jens Petersen spielen in verfremdeten Alltagswelten. Auf unterschiedliche Weise wird in ihnen eine Situation, die im Alltäglichen wurzelt durch Techniken der Perspektive verfremdet. Kafka ist hier ein großes Vorbild.

Über diese Vorstellung von literarischen Texten hinaus geben die Textstellen auch Aufschluss darüber, wie die Jurymitglieder die Rolle des Autors und des Lesers verstehen. 


\title{
6.3 Der Autor als Bürge für die Textqualität und das „richtige“ Ver- hältnis zur Wirklichkeit
}

Trotz des viel zitierten „Tod des Autors“31 bildet der Autor als Urheber und Gestalter, aber auch als ordnende Größe einen wichtigen Bezugspunkt für die Juroren. Alle Bewertungen beziehen sich zunächst auf die Texte. In deren Hintergrund wird aber immer der Autor als der für den Text persönlich Verantwortliche mitgedacht. Obwohl die Juroren mit der Trennung der fiktionalen und der realen Welt und damit verbunden mit der Trennung der Stimmen von Autor und Erzähler durchaus vertraut sind, weisen viele Diskussionssequenzen darauf hin, dass ein enger Zusammenhang von der im Text beschriebenen Welt und der vom Autor erfahrenen „realen“ Welt vorausgesetzt wird. Die Jurymitglieder erwarten, dass sich die Fiktionalität des literarischen Textes in den Grenzen der Wahrscheinlichkeit bewegt. Argumentativ ist der Garant für die Plausibilität der Textwelt - das sei hier noch einmal wiederholt - der Autor.

Die Diskussion zu der Autorin Dorothea Dieckmann, die 2004 mit einem Text aus der Perspektive eines Guantánamo-Häftlings antrat und auf massiven Widerstand in der Jury stieß, weil es „überhaupt keine Information“ (2004 Dieckmann, 12:47 Radisch) über Guantánamo gebe, stützt sich bei vielen Juroren auf die Annahme, Literatur über Guantánamo sei nur möglich, wenn der Autor selbst Lagererfahrungen gemacht habe. Ilma Rakusa schließt sich mit ihrer skeptischen Beurteilung der Meinung der anderen Juroren an:

\begin{abstract}
Ich kenne natürlich auch sehr gut die russische Tradition der Lagerliteratur, da müsste man Solschenizyn, viele andere dazurechnen, die wirklich auf authentischen Erfahrungen beruhen. Bei Kertész dito: Die Erfahrungen liegen unter dem Buch, auch wenn er es fiktionalisiert hat. Und das ist hier genau der Punkt. Die sogenannte Authentizität, die/ Ja, was macht man, wenn man sie nicht aus erster Hand hat, ja, wenn man sie sozusagen erborgt, ja? Ich meine, das könnte eventuell funktionieren, tut es aber hier eben nicht (2004 Dieckmann; 8:09 Rakusa)
\end{abstract}

Rakusa akzeptiert die Analogisierung von realer und vorgestellter Welt nicht, weil die Autorin keine legitime Repräsentantin der von ihr beschriebenen Welt ist. Ursula März, die den Text vorgeschlagen hat und argumentiert, dass es „in der Literatur natürlich noch überhaupt nicht gegen den Text [spricht]“ (2004 Dieckmann; 10:28 März), wenn der Autor das Erzählte nicht selbst erfahren habe, bemüht sich darum, das Problem genereller zu

\footnotetext{
31 Vgl. dazu etwa den von Jannidis et al. herausgegebenen Sammelband „Texte zur Theorie der Autorschaft“ (2002) und die ebenfalls von Jannidis et al. herausgegebene Aufsatzsammlung „Rückkehr des Autors. Zur Erneuerung eines umstrittenen Begriffs“ (1999), die schon im Titel auf den „Tod des Autors" anspielt.
} 
fassen und beschreibt dabei „Zeugenschaft“ als zentrales Element der Literatur des 20. Jahrhunderts:

Also, es hat sich in der Literatur des zwanzigsten Jahrhunderts, in seiner zweiten Hälfte kaum eine Haltung so durchgesetzt wie die der Zeugenschaft. Und in unserer ganzen Diskussion merkt man, wie für selbstverständlich wir es halten, dass Literatur unter dem Diktum der Zeugenschaft steht, dass sie sozusagen das erzählt, was erfahren worden ist, was geschichtliche Erfahrung ist. Und was sie verdrängt hat, vermute ich oder befürchte es, ist die Haltung der Imagination. Und ich verstehe diese große Skepsis, die Sie der Haltung der Imagination gegenüber haben, verstehe ich nicht ganz. Was heißt geborgte Erfahrung? (2004 Dieckmann, 28:18 März)

Obwohl März nicht im Sinne einer Parallelisierung von erlebter Welt und Textwelt argumentiert, muss sie die große Bedeutung dieser Haltung für die Literatur des 20. Jahrhunderts zugestehen. Nicht alle Juroren argumentieren mit dem illegitimen Repräsentantentum. Andere argumentieren, dass die von der Autorin vorgenommenen Methoden zur Herstellung eines Authentizitätseffekts, also die Analogisierung von Textwelt und realer Welt, fehlschlagen. In diesem Fall tritt der Autor nicht als Wahrnehmender, sondern als Gestalter des Textes stärker in den Vordergrund:

Die Skepsis verstehe ich sehr wohl. Die besteht schlicht und einfach darin, dass es uns als obszön erscheint, sozusagen ein erborgtes Leiden oder sozusagen ein erfundenes Leiden/ Und sozusagen das Ethos, was dahinter steht, wäre, zu sagen: kann man/ Der beste Fall wäre, die Leute selber sprechen zu lassen. Und das sozusagen/ Mit der geliehenen Stimme denen eine Stimme verleihen, ist immer sozusagen eine Kippe. Und dann kommt dazu/ eins dazu, wovon bislang noch nicht die Rede war. Ich glaube, es gibt so etwas - wie der entsteht, weiß ich auch nicht - aber es gibt so etwas wie einen Authentizitätseffekt. Es ist ja nicht wirklich authentisch. Es ist ja einfach Literatur, was etwas Anderes ist als die Sache selbst. Und dieser Authentizitätseffekt stellt sich, worüber auch immer, her. Das ist eine ästhetische Sache. Und wenn man skeptisch wird, dann hat er sich nun mal nicht hergestellt. (2004 Dieckmann, 27:48 Nüchtern)

Nüchtern geht zunächst auf die zuvor vor allem von Iris Radisch geäußerte Skepsis ein, um im Anschluss darauf hinzuweisen, dass er ein ästhetisches Problem für die Ursache dieser Skepsis hält. Martin Ebel äußert einen ähnlichen Zweifel, macht diesen jedoch stärker an konkreten Textmerkmalen fest, die er explizit als von der Autorin gemacht darstellt:

Mich hat etwas auch nicht überzeugt an diesem Text. Und da merkt man dann doch sehr die ordnende Hand der Autorin, die dann über ihrem Helden schwebt und sagt: Das gibt ihm fast das Gefühl, von Wirklichkeit umgeben zu sein. Oder: Was er erzählt „,rückt von ihm weg“. Oder „er vergaß sich selbst“. Das sind so abstrakte Begriffe. Da merkt man genau: Hier führt sie den Leser ein bisschen am Gängelband und dann sagt sie uns, was wir denken und was wir empfinden sollen mit dem Helden. (2004 Dieckmann, 6:10 Ebel)

Ähnlich wie Martin Ebel hatte es zuvor bereits Heinrich Detering formuliert, der ebenfalls die Meinung vertrat, dass erklärende und kommentierende Erzählerrede die Figurenperspektive und damit den Authentizitätseffekt störe: 
Es geht in manchen Passagen sogar so weit, dass ich denke, da wird durch die Figur hindurch eigentlich der europäische Leser angesprochen: die neunundneunzig Namen Allahs, die Erklärung, was ein Imam ist oder den Satz „er vergaß sich selbst“. Wer redet da eigentlich? Das sagt ja nicht/ das geht ja nicht in der Figur vor, sondern die Figur vergisst sich eben. Da müsste mit der Sprache was passieren in dem Text, dass die Sprache sich zersetzt, dass etwas passiert. (2004 Dieckmann, 3:58 Detering)

Zwei Aspekte werden an der Diskussion zu Dieckmanns Text sehr deutlich: Der Autor steht für die Juroren in der Verantwortung für die Textwelt, indem er mit seiner persönlichen Biografie als ihr Garant eintritt. Der Autor ist aber darüber hinaus auch dafür verantwortlich, die Textwelt für den Leser zu arrangieren, damit sie ästhetischen Ansprüchen genügt. Wenn sich also kein Gefühl von Authentizität einstellt und der Leser den Eindruck hat, die Handlung nicht ganz aus der Perspektive der Figur zu sehen, wie das im obigen Beispiel gezeigt wurde, dann liegt das an der Art, wie der Autor den Text gemacht hat. Dass Literatur als perspektivierte und arrangierte Alltagswelt und -sprache verstanden wird, die primär durch den Autor geordnet und hervorgebracht wird, zeigt sich nicht nur in der Diskussion zu dem ethisch umstrittenen Guantánamo-Text von Dorothea Dieckmann, sondern unter anderem auch in der Diskussion zum Text von Dirk von Petersdorff, in dem der Erzähler das erste Jahr seiner Vaterschaft von Zwillingen thematisiert. Thematisch stößt der Text zwar überwiegend auf Interesse, Argwohn löst dagegen seine vermutete Nähe zur biographischen Situation des Autors und im Zusammenhang damit seine Machart aus. So konstatiert Ilma Rakusa:

[B]ei allem Respekt. Ich finde es auch interessant, dass der Lyriker und Prosaautor Petersdorff hier etwas, wahrscheinlich, nehme ich mal an, sehr Persönliches erzählt und das eben auch versucht, zu literarisieren. Also, es soll ja eben Literatur sein. Deswegen sitzen Sie ja auch da. (Petersdorff 2006, 9:21 Rakusa)

Im weiteren Verlauf ihrer Argumentation geht Rakusa darauf ein, dass der Text ihr zu stark beschreibend sei und dass er „eine stärkere ästhetischen Prononciertheit“ (2006 Petersdorff, 9:21 Rakusa) vermissen lasse. Anders als im Fall Dieckmann, bei der mangelnde persönliche Erfahrung, das heißt mangelnde Kenntnis der beschriebenen Welt, Grund für Kritik war, wird bei Petersdorff argumentiert, die starke Unterfütterung durch persönliche Erlebnisse, behindere die Literarisierung des Textes, weil der Text zu wenig strukturiert würde.

Burkhard Spinnen beginnt seine Argumentation ähnlich wie Ilma Rakusa: „Wegen der sehr hohen/ Wegen des sehr hohen Grades der Übereinstimmung von Lebenserfahrung hat mich dieser Text unsympathisch berührt" (2006 Petersdorff, 12:16 Spinnen). Auch in dieser Aussage steht die vermutete Nähe zwischen Textthematik und persönlichem Erleben des Autors im Vordergrund. Im Schlusssatz seiner Bewertung schließt Spinnen sich 
Rakusa an und befindet „dass es nicht ganz klappt“ (Petersdorff 2006, 12:16 Spinnen). Auch Martin Ebel konstatiert eine starke Übereinstimmung von Lebenswelt des Autors und Textwelt, die er also vom Autor bewusst eingegangenes „Risiko“ wertet:

\begin{abstract}
Also mir ist sympathisch in dem Text, neben dem Thema, das Risiko, was er eingegangen ist, nämlich hier eine eins zu eins Geschichte abzuliefern. Also, das Ich ist der Autor, die Kinder sind die Kinder. Max ist Max. Und Luise ist Luise. Und das, was er erlebt hat, ist das, was hier drin steht. Ich konstatiere das jetzt einmal axiomatisch. [...] Also, man findet sich sehr schnell wieder. Das bringt den Text auch an die Grenze eines Verständigungstextes und auch, anders betrachtet, einer Tagebuchaufzeichnung. Also das Risiko des Textes ist, dass er eigentlich nicht zum literarischen Text wird und werden will, sondern dass er das Unfertige festhalten will. (2006 Petersdorff, 7:21 Ebel)
\end{abstract}

Ebel geht in seiner Bewertung so weit, anzunehmen, dass der Autor beim Verfassen des Textes gar keine Fiktionalisierung vorgenommen hat: „Also, das Ich ist der Autor, die Kinder sind die Kinder, Max ist Max und Luise ist Luise“. Im Gegensatz zu Rakusa und Spinnen wertet Ebel den geringen Grad der Fiktionalisierung, wenn auch als Risiko, so doch als ein Risiko, das gewinnbringend sein könnte. Letztendlich wird der Text aber aufgrund seiner Nähe zum „Verständigungstext“ und der Folge, nämlich, dass er „eigentlich nicht zum literarischen Text wird“ abgewertet. Ebel ist bemüht, seinen Eindruck auch anhand der sprachlichen Gestaltung des Textes zu belegen:

Das aber will ich mit einem Satz fassen, Seite acht: „Immer noch hatte ich nicht verstanden, nur das dringende Gefühl, etwas fassen zu müssen, von dem ich nicht wusste, was es war". Ja. Ist es nicht doch Aufgabe der Literatur, dieses Gefühl in Worte zu fassen? Also, das ist jetzt nicht das, was Sie hier wollten. Das ist nicht das, was Sie gemacht haben, aber einen solchen Text hätte ich lieber gelesen. Um es vorsichtig zu sagen. (2006 Petersdorff, 7:09 Ebel)

Literatur soll, so kann man aus diesem Beitrag folgern, auf der Grundlage von Erlebtem durch Sprache und Form, Dinge fassen, die sonst schwer fassbar sind. Obwohl sie sich argumentativ genau konträr zur Dieckmann-Diskussion verhält, zeigt auch die PetersdorffDiskussion zum einen, wie sehr der Autor als Dreh- und Angelpunkt des literarischen Textes verstanden wird, zum anderen, dass Literatur für die Juroren einen spezifischen Umgang mit Wirklichkeit und Alltagssprache bedeutet. Der literarische Text misst sich inhaltlich durchaus daran, dass er Zusammenhänge der realen Welt auf die fiktionale Welt überträgt. Das kann so weit gehen, dass Juroren fordern, dass Texte sachlich in allen Details „,korrekt“, das heißt, wie in der Wirklichkeit sind. Geradezu legendär für die Überprüfung von Aussagen in fiktionalen Texten daraufhin, ob sie mit Weltwissen übereinstimmen, ist der Juror Karl Corino, der, um nur ein Beispiel zu nennen, im Tübinger Gerichtsmedizinischen Institut anrief, um zu klären, ob Erhängte, im Gegensatz zu anderen Toten, 
geschlossene Augen haben, wie in Brodowskys (2006, 16:42 Corino) Text nahegelegt wird. In der Diskussion zu Dirk von Petersdorff wird klar, dass „Wirklichkeit“ nicht lediglich abgebildet werden soll, sondern dass sie geordnet, perspektiviert, in ihren sonst schwierigen Facetten erfasst und transportiert werden muss. Literatur wird die Fähigkeit zugesprochen, durch ihre besondere Form Dinge fassbar zu machen, die in der alltäglichen Betrachtung unzugänglich bleiben. Das umzusetzen ist die handwerkliche Aufgabe des Autors.

\subsection{Die Rolle des Lesers aus Perspektive der Jury}

Wurde dem Autor die Rolle des aktiven Produzenten zugewiesen, nimmt der Leser im Verständnis der Juroren eine reaktive Rolle ein. Er reagiert auf die durch den Autor im Text eingesetzten Mittel. Beschrieben werden die Reaktionen unter dem Blickwinkel des Emotionalen einerseits und der Intensität der Aufmerksamkeitsbindung andererseits. Dabei wird häufig ein universeller Leser vorausgesetzt. Zwar zeigen die Diskussionen an vielen Stellen, wie unterschiedlich die Rezeption bis hin zum Verständnis des Plots sein kann, auch wird das eigene Textverständnis mit Lesebiografie und Weltverständnis in Verbindung gesetzt, jedoch wird selten ein kausaler Zusammenhang zwischen diesen Lesevoraussetzungen und der Bewertung hergestellt. Es gibt also selten Argumentationen, die die Möglichkeit in Betracht ziehen, dass ein Text deswegen nicht gut bewertet werden kann, weil der Juror ihn aufgrund eines anderen Weltverständnisses und anderer Zugänge zu Literatur nicht verstehen kann. Wiederum steht der Autor als Schaltstelle im Mittelpunkt. Er hat die dargestellte Welt so zu vermitteln, dass der intendierte Leser - potentiell jeder Leser innerhalb der Zielgruppe - sie begreifen und, noch wichtiger, in sie hineinversetzten kann. Keine andere Forderung wird so oft wiederholt wie diese. An Literatur wird also der Anspruch gestellt, den Leser „abzuholen“, ihn „mitzunehmen“ und zu „verführen“. In den programmatischen Aussagen über Literatur (siehe oben) bilden diejenigen, die sich auf die Wirkung von Literatur, die Lust am Text beziehen einen Schwerpunkt. Aussagen dieser Art sind zahlreich und über das gesamte Korpus verteilt. Anders als die generellen Aussagen über den Zusammenhang von Wirklichkeit und Text werden die axiomatischen Aussagen zur Textwirkung kaum selbst Gegenstand der Diskussion. Es kann also davon ausgegangen werden, dass sie entweder wenig umstritten sind oder als zu unbedeutend für eine längere Auseinandersetzung wahrgenommen werden.

„Diese Geschichte rührt mich. Diese Geschichte bewegt mich intellektuell. Mehr kann ich von Literatur eigentlich nicht verlangen“ (2002 Glaser, 13:58 Scheck). So umschreibt Denis Scheck seinen Eindruck. „Rühren“ und „intellektuell bewegen“ bringen bereits zwei Vari- 
anten der Freude am Text auf den Punkt. An anderer Stelle spricht Scheck von „ein[em] existenzielle[n] Zittern, das gute Literatur für [ihn] auslöst" (2002 Arns, 0:05 Scheck).

Schindel (2000 Kieninger, 18:19) spricht dagegen vom (fehlenden) „Verführungspotential“ eines Textes. Ein Text brauche Verführungspotential, damit er ihn [Schindel KR] „hineinziehe“. Von Verführung spricht auch Meike Feßmann (2009 Bönt, 20:04): „Aber Literatur soll doch unbedingt verführen. Was denn sonst?“. Auch Alain Claude Sulzer (ebd., 15:36) meint wohl eine Art Verführung, wenn er in der selben Diskussion bemerkt, dazu sei ja Literatur auch da, ihn da so willenlos zu machen wie so Quecksilberkügelchen, die in der Luft herumschwirren.

Iris Radisch geht mehrfach auf die „Sinnlichkeit“ von Literatur ein (u. a. 2003 Parei, 5:41; 2004 Tellkamp, 7:12).

An anderer Stelle beschreibt Schindel (2001 Krupp, 18:22), dass der Leser sich nicht mehr für den Text interessieren könne und dass er „nicht mehr in eine Kommunikation mit einem Text" kommen könne. Hildegard Keller (2009 Winkler, 12:47) wiederum drückt ihren Wunsch aus, mit dem Text mitgehen zu können:

Vielleicht ist das eine ästhetische Wirkung von Literatur. Kann ich alles für möglich halten. Ist natürlich wiederum an die Bereitschaft gebunden, dass ich mitgehe. Und ich habe mich auch etwas verloren gefühlt. Beim mehrmaligen Lesen.

Besonders häufig trifft hedonistische Kritik Texte, die sich bemühen, Stimmungen wie Langeweile, das Gefühl von Sinnlosigkeit und Anteilnahmslosigkeit durch Parataxe, sachliche Beschreibung, monotone Rhythmik und ähnliches in die Sprache zu übertragen. Deutlich wird dies unter anderem in der Diskussion zu Helga Glantschnig (2002). Ihr Text beschreibt die Situation einer Frau, die sich das Leben nehmen will, dazu Orte aufsucht, die sie für ihren Selbstmord vorgesehen hat, es aber nicht wagt, zu springen: Schindel argumentiert:

\begin{abstract}
Und ich glaube auch, dass hier quasi ein Konstruktionsirrtum passiert ist. Die Autorin hat, glaube ich, versucht, die inneren Zustände dieser Selbstmörderin, auch die Leerheit, auch die Flachheit, auch die Albernheit, auch die Banalität, die Angst, all das eins zu eins in den Duktus der Sprache umzusetzen, etwas, was bekanntlich in der Literatur immer misslingt. Man kann die Langeweile nicht durch Langeweile darstellen. Man kann die Komik nicht durch Komik darstellen. Es bedarf bei der Darstellung immer des Indirekten (2002 Glantschnig, 12:27 Schindel)
\end{abstract}

Was zunächst als Beschreibung des Textes beginnt („eins zu eins in den Duktus der Sprache umzusetzen“), geht in eine apodiktische Aussage über Literatur über („etwas, was bekanntlich in der Literatur immer misslingt").

Auch Burkhard Spinnen (2005 Schirach, 12:59) kommt zu dem Urteil, dass Reduktion auf 
der Inhaltsebene und Reduktion auf der Formebene zusammen keine positive Wirkung des Textes erzielen können: „Ich teile Ihre Beurteilung der Figuren. Aber minus mal minus gibt nur in der Mathematik plus. [Gemurmel] In der Literatur nicht".

Auffallend bei den Urteilen, die die Lust am Text betreffen, ist die Korrelation zwischen negativer Bewertung und fehlender Lust am Text und umgekehrt positiver Bewertung und Freude am Text. Gute Texte sind also immer Texte, die sinnlich ansprechend sind, die beim Lesen Freude bereiten. In den seltensten Fällen jedoch bildet diese Freude einen Schwerpunkt in der Diskussion. Diese Korrelation wird auch sichtbar, wenn man betrachtet, welche der Autoren, die in den genannten Zitaten betroffen waren, Preise erhielten. Die in Hinblick auf die Sinnlichkeit ihrer Texte positiv bewerteten Autoren Glaser, Tellkamp, Bönt und Parei wurden mit Preisen ausgezeichnet (Glaser, Tellkamp und Parei mit dem Bachmann-Preis, Bönt mit den Kelag-Preis). Winkler, Krupp, Schirach und Arns, bei denen die Bewertungen jeweils ein Fehlen von Lesefreude anmerkten, erhielten keine Preise.

In den programmatischen Aussagen über Literatur, die die Reaktion des Lesers mit in den Blick nehmen, dominiert die hedonistische Perspektive. Das Lesen von Literatur soll lustvoll sein und der Autor kann diese Lust durch die Art, wie er den Text gestaltet, hervorrufen.

\subsection{Zusammenfassung}

In Diskussionen manifestiert sich ein Bild des Kommunikationsdreiecks Autor-Text-Leser, das den Autor in eine sehr starke Position rückt. Als Bauherr des Textes wird der Autor für alle Reaktionen des Lesers verantwortlich gemacht. Autoren werden als Handwerker gesehen, die Stoffe und Formen einsetzen, um beim Leser einen Zustand der lustvollen Aufmerksamkeit zu erreichen. Gleichzeitig gilt der Autor als Bürge für die im Text dargestellten Wirklichkeitsbezüge, wenn diese problematisch erscheinen. Es gibt dabei keine feste Regel, ob realitätsbezogene Faktentreue und durch den Autor verbürgte Erlebnisse als positiv oder negativ eingestuft werden. Hier scheinen vielmehr andere Wahrnehmungen ausschlaggebend zu sein. So konnte gezeigt werden, dass in der Diskussion zu Dorothea Dieckmanns Guantánamo-Text die Biografie der Autorin herangezogen wurde, um eine Begründung für das zweifellos moralische Unbehagen gegenüber dem Text zu begründen. Ihr wurde vorgeworfen, es fehle ihr an Wissen über das, was sie versucht in ihrem fiktionalen Text darzustellen. Dirk von Petersdorff dagegen wurde vorgeworfen, seinem Text, dessen biografischer Bezug den Juroren offensichtlich war, fehle es an Verfremdung. Das 
Spektrum der Argumentationen, die sich auf den Autor als reale Person beziehen, ist groß. Gemeinsam ist den Haltungen, dass der Autor niemand ist, der im Sinne Roland Barthes ([1968] 2000) vorgefundenes Sprachmaterial neu montiert, sondern vielmehr jemand, der als Komponist aus seinem Wissen, seinen Wahrnehmungen und seinem Sprachschatz Literatur intentional gestaltet.

Wenn die Juroren im Rahmen des Bachmann-Wettbewerbs über Literatur sprechen, meinen sie stets Literatur als Kunst. Literatur ist dabei schon ein wertender Begriff. Je mehr ein Text dem - niemals explizit ausformulierten - Bild von Literatur als Kunst entspricht, desto mehr ist er „echte“ Literatur.

Die Rolle der Juroren wird selten explizit angesprochen. Die Aussagen differieren von Juror zu Juror und hängen oft davon ab, welche Rolle der Literatur allgemein zugedacht wird, aber auch davon, welche argumentative Funktion mit der jeweiligen Äußerung verbunden ist.

Die programmatischen Aussagen der Juroren lassen auf drei Grundeinstellungen schließen. Dass sie so häufig wiederholt werden, kann sowohl auf das Prestige der Positionen als auch auf ihre Umstrittenheit hindeuten. Die Analysen im zweiten Teil dieser Arbeit werden das genauer aufschlüsseln. Häufig wird (erstens) die Forderung formuliert, dass Literatur den Leser in den Bann ziehen müsse. Dass ausgerechnet diese Forderung die Rangliste der Forderungen anführt, war unerwartet. Denn obwohl in der neueren Forschung vielfach angenommen wird, dass die hedonistische Textwirkung eine große Rolle bei der positiven oder negativen Wahrnehmung des Textes spielt (vgl. dazu die Kapitel 4.4-4.6, Kapitel 10.1 und Kapitel 11.1), konnten keine Arbeiten gefunden werden, die einen Zusammenhang zwischen der lustvollen Textwirkung und der Bewertung direkt herstellen.

Darüber hinaus werden häufig Forderungen formuliert, die (zweitens) die Wichtigkeit der formalen Gestaltung für die Einschätzung von Literatur fokussieren. Außerdem spielt (drittens) Originalität eine wichtige Rolle. Dass die Forderungen nach formaler Gestaltung des Inhalts und Originalität so häufig vorkommen, kann mit großer Wahrscheinlichkeit auf ihr Prestige zurückgeführt werden. Damit stimmen die programmatischen Aussagen der Jurymitglieder durchaus mit ihren konkreten Wertungen überein. Nicht reflektiert ist in ihnen allerdings die Bedeutung moralischer Vorbehalte. Wie auch Sabine Buck (2011) beobachtet hat, spielen moralische Wertungen in einigen Fällen eine große Rolle, werden aber selten von Kritikern als wichtiger Bestandteil ihrer Bewertungspraxis reflektiert. Das trifft auch für die Klagenfurter Diskussionen zu. Moralische Vorbehalte sind in der Tat ein Todesstoß für literarische Texte. Aber nur ein Bruchteil der in Klagenfurt diskutierten 
Texte wird eindeutig aus moralischen Gründen von der Mehrheit der Juroren abgelehnt: Jonigk (1999), Kempker (2000), Fischer (2001), Langer (2001), Tingler (2001), Balaka (2004), Dieckmann (2004), Kern (2007), Stift (2009). Es gibt weitere Diskussionen, in denen moralische Argumente eine Rolle spielen, aber nicht die Entscheidung über den Text dominieren. ${ }^{32}$

$\overline{32}$ Es gibt durchaus auch Texte, die durch inhaltliche Kritik bestimmt sind, die nicht unbedingt moralisch ist. Genannt seien beispielhaft: Goetsch (2000), Kuhn (2005), Schirach (2005) und Böldl (2005). 


\section{Gute Texte aus der Perspektive des Creative Writing}

\subsection{Die Normativität des Creative Writing}

Die Juroren sehen Autoren als Baumeister ihrer Texte, die zu einem großen Teil an ihrem handwerklichen Geschick, und nicht etwa an ihrem kreativen Genie, gemessen werden können. Damit nehmen die Juroren eine Perspektive ein, die eigentlich dem Creative Writing eigen ist. In der Literaturwissenschaft ist es dagegen verbreitet, von komplexen Interdependenzen zwischen Autor, Text und Leser auszugehen. Handwerkliches Können, das eingesetzt wird, um den Leser „,anzusprechen“, gehört nicht zu ihren kommunikativen Konventionen.

„Es gibt keine einheitlichen, verbindlichen Maßstäbe zur Beurteilung von Literatur“ konstatieren Heydebrand/Winko $(1996,107)$. Neben den Meinungspluralismus sei ein Wertungspluralismus getreten (ebd. 1996, 108). Auch Becker-Cantarino $(2007,126)$ schließt sich der verbreiteten Auffassung an, es gebe keinen auch nur annähernden Konsens über Wertekriterien, wenn es um die Bewertung von Gegenwartsliteratur gehe. Wenn überhaupt seien sie eine soziale Konstruktion einer Expertengemeinschaft und insofern zwar nicht beliebig, aber keinesfalls im Text selbst verankert (vgl. Fish 1980; Bourdieu 2001). Regelpoetiken werden lang vergangenen Epochen zugeordnet; spätestens seit der Goethezeit herrscht die Vorstellung vom Genie, das aus sich heraus ein eigenwillig geordnetes Kunstwerk schafft, das - so kann man in Aufsätzen bis weit in die 70er Jahre des 20. Jahrhunderts lesen - nicht an Maßstäben gemessen, sondern nur durch einen kompetenten Interpreten nachempfunden werden kann. Wirken kann das literarische Kunstwerk nur, wenn es auf einen genau dafür empfänglichen Interpreten stößt. In den Worten Emil Staigers: „Denn ohnehin wecke ich Leben nur, wo Leben in mir entzündet ist" (Staiger 1971, 27). „[D]as reiche und empfängliche Herz“ (Staiger 1971, 10) des Interpreten, sein „Gemüt mit vielen Saiten“ (ebd.) ist nicht durch jedes beliebige Schreibwerk zu erreichen. Die Selbstgewissheit, ein Kenner zu sein und sich daher nur von hochwertigen Produkten beeindrucken zu lassen, reicht letztlich zur Begründung. Letztendlich ließe sich von einem Geschmacksurteil sprechen. Zwar ist „seine [des Textes KR] Beschaffenheit [...] die Bedingung für seinen spezifischen Wert" (Wutz [1957] 1980, 170, Hervorhebung im Original), keinesfalls ließe sich dieser Wert aber durch Maßstäbe erfassen (Wutz [1957] 1980, 173). Egal welche literaturwissenschaftliche Perspektive auf die Spezifik literarischer Texte, und eng damit verbunden ihrer Wertung, man einnimmt, gute literarische Texte scheinen kaum nach Regeln produzierbar. Aus der Vorstellung Staigers, der hier beispielhaft genannt wur- 
de, heraus liegt die Qualität zwar im Text selber, kann aber nicht mittels Regeln erfasst oder geschaffen werden, sondern einem Künstler gelingt ein einzigartiges Sprachgebilde, das sich in der Reaktion des kompetenten Interpreten bestätigt. In der relativistischen Perspektive des späten 20. Jahrhunderts, beispielhaft wurden Fish und Bourdieu genannt, konstituieren sich der Text und sein Wert im konventionalisierten Sprechen über ihn.

Wird Lesen und Werten als ein Knowing-How betrachtet - eine Kenntnis darüber, wie etwas gemacht wird, die im Verlauf des Lebens durch den Umgang mit dem Gegenstand und den beteiligten Experten, gelernt wird (vgl. Kapitel 4) -, scheint aus literaturwissenschaftlicher Sicht diese Vorstellung auf das Schreiben von künstlerischen literarischen Texten nicht übertragbar zu sein. Literarisches Schreiben wird nicht als ein Knowing-How betrachtet. Dass es Regeln für das Schreiben von Literatur geben könnte, die im Umgang mit Literatur (unbewusst) erfasst und dadurch erlernt werden, scheint schwer vorstellbar zu sein.

Die Kehrseite des literaturwissenschaftlichen Relativismus bzw. des festen Glaubens an die Originalität hochwertiger literarischer Texte bildet das Kreative Schreiben als gelehrtes und lernbares Schreiben, das längst kein amerikanisches Phänomen mehr ist. Auch im deutschen Sprachraum erscheinen zunehmend Bücher, die Schreibinteressierten den Weg zu guten Texten weisen wollen. Wo aber etwas lehrbar erscheint, muss davon ausgegangen werden, dass es in irgendeiner Form regelhaft ist. Nur wenige Blicke in die entsprechenden Anleitungen genügen, um festzustellen: Im Bereich der erzählenden Texte, die den Hauptfokus vieler Anleitungen bilden, gibt es durchaus Einigkeit darüber, wie Texte beschaffen sein müssen, um als gelungen zu gelten. In ihren Grundregeln sind sich die Ratgeber frappierend einig.

Was also in der Literaturwissenschaft stets - mit Verweis auf die Einzigartigkeit des literarischen Kunstwerks, die Faktoren seiner Entstehungszeit, die Subjektivität des Lesers und die Dominanz des kommunikativen Codes - als unmöglich vorausgesetzt wird, wird im Bereich des kreativen Schreibens mit Selbstverständlichkeit vermittelt. Dabei betreiben Creative-Writing-Lehrer keine Esoterik, sondern stützen sich oftmals auf dasselbe Material wie Literaturwissenschaftler auch, nämlich auf erfolgreiche, oft sogar kanonische ${ }^{33}$ Texte und die Art, wie sie gemacht sind. Es lohnt sich also, die Ergebnisse der Wertungsanalyse im Rahmen des Ingeborg-Bachmann-Wettbewerbs in den Kontext dieser moderat normativen Ansätze zu stellen und zu sehen, wo Gemeinsamkeiten und wo Unterschiede zu finden

33 Gemeint sind Texte, die beispielsweise in Lehrveranstaltungen der Universitäten wissenschaftlich behandelt werden, also der Kanon der universitären Expertenleser. 
sind.

\subsection{Auswahl der Creative-Writing-Handbücher}

Für die Auswahl der hier begutachteten Creative-Writing-Bücher gab es keine spezifischen inhaltlichen Kriterien. Da es eine Unmenge von Handbüchern gibt, wurden Bücher, vorwiegend der letzten 25 Jahre, gesichtet, die „Creative Writing“ oder „Kreativ(es) Schreiben“ im Titel tragen oder unter diesem Stichwort in Bibliothekskatalogen, Buchhandlungen oder online Buchhandlungen gefunden werden können und in den örtlichen Bibliotheken ohne größeren Aufwand zugänglich waren. Auf eine Beurteilung der Qualität dieser Anleitungen wurde aus verschiedenen Gründen verzichtet: Da es sich um Lehrwerke, somit um pragmatische Texte handelt, müsste die Qualität daran bemessen werden, wie erfolgreich sie in der Vermittlung ihres Stoffes sind. Das ist allenfalls intuitiv möglich. Darüber hinaus stünde grundsätzlich die Frage zur Debatte, nach welchen Kriterien die Qualität der Ratgeber inhaltlich zu bemessen wäre. Literaturwissenschaftliche Kriterien greifen hier womöglich nicht oder führen in die Irre. Bei der Sichtung des Materials hat sich zusätzlich herausgestellt, dass eine solche Einschätzung unerheblich ist, weil sich die verschiedenen Handbücher inhaltlich stark ähneln. Nicht nur die behandelten Themen stimmen weitgehend überein, manche Anleitungen ähneln sich bis in die Formulierung hinein. Die Ratgeber unterscheiden sich hauptsächlich in der Darbietungsform und in der Differenziertheit bzw. Plakativität ihrer Regeln.

Die Übersicht, die hier über Inhalte in Creative-Writing-Anleitungen gegeben wird, ist also weder vollständig, noch stützt sie sich auf bestimmte Vorannahmen. Angesichts der Tatsache, dass das Ziel darin besteht, einen Einblick in die Welt des Creative Writing zu erhalten und mit Blick darauf, dass sich, wie sich herausstellte, die Anleitungen stark ähneln, scheint ein solches Vorgehen gerechtfertigt. Betrachtet wurden 13, überwiegend neue Ratgeber unterschiedlicher Ausrichtung.

\subsection{Zielgruppe der Creative-Writing-Handbücher}

Die Handbücher geben sehr breite Zielgruppen an. Sie richten sich in der Regel an Lehrer, die in ganz unterschiedlichen Rahmen Kreatives Schreiben lehren (wollen) und Handbücher als Fundgrube für ihren Unterricht nutzen, primär aber an Schreibinteressierte und Schreibende mit unterschiedlichen Vorkenntnissen. Oft soll das Buch sowohl Anfänger als auch Profis gleichermaßen ansprechen. Fritz Gesing sieht als seine Zielgruppe 
alle, die gern schreiben wollen und nicht recht wissen, wie sie es anstellen sollen; außerdem diejenigen, die zu schreiben begonnen haben und handwerkliche Hilfe benötigen. Aber auch selbstkritische Profis, die ihre Texte immer wieder neu auf Schwachpunkte und Wirksamkeit überprüfen. Nicht zuletzt wende ich mich an Lehrende und Lernende in Schule und Universität, kurzum, an alle, die sich eine Übersicht darüber verschaffen wollen, nach welchen Regeln erzählende Literatur funktioniert und unter welchen Bedingungen sie „gemacht“ wird. (Gesing 1994, 9)

Mara Laue möchte „alle Menschen mit Interesse an belletristischem (unterhaltendem) Schreiben, die das Handwerk des kreativen Schreibens von Grund auf erlernen oder ihre bereits erworbenen Fähigkeiten verbessern wollen“ (Laue 2014, 7), erreichen.

Das Buch „Creative Writing. A Workbook with Readings“ (2006) definiert seine Zielgruppe ähnlich breit. Neben Teilnehmern von Creative-Writing-Kursen an Universitäten sollen „aspiring writers who have begun to try things out as well as $[\ldots]$ more experienced writers who want to deepen their skills or seek new directions for their work" (Anderson 2006, 13) angesprochen werden. Die breite Zielgruppe - alle Schreibenden und Schreibinteressierten - ist typisch. Sie ist vermutlich der Tatsache geschuldet, dass der Adressatenkreis für die Anleitungen klein und die Konkurrenz groß ist. Niemanden auszuschließen heißt, alle anzusprechen. Im deutschsprachigen Raum richten sich Bücher, die „Kreativ Schreiben“ im Titel tragen, der Anlage nach oftmals eher an Anfänger. Hier wird sehr detailliert erklärt: dass Texte überarbeitet werden müssen (Brockhaus: Kreativ Schreiben 2013, 11) oder dass Füllwörter, Fremdwörter und Modewörter zu vermeiden seien (Brockhaus Kreativ Schreiben 2013, 113).

Die Einleitungen der untersuchten Handbücher setzen sich häufig zunächst mit der Vorstellung vom Autor als Genie und der Frage des Talents auseinander (Anderson 2006, 11; Brockhaus: Kreatives Schreiben 2013, 10). Sie stellen dabei der ihrer Ansicht nach veralteten, aber weitverbreiteten Position, Autorschaft könne nicht gelernt werden, sie müsse als Talent in einem Individuum angelegt sein, die Vorstellung vom Schreiben als Handwerk gegenüber. Schreiben sei zwar auch Inspiration, aber größtenteils Handwerk, das von jedem erlernt werden könne. Es handelt sich bei dieser Gegenüberstellung um einen Topos der Creative-Writing-Literatur, der davon zeugt, wie sehr einerseits das „Schreiben“ - gemeint ist immer das Schreiben von Literatur - zur Sehnsucht einer großen Menge von Menschen stilisiert wird und wie sehr andererseits Autorschaft mythisiert wird, und gegenüber dem sich die Verfasser der Anleitungen veranlasst fühlen, sich zu positionieren. Dem Talent-Topos wird ein Jeder-kann-schreiben-Topos gegenübergestellt. Obwohl diese Art der Darstellung möglicherweise auch ökonomischen Zielen geschuldet ist, unterstreicht sie doch auch, dass sehr stark davon ausgegangen wird, dass es Regeln für das Schreiben 
gibt.

\subsection{Ziele der Creative-Writing-Anleitungen}

Was genau Creative-Writing-Anleitungen erreichen wollen, wird oft nicht explizit gesagt. Es gibt Handbücher, die gar keine konkreten Ziele nennen. Das „Workbook with Readings “ (2006, 13) sieht sich als Unterstützung und Inspiration auf einem Weg, den der Autor selber gehen muss: „The most important aim of this book is to help you to discover and nurture your individual voice as a writer". Explizit wird darauf hingewiesen, dass das Buch keine Regeln biete, sondern lediglich Ratschläge. Sol Stein $(2015,11)$ versteht sein Buch als Praxisbuch, das Lösungen anbietet, „wie man einen verunglückten Text repariert, wie man einen guten Text noch verbessert und wie man es überhaupt anstellt, einen interessanten Text zu verfassen“. Fritz Gesing (1994, 9), der oben bereits zitiert wurde, hat als Resultat eine ganz bestimmte Literatur im Sinn:

Das Handwerk, von dem dieses Buch handelt, zielt auf ein Schreiben, das Leser ansprechen und verführen möchte. Es meint eine Literatur, die auf unterhaltsame Weise neugierig und nachdenklich macht, die weder Beichte noch Bildungsprüfung ist und auch kein Glasperlenspiel. Eher ein gefühlsbetontes Maskenspiel, bei dem weder Spaß noch Spannung, weder Erkenntnis noch Faszination fehlen dürfen und das auf triviale Effekthascherei, Stereotype und Klischees verzichtet. (Gesing 1994, 9)

Gesing entwirft hier das Bild einer Literatur, die sich an den Bedürfnissen eines Lesers ausrichtet, der eine angenehme, unterhaltsame Lektüre erwartet. Lesen soll, so Gesing, Spaß, Spannung, Erkenntnis und Faszination bieten. Implizit geht er davon aus, dass nicht jeder literarische Text dieses Ziel verfolgt. Über seine Ausschlüsse wird deutlich, was er als leserunfreundlich erachtet: ungefiltert auf das Innenleben des Autors ausgerichtete Lebensberichte („Beichte“), Literatur, die bildungsbürgerliches Wissen über Literatur als Voraussetzung benötigt, um einen Zugang zu ermöglichen („Bildungsprüfung“) und avantgardistische Formexperimente („Glasperlenspiel“). Er vertritt das Idealbild der gehobenen Unterhaltung. Während Gesing die Abgrenzung von einer Literatur, die es sich aufgrund ihres anerkannten Kunstcharakters leisten kann, den Ansprüchen einer breiten Leserschaft nicht gerecht zu werden, noch bewusst formulieren muss, verzichtet das englische „Workbook“ (2006) auf eine derartige, explizite Auseinandersetzung. Dass es dennoch ebenfalls eine auf die Interessen des Lesers ausgerichtete Haltung vertritt, wird deutlich, wenn man sich die Anleitungen im Einzelnen ansieht. Dort geht es kaum um etwas anderes als darum, wie man den Leser fesseln kann. Hier wird eine als weit verbreitet geltende Literatur vermittelt, deren Absicht ganz legitim darin besteht, einem breiten Publikum zu 
gefallen. Die Texte, die angeführt werden, um die Verfahren zu explizieren, entstammen sowohl Klassikern wie den Romanen von Charlotte Bronte oder den Short Stories Katherine Mansfields als auch aus den Werken zeitgenössischer Autoren wie Raymond Carver oder David Lodge.

Unterhaltung als Wert hat eine dominante Stellung in den Anleitungen im Bereich Erzählen. Konkret kann Unterhaltung auf sehr unterschiedliche Weise erreicht werden. Dennoch sind sich die Anleitungen in den Verfahren, die sie anbieten, um einen hohen Unterhaltungswert zu erreichen, relativ einig. Auf die konkreten Gestaltungsmittel, die als Garanten für die Bindung der Aufmerksamkeit des Lesers gelten, werde ich später zurückkommen.

\subsection{Aufbau der Creative-Writing-Handbücher}

Es gibt typische Elemente im Aufbau von Creative Writing Ratgebern. In der Regel umfassen sie Hinwiese für den gesamten Schreibprozess, angefangen von Methoden, die helfen sollen, das Schreiben als Tätigkeit überhaupt auszuüben (feste Arbeitszeiten, Organisation des Arbeitsplatzes, Inspiration, Notizbücher), über den Entwurf des Textes und jene Techniken, die nötig oder hilfreich sind, um einen gelungenen Text zu schreiben, bis hin zur Überarbeitungs- und Veröffentlichungsphase. Sie sind in Hinblick auf den Schreibvorgang prozessorientiert und nicht problemorientiert. Das heißt, das Schreiben soll angeregt und geleitet werden. Es geht nicht so sehr darum, Probleme, die sich beim Schreiben einstellen, zu beheben (z. B. Schreibblockaden).

Typisch ist eine Einteilung nach Genres: Besprochen werden in der Regel Techniken des Erzählens, der Lyrik und des (auto)biografischen bzw. faktenbasierten Schreibens. Der Schwerpunkt liegt auf den Erzählformen Kurzgeschichte und Roman. Lyrik hat ebenfalls einen festen Platz. ${ }^{34}$ Es gibt Ratgeber, die sich auf bestimmte Teilaspekte des Schreibens oder bestimmte Eigenschaften, die erreicht werden sollen, konzentrieren. Der ungarische Theaterregisseur Lajos Egri entwirft in seinem schon 1965 erstveröffentlichtem Buch „Literarisches Schreiben“ Anleitungen, die die Entwicklung der Figuren in den Mittelpunkt stellen. Mit der Entwicklung der Figur wird allerdings auch die Entwicklung des Plots und des Spannungsbogens verknüpft. Bei der im Duden-Verlag erschienenen Kreativ-SchreibenReihe werden unterschiedliche Genres in den Blick genommen. Die Reihe ist als Anregung konzipiert. Statt Checklisten zur Verfügung zu stellen, werden anhand von Beispieltexten

$\overline{34}$ Die Anleitungen für Lyrik wurden im Rahmen dieser Arbeit nicht berücksichtigt, weil der IngeborgBachmann-Wettbewerb auf Erzähltexte beschränkt ist. Viele Ratgeber, wie etwa der von Sol Stein, und das „Creative Writing Workbook with Readings“ (2006) enthalten außerdem Anleitungen für nicht fiktionale Texte. Auch diese wurden hier nicht berücksichtigt. 
Verfahrensweisen illustriert und im Anschluss durch Schreibaufgaben dazu angeregt, diese Verfahrensweisen nachzuahmen. Dabei werden keine Regeln formuliert, sondern darauf gebaut, dass der Leser selbständig aus der Illustration des Verfahrens - beispielsweise, Spannung herzustellen - entsprechende Rückschlüsse für sein Schreiben ziehen kann.

Die meisten Ratgeber enthalten Tipps und Schreibaufgaben, die graphisch deutlich abgesetzt sind. Manche enthalten außerdem Checklisten. Gerade in den Checklisten kommt die Normativität der Creative-Writing-Bücher zum Ausdruck.

Die deutschen Ratgeber tendieren mehr dazu, konkrete Tipps und Hinweise zu geben, was erlaubt ist und was nicht, während die englischsprachigen Ratgeber literarische Verfahren und deren Nutzen aufzeigen, ohne dabei konkrete Vorschriften zu machen. Checklisten sind hier unüblich. Sol Stein (2015) bietet gelegentlich Fragen, die man an seinen Text stellen kann, um zu prüfen, ob eine Umsetzung gelungen ist.

\subsection{Ratschläge und Anweisungen für erzählende Literatur}

In Hinblick auf die erzählende Literatur stellen alle Ratgeber, die untersucht wurden, weitestgehend dieselben Aspekte in den Vordergrund: Die Konstruktion einer runden, interessanten, lebendigen Figur, die Konstruktion einer fesselnden Handlung mittels der zeitlichen Strukturierung und des Aufbaus eines Konflikts, die Erzählperspektive und den Modus der Darstellung (Showing/Telling). Ratgeber aus den USA oder Großbritannien orientieren sich stark am Film. Explizit ausformuliert findet sich dieser Bezugspunkt bei Sol Stein $(2015,175)$ : Der Leser habe sich unter dem Einfluss von hundert Jahren Filmgeschichte daran gewöhnt, das Geschehen vor seinen Augen ablaufen zu sehen. Das Publikum wolle, so Stein (ebd., 69), ein authentisches Erlebnis. Es wolle, dass sich die Szenen direkt vor seinen Augen abspielen (ebd.). Der Erfolg eines Buches liege in nichts als der Wirkung, die es beim Leser erziele und die im Idealfall darin bestehe, dass der Leser das Buch gar nicht mehr zur Seite legen kann (ebd., 75). „Nicht das zählt, was gesagt wird, sondern die Wirkung dessen, was gemeint ist", formuliert Stein (ebd., 180; Hervorhebung im Original) als Grundregel. Das Buch, zu dem Stein anleitet - und mit ihm viele andere CreativeWriting-Lehrer - ist in Darbietung und Wirkung einem erfolgreichen Film vergleichbar. Die Ästhetik, die hier durchscheint, ist eine Ästhetik der Wirkung. Die Ratgeber bieten Strategien an, wie der Erlebnischarakter durch die Machart des Textes gesteigert werden kann. Die Form steht also im Dienste einer Wirkung. Diese Verbindung wird auch in den Bachmann-Preis-Diskussionen immer wieder deutlich werden: Literatur wird aktuell nicht am Letztwert Schönheit gemessen, sondern an ihrem Erlebnischarakter. An die Stelle von 
ruhiger Kontemplation ist in der Rezeption offenbar intensive Erregung getreten.

Die literarische Sprache ist ein relativ fester Bestandteil deutschsprachiger Ratgeber. Auch in der Betrachtung dieser Elemente geht es letztendlich darum, wie die Aufmerksamkeit des Lesers gebunden werden kann, das heißt, wie er zu einem interessierten Weiterlesen animiert werden kann. Eine Checkliste zur Sprache aus dem Buch von Fritz Gesing illustriert sehr anschaulich, welche Aspekte - nicht nur bei ihm - im Vordergrund stehen. Sie ist im Kapitel „Stil, nicht Stilisierung. Ratschläge zur sprachlichen Gestaltung“ nachzulesen. Diese Sprach-Checkliste illustriert außerdem beispielhaft, wie sich Creative-Writing-Lehrer gelungene Literatur vorstellen, das heißt vornehmlich, welche Wirkung sie auf den Leser hat.

- Meiden Sie unbeabsichtigte Monotonie durch Wiederholungen von Wörtern und syntaktischen Konstruktionen.

- Schreiben Sie ökonomisch. Streichen Sie alle Redundanzen und Verdoppler. Kumulierende Effekte, übertriebene Begeisterung und Sentimentalität führen oft zu Lyrismen und Kitsch.

- Sprachlicher Reichtum und differenzierte Ausdrucksweise sind anzustrebende Ziele. Bemühen Sie sich um den jeweils treffenden Ausdruck. Es gibt, wenn überhaupt, nur sehr weniger wirkliche Synonyme in einer Sprache.

- Alles Gestelzte und Geschraubte gehört in die Mottenkiste. Artifizielle Prosa, selbst wenn sie überzeugt, ist Zeitvertreib für Minderheiten.

- Schachtelsätze überlassen Sie Juristen.

- Stereotype, Klischees und Trivialitäten sind die Totengräber einer ausdrucksvollen Sprache und eines überzeugenden Stils.

- Achten sie auf Übereinstimmung von Form und Inhalt. Hohes Erzähltempo braucht eine andere Syntax als eine gemächliche Beschreibung (kürzere Sätze, unter Umständen Abbrüche, Auslassen). Jeder Sprecher muß sich von dem anderen unterscheiden, Ich-Erzähler benötigen Rollenprosa.

- Vorsicht bei zeitgebundener Wortwahl. Sie könnte schnell veralten. Dies gilt vor allem für Slang-Ausdrücke und modische Anspielungen (unter Umständen auch für Preisangaben und ähnliches).

- Erzählen Sie bildkräftig und vermeiden Sie Abstraktionen und unspezifische Ausdrücke. Einleuchtende Vergleiche und aufschließende Metaphern geben Ihrer Prosa Tiefendimension und Farbe.

- Denken Sie immer an die Devise „Show, don’t tell!“. Malen Sie nicht aus, sondern versuchen Sie zu evozieren: Durch den richtigen Appell an die Erinnerungen und Erfahrungen des Lesers entsteht eine „visuelle“ Zusammenarbeit zwischen ihm und dem Autor. Sind die Details richtig ausgewählt, sieht der Leser mehr, als geschrieben steht.

- Noch stärker als Visualisieren und Evozieren wirkt Suggerieren, also das indirekte Hervorrufen vergessener Bilder und unterschwelliger Gefühle. Wer diese Kunst beherrscht, ist ein Meister. [...] Die Wirkung des Indirekten ist intensiver, als es das Vergießen von Tränen auf dem Papier je vermocht hätte. 
- Ein Erzähler, der sich kommentierend ins Geschehen einmischt, findet heute seltener denn je Anhänger. Auf keinen Fall sollte er sich durch Kundgabe irgendwelcher Meinungen profilieren wollen. Dies gilt in verstärktem Maße für den Autor selbst. [...]

- Allerweltsweisheiten sind nichts anderes als gedankliche Klischees. Auch wenn sie „wahr“ sind. Ihre Wahrheit hat sich abgenutzt. Es gilt die Gleichung: Abstraktion + Klischee = schwerer Fehler.

- Reflexionen, intellektuelle Streitgespräche, Kommentare sollten einen ungewöhnlichen Aspekt einbringen. Extreme Standpunkte, aphoristische Überspitzungen, neuartige gedankliche Kombinationen können aufhorchen lassen, zum Widerspruch reizen und natürlich eine Person kennzeichnen. Aber generell gilt: Eine verkopfte Prosa wirkt auf die meisten Leser abstoßend und langweilig.

- Ironische Distanz, insbesondere in der Darstellung der Figuren, ist gerade bei Anfängern beliebt, aber schwerer zu realisieren, als sich die meisten vorstellen. Man sollte sich immer vor Augen halten, daß viele Menschen Ironie überhaupt nicht einordnen können, andere allergisch reagieren; außerdem wirkt sie sehr schnell überheblich. Also Vorsicht!

- Sprachliche Übertreibungen und Verzerrungen, bewußt eingesetzte Stilbrüche müssen in ihrer Funktionalität einleuchten und überzeugen. Sie dürfen nicht aufdringlich oder gekünstelt wirken oder gar zum Selbstzweck werden.

- Sprachliche Wirkung basiert nicht zuletzt auf Rhythmus und Klang. [... ] Lange Sätze und schwingende Rhythmen rufen im Leser ein anderes Gefühl hervor als hektisches Stakkato und atemloses Stolpern. Abgerundete Satzkadenzen verleiten eher zum Weiterlesen als holprige Ausgänge. Auch die Wortklänge, das Vorherrschen dunkler oder heller Vokale, Alliterationen, Assonanzen und unauffällige Reime, also der „Sprachkörper“, entfalten eine suggestive, ja magische Kraft, der sich sensible Leser kaum entziehen können.

- Die sprachliche Gestaltung darf den Leser nicht dauernd (ungewollt) aus seinem fiktionalen Traum reißen. Wenn sie dies soll, dann muß sie präzise treffen, überraschen und zusätzlich bezaubern. Schiefe Bilder, brüchige Rhythmen und ungeschickte Satzkonstruktionen sind nicht nur technische Fehler, sondern zerstören auch allzu leicht das Band zwischen Text und Leser und damit die Grundlage für eine freiwillig-lustvolle Hingabe an die Phantasie eines Fremden.

- Es gibt durchaus noch sprachliche Tugenden. Sie treten nicht marktschreierisch auf, wirken auf manche Autor(inn)en vielleicht altmodisch, aber man kann sich auf sie verlassen. Sie heißen: Klarheit, Präzision, Dynamik, Direktheit, Abwechslungsreichtum, Farbe und Eleganz. (Gesing 1994, 199 ff.; Hervorhebungen KR)

Aus Gesings Liste, die sich der Kapitelüberschrift folgend speziell auf die Sprache bezieht, lassen sich zum einen Rückschlüsse ziehen, welche Art von Wirkung Literatur beim Leser hervorrufen soll, beziehungsweise welche Art der Gestaltung seiner Meinung nach am ehesten dazu beiträgt, eine breite Masse von Lesern zu befriedigen; zum anderen zeigt sie aber auch, welche Eigenschaften von Texten er für erfolgsversprechend hält. Sieht man von der Aufforderung, Schachtelsätze den Juristen zu überlassen, ab (siehe oben), lässt sich aus allen Punkten der Checkliste ein Hinweis darauf erkennen, welche Wirkungen von Literatur im Sinne des Ratgebers wünschenswert sind. In erster Linie wird intendiert, dass der Leser in die fiktionale Welt eintauchen kann und ihr mit Spannung folgt. Gesing spricht von der „freiwilligen, lustvollen Hingabe“, in der der Leser nicht durch sprachliche Auffälligkeiten gestört werden solle. Auch die „verkopfte Prosa“, die auf den Leser 
„abstoßend und langweilig“ wirken kann, ist im Sinne einer solchen Unterbrechung des „fiktionalen Traum[s]“" zu verstehen. Der Stichpunkt verweist aber auch auf eine andere Facette gelungener literarischer Sprache, die eine wichtige Rolle zu spielen scheint, nämlich die intensive emotionale und sinnliche Aktivierung des Lesers. Rhythmen seien dazu geeignet, im Leser unterschiedliche Gefühle hervorzurufen. Durch den Modus des Showing „sieht der Leser mehr, als geschrieben steht“. Ganz allgemein konstatiert Gesing: „Die Wirkung des Indirekten ist intensiver". Damit bezieht er sich nicht nur auf die Intensität des Wahrgenommenen als wichtigen Faktor in der Wirkung, sondern verweist auch auf die geistige Aktivierung des Lesers durch indirekte Darstellungsverfahren, die sich auch in den Bachmann-Preis-Diskussionen als besonders wichtig erweisen wird. Bei indirekten Darstellungsverfahren ist der Leser veranlasst, Bezüge selbstständig finden und auf diese Weise einen kohärenten Text herzustellen (vgl. z. B. Kapitel 11.2). Verständlichkeit ist bei Gesing eine wichtige Textwirkung. Sie wird evoziert, wenn es etwa um „einleuchtende Vergleiche“ und aufschließende Metaphern“ oder die sprachlichen Tugenden „Klarheit“, „Präzision“ und „Direktheit" geht.

Wie genau eine sprachliche Gestaltung sein sollte, die zugleich von „Direktheit" als auch von der intensiven „Wirkung des Indirekten“ geprägt ist, die klar und präzise ist, gleichzeitig aber das „Visualisieren“, „Evozieren“ und „Suggerieren“ als Techniken der Aufmerksamkeitsbindungen nutzt, wird aus den Stichpunkten nicht klar. Einem guten Text gelingt es offenbar, dem Leser einen Eindruck von Transparenz zu vermitteln und ihn gleichzeitig geistig und emotional so zu aktivieren, dass er seine Aufmerksamkeit nicht vom Text lösen kann.

\subsection{Universelle Eigenschaften von guten Texten}

Aus der Sicht des Creative Writing sind Texte, das dürfte deutlich geworden sein, dann gut, wenn sie leserfreundlich sind. Leserfreundlich sind Texte dieser Auffassung zufolge dann, wenn sie dem Leser erlauben, leicht in die Welt des Textes einzutauchen und die Aufmerksamkeit anschließend für die Dauer des Textes zu binden, ohne dass der Leser dabei Mühe empfindet. Obwohl Aspekte der Verständlichkeit der Sprache als Grundlagen eines gelungenen literarischen Textes erwähnt werden, geht es vor allem um die Erzeugung von „Spannung“ als einen zentralen und erwünschten Effekt. Letztlich, das zeigt auch Gesings Liste, zielen die Anleitungen und Ratschläge des Creative Writing darauf ab, diesen Effekt beim Leser zu erzielen. Obwohl es sich bei Spannung um eine emotionale Reaktion des Lesers handelt (vgl. Langer 2008), sehen sowohl literaturwissenschaftliche 
Studien (Langer 2008; Anz 2002 S. 150 ff., Hillebrandt 2011) als auch die Anleitungen des Creative Writing den Effekt als „eine[n] vom Text [...] hervorgerufenen Mangel an Informationen bzw. einer Ungewissheit [...] auf Seiten des Lesers [...] im Zusammenspiel mit dem Wunsch, dem Bedürfnis oder der Erwartung nach einer Auflösung dieses Zustandes" (Langer 2008, 12 f.). Das Kreative Schreiben versteht das Kriterium der Spannung als universell, da die Anleitungen keine Unterscheidung zwischen unterhaltender und sogenannter ernster Literatur treffen. Handlungsbezogene Spannungstypen wie suspense (Zukunftsspannung) und mystery (Rätselspannung) spielen im Creative Writing eine größere Rolle als tension (zu den Spannungstypen vgl. Irsigler et al. 2008; Langer 2008). Insgesamt dominiert der Spannungstyp der Zukunftsspannung. Es liegt der in Gelehrtenkreisen typische Einwand nahe, es handle sich bei den angestrebten Schreibprodukten nicht um Literatur als Kunst, sondern um Unterhaltungsliteratur. Wie die Analyse der Diskussionen des Ingeborg-Bachmann-Wettbewerbs gezeigt haben, ist eine Trennung zwischen Literatur als Kunst, um die es beim Ingeborg-Bachmann-Wettbewerb geht, und Unterhaltungsliteratur, um die es dort dem Anspruch nach nicht geht, nicht anhand des Kriteriums der Spannung oder Unterhaltung zu treffen. Vielmehr bemisst sich der Unterschied am Grad der Komplexität und Offenheit, die der jeweiligen Lesergruppe - Expertenlesern oder Laienlesern - zugemutet werden kann.

Das „Creative Writing Workbook“ $(2006,161)$ fasst die Grundbewegung einer Geschichte zusammen:

In any story you communicate with your reader by building up a rhythm of disclosing or withholding information. By moderating what they know you are inviting you readers to use their imagination, to elaborate on the facts they are given and help create the story. (Creative Writing Workbook 2006, 161)

Die Anforderungen, die in den Ratgebern, aber auch in den Diskussionen des BachmannWettbewerbs an Figur und Dramaturgie, Erzählerstimme und Modus der Darstellung gestellt werden, entsprechen in vielen Aspekten diesem Muster. Immer geht es darum, das Interesse des Lesers zu aktivieren, seine Aufmerksamkeit zu halten und ihn emotional zu involvieren. Auf der Figurenebene werden mehrdimensionale Charaktere angestrebt, die möglichst authentisch und nicht vorhersehbar sind, die aber trotzdem zur Identifikation einladen. Eine typische Handlungsdramaturgie führt eine Figur, die einen starken Wunsch oder ein Ziel hat, das sie unbedingt verwirklichen will, in einen Konflikt oder eine Krise, die die Erreichung dieses Ziels in Frage stellt. ${ }^{35}$ Der Leser soll zusammen mit der Figur die

35 Von diesen Konstruktionsprinzipien der Figur („runde“ statt „flache“ Charakterisierung, starker Wunsch oder Ziel, eine charakterliche Schwäche neben sympathischen Zügen, Konflikt/Krise, starker 
Ungewissheit erleiden, nicht zu wissen, ob das Ziel erreicht werden kann. Er soll Lösungsmöglichkeiten der Figur antizipieren können und anschließend „mitfiebern“, ob die Figur diesen Weg einschlägt und ob sie erfolgreich sein wird (vgl. Ebenbach 2013; Reissenweber 2013; Gesing 1994). Entsprechend dieser Konzeption eines beteiligten, mitdenkenden Lesers wird bei der Erzählperspektive eine eingeschränkte Perspektive bevorzugt, die nicht alle Informationen preisgibt, sondern dem Leser Spielräume lässt, dieser Perspektive zu folgen, oder sich von ihr zu distanzieren. Gefragt ist in jedem Fall eine Perspektive, die nur Ausschnitte präsentiert; in der Regel ist das ein Erzähler in der dritten Person mit Innensicht auf das Geschehen (heterodiegetischer Erzähler, interne Fokalisierung). Der bevorzugte Modus der Darstellung - das Showing - fehlt in keiner der Darstellungen. Zeigen statt zu erzählen sei eine Art Literaturmantra (Steele 2013, 33). Für die amerikanischen Autoren laute der erste Grundsatz des lebendigen Erzählens, den sie nicht aufhören zu betonen: „Show, don’t tell “ (Gesing 1994, 71). Den Grund für diese Bevorzugung des Zeige-Modus sehen die verschiedenen Autoren in der Lebhaftigkeit der Darstellung, die nur auf diesem Wege erzeugt werden könne (Creative Writing „Workbook” 2006, 129). Außerdem entspreche dieser Modus auch den Bedürfnissen des Lesers: „Readers want to be involved; they want to ask questions and like to use their imagination in providing some of the answers themselves.” (Creative Writing „Workbook“ 2006, 129). Genauso sieht es Gesing (1994, 72), der meint, auf diesem Wege „[wird] [d]er Leser [...] eingeladen, an einem Phantasiespiel teilzunehmen, halb Kreuzworträtsel, halb Maskerade. Er darf aktiv sein und wird nicht bevormundet". Dass Informationen nicht einfach vom Erzähler „gesagt“, vor dem Leser ausgebreitet werden sollen, sondern es für die Textwirkung günstiger ist, wenn dem Leser Szenen präsentiert werden, aus denen er selbst seine Schlüsse ziehen kann, weist wiederum in die Richtung eines aktiven Lesers, der durch emotionale Teilnahme und intensives Nachvollziehen der Textwelt in den Text „eintaucht“ und auf diese Weise Spannung und Unterhaltung empfindet. Spannung und Unterhaltung sind in der Vorstellung des Creative Writing an die Bereitschaft des Lesers gebunden, sich geistig intensiv mit dem Text auseinanderzusetzen. Es ist die Aufgabe des Autors, diese Bereitschaft durch die Art der Darbietung zu ermöglichen. Dazu gibt es zwar keine Rezepte, die ein Autor eins zu eins befolgen kann, sie können aber „nach bestimmten Leitlinien Geschichten stärker und eindrucksvoller machen [...], auch wenn sie nicht auf den ersten Blick sichtbar sind, etwa so, wie sich irgendwann gezeigt hat, dass eine Zapfenverbindung einen Stuhl stabiler macht" (Steele 2013, 33).

Antagonist) wird in keinem der untersuchten Ratgeber abgewichen. Es wurde daher darauf verzichtet, Einzelbelege anzuführen. 


\section{Exkurs: Textqualität in Textlinguistik und linguistischer Leseforschung}

Thomas Anz (2002) hat mit Rückgriff auf verschiedene theoretische Entwürfe seit dem 18. Jahrhundert dargestellt, dass Leselust in verschiedenen Variationen aus einer Mischung aus Bestätigung und Stimulation entsteht. Nell (1988) geht in seinen empirischen Studien davon aus, dass Texte von Lesern freiwillig und gern gelesen werden, wenn sie ein ihrem Leseniveau angemessenes Maß an Komplexität besitzen und gleichzeitig stimulierend wirken. Die Annahme der mittleren Komplexität teilen Hoffstaedter (1986), Pette (2002) und Muth (1996). Creative Writing Lehrer betonen, dass dem Leser Möglichkeiten gegeben werden müssen, selber Sinn zu konstruieren, dass die Aufmerksamkeit des Lesers allerdings auch durch Techniken des Spannungsaufbaus gebunden werden kann. Auch diese Annahmen werden von Hoffstaedter (1986), Pette (2002) und Muth (1996) bestätigt. In verschiedenen Bereichen der Auseinandersetzung mit Literatur sind erfolgreiche Leseprozesse also immer als eine Wechselwirkung von Orientierung und geistiger und emotionaler Aktivierung gesehen worden. Auch deskriptive textlinguistische und leserpsychologische Ansätze weisen in diese Richtung. Aus den Beschreibungen, was Texte sind und was Kommunikation durch Texte ausmacht, lassen sich Rückschlüsse darauf ziehen, was als Text akzeptiert wird und auf diesem Wege, wenn man nämlich davon ausgeht, dass gute Texte diese Funktionsprinzipien besonders gut umsetzen, was gelungene Texte ausmacht. Im Zusammenhang dieser Arbeit ist dabei insbesondere die Frage interessant, wie sich diese Erkenntnisse über das Funktionieren von Texten aus deskriptiver Sicht zu den Erkenntnissen aus der Wertungsforschung zum einen und aus der Korpusanalyse zum anderen verhalten.

Zwei Ansätze möchte ich genauer betrachten. Zum einen die sehr bekannte und dezidiert sprachwissenschaftliche Bestimmung von „Textualität“ von de Beaugrande und Dressler (1981), zum anderen die sprachpädagogische Perspektive von Norbert Groeben. ${ }^{36}$

\subsection{Textualität nach R. de Beaugrande und W. U. Dressler}

Dass die Textualitätskriterien von de Beaugrande und Dressler (1981) im Zusammenhang mit der Frage nach Textqualität und Textbewertung herangezogen werden, mag zunächst überraschen; schließlich stellt die Einführung in die Textlinguistik einen Versuch dar, eine

\footnotetext{
$\overline{36}$ Eine differenzierte Auseinandersetzung mit Vorstellungen von gutem Text war im Rahmen dieser Arbeit
} nicht zu leisten. Die genannten Beispiele sind als Anregungen zu verstehen. 
Textgrammatik zu erschließen und zu beschreiben und damit überhaupt erst zu erfassen, was ein Text ist. Die Frage der Qualität spielt dem Anspruch nach gar keine Rolle. Allerdings machen die Autoren Beobachtungen, die sich durchaus mit Ergebnissen der Textwirkungsforschung und auch der Korpusanalyse in Verbindung bringen lassen. Was sie als notwendige Bestandteile eines Textes erfassen, findet sich - etwas anders formuliert, dem Inhalt nach aber ähnlich - in Bewertungen von Literatur wieder. Überlappungen gibt es auch mit den Anleitungen des Creative Writing. Das wirft die Frage auf, inwiefern es (erlernte) Ansprüche an Texte gibt, die zu einer bestimmten Zeit in einer bestimmten Gruppe universell sind. Möglich scheint, dass jene Eigenschaften, die de Beaugrande/Dressler als konstitutive Merkmale von Texten erkennen, sich in der Wertung von Texten durchaus unter dem Vorzeichen des Gelungenseins wiederfinden. Und wenn es tatsächlich Parallelen in der Beschreibung und Bewertung von Texten im Allgemeinen gibt, wirft das die Frage auf, ob und wie genau sich die Bewertung literarischer Texte von der Bewertung von Alltagstexten unterscheidet.

Die sieben Textualitätskriterien von de Beaugrande/Dressler, die erfüllt sein müssen, damit ein Text als Text gelten kann, sind: Kohäsion, Kohärenz, Intentionalität, Akzeptabilität, Informativität, Situationalität und Intertextualität. Diese Kriterien reflektieren neben der inneren grammatischen Organisation des Textes Spekulationen des Produzenten über die Reaktionen des Rezipienten, die Voraussetzungen und Strategien des Rezipienten bei der Einschätzung des Textes und auch Kontexte. Sie sind nicht voneinander zu trennen, sondern miteinander verwoben. Akzeptabilität beispielsweise beinhaltet nicht nur eine Prüfung des Rezipienten, ob der Text für ihn akzeptabel ist, sondern auch eine bewusste Kalkulation des Produzenten mit Annahmen darüber, was die Bereitschaft des Rezipienten, dem Text zu folgen, erhöht. So ließen „sich Textrezipienten durch Inhalt, den sie selbst beisteuern, leichter überzeugen, fast als ob sie die Behauptung selbst aufstellen würden“ (de Beaugrande/Dressler 1981, 10). Der Produzent kann also darauf setzen, dass Rezipienten einen Text besser akzeptieren, wenn sie Informationen ergänzen müssen. Um den Rezipienten anzusprechen - der Aspekt spielt durchaus eine Rolle - müssen die verschiedenen Kriterien auf eine spezifische Weise ausbalanciert sein. Man darf die Textualitätskriterien also nicht, wie man zunächst annehmen könnte, als eine Checkliste betrachten. Zum Kriterium der Informativität heißt es beispielsweise:

[U]nd [wir] meinen damit das Ausmaß der Erwartbarkeit bzw. Unerwartbarkeit oder Bekanntheit bzw. Unbekanntheit der dargebotenen Textelemente. [...] Die Verarbeitung von hochgradig informativen Nachrichten ist anstrengender als von weniger informativen, ist dafür aber auch dementsprechend interessanter. Doch ist Vorsicht geboten, die Verarbeitung nicht so stark zu belasten, daß der Kommunikationserfolg 
gefährdet wird. Kohärenz erfordert eben die Wiederholung oder leichte Rekonstruierbarkeit von bekanntem Material. (ebd., 10 f.)

Hier wird die Wirkung, die die verschiedenen Verhältnisse von Informationsdichte und Kohärenz auf den Rezipienten haben, mitreflektiert. Noch deutlicher wird das, wenn es heißt, dass „[b]esonders geringe Informativität [...] leicht störend [wirkt], da sie Langeweile verursacht oder sogar zur Ablehnung des Texts führen kann“ (ebd., 11). Wenn es um „Langeweile“ und eine „störende“ Wirkung geht, geht es nicht mehr allein darum, ob ein Text ein Text ist oder ob er überhaupt kommunikativ ist, sondern darum, ob er kommunikativ erfolgreich ist, erfolgreich auch in dem Sinne, dass der Leser dem Text gerne folgt. Entsprechend wird in den Textualitätskriterien auch Textqualität mitreflektiert.

Neben den Textualitätskriterien gehen de Beaugrande und Dressler (ebd., 14) von drei regulativen Prinzipien aus, „die die Text-Kommunikation nicht definieren, sondern kontrollieren“. Diese drei Prinzipien sind Effizienz, Effektivität und Angemessenheit. Effizienz betrifft dabei die Zugänglichkeit des Textes (Verständlichkeit), Effektivität die Intensität der Rezeption (nach Beaugrande/Dressler „Verarbeitungstiefe“). Die Angemessenheit reguliert, in wie weit diese beiden Prinzipien in einer spezifischen Situation passend sind. Dabei wird die besondere Balance von Effizienz und Effektivität wiederum mit der Akzeptanz durch den Leser verknüpft:

Man beachte, daß Effizienz und Effektivität dazu tendieren, gegeneinander zu arbeiten. Einfache Sprache und abgedroschener Inhalt sind sehr leicht zu produzieren und zu rezipieren, verursachen aber Langeweile und beeindrucken uns nur wenig. Im Gegensatz dazu üben schöpferische Sprache und ungewöhnlicher Inhalt eine starke Wirkung aus, können jedoch unverhältnismäßig schwierig zu produzieren und rezipieren sein. Daher muß Angemessenheit zwischen diesen einander entgegensetzten Faktoren vermitteln, um das richtige Gleichgewicht zwischen dem Konventionellen und dem Nichtkonventionellen in der Situation anzuzeigen. (ebd., $35 \mathrm{f}$.)

Nicht nur die Frage, ob ein Text beeindruckt oder Langeweile verursacht, wird hier mitgedacht; die Prinzipien Effizienz und Effektivität werden auch mit dem Konventionellen und dem Nichtkonventionellen parallelisiert. In Anbetracht der Tatsache, dass die Besonderheit von Literatur vielfach in einer Entautomatisierung der Sprache, also einer Arbeit mit dem Nichtkonventionellen gesehen wurde (vgl. u. a. Fricke 1981; Andreotti 2009; Fricke/van Peer 1999), liegt es nahe, dass im Fall von Literatur als Kunst die Dominanz von Effektivität gegenüber Effizienz akzeptiert ist.

In diesem Ausflug in die Textlinguistik konnte gezeigt werden, dass insbesondere im Kriterium der Akzeptabilität auch Potentiale der Wirkung von Texten mitgedacht sind. Im Prinzip der angemessenen Abstimmung von Effizienz und Effektivität finden sich Beobachtungen wieder, die auch in der literaturwissenschaftlichen Textwirkungsforschung und 
Wertungsforschung gemacht wurden, nämlich dass es ein ganz spezifisches Verhältnis von Bekanntem und Offenem in Texten braucht, damit der Leser sich vom Text so sehr angesprochen fühlt, dass er ihn mit ästhetischer Freude liest (u. a. Anz 2002; Nell 1988; Muth 1996). Die Vermutung liegt nahe, dass literarische Texte als Texte zunächst jene Voraussetzungen erfüllen müssen, die alle Texte erfüllen müssen, um Texte zu sein. Der entscheidende Unterschied zwischen literarischen und anderen Texten liegt darin, dass sie dazu konzipiert sind, freiwillig und mit dem Ziel, sich selbst eine Freude zu bereiten, gelesen werden - Schullektüre ist in diesem Sinne keine prototypische Literatur-Lektüre - und dass sie insbesondere in Wertungskontexten viel mehr als Alltagstexte mit Blick auf ihr Gelungensein gelesen werden. In Wertungssituationen ist also der Blick für die Konstruktionsprinzipien geschärft. Gegenüber Alltagstextsorten liegt das Augenmerk bei literarischen Texten dabei eher auf jenen Eigenschaften, die es dem Leser erlauben, ihn zu erleben; gleichzeitig werden die von de Beaugrande/Dressler als konstitutiv beschriebenen Merkmale - unter Verwendung eines anderen Vokabulars - bewusster, tendenziell normativ, an den literarischen Text herangetragen.

\subsection{Leserpsychologie}

Norbert Groebens (1982) Untersuchungen, wie Lehrbuchtexte effektiver in Hinblick auf das Verstehen und Behalten von Informationen gestaltet werden können, geben ebenfalls Hinweise darauf, dass eine gezielte Balance von Verständlichkeit, das heißt leichter Zugänglichkeit, und anregenden Impulsen, entscheidend für die Interessensbindung und damit die gelungene Vermittlung von Stoff ist. Während de Beaugrande und Dressler ihre Ergebnisse im Wesentlichen aus der genauen Untersuchung von Texten und letztlich sehr häufig aus Eigenerfahrung schöpfen, greift Groeben auf empirische Methoden wie Fragebögen zurück, um zu erfassen, wie Texte wahrgenommen und wie gut ihr Inhalt verarbeitet wurde. Literarische Texte sind in Groebens $(1982,156)$ Zweifaktorenmodell des ästhetischen Wertes „durch eine Integration von zwei gegenläufigen Polen gekennzeichnet: Spielraum und Bestimmtheit". Allerdings steht bei Literatur als Kunst der Aspekt des Spielraums im Vordergrund, während Sachtexte am besten behalten werden, wenn „Gestaltungsmerkmale der Dimension ,kognitive Strukturierung“ mit solchen der Dimension ,kognitiver Konflikt" kombiniert waren“ (Christmann/Groeben 1999, 182), wobei bei Sachtexten die Verständlichkeit im Vordergrund steht. Wie Nell (1988) und Muth (1996) bestätigen Christmann/Groeben die Bedeutung der mittleren Verständlichkeit für einen befriedigenden, aber auch in Hinblick auf die Behaltensleistung erfolgreichen Leseprozess. 
Vieles spricht also dafür, dass alle Texte sowohl Verständlichkeit als auch Problemlösungsanreize brauchen, um „erfolgreich“ zu sein, dass bei literarischen Texten jedoch „kognitiver Konflikt" bzw. Spielraum bedeutender für den Erfolg ist, bei Sachtexten dagegen die Verständlichkeit wichtiger als die Neugier weckende „motivationale[] Stimulanz“ (Christmann/Groeben 1999, 182). Erfolg haben, ist in diesem Zusammenhang noch nicht als „gut bewertet werden“ zu verstehen, sondern zunächst als eine Reaktion beim Leser, die in geistiger Aufmerksamkeit, Aufnahmebereitschaft und -fähigkeit besteht.

„Kognitive Konflikte“ entstehen in Sachtexten aus Informationen, die für den Leser auf dem Wissensstand, auf dem er sich befindet, keinen Sinn ergeben und ihn dazu anregen, darüber nachzudenken, wie dieser Sinn herzustellen ist. Was Christmann/Groeben für Sachtexte annehmen, lässt sich mühelos auf literarische Texte übertragen, die Spannung ebenfalls dadurch generieren, dass Leser mit fiktiven Situationen konfrontiert werden, deren Ausgang oder Entstehung unklar ist, und die der Leser „auflösen“ möchte (vgl. Langer 2008; Anz 2002, 157): Wie ist der Mord geschehen? Wie passen die aggressiven Verhaltensweisen zum sympathischen Protagonisten? Muss der Held die Strafe akzeptieren, obwohl er in bester Absicht gehandelt hat? Literatur führt den Leser ununterbrochen und gezielt in kognitive Konflikte - der Leser sucht diese Konflikte, wenn er auf der Suche nach „spannendem" Lesestoff ist.

Diese Ergebnisse geben auch Hinweise darauf, wie starke Bewertungsvarianzen zwischen einzelnen Personen erklärt werden können, denn wie viel der Text selber zu seiner Verständlichkeit durch strukturierende und klärende Gestaltungsmerkmale beitragen muss, oder anders gesagt, wie komplex er sein darf, um verständlich zu sein, hängt von der Lesererfahrung und dem Vorwissen des Lesers auf dem jeweiligen Gebiet ab (vgl. Christmann/Groeben 1999, 182). Man kann vermuten, dass grundsätzlich für alle Texte das Erfolgserlebnis, das beim Lesen einsetzen kann, und das laut Belke/Leder (2006) die Bewertung eines Textes deutlich beeinflusst, sowohl von der Vorbildung und Übung des Lesers als auch von der Strukturiertheit und Klarheit des Textes abhängt. Literarische Texte unterscheiden sich von Gebrauchstexten, zum Beispiel den untersuchten Lehrbuchtexten, in Hinblick auf die stimulierenden Elemente, die vom Leser als angenehm empfunden werden, das heißt insbesondere Offenheit und Mehrdeutigkeit.

\subsection{Zusammenfassung}

Sowohl der textlinguistische Ansatz von de Beaugrande/Dressler (1981) als auch der leserpsychologische von Groeben, die nicht nach der Qualität von Texten, sondern vielmehr 
nach der Effektivität der Kommunikation durch Texte fragen, weisen darauf hin, dass Texte dann besonders gut vom Leser angenommen werden, wenn sie eine Grundhaltung zu erzeugen vermögen, die durch Aufmerksamkeit einerseits und durch Interesse anderseits geprägt ist. Leser sollten in der Lage sein, dem Text zu folgen; gleichzeitig sollten Texte Fragen offen lassen, um die Neugier ihrer Leser zu wecken und über den Text hinweg aufrecht zu erhalten. Beide Ansätze gehen davon aus, dass textseitige Faktoren dazu beitragen, dem Leser einen angenehmen Leseprozess zu ermöglichen. Allerdings räumt insbesondere der leserpsychologische Ansatz auch ein, dass die Lesefähigkeit und Leseerfahrung eine bedeutende Rolle bei der Wahrnehmung des Textes spielen. Leser, denen das Lesen generell schwer fällt und die wenig Übung haben, bevorzugen nach Christmann/Groeben (1999) Texte, die auf Verständlichkeit zugeschnitten sind. Geübtere Leser dagegen, können größere Grade an Offenheit und Unbestimmtheit verkraften bzw. favorisieren diese. Für literarische Texte, deren Besonderheit Groeben (1982) zufolge in dem großen Spielraum liegt, den sie Lesern bei der Rezeption erlauben, ließe sich also vermuten, dass mit großer Leseerfahrung ein zunehmendes Maß an Offenheit honoriert wird. Dass die Aktivierung des Lesers eine große Rolle für das Gelingen literarischer Texte spielt, ist auch eine Grundannahme des Creative Writing (vgl. Kapitel 7), das großen Wert auf die Unvorhersehbarkeit der Handlung, komplexe Charaktere und den Modus des Showing legt.

Im Text angelegte Offenheit, die die (emotionale) Anteilnahme des Lesers erlaubt, erweist sich also als eines der zentralen Momente der Effektivität insbesondere literarischer Texte. Dabei sehen sowohl der textlinguistische Ansatz als auch der leserpsychologische als auch die Anleitungen des Creative Writing die Machart des Textes als einen entscheidenden Faktor in der Herstellung von Offenheit und Zugänglichkeit. Nimmt man als gegeben an, dass die Machart des Textes in Hinblick auf seine Verständlichkeit und Offenheit die Rezeptionshaltung des Lesers mit bedingen, wirft das für die Ingeborg-Bachmann-Preis-Diskussionen die Frage nach dem Verhältnis von Werten und den empirisch belegten (Lesespsychologie) oder postulierten Wirkungen der Textkonstruktion (Creative Writing, Textlinguistik) auf. 


\section{Teil II}

\section{Stichwortgeleitete Analyse}

\section{Wertungen und Werte in den stichwortgeleiteten Analy- sen}

\subsection{Ausgangslage}

In den vorausgegangenen Kapiteln sind die Rahmenbedingungen von Wertungen beim Ingeborg-Bachmann-Wettbewerb beschrieben und theoretische Hintergründe erläutert worden, die für die Beurteilung von Wertungsäußerungen während des Wettbewerbs hilfreich waren. Bevor das Wagnis unternommen wird, die Kernfrage dieser Arbeit - die Frage nach der Wichtigkeit und Beschaffenheit formal-ästhetischer Wertungen in den Diskussionen des Ingeborg-Bachmann-Wettbewerbs - zu beantworten, möchte ich noch einmal die entscheidenden Aspekte dieser Rahmenbedingungen ins Gedächtnis rufen.

Wenn im Rahmen des Ingeborg-Bachmann-Wettbewerbs Texte bewertet werden, entspricht das nicht einer TÜV-Untersuchung. Es gibt keine Fertigungsnormen und auch keinen Kriterienkatalog, der bei einer Bewertung abgearbeitet wird, weder einen manifesten noch einen mentalen. Vielmehr kann man annehmen, dass es kulturell vermittelte Wissensbestände gibt, wie man Wertungen diskursiv einsetzt (vgl. Kapitel 4). Vor jeder verbalen Wertung steht jedoch die Textrezeption, die zunächst einen spontanen, sinnlichen Eindruck hinterlässt: Der Leser, auch der professionelle Leser, reagiert irgendwie auf den Text, liest ihn mit Spannung, mit Interesse, gegen seinen eigenen Widerstand, irritiert oder gelangweilt. Dieser erste Leseeindruck ist, wie die Analysen zeigen werden, richtungsweisend für die Bewertung. Die ersten Leseeindrücke werden zu einer Gesamtwertung auf der bipolaren positiv-negativ-Skala verdichtet. Auch ungeübten Bewertern dürfte es leicht fallen, zu bestimmen, ob eine Lektüre für ihn persönlich gut, schlecht oder mittelmäßig war. Geprägt sind Laienleser wie professionelle Leser - und damit auch Wertende - von ihrem Vorwissen, das heißt von den Leseerfahrungen, die sie im Laufe ihres Lebens gesammelt haben und von Techniken, die sie erlernt haben, um Texten zu begegnen. Dieses literarische Vorwissen prägt selbstverständlich die Art der Rezeption und auch der Bewertung. Über dieses Vorwissen - sei es ein nominelles Wissen, sei es ein Knowing-How hinaus haben möglicherweise genetisch verankerte Programme Einfluss darauf, was Rezi- 
pienten als lustvoll empfinden (Tooby/Cosmides 2001; Eibl 2009; Mellmann 2008). „Lust“ als positive Emotion, die beim Leseprozess empfunden werden kann, und eine positive Bewertung müssen nicht Hand in Hand gehen. Belke/Leder $(2006,10)$ gehen davon aus, dass insbesondere Experten zu einer „Dissoziation von Affekt und Urteil“ kommen können. Trotz einer affektiv positiven Rezeption können insbesondere Experten ein Kunstprodukt als qualitativ minderwertig beurteilen. Die Bewertung von Literatur erweist sich damit als ein äußerst vielschichtiges Phänomen, in dem genetisch veranlagte Rezeptionspräferenzen sich mit individuellem Wissen und sozialen Zielen verknüpfen. Angesichts dieser Komplexität ist es wenig erhellend, Wertungen (und Werte) ausschließlich als textgeleitet oder ausschließlich als gesellschaftlich konstruiert zu betrachten. Weder sind Werte nur ein soziales Phänomen - ein Ausdruck herrschender gesellschaftlicher Ordnung im Extremfall noch sind sie universell und in Texten veranlagt. Die Analyse der machartbezogenen Textstellen in den Diskussionen des Ingeborg-Bachmann-Preises 1999-2009 hat gezeigt, dass es durchaus Aspekte der Machart gibt (Werteigenschaften), die von den Juroren übereinstimmend als Bezugspunkte ihrer Wertungen dienen: Strategien der Informationsvergabe, das Aufeinanderbezogensein von sprachlicher Gestaltung und Inhalt, die emotionale Wirkung der Figur, die Erzählhaltung, die sinnliche Qualität der Sprache, die Individualität des Stils. Es wurde aber auch schnell klar, dass es keine Wertmaßstäbe gibt, die per se gültig sind. Es gab Diskussionen, in denen die „musikalische“ Sprache als positive Eigenschaft hervorgehoben und die sinnliche Qualität gelobt wurde. In anderen Diskussionen wurde die Musikalität der Sprache, bei gleichzeitiger Anerkennung des Maßstabs Musikalität, negativ bewertet. Als entscheidende Frage erwies sich also diejenige nach den Zuordnungsvoraussetzungen (Heydebrand/Winko 1996): Wann und unter welchen Voraussetzungen wird eine Werteigenschaft einem bestimmten Maßstab zugeordnet? Es wurde mit zunehmender Analyse immer klarer, dass es nicht so sehr diskursive Regeln sind, die die Zuordnung leiten, sondern vielmehr die Wirkung des Textes während der Lektüre als lustvoll oder abschreckend. Damit kam eine neue Frage hinzu: Welche Rückschlüsse lassen sich von den verwendeten Werten auf die textuellen Voraussetzungen ziehen, die eine lustvolle Lektüre wahrscheinlicher machen. Dabei wurde vorausgesetzt, dass die in den Diskussionen genannten Wertmaßstäbe und Werteigenschaften nicht willkürlich eingesetzt werden, sondern neben der diskursiven Funktion, sich als Experten auszuweisen, die sie unweigerlich auch haben, dazu benutzt werden, einen Lektüreeindruck erklärbar zu machen.

Die Bachmann-Preis-Diskussionen lassen zwei Grundbedürfnisse der Leser erkennen: Den 
Wunsch, den Text zu verstehen ${ }^{37}$ und sich formal wie inhaltlich in ihm zu orientieren auf der einen Seite, und den Wunsch, aktiv am Text teilzunehmen, auf der anderen Seite, sei es durch Identifikation mit einer Figur, ${ }^{38}$ sei es durch die Notwendigkeit, Informationen zu ergänzen, damit ein kohärenter Textsinn hergestellt werden kann, sei es, indem der Leser sein Wissen über formale Strukturen bestätigt findet oder sei es durch ein intensives (emotionales) Erleben (Spannung) des Textes. Argumentativ werden diese Leserbedürfnisse in unterschiedliche konventionalisierte Wertmaßstäbe übertragen.

Professionelle Wertung beginnt nach dem ersten Leseeindruck und umfasst - wenigstens im Rahmen des Bachmann-Wettbewerbs - den Versuch, einen ersten Lektüreeindruck mit dem Text in Beziehung zu setzen, ihn aus dem Text heraus zu erklären und in eine Wertungssprache zu übertragen. Für diese Erklärungs- und Überzeugungsarbeit - denn verbale Wertungen haben auch appellativen, vermittelnden Charakter (Anz 1990, 195 „didaktisch-vermittelnde Funktion“) - steht professionellen Bewertern von Literatur ein erlerntes Repertoire von Regeln zur Verfügung, wie man Texten Informationen entnimmt und wie man Texte einschätzt. Die argumentative verbale Wertung ist also einerseits immer ein Versuch, den Texteindruck zu rationalisieren und nachvollziehbar zu machen (vgl. Kapitel 4.4), andererseits ein Versuch, die eigene Wertung durch Einsatz prestigeträchtiger Werte so überzeugend zu machen, dass andere sich ihr anschließen (vgl. Kapitel 5). Das Repertoire des Wertungswissens ist dabei sehr flexibel einsetzbar. Ein Wertmaßstab, der in dem einen Text zur Begründung einer positiven Bewertung herangezogen wird, kann im nächsten zu einer negativen Bewertung herangezogen werden, obwohl der Maßstab in beiden Fällen als erfüllt gilt. Es ist also möglich, dass in dem einen Text die große Stimmigkeit ausufernd gelobt wird, in einem anderen aber die Stimmigkeit mit Verweis auf Langeweile beim Lesen negativ bewertet wird. Grund für diese Widersprüchlichkeit ist die vorangegangene spontane, hedonistische Textwahrnehmung. Die Bewertung literarischer Texte ist eben kein TÜV, bei dem eine technische Checkliste überprüft wird. Andererseits erfolgt die Rationalisierung des sinnlichen Eindrucks nicht vollkommen willkürlich. Sie ist auch nicht einzig eine Reproduktion kulturell erlernter Versatzstücke zum Zweck der Prestigesteigerung (vgl. Kapitel 4.3). Jede Wertung ist Ausdruck einer Lektüre und gibt Hinweise darauf, was an einem Text überhaupt wahrgenommen wurde und wie es eingeordnet wurde.

Zwei große Wirkungskomplexe von Literatur wurden ausgemacht: Orientierung und $A k$ 37 Zum hier verwendeten Begriff des Verstehens vgl. Kapitel 10.1-10.2.
38 „Identifikation“ wird hier als „,konzeptueller Rahmen“ (Koppenfels/Zumbusch 2016, 22) für verschie-
dene Phänomene der Anteilnahme an Figuren verwendet. 
tivierung des Lesers. Zwischen diesen beiden Wirkungskomplexen muss, so kann man aus den Analysen schließen, eine spezifische Balance eingehalten werden. Wie genau Wertungen mit Bezug auf die Machart von Texten zustande kommen, lässt sich aufgrund der spezifischen Wirkungsweisen, die gefunden wurden, am besten mit Konzepten aus der kognitionswissenschaftlichen Literaturforschung und der Wirkungsforschung erklären. Für den Bereich der Orientierung spielen dabei die Konzepte des Foregrounding (Zyngier et al. 2007; Holt/Groeben 2005) und der Rekonstruktion von Textwelten (Schwarz-Friesel 2006), Simulation (Oatley 1994) bzw. mentaler Modelle (Schneider 1999) eine Rolle. Für den Bereich der Aktivierung waren vor allem Arbeiten zu Emotionen beim Lesen und zur Bedeutung der Figur von großer Bedeutung (u. a. Mellmann 2016; Mellmann 2010; Mellmann 2008; Miall 2007). Für Wertungsprozesse insgesamt wurde immer wieder auf das Modell ästhetischer Emotionen von Belke/Leder (2006) zurückgegriffen.

Ein Wertmaßstab, nämlich der Maßstab Originalität, wird separat behandelt, weil sein häufiges Vorkommen sich eher durch seine diskursive Bedeutung erklären lässt. Darüber hinaus kann er je nach argumentativem Kontext sowohl die Wirkung der Orientierung als auch die Wirkung der Aktivierung haben.

\subsection{Vorgehen bei der Analyse}

Die Analyse des Korpus war, der Fragestellung dieser Arbeit entsprechend, reduziert auf Äußerungen der Juroren über formal-ästhetische Eigenschaften der besprochenen Texte und formal-ästhetische Wertmaßstäbe. Die große Herausforderung für die Analyse bestand darin, das über 1000 Seiten (rund 586.000 Wörter, mehr als 3 Millionen Zeichen) umfassende Korpus für eine Analyse handhabbar zu machen. Dazu wurden in Anlehnung an Kodierverfahren der Grounded Theory (vgl. Kapitel 2) und der qualitativen Inhaltsanalyse (Mayring 2002) „Suchwörter“ festgelegt. Anders als in der qualitativen Sozialforschung üblich, wurde das Material allerdings nicht zeilenweise kodiert, sondern es wurden zunächst Ausdrücke gesucht, mit deren Hilfe relevante Textstellen aufgefunden werden konnten. Dabei wurden nicht die literaturwissenschaftlichen Termini für formale und sprachliche Eigenschaften gewählt, sondern jene Bezeichnungen, die die Juroren häufig verwenden. Statt des Suchwortes „Stil“, das sich aus literaturwissenschaftlicher Sicht angeboten hätte, um Bezugnahmen auf sprachliche Phänomene aufzuspüren, wurden die Suchwörter „Formulierung“, „Ton“, „Sound“ und „Klang“ gewählt, weil diese von den Juroren häufig gewählt werden. Der Ausdruck „Stil“ dagegen kommt selten vor. Die Suchwörter wurden dabei zunächst aus jenen Diskussionspassagen gewonnen, in denen Juroren explizit zu er- 
kennen geben, dass sie sich zur Form äußern. Zusätzlich zu den genannten Oberbegriffen wurden Ausdrücke mit Formbezug gewählt, die häufig in unmittelbarem Zusammenhang mit formbezogenen Äußerungen standen und somit als wichtiger Bestandteil der formalen Auseinandersetzung auftraten. Ein Beispiel:

Das ist ein bisschen die Machart dieses Textes. Und erkauft wird dieser Sound, dieser Blues mit einer großen Gewissheit, dass alles genau so ist, wie der Text es haben will. Nichts, was in diesem Text aufscheint, hat irgendeine Chance, etwas anderes zu sein als das, was die Dinge sind aus der Perspektive des Schelms, der sie satirisch vernichtet. (2000 Alfare, 11:23 Spinnen; Hervorhebungen KR)

Burkhard Spinnen gibt explizit zu verstehen, dass er sich nun zur „Machart“ des Textes äußern wird. Aufgrund dieser Äußerung wurde auch die sprachliche Umgebung genauer untersucht, ob Hinweise darauf fallen, was genau hier mit „Machart" gemeint ist, und ob sich Wörter isolieren ließen, die bereits aus anderen Textstellen bekannt waren, sodass davon ausgegangen werden konnte, dass sie zum typischen Wertungswortschatz der Juroren gehören. In diesem Fall waren das die Wörter „Sound“ und „Perspektive“. Sie bestätigten sich auch in anderen Textstellen immer wieder als relevante „Formmerkmale“. Diese Wörter wurden also als Suchwörter aufgenommen. „Blues“ dagegen wurde nicht aufgenommen, weil es sich in anderen Diskussionen nicht als typische Formulierung bestätigte. In der späteren Untersuchung der Textstellen, die Suchwörter enthielten, wurden auch die unmittelbaren sprachlichen Kontexte der Wörter mit betrachtet. Spinnens Argument verweist zwar zunächst auf den Stil des Textes und seine Klangqualitäten („Sound“, „Blues“), geht aber dann in ein anderes Argument über, das man als „Determiniertheit“ zusammenfassen könnte (,alles genau so ist, wie der Text es haben will“). Dieses Argument, der Text sei absolut determiniert, das heißt nicht offen, ist ebenfalls als Formargument zu werten. Es wäre aber über Suchwörter allein schwer auffindbar gewesen. Aus genau diesem Grund wurden die Suchwörter immer in ihrem Kontext betrachtet und lediglich als Schlüssel zu entsprechenden Textstellen verwendet.

Die Analyse des Korpus erfolgte in mehreren Schritten (vgl. Kapitel 2.2). Die bei der Korpusanalyse verwendeten Suchwörter wurden auf der Grundlage einer ersten, umfassenden Lektüre des Gesamtkorpus und einer anschließenden Überprüfung am Wettbewerbsjahrgang 2000 festgelegt. Die verwendeten Suchwörter waren: Erzähler, Figur, Form, Formulierung, Klang, Konventionalität, Komposition, Machart (gemacht), Musikalität, Originalität, Perspektive, Rhythmus, Sound, Sprache, Struktur, Ton. Wortbildungsprodukte, die das Suchwort enthalten, wurden ebenfalls berücksichtigt (z. B. Form, formal, Formprinzip etc.). 
Die Suchergebnisse wurden bereinigt, das heißt, es wurden nur relevante Suchergebnisse berücksichtigt. Nicht beachtet wurden dagegen Suchergebnisse, in denen das Suchwort eindeutig nicht formal-ästhetisch wertend verwendet wurde, wie etwa, wenn „Figur“ nicht für die literarische Figur, sondern für die Körperform eines Menschen verwendet wurde. Da in den Diskussionen nicht Werte formuliert, sondern komplexere argumentative Wertungen entwickelt werden, stehen die Suchwörter in einem argumentativen Kontext, der weitere formal-ästhetische Wertaussagen enthält. Einzelne Suchwörter führten also zu relevanten Diskussionsabschnitten. Zwar kann nicht der Anspruch erhoben werden, dass mittels der verwendeten Suchwörter alle relevanten Korpusstellen identifiziert wurden, die sich auf die formale Gestaltung der besprochenen Texte beziehen, aber indem die jeweiligen Kontexte einbezogen wurden, wurden verschiedene Konstellationen weitreichend abgedeckt. Eine letzte, vollständige Korpuslektüre, die nach Fertigstellen der Analyse vorgenommen wurde, hat bestätigt, dass die Äußerungen der Juroren über formale und sprachliche Phänomene sowohl in ihrer Bandbreite als auch in ihrer Häufigkeit angemessen berücksichtigt wurden.

Das Vorgehen der Jury in den Jurydiskussionen ist vorwiegend an Texteigenschaften orientiert. Seltener werden Wertmaßstäbe explizit benannt; in vielen Fällen lassen sie sich allerdings rekonstruieren. In einem zweiten Schritt wurden die zusammengetragenen Textstellen daher kategorisiert. In jedem einzelnen Fall wurde versucht zu entscheiden, welcher Wertmaßstab oder welche Wertmaßstäbe hinter einer Aussage stehen. Um den Kategorisierungsprozess nachvollziehbar zu machen, möchte ich ein Beispiel geben:

Das zeigt der eigentlich relativ einfach. Und ich finde, die Struktur ist gar nicht so undurchschaubar in der doppelten Bewegung von Landschaft und Personage. (1999 Erat, 19:42 Hettche)

Das Zitat steht im Kontext einer Diskussion, in der mehrfach moniert wurde, dass die Struktur des Textes - ein Auszug aus einem längeren Text - nicht verständlich sei. Das Suchwort, das zu der Textstelle geführt hat, ist „Struktur“. Kategorisiert wurde diese Diskussionsstelle als Verweis auf den Maßstab Verständlichkeit. Die entscheidenden Hinweise für die Einordnung gaben die Formulierung Hettches, dass der Text das „eigentlich relativ einfach“ zeige und dass „die Struktur gar nicht so undurchschaubar“ sei. Es fällt an Hettches Beitrag auch auf, wie schwer trennbar inhaltliche und formale Argumente sind. Mit dem Wort „Struktur“ macht der Juror klar, dass er seine Aussage als eine Aussage über die Konstruktion des Textes verstanden wissen will. „Struktur“ ist wie „Form“ ein Begriff, der standardmäßig auf die Gestaltungsebene verweist. Während „Form“ eher auf „gestaltenden Umgang mit dem sprachlichen und/oder thematischen Material“ (Schild- 
knecht 1997, 612) bezogen ist und damit mehr die Rolle des Autors als Gestalter betont, rückt der Begriff der „Struktur“ als eine „systematisch rekonstruierbare Ordnung“ (Titzmann 2003, 532) den Text in den Mittelpunkt, dessen „Bau“ vom Rezipienten freigelegt werden kann. Der Autor rückt in den Hintergrund. Gemeinsam ist den Begriffen die Annahme einer Ordnung, die im Text erkennbar ist. ${ }^{39}$ Die in dem Zitat folgende Erklärung, die erläutern soll, um welche Art von Struktur es Hettche geht, nämlich die „doppelte[] Bewegung von Landschaft und Personage“, kann ebenso gut als Beschreibung des Inhalts wie auch als Beschreibung eines Konstruktionsmechanismus gelten. In diesem und ähnlichen Fällen wurde der Juror beim Wort genommen. Was von einem Jurymitglied als Gestaltungselement (Struktur, Form, Machart) eines Textes dargestellt wird, wurde auch in der Analyse als solches behandelt.

Die Wertmaßstäbe, auf die Wertungen sich beziehen, sind nicht immer eindeutig und auch nicht immer klar voneinander abzugrenzen. Mitunter bilden Wertmaßstäbe ein Beziehungsgeflecht. Ein einzelner attributiver Wert kann zu mehreren Maßstäben in Beziehung stehen. Diese Mehrdeutigkeit wurde in der Analyse nicht zugunsten einer eindeutigen Zuordnung reduziert, sondern nach Möglichkeit mit Blick auf diese Mehrdeutigkeit analysiert. Formal-ästhetische Werteigenschaften werden von den Juroren genutzt, um Wertmaßstäbe ganz verschiedener Art zu begründen. Aufgrund des argumentativ hohen Ansehens formal-ästhetischer Werte, der auf dem Eindruck der Nachweisbarkeit beruht, kommt es zu sehr heterogenen Wertungen, in denen beispielsweise ein moralischer Wertmaßstab angelegt wird, dieser aber durch formale Eigenschaften des Textes begründet wird. Solche Textstellen wurden ebenfalls berücksichtigt, denn sie geben Aufschluss darüber, wann und wie der Machart der Texte Aufmerksamkeit durch die Juroren zukommt. Wenn es darum geht, die Frage zu beantworten, welche Rolle Eigenschaften des Textes für die Bewertung und in der Bewertung spielen, dann muss zunächst einmal jede Äußerung zur Machart berücksichtigt werden.

\subsection{Die verdeckte Ordnung: Textwirkungen im Spiegel formal-ästhe- tischer Werte}

Das zentrale Ergebnis der Analysen ist, dass die Juroren in ihren Wertungen verbal an einen konventionalisierten Code der wertenden Textarbeit, wie sie auch in der Literaturwissenschaft zu finden ist, anknüpfen, dass die konkrete Wahl von Wertmaßstäben zur

\footnotetext{
39 Man muss allerdings davon ausgehen, dass die Juroren die Begriffe „Form“ und „Struktur“ nicht trennscharf verwenden. Sie wurden daher in den Analysen als synonym betrachtet.
} 
Begründung einer Einschätzung aber letztlich auf die Wirkung des Textes bei der Rezeption zurückzuführen ist. Die Wurzel formal-ästhetischer Argumentationen ist also nicht unmittelbar in festen Eigenschaften des Textes zu suchen, sondern in dem Vermögen des Textes, mittels seiner Gestaltung ein Leseerlebnis zu ermöglichen. Statt um festumrissene Eigenschaften geht es um Strategien, die es ermöglichen, den Leser zu interessieren, Spannung zu erzeugen und ihn emotional zu involvieren. Die Wechselwirkung zwischen leserseitigen (top down) und textseitigen (bottom up) Faktoren, die aus der Leseforschung als Grundlage von Verstehensprozessen bekannt ist, ist auch in der Bewertung von Texten anzunehmen. Formal-ästhetische Werteigenschaften eines Textes spielen also erstens eine Rolle, weil sie einen Code bereitstellen, mit dem Begründungen für Werte gegeben werden können. Es wird damit einem Bedürfnis Rechnung getragen, dass jede Wertung durch intersubjektiv nachvollziehbare Eigenschaften des Gegenstands begründet wird. Darüber hinaus haben formal-ästhetische Wertungen eine vergleichbare Funktion für Wirkungen, die der Leser während der Lektüre hat: Sie machen die Ursachen einer Wirkung beschreibbar. Die Juroren gehen also vielfach von der - oft nicht verbalisierten - Frage aus, durch welche Mittel ein Text die Wirkung erzielen konnte, die er auf ihn bei der Lektüre hatte. Es ist davon auszugehen, dass dieser Zusammenhang zwischen der Wirkung und den Ursachen, die dafür gefunden (und anschließend in der erlernten Wertungssprache formuliert) werden, in keinem willkürlichen Zusammenhang stehen. Es kommt also zu einer Überlagerung von Beschreibung der Wirkungsursachen und einer anerkannten, konventionalisierten Wertungssprache, durch die Texteigenschaften beschreibbar werden.

Die Ergebnisse der Arbeit werden aufgrund dieses Zusammenhangs mit Blick auf die ihnen übergeordneten Wirkungswerte präsentiert, denn diese haben sich als entscheidend für den eigentlichen Verlauf der Wertungsbegründung erwiesen. Die beiden übergeordneten Wirkungswerte sind Orientierung und Aktvierung. Beide beziehen sich auf die Wirkungen, die die Juroren in Verbindung mit formal-ästhetischen Werten formulieren und die, so die Annahme, die hier gemacht wird, der spezifischen formal-ästhetischen Bewertung vorausgeht.

Hinzu kommt ein einzelner Wertmaßstab, der häufig verwendet wird, und sich weniger stark aus der Wirkung speist, sondern stärker durch kommunikative Funktionen (Prestige) geprägt ist.

Der Wertekomplex Orientierung umfasst alle Werte, die Ausdruck dafür sind, dass die Juroren sich im Text orientiert fühlen. Jeder Text stellt sich dabei als ein Puzzle dar, das der Leser zusammenzusetzen hat. Im Idealfall gelingt es ihm dabei, das Motiv des Puzzles 
zu erkennen (Kohärenzbildung) oder Regeln dafür zu erkennen, wie bestimmte Puzzleteile eingesetzt werden müssen, um das Motiv zu vervollständigen (Gestaltetheit). Der Wirkungseffekt einer gelingenden Textrekonstruktion auf inhaltlicher und formaler Ebene ist nach Belke/Leder (2006) mit Selbstbestätigung verbunden, die wiederum ästhetische Lust hervorrufen kann (vgl. dazu auch Kapitel 10.1).

Der Wertekomplex Aktivierung fasst Werte zusammen, die sich auf den Wunsch der Juroren beziehen, eine aktive Interaktion mit dem Text einzugehen. Darunter fallen Phänomene wie Betroffenheit, Anschaulichkeit, Lebendigkeit und vor allem Offenheit. Es wird gefordert, dass der Text einen Erlebnischarakter hat, der offenbar nur entstehen kann, wenn der Leser geistig gefordert und emotional angesprochen wird.

Der Wert Originalität nimmt eine Sonderrolle ein. Während die ersten beiden Wertekomplexe für die grundsätzliche Einordnung eines Textes auf der bipolaren Skala positivnegativ entscheidend sind, wird Originalität häufig eingesetzt, um Bewertungen mehr Gewicht zu verleihen und somit graduell abzustufen, aber auch, um den Juror als Kenner auszuweisen. Möglicherweise ist Originalität ein entscheidender Maßstab bei der Auswahl von Texten für den Wettbewerb, die auf der Entscheidung einzelner Juroren im Vorfeld des Wettbewerbs beruht. Zwar hat der Wert in den Diskussionen keine entscheidende Funktion für die Urteilsfindung, er hat aber dennoch ein hohes kommunikatives Prestige (vgl. insbesondere Kaptitel 19 „Detailanalyse Andrea Winkler“) und wird daher vielfach eingesetzt, um die positive oder negative Tendenz eines Urteils zu unterstreichen. Der Maßstab Originalität erlaubt zum einen, einen Text graduell auf- oder abzuwerten; vor allem erlaubt er aber, zu zeigen, dass der Juror die literarische Kenntnis besitzt, einen Text auf der Originalitätsskala einzuordnen. Somit ist der Wert Originalität ein starker Ausdruck des Knowing-How (vgl. Kapitel 4) der Juroren. 


\section{Orientierung}

\subsection{Orientierung als Textwirkung}

Die Juroren des Ingeborg-Bachmann-Wettbewerbs wissen es zu schätzen, wenn sie durch intensives und aufmerksames Lesen eines Textes erkennen können, auf welche Weise die Gestaltungselemente dieses Textes aufeinander bezogen sind und in welcher Absicht sie in genau dieser Weise verknüpft wurden. Sie gehen dabei davon aus, dass Gestaltungselemente bewusst gewählt werden, das heißt, dass sie nicht zufällig vorkommen. Sie gehen außerdem davon aus, dass jedes Gestaltungselement in einer bestimmten Absicht eingesetzt wurde. Beide Annahmen - die der Gestaltetheit und die der Intentionalität - stehen in einem engen Zusammenhang und lassen sich auch in der Argumentation selten scharf voneinander trennen.

Innerhalb dieser Arbeit soll Orientierung als ein übergeordneter Begriff für eine Reihe von Phänomenen verwendet werden, denen gemeinsam ist, dass der Text als absichtsvoll geformtes Gebilde wahrgenommen wird, dessen Bestandteile sowohl auf inhaltlicher als auch auf formaler Ebene so gewählt sind, dass sie sich kohärent in den Text einfügen. In der Wertesprache der Literaturwissenschaft - und teilweise auch der Juroren - gehören dazu Werte wie Stimmigkeit, Angemessenheit und Einheitlichkeit, die hier dem Maßstab Kohärenz (Kapitel 10.2) untergeordnet werden, aber auch dezidiert auf die formale und sprachliche Gestaltung ausgerichtete Werte wie Gestaltetheit, Präzision und Dichte, die im Kapitel „Sprache und Form“ (10.3) näher beleuchtet werden. Orientierung wird dabei als eine Wirkung, betrachtet, die der Leser empfindet, wenn er einen Text als absichtsvoll gestaltet wahrnimmt, und in seiner Bewertung in den Code der literaturkritischen Bewertung umsetzt. Es wird also davon ausgegangen und lässt sich auch an vielen Wertungen zeigen, dass am Anfang der Wertung die Wahrnehmung steht, das Textpuzzle weitreichend lösen (oder auch nicht lösen) zu können. Diese Wahrnehmung der Orientiertheit ist von Lust begleitet und wird anschließend in den konventionalisierten Code der Textbewertung „übersetzt".

\subsection{Kohärenz}

Viele der Phänomene, die sich dem Wirkungswert Orientierung unterordnen lassen, stehen dem nahe, was Heydebrand/Winko (1996, 112 ff.) unter dem Wert der Stimmigkeit, insbesondere in der Lesart „Kohärenz“ fassen: 
Strukturalistisch bezeichnet „Stimmigkeit“ rein formal das Aufeinanderbezogensein der verschiedenen Ebenen literarischer Texte, während der Begriff in hermeneutischen Arbeiten meist als „Kohärenz" verstanden und auf die harmonische Übereinstimmung der Elemente eines literarischen Textes bezogen wird. Eines der wichtigsten Postulate, das „Stimmigkeit“ in dieser zweiten Lesart konkretisiert, ist die Forderung nach Übereinstimmung von Gehalt und Gestalt. In dieser Interpretation korrespondiert „Stimmigkeit“ mit „Geschlossenheit" in der konkreteren Begriffsvariante. (Heydebrand/Winko 1996, 117)

In der Tat hat es sich als fruchtbar erwiesen, den hermeneutischen Wert der Stimmigkeit in der Explikation von Heydebrand/Winko als Leitidee für die Werte aus dem Komplex Orientierung zu nutzen. Statt der hermeneutischen wird allerdings eine textlinguistische, leserpsychologische Ausprägung von Kohärenz aufgegriffen, denn gerade der Blick auf die Wechselbeziehung zwischen dem Text mit seinen angelegten Strukturen und den Erwartungen des Lesers, den diese Teildisziplinen ermöglichen, lässt plausibel werden, warum Orientierung ein starker Wert ist. Die Wirkungskomponente des Wertes Kohärenz kann so besser erfasst werden. Der aus der Hermeneutik stammende Begriff der Stimmigkeit, den auch die Juroren verwenden, wird als Teil des literaturkritischen Codes betrachtet. Mit dem Wertbegriff der Stimmigkeit verbindet sich eine gewisse Emphase. Sie wird als Kunstmittel, als literarisches Können des Autors aufgefasst. Es geht daher nicht so sehr um die Herstellung von Textkohärenz und -kohäsion, wie sie die Textlinguistik (vgl. z. B. de Beaugrande/Dressler 1981) kennt, sondern vielmehr um ein kunstfertiges Verknüpfen, das zu einem semantischen Mehrwert führt. Die Diskussionen zeigen allerdings, dass es ganz wesentlich um das Verstehen des Textes geht, und zwar nicht nur auf einer übergeordneten Sinnebene, sondern auf der Textebene (vgl. 10.2.1). ${ }^{40}$ Ob die Elemente eines Textes zueinander passen, ist eine Frage, die mit dem Verstehen des Textes und Annahmen über seine Intention bzw. seine Gesamtaussage zusammenhängt. Dass insbesondere die vermutete Textintention ganz entscheidend für den Eindruck von Kohärenz ist, kann man auch an den Diskussionen nachvollziehen. Gehandhabt werden die Kohärenz-Werte von den Juroren oft im emphatischen Sinne - als Kunstfertigkeit. An der Oberfläche suggerieren Wertungen mit Bezug auf den Maßstab Kohärenz häufig, es ginge um den Einsatz kunstfertiger formaler Mittel. Erst bei einer genauen Analyse offenbart sich, dass hinter diesen formal-ästhetischen Wertungen ein Interesse steht, den Text umfassend in seiner Gestaltung nachzuvollziehen, ihn in diesem Sinne zu verstehen (Orientierung). Das Phänomen lässt sich besser nachvollziehen, wenn man Erkenntnisse darüber heranzieht, wie

40 Die Textsinnebene, also die Interpretationsebene, spielt durchaus auch eine Rolle. Sie ist allerdings häufig durch inhaltsbezogene Äußerungen geprägt und findet daher innerhalb dieser Arbeit wenig Beachtung. Eine Rolle spielt die Textsinnebene dann, wenn es um verschiedene Auslegungsmöglichkeiten, das heißt um die Werte Mehrdeutigkeit und Offenheit geht (vgl. Kapitel 11). 
Texte - ganz gleich welcher Art - gelesen werden. Die Textlinguistik und auch die kognitive Leseforschung gehen davon aus, dass Leser immer bestrebt sind, Texte als ein kohärentes Ganzes zu erfassen. Die Suche nach Bedeutung eint, so Jannidis et al. (2003, 13), auch den Normalleser und den professionellen Leser. Insgesamt steuert die Suche nach einer stimmigen und schlüssigen Bedeutung den Rezeptionsprozess. So gehen Christmann und Schreier $(2003,246)$ etwa davon aus, dass sich der Lesevorgang beim Erfassen literarischer Texte nicht grundsätzlich vom Lesen pragmatischer Texte unterscheidet. Der Leser verarbeitet im Lesevorgang Impulse des Textes und ist bemüht, diese Impulse in seinem Kopf zu einem kohärenten, einem nachvollziehbaren Ganzen zusammenzufügen. Fix (2003, 80 f.) spricht in diesem Zusammenhang vom „Text auf dem Papier“, der die Grundlage für den Leseprozess bildet und für jeden Leser identisch ist, und vom „Text im Kopf“, der Vorstellung, die der Leser in seinem Kopf vom Gelesenen hat, seine - im Idealfall in Hinblick auf die Verständlichkeit erfolgreiche - Rekonstruktion des Textes. Für literarische Texte geht Oatley (1994) sogar davon aus, dass das Textgeschehen als eine Art Simulation vor dem inneren Auge des Lesers abläuft. Jörg Schneider (1999) hat gezeigt, wie mentale Modelle für literarische Figuren die Rezeption strukturieren. Um diese Rekonstruktion möglich zu machen, setzt der Leser verschiedene Wissensbestände ein (vgl. Christmann/Schreier 2003; Fix 2003). Die Motivation für den geistigen Aufwand, „Schlussfolgerungen während des Lesens“ (Christmann/Schreier 2003, 256) zu ziehen, sehen die Autorinnen (ebd.) (in Anlehnung an Graesser et al.) in „d[em] Rezeptionsziel, d[em] Bemühen auf lokaler und globaler Ebene, Kohärenz herzustellen, sowie de[m] Versuch, Erklärungen für die im Text erwähnten Handlungen, Ereignisse und Zustände zu finden“. Sie fügen hinzu, dass der Leser auch ein Bedürfnis hat, das Gelesene zu bewerten (ebd.). Obwohl der Leser zum Herstellen von Kohärenz, gerade in literarischen Texten wie Christmann/Schreier (2003, 277) meinen, auf viele Wissensbestände außerhalb des Textes zurückgreift, „[gelingt] die Bedeutungskonstitution umso besser [...], je klarer und deutlicher der Text Hinweise gibt, wie Sätze und Textteile aufeinander zu beziehen sind“ (Christmann/Schreier 2003, 254). Damit nicht genug: Die Autorinnen weisen darauf hin, dass fehlende Kohärenz auf der Makroebene (Textebene) sich verlangsamend auf den Leseprozess auswirkt, u. z. stärker als fehlende Kohärenz auf der Mikroebene (Wort- und Satzebene) (Christmann/Schreier 2003, 253). Für den Leser ist es also bedeutender, das Thema oder die Aussage eines Textes zu verstehen, als die Bedeutung einzelner Sätze oder Wörter zu erfassen. Für literarische Texte gehen die Autorinnen davon aus, dass sie polyvalent sind und auch polyvalent rezipiert werden, dass sie also mehr als eine Bedeutung zulassen. Allerdings: 
Was speziell die Geltung der Polyvalenzkonvention betrifft, so konnte Ibsch im Rahmen einer Explorationsstudie [... ] zeigen, dass die Leser/innen einerseits dazu tendieren, für jeden der Texte im Sinne der Normalisierungshypothese [ein Leser realisiert nicht alle möglichen Bedeutungsvarianten, sondern solche, die im Rahmen seiner Erwartungen etc. relevant sind $\mathrm{KR}$ ] eine in sich stimmige monovalente Bedeutung zu konstituieren; zugleich sind sie aber durchaus bereit, auch andere valide zu akzeptieren. (Christmann/Schreier 2003, 272)

Für den Leser steht folglich nicht im Vordergrund, das gesamte Potential des Textes zu erfassen, sondern viel mehr, eine für sich befriedigende Bedeutungsvariante, eine „stimmige, monovalente Bedeutung“ zu konstituieren. All das weist darauf hin, dass, unabhängig vom Texttyp, die Bedeutungskonstitution für den Leser ein zentrales Anliegen beim Verarbeiten eines Textes darstellt. Der Text bietet für diese Bedeutungsfindung, da sind sich Christmann/Schreier und Fix einig, eine wichtige Grundlage. Dass der Leser gerade in literarischen Texten auch andere Wissensbestände in den Deutungsprozess mit einbezieht, kann ebenso vorausgesetzt werden. Christmann/Schreier $(2003,277)$ folgern, dass gerade beim Lesen literarischer Texte solche Wissensbestände eine immense Rolle spielen. Dazu gehört, das sei hinzugefügt, auch spezielles Wissen darüber, wie Literatur funktioniert: Kenntnisse darüber, was bestimmte Gattungen (z. B. Novelle, Schelmenroman, Short Story) typischerweise auszeichnet, Wissen über Epochen der Literatur und epochentypische Texte, Annahmen darüber, dass Literatur sich gemeinhin durch Fiktionalität auszeichnet (vgl. Schneider 2007, Gertken/Köppe 2009), die Vorannahme, dass literarische Texte in der Regel anders gelesen werden als Gebrauchstexte, und Strategien, mit denen Leser Texten begegnen können. Frühere Rezeptionserfahrungen helfen ihnen dabei, einen Zugang zu Texten zu finden.

Gerade im Kontext des Ingeborg-Bachmann-Wettbewerbs, in dem erfahrene professionelle Leser mit Texten umgehen, spielt Literaturwissen eine entscheidende Rolle. Immerhin hat ein großer Teil der Juroren ein Studium der Germanistik oder einer neueren Philologie abgeschlossen. ${ }^{41} \mathrm{Zu}$ diesem Literaturwissen gehört aber auch die Annahme, dass literarische Texte besonders sorgfältig gestaltet sind. Wer an Schule oder Universität lernt, mit literarischen Texten umzugehen, erlernt automatisch die meistens unhinterfragte, als selbstverständlich vorausgesetzte Grundannahme, dass es in literarischen Texten keinen Zufall gibt. Man kann also von einem erweiterten Kohärenzverständnis ausgehen: Von professionellen Lesern wird der literarische Text sehr genau daraufhin „überprüft“, ob er dem erweiterten Kohärenzverständnis standhält. Oder anders gesagt: Die große Lesererfahrung professioneller Leser führt dazu, dass sie schon beim Lesen empfindlich auf Inkohären-

$\overline{41}$ Von 32 Juroren, die im untersuchten Zeitraum in der Jury saßen, haben nur 4 kein philologisches Studium absolviert. 
zen, aber auch auf subtile Methoden, Zusammenhänge herzustellen, reagieren und diese auch in die Bewertung einbeziehen. Bewertungen der „erweiterten“ Kohärenz finden sich in den Diskussionen unter dem Label „Stimmigkeit“, aber auch als „Angemessenheit“, „Einheitlichkeit“, „Gestaltetheit“, „Präzision“ und „Dichte“. Es liegt also nahe, Werte des Komplexes Orientierung in Analogie zur textlinguistischen Kohärenz immer auch unter dem Aspekt eines gelungenen oder misslungenen Textverständnisses zu sehen. Dabei muss man im Blick behalten, dass die Erwartungen an die Verstehensangebote eines literarischen Textes andere sind als in einem pragmatischen Text. Eine solche Sicht ermöglicht auch eine pragmatischere Bestimmung dessen, was Wertbegriffe wie Stimmigkeit, Einheitlichkeit und Dichte immer als eine Komponente beinhalten, nämlich, dass Leser in der Lage sind, im Leseprozess Textelemente aufeinander zu beziehen und in Hinblick auf ein globales Textverständnis hin zu deuten. Konkret finden sich für den Wert Kohärenz unterschiedlichste Formulierungen. Mal ist von „Funktion“ von Textelementen die Rede, mal geht es um „Angemessenheit“ (z. B. 2004 Münzner, 00:15 März). Genauso gut kann es heißen, dass der Text „konsequent“ (z. B. 2003 de Vries, 11:18 Steinfeld) sei, dass Form und Inhalt „kongruent“ (z. B. 2004 Tellkamp, 10:09 Strigl) seien, dass ein Stil „nicht passt“ (z. B. 2004 Hahn, 00:25 Detering), oder aber, dass ein Text nicht verstanden worden sei. Es waren diese und ähnliche Ausdrücke, die während der Analyse des Korpus die Aufmerksamkeit darauf gelenkt haben, dass im Hintergrund vieler Bewertungen, in denen Kriterien wie Stimmigkeit, Angemessenheit oder Einheitlichkeit eingesetzt werden, möglicherweise eine viel grundlegendere Textwahrnehmung eine Rolle spielt, nämlich die der Orientierung. Ein formbezogener Wert ist Kohärenz, weil die Juroren die Ursache ihrer Reaktion auf den Text, das heißt Orientierung und Desorientierung, immer durch die Form des Textes begründen. Das Korpus weist große Mengen von Passagen auf, die sich auf die Machart des Textes beziehen und in deren Hintergrund letztendlich die Einschätzung steht, ob der Text verstanden wurde oder nicht. Denn, wie Fix beobachtet, ist das Verständnis eines Textes (im Sinne von Kohärenz) an den Text rückgebunden: „Für jeden dieser ,Texte im Kopf' müssen dieselben Zeichen, dieselben Formulierungen, muss dieselbe Materialität den Anstoß, die ,Rechtfertigung، für das jeweiligen Verstehen gegeben haben“ (Fix 2003, 80 f.). Für literarische Texte gilt allerdings, das soll an dieser Stelle noch einmal hervorgehoben werden, eine erweiterte Aufmerksamkeit für seine Form, seine Machart, die über das Textverstehen eines pragmatischen Textes hinausgeht. In der ganz besonderen Situation des Wettbewerbs wird vorausgesetzt, dass ein Autor einen Text intentional und auf allen Ebenen kohärent gestaltet. Gleichzeitig geht die Bewertung immer vom wahrgenommenen 
Leseeindruck aus. Das heißt, ein Textverständnis ist stets das Verständnis, das sich dem Juror als Leser im Verlauf seiner Lektüre erschließt, und dieses Verständnis wird immer als ein bewusst vom Autor angelegtes Verständnis angesehen. Die Wettbewerbssituation lässt nicht zu und hat auch nicht die Absicht, aufzudecken, welche Deutungspotentiale oder welche Bedeutungsgenese ein Text hat.

Befriedigendes Lesen, das haben empirische Studien außerdem belegt (vgl. Hoffstaedter 1984, Nell 1988, Pette 2001, Graf 2004), ist ein Lesen, das dem Leser erlaubt, den Text bei einiger Aufmerksamkeit mühelos zu erfassen. Zyngier et al. (2007) haben in einer Studie mit Studenten einen engen Zusammenhang zwischen Foregrounding (im Sinne sprachlicher Abweichung, siehe unten), Komplexität und Wertschätzung beobachtet. Höhere Komplexität führt demnach zu einer intensiveren Auseinandersetzung mit dem Text, die, wenn sie erfolgreich verläuft, positiv empfunden wird und in einer höheren Wertschätzung des Textes resultiert:

Such "extra meaning" could also have effects on the ways in which readers appreciate texts: since extra effort is involved in processing the extra structure, readers may either drop the reading or invest extra effort, resulting in a higher evaluation of the text and the feeling of reward. (Zyngier et al. 2007, 663)

Genau diese Konstellation konnte allerdings nur für eine Gruppe der Testpersonen, die niederländischen Studenten, bestätigt werden. Die brasilianischen und ägyptischen Studenten wichen vor allem in ihrer Bewertung ab, indem sie den komplexesten Text, eine Passage aus Virginia Woolfs „Mrs. Dalloway“, als ermüdend, langweilig und sinnlos einstuften, obwohl sie die Komplexität und Tiefe des Textes erkannten (ebd., 672 und 673). Zyngier et al. (2007, 674 ff.) erklären diese unterschiedlichen Einschätzungen durch unterschiedliche Lesesozialisationen. Die Bachmann-Preis-Diskussionen haben den engen Zusammenhang zwischen Selbstbestätigung (reward) beim „Ordnen“ komplexerer Texte und positiver Bewertung bestätigt. Sie haben aber auch gezeigt, dass der positiven Relation zwischen Komplexität und Bewertung Grenzen gesetzt sind, nämlich genau dort, wo eine Grenze der Effizienz erreicht wird, das heißt, wo der geistige Aufwand, um den Text zu „ordnen“ als abschreckend empfunden und der Text daher abgelehnt wird.

Das Konzept des Foregrounding erweist sich als äußerst hilfreich, um zu erfassen, wie die Juroren mit Bezug auf die Wirkung der Orientierung werten. Nach van Holt/Groeben (2005, 325) lässt sich Foregrounding auch als „Figur-Grund-Konzeption“ verstehen, die sowohl inhaltlich als auch auf sprachlich-formaler Ebene zum Lese- und Textverstehen beiträgt. Sprachlich-formal besteht Foregrounding darin, dass bestimmte Merkmale des Textes als speziell (abweichend, verfremdet) bewusst vom Leser registriert werden. Auf 
inhaltlicher Ebene (nach van Holt/Groeben „pragmatisches Foregrounding“) bezieht sich Foregrounding auf „Fokussierungsprozesse auf basalen Verstehensebenen“ (ebd., 316) und konkreter auf „eine[] Fokussierung von Hauptperson(en) und zentrale[n] Handlungsstrang“ (ebd., 329). Versteht man Foregrounding also allgemeiner als Mechanismus der Aufmerksamkeitslenkung, verweist es auf alle Elemente von Texten, die dem Leser während der Lektüre bewusst als „gemacht“, als „eingesetzt“ vor Augen treten.

Für den Leser und Kritiker von literarischen Texten heißt das, dass das Erfassen von Formmerkmalen und die Herstellung passender Bezüge zum Inhalt zu den grundlegendsten Prozessen der Textverarbeitung und -bewertung gehören. Verstehen (im Sinne von Ordnen und Nachvollziehen der sprachlichen und inhaltlichen Textinformationen) wird, wie verschiedene Studien gezeigt haben, außerdem durch das Empfinden von Lust kognitiv belohnt. Daher verwundert es nicht, dass die Auseinandersetzung mit den von den Juroren hergestellten Bedeutungszusammenhängen quantitativ wie qualitativ eine wichtige Rolle spielt und dass viele Diskussionen Hinweise auf das Lustempfinden beim Verstehen geben. Das Konzept des sprachlichen Foregrounding ist hilfreich, um die höchst unterschiedlichen literarischen Mittel zu erfassen, die von den Juroren als formale Gestaltungsmittel angeführt werden. Es sind nicht konkrete formale Eigenschaften von Texten, die per se zu einer positiven Bewertung führen, sondern es sind solche Eigenschaften, die erstens bemerkt werden und zweitens als Teil des Textpuzzles nachvollzogen werden können.

Eine Ausnahme bilden Texte, deren formale Gestaltung so deutlich hervortritt, dass sie den Text vorhersehbar macht (vgl. Kapitel 10.3.1) Überdeterminiertheit). Neben das Bedürfnis nach Verstehen tritt dann das Bedürfnis nach Aufmerksamkeitsbindung, das die gelungene Rekonstruktion einer intentionalen Form bisweilen in den Hintergrund stellen kann (vgl. Kapitel 11.2.3).

\subsubsection{Explizite Formulierungen des Wunsches nach Verstehen}

Dass ein Grundverständnis der Handlung und des Themas der beim Bachmann-Wettbewerb vorgelesenen Texte von enormer Bedeutung ist, zeigt bereits die Menge und Länge an Äußerungen, die allein darauf gerichtet sind, den Text inhaltlich als Diskussionsgegenstand zu etablieren (vgl. Kapitel 5). In der Diskussion zu Ruth Erat (1999) bietet Dieter Bachmann (0:43) seinen Jurykollegen, die ihre Ratlosigkeit gegenüber dem Text signalisiert haben, zunächst eine detaillierte Nacherzählung des Plots an. Er wird im Verlauf seiner Nacherzählung allerdings von Ulrike Längle unterbrochen:

Herr Bachmann, Sie meinen es sicher gut, aber das finde ich ja absurd, wenn dann ein 
Juror den Roman der Autorin, die gelesen hat, noch mal erzählt und erklärt, wer wer ist. Also ich finde, es muss schon der Text für sich selber sprechen. (1999 Erat, 4:15 Längle)

Bachmanns Impuls, den Text durch eine Nacherzählung zugänglicher zu machen, illustriert das Bedürfnis nach Kohärenz ebenso wie Längles Hinweis, der Text müsse für sich selber sprechen. Sehr deutlich wird das in Längles Hinweis, dass es nicht darum geht, sich einen Text im Nachhinein durch Analysen zugänglich zu machen, sondern dass es durchaus von hoher Bedeutung ist, dass ein Zugang unmittelbar, das heißt schon während des Lesens, möglich ist.

Der eindeutigste Hinweis darauf, dass Verständlichkeit, insbesondere in ihrer erweiterten Bedeutung (Verständlichkeit auf der Formebene), ein starker Wert ist, ist jedoch die explizite Formulierung, dass der Text (nicht) verständlich sei. In vielen Beiträgen wird dieser Wunsch, den Text zu verstehen, ganz explizit formuliert; so etwa auch von Ijoma Mangold:

[Ich] mache hier bei dem Wettbewerb immer die Erfahrung, [...] dass mir erst im Hören so der Sound, der Stil einleuchtet. Als ich es gelesen habe, fand ich den Text/ hat der Text mir sprachlich nicht gefallen. Jetzt in diesem Vortrag habe ich, glaube ich, so seine innere Rhythmik und auch sein Strömen verstanden. Und das hat mir sehr gut gefallen. Ich verstehe auch die Komik/ Also ich sehe auch die Komik. Ich verstehe aber überhaupt nicht, welche Funktion diese Komik einnimmt. Und ich habe so ein bisschen den Verdacht, dass bei mir die Grenze, ab der ich etwas ästhetisch goutiere, dass da bei mir ein höherer Grad des Verstehens Voraussetzung sein muss. (2007 Becker, 6:42 Mangold; Hervorhebungen KR)

Hier springt direkt ins Auge, dass Gefallensurteile, die auf die Lektürewirkung zurückgehen und die sogar direkt als Gefallensurteile gekennzeichnet sind, mit der Frage des Verstehens parallelgeschaltet werden. Beim stillen Lesen hat der Text Mangold „nicht gefallen“, dagegen hat er ihm „jetzt in diesem Vortrag [...] sehr gut gefallen“. Mangolds Urteil über den Text ändert sich in dem Maß, wie er ihm „einleuchtet“. Indem er darauf hinweist, erst im Hören habe ihm der Sound, der Stil eingeleuchtet, ${ }^{42}$ gibt er auch zu erkennen, dass die unmittelbare sinnliche Wirkung des Vortrags einen Einfluss darauf hat, wie er den Text beurteilt. Mangold ordnet das „Verstehen“ sogar explizit als ästhetisches Phänomen ein (,ästhetisch goutierbar“). Mit der Vorstellung, dass im Text eingesetzte Mittel eine Funktion haben („welche Funktion diese Komik einnimmt“), verwendet Mangold außerdem eine weitere typische Formulierung für Verstehenswertungen. Das Zitat illustriert auf anschauliche Weise die komplexe Überlagerung von Wirkungswerten und Bezugnahme auf die Nachvollziehbarkeit des Textes.

$\overline{42}$ In diesem Zitat lässt sich auch ablesen, dass, wie in Kapitel 9.1 angesprochen, „Stil“ häufig in Formulierungen verpackt wird, die auf die klangliche Qualität hinweisen (Sound, Klang, Ton). 
Das Schlagwort „Funktion“, das Mangold verwendet, benutzt u. a. auch Daniela Strigl in einem ihrer Beiträge von 2003 mit explizitem Hinweis auf das Verstehenwollen: „Aber ich habe auch kleinere Einwände. Also formal verstehe ich zum Beispiel die Funktion dieser Kohlmeyer-Geschichte nicht ganz" (2003 Schreuf, 0:05 Strigl; Hervorhebung KR). Ganz explizit wird hier auch ausformuliert, dass „Funktionen“ Teil der Form sind. Auch Ebel spricht von Logik und Konsequenz: „Also, das gefällt mir gut. Das ist sehr logisch, von großer Konsequenz. Dann umgesetzt in diese manische Sprache, die dem manischen Herumwandern in Wien entspricht" (2007 Stangl, 6:48 Ebel). Sehr deutlich tritt hier wiederum die Kopplung von positiver Gefallens-Bewertung („gefällt mir gut“), Nachvollziehbarkeit („das ist sehr logisch“) und der Wahrnehmung einer Stimmigkeit von Inhalt und Form/Sprache („manische Sprache“, „manisches Herumwandern“) hervor.

Für Daniela Strigl sollte ein Text Plausibilität haben: „Man kann es sich vorstellen, dass nichts in dem Zimmer passiert. Ich halte es nur nicht für plausibel, denn es wird ja auch vorher aufgebaut im Text" (2004 Helminger, 15:52 Strigl). Auch bei ihr zeigt sich, dass vom Text erwartet wird, dass er den Leser führt, um ein Verständnis zu ermöglichen. Eine Bedeutungskonstitution, die weitreichende Ergänzungen des Lesers voraussetzt, wird von Strigl zwar als Option erwähnt, jedoch als unbefriedigend zurückgewiesen. In eine ähnliche Richtung geht auch Birgit Vanderbeke, wenn sie darauf hinweist, dass sie „nicht sicher [ist], ob es gut gemacht ist, weil es ist in gewisser Weise ungeheuer willkürlich gemacht“ (2001 Laher, 14:01 Vanderbeke). Willkürlichkeit und Gelungensein schließen sich in dieser Wertung gegenseitig aus. Vanderbeke (ebd.) fasst zusammen, dass sie den Assoziationen dann schon nachgehen können müsse. Letztlich ist der Text für sie „eben nicht gut gemacht, wenn [sie] nicht weiß, wo es herkommt“ (ebd.). Dagegen meint Fliedl (15:00), Lahers (2001) Text „hat eben überhaupt keine Beliebigkeit“, indem er „diese Vorgänge [...] durch die Komposition dieser Sprache [bändigt]“. Sie sieht also die Sprache des Textes in einem klaren, verstehbaren und interpretierbaren Verhältnis zum Inhalt.

Heinrich Detering räumt Autor und Text einen großen Spielraum in der Textgestaltung ein, weist aber ebenfalls ausdrücklich darauf hin, dass der Text für den Leser plausibel sein muss:

Da müsste mit der Sprache was passieren in dem Text, dass die Sprache sich zersetzt, dass etwas passiert. Um einen großen Namen zu nennen hier, der, weiß Gott, nichts mit dem Islam zu tun hat: Gottfried Benn am Ende der „Gehirne“-Novelle, wo tatsächlich ein solcher Ich-Zerfall nicht nur beschrieben, in wohlgesetzten Worten beschrieben, wird, sondern im Gegenteil, wo die Sprache anfängt sich aufzulösen und mir zur sinnlichen Leseerfahrung wird, was da umschrieben werden soll. Das soll dann von mir aus gerne die Imagination einer europäischen Intellektuellen sein, die das eigentlich 
nicht kann, aber wenn sie es mir plausibel macht, dann ist das eben eine Phantasie, mit der ich weiterarbeiten kann. Aber die sehe ich hier nicht. (2004 Dieckmann, 3:58 Detering)

Auch in diesem Beitrag von Detering verbinden sich konventionelles Wertungswissen und Wirkungsansprüche an den Text in komplexer Weise. Detering geht zunächst von einem typischen Stimmigkeitsargument aus: die Sprache sollte dem Inhalt angemessen sein. Dieser konventionalisierte formal-ästhetische Wert wird unmittelbar mit einer Forderung an die Wirkung des Textes gekoppelt: Detering fordert, dass ihm über die Sprache eine „sinnliche Leseerfahrung“ zuteil werden sollte. Die Plausibilität, die im letzten Schritt gefordert wird, knüpft offenbar direkt an die Sinnlichkeit der Erfahrung an. Verknappt man die Aussage Deterings, könnte man die Argumentation so rekonstruieren: Der Text überzeugt nicht, weil die Sprache in keinem nachvollziehbaren Verhältnis zum Inhalt steht. Durch die mangelnde Aufbereitung der Sprache wird der Inhalt nicht sinnlich erfahrbar. Mangelnde sinnliche Erfahrung beim Lesen führt dazu, dass der Leser den Text nicht plausibel findet. Oder noch knapper: Plausibel ist ein Text dann, wenn sein Thema sinnlich erfahrbar wird.

Die zitierten Passagen und Formulierungen unterstreichen, dass die Juroren den Autor in der Pflicht sehen, mit sprachlichen und formalen Gestaltungsmitteln ein Verständnis des Textes zu ermöglichen. Dieses Verständnis soll plausibel sein, soll einleuchten, Gestaltungselemente sollen funktional sein. Gleichzeitig signalisieren die Aussagen, dass die Nachvollziehbarkeit der Form keine rein rationale Prüfgröße ist, sondern dass die Juroren das Verstehen während der Lektüre als Lust/Unlust erfahren. In sehr vielen der besprochenen Zitate wird eine deutliche Parallele zwischen 1. positiver/negativer Bewertung auf der Gefallensebene, 2. Nachvollziehbarkeit und Verständlichkeit sowie 3. der Abstimmung von Form/Sprache und Inhalt deutlich.

\subsubsection{Passungsverhältnisse - Stimmigkeit und Angemessenheit}

Von literarischen Texten wird eine Sprache und eine Form erwartet, die intensiver als in Alltagstexten gestaltet und dabei auf den Inhalt des Textes abgestimmt ist. Im Idealfall leistet die Form/Sprache einen eigenen Beitrag zur Aussage des Textes. Das ist ein verbreitetes Bild, das hier als Konvention vorausgesetzt werden soll und dass auch die Juroren vielfach aufgreifen. Inhalt und Form müssen zueinander passen, so kann man verkürzt formulieren. Es muss den Juroren irgendwie - in der Tat nur irgendwie - nachvollziehbar sein, warum in einem Text eine bestimmte Form und ein bestimmter sprachlicher Stil gewählt wurde. Verschiedene Bezugsgrößen werden für die Bewertung der Passung von den Juro- 
ren gewählt: zum einen die Thematik oder vermutete Intention des Textes, zum anderen außertextuelle Wissensbestände. Dabei wurden Argumentationen, in denen die Form als (un)passend für den Inhalt/die Intention des Textes bewertet wird, als Argumente im Sinne des Maßstabs Stimmigkeit kategorisiert; solche, in denen es um die authentische Wiedergabe der Sprache sozialer Milieus oder die Abbildung außerliterarischer Wirklichkeit geht, unter dem Maßstab Angemessenheit. Eine trennscharfe Kategorisierung war nicht immer möglich. Ausgangspunkt der Einordnung war immer die Beobachtung, dass die Juroren versuchen, sich den Stil und die Form des Textes zu erklären, um den Text insgesamt, im erweiterten Sinne als kohärentes Ganzes zu verstehen.

Nur selten wird der Maßstab Stimmigkeit - Abstimmung von Form und Inhalt - wortwörtlich benannt, sporadisch lassen sich jedoch entsprechende Beispiele finden, so etwa im folgenden Beitrag von Ilma Rakusa:

Und ich spüre hier eine wirkliche Stimmigkeit zwischen Plot und Sprache. Auch das, was ich als literarischen Mehrwert gerne bezeichne, das ist hier wirklich eingelöst. (2006 Meyer, 5:50 Rakusa; Hervorhebung KR)

Rakusa benennt die klassische Abstimmung von Gehalt und Gestalt, von Form und Inhalt (vgl. Schildknecht 1997), in ihren Worten von „Plot und Sprache“. Der folgende Satz, der auf den „literarischen Mehrwert“ des Textes hinweist, lässt sich mit der Aussage zur Stimmigkeit sprachlich nicht klar in Verbindung bringen. Gerade weil die beiden Aussagen allerdings unmittelbar aufeinander folgen, kann man davon ausgehen, dass ein gedanklicher Zusammenhang besteht. Der sogenannte „literarische Mehrwert“ (vgl. auch 2009 Bönt, 4:29 Fleischanderl, „poetischer Mehrwert“) ist ein starker Wert, der im Wettbewerb gelegentlich fällt. Gemeint ist, wie sich rekonstruieren lässt, dass die formale und sprachliche Gestaltung Bedeutungsinformationen enthält, die über die rein inhaltliche Bedeutung des Textes hinausgehen. Ein solches Verhältnis von Form und Inhalt wird von einigen Juroren, so auch von Rakusa, als ideal aufgefasst.

Auch Klaus Nüchtern benennt in einer seiner Bewertungen explizit den Wert Stimmigkeit:

Was mich verstört hat oder wo ich mir nicht so ganz klar war, war der Tonfall. Und da bin ich mir jetzt auch nicht so sicher, ob der authentisch ist. Der scheint mir dann doch etwas wackliger oder widersprüchlicher. Das Ganze hat mich so eigenartig, so ein bisschen so butzenscheibenhaft berührt. Und da bin ich mir auch nicht sicher, ob das wirklich eine Tonlage ist. Also auf der einen Seite „zog das Wort ,Einzelkind“ im Waldtal ein“. [zitiert weitere Beispiele KR] Dann dieses „ein lustiges Dahintoben“, „ein Tanz, ein Reigen“, „ein Trupp“. [...] Und da bin ich mir jetzt nicht sicher, ist das authentisch? Manchmal ist es an der Grenze zur Parodie, zum Übersteigerten. Oder ist es schon wieder eine künstlich hergestellte Authentizität? Aber ganz stimmig scheint mir das dann nicht zu sein. Und ich hätte mich auch wohler gefühlt, wenn da 
irgendeine viel artifiziellere Sprache oder eine größere ästhetischen Distanz aufgebaut worden wäre. (2007 Oesterle, 11:03 Nüchtern; Hervorhebung KR)

Ein klarer Wertmaßstab ist für diesen Beitrag schwer zu rekonstruieren. Klar ist zunächst, dass die sprachliche Gestaltung des Textes, sein „Tonfall“, Nüchtern verunsichert. Es überlagern sich Überlegungen zu den Werten Stimmigkeit und Angemessenheit. Thema des Oesterle-Textes ist eine Fünfzigerjahre-Kindheit. Nüchtern stellt nun zunächst fest, dass ihm nicht klar ist, wie der Tonfall des Textes zu verstehen ist. Er sucht nach einer Erklärung für den Sprachstil („Tonfall“) und bietet dabei verschiedene Möglichkeiten an: Er könnte milieuauthentisch oder zeitauthentisch sein. Er könnte eine „künstlich hergestellte Authentizität" sein - also ein Stil, der zwar nicht notwendigerweise dem typischen Duktus der Fünfzigerjahre entspricht, für den Leser aber eine Hinweisfunktion hat und dadurch authentisch wirkt. All diese Möglichkeiten betreffen eher die Angemessenheit des Textes in Hinblick auf seinen Schauplatz und sein Milieu. Nüchtern bietet aber auch eine Option an, die stärker auf den eigentlichen Wert Stimmigkeit hinweist, nämlich, dass der Stil des Textes eine neue Perspektive auf die Handlung erlauben könnte („größere ästhetische Distanz") und insofern dem Verständnis eine Facette hinzufügen würde, die über den Inhalt hinaus geht. Stimmigkeit in dieser Variante wäre eine Abstimmung von Form und Inhalt in Hinblick auf eine Intention, wobei die Form eine eigene Funktion hat. Nüchtern verwendet den Wert Stimmigkeit zwar wörtlich, dafür aber äußerst vage. Der sprachliche Kontext, in den die Aussage eingebunden ist, lässt darauf schließen, dass hinter dem Wert kein klar abgrenzbares Konzept steht - also beispielsweise, die Abstimmung von Form und Inhalt -, sondern vielmehr die Puzzletätigkeit des Lesers, die darauf ausgerichtet ist, sich ein möglichst komplettes Bild von dem Text zu machen. Aussagen wie diese unterstreichen besonders eindrücklich, dass Werte wie Stimmigkeit und Angemessenheit sich einem Komplex von Wertungen zuordnen lassen, in denen es um Nachvollziehbarkeit, um die Orientierung des Lesers geht. Es handelt sich um flüssige Konzepte, die variabel eingesetzt werden können, um Prozesse des Nichtverstehens in Werte zu transformieren.

Diese Auffälligkeit, dass insbesondere der Wert Stimmigkeit eingebettet ist in die aktive Anstrengung der Juroren, den Text in Inhalt und Gestaltung umfassend nachzuvollziehen, lässt sich auch dann noch zeigen, wenn der Wert Stimmigkeit in seiner eigentlichen Bedeutung eingesetzt wird. Obwohl die Abstimmung von Form und Inhalt ein zentrales Thema in den Diskussionen ist, wird der Wert meistens nicht wörtlich benannt, dem Inhalt nach aber eindeutig herangezogen:

Das hohe Ziel, das sich ein Text stellt, sollte auch irgendwo sprachlich eingelöst werden. 
Die Widersprüche, die in einem Text aufgedeckt werden sollen, der Absicht des Autors nach, sollten auch irgendwie in der Sprache vorhanden und spürbar sein. Das war beim letzten Text nicht so wirklich die Tatsache und das ist auch bei diesem Text nicht die Tatsache. Sie haben ein paar Sätze vorgelesen. Ich finde hier einen Satz „Er hatte ein nahezu skelettiertes Ex-Model erlebt, das sich in ihrer Villa mit Whiskey das Fleisch von den Knochen soff, während ihr Mann Damen in schwarzem Lack den blanken Hintern hinhielt". Das ist für mich Zynismus pur. Es ist auch keine Parodie auf die Analyse. Das ist ein flapsig hingeschriebenes/ Hat nichts mit dem Konflikt eines Analytikers zu tun. Es hat auch gar nichts mit Analyse/ mit Parodie einer Analyse zu tun oder der analytischen Zunft. (2009 Preisendörfer, 18:23 Fleischanderl; Hervorhebungen KR)

Mit dem Hinweis „das hohe Ziel, das sich ein Text stellt, sollte auch irgendwo sprachlich eingelöst werden" ruft Fleischanderl ganz eindeutig den Wert Stimmigkeit auf. Der Beitrag wurde in seiner vollen Länge zitiert, weil sich an ihm eine Reihe von typischen Merkmalen von Stimmigkeitsargumentationen zeigen lassen. Der Kern der Wertung steht am Anfang des Beitrags: die Forderung nach einer dem Inhalt angemessenen Sprache. Damit wird der Sprache in der Wertung ein ganz zentraler Platz eingeräumt. Anschließend unternimmt Karin Fleischanderl den Versuch, ihre Wertung durch den Text zu verdeutlichen. Sie formuliert ihre Annahme über die Absicht des Textes: Es gehe um „de[n] Konflikt eines Analytikers“. Die im Text verwendete sprachliche Gestaltung bezeichnet sie zum einen als „Zynismus pur“, zum anderen als „flapsig hingeschrieben[]/“. Während das Zynismus-Argument ein moralischer Schlag gegen den Text ist, der durch die Einbettung in die Form-Argumentation getarnt wird, kann man das Flapsigkeits-Argument als Kritik an einer wenig sorgfältig gearbeiteten, nicht durchdachten Sprache verstehen. Letzteres Argument ist damit eine deutlich allgemeinere Kritik an der Sprachgestaltung. Beide Argumente sind für das Verständnis, warum der Text laut Fleischanderl sein Anliegen nicht ausreichend in Sprache umsetzt, wenig aufschlussreich.

Obwohl die zentrale Kritik die Unangemessenheit der Sprache betraf, geben die dann folgenden Ausführungen im Wesentlichen Hinweise darauf, was Fleischanderl als Absicht des Textes verstanden hat, nämlich „de[n] Konflikt eines Analytikers“ und darauf, dass sie ihn nicht sorgfältig geschrieben findet.

Versucht man aus diesen lose verbundenen Gedanken eine Argumentation zu rekonstruieren, könnte diese so aussehen:

a) Der Text stellt inhaltlich „de[n] Konflikt eines Analytikers“ (gemeint ist ein Psychoanalytiker KR) dar.

b) Absicht des Autors ist es, „Widersprüche“ aufzudecken; sehr wahrscheinlich handelt es sich um Widersprüche im Denken oder Leben des Psychoanalytikers, 
die zu Konflikten führen.

c)

Die Sprache des Textes spiegelt diese „Konflikte“ und „Widersprüche“ nicht wieder. Darin besteht ein großer Mangel des Textes. Die Sprache sollte die Konflikte der Hauptfigur spiegeln. Statt dessen nutzt sie Spott, um den Leser zu unterhalten, und sie ist sprachlich nicht sorgfältig gearbeitet.

Dieser Versuch einer Rekonstruktion des Wertungsvorgangs zeigt einige typische Bestandteile von Argumentationen, die auf das Funktionsverhältnis von Sprache und Inhalt und vermuteter Intention abzielen. Die Rekonstruktion des Inhalts, also die Rekonstruktion der Textwelt (Schwarz-Friesel 2006) bildet den Ausgangspunkt für die Ableitung einer Autorintention. Erst dann fragt die Jurorin nach dem Passungsverhältnis von Sprache und Inhalt. Wichtig ist dabei, dass der Sprache die Funktion zugewiesen wird, die Botschaft des Textes zu stützen. Obwohl der Sprache in ihrer konkreten Ausprägung im Analyseprozess erst relativ spät Aufmerksamkeit zukommt, ${ }^{43}$ nimmt sie in der Formulierung der Wertung eine ganz zentrale Stelle ein. Sie ist im Aufbau der Argumentation der Hauptgrund für die negative Beurteilung des Textes. Trotzdem fällt es der Jurorin offenbar nicht leicht, die sprachliche Unzulänglichkeit konkret zu benennen. Darüber hinaus bleibt offen, wie die zwei Argumente gegen die Sprache - Spott und mangelnde Sorgfalt - mit der Einschätzung, die Sprache sei nicht stimmig, in Hinblick auf die Intention zusammenpassen. Sie können letztendlich nur als ein persönliches Missfallen an der Sprache, möglicherweise sogar moralische Vorbehalte gegenüber der Art der Darstellung aufgefasst werden, das durch die Bezugnahme auf den anerkannten Wert Stimmigkeit legitimiert wird.

In einem anderen Beispiel kann man diesen Bewertungsprozess in einer sehr ähnlichen Ausprägung beobachten. In diesem Beispiel tritt die argumentative Logik klarer, in der „richtigen“ Reihenfolge zutage:

Also, das heißt die Trauer - darum geht es ja hier auch, er ist ja wie abgeschnitten von der Welt - die Trauer hat ihn vollkommen autonom gemacht, was ein Schutz ist. Es ist auch ein Schutz, weiter, nehme ich an, existieren zu können. Und dieses Autonome ist, denke ich, auch im Formalen dieses Textes drin. Der ist, wenn man so will, in gewisser Weise so - also, ich benutze das ungern - so glatt oder so genau, wie eben das Leben dieses Menschen ist. Und ich sehe keine andere Möglichkeit, diese Szenen zu beschreiben als eben gerade so. (2009 Schäfer, 11:00 Sulzer)

43 Über den genauen Verlauf der Lektüre und Analyse kann auf der Grundlage der Diskussionen nur spekuliert werden. Legt man allerdings das kognitionspsychologische Schema ästhetischer Erfahrung von Belke/Leder (2006) zugrunde, kann man annehmen, dass die sinnliche Wahrnehmung (das Lesen) und das Ordnen der Informationen vor einer Analyse in Hinblick auf eine stilistische Beurteilung erfolgt. Wechselwirkungen sind allerdings möglich. 
Sulzer benennt zunächst das Thema des Textes („Trauer“). Er zeigt dann sehr verkürzt, woran er festmacht, dass es in dem Text um Trauer geht („er ist ja wie abgeschnitten von der Welt"). Und er kommt schließlich zu der Einschätzung, dass „dieses Autonome [...] auch im Formalen dieses Textes drin [ist]“. Inhalt und Sprache sind in Schäfers Text, so Sulzer, genau aufeinander abgestimmt. Das Passungsverhältnis ist so gut, dass Sulzer sagen kann, er sehe keine andere Möglichkeit, diese Szenen zu beschreiben als eben gerade so. Auch in diesem Beitrag werden inhaltliche Zusammenhänge im weiteren Verlauf der Wertung mit Beispielen aus dem Text belegt. Die Feststellung, dass der Text formal absolut auf sein Thema abgestimmt ist, findet allerdings keine detaillierte Erklärung. Es wird indirekt davon ausgegangen, dass die inhaltlichen Analysen sich eben aufgrund ihrer gelungenen Abstimmung leicht auf die Form übertragen lassen. Die Größe, anhand derer bemessen wird, ob die formale Gestaltung gelungen ist, ist in diesem Fall der Inhalt des Textes selber.

Was bei Fleischanderl (18:23) als Forderung (,sollte auch irgendwo sprachlich eingelöst werden" (2009 Preisendörfer)) formuliert ist, findet sich bei Sulzer (11:00) als Notwendigkeit („ich sehe keine andere Möglichkeit, diese Szenen zu beschreiben als eben gerade so“ (2009 Schäfer)). Mangold spricht in der Diskussion zu Heike Geißler (2008, 23:02), von einem ,zwingend[en] Zusammenhang zwischen der Figur des Engels und dem gewählten Stil“. In allen drei Beispielen kann man deutlich an den gewählten Formulierungen erkennen, für wie grundlegend die Passung von Form und Inhalt gehalten wird. In allen dreien führt der logische Weg von der Wahrnehmung des Inhalts über die Rekonstruktion einer Textintention hin zu einer Beurteilung der Sprache. Die Messlatte für die Sprache ist dabei die Frage, ob sie in Einklang mit dieser Textintention zu bringen ist. Bei Fleischanderls (2009 Preisendörfer, 18:23) Argumentation wurde deutlich, dass dieses Argumentationsgerüst auch dazu verwendet werden kann, um unter dem Mantel des anerkannten Wertes Stimmigkeit andere Wertungen vorzunehmen.

Der Maßstab Stimmigkeit wird allerdings überwiegend indirekt verwendet, das heißt, er wird selten als Stimmigkeit benannt. Dennoch gibt es sehr viele Formulierungen, die den Maßstab dennoch aufrufen. So argumentiert Strigl (20:44) beispielsweise, der Autor Vennemann (2006) habe „nicht die adäquate Form für diesen hoch komplexen und schwierigen Stoff“ gefunden. Mit der Wortwahl „adäquat“ wird Stimmigkeit als Wert aufgerufen. Auch hier bestätigt sich, dass der Stoff immer vorausgesetzt wird. Die Form muss sich, so die Annahme, dem Inhalt anpassen. Sie steht im Dienst des Inhalts. In der Diskussion zu Tellkamp (2004) spricht Strigl (9:58) von einer Kongruenz von Sprache und Inhalt: „Hier ist 
die Fülle kongruent im Inhalt und in der Sprache“. Silvia Bovenschen (1999 Jonigk, 6:38) spricht davon, dass „diese Aufspaltung, die das mit sich bringt, diese Ich-Aufspaltung, [...] dann ihr formales Korrelat in einer Textstruktur [hat]" (Hervorhebung KR). Auch diese Formulierungen verweisen sehr eindeutig auf den Maßstab Stimmigkeit, ohne ihn zu benennen. Rakusa (2003 Griebel, 18:17) spricht dagegen davon, dass die Aussage eines Textes durch die Sprache „eingelöst“ werden müsse: „Wie wird das eingelöst durch die Sprache?“. Schindel (2002 Pehnt, 9:22) verwendet das Wort „Balance“: „Ja, das ist für mich eine Sprache, die ganz durchsichtig ist, klar ist, die sozusagen auf ihr Ziel zugeht, die immer in einer guten Balance steht zu dem, was berichtet wird“. Die Sprache sei „klar“ und „ganz durchsichtig“. Solche Formulierungen machen darauf aufmerksam, wie sehr der Wert Stimmigkeit - im sprachlichen Code der Literaturbewertung - ein Wert ist, der mit dem Eindruck der Nachvollziehbarkeit zu tun hat. Stimmigkeit ist, ähnlich wie Mirco Limpinsel (2013) es für den Begriff der Angemessenheit in literaturwissenschaftlichen Theorien gezeigt hat, keine bemessbare Größe, sondern vielmehr ein Ausdruck dafür, dass den Juroren die formale Gestaltung des Textes nachvollziehbar ist. Inwiefern eine formale Gestaltung für einen Text „angemessen“, „stimmig“, „ausbalanciert“ oder ähnliches ist, ist durch nichts zu bemessen, sondern ein Resultat der Textwahrnehmung auf der Ebene der Nachvollziehbarkeit. Bei Schindel (2000 Frank, 5:32) findet sich auch die Formulierung, dass der Text ihm „,ausgezeichnet gefallen“ habe, „gerade weil es sprachlich dem [Inhalt KR] so entspricht". Auch hier gehen, wie so oft, Stimmigkeits-Argument und positive Gefallenswertung Hand in Hand. Sehr direkt formuliert es auch Dieter Bachmann (1999 Kunkel, 11:54), wenn er urteilt, dass es schön sei, „wie die Machart mit der Intention und dem Inhalt übereinstimmt“. Den Wunsch nach einer genauen Abstimmung von Form und Inhalt könnte man kaum deutlicher formulieren.

Zu den indirekten Formulierungen, die auf eine absichtsvolle Planung der Form und Sprache eines Textes, abzielen, gehört auch die, dass der Text „durchgeführt" sei. Auch dieser Ausdruck impliziert die Aspekte des Plans und seiner erfolgreichen Umsetzung. „Aber zuletzt: Was sich die Geschichte selber vorgenommen hat, sprachlich, hat sie durchgeführt. Und das ist ein ordentliches Stück Literatur" konstatiert Schindel (2000 Schwerdtfeger, 9:13) in seinem abschließenden Urteil über den Text von Malin Schwerdtfeger und unterstreicht damit auch den hohen Rang, den Stimmigkeit für ihn hat. Genauso klar wie in einigen anderen Beispielen tritt hier der Nexus zwischen gelungener, konsequenter Durchführung und „guter“ Literatur zutage. Dass „durchgeführt sein“ ebenso wie „durchgehalten sein“ (siehe 1.2 Einheitlichkeit) wiederum damit zusammenhängt, ob die Formelemente als 
funktional in Hinblick auf eine Intention verstanden werden können, zeigt dieser Beitrag:

Das ist schon durchgeführt. Also, ich finde das ungerecht, Frau Radisch, dass Sie dem Text so eine Beliebigkeit vorführ/ [verbessert sich] -werfen. Ich finde eher diese Sachen manchmal zu stark. Also, ich finde diese Hinweise, diese Verweisketten und diese Hinweise, die finde ich manchmal ein bisschen zu stark. Und das mit dem Dialog, da würde ich konzedieren, die finde ich auch manchmal ein bisschen lapidar. Sagen wir es mal so. (1999 Stamm, 26:36 Bonvenschen)

Die Jurorin Bovenschen macht einen Kontrast auf zwischen „durchgeführt“ sein und der von Iris Radisch vorgeworfenen „Beliebigkeit“. Durchführung und Willkür schließen sich offenbar gegenseitig aus. Interessant an diesem Beitrag ist außerdem der Hinweis, dass es auch eine überdimensionierte Einheitlichkeit gibt. Bovenschen findet „diese Verweisketten und diese Hinweise [...] manchmal ein bisschen zu stark“. Möglicherweise wird hier auf das Bedürfnis des Lesers nach geistiger Aktivität (vgl. Kapitel 11), die durch zu große Eindeutigkeit verhindert wird, verwiesen. Einheitlichkeit und Eindeutigkeit sind also deutlich voneinander zu trennen. Besonders auffällig an den zitierten Beiträgen, die sich auf den Wert Einheitlichkeit beziehen, ist die geringe Varianz in den Formulierungen.

Neben jenen Argumentationen, in denen es primär um eine intentionsadäquate Sprache geht, gibt es solche, in denen Texte in Bezug auf Wissen aus der außertextuellen Wirklichkeit beurteilt werden. Diese Textstellen wurden unter der Kategorie Angemessenheit zusammengefasst. Die Angemessenheit der Sprache für die soziale Rolle oder Lebenslage einer Figur bildet den Kern solcher Wertungen, aber auch andere Wissensbestände können aktiviert werden. In der Diskussion zu Silke Scheuermann (2007) etwa wird der Autorin vorgeworfen, sie verwende ein „kolloquiales Deutsch“ (5:26 Corino) bzw. eine „aufgekratzt[e], umständlich[e], kleinbürgerlich[e]“ (ebd., 10:46 Radisch) Sprache. Es entbrennt eine Diskussion darüber, ob eine - gemessen an Alltagserfahrungen - figurenadäquate Sprache auch dann noch positiv zu bewerten ist, wenn sie beim Leser ein Missbehagen auslöst. Radisch geht mit ihrer Begründung, warum sie die Sprache ablehnt, in mehrere Richtungen und greift dabei jeweils verschiedene Wissensbestände auf. Betrachtet man Radischs Argumentation im Detail, kann man nachvollziehen, wie verschiedene Wissensbestände lebensweltliche und literarische - genutzt werden, um die Sprache des Textes abzuwerten:

Ich finde die aufgekratzt, umständlich, kleinbürgerlich, sehr im Ton der Jungmädchenliteratur. [...] Warum dieses aufgekratzte, jungmädchenhafte „Ich fegte einen Stapel Papier vom Tisch" [zitiert frei KR], „der Wolf fegt über den Schnee" [zitiert frei KR], „,ich inspizierte den Wäscheständer“, „Ich fummelte meinen Hefter aus der Schultasche" [zitiert frei KR]? [...] Das ist aufgekratzter Kleinbürgersprech, wie ich ihn jeden Morgen im Frühstücksfernsehen angucken kann. Wer jetzt umschaltet, sieht das/ hört das sofort. Und nun ist natürlich die Frage: Warum haben wir das in Literatur? Die Frage muss man sich stellen. [...] Und da muss ich sagen: Das ist mir nicht 
einleuchtend. Also, wer so humorige, oder pseudohumorige Sprechakte eins zu eins nachplappern lässt, muss damit etwas im Schilde führen, in der Kunst doch zumindest. [...] Also ich bekomme Erstickungsnot. Ich bekomme sprachliche Erstickungsnot in/ (2007 Scheuermann, 10:46 Radisch)

Radisch identifiziert die Sprache der Figuren als "Ton der Jungmädchenliteratur" und weist sie damit als typisch für ein niederrangiges Genre aus. Gleichzeitig bezeichnet sie die Sprache als „Kleinbürgersprech“, den sie aus dem Frühstücksfernsehen kenne. Sie ordnet die Sprache also einem offensichtlich nicht prestigeträchtigen Milieu zu. Diese Verortungen der Sprache in der Literatur und im Alltäglichen scheinen allerdings als Argument unzureichend zu sein, denn Radisch fährt in ihrer Argumentation fort und hebt die zunächst persönlich gefärbten Abneigungen gegen eine Sprechweise auf eine Wertungsebene, die eher dem anerkannten Code entspricht. Auf dieser Ebene argumentiert sie mit der erweiterten Kohärenz: Textelemente sollten eine Funktion in Hinblick auf die Intention haben, die für den Leser nachvollziehbar ist. Dass Radisch ihre Reaktion auf den Text als „sprachliche Erstickungsnot“ bezeichnet, ist zum einen ein rhetorischer Schachzug, um die Intensität ihrer Aussage zu steigern, verortet die gesamte Wertung aber auch in einem Kontext der emotionalen Wirkung des Textes, in diesem Fall allerdings nicht einer durch den Text angelegten.

Klaus Nüchtern (2007 Scheuermann, 13:54), der Scheuermanns Text insgesamt eher positiv bewertet, erwidert auf Radischs Kritik, es könne sein, dass es ein kleinbürgerlichen Milieu sei und da dürfe man dann auch kleinbürgerlich reden. Martin Ebel, der Scheuermanns Text sehr lobt, argumentiert in seiner Reaktion ebenso, dass die Sprache der Figur angemessen und daher auch nicht vom Text zu trennen sei:

Es nutzt der Charakterisierung der Personen. Also, Sie machen jetzt auch einen Fehler. Sie trennen die Geschichte von der Sprache. Sie sagen, die Geschichte ist das und die Sprache ist das. Und die Sprache gefällt Ihnen nicht. Die Sprache ist aber das, was die Personen zu ihrer Artikulation zur Verfügung haben. Die Tochter ist so, wie ein achtzehnjähriges Mädchen eben denkt, und das ist halt manchmal voller Klischees und voller Träume [unv.]. (2007 Scheuermann, 14:06 Ebel)

Hier werden also - rein rhetorisch, versteht sich - zwei verschiedene Vorstellungen davon, was literarische Sprache können sollte, gegeneinander ausgespielt. Rein rhetorisch - denn es ist nicht undenkbar, dass Radisch in einer anderen Diskussion, bedingt durch eine andere - eine positive - Textwirkung im Sinne einer figurenauthentischen Sprache für den Stil eines Textes argumentieren würde, Ebel und Nüchtern dagegen im Sinne eines literarischen Mehrwerts (zum „literarischen Mehrwert“ vgl. 2006 Meyer, 5:50 Rakusa; 2009 Bönt, 4:29 Fleischanderl „poetischer Mehrwert“) gegen den Stil der Sprache. Ob die gewählte Sprache 
als figurenangemessen oder im Sinne eines Stimmigkeitsarguments als funktional bedeutungslos eingestuft wird, scheint eine Entscheidung zu sein, die vom ersten Eindruck oder möglicherweise vom Gesamteindruck abhängt, den der jeweilige Text hinterlassen hat. Ob die Sprechweise einer Figur als der Figur angemessen und insofern stimmig angesehen wird oder ob sie als unliterarisch (in diesem Sinne unstimmig) eingestuft wird, ist, so lässt sich annehmen, keine auf konkreten Texteigenschaften beruhende Entscheidung, sondern vielmehr ein Resultat des Leseeindrucks und der daraus hervorgegangenen polaren Bewertung des Textes als gelungen oder nicht gelungen. Hat der Text eine positive Lektüre-Wirkung, gilt er erst einmal als gelungen. Formal-ästhetische Werte werden dann als bewusst vom Autor eingesetzte Kunstmittel verstanden. Ist die Lektüre-Wirkung des Textes hingegen negativ, gilt er als nicht gelungen und dem Autor wird entweder mangelndes handwerkliches Können attestiert, oder die Leseeindrücke werden auf falsche Formentscheidungen zurückgeführt. Diese Tendenz - die sich in vielfacher Hinsicht differenzieren ließe - lässt sich in vielen Diskussionen deutlich erkennen. ${ }^{44}$

Im folgenden Beispiel - Strelow (2006) - entsteht eine ganz ähnliche Auseinandersetzung der Juroren über die Frage der Figurenangemessenheit bzw. der literarischen Angemessenheit. Hier bildet die Frage, ob überhaupt eine plausible Erklärung für eine bestimmte Sprachverwendung gefunden werden kann, die Folie für die Diskussion. Gefallensurteile werden nicht thematisiert, sondern bilden allenfalls den Hintergrund. Grund dafür ist, dass der Text Strelows, anders als der Scheuermann-Text, größere Probleme bereitet, verstanden zu werden. In der Diskussion zu Strelow begegnen die Juroren einander mit Argumenten, die sowohl die Abstimmung der Sprache auf die Aussage des Textes betreffen als auch die Abstimmung der Sprache auf die Figurenrolle. Heinrich Detering (2006 Strelow, 0:19) eröffnet die Diskussion und macht die Sprache zum zentralen Kritikpunkt seines Beitrags. Ausgehend von einigen Zitaten möchte er zeigen, dass die Sprachverwendung „durch nichts gedeckt“ ist. Er stellt dabei zwei Möglichkeiten der Deckung zur Auswahl: zum einen die Deckung durch die Figurenperspektive, zum anderen die bewusste Entscheidung für eine „manieristische“ Sprache, also eine Deckung durch die Intention:

Das ist wahnsinnig viel. „Eine Flasche Wein wäre ein Anfang gewesen“, hätte sie sagen können aber statt dessen sagt sie: „Eine Flasche Wein wäre ein Beginnen geworden“. Das ist durch nichts gedeckt, scheint mir. Durch die Figurenperspektive nicht, nicht

$\overline{44}$ Die Juroren sind durchaus bereit, ihren ersten Leseeindruck selbstkritisch zu hinterfragen und zu relativieren. Es kommt vor, dass Juroren ihre Urteile im Verlauf der Diskussion relativieren, weil sie den Argumenten ihrer Mitjuroren stattgeben können. So korrigierte Dieter Bachmann seine zwiespältige Bewertung des Textes von Jens Petersen (2009) im Verlauf des Wettbewerbs zu einer positiven. Nichtsdestotrotz wird aus einem eingangs schlecht bewerteten Text in aller Regel auch durch gute Gegenargumente kein gut bewerteter Text. 
durch den Willen zu einer manieristischen Übersteigerung der Sprache. Das ist als avantgardistische behelfsweise Geste eine Plattitüde. (2006 Strelow, 0:18 Detering)

Auf diesen, von Detering noch sehr breit ausgeführten, Kritikpunkt, reagiert Ursula März (2006 Strelow, 3:34) unmittelbar. Sie argumentiert im Sinne der Figurenangemessenheit: Die „falsche Sprache“ gehe schon in Ordnung, denn „wir haben es mit einer Buchhalterin zu tun, die eine doppelte Buchführung treibt".

Martin Ebel schließlich geht sogar so weit, dass er die Sprache des Textes als solche deutlich ablehnt, sie aber aufgrund ihrer Angemessenheit für die Rolle der Figur als legitime Gestaltungsform akzeptiert. Der Wert Angemessenheit wird in diesem Zusammenhang gegenüber dem, ohnehin sehr schwer fassbaren, Wert Schönheit der Sprache bevorzugt:

Ja, die Sprache ist natürlich schon schrecklich. Also in ihrem Schwanken zwischen der übertriebenen Bildhaftigkeit und dann der kalten Abstraktion. Aber, wenn ich das richtig verstanden habe, wird doch hier ein krankes Bewusstsein abgebildet. (2006 Strelow, 12:25 Ebel)

Die zitierten Beiträge setzen mit ihrer Kritik im Konkreten an unterschiedlichen Stellen an. Hatte Detering noch bestimmte Ausdrücke als „Plattitüden“ bezeichnet und die Sprache des Textes als unangemessen umständlich empfunden, geht es Ebel und offenbar auch März („doppelte Buchführung“) um eine Sprachgestaltung, die zwischen zwei gleichermaßen übersteigerten Polen (,übertriebene Bildlichkeit“, „kalte Abstraktion“) schwankt, dabei aber der Figur angemessen ist.

Ein weiteres, sehr eindeutiges Beispiel für die Frage nach der Figurenangemessenheit einer Sprache bietet die Diskussion zu Behrens (2006). Ganz explizit wird in dieser Diskussion danach gefragt, wie die Hauptfigur des Textes - ein Eisenbahner - eine hohe literarische Sprache haben kann. Ursula März (2006 Behrens, 5:55) etwa formuliert diese Erwartung: „Wir haben es mit einem kleinen Mann in einer kleinen Wohnung in einem kleinen Leben zu tun, dem natürlicherweise eine kleine Sprache zustehen würde“. Hier wird also ein Standard der Angemessenheit formuliert, der auf den ersten Blick nicht erfüllt wird. März sieht nun eine mögliche Idee des Textes gerade darin, dass dieser „kleine Mann“ seine Rolle durchbricht und sich mittels der Sprache aus dieser Rolle herauszuheben versucht:

Und er erfindet jetzt nicht nur sozusagen die schönste Liebesgeschichte, Liebeskonstellation, die es gibt, nämlich eine heimliche Geliebte in Paris zu haben. Sondern er erfindet eine Sprache, nämlich sozusagen den Sound der pathetischen Bühnensprache und des Bühnenrhythmus des achtzehnten Jahrhunderts. Wenn er das ernst meint, muss das etwas schärfer begründet sein, dass sich hier sozusagen ein Liliput in einen Elefanten/ in die Elefantenhaut einnäht, in das Idiom eines Elefanten. (2006 Behrens, 5:55 März) 
März sucht also in der Abstimmung auf die Intention des Textes einen Ausweg aus der auffallenden Unangemessenheit. Sie nimmt an, dass eine klar erkennbare Intention, Sprache und Leben der Figur widersprüchlich zu gestalten, die Angemessenheit wieder herstellen würde. In ihrer Argumentation spiegelt sich also auch das Bedürfnis das Wahrgenommene als absichtsvoll aufzufassen. Letztlich wertet März allerdings negativ, weil sie diese vermutete Absicht im Text nicht eindeutig genug umgesetzt sieht. Ganz deutlich wird hier, dass von den Juroren sehr viele sprachliche und formale Gestaltungsweisen akzeptiert werden, wenn es ihnen möglich ist, den Gestaltungselementen eine Funktion entweder für die Charakterisierung der Figur (Angemessenheit) oder für die Aussage des Textes (Stimmigkeit) zuzuordnen. Auch März‘ (2006 Behrens, 5:55) Einstieg, sie habe „etwas Wesentliches an diesem Text nicht verstanden“, ist ein Hinweis auf diese Dominanz des Bedürfnisses nach Nachvollziehbarkeit. März gelingt immerhin eine potentielle Deutung der problematischen Sprachverwendung. Für Martin Ebel (2006 Behrens, 7:50) dagegen erschließt sich die Absicht des Textes nicht. Er geht von derselben Dissonanz von Sprache und Inhalt aus. Für ihn bleibt die Frage, wie dieser Mensch diese Sprache haben könne, unbeantwortet. „Mir ist das nicht wurscht. Ich möchte es gern begreifen“, fügt er hinzu und unterstreicht damit, wie wichtig es für ihn ist, die Form des Textes umfassend nachvollziehen zu können.

Gleich mehrere Aspekte von Angemessenheit treffen in Deterings Eröffnungsbeitrag der Diskussion zu Anna Katharina Hahn (2004) aufeinander. Er findet: „Das hat sich im Ton vergriffen. Das ist/ Es passt nicht in die Perspektive. Es passt auch nicht in den satirischen Ton. Es ist eine Nummer zu dick. Zu gewollt rotzig“ (2004 Hahn, 0:25 Detering). Zum einen stellt Detering die Angemessenheit an die Figurenperspektive in Frage. Die gewählte Sprache passe nicht zur Sichtweise eines „lateinische[n] Polyhistoren“ (ebd.). Es lässt sich nicht genau nachvollziehen, ob es hierbei um die soziale Rolle der Figur geht oder ihre Persönlichkeit. Zweitens stellt er fest, dass der Sprachstil („Ton“) dem gewählten Genre („Satire“) nicht angemessen sei. Nicht zuletzt macht er auf eine Unangemessenheit der Intensität, mit der der Stil eingesetzt wird, aufmerksam (,zu dick“, „zu gewollt rotzig“). Dieses Statement kann im Sinne der Unangemessenheit für die soziale Rolle der Figur verstanden werden. Es lässt sich aber auch als ein Hinweis auf Überdeterminiertheit lesen (vgl. Kapitel 10.3.1 „Dominanz der Form“).

Die Beispiele aus den Diskussionen zu Scheuermann, Strelow, Behrens und Hahn illustrieren, dass die Juroren eine sprachliche Gestaltung erwarten, die sie sich erklären können. Oft stehen dabei Argumente, die die sprachliche Gestaltung in Hinblick auf die Intention des Textes betrachten, Argumenten gegenüber, die die Sprache als Ausdruck einer Figu- 
renrolle sehen. Erklärbarkeit ist dabei von entscheidender Bedeutung. Zur Erklärung wird dabei vielfach Wissen darüber herangezogen, wie soziale Gruppen in der außertextuellen Wirklichkeit sprechen. Daneben kann aber auch ein spontanes Missfallen an der Sprache die spezifische Ausprägung des Arguments mitbestimmen.

Ebenso ist es möglich - die folgenden Beispiele illustrieren das -, dass Alltagswissen für die Beurteilung der Angemessenheit der Form/Sprache herangezogen wird. So etwa, wenn Mangold sich Gedanken darüber macht, welche Sprache dem Thema „Engel“ angemessen ist:

Weil wir das Göttliche direkt nicht anschauen können, nehmen wir es im Schönen wahr. Und deswegen finde ich bei einem Thema, wo es um Engel geht, es vollkommen zwingend, dass diese Engelsbilder in einer Sprache generiert, heraufbeschworen werden, die den Mut hat, schöne Bilder zu generieren. Da, finde ich, liegt nichts Läppisches oder Idyllisierendes drin. (2008 Geißler, 23:03 Mangold)

Tatsächlich geht Mangold nicht direkt von einer Alltagsvorstellung, sondern von einem philosophischen Grundgedanken aus. Der Konnex zwischen dem Engel und dem Schönen (einer „schönen“ Sprache) bedürfte dieser philosophischen Begründung allerdings kaum. Es entspricht dem alltäglichen Bild vom Engel, dass er ein schönes Geschöpf ist. Der Aufbau des Arguments ist dabei in seiner Logik vergleichbar mit einigen bereits erwähnten: Es gibt ein „Thema, bei dem es um Engel geht“. Es ist daher für Mangold „zwingend“, dass die Sprache passend dazu viele „schöne Bilder“ hervorbringt. Viel deutlicher als bei Mangold wird die Bedeutung von Alltagswissen dann, wenn Juroren auf Wissen ihrer Lebenswelt zurückgreifen, um zu beurteilen, ob ein Text angemessen gestaltet ist. So beobachtet Spinnen etwa ein Fehlen von Emotionalität in der Sprache Claudia Klischats, das er zu erklären versucht, indem er Textthema und Alltagserfahrung in Beziehung setzt:

Und da sind wir jetzt bei der ästhetischen Aufgabe dieses Textes. Der birst im Grunde genommen immer vor Drama und Schicksal und so weiter, dürfte das aber sprachlich ja gar nicht realisieren, weil er ansonsten eine andere Zeit und in eine andere Wirtschaft meint, aus der wir solche Verhältnisse, so beschrieben auch ganz richtig kennen. (2006 Klischat, 20:26 Spinnen)

Der Text, so das Grundargument Spinnens, muss sich einer sachlichen Sprache bedienen, damit er der gesellschaftlichen Gegenwart, die im Text dargestellt werden soll, gerecht wird. In der Diskussion wurde dem Text eben diese unemotionale Sprache vorgeworfen. Indem Spinnen sie als im Hinblick auf die Wirklichkeit angemessen beschreibt, versucht er das Argument positiv zu wenden. Ganz analog argumentiert Meike Feßmann in einer anderen Diskussion, wenn sie kritisiert, eine poetische Sprache sei der Situation von Flüchtlingen auf einem Lastwagen nicht angemessen: 
Und zur Sprache: Ich finde auch, dass man so ein Thema nicht so unpräzise behandeln darf. Also es fängt damit an im ersten Satz. Es erzählen ja diese Flüchtlinge. Und die sprechen von ihrer/ Die treffen sich zur „blauen Stunde“. Das ist wirklich eine poetische Überhöhung, die zu dem Kontext überhaupt nicht passt. (2009 Stift, Feßmann 4:06)

Implizit macht Feßmann hier auch klar, dass die poetische Sprache als eine beschönigende Sprache wahrgenommen wird. („poetische Überhöhung“). Diesen Spracheindruck kann sie nicht mit ihrem lebensweltlichen Wissen über Flüchtlinge in Einklang bringen. Es entsteht ein Konflikt zwischen Sprachwahl und Erfahrung, den Feßmann offenbar in ihren Deutungsversuchen nicht zu einem Verstehen zusammenführen kann.

\subsubsection{Zusammenfassung}

Im Leseprozess ist das Herstellen von Kohärenz und dadurch einer Textaussage das oberste Interesse des Lesers (vgl. 10.1). Dieses grundlegende Interesse spiegelt sich in den Diskussionen auf verschiedenen Ebenen. Die Rekonstruktion des Plots und der Textaussage sowie die Konstitution einer gemeinsamen Gesprächsgrundlage (vgl. Kapitel 5) können in den Diskussionen erheblichen Raum einnehmen, wenn der Text schwer zugänglich ist oder sehr unterschiedliche Lesarten ermöglicht. Aber auch die Ebene der erweiterten Kohärenz, die Formmerkmale mit in die Konstitution eines Textverständnisses einbezieht, ist prägend für die Bewertung der formal-ästhetischen Beschaffenheit des Textes.

Der Wert Kohärenz findet sich auf formal-ästhetischer Ebene in unterschiedlichen Ausprägungen: Angemessenheit (Verhältnis von Figur und Sprache), Stimmigkeit (Abstimmung von Inhalt und Gestaltung) und Einheitlichkeit (Abstimmung der Elemente untereinander). Als Bezugsgrößen für Stimmigkeit und Angemessenheit wird sowohl das in Betracht gezogen, was der Text selber aufbaut, als auch andere Wissensbereiche wie etwa soziales Wissen. Die Auseinandersetzung mit sprachlichen und formalen Texteigenschaften erfolgt im Bewertungsprozess erst dann, wenn die Textwirklichkeit (vgl. Schwarz-Friesel 2006) rekonstruiert und der Text auf diese Weise als Gesprächsgegenstand konstituiert wurde; dann wird den formalen Eigenschaften allerdings eine zentrale Position zugewiesen. Explizite Gefallensurteile und Kohärenzwerte sind dabei im Bewertungsprozess sehr eng miteinander verknüpft. Textverständnis und erster Leseeindruck (positiv/negativ) gehen Hand in Hand und spiegeln sich in der Zuerkennung von Werten wie Stimmigkeit, Angemessenheit und Einheitlichkeit. Aus den Diskussionen wird deutlich, dass nicht so sehr zählt, welche formalen Mittel genau eingesetzt werden, um den Eindruck von Kohärenz, Stimmigkeit oder Einheitlichkeit zu erreichen, sondern vielmehr, dass überhaupt erkennbar ist, dass Gestaltungsmittel intentional eingesetzt wurden. Damit ist klar, dass es sehr 
selten um die konkrete formale Ausführung eines Textes geht, sondern eher um einen Eindruck von Intentionalität und Gestaltetheit, der nur entstehen kann, wenn dem Leser die Möglichkeit zum Nachvollzug gegeben wird. Werteigenschaften mit Bezug auf die Maßstäbe Stimmigkeit und Angemessenheit sind also kaum prinzipiell und für sich genommen wertvoll, sondern sie sind es dann, wenn die Juroren-Leser aus ihnen eine Orientierung gewinnen können.

Gerade in den Argumenten zur Stimmigkeit offenbart sich das Wesen von Wertungen im Rahmen des Ingeborg-Bachmann-Wettbewerbs. Die Juroren setzen sich zunächst mit Plot und Thema auseinander. An diese erste Betrachtung knüpft sich ein Gefallensurteil, das stark von der Frage geprägt, ist, wie gut sich der Text im Einzelnen erschlossen hat. Im Idealfall erschließt sich der Text unmittelbar als intentional gestaltet, als bis in die Einzelheiten geplant und dennoch nicht voll auflösbar. Erst in einem Rationalisierungsprozess werden die Gefallensurteile in die eigentlichen formal-ästhetischen Wertungen übersetzt. Dabei gibt das Wertungswissen nur die Rahmenbedingungen für die Argumentation vor, das eigentliche Argument wird ad hoc aus dem gewonnen, was für den Juror am Text greifbar ist.

Wie genau Textwahrnehmung und Textbewertung im Lesevorgang ineinander greifen, könnte befriedigend nur im Rahmen einer empirischen Studie erforscht werden. Es soll hier dennoch die These zur Diskussion gestellt werden, dass die sprachliche Umsetzung der Wertungen in den Diskussionen, die Art und Weise repräsentiert, wie Wertungen ablaufen: Je besser ein Text inhaltlich und formal nachvollzogen werden kann, desto positiver ist die Wirkung auf den Leser und desto positiver fällt tendenziell die darauf folgende verbale Bewertung aus. ${ }^{45}$ Dass Orientierungs-Werte allerdings nur ein Baustein - allerdings ein bedeutender - für eine positive Textbeurteilung sind, wird deutlich werden, wenn es um Aktivierungswerte geht (vgl. Kapitel 11).

\subsection{Sprache und Form}

\subsubsection{Gestaltetheit}

\section{Der Wert Gestaltetheit}

Ein überwiegender Teil der Wertmaßstäbe, die in Klagenfurt zum Tragen kommen, sieht Form in funktionalen Zusammenhängen. Eine Betrachtung der Form, die sich jenseits der

$\overline{45}$ In der verknappten Darstellung werden viele Faktoren ausgeblendet, u. a. dass schon der Lektüreprozess auch vom Vorwissen der Juroren über anerkannte Werte, über Auffassung über Literatur u. ä. mit geprägt wird. 
Frage abspielt, ob die Form dem Inhalt angemessen ist und wirkungsvoll eingesetzt wird, findet seltener statt. Wenn sie dennoch stattfindet, dominieren die Maßstäbe Dichte, Präzision und ein Wert, der in dieser Arbeit als Gestaltetheit bezeichnet werden soll. Die Juroren zeigen Genugtuung, wenn sie die Gestaltung eines Textes, seine Form und Sprache, erkennen und nachvollziehen können. Anders als bei den Werten Stimmigkeit und Kohärenz spielt es bei diesen speziellen Argumenten weniger eine Rolle, wie sich die Gestaltungselemente, die bewertet werden, zum Inhalt verhalten.

Oft gibt es auch keine spezifischen Ausprägungen von Gestaltetheit, die erwartet werden. Nichts deutet darauf hin, dass bestimmte Stile prinzipiell anderen vorgezogen werden. Viel entscheidender ist, dass eine Entscheidung für eine bestimmte Gestaltung erkannt und nachvollzogen werden kann (Foregrounding). Prototypische Formulierungen, die Aussagen zur Gestaltetheit enthalten, sind „gut gemacht“, „, gut gebaut“, „gut erzählt“ und „,gut gearbeitet“. Weil es bei den genannten Werten primär um das Erkennen und Nachvollziehen der Machart geht, ordnen sie sich unter den Werten ein, deren Wirkung in Orientierung besteht. Zu erkennen, wie ein Text aufgebaut ist, bestätigt die Juroren als Leser in ihrem Können. Belke/Leder $(2006,5)$ sprechen von „perzeptuellem Problemlösen[]“, dessen Erfolg emotional belohnt werde. Einige der aufgeführten Werte, insbesondere Musikalität werden in der Tat mit Verweis auf ihre sinnliche Wirkung begründet.

Argumentativ ist der Wert Gestaltetheit allerdings mit einem erheblichen Makel verbunden. Gestaltetheit lässt sich nicht begründen, sondern nur beschreiben. Es ist möglich zu sagen: „Mir gefallen die Bilder, die der Autor in diesem Text gewählt hat“. Mit nahezu jeder begründenden Aussage jedoch würden andere Wertmaßstäbe, die nicht den Wert von Gestaltungsmerkmalen an sich in den Blick nehmen, herangezogen. Würde der Juror etwa sagen „Mir gefallen die Bilder, weil sie mir besonders treffend gewählt zu sein scheinen“, kann das entweder heißen, dass er sie dem Inhalt angemessen (kohärent/stimmig) findet oder dass er sie geeignet findet, einen Sachverhalt der Wirklichkeit abzubilden. Mit der Begründung „mir gefallen die Bilder des Textes, weil sie mich berühren“ würde der Wertenden dagegen auf die Wirkungsebene wechseln und nicht mehr die Bilder an sich bewerten. Hinzu kommt, dass beschreibende Wertungen zwar prinzipiell Überzeugungskraft haben können, dass aber in der Regel die Zeit fehlt, ausführlich auf die formale Machart eines Textes einzugehen. Da jeder Juror aber durchaus unter dem Druck steht, seine Wertentscheidung zu begründen, muss eine Aussage wie „Mir gefallen die Bilder dieses Textes“ unzulänglich wirken. Sie besitzt nur eingeschränkte Überzeugungskraft. Eine Analyse der Machart des Textes kann also selten in der Breite dargelegt werden, um eine 
möglichst große Überzeugungskraft zu entwickeln. Das führt dazu, dass der Wertmaßstab Gestaltetheit rein quantitativ im Vergleich zu anderen Wertmaßstäben, die mit formalen oder sprachlichen Argumenten belegt werden, einen relativ geringen Raum einnimmt. Dennoch gibt es immer wieder Beispiele für Aussagen in Diskussionsbeiträgen, die sich darin erschöpfen, die Freude über bestimmte Gestaltungsmittel, darüber, wie ein Text gemacht ist, zu konstatieren.

\section{Musikalität und Sinnlichkeit der Sprache}

Und dieser Text ist gebaut oder arbeitet natürlich/ ist jetzt eine tautologische Aussage, dass Texte mit Rhythmen arbeiten und Musikalität haben. Und man hat auch irgendwie das Problem, dass man dann immer mit Evidenzen argumentieren muss, weil man sozusagen das auch nicht so sozusagen nachweisen kann. Aber mir geht es mit dem Text wie gestern Burkhard Spinnen, dass ich das Versmaß mithöre und auch mitwippen möchte. Und natürlich ist der Text, in dem ich - da stimme ich Daniela Strigl zu - ist kein falscher Ton drin. (2008 Mohafez, 10:53 Nüchtern)

Diese Aussage Klaus Nüchterns bündelt alle wesentlichen Aspekte des Wertes Gestaltetheit, insbesondere des Wertes Musikalität, den man dem Wert Gestaltetheit unterordnen kann. Nüchtern beginnt das Argument mit einer Formulierung, die zunächst darauf verweist, dass er nun auf der formalen Ebene argumentieren möchte: „[D]ieser Text ist gebaut oder arbeitet natürlich/“. Er vollendet den Satz allerdings nicht, da ihm offenbar in den Sinn kommt, dass es nicht zutreffend wäre, zu sagen, dass der Text mit Musikalität „arbeitet“. Stattdessen weist Nüchtern darauf hin, dass literarische Texte prinzipiell musikalisch seien („tautologische Aussage“). Dieser Hinweis, dass klangliche und rhythmische Gestaltung Grundbestandteil von Literatur seien, macht auch darauf aufmerksam, wie sehr professionelle Leser bei Texten, bei denen sie davon ausgehen, dass sie hochwertig sind, erwarten, dass eine formale Gestaltung deutlich erkennbar wird. Hochwertige Literatur ohne eine erkennbar aufwändige formale Gestaltung, die als solche die Aufmerksamkeit auf sich zieht (Foregrounding) ist, so scheint es, nicht denkbar. Im nächsten Gedankengang reflektiert Nüchtern die Erwartung an die Juroren, ihre Wahrnehmungen und Bewertungen am Text nachzuweisen. Musikalität ist, so legt Nüchtern nahe, eine primär sinnliche Qualität, die der Leser wahrnehmen, aber nicht verbalisieren kann. Nüchtern begreift also einen bestimmten Aspekt der Form (die „Musikalität“) als einen elementaren Bestandteil von literarischen Texten, der zwar sinnlich wahrgenommen, aber schwer erklärt werden kann. Dieser Zusammenhang ist charakteristisch für Argumente, die die Gestaltetheit insgesamt, ganz besonders aber die Musikalität als Wert betreffen. Rakusa (2005 Heinrich, 2:25) urteilt, Heinrichs Prosa habe eine große Musikalität und meint damit, es sei eine „eben mit 
dem Ohr auch gebaute Prosa“. Dass Rakusa hier darauf verweist, dass die Geschichte Susanne Heinrichs lautlich sehr präsent ist, unterstreicht den Aspekt der Sinnlichkeit, der sich mit dem Wert Musikalität verbindet. Schindel (1999 Uetz, 15:00) bezeichnet das Phänomen als „eine phonetisch artikulierte Musikalität" und weist extra noch einmal darauf hin, dass „[e]s [...] Rosinen drinnen [gibt], [...] wo ich dann nicht sagen kann, das ist nur Zufall“. Auch in diesem Argument schließt sich an die Beschreibung des akustisch sinnlichen Erlebnisses der Hinweis an, dass dieser Effekt im Text angelegt sei. Fliedl hebt gar die Musikalität gegenüber den Schwächen eines Textes deutlich hervor:

Das heißt, es gibt da einmal eine Unvereinbarkeit des Bildes. Das halte ich für das Problem des Texts. Gleichwohl, jetzt kommt das große Aber, finde ich, dass die Sprache des Textes unheimlich eindrucksvoll ist, dass der Rhythmus und die Musikalität eindrucksvoll ist. (2002 Urweider, 20:48 Fliedl)

Rationales Verstehen und sinnliches Wahrnehmen stehen sich in diesem Beitrag direkt gegenüber. Während Fliedl sich die Bildwelt des Textes nicht erschließen kann, zeigt sie sich von seiner sinnlich wahrnehmbaren sprachlichen Seite („Rhythmus und Musikalität“) beeindruckt. In vergleichbarer Weise wägt Reinacher die sprachlichen „Probleme“ eines Textes, die nicht genauer definiert werden, gegen seine rhythmische Sprachgestaltung ab und entscheidet wie Fliedl, dass der Text in seiner sinnlichen Qualität überzeugt:

Was zuerst ins Auge springt, ist die große Qualität der Sprache, selbst wenn es eben vielleicht da und dort etwas einzuwenden gäbe. Aber trotzdem hört man gerne zu. Im mündlichen Vortrag gewinnt es noch mehr an Musikalität. (2002 Bauer, 3:57 Reinacher)

Die sinnliche Komponente einer musikalischen Sprache wird hier besonders deutlich, indem Reinacher darauf hinweist, dass der Text „[i]m mündlichen Vortrag [...] noch mehr an Musikalität [gewinnt]“. Literarische Texte werden also nicht nur als Lesetexte verstanden, denen man sich intellektuell annähern muss, sondern auch als Hörtexte, die entweder beim stillen Lesen in eine Vorstellung seiner Lautung übersetzt werden oder aber im Vortrag besondere Qualitäten gewinnen. Wie die Beispiele aus den Diskussionen zu Urweider (2002) und Uetz (1999) zeigen, kann die musikalische Gestaltung der Sprache auch dann gelobt werden, wenn der Text auf inhaltlicher Ebene schwer zugänglich ist und die Kohärenzherstellung Probleme bereitet. In dieser Hinsicht unterscheiden sich die Argumente zur Gestaltetheit deutlich von jenen, die auf dem Prinzip der Kohärenzherstellung basieren (vgl. Kapitel 10.2). Allerdings führt die Zuerkennung des Wertes Musikalität in der Regel nicht allein zu einer positiven Gesamtwertung. 
Die Jurorin, die sich am nachdrücklichsten für eine musikalisch und rhythmisch gestaltete Sprache einsetzt, ist Karin Fleischanderl. Sie sieht Musikalität nicht nur als einen Bonus, der den Text zusätzlich aufwertet, sondern als ganz zentrale Eigenschaft von Literatur. Karin Fleischanderl geht noch über Nüchterns eingangs zitierten Hinweis, dass Texte ohnehin mit Rhythmus arbeiten und Musikalität haben, hinaus und fordert Musikalität als ein herausstechendes Merkmal von guten Texten:

\begin{abstract}
Also, ich finde, ein Kriterium, was im ganzen Bewerb eigentlich noch nicht gefallen ist, ist Musikalität. Ich finde, Musikalität ist ebenfalls eine große Eigenschaft der Literatur. Ich finde auch, einige Text, die hier vorgelesen wurden, besaßen Musikalität, aber die Jury versucht immer nur deutsch-deutsche Beziehungen oder politische Beziehungen oder Geschichte oder irgendwie massig Stoff und Inhalt zu suchen, symbolische Überfrachtungen. Dass ein Text Form ist, reine Konzentration, Musikalität, fast auf die Ebene von Musik gehoben wird aufgrund einer sublimierenden Anstrengungen [sic], ist, glaube ich, in diesem Bewerb noch nie gefallen. [Applaus] (2009 Winkler, 5:58 Fleischanderl)
\end{abstract}

Fleischanderl setzt sich in diesem Beitrag prinzipiell für eine Höherbewertung formaler Eigenschaften ein und grenzt sich dabei scharf von den anderen Juroren ab, die ihrer Meinung nach stofflastig argumentieren. Das Moment der Sinnlichkeit betont die Jurorin vergleichsweise wenig. Sie postuliert vielmehr einen generellen Vorrang der Form vor dem Inhalt. Burkhard Spinnen reagiert in der Diskussion zu Winkler auf Fleischanderls Beitrag und gibt zu verstehen, dass Musikalität im sprachlichen Bereich sich deutlich von instrumentaler Musik unterscheide, weil Sprache sich nicht von ihrer Bedeutung lösen lasse (vgl. auch Kapitel 19 „Detailanalyse Andrea Winkler“):

Denn die [Musik KR] hat den Vorteil, dass Töne und Akkorde und Melodien zwar semantisch sind, aber nicht sprachlich. [... ] Und nun hat die Frau Fleischanderl wahnsinnig recht damit, wenn sie sagt, wir vergessen dauernd [.. . ] dieses Erbe der Moderne, das immer wieder aufs Sprachliche hinweist. Aber, ich denke, das alles ist ein Streit. Das ist ein Zweikampf miteinander. Denn in dem Moment, wo ich mit Worten arbeite, wo ich diese ganze Musikalität durch Worte und Sätze/ ausgedrückt wird, habe ich semantisches Material, das mir nicht ausschließlich allein gehört. Das kommt alles aus dem Duden. Das kommt aus der Sprechergemeinschaft. (2009 Winkler, 6:43 Spinnen)

Ein wirklich guter Text, fügt Spinnen im weiteren Verlauf seines Beitrags hinzu, habe beides: sowohl die sprachliche Musikalität als auch einen semantischen Zugang. Spinnen bringt damit auch auf den Punkt, was sich in den Bewertungen immer wieder bestätigt. Für den überwiegenden Teil der Juroren ist es essentiell, den Text semantisch zu verstehen. Es ist entscheidend, dass der Leser auf der Bedeutungsebene einen Zugang zum Text findet. Auf der anderen Seite wird eine formale, klangliche Gestaltung erwartet, nicht nur als besonderer geistiger Anreiz, sondern vor allem auch zur Steigerung der Sinnlichkeit 
und der emotionalen Beteiligung des Lesers am Text. Musikalität erweist sich als eines jener Merkmale, das den Text sinnlich wahrnehmbar machen kann. Gelobt wird also mit dem Wert Musikalität das sinnliche Wirkungspotential des Textes. Gerade aufgrund dieser intensiven sinnlichen Wirkung liegt der Wert Musikalität auf der Grenze zwischen den zwei Wirkungsmechanismen Orientierung und Aktivierung. Dem Komplex Orientierung wurde er zugerechnet, weil die Wirkung auf dem Erkennen kleinteiliger, klanglicher Gestaltungselemente beruht, nicht so sehr dagegen auf der Erzeugung einer Spannung. Laut Kneepken/Zwaan (1994) gehört das Erkennen von Musikalität eher zu den ArtefaktEmotionen, Wirkungen also, die sich auf die Wahrnehmung des Textes als Kunstwerk beziehen.

\section{Selbstbestätigung des Lesers - Kunstfertigkeit des Autors}

Dass ein Text durch bestimmte formale Eigenschaften wie die rhythmische und klangliche Gestaltung sinnlich besser oder überhaupt erst wahrnehmbar wird, ist ein Aspekt der Gestaltung, der an und für sich gewürdigt wird. Daneben gibt es aber auch Bewertungen, die die Zufriedenheit über die eigene Fähigkeit, die Form eines Textes nachvollziehen zu können, in ein Lob der Kunstfertigkeit des Autors verkehren. Wenn durch die Handlung hindurch erkennbar wird, wie die Handlung aufgebaut und sprachlich gestaltet wurde, um einen bestimmten Effekt beim Lesen zu erzielen, loben die Juroren die Kunstfertigkeit des Autors, Informationen zu gestalten und zu arrangieren. „Kunstfertigkeit“ in diesem Sinne ist also eine Eigenschaft, die nur in Wechselwirkung mit dem Leser entstehen kann. Die Nachvollziehbarkeit der Gestaltung bestätigt, so kann man zumindest annehmen, den lesenden Juror in seinen Lesefertigkeiten. Er ist in der Folge bereit, diese gelungene Interaktion mit dem Text als intentionale Anlage durch den Autor zu sehen und diesem seine Kunstfertigkeit zu bestätigen. Dieser Argumentationsweg ist häufig zu finden. Allerdings gilt auch in Bezug auf diesen Maßstab das Prinzip der Balance: Erscheint die Gestaltung als Selbstzweck, geht das Lob in Kritik über (vgl. Kapitel 11.2.3 und 10.3.1 „Dominanz der Form“).

In den gestaltungszentrierten Argumentationen wird nicht die besondere Bedeutung hervorgehoben, die die Form für den Inhalt hat, sondern der kunstvolle Umgang mit der Form wird statt dessen in den Mittelpunkt der Aussage gestellt. Der Unterschied zwischen beiden macht sich primär in der Art bemerkbar, wie die einzelnen Argumente verbalisiert werden.

Typische Aussagen, die die Gestaltung des Textes als solches loben, geben eine interpre- 
tierende Zusammenfassung des Inhalts und konstatieren anschließend die Qualität der Gestaltung. Es geht dabei weder um genuin inhaltliche Fragen, noch wird genauer ausgeführt, welche formalen Merkmale des Textes im Speziellen gelungen sind. Es gilt als selbstverständlich, dass die Handlung eines Textes, das heißt eine inhaltliche Aussage, nur vermittelt werden kann, wenn dafür literarische Gestaltungstechniken eingesetzt werden. Strigl (0:00) schlussfolgert beispielsweise, nachdem sie auf den Inhalt des Textes von Stangl (2007) eingegangen ist: „Und dass das alles mit großer Kunstfertigkeit gemacht ist, war auch durch den Vortrag zu hören“. Die „Kunstfertigkeit“ wird auf formaler Ebene nicht beschrieben. Offenbar geht Strigl davon aus, dass ihre Ausführungen zum Inhalt als Nachweis genügen bzw. sich in Zusammenhang mit der Kenntnis des Textes selbst erklären. Von Stimmigkeits-Wertungen unterscheidet sich Strigls Aussage insofern, als es nicht in erster Linie darum geht, festzustellen, ob die Form in Relation zum Inhalt nachvollziehbar ist. Gegen eine Auslegung als inhaltliche Aussage spricht, dass Strigl mit ihrer Wortwahl eindeutig die formale Gestaltung im Blick hat. Die positive Wirkung an sich - Strigls Fähigkeit, sich im Text zu orientieren - führt dazu, dass dem Autor „Kunstfertigkeit“ attestiert wird. Man könnte das Argument für ein inhaltliches halten; durch Strigls Wortwahl wird es jedoch in den Bereich einer Form-Wertung überführt. Zwei Dinge werden daran deutlich: Zum einen, dass ein hoher Grad von Orientierung dazu führt, dass der Text als formal gelungen eingeschätzt wird, zum anderen, dass es den Juroren wichtig ist, ihre Argumente mit Hinweis auf die Form zu untermauern. Ganz analog verhält es sich in einem Beitrag Radischs:

Also dass Sprache, Erde und Pilze auf so eine wunderbare Weise symbolisch verbundenwerden/ Und dann wird ja mehrmals gesagt, die Zeit rutscht aus ihrer Verankerung. [...] Und das finde ich wunderbar gebaut, allein in der Geschichte. (2000 Riedel, 12:15 Radisch)

Radisch verwebt eine interpretierende Beschreibung des Inhalts mit einigen, relativ unpräzisen Bemerkungen zur formalen Gestaltung. Erst aus dem Hinweis, dass sie die Geschichte wunderbar gebaut finde, geht ganz eindeutig hervor, dass ihre vorherigen Aussagen als Auseinandersetzung mit der Gestaltung gemeint sind. Ihre Zustimmung speist sich, wie Strigls Zustimmung zu Stangls Text, offenbar daraus, dass sie die Gestaltung des Textes erkennen und nachvollziehen konnte.

In dasselbe Schema passt die folgende Aussage Schecks über den Wechsel der Erzählperspektiven in Kieningers Text:

Hinzu kommt aber, und jetzt wird es für mich interessant, ein Spiel mit Perspektiven, wie ich sie aus Texten einfach noch nicht kenne. Das ist so toll gemacht, wie wir hier in 
die Köpfe einer/ aus dem Kopf der Emma in den Kopf eines als Versuchsanordnung, als Variable eingeführten russischen Schauspielers kommen und wieder zurück. Das finde ich schon sehr souverän. Toll! (2000 Kieninger, 0:07 Scheck; Hervorhebung KR)

Scheck begeistert sich für die Regie der Perspektiven und drückt seine Bewunderung für das Können der Autorin aus. Der Fokus des Arguments liegt auf dem Lob dieser Gestaltung der Perspektivwechsel an sich. ${ }^{46}$ Und auch Bronfen (2000 Kieninger, 15:05) betont zufrieden das Vorhandensein der Struktur: „Also jetzt einfach nur mal strukturanalytisch gesehen, hat das absolut eine Form“. Allerdings erklärt Bronfen vorher sehr genau, wie der Text strukturiert ist. Das Urteil ist also eigentlich sehr viel präziser als hier dargestellt. Im Detail scheint das aber gar nicht so wichtig zu sein, denn sie betont, auch in Auseinandersetzung mit den anderen Juroren in dieser Diskussion, primär, dass eine klar erkennbare Form vorhanden ist. Fliedl spricht in einer anderen Diskussion von „eine[m] wunderbar klaren Bau, der so einen Zirkel beschreibt von Anfang bis zum Ende und in der Mitte ist tatsächlich eine Antiklimax“ (2001 Askan, 8:30 Fliedl). In der Formulierung „wunderbar klare[r] Bau" spiegelt sich der komplexe Zusammenhang von Erkennen der Form und Zuschreibung besonderer Kunstfertigkeit. Weil Fliedl die Machart des Textes besonders gut nachvollziehen kann, nimmt sie seine Form als besonders klar wahr. Diese Klarheit wird dem Text als positives Formmerkmal zugutegehalten („wunderbar“). Elemente dieses „Bau[s]“ zählt Fliedl auf. Auch März begnügt sich damit, Formmerkmale aufzuzählen, deren Berechtigung als Gegenstand einer positiven Bewertung vorausgesetzt wird: „Mir gefällt die Geschichte auch sehr gut in ihrer Machart, Erzählweise, in ihrer Figurentechnik, in der Dynamik, in vielem anderem. Auch in ihrem Realismus“ (2006 Merkel, 2:21 März). „Machart“, „Erzählweise“, „Figurentechnik“, „Dynamik“ und „Realismus“ werden als positiv gewertete formale Attribute des Textes genannt. Weder begründet März diese Werteigenschaften, noch gibt sie zu verstehen, was sie unter ihnen versteht. Sie führt dies in ihrem Beitrag auch nicht umfassend aus, sondern kommt dann unmittelbar auf inhaltliche Bedenken gegenüber dem Text zu sprechen.

Gestaltetheit wird aber nicht nur als Kunstfertigkeit des Autors bewundert, sondern bisweilen auch als Ausweis des Literarischen schlechthin gesehen. Meike Feßmann deutet an, dass Gestaltung - sie spricht von „Handwerk“ - ein ganz elementares Merkmal von (literarischen) Texten sei, das dazu geeignet sei, „Freude“ beim Lesen hervorzurufen. Die Gestaltetheit des Textes zu erkennen, wird eindeutig als ein Vorgang benannt, der Freude bereitet:

$\overline{46}$ Mit dem ersten Satz des Ausschnitts, der hier zitiert wurde, wird auch auf Originalität als Maßstab verwiesen („wie ich sie aus Texten einfach noch nicht kenne“). Dieser Aspekt spielt also für Scheck sicherlich eine Rolle. Er wird dann aber nicht weiter verfolgt. 
Ich verstehe gar nicht, dass Sie sich alle sträuben, das als Text wahrzunehmen. Also warum haben Sie keine Freude an dem Handwerk? Wie unglaublich witzig das gemacht ist, dieses Hin und Her! (2009 Preisendörfer, 13.40 Feßmann)

Ganz selbstverständlich koppelt Feßmann das Textsein („das als Text wahrzunehmen“) mit Handwerk und dies wiederum mit der positiven Wirkung des Textes. Allerdings zeigt auch dieser Beitrag die enge Verquickung von verschiedenen Bewertungsebenen. Handwerk, das, so darf man vermuten, ganz eng mit der formalen Gestaltung verknüpft ist, wird mit dem Wertmaßstab humoristische Wirkung („witzig“) verbunden und an inhaltlichen Eigenschaften des Textes illustriert („diese Idee mit den Krokodilsgeschichten“).

Als elementarer Bestandteil von literarischen Texten spielt Gestaltetheit auch bei Radisch eine Rolle:

Ich sehe überhaupt keine kompositorische Kraft in dem Text, die das Ganze bündeln würde, die die Bilder aufeinander beziehen würde. Also es ist ein/ Ja. Ein etwas hilflos dahinplätschernder Text, der sich in keiner Stelle konzentriert. (2007 Grill, 7:35 Radisch)

In diesem Beitrag scheinen sich mehrere Maßstäbe zu überlappen. Es geht um Verdichtung (vgl. Abschnitt 10.3.3 „Dichte als Intensität“), genauso wie um kunstfertige Gestaltung. Die Formulierung „kompositorische Kraft“ ist ein ziemlich eindeutiger Hinweis, dass Radisch Gestaltung vermisst. „Bündeln“, „aufeinander beziehen“, „konzentrieren“ ist das, was Radisch fehlt; „hilflos[es] [D]ahinplätschern[]“ ist, was sie wahrnimmt. Alle Ausdrücke verweisen deutlich darauf, dass sie den Text als zu ungeformt wahrnimmt. Sie betont, sie habe die Lektüre als „quälend“ empfunden, denn „[sie hat] nicht einen Anker gefunden, an dem [sie ihr] Leseschiffchen mal festmachen konnte“ (2007 Grill, 5:52 Radisch). In literarischen Texten wird eine intensive formale Gestaltung erwartet. Das betont Radisch auch in ihrem Urteil über den Text Sabatos, in dem sie äußert, es sei ein bisschen so wie das Telefonbuch lesen. Das Telefonbuch sei auch nicht besonders strukturiert, außer alphabetisch (2004 Sabato, Radisch 26:37), und so einen Gegensatz zwischen Alltagstext und literarischem Text aufmacht, um ihren Anspruch an Literatur, sie solle strukturiert sein, zu unterstreichen. Diese Notwendigkeit der Gestaltung, die die Juroren im Zusammenhang mit literarischen Texten sehen, führt so weit, dass Gestaltetheit sogar dann gelobt wird, wenn überhaupt nur irgendeine Art von Gestaltung sichtbar ist. Etwa in der Diskussion zu Albrecht:

Aber ich glaube, das ist jetzt gar nicht so wesentlich. Wesentlich ist das Tempo und der Rhythmus. Und da finde ich manches, wie Sie, Herr Heiz, eigentlich gut $\overline{\text { gearbeitet. Also, das ist nicht irgendwie egal, was er sagt. Also, der Text ist schon/ }}$ 
der hat schon, der hat seine Technik und er hat bestimmte Wiederholungs- und Parallelisierungstechniken. (2007 Albrecht, 15:01 Ebel; Hervorhebungen KR)

Nicht die spezielle Art des Rhythmus ist entscheidend für die Bewertung, nicht ganz bestimmte Strukturmerkmale, sondern die Tatsache an sich, dass eine „Technik“, das heißt eine Gestaltung, erkennbar wird, sodass es „nicht irgendwie egal [ist], was er sagt“. Impliziert wird hier auch, dass die Form in der Lage ist, dem Gesagten überhaupt erst Relevanz $\mathrm{zu}$ verleihen.

Selbst in einem Urteil, das die Gelungenheit der Gestaltung gegen ihre Innovation abwägt, überwiegt das Lob der Gestaltung deutlich:

Wir müssen auf dieser Ebene, auf der wir uns hier befinden, auch zu einer Einschätzung, zu einer Bewertung kommen. Und da kann ich nicht anders, als zu sagen: Das ist brillant. Es ist virtuos gemacht. Aber es ist zusammengesetzt aus Motiven, von denen ich keines nicht kannte. [...] Das ist eine gut gemachte, eine blendend komponierte, geradezu - man hat es im Vortrag gehört - ein blendend komponiertes Potpourri oder Medley aus solchen Figuren. Ich weiß aber am Ende, ehrlich gesagt, nicht, was er denen, außer der Summe dessen, was ich da alles schon einmal gehört habe, hinzuzufügen hat. (2008 Rammstedt, 8:25 Spinnen; Hervorhebungen KR)

Die Formulierungen, die ausdrücken, wie sehr Spinnen die Gestaltung des Textes imponiert, sind reichlich: „brillant“, „,virtuos“, „blendend“. Eine positive Bewertung kann kaum stärker zugunsten der Fähigkeit des Autors ausgedrückt werden. Angesichts des großen Lobs tritt die Kritik, die Motive des Romans seien nicht originell, in den Hintergrund. Tilman Rammstedt gewinnt schließlich auch den Bachmann-Preis, allerdings ohne die Stimme Spinnens, der sich - im ersten Wahlgang jedenfalls - für Patrick Findeis entscheidet.

Iris Radisch wägt in ihrem Urteil zu Magnussons Text die Effektorientiertheit, die ihm vorgeworfen wird, gegen das Maß an Gestaltung ab, das der Text aufweist und kommt ebenso zu dem Ergebnis, dass der Vorwurf gegen den Text nicht haltbar sei:

\footnotetext{
Also, das ist ein Text, der sehr wohl auch seine Absichten aufdeckt und sagt: So komisch möchte ich bitte verstanden werden. Das spricht ja nicht gegen ihn. Aber das spricht ja doch zumindest für das, was ich meinte, wie klar und makellos und sauber der gebaut ist und in jedem Augenblick wirklich weiß, was er macht. (2005 Magnusson, 15:39 Radisch; Hervorhebung KR)
}

Radischs Formulierungen legen zunächst nahe, dass dem Text eine starke Instrumentalisierung formaler Mittel für seine Absicht vorgeworfen werden kann. „Das spricht nicht gegen ihn“, konstatiert Radisch. Sie setzt sich auf diese Weise mit einer Kritik auseinander, die zwar so nicht geäußert wurde, die sie aber antizipiert. Sie bemüht sich, das 
(vermutete) Problem positiv zu wenden, indem sie darauf hinweist, dass Instrumentalisierung genauso gut als ein Vorzug der Gestaltung gesehen werden kann. Paraphrasieren könnte man diese Argumentation so: Der Text forciert nicht seine Witzigkeit, sondern er ist so gut gemacht, dass dem Leser die Witzigkeit des Textes unmittelbar ins Augen springt. Gestaltetheit wird also als höherwertig gegenüber einer Stimmigkeit gesehen, die ins Langweilige, Vorhersehbare kippt. In diesem kurzen Auszug zeigt sich wiederum, dass der Einsatz formal-ästhetischer Wertmaßstäbe immer relativ zu einer Textwahrnehmung steht, die der Wertung vorausgeht, und in der Lektüre angelegt ist. Sowohl Stimmigkeit als auch Gestaltetheit sind für Radisch anerkannte Werte. Weil sie den Text als einen witzigen wahrgenommen hat (positive Lektürewirkung) und eine Abwertung aufgrund von Überdeterminiertheit erwartet, setzt sie Gestaltetheit als höheren Maßstab ein.

Die in diesem Abschnitt ausgewerteten Diskussionsabschnitte könnten wie ein buntes Durcheinander von Textstellen gelesen werden, in denen explizit auf die Gemachtheit literarischer Texte verwiesen wird. Sie geben aber wichtige Aufschlüsse. Zum einen zeigen sie sehr deutlich, wie wichtig es für die konventionalisierte Verständigung unter den Juroren ist, sich auf die Machart des Textes zu beziehen. Sie gehört in jeder Wertung dazu. Wichtiger noch ist aber die Wertungstendenz, die sich mit Bewertungen verbindet, die auf die Machart im Allgemeinen bezogen sind. Wenn eine intensive formale Gestaltung erkannt wird, wird das immer zunächst positiv gewertet. Es gibt im ganzen Korpus keine einzige Diskussion, in der eine intensive Durchgestaltung an sich negativ bewertet wird. Dagegen geht fehlende (oder nicht erkannte) formale und sprachliche Gestaltung immer mit negativen Urteilen einher. Welcher Art diese formalen Eigenschaften sind, ist zunächst einmal nicht von Bedeutung. Dass die formale Gestaltung eines Textes erkannt wird, kann also offenbar nicht als solches Gegenstand der Kritik werden, sondern nur, wenn sie als inadäquat für die Darstellung eines bestimmte Inhalts (vgl. Kapitel 10.2.2) oder als kontraproduktiv für die hedonistische Gesamtwirkung angesehen wird. In der Diskussion zu Winkler (2009) wird beispielsweise die Überkomplexität der formalen Gestaltung und die damit zusammenhängende Überforderung des Lesers beklagt. Das heißt, formale Gestaltung wird erst dann negativ bewertet, wenn sie mit der Textwirkung oder dem Wert Stimmigkeit in Konflikt gerät. Als Grund für die positive Bewertung von formalen Merkmalen im Allgemeinen können die von Belke und Leder $(2006,5)$ erwähnte emotionale Belohnung von „perzeptuellem Problemlösen“ oder aus einer literaturwissenschaftlichen Perspektive die Artefakt-Emotionen von Kneepken und Zwaan (1994) gesehen werden. 


\title{
Persönliche Vorlieben für bestimmte Gestaltungsmerkmale
}

Welche Gestaltungsmittel und Schreibstile im Einzelnen als gut/angenehm bzw. schlecht/ störend empfunden werden, ist durchaus subjektiv und hängt vom Lesertemperament des einzelnen Jurors ab. Ob beispielsweise ein nachdenklicher oder emotionaler Sprachstil bevorzugt wird, ist nicht eine Frage literaturkritischer Konventionen. In solchen Fällen zählt das Vorhandensein des Gestaltungsmerkmals an sich. Es ist dabei in der Tat wichtig, zu sehen, dass im Fall einer subjektiven Bevorzugung niemals das Nichtvorhandensein bestimmter Gestaltungsformen moniert wird. Es kann kein Anspruch auf subjektiv bevorzugte Gestaltungsarten gestellt werden, da dieser Anspruch nicht durch die gemeinsame Wertebasis gesichert ist und daher auch nicht mit argumentativen Gewinn eingefordert werden kann. Die Schönheit der betreffenden Formelemente kann also gelobt werden, wenn diese vorhanden sind, aber nur schwer eingefordert werden, wenn sie nicht vorhanden sind.

\begin{abstract}
Also das ist alles in einer sehr unaufgeregten Sprache erzählt. Es sind verschiedene Motive verteilt. Also, der Fisch, das Kaninchen. Es wird geliebt. Der Fisch und das Kaninchen. Es wird aber auch verzehrt. Es ist eine durch und durch ausgewogene Erzählung, die mir sehr gut gefallen hat in ihrer Ruhe und in ihrer/ in ihrer Schlichtheit auch. (2009 Sander, 0:10 Sulzer; Hervorhebungen KR)
\end{abstract}

Sulzer erwähnt in diesem Beitrag gleich mehrere gestalterische Merkmale des Textes: die „unaufgeregte Sprache“, die „verschiedene[n] Motive“, die Ausgewogenheit („durch und durch ausgewogene Erzählung“), die „Ruhe“ und „Schlichtheit“. Explizit sagt er, dass ihm die „Ruhe“ und „Schlichtheit“ der Erzählung gefallen haben. Eingefasst sind diese Äußerungen zur Gestaltung allerdings, wie für diese Art von Argumentation typisch, in eine inhaltliche Auseinandersetzung, die noch umfangreicher ist, als hier zitiert, und die Nennung von Beispielen für Motive. Begründet oder erklärt wird das Lob für die Gestaltung nicht. Es ist davon auszugehen, dass die Motive und der gewählte Stil in Sulzers Augen für sich genommen eine Qualität darstellen, zum einen, weil er sie erkennen kann (vgl. Abschnitt „Selbstbestätigung“ (oben)), zum anderen, weil sie ihm in ihrer speziellen Ausprägung gefallen. Die Äußerungen zur Sprache lassen darauf schließen, dass Sulzer eine „ruhige“ Sprache bevorzugt. Ruhe und Unaufgeregtheit sind Merkmale, die Sulzer persönlich als schön empfindet. Ähnlich verhält es sich in einer Aussage von Heiz, der allerdings einen anderen Stil bevorzugt:

Ich habe überall hier hingeschrieben „Lebendigkeit der Sprache“. Ich beurteile nicht Ihren Metaphernsalat. Was machen Sie dann damit? Warum muss Virtuosität, Lust am Schreiben, Liebe zum Detail, legitimiert werden durch metaphysische Größe? Kranke Leute. Klare Novellen. Ist das Angst vor der Lust am Schreiben? Also es ist so wie 
die Agonie der Mittel. Und statt mit Mitteln etwas Neues zu erfinden, werden die in etwas eingepackt, wo es dann auch nicht mehr aufgeht. Also hier kann ich zuhören und Ihr Sprachlabor genießen. Aber die Geschichte ist mir vollkommen gleichgültig. (2007 Kern, 12:23 Heiz; Hervorhebungen KR)

Heiz ist offenbar der Meinung, dass der Text sprachlich lebendig gestaltet ist und auch sein sollte, dass der Autor diese „Lebendigkeit“ allerdings auf unangemessene Weise mit „metaphysischer Größe“ zu koppeln versucht. „Metaphysische Größe“ und „Metaphernsalat" werden der mit „Lebendigkeit“ verbundenen „Virtuosität“, „Lust“ und „Liebe“ gegenübergestellt. Das hedonistische Vergnügen an der Sprache überwiegt für Heiz gegenüber der inhaltlichen Tiefe und gesellschaftlichen Relevanz des Themas (vgl. Kapitel 18 „Detailanalysen Björn Kern“ und Kapitel 13 „Detialanalayse Ute-Christine Krupp“). Heiz nimmt damit eine diametral entgegengesetzte Position zu Sulzer ein - allerdings in ganz unterschiedlichen Diskussionen. Während der eine Gefallen an der „Ruhe“ der Sprache findet, lobt der andere die „Lebendigkeit“ der Sprache. Insgesamt lässt sich im Klagenfurter Wettbewerb keine grundsätzliche Präferenz für temporeiche, handlungsintensive Texte oder nachdenkliche, handlungsarme Texte ausmachen. Welcher Stil bevorzugt wird, scheint im Wesentlichen ein Produkt persönlicher Vorlieben, das heißt im Laufe einer Lesebiografie erworbenen Wissens zu sein. Während im Wertungsverhalten einzelner Juroren durchaus eine Kontinuität der bevorzugten formalen und sprachlichen Eigenschaften beobachtet werden kann, sind sich die Jurymitglieder untereinander oftmals nicht einig über die grundsätzliche Qualität solcher Eigenschaften. Es gibt also keine Einigkeit über die Beschaffenheit sprachlicher Schönheit.

Auch wenn Meike Feßmann (2009 Born, 3:28; Hervorhebungen KR) sagt „Ich möchte jetzt auch nicht unbedingt weiter auf den Hunden herumreiten, sondern nur auf dem einen Hund am Anfang. Wie sprachlich das schön gemacht ist: , ein Rosenbeet überrollt und beinahe noch den Hund'. Also das finde ich gut ausgedrückt", steht die sprachliche Gestaltung eindeutig im Vordergrund. Sie wird als attributiver Wert konstatiert, an einer Textstelle belegt und anschließend noch einmal betont. Im Gegensatz zu Argumentationen, in denen formale oder sprachliche Argumente mit Bezug auf bestimmte formale Wertmaßstäbe vorgebracht werden, soll hier die Textstelle für sich sprechen. Was genau die „schöne“ Ausdrucksweise ausmacht, wie sich nach Feßmanns Vorstellung möglicherweise erklären ließe, warum der zitierte Satz bei ihr den Eindruck von Schönheit erweckt, bleibt genau wie in den anderen zitierten Beiträgen im Dunkeln.

In der Diskussion zu Heike Geißlers (2008) Text „Das luftige Leben“ wird die Intensität der Gestaltung kontrovers diskutiert. Ijoma Mangold (22:37) betont mehrfach die Schönheit 
der Sprache, die Heike Geißler wählt: „Ich würde schon noch einmal die Schönheit der Sprache, die Sie ja auch festgestellt, nur als deplatziert empfunden haben, verteidigen“. Außer der Vorliebe für eine schöne Sprache, die nicht weiter begründet wird, wird deutlich, dass ein Unterschied wahrgenommen wird zwischen einer Bewertung der Sprache an sich und der Bewertung der Sprache im Zusammenhang mit der inhaltlichen Gestaltung des Textes. Eine Sprache kann also als schön empfunden werden, obwohl sie als unpassend für einen Text eingestuft wird. Schönheit lässt sich in den Bachmann-Preis-Diskussionen als ein subjektives Kriterium identifizieren, über das wenig Verständigungsversuche stattfinden. Wertungen über „schöne“ Passagen stehen sich mitunter diametral gegenüber. Während der eine Juror die sprachliche „Schönheit“ (2008 Geißler, 22:37 Mangold) mehrfach hervorhebt, kann es vorkommen, dass dieselbe Sprache einem anderen Juror „einen Schlag in die Magengrube versetzt“ (2008 Geißler, 5:29 Strigl).

\section{Dominanz der Form/Forciertheit}

Zwar wird eine intensive formale und stilistische Gestaltung niemals per se negativ beurteilt (vgl. Abschnitt „Selbstbestätigung“ (oben)), jedoch kann sie dann zu einem Problem werden, wenn sie mit Werten des Komplexes Aktivierung in einen Konflikt tritt. ${ }^{47}$ Die Diskussionsanalysen legen nahe, dass das häufig genau dann der Fall ist, wenn sich der Aufmerksamkeitsfokus unfreiwillig dauerhaft von der Handlungsebene auf die Analyseebene verschiebt, das heißt, wenn die Juroren sich als Lesende dabei beobachten, wie sie die Mechanismen der Aufmerksamkeitslenkung und des Textaufbaus verfolgen, anstatt die Figurenentwicklung oder Thematik des Textes.

Auch diese Variante der Argumentation eröffnet der sprachlich kontrovers diskutierte Text von Heike Geißler:

Als ersichtlich/ für mich ersichtlich GEMACHT. Es kommt immer wieder ein schöner Satz. Dann kommt auch wieder ein realistischer Satz. Und ich möchte doch auch darauf bestehen, dass dieser Mann, der doch die Hauptfigur ist, der ergibt/ ich kann mir unter dem nichts vorstellen. (2008 Geißler, 22:44 Sulzer)

Es stört Sulzer offenbar, dass sich die Gestaltetheit des Textes dem Leser aufdrängt. Der Text wird als forciert empfunden. Es ist davon auszugehen, dass die scheinbar lose Verbindung zwischen der Kritik an der Konstruiertheit des Textes und der Kritik an der

$\overline{47}$ Überdeterminiertheit ist das negative Pendent zu Offenheit. Auch im Kapitel „Offenheit“ (Kapitel 11.2) gibt es daher einen Abschnitt zur Überdeterminiertheit. Die Textstellen wurden je nach dem Schwerpunkt ihrer Aussage zugeordnet. Lag der Fokus der Aussage auf den überdeutlichen Signalen durch die formale Gestaltung, wurden sie unter dem Wert Gestaltetheit besprochen, wurde dagegen die mangelnde Offenheit ins Zentrum gerückt, würde die Textstelle unter dem Wert Offenheit analysiert. Diese Teilung war Resultat des Analyseverfahrens. 
Hauptfigur, die Sulzer nicht plastisch wird, gerade dadurch zusammenhängen, dass seine Aufmerksamkeit von der Entwicklung der Geschichte auf die Machart des Textes gelenkt wird.

Auch Längle (3:05) beklagt, dass ihr Wagners (2000) Text „einfach zu überdeutlich geworden [ist]". Sie habe, so Längle, im Laufe der Geschichte immer mehr im Hintergrund die Scharniere knarren hören, wie das gemacht ist.

Längle begründet ihren Eindruck der Überdeutlichkeit nicht inhaltlich, sondern rein formal. Die Gestaltung schiebt sich in der Wahrnehmung des Lesers in den Vordergrund und lenkt dessen Aufmerksamkeit von Textgeschehen auf dessen Funktionsmechanismen. Ruoss dagegen nimmt denselben Text zwar ebenfalls als sehr stark strukturiert wahr, stört sich jedoch nicht an der Vordergründigkeit der Konstruktion:

\begin{abstract}
Dann wenn wir aber schon jetzt eben sagen, er macht es gut. Was macht er gut? Und warum sage ich nicht sehr gut? Ich finde sehr schön gemacht und sehr gut erzählt, wie dieser junge Mann die Grenze zu dieser Frau nicht überschreiten kann. Das finde ich ausgezeichnet. Sehr schön erzählt. Er kommt mit seinen Floskeln, mit seinen Versatzstücken. Sie ist Künstlerin, offenbar kann sie mit dem Malen auch nicht ausdrücken, was sie will. Es heißt einmal: „Was ich nicht malen kann, darüber muss ich erzählen“, aber niemand hört ihr zu. Das finde ich sehr schön gemacht. Und dann auch dieses leicht schlechte Gewissen, das dort mitzittert in dieser Erinnerung. Das finde ich sehr gut. Wo ich auch Fragezeichen habe an den Text, Ulrike Längle: Bei mir ist es nicht so, dass die Scharniere knarren. Ich finde, sie sind sehr gut geölt. Aber ich sehe sie doch in den Bewegungen des Textes. Macht aber nichts. Das könnte auch für unsere Hellsicht sprechen, nicht. Muss ja nicht gegen den Text sprechen. (2000 Wagner, 4:39 Ruoss)
\end{abstract}

Das Zitat zeigt ein für Klagenfurt typisches Muster, für die Interpretation beispielhafte Teile des Plots herauszugreifen, sie zu abstrahieren und als Strukturmuster des Textes zu präsentieren. Wie in vielen anderen Diskussionsbeiträgen wird dafür die Formulierung „sehr schön gemacht“/,,sehr gut erzählt“ verwendet. Ruoss nimmt aber außerdem die Kritik Längles auf und kommentiert sie. Dabei macht er bewusst, was durchaus bezeichnend für die Beurteilung der Gestaltung ist, nämlich, dass die Frage danach, ob ein Text in der Gestaltung eine Balance zwischen Strukturiertheit und Überdeterminiertheit einhält, nicht nur eine Frage des Textes, sondern auch eine der Lektüreerfahrung und Sensibilität des Lesers ist. Er betont ausdrücklich, dass das starke Hervortreten von Formmerkmalen „nicht gegen den Text sprechen [muss]“"

Auch Iris Radisch zeigt sich in einer anderen Diskussion unzufrieden mit der formalen „Makellosigkeit“ des Textes. Allerdings steht dabei eine andere Nuance im Vordergrund. Nicht, dass die Gestaltung sich in den Vordergrund schiebt, stört sie, sondern viel mehr, dass sie „perfekt“ ist, dass die Form zum Selbstzweck geworden zu sein scheint: 
[W]o man sich fragt: Ja, da muss doch noch etwas kommen. Also diese perfekte Oberfläche, wo es stimmt, diese Dialoge, das geht alles/ So tiptop tiptop fliegen die Bälle und alle haben auch so originelle Namen und alles passt. Und diese Makellosigkeit/ [... Es müsste irgendwo reißen. Es müsste irgendwo einmal im Gebälk krachen. [...] Es hält sich alles in so einer wohltemperierten Balance. (2005 Magnusson, 2:08 und 3:12 Radisch)

In der Diskussion zu Draesner bemerkt Radisch analog, der Text sei ihr „ein bisschen zu sauber gebaut" (2000 Draesner, 00:59 Radisch). Auch hier wird die Machart nicht an sich abgelehnt, sondern ihre Vorhersehbarkeit bemängelt.

Die Wahrnehmung der Gestaltetheit eines Textes verschafft den Juroren, wie gerade die letzten Zitate noch einmal unterstreichen, genau so lange Befriedigung, wie sie zum einen seinem Lesetemperament gerecht wird, und zum anderen so lange, wie der Juror als Mitdenker, als teilnehmender Problemlöser an der Konstruktion des Textes teilhaben kann. Eine Form, die vorhersehbar ist, verliert offenbar ihren Reiz (vgl. Kapitel 11.2). Aber auch, wenn die formale Gestaltung des Textes die Aufmerksamkeit der Juroren so sehr in Anspruch nimmt, dass die Entwicklung von Plot, Figuren und Thema in den Hintergrund treten, reagieren die Juroren mit Abwertung.

\section{Zusammenfassung}

Der Wert Gestaltetheit wurde dann angesetzt, wenn der Fokus der Bewertung auf der Betrachtung des Formelementes selbst lag, das heißt, wenn er nicht in Hinblick auf seine Wirkung oder seine Funktion für den Gesamttext betrachtet, sondern an und für sich bewertet wurde. Oft sind die Übergänge zu Wertmaßstäben wie Sinnlichkeit, Lebendigkeit oder Stimmigkeit dabei fließend. Wertungen der Gestaltetheit sind einerseits Wertungen, an die sich der Anspruch knüpft, das Essentielle von Literatur zu betrachten, denn Literatur wird als intensiv geformtes und bearbeitetes Sprachmaterial gesehen; andererseits sind sie argumentativ schwierig zu handhaben, weil sie leicht den Eindruck reiner Gefallensurteile erwecken. Die Wertungen decken dabei ein großes Spektrum von relativ subjektiven Bevorzugungen eines bestimmten Stils, über den Erlebnischarakter der Sprache (Musikalität) bis hin zur Hochwertung der eigenen Entschlüsselungsleistung, die aber dem Aztor als Kunstfertigkeit zugeschireben wird, ab. Es liegt nahe, dass nicht die spezielle Ausprägung der formalen und sprachlichen Gestaltung wichtig für die Wertungen ist - es gibt offenbar keine Formen oder Stile, die für sich genommen als gelungen oder gut gelten -, sondern dass ihr Auffallen, ihr Insbewusstseintreten, der entscheidende Auslöser für Wertungen der Gestaltetheit ist (Foregrounding). Weil Literatur Sprache ist und weil das 
Konzept von Literatur, auf das die Juroren zurückgreifen, formale Gestaltung unbedingt mit einschließt, wird eine auffallende sprachliche und formale Gestaltung honoriert. In der konkreten Ausprägung der Argumente lässt sich außerdem in vielen Fällen nachvollziehen, was Belke und Leder (2006) als ästhetische Emotionen beschrieben haben und was sich bei Kneepken/Zwaan (1994) unter dem Label Artefakt-Emotionen verbirgt. Das Erkennen und Nachvollziehen von Strukturen wird auf der kognitiven Ebene durch Lust belohnt. Kneepken/Zwaan $(1994,6)$ sprechen von Artefakt-Emotionen, wenn dieses Nachvollziehen der eingesetzten Mittel dem Leser als Kunstfertigkeit ins Bewusstsein tritt. Die Autoren gehen aber auch davon aus, dass A-Emotionen das fiktionale Erleben stören: „A-Emotions diminish the diegetic effect (the experience of being in a fictional world" (ebd.). Dieser Effekt konnte in einigen Bewertungen aus dem Abschnitt „Dominaz der Form“ (10:3.1) nachvollzogen werden. Daneben verweisen die Bewertungen zur Forciertheit auch darauf, dass nicht nur „kognitive Bewältigung“ (Belke/Leder 2006, 8) eine notwendige Voraussetzung für ästhetische Lust ist, sondern auch eine „kognitive Herausforderung“ (ebd., $7)$.

In vielen Beispielen zeigt sich auch die enge Verknüpfung von Orientierungs- und Aktivierungswerten. Die Zuschreibung des Wertes Musikalität fußt auf der bewussten Wahrnehmung von Strukturen, ist aber, folgt man dem, was die Juroren über die Wirkung von Musikalität sagen, begleitet von großer sinnlicher Intensität. Forciertheit als negatives Urteil wird unter anderem damit begründet, dass die Anteilnahme an der fiktionalen Welt sinkt, weil die Aufmerksamkeit auf die Gestaltung gelenkt wird. Die intensive sprachlichformale Gestaltung von Texten wird, das ist auffäliig, niemals an sich negativ gewertet, sondern nur dann, wenn sie mit anderen, höherrangigen Werten in Konflikt gerät. Das sind insbesondere Wirkungswerte wie Langeweile.

\subsubsection{Präzision}

\section{Der Wert Präzision}

Präzision spielt in den Bachmann-Preis-Diskussionen eine eher untergeordnete Rolle. Argumentationen mit dem Bezugspunkt Präzision gründen sich auf einen Erkenntnis-Effekt beim Leser, der darauf basiert, dass sich ein (zusätzlicher) inhaltlicher Zusammenhang eine Aussage des Textes - primär durch die Exaktheit der formalen Gestaltung erschließt. Die Argumentation kann dabei im Wesentlichen zwei Ausprägungen haben. Entweder sie ist auf den Textzusammenhang ausgerichtet, das heißt, es wird argumentiert, dass mit- 
tels der formalen Gestaltung inhaltliche Aspekte des Textes bewusst gemacht werden; oder aber sie ist auf Zusammenhänge der textexternen Wirklichkeit gerichtet, das heißt, es wird argumentiert, dass durch die Gestaltung des Textes ein Zusammenhang der Wirklichkeit deutlich(er) vor Augen tritt. In beiden Fällen empfinden die Juroren es als Gewinn, dass durch die „präzise“ Gestaltung des Textes ein Zusammenhang erst offenkundig wird. Präzision reiht sich damit ebenfalls in die Gruppe jener Werte ein, die auf einem Sichtbarwerden und Nachvollziehen aufbauen. Was genau mit Präzision in literarischen Texten gemeint ist, lässt sich oft nur erahnen. Hilfreich ist dabei eine Vorstellung davon, was Präzision im handwerklichen Bereich bedeutet: Passgenauigkeit und Detailliertheit.

\section{Präzision ,textintern“"}

Sehr deutlich wird der Erkenntnis-Effekt, den Präzision haben kann, von Robert Schindel formuliert. Er nennt dabei unter anderem Genauigkeit und Präzision als entscheidende Eigenschaften der Form, die dazu beitragen, eine Bedeutungsebene aufzudecken, die rein inhaltlich nicht vorhanden ist:

Ich denke ja dennoch, dass sozusagen der ganze Verband, die ganze Kombination dieser Erzählung ausbalanciert ist, sprachlich ökonomisch sehr genau, sehr präzise, dass eben dort in dieser Geschichte das passiert, was man sich doch sehr oft wünscht, dass etwas sichtbar gemacht wird. Und dass ein Text von etwas handelt, von dem er eben nicht spricht. (2002 Bonné, 20:34 Schindel; Hervorhebungen KR)

Zwar wird in diesem Zitat sehr gut deutlich, welche Funktion der formalen Gestaltung von Texten zugeschrieben wird („dass ein Text von etwas handelt, von dem er nicht spricht“), allerdings ist dieser Effekt nicht der Präzision der Darstellung allein zuzuschreiben, sondern auch ihrer „Balance“ und ihrer „Ökonomie“. Inwiefern genau die „präzise“ Darstellung dazu beiträgt, „dass etwas sichtbar gemacht wird“, bleibt im Dunkeln.

Einen besonderen Gewinn, der ausschließlich aus der Präzision der Sprache resultiert, deutet Schindel (1999 Seidenauer, 22:30) an, wenn er sagt, dass er glaubt, „dass in der poetischen Sprache und in der Präzision der Sprache auch die Klischees als Klischees erkennbar werden und auch sich auflösen“. Er gibt also zu verstehen, dass durch die „Präzision der Sprache“ die im Text verwendeten Klischees für den Leser als bewusst verwendetes Sprachmittel erkennbar gemacht werden. Eine Paraphrase macht den Gedankengang Schindels deutlicher: Ein Text, der sprachlich so bewusst gestaltet ist, kann keine „echten“ Klischees enthalten. Sie sind unter diesen Umständen bewusst gewählte, funktionale Elemente des Textes. Das heißt, dass Schindel der sprachlichen Präzision die positive Funktion zuspricht, 
dem Leser zu versichern, dass der Text nicht zufällig zusammengesetzt ist, sondern dass er bewusst gestaltet wurde. Indirekt unterstellt er, dass Klischees in „echter“ Literatur üblicherweise nicht als ernstgemeintes Sprachmittel eingesetzt werden können. Sie werden entweder gezielt eingesetzt, oder aber sie unterlaufen Autoren versehentlich. Ist Letzteres der Fall, spricht das gegen das Können des Autors. Diese Argumentation bestätigt die Bevorzugung von Texten, deren formale Gestaltung sich dem Leser als nachvollziehbar und intentional erschließt, selbst wenn die eingesetzten sprachlichen Mittel (in diesem Fall Klischees) für sich genommen, der Wertungskonvention folgend, negativ bewertet werden müssten. Etwas versteckter zeigt sich dieses Verständnis von Präzision auch in Radischs Argumentation. Präzision wird als Wertmaßstab nicht direkt benannt:

Mir gefällt sein Ton, sein Rhythmus, diese Sätze, die alle so wie mit der Nagelschere ausgeschnitten sind und so einsam dastehen, Stakkato-Sätze, die überscharfen Bilder, die Härte, die das/ die dieser Ton hat. (1999 Mora, 0:03 Radisch; Hervorhebungen KR)

Dass die Sätze „wie mit der Nagelschere ausgeschnitten sind“, deutet auf Feinheit und Exaktheit hin. Radisch lobt also, dass sprachliche Elemente dem Leser ganz klar vor Augen treten. Auch die „überscharfen Bilder“ legen Präzision als Wertmaßstab in diesem Sinne nahe.

Reinacher konstatiert die Präzision auf der Formebene eines Textes und bewertet sie positiv. In welcher Hinsicht genau der Text präzise ist, kann man ihrer Aussage nicht entnehmen: „Mir gefällt das gerade. Ich finde, dass dieser Text so genau gebaut ist, am

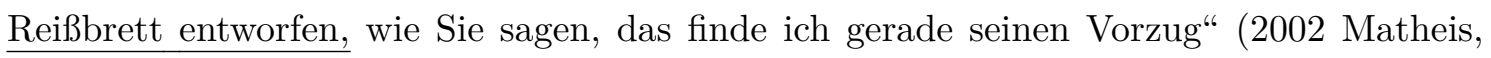
4:33 Reinacher; Hervorhebung KR). Der Text wird als Handwerksprodukt beschrieben („am Reißbrett entworfen“), das sehr fein und genau bearbeitet wurde. Unterstellt wird dabei auch ein sehr hoher Grad an Intentionalität, der den üblichen Grad an Intentionalität in sprachlichen Äußerungen übersteigt. Die Umsetzung der Grundidee des Textes folgt, so kann man Reinacher verstehen, einem ganz genauen Plan.

Die rein konstatierende Positivbewertung der Präzision, wie sie an Reinachers Aussage illustriert wurde, findet sich beispielsweise auch bei Ruoss (0:04), wenn er sagt, Maiers (2000) Sprache sei „wirklich präzise“, „geschliffen“ und „ohne Ausrutscher“. Präzision rückt hier in die Nähe von Gestaltetheit (,geschliffen“) und Einheitlichkeit („ohne Ausrutscher“). Gerade das Attribut „geschliffen“ vermittelt zwar eine unmittelbare Vorstellung, die sich aber nicht ohne weiteres in einen Wertmaßstab übersetzen lässt. „Geschliffen“ bedeutet sowohl intensiv bearbeitet als auch glatt, glänzend, fein. Entsprechend erinnert das Wort sowohl an Gestaltetheit, als auch an Stimmigkeit und Präzision. Die Reihung von „prä- 
zise“, „geschliffen“ und „ohne Ausrutscher" macht den engen Zusammenhang der Werte deutlich. Viel mehr als um alles andere geht es darum, dass für den Juror der Eindruck entsteht, alle Elemente fügen sich ohne große Redundanzen und für den Leser störungsfrei zu einer kohärenten Textwirklichkeit zusammen. Wie dieser Eindruck benannt und festgemacht wird, ist in einem gewissen Rahmen variabel. Sehr knapp und ohne weitere Erklärungen, dafür aber sehr deutlich mit Bezug auf die Form des Textes, bringt Mangold sein Lob der Präzision zum Ausdruck: „Das ist alles sehr genau, sehr gebaut und solide erzählt" (2008 Selg, 0:20 Mangold; Hervorhebung KR). Lediglich der unmittelbare sprachliche Kontext gibt Aufschluss darüber, dass Mangold mit „sehr genau“ einen Aspekt der formalen Gestaltung meint. Nebenbei sei bemerkt, dass Mangold zwar die sprachliche Präzision des Textes lobt, dass er aber unmittelbar darauf, eher auf inhaltlicher Ebene, kritisiert, er „finde es einfach nicht so richtig spannend“ (0:20 Mangold). Hier zeigt sich wieder die Bedeutung der Leseraktivierung für eine positive Gesamtbewertung. Obwohl Mangold dem Text zugesteht, formal präzise und in dieser Hinsicht gelungen zu sein, bewertet er ihn aufgrund der fehlenden Aufmerksamkeitsbindung nicht insgesamt positiv. Schon der Ausdruck „solide“ weist darauf hin, dass der Text zwar handwerkliches Geschick erkennen lässt, dass er aber das Ziel verfehlt, Mangold als Leser zu beeindrucken. In der Diskussion zu Claudia Klischat (2006) fordert Strigl (9:10) eine präzisere Sprache ein: „Also das Schnörkellose, diese gradlinige Erzählweise würde mich nicht irritieren. Nur bei manchen Formulierungen ist es einfach nicht präzise“. Die Beispiele, die Strigl anschließend gibt, lassen eine ungefähre Vorstellung zu, was sie unter „Präzision“ versteht. Sie bezieht sich auf eine Textstelle, in der es heißt „wenn er [der Protagonist KR] Glück haben würde, was er sehr stark vermutete“ (ebd.). Strigl merkt an, es sei ja kein Glück, wenn er es vorher schon vermute (ebd.). Die Kritik an der Formulierung zielt also auf ein Bewusstsein für die Semantik der einzelnen Bestandteile der Formulierung. Obwohl natürlich auch hier Wissen über „Glück“ eine Rolle spielt, das nicht aus dem Text selbst generiert wird, sondern aus der Lebenswelt stammt, geht es in ihrer Kritik nicht um eine Genauigkeit der Abbildung eines lebensweltlichen Wissens, sondern um eine überlegte Wortwahl.

Präzision als Eigenschaft der Form eines Textes ist ein Wert, bei dem nur sehr schemenhaft fassbar wird, was die Juroren genau darunter verstehen. Auffallend häufig werden damit Phänomene bezeichnet, die dem Wert Gestaltetheit nahestehen. Das heißt, es geht möglicherweise weniger darum, eine ganz bestimmte Formeigenschaft als präzise zu benennen, als vielmehr darum, darauf hinzuweisen, dass die Form bzw. Formelemente des Textes an sich sehr klar hervortreten und in ihrer Funktion gut zu beurteilen sind. 


\section{Präzision als formal erzeugter Erkenntnisgewinn (Präzision „textextern“)}

Dem gegenüber stehen viele Äußerungen, die nahelegen, dass dem Text das Attribut „präzise" zugeordnet wird, weil es ihm mittels seiner Form gelingt, Wahrnehmungen, die als zutreffend, als richtig erkannt werden, durch seine Machart auf den Punkt zu bringen. Diese Richtigkeit kann sich sowohl am Weltbild der Juroren bzw. ihrer Wirklichkeitswahrnehmung bemessen als auch an der vom Text selbst produzierten Textwirklichkeit. Rein argumentativ liegt der Anspruch dabei auf der Ebene der Gestaltung. Es geht nicht darum, was der Text sagt, sondern wie er gemacht ist. In manchen Fällen ist diese Zuordnung zum Bereich des Formalen eine rein rhetorische. Wenigstens für einen Teil der Zitate muss angenommen werden, dass ihnen eigentlich die Forderung nach einer realistischen Darstellung zugrunde liegt. So zeigt Radisch etwa ihre Begeisterung darüber, wie es Inka Parei in ihrem Siegertext von 2003 gelingt, durch gelungene Bilder die Welt des alten Mannes, um den es in dem Text geht, darzustellen. Die zugeschriebene Präzision bemisst sich an einem Wissen darüber, wie die beschriebenen Gegenstände und Handlungen aussehen. Es geht bei Radischs Lob aber nicht darum, dass diese Dinge dargestellt werden (inhaltliche Argumentation), sondern darum, dass es Parei durch Sprache gelingt, Bilder zu generieren, die so plastisch sind, dass Radisch als Leserin aufmerksam wird:

Alles, was hier an Sinnlichkeit vorkommt: Das trockene Putztuch über dem Eimer. Das Scharren der Fleischwannen auf dem Auto. Der wunderbare Umgang mit den Krücken. Das ist sowas von/ Also mir bleibt wirklich fast der Atem stehen, so genau, präzise und auch für mich überraschend ist das gemacht. (2003 Parei, 5:43 Radisch; Hervorhebung KR)

Dieser Auszug ist auch ein eindrückliches Beispiel für die Bedeutung der hedonistischen Wirkung für das Urteil. Es lässt sich nicht beurteilen, inwieweit Radischs Aussage wirklich der Wirkung des Textes während der Rezeption entspricht. Es ist jedoch auffallend, dass sie die Textwirkung in diesem Fall sogar ins Zentrum ihrer Wertung stellt.

Deutlicher wird der Bezug auf Alltagswissen in der folgenden Argumentation:

Das ist auch sehr schön und sehr subtil gemacht, wie die Mutterdiskurse so resümiert werden, ganz fragmentarisch, aber ganz genau auf den Punkt gebracht. (2005 Balkow, 2:18 Ebel; Hervorhebung KR)

Auch hier geht es nicht um die Mutterdiskurse an sich, sondern darum, dass der Juror den Eindruck hat, dem Text gelinge es, diese durch seine spezifische formale Gestaltung sehr treffend umzusetzen. Dass die „Mutterdiskurse“, wie im Zitat behauptet, ganz genau auf den Punkt gebracht seien, lässt sich allerdings nur mit Blick auf die Kenntnis von 
„Mutterdiskursen“ auch außerhalb des Textes sagen.

Scheck (0:00) beurteilt „die Psychologie“ in Annegret Helds (2001) Text als "gut gemacht“ und urteilt abschließend: „Ein sehr scharfer Blick“. Auch der „scharfe[] Blick“ lässt sich als Bestätigung lesen, dass die Darstellung der Figuren, gemessen an Erfahrungen, die Scheck gemacht hat, zutreffend ist, wobei diese Bestätigung ausdrücklich auf die Art der Darstellung bezogen wird (,gut gemacht“). Genauso sind die Urteile „Es wird sehr genau gemacht, wie das riecht und was man tun muss, um das und jenes zu erreichen" (2001 Held, 17:46 Schindel) und „Ich finde, dass das alles sehr präzise gemacht ist, quasi mit ihr selbst auf/ mit ihrem Körper zusammen zu sterben“ (2009 Petersen, 7:57 Spinnen) als Urteile über die Plausibilität im Rahmen des lebensweltlich Vorstellbaren zu verstehen. Allen diesen kurz angeschnittenen Argumenten ist gemeinsam, dass sie Präzision als Wertmaßstab wörtlich benennen und als ein Vermögen begreifen, Zusammenhänge oder Textgegenstände so abzubilden, dass sie den Eindruck des Fassbaren und klar Konturierten vermitteln, ohne dass aber damit gemeint ist, dass sie gemessen an der außertextuellen Wirklichkeit zutreffend wären. Sie sind, gemessen am Wissen über die Welt, jedoch im Rahmen der jeweiligen Textwelt, plastisch (zum Thema „Plastizität“ vgl. auch das Kapitel 11.3). Etwas anders, aber von der Aussage letztendlich vergleichbar, verhält es sich in einer Argumentation Sulzers. Das Zitat, das auch im Kapitel „Originalität“ genauer betrachtet wird, möchte ich ausführlich besprechen, weil es sehr gut die indirekte und komplexe Verknüpfung von Wertmaßstäben zeigt. Gleichzeitig lässt sich an ihm geradezu prototypisch zeigen, wie Präzision als Bestätigung einer Weltwahrnehmung und als formales Wertkriterium zusammenpassen:

\begin{abstract}
Und was mir ausgesprochen gut gefällt, ist: Es ist eine sehr präzise, sehr klare Sprache. Absolut nicht um Originalität bemüht. Aber das macht vielleicht gerade/ oder macht, finde ich, gerade die Originalität dieses Textes aus. Man hat nie den Eindruck, also hier macht jetzt einer Literatur. Es ist/ Es ist aber Literatur. Das will ich jetzt damit gar nicht gesagt haben, nicht. Es entwickeln sich vor mir eine Fülle von Bildern. Man könnte jetzt vorwerfen, klar, es ist global. Er fliegt da um die Welt und sieht da/ Aber jedes dieser kurzen Bilder, die da aufflackern, wenn er mal da ist, mal hier, tragen alle zu dieser Geschichte bei. (2009 Schäfer, 3:46 Sulzer)
\end{abstract}

Die Argumentation beginnt mit der Aussage, der Text habe eine sehr präzise, klare Sprache, die ihm ausdrücklich ,ausgesprochen gut gefällt“. Sulzer unterstreicht diese Aussage mit dem Hinweis darauf, dass der Text nicht um Originalität bemüht sei. Er stellt, so darf man vermuten, also eine abbildende, auf die Vermittlung einer Idee ausgerichtete Sprache einer spielerischen Sprache der Abweichung gegenüber, die den Blick auf die Form selbst lenkt. Gleichzeitig ist Sulzer offenbar die Auffassung bekannt, dass Originalität (im Sinne 
von Abweichung) ein zentrales Moment der Literatur sei (vgl. Kapitel 12). Er möchte also in der Folge den Text, dem er das aktive Bemühen um Originalität abgesprochen hatte, gegen den Vorwurf verteidigen, er sei nicht literarisch (hochwertig), weil er nicht originell sei. Schließlich versucht er, die Literarizität des Textes zu zeigen, indem er auf seine Bilder eingeht. Er weist zunächst darauf hin, dass es dem Thema des Textes angemessen sei, wenn viele Bilder vorkommen („es ist normal und er fliegt da um die Welt und sieht“). Allerdings „tragen [die Bilder KR] alle zu dieser Geschichte bei“. Dieser Schlusssatz lässt mehrere Auslegungen zu. Er kann als Hinweis auf den Wertmaßstab Dichte verstanden werden, wenn man voraussetzt, dass es darum geht, dass es nichts Überflüssiges gibt. Man kann ihn abermals als Hinweis auf Stimmigkeit lesen. Angesichts des Verlaufs der Argumentation kann man ihn aber auch als eine Illustration des einleitenden Satzes und damit des Wertmaßstabs Präzision lesen. Das Argument würde dann verkürzt heißen: Die Präzision des Textes auf der Ebene der Bilder ist originell, weil sie sich gerade durch ihre auf das Anliegen des Textes gerichtete präzise Darstellung von anderen Texten abweicht. Durch diese Art der Originalität, die auf den Gegenstand gerichtet ist und nicht auf den Effekt der Innovation, qualifiziert sich der Text als (gelungene) Literatur. Sulzer ist also bemüht, den Wertmaßstab Präzision so zu definieren, dass er zum Wertmaßstab Originalität wird, der schließlich ein Garant für Literarizität zu sein scheint. Die Vermutung, dass Präzision als Wertmaßstab keinen besonders hohen Rang hat, liegt nahe, lässt sich allerdings durch andere Zitate weder beweisen noch widerlegen.

\section{Zusammenfassung}

Präzision ist quantitativ wie qualitativ kein bedeutender Maßstab. Allerdings wird er, im Gegensatz zu vielen anderen Werten, häufig direkt benannt. Der Maßstab reiht sich nahtlos in die Werte aus dem Komplex Orientierung ein, indem er unterstreicht, dass eine reibungslose Lektüre, die den Eindruck vermittelt, der Text sei in allen Einzelheiten intentional gestaltet, eine positive Wirkung auf die Juroren hat und eine positive Wertung fördert.

Der Wertmaßstab Präzision illustriert besonders aussagekräftig, wie stark die orientierende Funktion der Form ist. Auf der textinternen Ebene bedeutet das Zuweisen des Maßstabs Präzision, dass die formale Machart des Textes besonders gut nachvollzogen werden kann. Präzision hat hier eine starke handwerkliche Komponente und verweist darauf, dass der Text als „sauber“ und detailliert gearbeitet wahrgenommen wird. Bezugspunkte können semantische Aspekte der Formulierungen sein, aber auch die Plastizität von Bildern oder 
der gut nachvollziehbare Einsatz von Motiven. Den Horizont für Äußerungen dieser Art bildet allerdings der Text selbst. Präzision „textintern“ ist damit an das Vermögen des Lesers gekoppelt, formale Strukturen erkennen zu können. Der Maßstab hat die Bedeutung von „Genauigkeit“.

Präzision in der zweiten Variante („textextern“) setzt die Präsentationsform des Inhalts stärker mit Wissen über die außertextuelle Wirklichkeit in Bezug. Von Texten wird erwartet, dass sie Alltagswissen in einer Weise präsentieren, dass es bewusst und plastisch wird. Als übergeordneter Wertmaßstab wäre hier an Erkenntnisgewinn zu denken, allerdings spielt dieser argumentativ kaum eine Rolle. Zentral für die Argumentationen ist, dass durch die Anordnung von Informationen im Text eine Aufmerksamkeitslenkung vorgenommen wird, die dem Leser Zusammenhänge zugänglich macht.

Insgesamt bleibt die Auswertung der Textstellen mit Bezug auf den Maßstab Präzision unergiebig, jedenfalls dann, wenn es darum geht, genau zu verstehen, wie Texte beschaffen sein müssen, um als präzise eingestuft zu werden. Von der Grundtendenz her reihen sich die präzisionsbezogenen Wertungen sehr gut in die anderen Orientierungswerte ein, indem sie die Informationsvergabestrategien des Textes als Bezugspunkt für den beim Lesen entstandenen Eindruck der Klarheit ${ }^{48}$ und Kohärenz fokussieren.

\subsubsection{Dichte}

\section{Der Maßstab Dichte}

Wie Präzision spielt dieser Maßstab Dichte nicht allzu oft eine Rolle. Diskussionsbeiträge, die den Maßstab Dichte nutzen, legen zwei unterschiedliche Auffassungen dessen, was Dichte bedeuten kann, nahe. Zum einen geht es häufig um das Verhältnis von Textlänge und „Informationswert“. Auch bzw. gerade in literarischen Texten wird erwartet, dass viele Informationen mit möglichst geringem Aufwand vermittelt werden. Es wird eine Ökonomie der Form und Sprache erwartet. Informationen, deren Wert für die Erschließung der Bedeutung oder einer Bedeutungsebene nicht ersichtlich ist, gelten als überflüssig. Spinnen hält beispielsweise Texte für besonders gelungen, wenn man nichts mehr streichen kann, ohne den Sinn zu verändern:

Ich persönlich, Offenlegung der Kriterien, mag Texte, die nach dem Prinzip Saint Exupérys gebaut sind, und das heißt, etwas ist perfekt, nicht, wenn man noch etwas hinzu/ wenn man nichts mehr hinzugeben kann, sondern wenn man nichts mehr

$\overline{48}$ Bortolussi et al. (2008) nennen in ihrer empirischen Untersuchung „Clarity“ als einen stärker durch den Text gesteuerten Wert, der auf der Einschätzung basiert, ob der Text klar oder opaque ist. 
wegnehmen kann. Der Text scheint mir auch eine Ästhetik zu vertreten des Nichtsmehr-wegnehmen-könnens. (2001 Krupp, 0:00 Spinnen)

In diesem Sinne bedeutet „Dichte“ Ökonomie und Reduktion auf das Notwendige.

Dichte kann zum anderen aber auch meinen, dass viele Informationen kunstfertig in sprachlichen Mitteln verpackt werden. Dichte in diesem Sinne zielt auf Intensivierung statt Verknappung. Durch den kunstfertigen Einsatz sprachlicher Mittel können auf kleinem Raum viele Informationen, beispielsweise verschiedene Bedeutungsebenen, aufgerufen werden. Entscheidend ist bei beiden Varianten, dass sich unter Einsatz möglichst weniger Worte, ein möglichst großes Maß oder Spektrum an Bedeutung vermitteln lässt, sodass es in den Worten von Heydebrand/Winko $(1996,119)$ zu „eine[r] Intensivierung des Dargestellten“ kommt.

\section{Dichte als Ökonomie}

Dichte als Ökonomie wird oft sehr „materiell“ mit Verweis auf die Seitenmenge eines Textes beurteilt. Einer jener Texte, in denen ein Juror - Thomas Hettche - ein Missverhältnis von Textlänge und Informationsmenge sieht, ist der von Uetz (1999):

Die Voraussehbarkeit, dass eben das Durchstreichen einen Strich ergibt. Und diese Maschine kann man auch/ Ich sehe auch nicht die Assoziationsfreiheit wie Frau Radisch. Ich sehe eher eine Durchführung, die an ganz vielen Sachen auch mechanisch ist. Da taucht manchmal ein Wort wie „Verzicht“ auf, auf Seite sieben, und das wird dann über sieben Zeilen durchdekliniert bis es dann bei Sinfonien ankommt. Also auf die Art geht es im nächsten Motiv weiter. Das wirkt für mich alles sehr, sehr maschinell und überhaupt nicht spaßig und mir ist überhaupt nicht klar, warum der Text auch irgendwie elf Seiten braucht. Ist mir ein Rätsel, warum er das nicht auf zwei Seiten machen kann. Ich sehe die Struktur nicht, die diese Länge gibt. Es hat für mich keine geschlossene Form, keine Notwendigkeit des Textes. Oder ich bin zu dumm es zu verstehen. (1999 Uetz, 9:40 Hettche)

In diesem speziellen Fall geht es nicht nur um die Menge der vermittelten Informationen, sondern es kommt zusätzlich ein Verstehensargument ins Spiel. Dass die Frage der

Ökonomie in diesem Text an die Frage des Verstehens gekoppelt ist, wird besser verständlich, wenn man eine ungefähre Vorstellung vom Text hat. Christian Uetz‘ Text „Hirnhelle Heroine“, wie er in Klagenfurt gelesen wurde, beginnt so:

Sie kann nicht das Wort sein. An diesem Wort bleibt sie nicht hängen. Sie kann nicht das Wort sein, das nicht sein kann. In dieses Wort wird sie sich nicht hengeln. Das Wort ist ja nicht. Sie aber ist nicht das Wort. Das ist nicht zum Kopfzerrn. Sie muss sich nicht übergeben, sie muss nicht sein, wie das Wort. Sie kann es nicht erbrechen. (Uetz 1999) 
Nicht so sehr die Menge der vermittelten Informationen ist das Problem, sondern dass die Informationen für Hettche in ihrer Menge durch fehlende Ordnung (,ich sehe die Struktur nicht“, „keine geschlossene Form“) wertlos werden. Man darf annehmen, dass in der Literatur eine Redundanz an Informationen durchaus erlaubt ist, dass Redundanz sogar gewollt ist, sofern diese sich für den Leser durch ihre formale Einbettung als sinnvoll für den Text erweist. Der Text von Uetz ist sprachexperimentell. Er baut auf die rhythmischklangliche Anordnung von Sätzen, die zwar für sich genommen grammatisch und semantisch nachvollziehbar sind, sich aber nicht ohne erheblichen gedanklichen Aufwand zu einer Gesamtaussage zusammenfügen lassen. Der Text entzieht sich damit dem häufig vertretenen Anspruch, im besten Fall eine Handlung, wenigstens aber ein Thema zu entwickeln (vgl. beispielsweise Kapitel 7 „Creative Writing“). Vielmehr kreist er um ein Thema. Dabei stellt der Text mit Freude aus, was durch Sprachspiel möglich ist. Hettche erkennt zwar, dass der Text im Detail nach einem strukturellen Prinzip gearbeitet ist („maschinell“), für ihn erschöpft er sich allerdings darin, diese Struktur im Kleinen zu wiederholen, sodass er auf die Länge nichts Neues bietet. Der Text liefert also nur noch für das Verstehen wertlose Informationen (,und überhaupt nicht spaßig und mir ist überhaupt nicht klar, warum der Text auch irgendwie elf Seiten braucht. Ist mir ein Rätsel, warum er das nicht auf zwei Seiten machen kann“). Mangelnde Dichte ist in diesem Fall also als ein Missverhältnis von Information und Textlänge zu verstehen. Dabei wird nur die Information als relevant eingestuft, die für Hettche zugänglich ist, also das, was zur Kohärenz des Textes beiträgt. Es läge nahe, dass der Text in Hinblick auf Dichte als Intensität als sehr gelungen bewertet würde. Das ist allerdings ebenfalls nicht der Fall, weil den Informationen keine Bedeutung in Hinblick auf ein kohärentes Textverständnis zugewiesen werden kann. Ein Großteil seines Redebeitrags entfällt darauf - auch das klang in der eingangs zitierten Passage aus dem Beitrag Hettches schon an -, sich den Text mithilfe philosophischen Vorwissens, aber auch mithilfe der Rekonstruktion der sprachlichen Form, verständlich zu machen.

Auch in Ursula März‘ Urteil über den Text von Kim (2005) geht es letztlich darum, die Ökonomie des Textes durch Kürzung zu steigern:

Ich glaube wirklich, wenn er zwei Seiten kürzer wäre, wenn diese Monotonie noch kälter, noch naturwissenschaftlicher rauskäme, wenn viele Sätze wegfielen, die dann doch ein bisschen ins Gefühlsmäßige gehen, dann hätte er eine noch größere Qualität. (2005 Kim, 20:27 März)

Anders als Hettche in der Diskussion zu Uetz ist März das Gestaltungsprinzip des Textes von Anna Kim durchaus klar und sie erkennt es auch an. Allerdings empfindet sie manche 
Stellen als überflüssig. Diese Stellen identifiziert sie außerdem als Brüche („ins Gefühlsmäßige“) mit dem von ihr erkannten Gestaltungsprinzip („Monotonie“).

Auch in März' Aussage, sie habe „fast manchmal angefangen [...] sozusagen von einer Stelle zur nächsten zu lesen, von einer kulturgeschichtlichen Signalinformation zur nächsten“ (2008 Ziegler, 0:42 März), kommt die Missbilligung von Informationen, die nicht unmittelbar für den Erzählzusammenhang wichtig zu sein scheinen, zum Tragen. Dabei geht es, das soll an dieser Stelle noch einmal betont werden, nicht so sehr darum, dass die Informationen nicht zum Text passen - im Gegenteil, sie lassen sich gut als Teil des Textes verstehen -, sondern vielmehr darum, dass sie den Text nicht bereichern, keinen informativen Mehrwert für ihn haben. Beide Argumentationen haben zum Gegenstand, dass Teile des Textes überflüssig erscheinen.

Überflüssiges wird unter anderem auch von Scheck moniert, der bei Bärfuss feststellt, dass der Text „in [s]einen Augen komplett überflüssige Figuren“ (2002 Bärfuss, 2:13 Scheck) enthält und der sich in der Diskussion zu Bonné ganz grundsätzlich die Frage stellt, wieso ihm „hier noch neue Figuren präsentiert [werden]“ (2002 Bonné, 5:12 Scheck). Offenbar erschließt sich die Funktion der Figuren nicht. Während sich die beiden zuletzt angeführten Aussagen auf die Notwendigkeit beziehen, die Figuren für einen Text haben, deuten die folgenden zwei wiederum auf eine Angemessenheit der Menge an Informationen hin. So bemerkt Ebel (2007 Oda, 6:00), die Anlage der Figur fresse den Text auf. Auch in diesem Argument schimmert die Erwartung durch, dass eine Handlung - nicht nur eine statische Figur oder eine Szene - entwickelt wird. Die Kritik am langwierigen Figurenaufbau lässt sich als impliziter Wunsch nach der Entstehung einer intensiveren Handlung lesen. In Scheuermanns Text dagegen lobt Ebel (2007, 0:05), dass die beiden Ich-Erzählerinnen „außerordentlich diszipliniert“ seien und die Leser nicht „[zu]quatschen“. Er kommt zu dem Schluss, der Text sei „,ausgezeichnet gemacht‘: „Es wird nichts erzählt, was nicht in diesem Moment genau nötig ist" (ebd.). Dieses Argument zielt in dieselbe Richtung wie Spinnens Aussage, ein Text sei dann perfekt, wenn man nichts mehr wegnehmen könne. Auch Scheuermanns Erzählerinnen erzählen nur so viel, wie unbedingt notwendig ist jedenfalls nicht zu viel.

\section{Dichte als Intensität}

Wenn es um die Kunstfertigkeit geht, mit der viele Informationen/Informationsnuancen in wenig sprachlichen Mitteln verpackt werden, läuft die Argumentation eher auf Vernetzung und Kompaktheit hinaus als auf Länge. Auch bei diesen Beispielen kommt das Wort 
„Dichte“ nicht unbedingt wörtlich vor. Miller spricht beispielsweise von „eng aufeinander bez[ogenen] [thematischen Einheiten]":

\begin{abstract}
Ja, ich habe gegen die Charakterisierung als einer Etüde nichts. Das ist ein außerordentlich streng in sich, einem bestimmten Muster nachgehender Text, der seine Motive, die darin vorkommen, die thematischen Einheiten, eng aufeinander bezieht, sie spiegelt, sie umdreht, sie wiederholt. Das ist alles sehr virtuos gemacht. Die Frage ist: Sie verbinden mit der Etüde die Klavierübung für Anfänger im Metier. Die Etüde kann für sich ein bedeutendes Kunstgebilde sein, das diesen Charakter der Etüde durchaus beibehält. (2003 Lewejohann, 18:52 Miller; Hervorhebung KR)
\end{abstract}

Miller geht es um die enge Verknüpfung von Informationen durch sprachliche Kunstmittel wie Motive und Bilder. Fliedl spricht in einer anderen Diskussion davon, dass die Wörter „eine Dichte herstellen von Bezügen“:

\begin{abstract}
Was mich so beeindruckt hat an diesem Text, das ist dieses Moment der Komposition, also des Musikalischen und Rhythmischen Anordnens von Assoziationsschleifen zu Wörtern, die sozusagen in ihren semantischen Gegensätzen auch abgegangen werden. Was weiß ich, „Portal“ oder „Maß“ oder „Kurs“, die dann sozusagen eine Dichte herstellen von Bezügen. [...] Das erzeugt für mich eine Spannung, die einfach sozusagen auf einer anderen Ebene liegt als diese inhaltliche Addition. Dieses Mäandern der Form, das geschieht um bestimmte Topoi herum, die konstant sind. (2001 Laher, 9:18 Fliedl)
\end{abstract}

Anders als in den Beiträgen zur Stimmigkeit geht es bei Fliedl nicht um das Aufeinanderbezogensein von Inhalt und Form, sondern um das Vermögen, bestimmte formaler Elemente zu verknüpfen. Inhaltlich konstante „Informationen“ („Topoi“) werden durch formale Variation („Mäandern der Form“) in unterschiedlichem Licht präsentiert. Dadurch entsteht eine Verdichtung des Inhalts. Dichte ergibt sich also, so findet sich die Aussage auch bei Miller, aus einer Variation des Gesagten durch Einsatz verschiedener formaler Mittel: Eine „sehr dichte Form des Beschreibens“ meidet, so Miller „die Repetition des Gesagten“ (2003 Flor, 0:14 Miller). Was unter formaler/sprachlicher Dichte verstanden wird - denn das wird selten direkt ausgesprochen - kann man in einem Beitrag Rakusas erkennen:

Ich habe eben schon das Wort rhizomatisch gebraucht, eher so wie ein Wurzelgeflecht. Der Text ist/ hat so Verästelungen, ja. Und Struktur, ich weiß nicht, was wir unter Struktur/ Wir müssen das Wort „Struktur“ erstmal definieren vielleicht, was wir darunter verstehen. Er hat nicht die übliche Dramaturgie auch so einer großen Verdichtung und von Höhepunkten und so weiter. Das hat er ja überhaupt nicht. Aber rhizomatische Texte haben das nie. Die bewegen sich so. Weder in die Tiefe noch in die Höhe, sondern so, ja. So geschwürartig ein bisschen. (2004 Sabato, 28:34 Rakusa)

Rakusa gibt hier eigentlich die Definition eines rhizomatischen Textes, dem sie Texte mit der „,̈̈bliche[n] Dramaturgie“ gegenüberstellt, die wiederum sich durch „große[] Verdichtung" auszeichnen. Verdichtung meint hier intensivieren, auf den Punkt bringen, aber auch 
(emotionale) Spannung aufbauen („Höhepunkten“ versus „weder in die Höhe, noch in die Tiefe“) und Strukturen erkennbar werden lassen (im Gegensatz zu „geschwürartig“). Dass eine Reduktion strukturierender Mittel gleichzeitig eine Verringerung der Dichte bedeutet, wie Rakusa es andeutet, erweist sich als eine Korrelation, die auch andere Juroren annehmen:

[S]o bescheiden bin ich da nicht und ist der Text auch nicht, zu sagen: es ist eben die völlige Zurücknahme aller Kunstmittel zugunsten eines dokumentarischen Erzählens. Hier wird nicht dokumentiert, sondern hier wird ungeheuer straff und ökonomisch komponiert. (2006 Klischat, 16:06 Detering; Hervorhebung KR)

Detering stellt dokumentarische und künstlerische Texte gegenüber. Implizit sagt er dabei, dass sich dokumentarisches Schreiben durch „die völlige Zurücknahme aller Kunstmittel“ auszeichnet. Diesen Weg wählt der Text nicht. Klischats Text ist kein dokumentarischer Text, denn er ist „ungeheuer straff und ökonomisch komponiert“.

\section{Zusammenfassung}

Von literarischen Texten wird erwartet, dass Informationen, die sie präsentieren, stets relevant sind (Dichte als Ökonomie). Die Relevanz der Information hängt dabei nicht allein vom Textgefüge ab, sondern auch davon, wie sehr der Leser das Vermögen hat, die gegebenen Informationen in das Textganze einzuordnen.

Dichte als Intensität nimmt die erkennbare Vernetzung und Nuancierung von Inhalten durch formale Mittel in den Blick, die sich mit einer Steigerung der geistigen und emotionalen Anteilnahme des Lesers verknüpfen sollte.

Grundsätzlich wird auf beiden Ebenen (Ökonomie und Intensität) ein möglichst hoher Grad angestrebt, jeweils jedoch unter Wahrung der Zugänglichkeit. Eine Intensivierung durch formale Vernetzung führt, wie das Beispiel Uetz (s. o.) zeigt, nur so lange zu einer Aufwertung, wie der Leser auch in der Lage ist, die Komplexität noch zu verarbeiten. Andernfalls wird der Text als unökonomisch wahrgenommen. Ökonomie wird also nur in dem Maße anerkannt, wie der Leser in der Lage ist, den Text nachzuvollziehen. 


\section{Aktivierung}

\subsection{Aktivierung als Textwirkung}

Im Kapitel „Orientierung“ wurde gezeigt, wie elementar die Rekonstruktion eines kohärenten, nachvollziehbaren Textes für den Lesegenuss und damit die positive Bewertung des Textes ist. Es wurde außerdem gezeigt, dass bei geübten Lesern das gelungene Erkennen und Einordnen formaler Strukturen und sprachlicher Stile als Prozess der Selbstbestätigung im Sinne von Belke/Leder (2006) die Bewertung des Textes positiv beeinflusst. Dabei zeichnet sich das Bewerten als ein Prozess ab, der in der positiven Wahrnehmung von Lust während der Lektüre wurzelt. Erst im Nachgang wird dieses Lustempfinden (oder ggf. Unlustempfinden) rationalisiert und mithilfe bewusst wahrgenommener Textmerkmale (Foregrounding) in eine konventionalisierte Wertsprache übertragen. Anhand der Diskussionsbeiträge lässt sich zeigen, dass ein Wertmaßstab wie Stimmigkeit sich nicht auf spezifische Eigenschaften des Textes bezieht, sondern auf den lustvollen Prozess des Nachvollziehens. Alle Mechanismen des Foregrounding (vgl. van Holt/Groeben 2005) sind grundsätzlich dazu geeignet, diesen Lusteffekt zu erzielen. Da allerdings Texte immer auch durch ihre Machart dazu beitragen, wie viel Orientierungspotential sie haben, ist die Wirkung der Orientierung keine reine Konstruktionsleistung durch den Leser. Die positive Bewertung literarischer Texte hängt also, so das vorläufige Ergebnis, davon ab, wie gut das Textpuzzle zu einem kohärenten Ganzen zusammengefügt werden kann. Dabei reagieren die Juroren auf Impulse des Textes. Es ist aber auch davon auszugehen, dass Leseerfahrung eine Rolle spielt. Im Gegensatz zu Sachtexten wird bei literarischen Texten die Kohärenz auch auf der Ebene der Form beurteilt. Es liegt nahe, dass dabei das „literarische Foregrounding“ (van Holt/Groeben 2005), also die Lenkung der Aufmerksamkeit des Lesers auf die Sprache, von großer Bedeutung ist. Doch der positiven Bewertung von orientierungsstiftenden Merkmalen sind Grenzen gesetzt. Sie funktioniert nicht nach einem Je-mehr-desto-besserPrinzip. Streut ein Text zu viele Signale, die sich als potentiell bedeutungsvoll abheben, kann es zu Negativbewertungen kommen. Zum einen kann es passieren, dass Langeweile auftritt, weil im Text Signale erkannt werden, die einen Mehrwert für das Verständnis suggerieren, obwohl bei näherer Prüfung kein Mehrwert erkannt werden kann. Zum anderen ist es möglich, dass die angebotenen Signale das Verarbeitungsvermögen der Juroren übersteigen. Aus der Überforderung folgt Frustration. In beiden Fällen kann mangelnde Effizienz als Grund der Frustration angenommen werden. Schon in diesem Zusammenhang wird deutlich, dass Orientierung nicht die einzige Wirkung sein kann, an der sich die 
Wertschätzung eines Textes bemisst.

Neben Kohärenz und Nachvollziehbarkeit der Machart hat sich ein zweiter Wertekomplex - die Aktivierung des Lesers durch den Text - als entscheidend für eine positive Bewertung erwiesen. Unter Aktivierung fasse ich Phänomene zusammen, die entweder ein Nichtverstehen im Verstehen zur Grundlage haben, sodass der Leser veranlasst wird, viel gedankliche Eigenleistung in den Text einzubringen, sowie Mechanismen der Aufmerksamkeitsbindung durch mentale und emotionale Anteilnahme an Figur und Plot. Aktivierung kann aus verschiedenen formalen Mechanismen resultieren. Neben einer bewusst vom Autor angelegten künstlerischen Offenheit, kann auch der Wunsch, zu erfahren, wie es weitergeht, Aktivierung ermöglichen. Auch der Grad, in dem der Text eine Empathie mit den Figuren ermöglicht, kann ein Mittel sein, Anteilnahme zu gewährleisten. Wie auch im Komplex Orientierung sehen die Jurymitglieder aufgrund ihrer Rolle als Textkritiker die Gründe für eine gelungene Aktivierung selten bei sich selbst oder in den eigenen Lesevoraussetzungen, sondern in der Anlage des Textes.

Der Wertekomplex Aktivierung umfasst neben dem zentralen Wert Offenheit auch noch die Lebendigkeit und Anschaulichkeit von Figur, Erzähler und Perspektive. Auf der Wirkungsebene ist Spannung Ausdruck von Aktivierung. Allerdings wird der Begriff in den Jurydiskussionen überwiegend zugunsten anderer Ausdrucksweisen mit ähnlicher Bedeutung umgangen.

Während der Wertungskomplex Orientierung erst dann spezifisch literarisch wird, wenn es um die formale Umsetzung des Inhalts bzw. den Mehrwert formaler und sprachlicher Eigenschaften für das Verständnis des Textes geht, ist der Wertungskomplex Aktivierung eindeutig ein spezifisch literarischer. Empirische Studien, die danach gefragt haben, warum Menschen freiwillig Bücher lesen (Nell 1988) bzw. wie Leser ihrem eigenen Verständnis nach überhaupt lesen und ihr eigenes Lesen einschätzen (Graf 2004), sehen als zentrale Voraussetzung für eine gelungene (lustvolle) Lektüre, dass die Aufmerksamkeit so stark auf den Text fokussiert ist, dass der Leser nicht merkt, wie die Zeit vergeht, und völlig im Lesen (in der Regel eines erzählenden Textes) aufgeht. ${ }^{49}$ Graf (2004) erarbeitet in seiner Lesebiografien-Studie Lesemodi - „erworbene Handlungsdispositionen, die spezifische Rezeptionsweisen ermöglichen, um Texte subjektbezogen zu nutzen“ (Graf 2004, 120) -, mit denen Leser Texten begegnen können. Dabei geht er davon aus, dass nicht der Text den Modus der Lektüre vorgibt, sondern dass Leser auf der Grundlage ihrer Einübung in die

49 Die Aufsatzbände von Baisch et al. (2013) sowie Irsigler et al. (2008) versammeln Aufsätze zur affektiven Aufmerksamkeitsbindung und Spannung und weisen immer wieder auf die Bedeutung der Aktivierung des Lesers hin. 
verschiedenen Modi im Laufe ihrer Lesesozialisation einen ihnen angemessen scheinenden Lesemodus wählen (ebd., 121). Die Modi, die primär mit der Rezeption fiktionaler Texte verbunden sind, sind das „intime Lesen“ (ebd., 49 ff.) und der „ästhetische Lesemodus“ (ebd., 107 ff.). „Intime Lektüre“, deren Gegenstand laut Graf (ebd., 49) der Unterhaltungsroman ist, zeichnet sich „durch de[n] hohe[n] Grad der emotionalen Involviertheit des Lesers“ (ebd.) aus. Als zentrales Kriterium für eine gelungene „intime Lektüre“ geben die Teilnehmer der Studie in ihren Sprachbiografien „Spannung“ an (ebd., 53). Graf (ebd., 53) verweist allerdings darauf, dass die Texte, denen das Merkmal „spannend“ zugewiesen wird, extrem heterogen seien. Spannung ist ein Phänomen, das mit einem Zustand großer Konzentration und Teilnahme am Geschehen einhergeht (Irsigler et al. 2008, 8). Darüber hinaus ist das Phänomen der Spannung begrifflich schwer fassbar. Mellmann (2016, 166) fasst „Spannung“ als „Leseremotionen mit starkem Erregungspotential (arousal)“ zusammen. Mit Blick auf persönliche Erfahrungen ist diese Beschreibung sicherlich für jeden Leser sofort nachvollziehbar. Koppenfels/Zumbusch (2016, 23) und Mellmann (2016, 166 f.) machen aber auch auf die Bandbreite dessen aufmerksam, was Spannung meinen kann: Sie kann als „Denkemotion[]“ (Koppenfels/Zumbusch 2016, 23) Effekte wie Überraschung, Neugierde und Langeweile hervorrufen. Als Rätselspannung (mystery) fordert sie das Mitdenken des Lesers und als suspense fördert sie die Anteilnahme des Lesers an Figur und Plot (vgl. Langer 2008). Mellmann hält fest, dass Studien darauf hinweisen,

dass solche affektiven Präferenzen des Lesers [Bangen und Hoffen in Bezug auf den Handlungsverlauf KR] mindestens ebenso wichtig für das Verstehen und Nachvollziehen der Handlung sind wie kognitive Antizipationen des wahrscheinlichsten Entwicklungsgangs. (Mellmann 2016, 167)

Die Werte, die im Komplex Aktivierung präsentiert werden, nehmen viele der Aspekte auf, die unter dem vagen Begriff der „Spannung“ subsumiert werden. Obwohl das Phänomen ungeheuer vielschichtig und von daher aus wissenschaftlicher Perspektive unhandlich ist einige dieser Schichten werden in diesem Kapitel beschrieben -, ist es doch kommunikativ besonders handlich, weil sich mit ihm eine unmittelbare Vorstellung verbindet.

Die Fähigkeit des Textes, die Aufmerksamkeit vollkommen zu binden, sodass der Text geradezu erlebt wird, ist laut Graf (2004, s. o.) ein zentrales Moment des Lesemodus der intimen Lektüre. Die Jury des Bachmann-Wettbewerbs, die, so muss man zumindest mit Blick auf ihre Funktion annehmen, nicht ausschließlich im Modus der „intimen Lektüre“ liest, argumentiert zwar selten mit dem Begriff „Spannung“; vielfach kann man allerdings vermuten, dass die Gesamtwirkung eines Textes durchaus davon abhängt, ob ein Juror Spannung empfunden hat. 
Im „ästhetischen Lesemodus“ ist die Aufmerksamkeit des Lesers Graf $(2004,107)$ zufolge auf die formale und sprachliche Gestaltung gerichtet. Durch die Konzentration auf die Sprache werden „äußere und innere Zwänge negier[t], wodurch feste Wahrnehmungskonventionen, mechanische Deutungsschemata und unreflektierte Vorurteile gelockert werden“ (Graf 2004, 107). Die Zwangfreiheit des literarischen Kunstwerks versteht Graf ganz im Sinne der Autonomieästhetik. Dieser Lesemodus schütze davor, dass das Lesen in Funktionen für den Alltag, die Psychologie oder die Wissenschaft aufgehe (ebd., 108). Der literarische Text wird als ein Angebot gesehen. „Sprachliche Kunstwerke sprechen nicht von Unbestimmbarkeit, sie verkünden diese nicht als Botschaft, sondern sie vergegenwärtigen in ihrem Erscheinen das Unbestimmbare an den Gegenständen, von denen sie handeln“ (ebd., 110). Zwei Aspekte, die auch von den Juroren im Wertungskomplex Aktivierung immer wieder als Werte eingesetzt werden, spricht auch Graf in diesem Zitat an: Zum einen, dass „Unbestimmbarkeit“ im literarischen Kunstwerk überhaupt eine große Rolle spielt, zum anderen, dass „Unbestimmbarkeit“ nicht als Thema benannt wird, sondern sich dem Leser durch die Gestaltung des Textes offenbart. Die Eigenaussagen von Lesern über ihre Beziehung zu literarischen Texten, die sich in Grafs Lesemodi spiegeln, zeigen also deutlich, dass Leser eine Anteilnahme am Text wünschen. Diese kann verschiedene Facetten annehmen, von Absorption während der „,intimen“ Lektüre („,Spannung“) über die Zweckentbundenheit des literarischen Textes, die dem Leser die Möglichkeit gibt, jenseits der Alltagslogik selbständig mit Hilfe des Textes andere Perspektiven zu entdecken („Autonomie“), bis hin zur angelegten Offenheit, die den Leser herausfordert, selber Zusammenhänge herzustellen („Unbestimmbarkeit“). Betrachtet man die Ingeborg-BachmannPreis-Diskussionen genauer, muss man davon ausgehen, dass professionelle Leser nicht den einen oder den anderen Modus einnehmen und auf diese Weise einen gesamten Text rezipieren, sondern dass die Einstellung auf den Text je nach situationeller Anforderung angepasst werden kann. Ohnehin scheint es, insbesondere bei längeren Erzähltexten, unwahrscheinlich, dass die Aufmerksamkeit des Lesers bewusst darauf gerichtet ist, sprachliche Abweichungen zu erkennen, wie Graf das nahelegt. Vielmehr ist es wahrscheinlich, dass professionelle Leser sich in einen Modus begeben, in dem sie bereit sind, sich auf solche Funde im Text einzulassen, ohne aktiv danach zu suchen, während sie weitgehend „normal“ lesen.

Nell (1988) hat Laien-Leser bei freiwilliger, lustvoller Lektüre untersucht und danach gefragt, was die lustvolle Lektüre ausmacht. Er kommt zu dem Ergebnis, dass der entscheidende Faktor das „entrancement“ (ebd., 73) bzw. „trance potential“ (ebd., 146) ist. 
Letzteres sieht er als entscheidenden Faktor bei der Buchauswahl (ebd., 146). „Entrancement" bedeutet bei Nell in etwa dasselbe wie bei Graf die „Spannung“ im Lesemodus der „,intimen Lektüre“. Vorderer $(2004,396)$ nennt als weitere Versuche, den Zustand der intensiven Aufmerksamkeitsbindung und Anteilnahme zu beschreiben, die Begriffe „involvement, [...] immersion, flow, transportation, [...] absorption, [...] presence“.

Nell wie Graf bleiben sehr vage in ihrer Vorstellung dessen, was „Spannung“ ausmacht. Entscheidend ist jedoch, dass beide in ihren Leserbefragungen ${ }^{50}$ darauf gestoßen sind, dass der Grad der Involviertheit für den Leser eine große Rolle in der Bewertung von Texten spielt.

Während „Spannung“ bzw. die Involviertheit des Lesers in der empirischen Forschung zur Lektüre-Wirkung als Voraussetzung für eine lustvolle Lektüre anerkannt ist, haben beide Phänomene in der theoretischen Literaturwissenschaft und der literarischen Wertungsforschung bisher wenig Aufmerksamkeit erhalten (vgl. Irsigler 2008; Anz 2002, 152). Hillebrandt (2011) sieht Spannung als einen der wichtigsten Faktoren für emotionales Texterleben, das durch Prozesse der Informationsvergabe gesteuert wird. Spannung wird laut Anz erzeugt, indem literarische Techniken eingesetzt werden, die „systematisch und auf vielfältige Weise mit der mehr oder weniger großen Informiertheit der literarischen Figuren und der Leser [spielen]“ (ebd., 157). Spannung entsteht demnach dann, „wenn man nicht genau weiß, aber geradezu begierig wissen will, wie es in der Zukunft weitergeht" (ebd., 157). ${ }^{51}$ Als Auswirkung auf den Leser bedeutet das, dass Texte „ein hohes Maß anhaltender Aufmerksamkeit und emotionaler Erregung an sich binden“ (Anz 2003, 646). Langer $(2008,19)$ spricht von der „Erlebnisqualität von Spannung“. Genau diese Auswirkungen auf den Leser sind prägend für den Wertungskomplex Aktivierung in den Diskussionen des Ingeborg-Bachmann-Wettbewerbs. Spannung entsteht also, kurz gesagt, daraus, dass etwas offen gelassen wird, der Leser diese „Wissenslücke“ aber unbedingt schließen möchte. Insofern ist das Phänomen Spannung, das für viele Freizeitleser für die Bewertung des Lektüreerfolgs tatsächlich zentral zu sein scheint (vgl. Graf 2004), Bestandteil des Komplexes Aktivierung. Der Leser ist geistig, in Anz' $(2002,157)$ Worten, „begierig [zu] wissen“, wie sich eine im Text aufgebaute Situation klären wird. Anz zeigt in seiner theoretischen Auseinandersetzung mit dem Lustfaktor bei der Lektüre nicht nur am Beispiel „Spannung“, welche Bedeutung die geistige und emotionale Anteilnahme am Nachvollzug der Textwelt hat. Auch in seinem Versuch, zu fassen, wie das „Wohlgefallen am Schönen“ (Anz 2002,

50 Nell nimmt neben Befragungen auch andere Experimente vor.

51 Anz greift damit nur einen bestimmten Spannungstypus auf (suspense). Spannung kann u. a. auch einen allgemeinen Zustand der Erregung (vgl. Mellmann 2016) bedeuten, Rätselspannung (mystery) (vgl. Langer 2008, 21) und Anspannung (tension) (vgl. Langer 2008, 29). 
77 ff.) funktioniert, kommt er in Anlehnung an Fechner zu dem Schluss, dass die „Voraussetzung für ästhetisches Wohlgefallen [...] demnach also [ist], daß zum einen der ästhetische Gegenstand überhaupt eine Ordnung erkennen läßt und daß zum anderen die Entdeckung dieser Ordnung mit Anstrengung und Aktivität verbunden ist" (ebd., 109; Hervorhebung KR). Mitfühlen, Mitdenken und Mitfiebern sind Anz zufolge ganz elementare Regungen des Lesers, die zu seiner Lust am Text beitragen. Die Bachmann-Preis-Diskussionen bestätigen das in den Bewertungen.

De Beaugrande und Dressler, die eigentlich auf der Suche danach sind, was Texte zu Texten macht, beobachten, dass „Textproduzenten [...] oft mit der Einstellung des Rezipienten, Texte zu akzeptieren [spekulieren], und [...] Texte, die wichtige Zusätze durch den Rezipienten verlangen, [bieten,] um verstanden zu werden“. „Offensichtlich“, folgern die Autoren, „lassen sich Textrezipienten durch Inhalt, den sie selbst beisteuern, leichter überzeugen, fast als ob sie die Behauptung selbst aufstellen würden“ (de Beaugrande/Dressler 1981, 10). In ihrem Beispiel geht es eigentlich nicht um literarische Texte und auch nicht um ästhetische Qualitäten. Das Beispiel stammt allerdings aus einem Werbetext. Da Werbetexte sich oftmals literarische Verfahren (u. a. sprachliche Abweichung, Sprachspiel, Unterhaltung) zunutze machen (vgl. Janich 2010, 130 f.), kann man vermuten, dass die Annahme der besseren Akzeptanz von Texten, die Leser dazu anregen, Informationen zu vervollständigen, auch für die Literatur gilt. Janich $(2010,203)$ zufolge dienen Sprachspiele in der Werbesprache ebenfalls dazu „die Aufmerksamkeit zu erregen“ und zielen als ästhetische Elemente auf eine „emotionale Aktivierung“ (ebd. 212). Damit weist auch sie auf die Aktivierungsfunktion von Textmerkmalen hin, die primär in der Literatur, aber eben auch in der Werbung, zu finden sind. Genau besehen, geht es de Beaugrande und Dressler um angelegte Offenheit. Außerdem beobachten die Autoren insgesamt eine höhere Akzeptanz von Texten, die offen angelegt sind (vgl. auch Kapitel 8).

Dass sich die Akzeptanz von Texten erhöht, wenn dem Leser eine begrenzte Freiheit gelassen wird, an der Konstruktion einer kohärenten Textwelt mitzuwirken und den Text intensiv zu erleben, ist also bereits an verschiedenen Stellen gezeigt worden. In den Bewertungen im Rahmen des Ingeborg-Bachmann-Wettbewerbs finden sich verschiedene Typen von Aktivierung wieder. Die beiden häufigsten Bezugspunkte sind der Wert Offenheit (geistige Aktivierung) und die sinnlich-emotionale Aktivierung des Lesers durch Anteilnahme an Figurenentwicklung, Lebendigkeit und Plastizität des Dargestellten. 


\subsection{Offenheit}

Offenheit ist ein Wert, dem innerhalb des Ingeborg-Bachmann-Wettbewerbs eine hohe Bedeutung zukommt. Sie umfasst Phänomene der Mehrdeutigkeit, denen unterstellt wird, dass sie bewusst vom Autor mit dem Ziel angelegt wurden, während der Lektüre oder mit Blick auf die Gesamtdeutung des Textes, mehrere Verständnismöglichkeiten zuzulassen, aber auch Mechanismen der indirekten Informationsvergabe. Offenheit wird dabei als Angebot an den Leser verstanden, aus dem gelesenen Text eigene Schlüsse zu ziehen. In diesem Sinne umfasst Offenheit ein breiteres Spektrum an formalen Umsetzungsmöglichkeiten. Angefangen von „einfacher“ Mehrdeutigkeit (eine Formulierung kann auf unterschiedliche Weise gedeutet werden) über mehrere Erzählstränge und -ebenen, eine ambigue Erzählhaltung bis hin zu bewusst vielschichtig, fragmentarisch und unabgeschlossen gestalteten Kunstwerken der Moderne, kann Offenheit sehr unterschiedliche Phänomene umfassen. Zentral ist jedoch, dass der offene Text „mehrdeutig und vielfach interpretierbar [ist]“ (Heydebrand/Winko 1996, 118). Aus dieser Formulierung wird gleichzeitig klar, dass Offenheit sehr eng mit Mehrdeutigkeit, die häufig auch als eigener Wert aufgeführt wird (vgl. Heydebrand/Winko 1996, 116 „Polyvalenz“), verbunden ist. Mehrdeutigkeit hat häufig Offenheit zur Folge. Selten lassen sich die beiden Phänomene streng voneinander trennen, weder auf der Textebene noch auf der Bewertungsebene. In den Bachmann-PreisWertungen ist eine Trennung von Mehrdeutigkeit und Offenheit nicht erkennbar.

Für Umberto Eco zeichnet sich das moderne literarische Kunstwerk, wie bereits der Titel seines Buches „Das offene Kunstwerk“ andeutet, durch Offenheit aus. Als eines der gängigsten Mittel, Offenheit zu erzeugen, sieht Eco die Mehrdeutigkeit. Zwar „[gilt] das Kunstwerk [...] als eine grundsätzlich mehrdeutige Botschaft, als Mehrheit von Signifikaten (Bedeutungen), die in einem einzigen Signifikanten (Bedeutungsträger) enthalten sind“ (Eco 1990, 8), jedoch hält er Mehrdeutigkeit in der Gegenwartsliteratur für „eines der ausdrücklichen Ziele des Werkes [...], ein[en] vor anderen zu realisierenden Wert“ (ebd.). Entscheidend bei Eco ist, dass Offenheit zwar „im Sinne einer fundamentalen Ambiguität der künstlerischen Botschaft eine Konstante jedes Werkes aus jeder Zeit ist" (Eco 1990, 11), dass aber „heute [...] vor allem die Künstler dieses Bewußtsein [haben]; sie machen die ,Offenheit', anstatt sie als unvermeidliches Faktum hinzunehmen, zu ihrem produktiven Programm und suchen sie in ihren Werken soweit als möglich zu verwirklichen" (ebd., 32). Die Juroren des Ingeborg-Bachmann-Wettbewerbs lassen in ihren Äußerungen nur selten erkennen, dass ihnen Offenheit als Programm wichtig ist. Ihre Argumentationen lassen aber durchaus erkennen, dass Offenheit, möglicherweise allerdings auf einer nied- 
rigeren Ebene als der von Eco anvisierten, dass Lektüre-Erlebnis positiv beeinflusst. Es muss also nicht direkt die kafka'sche Vielschichtigkeit sein; gerade „einfachere“ Verfahren wie das offene Ende und der Modus des Showing (s. u.) finden Zuspruch.

Den negativen Gegenpol zu Offenheit bildet auf formaler Ebene Geschlossenheit (vgl. Heydebrand/Winko 1997, 116). Von den Juroren wird allerdings häufiger Überdeterminiertheit negativ bewertet. „Überdeterminierte“ Texte werden abgewertet, weil sie, so die Juroren, ihre Botschaft forcieren, d.h. ihr Thema oder ihre Grundidee überdeutlich formal umsetzen. Es entsteht ein Ungleichgewicht zwischen Form und Inhalt zugunsten der Form. Die Juroren bemängeln dann die Überdeutlichkeit, die die Lektürewirkung negativ beeinflusst (vgl. auch Kapitel 10.3.1 „Dominanz der Form“). Auch hier kann man Offenheit als positiven Maßstab ansetzen.

\subsubsection{Offenheit als Angebot an den Leser}

Diskussionsstellen wurden dann als dem Wert Offenheit zugehörig kategorisiert, wenn es in ihnen explizit darum geht, dass ein Text eine Menge von Bedeutungsangeboten offeriert und/oder wichtige Informationen ausspart, die entweder vom Leser selbst ergänzt werden müssen oder erst im weiteren Verlauf der Lektüre preisgegeben werden. ${ }^{52}$ Offene Texte konfrontieren den Leser mit „losen Enden“, die sowohl - im typischsten Fall - das Ende des gesamten Textes betreffen können als auch Passagen und Handlungsstränge innerhalb des Textes. Typischerweise wird Spannung aufgebaut, indem eine Handlung begonnen, aber nicht abgeschlossen wird. Diese Spannung wird nicht durch den Text selbst abgebaut. Der Leser muss den Handlungsstrang selbst zu Ende denken oder aber die Offenheit akzeptieren.

Der Wert Offenheit steht immer in Konkurrenz zu Kohärenz, jenem Wert also, der eine möglichst weitreichende Nachvollziehbarkeit des Textes fordert. Intendierte Offenheit entbindet daher nicht von der Forderung nach einem möglichst kohärenten Text. Genau das wird in der Diskussion zum Bachmann-Preis-Träger Georg Klein in einem Beitrag von Iris Radisch deutlich:

Also das ist einerseits auch wieder ein sehr präzise gebautes Rätsel, andererseits, ja, wohin soll es führen? Es ist mit/ Also diese Offenheit ist, glaube ich, sehr genau gebaut. (2000 Klein, 14:14 Radisch)

Radisch erkennt einerseits ein formales Prinzip, nach dem der Text gebaut ist. Auf der

52 Im Gegensatz zu Sachtexten, die auch immer ein gewisses Maß an Vagheit besitzen, wird Offenheit in literarischen Texten als Kunstmittel eingesetzt. 
anderen Seite führt das klare Formprinzip nicht zu einer Eindeutigkeit. Bei Georg Klein werden also die beiden Bedürfnisse des Lesers befriedigt. Offenheit wird innerhalb eines klar erkennbaren formalen Aufbaus begrüßt. Ebenfalls einen Bachmann-Preis erhielt 1999 Terézia Mora. Thomas Hettche argumentiert in seinem Beitrag zu diesem Text ganz ähnlich wie Iris Radisch bei Georg Klein:

\begin{abstract}
Das heißt, sie hat eine ganz große Sprachvielfalt auch. Und das alles wird zusammengehalten, finde ich sehr schön, durch diese einfachen, archaisch wirkenden Oberbegriffe. Das ist für mich der erste Text hier eigentlich, der nicht eine Käseglocke über sich hat, sondern der unter so einer Oberstruktur nach allen Seiten offen ist und GANZ viele Sachen von außen in sich hinein nimmt, ohne sie wie im Baukasten zu kasteln, sondern die Sachen bleiben offen nach den Seiten. Ich erspare mir jetzt die sprachlichen Sachen, weil der Text/ Dass der durchgearbeitet ist und dass er rhythmisch stimmt und dass da ganz viele Bilder drin sind, ist eh klar, denke ich mir. (1999 Mora, 16:07 Hettche; Hervorhebungen KR)
\end{abstract}

Hettche betont, dass der Text zwar eine klar erkennbare Organisationsform hat („zusammengehalten [...] durch diese [...] Oberbegriffe", „dass der Text durchgearbeitet ist", „dass er rhythmisch stimmt“), dass aber nicht alle Möglichkeiten, die diese Struktur eröffnet, restlos ausgeführt werden (,der nicht eine Käseglocke über sich hat, sondern der unter so einer Oberstruktur nach allen Seiten offen ist“, „ohne sie wie im Baukasten zu kasteln“). Dem Leser bleibt also die Möglichkeit, Seitenstränge und angedeutete Bedeutungsvarianten selber zu entdecken. Hettche argumentiert mit Sprachvielfalt und Rhythmik, um zu überzeugen, und befolgt damit ein jurytypisches Argumentationsmuster.

Ein ganz typisches Lob der Offenheit bietet auch Mangold (6:37), wenn er in der Diskussion zu Sander (2009) vermutet, dass der Text „mit einer sachten Verschränkung von [...] politischer Geschichte und von individueller Biografie auf der anderen Seite [spielt]“ und dabei aber kein „,schematisches Abhängigkeitsverhältnis“ herstellt. Mangold kann also sehr genau sagen, welche Gedanken im Text gegeneinander abgewogen werden. Er kann sie offenbar in einen sinnvollen Zusammenhang stellen. Gleichzeitig bekundet er seine Freude darüber, dass der Text nicht „schematisch“ vorgeht und damit - so kann man folgern vorhersehbar wird, sondern „unterschiedliche Antworten darauf finde[t]“". Am Ende folgert Mangold: „Das lässt der Text offen. Er bietet verschiedene Biografien an“.53 Ganz deutlich ist in dieser Aussage der Wert Offenheit mit einem Angebot an den Leser verknüpft. Abgegrenzt wird dieser positive Umgang mit der Fragestellung, wie politische Geschichte

53 Mangolds Argument müsste streng genommen als inhaltliches Argument betrachtet werden. Es wurde dennoch zur Illustration des formal-ästhetischen Wertes Offenheit herangezogen, weil Mangold zum einen nahelegt, dass die thematische Verschränkung von Biografie und Geschichte durch die Art und Weise sichtbar gemacht wird, wie der Text sie kombiniert. Zum anderen verhält sich dieses eigentlich inhaltliche Argument der Struktur nach analog zu formal-ästhetisch ausgerichteten Argumenten. 
und Biografie sich bedingen, von einem „schematischen“ Umgang, der, so jedenfalls kann man Mangolds Hinweis auf „unterschiedliche Antworten“ deuten, keine klaren Lösungen bietet.

Schindel geht sogar so weit, klar auszuformulieren, dass er Offenheit für einen konventionalisierten Wert hält.

Und das Ganze ist aber natürlich nicht eindeutig. Da würden ja auch alle aufschreien: Ach, wie eindeutig! Ach wie geheimnislos! Sondern es bleibt Raum, wie Thomas Hettche in einem anderen Zusammenhang schon einmal gesagt hat. Die Geschichte bleibt offen. (16:24 Schindel, 1999 Beuse)

Eindeutigkeit und Geheimnislosigkeit werden „Raum“ und Offenheit („die Geschichte bleibt offen") gegenübergestellt. Dass Eindeutigkeit nicht gut sein kann, wird als Selbstverständlichkeit („,natürlich nicht eindeutig“) präsentiert. Ebenfalls als selbstverständlich präsentiert Ruoss den Wert Offenheit in derselben Diskussion, obwohl Ruoss denselben Text eher als einen nicht offenen betrachtet:

Was mich bis heute und jetzt hier überhaupt nicht überzeugt und mir nicht einleuchtet, ist Folgendes: Dass es offen bleiben soll hier, [...] das ist/ Das finde ich auch. Es soll offen bleiben. Es soll mir/ Verschiedene Möglichkeiten des Verstehens soll es mir belassen. Wir hatten heute und gestern über Überorchestrierung geredet, über Übereindeutigkeit. Das ist etwas, was niemand erträgt. (1999 Beuse, 19:27 Ruoss)

Ruoss geht sehr selbstverständlich davon aus, dass zu große Eindeutigkeit „etwas [ist], das niemand erträgt". Er formuliert sogar aus, was Offenheit für ihn bedeutet, nämlich, dass ein Text ihm „verschiedene Möglichkeiten des Verstehens“ belassen solle. Interessant ist außerdem, dass er den Effekt der Übereindeutigkeit ganz klar auf eine Eigenart der Gestaltung, die „Überorchestrierung“ zurückführt. Dieses Phänomen der Überdeterminiertheit - alle oder zu viele Textelemente werden eingesetzt, um auf die "Botschaft" des Textes aufmerksam zu machen, sodass der Leser immer wieder auf diese „Botschaft“ aufmerksam gemacht wird (vgl. Kapitel 11.2.3 und 10.3.1 „Dominanz der Form“) - bildet den Gegenpol zu Offenheit. Dass Offenheit eine positive Qualität ist, macht auch Ulrike Längle deutlich, wenn sie sagt: „Ich meine, das ist eine Qualität der Geschichte, dass der Schluss nicht so eindeutig ist, wer da gesiegt hat. [...] Und der Schluss ist jedenfalls immerhin noch offen. Das empfinde ich jetzt als Qualität wieder“ (2000 Franck, 19:23 Längle). Sie äußert dieses Argument gleich zwei Mal im selben Redebeitrag. Zwischen den beiden Äußerungen steht lediglich eine kurze Erklärung, wie sich diese Offenheit am Text festmachen lässt. Das lässt darauf schließen, dass es ihr durchaus wichtig ist, dass alle Kommunikationspartner erkennen, dass sie Offenheit für einen positiven Wert hält. 
Spinnen (1:22) gibt sich „begeistert“ vom Text David Wagners (2000) und begründet diese Begeisterung damit, dass er sich nach Wochen immer noch an den Text erinnert hat, „weil da etwas offen bleibt am Schluss, das absolut nicht ausgesprochen ist, sondern als Aufgabe für den Leser bleibt". Nicht nur wird hier ein positives Urteil zentral mit der Offenheit des Textes begründet, sondern es wird auch ausformuliert, was diese Offenheit bedeutet, nämlich, dass der Leser selber die Aufgabe hat, den Text für sich zu Ende zu denken. Dass Spinnen in Zusammenhang mit der Offenheit des Textes darauf hinweist, dass er sich nach Wochen noch an den Text erinnert habe, bestätigt, dass formale Gestaltungsstrategien zu einer intensiveren Verarbeitung führen, die an eine positive Wahrnehmung und Wertung des Textes gekoppelt sind. Auch Denis Scheck lobt in derselben Diskussion die Offenheit des Textes, die ihm zufolge darin besteht, dass der Text für den Selbstmord einer seiner Figuren keine Erklärungen anbietet: „Das ist das Geheimnis der Erzählhaltung. Das lässt der Text sehr schön offen“. Unzufrieden ist er dagegen damit, dass der Text „Erklärungen [...] gegen die eigene Intention anbietet“, die ihm „ein bisschen dünn“ erscheinen (2000 Wagner, 15:25 Scheck). Scheck stellt hier also zwei Eigenschaften des Textes gegenüber, die sich, zumal in der Bewertung, wiedersprechen. Er lobt zum einen die Offenheit des Textes in Hinblick auf die Gründe für den Selbstmord einer Figur. Auf der anderen Seite kritisiert er, dass der Text seine eigene Offenheit einschränke, indem trotzdem Erklärungen angeboten werden. Dass diese Erklärungen Scheck zufolge auch noch „gegen die eigene Intention“ des Textes verstoßen, lässt das Argument in sich noch widersprüchlicher erscheinen. Es ist davon auszugehen, dass das Ansehen des Wertes Offenheit so hoch ist, dass tendenziell vereindeutigende Elemente des Textes als „Flüchtigkeitsfehler“ wegargumentiert werden. Der unterstellten Intention des Textes wird der Vorrang gegeben, um den Text, der dem Juror offenbar gefallen hat, gegen die eigenen Einwände zu schützen.

Die genannten Beispiele zeigen, dass Offenheit ein anerkannter, stark konventionalisierter Wertmaßstab ist. Es wird der Eindruck erweckt, dass absolute Einigkeit darüber besteht, dass Eindeutigkeit und Geschlossenheit die Lesefreude erheblich schmälern und daher auch nicht positiv zu bewerten sind. Offenheit wird prinzipiell positiv eingeschätzt.

Eine letzte Variante des Wertmaßstabs Offenheit illustriert ein Beitrag Mangolds aus dem Jahr 2009, dessen argumentativer Kern das von Sabine Buck (2011, 231) beobachtete „Belehrungsverbot“ ist. Der Bezug auf den Wert Offenheit ist dabei lose; es bestätigt sich aber derselbe Mechanismus wie in vielen Argumenten zur Offenheit. Es wird erwartet, dass literarische Texte es ihren Lesern überlassen, das im Text Dargestellte, ethisch zu beurteilen. Ein Text sollte durch die Art, wie er Informationen arrangiert und präsentiert, 
den Eindruck vermitteln, der Leser könne selbstständig zu einer Einstellung zur Figur oder zum Plot finden. Das gilt insbesondere für Texte, die ein ethisch schwieriges oder tabuisiertes Thema behandeln. Mangold verwendet genau dieses Argument der durch Informationspräsentation „erzwungenen“ Leserreaktion in einem Argument zum Text von Linda Stift:

Ja, es ist ein Text, den ich sehr ärgerlich finde. Ich habe den Eindruck, dass er eine emotional oder eine politmoralisch erpresserische Struktur hat. Er setzt mich unter Druck und schafft so eine emotional-moralische Kulisse, der ich mich schwer entziehen kann. Aber die Mittel, mit der er sie erzeugt, empfinde ich als unlauter. Ich glaube, das Hauptmoment dieser Unlauterkeit ist tatsächlich auch in der Form, in der Ästhetik zu beobachten. Die Haupterzählstrategie dieses Textes ist ein Wir. Und dieses Wir changiert. Es ist nicht geschlechtlich genau zuordbar. Es ist nicht genau individualisierbar. Es steht immer für eine Allgemeinheit. Und das ist das Problem dieses Textes. (2009 Stift, 0:17 Mangold)

Mangold fühlt sich von dem Text zu einer bestimmten moralischen Schlussfolgerung genötigt. Er erklärt sich diese Wirkung des Textes mit einer erzählerischen Besonderheit: Der Text wird nicht von einem einzelnen Erzähler erzählt, sondern von einer Gruppe. Dieses Wir, so kann man Mangolds Aussage verstehen, suggeriert dem Leser etwas diffus Menschliches, das ihm nicht erlaubt, sich in ein kritisches Verhältnis zum Erzähler zu setzen. Auf diese Weise erzwingt Stifts Text, so das Argument, eine mitleidige Reaktion des Lesers. Auch dieses Argument illustriert sehr anschaulich, dass eine unmittelbare emotionale Reaktion die Richtung der Wertung bedingt. Mangold findet den Text „ärgerlich“.

\subsubsection{Der Erzählmodus des Showing}

In seinem Buch „Schreiben dicht am Leben“, das Schreibinteressierte dazu anleiten soll, Alltägliches zu notieren und daraus Literatur zu machen, beschreibt Hanns-Josef Ortheil das Verfahren des „Notieren[s] als Drehbuch“. Das Schreibverfahren soll durch eine kameraartige Perspektive auf Objekte eine Geschichte oder einen nicht offensichtlichen Zusammenhang sichtbar werden lassen. Als Beispiel dafür gibt er den japanischen Autor Akutagawa an:

So entsteht eine Handlung vor allem aus Bildern, die eine starke Magie ausüben. Akutagawa entwirft sie genau und plastisch und er geht mit der inneren Kamera nahe an das Objekt heran. Die Bewegungen und das Aussehen des Objekts erhalten durch diese Nähe etwas Verführerisches. Als Leser spürt man förmlich, wie der Blick des Jungen an den Details des Objekts hängen bleibt und sich in dieser (abgedunkelten) kleinen Blickbühne verliert. (Ortheil 2012, 80)

Ortheil beschreibt also eine Schreibtechnik, bei der der Erzähler sich vollkommen zurückhält. Der Erzähler präsentiert ausschließlich Material, das aufgrund seines Arrangements 
den Leser dazu anleitet, Schlüsse zu ziehen. Es wird also nicht nur eine Geschichte erzählt, sondern der Erzähler zeigt. Er führt vor. Der ideale Leser übernimmt statt des Erzählers eine aktive Rolle, wenn er die Bilder zu einer Geschichte zusammensetzt. Dieser aus dem Creative Writing als „Showing“ (vgl. Kapitel 7) bekannte Erzählmodus, der dem „Telling“ gegenübergestellt wird, wird im Ingeborg-Bachmann-Wettbewerb häufig als Wert verwendet. Es ist bezeichnend für die Wichtigkeit des Wertes, dass er, wenn auch nicht direkt benannt, in Ortheils Schreibanleitung eine zentrale Rolle spielt. Immerhin geht es darum, Schreibinteressierte zu guten Texten anzuleiten. Nicht nur das Kapitel zum „Notieren als Drehbuch“, auch viele andere Techniken, die der Autor vorstellt, basieren auf diesem Prinzip. Bezeichnend ist allerdings auch, welchen Effekt Ortheil diesem, im Modus des Showing geschriebenen Text zuschreibt. Er spricht von „Magie“, vom „Verführerische[n]“ und davon, dass „[man] als Leser [...] förmlich [spürt]“, was geschieht. Er spricht dem Showing also das Vermögen zu, den Leser zu fesseln und ihn miterleben zu lassen. Der Modus des Showing bildet in vielen Anleitungen zum Kreativen Schreiben das zentrale Mittel der gelungenen Gestaltung von konkreten Szenen. Als Wirkung wird eine indirekte Vermittlung von Inhalten angegeben, die das Interesse des Lesers aktiviert und ihm interpretative Spielräume ermöglicht. Der dadurch erzielte Effekt ist möglicherweise der, dass, in den Worten von de Beaugrande und Dressler $(1981,10)$ „sich Textrezipienten durch Inhalt, den sie selbst beisteuern, leichter überzeugen [lassen], fast als ob sie die Behauptung selbst aufstellen würden".

Der Anspruch, Texte sollen etwas vorführen, damit der Leser selbständig seine Schlüsse daraus ziehen kann, wird auch in den Diskussionen immer wieder formuliert - nur gelegentlich wörtlich, sehr oft aber implizit. Obwohl in den Diskussionen, insbesondere von Denis Scheck, häufig die Formulierung „sagen“ und „zeigen“ verwendet wird, benutze ich zur Beschreibung des Phänomens die „in der älteren angloamerikanischen Erzähltheorie [...] übliche [...] metaphorische Bezeichnung“ (Weimar 1997, 360) „Showing“ bzw. „Telling“. Showing umschreibt

eine Erzählweise, die das Erzählte sozusagen zeigt und sichtbar werden läßt, so daß beim Lesen die Illusion der Unmittelbarkeit zum erzählten Geschehen entstehen kann. „Showing“ ist keine Beschreibungskategorie, sondern Inbegriff der heterogenen erzähltechnischen Mittel, die als geeignet erscheinen, die Distanz zwischen Erzählen und Erzähltem zu vermindern und jene Illusion oder Präsenz und Unmittelbarkeit zu befördern. (ebd.)

In den Diskussionen nimmt die Kategorie neben der von Klaus Weimar erwähnten Unmittelbarkeit noch eine andere Dimension an. Es geht zusätzlich um die Anforderung, die eine solche Erzählweise an den Leser stellt, der durch ein unmittelbares Erzählen mehr als 
durch ein mittelbares vor die Aufgabe gestellt wird, das Erzählte selbstständig zu deuten und Schlüsse zu ziehen.

Die Forderung, ein Text solle zeigen, was er sagen will, und es nicht ausformulieren, korreliert mit der Annahme, dass es ein Bedürfnis des Lesers gibt, selbstständig eine mentale Repräsentation und ein Verständnis für einen literarischen Text zu konstruieren.

Die Kategorie Showing fügt sich damit exakt in das Profil des Wertes Offenheit ein. Die Jurorin Ulrike Längle beispielsweise sieht die zentrale positive Eigenschaft des Textes von Reimertz darin, „[d]ass eben viel hier gezeigt wird und nicht behauptet wird“ (2000 Reimertz, 10:09 Längle). Noch deutlicher formuliert Denis Scheck diesen Anspruch:

\begin{tabular}{l} 
Aber das ist einfach zu direkt, ja: „Nichts zu machen, lässt sich nicht vom Sockel \\
\hline stürzen“. Ich weiß nicht. Also das löst so einen pawlowschen Interpretationsinstinkt \\
hier aus/ -reflex aus, der mich von der Anlage her schon vom Lesen also enorm nervt \\
\hline - kann ich nur anders sagen/ kann ich nicht anders sagen - weil klar ist, hier wer- \\
den jetzt Kabinettstückchen abverlangt einem. Und das ist zu mechanisch. Das ist \\
nun wirklich am Reißbrett geschrieben. Weil sprachlich hier nichts los ist. Weil kaum \\
was erzählt wird in Sätzen wie gleich zu Anfang: „Ich selbst habe alle Kontakte ab- \\
gebrochen“. Sag mir das nicht! Zeig es mir! "Meine Tage und Nächte verlaufen jetzt \\
vollkommen gleichförmig“. Sag es mir nicht, zeig es mir! Das ist das Gegenteil von \\
meiner Vorstellung von Literatur. (2002 Kern, 10:30 Scheck; Hervorhebungen KR)
\end{tabular}

An dieser Diskussionsstelle greifen eine ganze Reihe interessanter Wertungen ineinander, wie sie auch aus anderen Diskussionsbeiträgen bekannt sind. In der Kritik, dass der Text „zu direkt" ist und „einen pawlowschen Interpretationsreflex [auslöst]“, ist erkennbar, dass eine intensive Gestaltung des Textes dann nicht mehr honoriert wird, wenn sie die Aufmerksamkeit zu sehr auf sich lenkt (vgl. Kapitel 10.3.1 Abschnitt „Dominanz der Form“). Den Text von Elfriede Kern beschreibt Scheck außerdem als „mechanisch“. Dass Scheck im nächsten Schritt versucht, diesen Eindruck vom Text auch sprachlich zu belegen, zählt ebenfalls zu den typischen argumentativen Vorgehen der Diskussion. Schecks Argumentation gipfelt in dem Ausruf: „Sag es mir nicht, zeig es mir! Das ist das Gegenteil von meiner Vorstellung von Literatur“. Zum einen wird hier das Prinzip des Showing wörtlich formuliert. Zum anderen zeigt sich die ganz enge Verbindung, die zwischen dieser Darstellungsstrategie und der Vorstellung von gelungener Literatur hergestellt wird. Auch hier lässt sich insgesamt ein sehr bekanntes Argumentationsschema wiederfinden: Ausgehend von der Wirkung (der Text nervt, weil er einen „pawlowschen Interpretationsreflex“ auslöst) wird ein Kritikpunkt formuliert, der sich an der Form/Sprache des Textes festmachen lässt. Auf der Grundlage dieser texteigenschaftsbasierten Kritik wird dann ein Wertmaßstab formuliert, der in diesem Fall sogar deutlich als solcher gekennzeichnet wird. Scheck, der seine Forderung nach einer vorführenden Literatur sehr explizit ausspricht, 
nutzt in seinem Argument außerdem die Formulierung, der Text sei „einfach zu direkt“. Auch andere Jurymitglieder benutzen häufig die Formulierung Direktheit/Indirektheit, wenn sie die Kategorie Showing/Telling meinen. So etwa Ebel (14:43) in der Diskussion zu Silke Scheuermann (2007): „Das erfahren wir zum Teil über die Frau selbst, zum Teil über die Tochter. Ich finde das großartig gemacht. Es ist alles indirekt. Aber alles wunderbar plausibel“. Gelobt wird hier ganz direkt, dass der Text Informationen indirekt vermittelt, indem sie Stück für Stück von verschiedenen Figuren nebenbei preisgegeben werden. Ebel begreift dieses Vorgehen als besonderen Kunstgriff („großartig gemacht“). Andererseits bestätigt sich hier erneut das intensives Bedürfnis nach sinnhaften Zusammenhängen. Indirektheit darf nicht auf Kosten der Plausibilität gehen. Ebel fühlt sich animiert, zu äußern, dass der Text - man kann hier ein unausgesprochenes „trotzdem“ mitdenken - „wunderbar plausibel“ ist.

Um Indirektheit geht es auch in Längles Urteil zu Monika Helfer:

Und was ich auch sehr kunstvoll gemacht finde, ist die Art, wie die Personen charakterisiert werden. Es wird ja nie gesagt: Die ist traurig oder leidet, sondern es kommt immer nur: Sie rührt das Gulasch und seufzt [paraphrasiert KR]. Fertig. (1999 Helfer, 19:22 Längle)

Längle lobt, dass Gefühle der Figuren nicht als Gefühle benannt werden, sondern sich über das Verhalten der Figuren mitteilen. Sie betont dabei, dass sie genau das für eine Kunst hält („kunstvoll gemacht“). Auch Karin Fleischanderl würde sich „viel mehr wünschen, in irgendeiner Weise, also, nicht jetzt konkret durch Benennung, aber diese Strukturen vorgeführt zu bekommen“ (2009 Born, 10:29 Fleischanderl; Hervorhebung KR).

Detering empfindet es sogar als belehrend, dass der Autor Raab über den Erzähler „Zusatzinformationen" an den Leser vermittelt, anstatt sie indirekt über die Handlung zu transportieren:

Und es ist nicht die einzige Passage, die so sehr didaktisch formuliert wird. Manchmal gibt es dann Sätze, die den inneren Monolog aufladen mit so Zusatzinformationen an den Leser hinten rum: „die Handbewegungen in der Solochoreografie, die mir immer soviel Schwierigkeiten gemacht haben“, das klingt schon ein bisschen wie: „dein Vater, der, wie du weißt, ein reicher Kommerzienrat ist". Und das ist unbeholfen, finde ich. (2004 Raab, 5:09 Detering)

Das Kommerzienrat-Beispiel, das Detering zur Illustration anführt, zeigt zunächst einmal, dass die gegebene Information aus der Figurensicht unrealistisch ist, weil sie zum Wissen der Figur gehört. Sie muss daher als ausschließlich für den Leser eingefügt eingestuft werden. Dass dieses Vorgehen des Autors von Detering als „didaktisch“ und nicht etwa 
als unrealistisch verstanden wird, weist darauf hin, dass Detering Offenheit vermisst und nicht Realitätsnähe.

Scheck bezeichnet diese Form der Darstellung, in der es darum geht, Informationen so anzuordnen, dass der Leser sie verstehen kann, ohne dass sie benannt werden als „sinnlich“: „Das ist ein ungeheuer sinnlicher Text. Hier wird über den Körper erzählt. Das ist sehr gut gemacht" (2001 Held, 0:00 Scheck). Die Argumentationsstruktur gleicht jener des zuletzt analysierten Scheck-Zitats:

1. Wirkung (,sinnlicher Text“),

2. Texteigenschaft bzw. inhaltlicher Referenzpunkt („über den Körper erzählt“)

3. Formulierung der Wertung (,sehr gut gemacht“).

Wie zentral eine indirekte Darstellung und damit das Angebot an den Leser, selber zu ergänzen, für das Verständnis von „guter“ Literatur ist, illustriert folgendes Zitat:

\begin{abstract}
Aber im Ganzen und Großen halte ich nichts von einer [unv.] Trennung von Hochliteratur und Unterhaltungsliteratur, wenn sie sozusagen über die Bande gespielt ist, wenn sie indirekt ist, wenn sich hinter dem direkt Gesagten noch eine zweite Ebene auftut, und das ist hier der Fall, dann kann man damit zufrieden sein. (1999 Kapielsky, 13:13 Schindel)
\end{abstract}

Dass ,gute“ Literatur sich an ihrer Indirektheit bemisst und nicht etwa daran, ob sie ernst oder unterhaltend ist, ist angesichts der Tatsache, dass die Unterscheidung zwischen unterhaltend und ernst in Deutschland immer noch von großer Bedeutung für die Einschätzung der Qualität eines Textes ist, durchaus bedeutend. Offenheit im Sinne von Indirektheit, von „über die Bande spielen“, von Mehrdeutigkeit („eine zweite Ebene auftut“) ist bei Schindel das zentrale Argument seiner Argumentation.

\title{
11.2.3 Überdeterminiertheit
}

Dass Offenheit ein Kriterium ist, das andere Kriterien in den Hintergrund stellen kann, zeigt sich in Fällen, in denen Juroren kritisieren, dass alle Elemente sich so gut zu einem Ganzen zusammenfügen, dass dem Leser der interpretative Spielraum genommen wird. Die Texte werden dann zwar als kunstvoll gearbeitet anerkannt und erhalten auch entsprechendes Lob, gleichzeitig behalten die Juroren sich eine gewisse Skepsis vor (vgl. auch Kapitel 10.3.1 Abschnitt „Dominanz der Form“). Am deutlichsten ist dies der Fall, wenn Texten vorgeworfen wird, sie seien forciert oder überdeterminiert. Aber nicht nur unter dem Stichwort „Überdeterminiertheit“ tritt die Abwertung auf: 
Das ist wirklich ihr Problem. Sie [die Geschichte KR] löst sich auf. Ich halte die Lösung auch nicht so richtig für eine glückliche, eben weil sie so restlos aufgeht. Wie beim Bruch, wo man oben und unten alles rauskürzt und plötzlich ist der Bruch weg. Und deswegen löst diese Erzählung bei mir keine letzte Begeisterung aus, aber sie ist eindeutig eine sehr gut gebaute Erzählung, an der man viel Freude haben kann. (2007 Scheuermann, 16:27 Mangold)

Mangold stellt einen Vergleich mit einer mathematischen Rechenoperation auf und will auf diese Weise auf einen charakteristischen Unterschied zwischen Literatur und exakter Wissenschaft aufmerksam machen. Während es in der Mathematik darum gehe, zu vereinfachen und zu eindeutigen Ergebnissen zu gelangen, erwartet Mangold von der Literatur, dass sie nicht restlos aufgehe. Es wird also die Forderung nach einem klassischen, intendiert offenen Schluss gestellt.

Überdeterminiertheit ist mehr noch als Eindeutigkeit der Gegenpol zu Offenheit. Wenn der erfahrene Leser den Eindruck hat „ununterbrochen Hilfen [zu] kriege[n]“ (1999 Stamm, 41:04 Bovenschen), ist er als Mitwirkender nicht gefordert. Es bleiben keine oder wenig Möglichkeiten, Spannung aufzubauen. Die Juroren fühlen sich, folgt man ihren Selbstauskünften, unterfordert und/oder gelangweilt und verlieren das Interesse. Es tritt genau das ein, was Christmann/Groeben (1999) auch für Sachtexte festgehalten haben: Wenn der Leser durch zu viel Klarheit unterfordert ist, verliert der Text seine positive Wirkung. Im Gegensatz zu „nur“ eindeutigen Texten, sind überdeterminierte Texte solche, die auf ihre, nicht unbedingt eindeutigen, Textaussagen immer wieder gezielt sprachlich hinweisen. Die Juroren als geübte Leser werten diese geballten Hinweise als überflüssig. So weist etwa Detering darauf hin, dass ein Text eine bestimmte Aussage immer wieder verbalisiere, obwohl der Autor davon hätte ausgehen können, dass sie bereits verstanden wurde:

Jemand wird ohnmächtig und fragt sich danach, ,wie lange er in diesem Land des Nichts gewesen war". Schon eine sehr pathetische Formulierung. Dann geht es aber dann leider weiter: „Sekunden“ Fragezeichen. „Minuten“ Fragezeichen. „Eine Ewigkeit" Fragezeichen. Das ist einfach too much. (2004 Becker, 3:07 Detering)

Das „wie lange“ im ersten Textzitat wird ergänzt durch verschiedene Zeitangaben, die, so Detering, nicht ausgesprochen werden müssten, weil sie in der ersten Formulierung ohnehin inbegriffen sind. Der intendierte Effekt, den Detering unterstellt, ist emotionale Anteilnahme (,pathetische Formulierung“). Diese kann sich, so die implizite Argumentation, nicht einstellen, wenn die Funktion der Formulierung allzu deutlich hervortritt. An dieser Stelle zeigt sich auch eine große Schwierigkeit der beiden postulierten Wertkomplexe. Die spezifische Balance zwischen Orientierung und Aktivierung wird offenbar immer neu ausgehandelt. Es lässt sich durchaus intuitiv, aufgrund von eigener Leseerfahrung erraten, 
in welche Richtung die Argumentation ausschlagen wird. Was aber genau dazu führt, dass entweder eine Gestaltungsweise als funktional oder unangemessen verdeutlichend wahrgenommen wird, ist anhand der Diskussionen schwer festzumachen. Möglicherweise spielt die Leseerfahrung eine entscheidende Rolle. Obwohl also intuitiv nachvollziehbar ist, warum Detering die zitierte Textstelle „pathetisch“ findet, kann anhand der Diskussionen nicht erklärt werden, warum sie als „pathetisch“, aber nicht als funktional in Hinblick auf die Umsetzung einer Wirkung betrachtet wird.

Ganz ähnlich wie Detering äußert sich Martin Ebel in einer anderen Diskussion desselben Jahrgangs:

Der Satz „meinetwegen“ im Dialog sagt alles aus. Der sagt auch den Tonfall aus. Der sagt auch aus, wie man denjenigen, der einen um etwas gebeten hat, enttäuscht. Und genau das wird dann ausformuliert. Also, das ist alles zu viel. Ich habe aber auch Sympathie für den Text und ich glaube verstanden zu haben, was der Text möchte. (2004 Geiger, 6:37 Ebel)

Ebel weist darauf hin, dass die Hauptaussage zum einen auf der nicht unmittelbar semantischen Ebene des „Tonfalls“ schon enthalten ist und zum anderen dann auch noch zusätzlich ausformuliert, das heißt, erklärt wird. Dass der Text seine Aussage in mehreren Varianten wiederholt, wird negativ bewertet. Zugleich wird aber auch betont, dass es sich nicht um einen schlechten Text handelt, denn Ebel glaubt „verstanden zu haben, was der Text möchte“ und er ",[hat] auch Sympathie für den Text“.

Den Konflikt zwischen Nachvollziehbarkeit und Offenheit empfindet auch Daniela Strigl:

Ich habe allerdings auch diese Beobachtungen gemacht, die Frau März gemacht hat, und ich sehe sie auch durchaus als strukturelles Problem des Textes und nicht nur als letztliche kleine Sünden. Ich habe das Gefühl, dass es manchmal etwas angestrengt ist, etwas gesucht, dass zu viel erklärt wird und eine überdeutliche Symbolisierung stattfindet. Auch eine überdeutliche Motivkette. Also, das ist natürlich schön, wenn man sieht, ein Text ist durchdacht und ist dicht strukturiert, aber hier tropft es irgendwie an allen Ecken und Enden. Und das hat auch etwas Reizvolles, aber man fühlt sich dann immer wieder zu stark mit der Nase auf etwas gestoßen. (2005 Vogel, 12:32 Strigl)

Der Konflikt, der ganz deutlich als ein strukturelles Problem des Textes gekennzeichnet wird, könnte kaum deutlicher formuliert werden. Auf der einen Seite stehen Ausdrücke wie „angestrengt“, „gesucht“, „zu viel erklärt“, „überdeutliche Symbolisierung“, „überdeutliche Motivkette“ und schlussendlich „zu stark mit der Nase auf etwas gestoßen“. Auf der anderen Seite stehen „durchdacht“ und „dicht strukturiert“ und „etwas Reizvolles“. Verstehen und Partizipieren stehen in einem typischen Grundkonflikt. Dieser Konflikt prägt die Bewertungen und wird an konkreten strukturellen Merkmalen festgemacht. Ganz analog zu diesem Beispiel empfindet Ebel (0:01) Susanne Heinrichs (2005) Text zwar an vielen 
Stellen als „sehr gelungen“, aber auch als „zu sehr Plan“. Und Detering (18:57) bewertet Bongartz“ (2005) Text als „intelligent“ aber letztlich „unerträglich intelligent“ beziehungsweise „zu gut gemacht“.

Insgesamt zeigen die Beiträge, die mit Überdeterminiertheit als Negativkriterium argumentieren, prototypisch die komplexe Balance zwischen Kohärenz/Gestaltetheit sowie Offenheit, die in der formalen Umsetzung eines Plots erwartet wird. Wie genau literarische Texte in einem Gleichgewicht gehalten werden, lässt sich nicht klären. Allerdings liegt es nahe, dass die Leseerfahrung der Juroren, das heißt, ihre Fertigkeit, Spach- und Gestaltungselemente von Texten als Signale zu lesen (Foregrounding), ein Faktor in der Beurteilung ist. Christmann/Groeben $(1999,182)$ heben für Sachtexte hervor, dass Texte mit „maximal kohärenter Textstruktur" nur bei Lesern ohne Vorwissen erfolgreich in Hinblick auf Lernprozesse sind. Ansonsten sei eine mittlere Verständlichkeit angezeigt. Dass sich auch in der Bewertung von literarischen Texten das Ideal der mittleren Verständlichkeit wiederfindet, lässt die Annahme zu, dass es möglicherweise eine prinzipielle Balance in der Informationsdarbietung gibt, die das Lesen von Texten angenehmer macht.

\subsubsection{Zusammenfassung}

In den Bewertungen der Juroren zeigt sich, dass neben einer Orientierung im Text auch eine bewusst angelegte mentale Aktivierung das Leseerlebnis und damit die Wertung positiv beeinflussen. Diese bewusst wahrgenommene kognitive Aktivierung findet vor allem im Wert Offenheit ihren Ausdruck. Besonders gut greifbar wird der Wert in den Diskussionen, wenn der Erzählmodus des Showing eingefordert oder gelobt wird. Es wird erwartet, dass der Text seine Handlung möglichst unmittelbar vorführt, sodass es den Lesern überlassen bleibt, die Arrangement an Szenen und Dialogen zu einer kohärenten Textwelt zu verknüpfen, um so zu einer Deutung des Textes zu kommen. Wie im Kapitel Creative Writing (vgl. Kapitel 7) bereits dargestellt, wird mit dem Modus des Showing eine Informationspräsentation bezeichnet, die dem Film ähnelt, indem verschiedene Szenen hintereinandergechaltet werden, ohne dass die Figuren vorgestellt oder Orts- und Zeitwechsel erklärt würden. Es bleibt dem Rezipienten überlassen, selbst eine Ordnung herzustellen. Handelt es sich beim Modus des Showing um eine Präsentationsform, deren Effekt eine kognitive Aktivierung des Lesers ist, geht es bei Offenheit als Wert um ein als intentional angelegt wahrgenommenes Fehlen von Informationen oder um Mehrdeutigkeit, die dem Rezipienten die Möglichkeit lässt, verschiedene „Prognosen“ für die Entwicklung der Handlung gegeneinander abzuwägen (vgl. Iser 1994, S.181 ff.). Der negative Gegenpol zu Offenheit ist in 
der Wertungssprache der Juroren die Überdeterminiertheit, ein wahrgenommenes Zu-viel an Hinweisen, welche „Prognose“ die intendierte ist.

Wenn Texte, die in Bezug auf Orientierungs-Werte positiv beurteilt wurden, außerdem Offenheit - bestenfalls sowohl als Deutungsangebot an den Leser als auch als Showing aufweisen, werden sie tendenziell besser bewertet als Texte, die nur durch ihre Gestaltetheit überzeugen. Dennoch baut der Effekt von Offenheit als gezielte Aktivierung des Lesers als Interpret auf einer weitreichenden Orientierung im Text auf. Texte, die als inkohärent oder formal nicht nachvollziehbar eingestuft werden, können nicht als offene Texte bewertet werden. Der Eindruck der Intentionalität geht dem Wert Offenheit notwendig voraus. Es ist zu vermuten, dass sich mit den Werten Offenheit und Showing die Wahrnehmung von Spannung verbindet, die wohl der zentrale Mechanismus ist, die Aufmerksamkeit des Lesers zu steuern.

\subsection{Lebendigkeit, Anschaulichkeit und Akzeptanz (Figur, Erzähler, Per- spektive)}

\subsubsection{Die Bedeutung von Figuren und Erzähler für die Textwirkung}

Eine große Rolle für die Auseinandersetzung mit Texten in Klagenfurt spielt das „Personal" literarischer Texte: der Erzähler, die Figuren und damit verbunden die Perspektive(n) auf die Handlung. Erzähler und Figur sind integrale Bestandteile literarischer Texte. Unter anderem durch den Einsatz von Figuren unterscheiden sich literarische Texte von Sachtexten. Zwar sind Figuren keineswegs notwendig für einen literarischen Text, ${ }^{54}$ jedoch haben es Texte, die Figuren und eine Handlung aufbauen, in Klagenfurt leichter als solche, in denen ein Sprecher im klassischen Sinne „erzählt“ (vgl. Kapitel 11.2.2) oder als reine Stimme eine sprachlich-musikalische Performance darbietet (vgl. Kapitel 19 „Detailanalyse Andrea Winkler"). Weil der Erzähler und die Figuren eine zentrale Funktion für die Entwicklung der Handlung haben, schenken die Juroren diesen beiden Instanzen in ihren Bewertungen große Aufmerksamkeit. ${ }^{55}$ Ausschlaggebend für die Bezugnahme auf die Gestaltung von Figur und Erzähler ist dabei, neben der Bewertung auf Ebene der Kohärenz (vgl. Kapitel 10.2), häufig die Beobachtung der eigenen emotionalen Reaktion während der Lektüre.

Das Textpersonal befindet sich in besonderem Maße im Schnittbereich zwischen Inhalt und Gestaltung. Während die Erzähltheorie Fragen der Erzählinstanz und -perspektive

54 Umgekehrt werden auch in Sachtexten Figuren eingesetzt, so zum Beispiel, wenn in Beratungstexten Fallbeispiele konstruiert werden.

55 Das spiegelt sich beispielsweise in Creative-Writing-Anleitungen, die größten Wert auf die Entwicklung der Figuren und die Konzeption des Erzählers legen. 
- Zeit, Modus, Stimme (vgl. Martínez/Scheffel 2012, 29 ff.) - der narrativen Form zuordnet, wird die Figur tendenziell als Bestandteil des „Was“ von Erzählungen, also des Inhalts (Martínez/Scheffel 2012, 111 ff.), gesehen oder als der Handlung untergeordneter Bestandteil der Erzählung betrachtet (Eder et al. 2010, 20). Eder et al. (2010, 26) machen aber auch darauf aufmerksam, dass beispielsweise Figurenkonstellationen ein strukturelles Element von erzählenden Medien sind. Durch ihre enge Verknüpfung mit der Handlung, aber auch weil ihre körperliche und psychologische Ausgestaltung viel inhaltlichen Raum in erzählenden Texten einnimmt, sind Figuren wichtiger Bestandteil der inhaltlichen Ebene von Texten. Wenn aber andererseits von der Komplexität und Dynamik (Martínez/Scheffel 2012, 144 ff.) von Figuren die Rede ist, von Figurenkonstellationen und Funktionen für die Handlung, dann ist es zumindest naheliegend, dass Figuren auch mit formalen Aspekten verknüpft sein können.

Gehört die Handlung an sich zum Inhalt, werden Erzähler und Figur von den Juroren als vom Autor intentional und nach handwerklichen „Regeln“ angelegte Elemente von Texten betrachtet. Die Juroren reagieren zwar zunächst intuitiv auf das Personal einer Erzählung, sie gehen aber stets davon aus, dass sowohl die Figuren als auch der Erzähler gezielt auf eine bestimmte Art und Weise gebaut werden, um bestimmte Effekte zu erzielen, und sie haben Beschreibungssysteme zur Hand, die ihnen ermöglichen, die Wirkung einer Figur oder eines Erzählers in abstraktere Funktionen zu übersetzen.

Aufgrund seiner handlungskonstituierenden Rolle wird das Textpersonal oft moralisch bewertet. Da aber jedes Urteil nach Möglichkeit auf eine Eigenschaft des Textes zurückgeführt wird, die als intentional angelegt gilt, wird selbst in moralischen Wertungen danach gefragt, wie der entstandene Eindruck auf der Formebene des Textes angelegt ist.

Diskussionsbeiträge zum Komplex Figur/Erzähler/Perspektive weisen zwei große Tendenzen auf. Sie beziehen sich entweder auf die Lebendigkeit und Plastizität des Textpersonals. Diese Vorstellung beinhaltet vor allem einen sinnlichen und emotionalen Zugang zur Figur. Oder aber sie haben die Vielschichtigkeit, Komplexität und Unvorhersehbarkeit der Handlung im Visier, die über Perspektiven vermittelt wird. Bei diesen auf Vielschichtigkeit zielenden Argumentationen geht es um eine intellektuelle Auseinandersetzung mit den Figuren. Hier spielt auch die moralische Bewertung der Figuren oder des Erzählers eine Rolle, die beispielsweise durch die Anlage unterschiedler Perspektiven und Ebenen kanalisiert werden kann und soll.

Insbesondere die lebendige und plastische Ausgestaltung der Figuren kann als grundlegende Voraussetzung einer positiven Textwirkung verstanden werden. Wie Mellmann 
(2010, 424 f.) beobachtet, bevorzugen Leser es, Informationen aus einer „anthropomorphen" Perspektive vermittelt zu bekommen. Tooby/Cosmides (2000, 24) gehen davon aus, dass Menschen Informationen besser verarbeiten können, wenn sie aus individueller Erfahrung stammen oder durch Kommunikation als individuelle Erfahrungen präsentiert werden. Eine anthropomorphe Fokalisierung ist, so Mellmann (2010, 423), eine Nachahmung individueller Erfahrung. Die Bindung des Geschehens an eine menschliche Perspektive, in der Regel Figuren, ermöglicht die Aktivierung evolutionär veranlagter Verarbeitungsmechanismen, die im Medium Literatur mit Lust belohnt werden (Mellmann 2008).

Die Bedeutung des Textpersonals für die Wirkung auf den Leser hätte auch, und mit gutem Recht, in den Komplex Orientierung aufgenommen werden können, bedenkt man, dass die Figuren und der Erzähler einen erheblichen Teil dazu beitragen, dass der Leser das Textgeschehen nachvollziehen kann (vgl. Mellmann 2010, 425; Schneider 1999). Es wurden deswegen in den Komplex Aktivierung aufgenommen, weil mit ihnen eine starke emotionale und geistige Anteilnahme einhergeht.

\section{Literarische Figuren}

Die Figuren sind in erster Linie Handlungsträger. Der Leser verfolgt ihre Handlungen und damit ihre (innere) Entwicklung im Verlauf des Textes. Für die Logik der Geschichte ist die Motivation der Figuren als „Schnittstelle zwischen Figuren und Handlung“ (Eder et al. 2010, 24) von entscheidender Bedeutung. Figuren binden auf diese Weise die Aufmerksamkeit besonders stark und sind so an der Erzeugung von Spannung (suspense) beteiligt. Wissen zu wollen, wie es weiter geht, mit den Figuren zu „[h]offen[] und [b]angen[]“ (Mellmann 2016, 165) gehört, das dürfte jedem freiwilligen Leser aus eigener Erfahrung einleuchten, zu den Grunderfahrungen, die Leser machen (vgl. auch Graf 2004, 49). Entsprechend sind sie eine besonders sinnliche Komponente des Leseprozesses. Wolfgang Iser (1994, 205) rechnet der Figuren- und Handlungsebene insofern eine Schlüsselrolle zu, als sie den Ausgangspunkt für zwei basale Prozesse des Lesens bildet. Sie bildet in der Vorstellung des Lesers die Grundlage für die Repräsentation des Textes und ist daher auch intersubjektiv gut fassbar. Die intersubjektive Zugänglichkeit der Figuren- und Handlungsebe spiegelt sich in den Diskussionen deutlich wieder, wenn zunächst der Versuch unternommen wird, das eigene Verständnis der Handlung offenzulegen und so den Text als Kommunikationsgegenstand zunächst zu konstituieren (vgl. Kapitel 5). Die „Sinnhaftigkeit“ stellt sich für Iser allerdings als ein Prozess dar, in dem der Leser sein Verständnis des Textes laufend anhand von neuen Informationen modifiziert. Aufgrund dieser Prozesshaftigkeit entsteht 
im Text Offenheit, die der Leser zu vereindeutigen versucht:

Die Offenheit läßt ferner erkennen, daß in ihr verschiedene Möglichkeiten angelegt sind, durch die die Gestalt erster Stufe in eine Kohärenz zweiter Stufe aufgehoben werden kann. Das aber heißt, in der latenten Offenheit erzeugter Gestalten sind Selektionsentscheidungen für ihre mögliche Schließung angelegt. (Iser 1994, 199)

Diese Offenheit ermöglicht es dem Leser, den Text zu erleben (vgl. Iser 1994, 210). Ralf Schneider (1999) hat die Figurenkonstruktion aus kognitionspsychologischer Sicht als mentales Modell dargestellt. Auch er geht davon aus, dass es in Abstimmung mit den im Text gegebenen Informationen zu einer ständigen Aktualisierung des Modells kommt.

Die Ebene der Kohärenzbildung auf der Handlungs- und Figurenebene findet in den Bewertungen eine Entsprechung im Wert Kohärenz, der eine große Rolle spielt. Die Juroren erwarten als Leser allerdings auch eine angelegte Offenheit (vgl. Kapitel 11.2). Diese wird nicht zuletzt durch offene, entwicklungsfähige Figuren realisiert. Erst Figuren, deren Entwicklung so offen ist, dass die Juroren den Impuls verspüren, sie für sich zu „schließen“, vermögen die Aufmerksamkeit zu binden.

\section{Der Erzähler}

Der Erzähler gibt dem Text eine Stimme und eine Perspektive. Wie die erzählte Welt vermittelt wird, hängt also davon ab, wie der Autor seinen Erzähler gestaltet. Sowohl Fragen der sprachlichen Gestaltung als auch Fragen der Perspektive werden daher von den Juroren unter anderem als Aspekte des Erzählers behandelt, der als im Lektüreprozess greifbarer Urheber des wahrgenommenen Textes gilt. Darüber hinaus ist ein Wissen über Erzählperspektiven in Form des Stanzel'schen Modells der Erzählperspektiven (Stanzel 2008) in seiner grundlegendsten Form vor allem auch durch den Deutschunterricht an Schulen weit verbreitet. Die Juroren können auf dieses Wissen aufbauen und damit rechnen, dass das interessierte Publikum sie versteht. Ganz deutlich wird dieses vorausgesetzte gemeinsame Wissen in einer Aussage Haslingers:

Wie macht das der Text? Er macht das in der sogenannten, wie Stanzel es einmal genannt hat, personalen Erzählperspektive, eine Perspektive, die uns nicht unvertraut ist. Wir kennen sie aus der Literatur, zum Beispiel von Franz Kafka. [... ] Dieser Text ist allerdings, gemessen an der „Verwandlung“ oder überhaupt an der personalen Perspektive, wie Kafka sie anwendet/ Es ist nicht identisch damit. Er ist sozusagen einen Schritt/ Der Erzähler, die Erzählerin tritt einen Schritt zurück. Sie hat zwischendurch auch eine Außenansicht auf den Mann. (2003 Parei, 0:04 Haslinger)

Haslinger rekurriert in dieser Aussage mit großer Selbstverständlichkeit auf die Erzähltheorie Stanzels (2008). Er sieht sich nicht veranlasst, genauer zu erläutern, was genau 
die personale Erzählperspektive beinhaltet oder wie Stanzels Modell beschaffen ist. Zwar nennt er das Beispiel Kafka, geht aber wiederum davon aus, dass das Beispiel selbsterklärend ist. Haslinger fährt dann fort, den Erzähler aus Inka Pareis Erzählung zu analysieren. Dabei setzt er das Wissen voraus, dass der personale Erzähler in der strengsten Form als Persönlichkeit vollständig in der Perspektive der Figur aufgeht. Nur wenn er auf dieses Wissen aufbauen kann, ist sein Argument schlüssig, dass Inka Pareis Erzähler die Rolle eines genuin personalen Erzählers (homodiegetisch, interne Fokalisierung, dritte Person) überschreitet. Durch die weit verbreitete Kenntnis des Stanzel'schen Erzählmodells haben die Juroren die Möglichkeit, ein Textelement - den Erzähler - in ein intersubjektiv verfügbares und damit objektorientiert wirkendes Beschreibungssystem zu übersetzen. Die Kenntnis des Beschreibungssystems ermöglicht es, den Erzähler als formales Gestaltungsmittel des Textes auszuweisen und zu bewerten. Bewertungen mit Bezug auf Erzählperspektiven haben also das Potenzial, besonders überzeugend zu wirken, weil besonders textnah argumentiert werden kann.

Dem Erzähler kommt außerdem, wenn man die Diskussionen im Ingeborg-BachmannWettbewerb genauer betrachtet, die zentrale Rolle zu, dem Leser die „richtige“ Perspektive auf den Text zu vermitteln. Moralische Anforderungen spielen dabei eine große Rolle. Texten wird durchaus zugebilligt, dass sie moralisch problematische Themen behandeln, wenn sie dabei auch die „richtige“ Einstellung zu diesem Thema vermitteln. Die „Distanz“ zum Erzählten kann eine entscheidende Rolle spielen, wenn ein moralisch problematisches Thema behandelt wird. Das von Sabine Buck $(2011,237)$ beobachtete „Distanzierungsgebot“, das beinhaltet, dass Texte „sich mithilfe von darstellerischen Mitteln wie z. B. Stil, Erzählperspektive, Figurenkonstellation oder Handlungsverlauf von moralisch verwerflichen Aussagen oder moralischen Tabubrüchen [...] distanzieren“ sollten, bestätigt sich im Rahmen der Bachmann-Preis-Diskussionen.

Der Rückgriff auf den Erzähler als Gestaltungsmerkmal leistet also in den Diskussionen vor allem eines: Es trägt dazu bei, Wahrnehmungen, die sich auf die Anschaulichkeit, Lebendigkeit oder ethische Akzeptanz des Erzählten beziehen, als Texteigenschaft greifbar zu machen. Welche Erzählperspektive genutzt wird, um Effekte wie Anschaulichkeit und Lebendigkeit zu erzeugen, ist weitgehend egal - mit einer Ausnahme: Intern fokalisierte Texte werden bevorzugt, weil sie leichter mit dem Modus des Showing zu vereinen sind. 


\subsubsection{Lebendigkeit und Plastizität als Bewertungskriterien für literarische Figuren}

An die Figuren als Handlungsträger wird die Anforderung gestellt, „interessant“ zu sein. Diese Anforderung wird in den Bewertungen - freilich nicht als Anforderung, sondern als Lob oder Kritik - deutlich formuliert.

Das alles ist doch/ macht die Figur doch interessant. (1999 Helfer, 14:10 Hettche)

Nur: die Figur ist halt nicht interessant. (1999 Mähr, 7:42 Hettche)

Es müsste hier etwas geschehen, was mich über zehn Seiten für diese Figur interessiert. (2002 Glantschnig, 1:16 Scheck)

Es sind zwei sehr interessante Figuren aufgebaut worden. (2004 Helminger, 9:54 Spinnen)

Das ist eine interessante Figur, weil es kann so nicht stimmen. (2004 Zeh, 4:48 Nüchtern)

Diese Homogenität in den Formulierungen wirft die Frage auf, was Figuren „interessant“ macht. Denn so homogen die Wortwahl ist, so nichtssagend ist sie auch. Die Wertungen mit dem Ausgangspunkt „Figur“, die untersucht wurden, lassen darauf schließen, dass Figuren die Aufmerksamkeit der Juroren erlangen, wenn sie „lebendig“ wirken. Literarische Figuren sollten, so die Juroren, nicht den Eindruck vermitteln, bloßes Illustrationsmaterial für eine Idee zu sein, obwohl sie sich andererseits in die Kohärenz des Textes einfügen müssen. Darüber hinaus wird erwartet, dass Figuren mehrdimensional sind und sich in ihrer Entwicklung nicht vorhersehen lassen. Auch diese Erwartung deckt sich mit den Vorschlägen von Creative-Writing-Lehrern in Hinblick auf die Anlage der Figur. ${ }^{56}$ Von literarischen Figuren erwarten die Juroren, dass sie nicht eindeutig und funktional, sondern plastisch und emotional anrührend sind. „Die [Figuren KR] werden für mich nicht wirklich plastisch“ (2003 Ahrens, 19:49 Rakusa), gibt Rakusa zu Protokoll. „[N]icht wirklich plastisch bis zum Ende“ bleibt Hildegard Keller (0:16) Bönts Ich-Figur (2009). Und Spinnen (8:29) wird in Hamanns Text (2003) „die Figur [...] nicht plastisch“. Steinfeld (2003 Ahrens, 8:49) freut sich über die Plastizität von Ahrens' Figuren: „Er [der Autor KR] zeichnet diese Figuren. Diese Figuren werden plastisch“. Und Haslinger (2004 Müller, 17:14) ist erfreut über eine „klar fassbare, konturierte Figur“. Wenn Scheck (2001 Askan, 4:42) urteilt, „dass die Figuren doch Gefahr laufen, zu Typen zu werden“, gibt das bereits den entscheidenden Auch hier gilt, wie für viele andere Aspekte auch, dass die Einschätzung einer Figur als eindimensional
und vorhersehbar durchaus auch von der Leseerfahrung des jeweiligen Lesers abhängt. 
Hinweis, dass Figuren „rund“ sein sollten, also idealerweise keine Typen, sondern Individuen, keine Vorführobjekte, sondern Subjekte, deren Entwicklung verfolgt wird. Schindel (2000 Goetsch, 11:46) sagt es in einer Kritik ganz direkt: „Nina ist keine lebendige Figur“. Detering (1:39) bemängelt an Juli Zehs (2004) Textausschnitt aus „Spieltrieb“ „wie diese beiden Figuren - gut und böse - gegeneinander gestellt werden und wie die Böse mit allen Elementen dessen, was den Leser aggressiv machen soll, ausgestattet wird“. Die Figuren werden also funktionalisiert, um Positionen darzustellen. Das ist, so lässt sich schließen, nicht im Sinne des Lesers. In vergleichbarer Weise problematisiert Spinnen, dass Figuren sich ausschließlich funktional zum Inhalt verhalten können und damit für den Leser uninteressant werden:

[A]us einigen [...] Andeutungen spricht natürlich der große philosophische Anspruch eines solchen Buches und damit natürlich das große Problem eines philosophischen Textes, das, was er verhandeln will, auf seine Handlung und seine Figuren so zu verteilen, dass die nicht wie bloße Statthalter bestimmter Theoreme, Äußerungen, Standorte - kultureller, religiöser und so weiter - wirkt. (2003 Lenze, 21:12 Spinnen; Hervorhebung KR)

Radisch (1999 Jonigk, 2:39) spricht von einer Figur, die „eigentlich überhaupt keine Figur“ ist, sondern „ein Demonstrationsobjekt für eine Spannungslage“. Auch sie deutet damit an, dass die Hauptfigur ein Eigenleben haben sollte, dass sie nicht ausschließlich ein Ausdruck von einer im Text vorgeführten Idee sein darf. Fliedl (2001 Askan, 16:39) stößt in eine ähnliche Richtung, wenn sie meint, es gehe nicht an, „dass es zu überhaupt keiner psychologischen Markierung kommt, denn sonst wären diese Figuren dann tatsächlich abstrakte Spielmarken eben“. Nüchtern (2006 Klischat, 9:52) spricht von „eine[r] Pappfigur, die durch die Kulisse geschoben wird“. Scheck (2001 Erpenbeck, 0:18) lobt, dass Erpenbecks Figuren „nicht nur Verfügungsmasse [sind]“. „Typen“, „Statthalter bestimmter Theoreme“, „Demonstrationsobjekte“, „abstrakte Spielmarken“, „Pappfigur“, „Verfügungsmasse“ - all das sind Formulierungen dafür, wie literarische Figuren nicht sein sollten. Psychologie und Entwicklung sowie ein individueller Charakter gehören demzufolge zur Grundausstattung von Figuren. Eine psychologisch ausgestattete Figur ist allerdings nicht automatisch eine gute Figur. Von einer guten Figur wird außerdem erwartet, dass sie für den Leser lebendig wird:

Und wenn die Stimmen so deutlich geworden sind, wie diese Stimmen geworden sind, auch durch das Typisierende, ganz klar, auch durch das Changieren der Figuren, dann kann ich das/ Dann habe ich die im Kopf. Und ich finde, das ist so vorgebracht, dass ich diese Stimme selber ausprägen kann. (2000 Maier, 17:21 Spinnen; Hervorhebung KR) 
Nicht etwa die Charaktereigenschaften oder die Gedanken der Figur werden laut Spinnen deutlich, sondern vielmehr ihre „Stimme“. Die Stimme als sinnlich Wahrnehmbares erlaubt es der Figur, sich dem Leser einzuprägen („habe ich die im Kopf“). Positiv bewertet wird außerdem die Freiheit des Lesers, diese Stimme selber „auszuprägen“. Spinnen erhebt Anspruch auf die Möglichkeit, den Text als Leser mit konstruieren zu können. Diese Forderung nach einer emotionalen Beteiligung des Lesers spricht aus vielen Diskussionsbeiträgen. Mitunter kann die Forderung nach Lebendigkeit auch in einem Konflikt mit der Intensität der formalen Gestaltung stehen:

Eigentlich nur deshalb, weil diese Konstruktion ein sehr stabiles, klug konstruiertes Gerüst ist, an dem ich wenig lebendige Figuren, Bewegungen, Empfindungen sehe. Es müsste eigentlich viel erschütternder sein, was wir am Schluss über Anuschka erfahren und über Anuschkas Eigensinn im Verweigern einer bestimmten Wirklichkeitssicht. (2005 Kim, 0:19 Detering; Hervorhebung KR)

Detering (ebd.) ergänzt, dass er deswegen so wenig berührt sei, weil er „,von den Figuren [...] so wenig s[ieht] oder gar riech[t]“. Den Gesamtaufbau des Textes sieht er allerdings als „stabiles, gut konstruiertes Gerüst“. Das Zitat illustriert sehr eindrücklich die Priorität der emotionalen Wirkung vor der formalen Gestaltung. Der Anspruch, dass Figuren sinnlich wahrnehmbar sein sollten, wird in diesem Statement explizit ausformuliert. Der Juror unterstreicht seine Aussage wenig später noch einmal, wenn er sagt, es handle sich um „leblose Figuren auf einem Spielfeld wie diesem hier“ (2005 Kim, 10:53 Detering). Das Argument scheint Detering insgesamt wichtig zu sein. Er unterstreicht auch in der Diskussion zu Bongartz (2005, 18:57), dass der Text zwar formal gut gemacht sei, dass diese formale Perfektion allerdings auf Kosten der Lebendigkeit der Figuren gehe: „[D]iese Austüftelung hat den Figuren, dem Konflikt, der Handlung, auch der Metaphorik das Leben ausgetrieben“. Sehr deutlich wird in dieser Argumentation, dass eine intensive stilistische und konzeptionelle Gestaltung (Form) nicht ausreicht, um die Juroren vollends zu überzeugen. Erst wenn ein Erlebnis-Moment hinzukommt, wird der Text wirklich positiv bewertet.

Auch Sulzer (2009 Petersen, 3:18) ist Sinnlichkeit und eine dadurch erzeugte Plastizität der Figuren sehr wichtig. „Ich glaube jedes Wort. Ich sehe diese Figuren“ (Hervorhebung KR), urteilt er. Für die Lebendigkeit ist außerdem die Psychologie der Figuren von zentraler Bedeutung. Die Juroren wünschen sich Figuren, deren Seelenleben sie verfolgen und verstehen können. Es kommt den Figuren ebenso zugute, wenn ihre Biografie angedeutet wird und sie im Verlauf der Handlung eine Entwicklung durchmachen.

So wünscht sich beispielsweise Ebel, dass die Figuren in Scheuers Text individueller ge- 
staltet werden:

Also mich stört, dass diesen Figuren, also für mein Empfinden zumindest, nichts Individuelles, Einzigartiges, Besonderes anhaftet, sondern dass das Figuren sind, die, scheint mir/ denen ich schon so oft begegnet bin und denen begegne ich hier wieder. (2006 Scheuer, 8:02 Ebel)

Mangold (2008 Geißler, 23:03) spricht sogar ganz explizit von der „Psychologie“ der Figur, wenn er sagt, dass er den Fremdenführer in Heike Geißlers Text nicht „zu wenig psychologisch ausgeleuchtet" findet. Er reagiert hier auf Alain Claude Sulzer (2008 Geißler, 22:44), der bemängelt, dass er sich unter der Hauptfigur „nichts vorstellen“ könne. Dass Sulzer die „psychologische Ausleuchtung“ der Figuren fehlt, ist freilich eine Auslegung der Argumentation durch Mangold. Sulzer selber spricht nicht direkt von der Psychologie. Umso interessanter ist Mangolds Schlussfolgerung. Sulzers Argument läuft zunächst wiederum auf die Sinnlichkeit der Figur hinaus. Sie wird ihm nicht plastisch. Mangold folgert daraus, dass die psychologische Verfassung und Entwicklung der Hauptfigur im Text nicht ausreichend entwickelt ist. Man kann also einen engen Zusammenhang von Plastizität und psychologischer Darstellung annehmen. Bei Ruoss (1999 Mähr, 14:51) ist es zwar nicht das Seelenleben der Figuren, das entscheidend für eine gelungene Figur ist, dafür aber die Darstellung der Hintergründe und Perspektiven einer Figur: „Das Problem, das ich jetzt habe, ist auch, dass ich nicht weiß, woher die Figur kommt und wohin sie geht". Radisch (2003 Griebel, 24:38) hingegen vermisst eine Individualität, ein Eigenleben der Figur: „Aber was ich weiß, ist, dass das keine Figur ist, sondern dass das eine Figur ist, an die sehr viel Literatur und sehr viel Symbole gehangen werden wie an so/ wie Lametta an einen Weihnachtsbaum“. Ähnlich wie bei den bereits zitierten Argumentationen verlangt Radisch eine individuelle Figur, die nicht die Wirkung eines Demonstrationsobjektes hat. Im Fall der Autorin Christina Griebel ist die Figur jedoch weder ein Typus, noch ist sie Anschauungsmaterial für eine Idee. Radischs Argumentation drückt aus, dass die Figur benutzt wird, um literarisch-sprachliche Kunstfertigkeit unter Beweis zu stellen.

Alle diese Aussagen zur Figur - und es ließen sich weit mehr Beispiele anführen - haben gemeinsam, dass sie das Ideal einer Figur zum Gegenstand haben, die sich im Wesentlichen verhält wie ein Individuum der außertextuellen Wirklichkeit, eingepasst in den spezifischen Zusammenhang des jeweiligen Textes. Das heißt, dass selbstverständlich erwartet wird, dass die literarische Figur sich in das Anliegen des Textes nahtlos einfügt, dass sie aber möglichst „natürlich“ wirken sollte. Es wird also eine menschliche Figur mit Stärken und Schwächen erwartet, deren Handlungen motiviert sind und sich in ihre Vorgeschichte und ihre Absichten auf eine nachvollziehbare Weise einfügen. Offenbar ist für die Akzep- 
tanz der Figuren aber ebenso wichtig, dass sie nicht vollständig erklärbar und vorhersehbar sind.

Viele Argumentationen zur Lebendigkeit der Figuren verweisen auf die Anteilnahme, die die Juroren als Leser den Figuren gegenüber empfinden. Literarische Figuren sollten, so viele der aufgeführten Argumente, so beschaffen sein, dass sie den Lesern emotionale Anteilnahme erlauben. Nachvollziehbarkeit und Entwicklungsfähigkeit der Figuren tragen zur Ermöglichung emotionaler Anteilnahme bei. Jedoch scheint die Offenheit und Entwicklungsfähigkeit der Figuren insgesamt bedeutender für die positive Einschätzung, denn Typen und Figuren, die als Repräsentanten bestimmter Ideen aufgefasst werden, und die daher als besonders gut nachvollziehbar gelten müssen, werden in aller Regel abgelehnt. Katja Mellmann (2010) hat darauf aufmerksam gemacht, dass es aus evolutionspsychologischer Sicht plausibel ist, dass literarische Figuren wie Simulationen realer Wahrnehmungen und Erfahrungen verarbeitet werden. Das Mitgefühl mit literarischen Figuren lässt sich erklären, weil der Leser in dieser Simulation so wahrnimmt, wie die Figur wahrnimmt. Eine wichtige Voraussetzung dafür ist, dass der Text eine klare und menschliche bzw. menschenähnliche Fokalisierung hat: „A focalized depiction of a narrative situation thus should be processed by more or less the same second-order circuits as are involved with processing sensory inputs" (ebd. 425). Gerade weil der Mensch ein hochgradig soziales Wesen ist, sucht er diese Art von Erfahrung und das menschliche Gehirn belohnt entsprechende Erfahrungen (ebd. 423). Es ist davon auszugehen, dass in der Rezeption literarischer Texte durch Expertenleser noch weit mehr abläuft als eine „bloße“ Simulation der Erfahrung der fokussierten Figur. Informationen aus dem Text werden gegen verschiedene Kontexte abgewogen und mit verschiedenen Wissensbeständen in Beziehung gesetzt. Dennoch ist es plausibel, die Bevorzugung psychologisch komplexer, facettenreicher, unvorhersehbarer Figuren als Erfahrungssimulation mit Belohnungsmechanismen (Lust) in Beziehung zu setzen. Die Rede von plastischen und lebendigen Figuren ist nicht willkürlich, sondern lässt sich als die spezifische Wirkung einer Figurensimulation erklären, die positiv wahrgenommen wird, weil sie als neue Erfahrung die erfahrenen Leser kognitiv „beschäftigt“.

\subsubsection{Erzähler und Erzählperspektive}

Die zentrale Frage in der Beurteilung des Erzählers ist die nach der Involviertheit in das Erzählte. In Beiträgen, die sich mit diesem Thema befassen, geht es vielfach um die Distanz des Erzählers zur Handlung. Sie findet überwiegend dann Erwähnung, wenn der Erzähler sich nach Meinung der Juroren zu wenig distanziert verhält. In solchen Argumentationen 
schwingt oftmals eine moralische Komponente mit. Es wird grundsätzlich erwartet, dass der Erzähler nicht über seine Figuren urteilt, sondern sie entweder urteilsfrei darstellt oder sie empathisch betrachtet (vgl. auch Kapitel 11.2.2).

Wie auch die Lebendigkeit der Figur hängt die gelungene Perspektive außerdem davon ab, ob sie Offenheit erlaubt. Von den Perspektiven - bei den Juroren kann dies sowohl die Erzählperspektive als auch eine Sichtweise, die der Text nahelegt, meinen - wird Vielschichtigkeit erwartet. Begreift man Perspektive mit Iser als „Zugang zu einem Sachverhalt, der von einem bestimmten Punkt aus intendiert ist" (Iser 1994, 185), wird deutlicher, wieso Perspektiven so wichtig in der Bewertung sind. Die Darstellung der Handlung aus verschiedenen Perspektiven verlangt dem Leser ab, dass er selbst eine große Integrationsleistung vollzieht, damit der Text als Ganzes interpretiert werden kann.

In der Tat erwarten die Juroren, dass der Text ihnen ein Angebot an Perspektiven macht. Detering fordert beispielsweise eine zusätzliche Außenperspektive, die dem Leser ermöglicht, sich von der Hauptfigur zu distanzieren.

Ich glaube, das könnte gehen, und ich glaube, es geht so nicht. [...] Es könnte sogar
klappen, das in die Nähe so eines Immensee-Tones oder so [...] zu bringen, wenn -
und das ist das Entscheidende, glaube ich - wenn eine prägnante, mindestens eine
prägnante Gegenstimme eingezogen würde, irgendetwas, was es, wenn nicht den Alten
selbst, zumindest uns als Lesern ermöglicht, eine Außenperspektive einzunehmen. Das
würde verhindern, dass es sozusagen doch hinausläuft auf eine Verklärung der Vergan-
genheit aus einem/ irgendwie einem besonnten Lebensabend heraus. (2005 Schiffner,
0:04 Detering)

In seinem Beitrag kommt unterschwellig auch ein moralisches Argument zum Tragen. Der Text nimmt das Mitläufertum seiner Hauptfigur im Nationalsozialismus ins Visier. Von Texten, die sich mit dem Nationalsozialismus auseinandersetzen, wird grundsätzlich erwartet, dass sie klar Position beziehen (vgl. Buck 2011).

Der Anspruch, dass eine weitere Perspektive nötig ist, ist aber keineswegs immer an moralische Vorbehalte gekoppelt:

Hier ist nun ganz eindeutig, dass die Geschichte aus der Sicht der Frau erzählt wird. Und wenn mich etwas stört, dann dass die Autorin vielleicht für/ Wenn man eben in Betracht zieht, dass die Perspektive eindeutig ist und ganz klar feststeht, dann würde ich vorwerfen der Autorin eine gewisse/ vielleicht ein bisschen zu starke Plakativität. Es wird relativ stark plakatiert. (2001 Askan, 0:09 Widmer; Hervorhebungen KR)

Für Widmer führt die einfache Perspektive der Geschichte zu einer Überdeutlichkeit (vgl. die Kapitel 10.3.1 „Dominanz der Form“ und 11.2.3). Beide Argumente - das der übergroßen Einfachheit und das der Gefahr einer Darstellung der Figur, die zu Sympathieverlust führt - kommen bei Keller zusammen: 
Ich meine, in der Art, eine Trennungsgeschichte aus dieser singulären Figurenperspektive zu zeigen, ist möglicherweise eine Sackgasse. Möglicherweise. Ich empfand diese Naivität der Figur, diese Schlichtheit [als KR] etwas, vor der ich die Figur selbst ein wenig schützen würde, vielleicht durch eine kontrastive andere Figur, die da wäre, sodass es nicht zu dieser ungebrochenen Lebenshilfeprosa wird. (2009 Satamik, 6:50 Keller)

Sie merkt zunächst an, dass die einfache, ungebrochene Perspektive auf die Handlung ihr problematisch erscheint. Sie gibt anschließend zu verstehen, dass sie sich bei dieser „Trennungsgeschichte“, die aus der Perspektive der Frau erzählt wird, gewünscht hätte, auch die Perspektive einer zweiten Figur präsentiert zu bekommen. Dieser Wunsch spiegelt das Interesse des geübten Lesers, sich selber ein Bild zu machen. Das zweite Argument, dass sie „die Figur selbst ein wenig schützen würde“ weist dagegen darauf hin, dass Keller als Leserin ein Bedürfnis nach einem Sympathieträger hat. „Naivität“ ist offenbar eine Eigenschaft, die die Figur der Gefahr der Lächerlichkeit preisgibt, vor der sie Keller bewahren möchte, um selbst eine positive Haltung einnehmen zu können.

\subsubsection{Die Wohlwollende Neutralität des Erzählers}

Zur Grundausstattung eines guten Erzählers gehört die moralisch richtige Einstellung zum Inhalt, aber auch eine besondere Einstellung zur Figur, die man als wohlwollende Neutralität bezeichnen könnte. Sie besteht, fasst man die Diskussionen zusammen, darin, dass der Erzähler über die literarischen Figuren nicht urteilt, sie auch nicht verurteilt oder durch die Art, wie die Figur beschrieben wird, eine ablehnende Haltung beim Leser erzeugt. Vielmehr soll der moralische Konflikt, der sich mit einer Figur verbindet, so die Idealvorstellung, die aus den Bewertungen deutlich wird, im Rahmen der Handlung des Textes gelöst werden. Eine klare Trennung zwischen Autor und Erzähler gehört dabei zwar theoretisch zum Allgemeinwissen der Juroren - sie weisen auch explizit darauf hin - in vielen Diskussionen wird dennoch nicht klar zwischen den beiden Instanzen getrennt. Für die Analyse wurde diese Differenzierung daher vernachlässigt. Schindel spricht in seiner Kritik vom „Denunzieren der eigenen Figuren“:

Daher bleibt bei diesem Text überhängen die etwas groben, manchmal lustigen, manchen gefallenden, manchen weniger gefallenden Formulierungen, Denunzierungen der eigenen Figuren, was mir persönlich nicht so liegt. Ich halte das für eine Todsünde in der Schriftstellerei, die eigenen Figuren zu denunzieren, darf aber trotzdem sein, wenn das hier die Absicht ist. (2001 Tingler, 5:58 Schindel)

Obwohl Schindel zugestehen muss, dass der „Verrat“ an den eigenen Figuren „trotzdem sein [darf]“, bezieht er mit der Einordnung „Todsünde in der Schriftstellerei“ eindeutig Stellung gegen die Erzählweise Tinglers, dessen Erzähler die Figuren seines Textes durch einen 
satirischen Blick bloßstellt. Dass moralisch argumentiert wird, macht die Wortwahl „Todsünde" eindeutig. Allerdings geht es nicht um die Umsetzung einer moralischen Vorstellung im Inhalt des Textes, sondern vielmehr darum, wie „menschenfreudlich“ erzählt wird. Dahinter steckt möglicherweise ein humanistischer Gedanke. Bemerkenswert ist außerdem, dass Schindel hier eine ganz grundsätzliche Aussage über seine Anforderungen an Literatur formuliert. Solche Formulierungen sind vergleichsweise selten.

Schindel ist nicht der einzige Juror, der mit der Formulierung „Denunziation“ arbeitet. Ebel etwa findet, dass Roß $(2004,17: 11)$ „so ganz kleine böse Beobachtungen“ nutzt, „die die Figur überhaupt nicht denunzieren“. Detering nennt in einem seiner Beiträge einen Hinweis darauf, warum emotionale Distanz gegenüber einer Figur für den Leser unattraktiv ist:

\footnotetext{
Das ist ja gerade das Unheimliche, [.. . ] dass diese Figur nicht im geringsten denunziert wird. Dass wir uns nicht im Geringsten ihr überlegen fühlen können, sondern dass wir so - wir heißt unsereiner, meine ich, jemand wie ich, ich oute mich gerne - auf diese Weise reflektierend sein Leben führt [...]. Ich hasse es, diesen Satz zu sagen, aber ich sage Ihnen mit dieser Prämisse doch. Diese Erzählerin ist wir. Das sind wir. (2006 Passig, 15:58 Detering)
}

Offenbar spielt für die Juroren ein identifikatorisches Element eine Rolle. „[D]as Unheimliche“ wie Detering sagt - und es muss hinzugefügt werden, dass „unheimlich“ hier positiv im Sinne von „fesselnd“ oder „stimulierend“ gemeint ist - „das Unheimliche“ besteht darin, dass die Juroren sich als Leser mit dieser Figur identifizieren können, obwohl es sich nicht per se um eine positive Figur handelt. Gewünscht wird eine erzählerische Distanz zur Figur, die gleichzeitig die Möglichkeit zur Anteilnahme offen hält, sodass der Leser in einen inneren Sympathiekonflikt gerät. Diese Vorstellung von einer wohlwollenden Distanz spiegelt sich auch in Strigls (2004 Helminger, 6:34) Aussage, „dass die Perspektive genau den richtigen Abstand einhält“. Das bedeutet für sie, dass „,in den Kopf hineingeschaut [wird], aber [...] nichts interpretiert [wird]“ (ebd.). Die große Analogie zu Wertungen mit dem Bezugspunkt Showing wird hier unmittelbar erkennbar. Strigl entwirft den Idealfall eines Textes, in dem die Handlung ganz klar perspektiviert dargestellt wird, der Leser aber, so als wäre er die wahrnehmende Figur selbst, die Informationen interpretieren muss. Dass der Text selbst Interpretationshinweise gibt, wird von Strigl eindeutig abgelehnt.

Hatte Detering noch Wert auf ein gewisses Identifikationspotential der Figur gelegt, weist Schindel darauf hin, dass eine eindimensionale Figurenperspektive die Aufmerksamkeit des Lesers verliert, wenn sie zu eindeutig wird, wenn also keine Distanz des Erzählers zur Reflektorfigur aufgebaut wird: 
Ich glaube, das Problem bei der Erzählung ist, dass der Erzähler selbst sich ein bisschen zu sehr von diesem Holzmann umarmen lässt. Würde der Erzähler in dieser Geschichte den Holzmann ein bisschen distanzieren, [...] dann würde ihm sozusagen auch passieren, dass ihm der andere, der Architektenchef, zur Knallcharge wird und damit/ sodass sozusagen von den drei kärglichen Figuren oder vier kärglichen Figuren, die es hier gibt, eine schon vollkommen denunziert wird vom Erzähler. Und er denunziert sie deswegen, weil er sie von seiner eigenen Figur, vom Holzmann, derartig manipulieren hat lassen, dass er dann die Sicht durch den Holzmann auf die ganzen Figuren hat. [...] Auch als Ich-Erzähler gibt es noch den Erzähler dahinter, der zu diesem Ich-Erzähler in einer gewissen Distanz stehen könnte. Und in diesem Fall würde das der Geschichte gut tun, weil diese erzählerische Ungerechtigkeit, die hier bei vier Personen vorhanden ist, dadurch diese Geschichte, glaube ich, etwas zum Kippen bringt. (2002 Matheis, 8:40 und 11:34 Schindel)

Schindel kritisiert in diesem Beitrag die Figurenkonstellation und die Reduktion der Perspektiven auf die des Erzählers, sodass kein Blick von außen auf den Erzähler möglich ist. Matheis“ Text „Schnitt“ stellt zwei Architekten gegenüber, die nicht nur zwei unterschiedliche Auffassungen von gelungener Architektur haben, sondern auch um eine Frau konkurrieren. Dass dabei nur die Perspektive des einen Kontrahenten (Holzmann) für den Leser nachvollziehbar gemacht wird und der andere (der „Architektenchef“ Meinhard) lediglich eine Kontrastfigur abgibt, macht den Text, so kann man das Argument auswerten, zu eindeutig und geschlossen. Er bietet dem Leser nicht die Möglichkeit, sich selbstständig eine Interpretation aus den Angeboten des Textes zu erarbeiten.

Der Grad des Identifikationspotentials steht auch im Mittelpunkt der folgenden Aussage Radischs, in der sie sich kritisch mit der Frage auseinandersetzt, ob es möglich ist, aus der Perspektive eines Massenmörders zu schreiben:

Gestern hatten wir die Geschichte eines Opfers in einem Lager, in einem/ Jetzt haben wir die Geschichte eines Holocausttäters aus - und ich hoffe, dass wir jetzt nicht wieder in so eine Erzählperspektivendiskussion kommen, wie nah dran das nun erzählt wird - also aus einer relativen Innenansicht. Ein Massenmörder wird aus einer relativen Innenansicht geschildert. Das ist ein solch ungeheures Unterfangen, dass es eigentlich fast nicht gelingen kann. Ich finde auch, dass es überhaupt nicht gelingt. (2004 Becker, 0:13 Radisch)

Die Folie dieser Aussage ist eine moralische Einschätzung, derzufolge es ein „ungeheures Unterfangen“ ist, aus der Perspektive eines Massenmörders zu schreiben. Dieser moralische Hintergrund ist auch deswegen so deutlich, weil Radisch auf die Diskussion zu Dorothea Dieckmanns Text („Guantánamo“) aus demselben Jahr referiert, der ebenfalls aus moralischen Gründen abgelehnt wurde. Insbesondere geht es Radisch um die „Innensicht“. Grundsätzlich kann angenommen werden, dass die Innensicht Lesern besonders entgegenkommt, weil sie es erlaubt, die erzählte Situation zu verarbeiten, als wäre es eine selbst erlebte (vgl. Mellmann 2010, 425). Allerdings ist der Massenmörder als Figur moralisch 
so problematisch, dass Radisch als Leserin Schwierigkeiten hat, dessen Perspektive anzunehmen, zum einen, weil es dieser Perspektive an Glaubwürdigkeit fehlt - so wurde in der Dieckmann-Diskussion argumentiert -, zum anderen, weil offenbar eine moralische Abwehrhaltung dagegen besteht, sich in das Denken und Fühlen einer solchen Figur hineinzuversetzen. In diesem speziellen Fall wird also vom Erzähler eine Distanz zur Figur erwartet, die dem Leser erlaubt, zu einer moralisch „richtigen“ Einstellung zu der Figur zu finden. In allen drei bisher besprochenen Fällen - die Identifikation mit Passigs Hauptfigur, die vereinnahmende Sicht des Holzmann in Matheis ${ }^{6}$ Text und der Massenmörder aus der Innensicht - nehmen Bezug auf ähnliche Phänomene, nämlich die Präsentation von Informationen aus der Perspektive eines bestimmten Bewusstseins. Obwohl die Innensicht grundsätzlich eine gute Voraussetzung für ein positives Lektüre-Erlebnis ist, weil sie die emotionale Anschlussfähigkeit erleichtert, hängt die tatsächliche Bewertung von einem Zusammenspiel mit anderen Faktoren ab. Eine ungebrochene Innenperspektive (der Fall Matheis) kann dem Anspruch entgegenstehen, durch intensive, aufmerksame Lektüre Informationen selbstständig zu einem Gesamtbild zusammenzusetzen (Wert Offenheit). Gleichzeitig wird erwartet, dass Figuren zugänglich sind, das heißt, dass sie die Möglichkeit erlauben, den Leser emotional zu aktivieren. Moralisch problematische Charaktere sind für die emotionale Anteilnahme und das Nacherleben besonders schwierig; daher wird in solchen Fällen eine Erzählhaltung erwartet, die einen distanzierten Blick auf die Figur erlaubt. In der Diskussion zu Vladimir Verlibs (1999) Text „Innere Werte“, der eine zwiegespaltene Bewertung erhielt, wird genau dieser Konflikt ausgetragen. Im Mittelpunkt des Textes steht eine Figur, die von den Juroren wiederholt als „Schwein“ betitelt wird, weil sie nach Russland fährt, um sich dort gegen Geld eine Ehefrau auszusuchen. Die Geschichte wird von einem Ich-Erzähler präsentiert, der dem Protagonisten in einem Gespräch die Details zu seiner Reise entlockt und diese kommentiert, sodass die Rahmenhandlung eine Distanzierung gegenüber der Binnenhandlung erlaubt. Gleichzeitig bietet der Text eine intern fokalisierte Binnengeschichte als „Erlebnishorizont“ an. Je nachdem, wie verwerflich die Juroren die Hauptfigur einschätzen, bewerten sie auch die Rahmenhandlung als notwendig oder nicht notwendig. Radisch (3:32) nimmt eine mittlere Position ein, wenn sie sagt, „dass dieses Spiel mit den verschiedenen Wertschätzungen, dass das sehr raffiniert gemacht ist“. Die Kopplung von Rahmenhandlung und Binnenhandlung schafft also „verschiedene Wertschätzungen“, das heißt Einschätzungen des Geschehens, die die Geschichte offen machen und Radisch daher „ganz gut gefallen [haben]“ (ebd.). Bovenschen (0:03) lehnt die kommentierende Erzählerstimme der Rahmenhandlung dagegen ab: 
[W]as mich ein bisschen stört, ist diese kommentierende Erzählerstimme und auch noch sozusagen dieser moralische/ diese Stimme dieses Freundes, diese Ich-Perspektive, die dann das moralisch so ein bisschen konterkariert und zurechtrückt. Ich glaube, das bräuchte dieser Text gar nicht. (1999 Vertlib, 0:03 Becker)

In vielen Beiträgen dieser Diskussion wird der Konflikt ausgetragen, inwieweit es für den Text günstiger gewesen wäre, wenn der kommentierende Erzähler weggelassen worden wäre und der Leser den Protagonisten selbst als „Schwein“ hätte entlarven müssen. Beide von den Juroren positiv gewertete Möglichkeiten - die realisierte mit Rahmenerzählung und die Version ohne Rahmenerzählung - werden mit Blick auf das Potential an Leseraktivierung gewertet. Die Version mit Rahmenerzählung ermöglicht das von Radisch angesprochene perspektivische Spektrum, in dem unterschiedliche Bewertungen der Hauptfigur angelegt sind. Die von Bovenschen imaginierte Version ohne Rahmenerzähler ließe dem Leser im Sinne des Wertes Showing (vgl. Kapitel 11.2.2) die Möglichkeit, selbst zu einer Beurteilung der Hauptfigur zu gelangen.

Auch März hat eine sehr klare Meinung dazu, wie der Erzähler - dass sie wortwörtlich vom „Autor" spricht, sollte nicht darüber hinwegtäuschen, dass es letztlich um den Erzähler geht - zu seinen Figuren stehen sollte und auch sie greift auf ein ethisch gefärbtes Vokabular zurück. Sie spricht von der "Güte“ des Autors seiner literarischen Figur gegenüber:

Es gibt die Güte in der Literatur. Und sie hat mit dem Verhältnis des Autors zu seiner Figur zu tun. Und das gütige Verhältnis des Autors zur Figur entsteht eben nicht durch Nähe, sondern durch Distanz. (2004 Roß, 4:22 März)

„Distanz" ist hier vermutlich nicht als eine Distanzierung von der Figur zu verstehen. Vielmehr geht es um eine unparteiische Haltung gegenüber der Figur. Nur die Art der Informationen und ihr Arrangement - möglichst im Modus des Showing - sollen Aufschluss über den Charakter der Figur geben. Aufgabe des Erzählers ist es, die Informationen zu arrangieren, nicht aber, sie zu kommentieren oder zu deuten.

\subsubsection{Zusammenfassung}

Kein literarischer Text ist denkbar ohne einen Erzähler. Genauso gehören Figuren zur Grundausstattung erzählender Texte. Für die Juroren des Ingeborg-Bachmann-Preises ist das Textpersonal ein häufiger Bezugspunkt und das nicht nur, weil eine Kommunikation über Texte kaum denkbar wäre, ohne dabei auch inhaltlich auf die Figuren Bezug zu nehmen. Das Textpersonal wird durchaus als Bestandteil der formalen Gestaltung von Erzähltexten präsentiert. Im Mittelpunkt steht dabei die Frage der Art und Anordnung 
von Informationen im Rahmen der gewählten Perspektive(n). Sowohl eine Beschränkung der Perspektive, und somit der verfügbaren Informationen, als auch eine Gegenüberstellung sich ergänzender oder widersprechender Perspektiven kann dabei effektvoll sein. Die formalen Umsetzungsmöglichkeiten sind vielfältig und unterliegen keiner grundsätzlichen Wertung. Homodiegetische Erzählweisen werden nicht grundsätzlich gegenüber heterodiegetischen bevorzugt (oder umgekehrt). Erzählungen in der dritten Person werden nicht grundsätzlich gegenüber solchen in der ersten Person bevorzugt. Gemessen werden die Figuren vielmehr daran, wie sehr sie in der Lage sind, die Juroren gedanklich in den Bann zu ziehen und emotional zu aktivieren.

Dass die Anziehungskraft von Erzähltexten ganz wesentlich von der Bewertung der Figuren und der Situation abhängig sein könnte, haben schon Bortolussi et al. (2008, 420) vermutet. ${ }^{57}$ Eder et al. $(2010,24)$ konstatieren, dass die Motivation [der Figuren] tendenziell der Motor und das Zentrum einer Geschichte sei, dass sie ihr Thema vermittle und sich als signifikanter Einflussfaktor auf emotionale Reaktionen darstelle. ${ }^{58}$ „Motivation“ beschreiben sie (ebd.) als „the inner life and personality traits: the entirety of psychical processes that initiate, maintain and regulate behaviour". Mellmann (2010) geht davon aus, dass Leser über Figuren eine Simulation von Erfahrungen erleben und dass dieses Sammeln von Informationen durch simulierte Erfahrung kognitiv belohnt wird. Am besten gelingt das, wenn eine menschliche (anthropomorphe) Perspektive eingenommen wird. Sowohl die Wichtigkeit der Figuren-Wahrnehmung für die Wertung als auch die in der kognitiven Forschung beobachtete Tendenz, Figuren zu bevorzugen, die menschlich sind, und Perspektiven, die persönliche Wahrnehmung simulieren, bestätigen sich in den Diskussionen. Typen werden im Kontrast dazu in der Regel abgelehnt, ${ }^{59}$ genauso Figuren, die ausschließlich als Repräsentanten von Ideen erscheinen. Der Effekt dieser Darstellung im Modus der Als-Ob-Erfahrung ist eine emotionale Aktivierung, die die Juroren unterschiedlich formulieren und die zum Teil auch in der Emotionalität der damit verbundenen Wertungen erkennbar wird. Mit der Bezeichnung „emotionale Aktivierung“ wird hier bewusst eine eher vage Formulierung gewählt. Es ist zwar klar, dass Leser emotional auf Texte reagieren. Welcher Art genau diese Emotionen sind und wie sie sich sprachlich am besten fassen lassen, ist alles andere als klar (vgl. Koppenfels/Zumbusch 2016). Immerhin besteht in der literaturwissenschaftlichen Emotionsforschung „ein Grundkonsens darüber,

\footnotetext{
$\overline{57}$ Englischer Originaltext: „We suspect, for example, that overall appeal is substantially determined by readers" evaluation of the characters and the situation".

58 Englisches Original: „motivation tends to be the motor and the centre of a story, transmits its theme and presents a significant influence on emotional reactions".

59 In Genres, in denen Typen zum Genremuster gehören (etwa in der Satire), werden sie akzeptiert.
} 
dass Emotionen, die im Zusammenhang mit literarischen Texten erlebt werden, prinzipiell von denselben psychischen Dispositionen herrühren, die auch das emotionale Erleben in außerliterarischen Kontexten bestimmen“ (Mellmann 2016, 158). Weil Emotionen beim Lesen rein mental erfahren werden , [treten] bewusster Erlebnisaspekt und Lustempfinden [...] umso deutlicher hervor" (Mellmann 2016, 159). Da im Rahmen des Wettbewerbs ohnehin nicht die spezifische Emotion, die die Texte hervorrufen, von Bedeutung ist, sondern vielmehr, dass das entsteht, was Mellmann als „Erlebnisaspekt“ beschreibt, scheint es gerechtfertigt, mit dem vagen Begriff „emotionale Aktivierung“ zu arbeiten. Die literarische Emotionsforschung erweist sich aus diesem Blickwinkel allerdings als ein besonders vielversprechendes Forschungsfeld.

Neben der emotionalen Aktivierung können sich die Werte Anschaulichkeit und Lebendigkeit aber auch auf eine geistige Aktivierung beziehen, die durch die Spezifik der Informationsvergabe hervorgerufen wird. Solche Wertungen verhalten sich in vielerlei Hinsicht analog zu Bewertungen, die im Unterkapitel zum Erzählmodus des Showing beschrieben wurden. Positiv gewertet wird die Figurendarstellung und Perspektivennutzung auch, wenn sie es erforderlich macht, dass der Leser selbst die gegebenen Informationen als perspektivierte Informationen zu einem Bild zusammenfügt und sie gegen andere Informationsquellen - eine andere Perspektive aus dem Text oder aber eigene Erfahrungen abwägt. Sowohl das aktive Rekonstruieren, das an eine einfach Kohärenzbildung anknüpft, aber auch darüber hinaus geht, als auch das Kontrastieren erfordern ein verstärktes Mitdenken des Lesers, das von den Juroren honoriert wird, solange es nicht zu Störungen der Kohärenz kommt.

Obwohl die Juroren eine Erzählsituation begrüßen, die die Erfahrungen der Figur zugänglich und daher emotional und logisch nachvollziehbar macht, werden allzu eindeutige, parteiische Perspektiven in der Regel abgelehnt. In Texten mit ethisch problematischen Themen (beispielsweise Holocaust, Schwelgen in Gewalt, Verhöhnung von sozialen Gruppen) wird eine Möglichkeit des „Opting Out“ erwartet. Dem Leser soll mithilfe formaler Mittel der Textgestaltung die Möglichkeit gegeben werden, aus der Perspektive der ethisch problematischen Figur „auszusteigen“. Aber auch bei Sympathieträgern, die keinen ethischen Vorbehalten ausgesetzt sind, schätzen es die Juroren, wenn über erzählerische Mittel der Kontrastierung (z. B. zusätzliche Erzählstimme, Kommentare und Verhalten anderer Figuren, Missverhältnis von Figurenwissen und Leserwissen) eine oder mehrere zusätzliche Perspektiven auf die Hauptfigur zulassen. Die Bewertung der Figur schwankt also insgesamt zwischen zwei Polen: Zum einen soll die Figur so beschaffen sein, dass sie den 
Leser durch emotionale und mentale Aktivierung in die Textwelt hineinzieht und so seine Aufmerksamkeit fesselt. Zum anderen wird es begrüßt, wenn dieser Zugang, den die (Haupt-)Figur vor allem bei interner Fokalisierung garantiert, in Frage gestellt wird, sodass Offenheiten entstehen. Es kann davon ausgegangen werden, dass es eine lustvolle Herausforderung für die Juroren ist, die komplexeren Informationsstrukturen, die durch sich wiedersprechende Signale entstehen, abzuwägen. Möglicherweise ist diese Fähigkeit, komplexe Informationen zu managen ein Produkt großer Lektüreerfahrung. 


\section{Originalität}

\subsection{Der Wert Originalität}

Dass der Wertmaßstab Originalität - nach Heydebrand/Winko (1996, 121 f.) ein relationaler Wertmaßstab - überhaupt in einer Arbeit aufgenommen wird, in der es eigentlich um formal-ästhetische Werte gehen soll, mag verwundern. Dass Originalität eine so zentrale Stellung im Rahmen der Auswertung zugestanden wird, liegt in der Methode begründet. Es wurden für die Analyse alle Textstellen berücksichtigt, in denen die Juroren auf die sprachliche und formale Gestaltung der Texte - die Machart - Bezug nehmen. Erst in einem zweiten Schritt wurde untersucht, welchen Wertmaßstäben diese Werteigenschaften in der Diskussion zugeordnet werden und warum (Zuordnungsvoraussetzungen). Der Maßstab Originalität in seinen verschiedenen Facetten lässt sich in sehr vielen Diskussionspassagen mit Form-Bezug als Bezugsgröße ausmachen. Wenn also nicht die Frage gestellt wird, welche formal-ästhetischen Wertmaßstäbe im aktuellen Wertungsdiskurs bedeutend sind, sondern vielmehr die Frage, an welchen Stellen die Form des Textes als Werteigenschaft wahrgenommen und in die Bewertung mit einbezogen wird, dann erweist sich Originalität als eine wichtige Bezugsgröße. An diesem Maßstab lässt sich besonders gut nachvollziehen, dass die Beurteilung formal-ästhetischer Werteigenschaften noch lange nicht eine insgesamt formal-ästhetische Auseinandersetzung mit dem Text bedeutet. Formal-ästhetische Eigenschaften werden in den Bachmann-Preis-Diskussionen herangezogen, um alle möglichen Arten von Wertmaßstäben zu begründen. Dieser argumentative Weg von der Werteigenschaft zum Wertmaßstab ist kein zufälliger, sondern entspricht dem Prozess der (bewussten) Wahrnehmung. Zunächst wird ein Merkmal des Textes aufgrund seiner Wirkung bewusst wahrgenommen. Erst dann erfolgt die Verknüpfung mit erlernten Wertmaßstäben. ${ }^{60}$

Dass der Wertmaßstab Originalität nicht unter die beiden Wirkungskomplexe Orientierung und Aktivierung subsumiert wurde, hat verschiedene Gründe. Zwar steht der Maßstab nicht jenseits der Wirkungswertungen, sondern ist, wie die formal-ästhetischen Werte auch, an Wirkungen gekoppelt, dennoch hat er eine stärkere argumentative Eigenbedeutung. Je nach Gesamtwirkung und -wertung kann der Maßstab Originalität sowohl die Wirkung der

60 Es ist denkbar, aber am Korpus nicht beweisbar, dass die Wahrnehmung von Texteigenschaften (Werteigenschaften) durch die Kenntnis des Koordinatensystems Wertung mitbestimmt wird. Es gibt bei der Wahrnehmung künstlerischer Gegenstände wie Belke/Leder (2006) sie beschrieben haben, verschiedene Rückkopplungen von Wissen und Wahrnehmung, die auch für die Wahrnehmung und Beurteilung der Wettbewerbstexte grundsätzlich angenommen werden können. Der argumentative Weg geht allerdings von der Wahrnehmung der Texteigenschaften zum Maßstab. 
Orientierung als die der Aktivierung zugestanden werden. Aktiviert fühlen sich die Juroren, wenn der Text durch seine originelle Gestaltung ihnen - so der Tenor der Diskussionen - abverlangt, sich intensiv mit dem Text zu befassen, weil er gewohnte Wahrnehmungsmuster durchbricht (Normbruch). Gleichzeitig wird Originalität als positiver Maßstab nur dann zuerkannt, wenn die ungewohnte Machart eines Textes überhaupt als ein Prinzip verstanden wird und nicht als Zufall. Hier greifen offenbar Mechanismen der Orientierung. Wertungen mit dem Bezugspunkt Originalität überschneiden sich also durchaus mit den Werten aus den Komplexen Aktivierung und Orientierung. Die Beispiele aus den Diskussionen werden zeigen, dass die Wertmaßstäbe zum Teil stark ineinander greifen. Ob und unter welchen Umständen statt genuin formal-ästhetischer Werte wie Gestaltetheit oder Offenheit der Wertmaßstab Originalität in den Argumenten in den Vordergrund gerückt wird, ist nicht so sehr eine Frage der konkreten Beschaffenheit des Textes, sondern des argumentativen Kontextes. Originalität erweist sich als ein stark konventionalisierter positiver Wertmaßstab. Indem ein Text als (nicht) originell eingestuft wird, kann seine Gesamtbewertung graduell verschoben werden. Der Maßstab wird also oftmals dann in die Waagschale geworfen, wenn die Juroren sich nicht einig sind, ob es sich um einen guten oder sehr guten, um einen tendenziell guten oder tendenziell schlechten, einen schlechten oder einen sehr schlechten Text handelt. In Hinblick auf seine abstufende Funktion ist Originalität zwar ein aufgrund seines argumentativen Prestiges häufig verwendeter, dennoch aber ein schwacher Wert, insofern als er Wertungen nicht grundsätzlich entscheiden kann. Im Korpus gibt es keine einzige Diskussion, in der die Originalität eines Textes übereinstimmend als zentraler Wert anerkannt wird. Es gibt immer einzelne Juroren, die in diesem Sinne argumentieren oder auch Übereinstimmung darin, dass die originelle Gestaltung auch ein positiver Faktor ist, niemals ist es aber die Originalität eines Textes allein, die ihn erfolgreich macht. Argumentatives Prestige und tatsächliche Bedeutung für die Gesamtbewertung stehen beim Maßstab Originalität im Rahmen des Ingeborg-BachmannWettbewerbs in einem deutlichen Missverhältnis. Nimmt man theoretische Annahmen aus der Literaturwissenschaft, wie etwa Frickes (1981) Theorie des Normbruchs in literarischen Texten, mit ins Bild, scheint es naheliegend, dass immer neue Abweichungen von alltagssprachlichen, aber wohl auch von alltäglich gewordener literarischer Sprache, als besonderes Kennzeichen des Literarischen gelten. Andreotti (2009, 407 ff.) stellt zehn Kriterien für gelungene Literatur vor. Von diesen zehn Kriterien nehmen drei direkt Bezug auf den Abweichungscharakter von hochwertiger Literatur: Gute Texte „[vermeiden] längst verfestigte sprachliche Wendungen und Bedeutungen“, „[stören] gewohnte ,Regeln““ und 
widersetzen sich den Erwartungen des Publikums (ebd.). Andreotti (ebd.) weist außerdem darauf hin, dass Klischees vermieden werden sollten. In Bezug auf das Kriterium der Abweichung fasst Andreotti (ebd., 408) zusammen, die Distanz zwischen dem Vertrauten und dem mit der Rezeption geforderten „Horizontwandel“ bestimme weitgehend den Kunstcharakter eines literarischen Textes. Für die Bewertung von Texten im Rahmen des Ingeborg-Bachmann-Wettbewerbs bewahrheitet sich dieses Postulat nicht. Hier liegt offenbar ein deutlicher Unterschied zwischen Literaturwissenschaft und Literaturkritik im Rahmen eines Literaturpreises. Möglicherweise liegt der Unterschied aber auch, wenigstens zum Teil, in der Organisation des Wettbewerbs begründet, denn jene Texte, die im Rahmen des Wettbewerbs zueinander in Konkurrenz treten, unterliegen bereits einer Vorauswahl. Sie sind schon die vielversprechendsten unter den zugesandten Texten. Es ist durchaus wahrscheinlich, dass der Maßstab Originalität bei der Vorauswahl eine größere Rolle spielt. Ganz sicher kann allerdings gesagt werden, dass Andreottis Annahme, dass die literarische Qualität mit dem Grad der Innovation wachse, für die Klagenfurter Wertungen nicht zutrifft.

Originalität umfasst im Verständnis der Juroren alle Phänomene, bei denen die neuartige und/oder abweichende, als ungewöhnlich empfundene Gestaltung eines Textes im Vordergrund steht. Damit verknüpft sich oftmals die Vorstellung, dass ein Autor etwas Eigenes, Anderes, das heißt von anderen Autoren oder literarischen Traditionen deutlich Verschiedenes geschafften hat. Der Begriff Originalität fasst also generell Phänomene der Neuartigkeit und Einzigartigkeit. Eine Trennung von Originalität im eigentlichen Sinne (ein Autor schafft etwas Neues und für ihn Charakteristisches), Novität (das Modische) und Abweichung/Normbruch (Differenz zur Alltagskommunikation) wie sie etwa Heydebrand/Winko (1996, 121 f.) vornehmen, wird in dieser Arbeit vernachlässigt, vor allem deshalb, weil sich diese Varianten im Korpus schwer trennen lassen. So kann durchaus als originell benannt werden, was eigentlich als Normbruch kategorisiert werden müsste. Als Gegenpol des Wertes Originalität betrachte ich mit Blick auf das Korpus Konventionalität. Originalität fällt gegenüber anderen Maßstäben wenig ins Gewicht, wenn es um die Grundtendenz der Bewertung geht. Zwei Hauptlinien der Argumentation lassen sich ausmachen: Zum einen wird bewertet, wenn ein Autor sich in einem Text ungewöhnlicher Gestaltungsmuster bedient oder, negativ gewendet, wenn er formal als sehr konventionell empfunden wird. Dieser Argumentationstypus soll als Originalität als Innovation bezeichnet werden. Dass Originalität als Innovation ein eher untergeordneter Wert ist, spiegelt sich auch darin, dass Originalität dann nicht mehr gutgeheißen wird, wenn sie mit anderen Werten 
wie Kohärenz oder Offenheit in Konflikt steht. Dafür, dass Originalität zwar ein absolut positiv gesehener Wertmaßstab ist, aber kein uneingeschränkt positiver Wert eines Textes (attributiver Wert), spricht auch die Tatsache, dass bei besonders originellen Texten mitunter darauf verwiesen wird, dass der Autor viel „Mut" habe oder, dass der Autor ein hohes „Risiko“ eingegangen sei. Der Risiko-Topos tritt typischerweise in Diskussionen auf, in denen ein Text eher negativ bewertet wird, seine Originalität aber als ein positives Gegengewicht ins Spiel gebracht werden soll. Verkürzt heißt der Risiko-Topos: Originalität ist prinzipiell gut. Aber sie geht ein hohes Risiko ein, dem Leser den Zugang zum Text zu erschweren. Wertmaßstab und Werteigenschaft stehen in einem Konfliktverhältnis, das nicht darin besteht, dass der Text dem Wertmaßstab nicht gerecht wird, sondern dass die Werteigenschaften mit anderen Wertmaßstäben in Konflikt stehen.

Die andere Argumentationslinie nutzt Originalität im Sinne von Individualität. Dabei geht es überwiegend um die sprachliche Gestaltung des Textes. Die Jurymitglieder sprechen dann typischerweise vom „Sound“ des Textes oder vom „eigenen Ton“ des Autors. Der „eigene Ton“ wird immer positiv gewertet. Hier zeigt sich also deutlich die Erwartung einer Abweichung in der Sprache, sowohl von der Alltagssprache als auch von anderen Autoren, die dem Text ein Alleinstellungsmerkmal verleiht, ihn allerdings nicht kryptisch werden lassen darf. Obwohl das Kriterium grundsätzlich positiv gewertet wird, ist es nicht direkt mit Frickes (1981) Konzept der Abweichung oder dem Kriterium der „erschwerten Form“ und der Verfremdung bei den russischen Formalisten vergleichbar.

\subsubsection{Originalität als Innovation}

Ein überwiegender Teil der dem Maßstab Originalität zugeordneten Wertungen bezieht sich auf Originalität als Innovation. Es soll hier noch einmal betont werden, dass die beiden Varianten - Innovation und Individualität - in vielen Diskussionen nicht scharf voneinander zu trennen sind. Einige der gewählten Beispiele erlauben beide Varianten.

Originalität als Innovation ist ein hoch angesehener Wertmaßstab, der sich in der Vorstellung der Juroren eng mit dem Begriff von Literatur als Kunst verknüpft. Gleichzeitig gibt es keine originelle Narrenfreiheit. Auch originelle Texte müssen anderen Ansprüchen, etwa dem der Kohärenz, genügen. Insbesondere die sprachlich-stilistische Gestaltung des Textes, nicht aber so sehr die konzeptionell-formale, wird daraufhin untersucht, ob der Maßstab Originalität erfüllt ist. Wie in den meisten Fällen muss ein Text zunächst Anhaltspunkte liefern, die überhaupt erst eine gedankliche Verknüpfung mit dem Maßstab Originalität erlauben. 
Spinnen etwa macht darauf aufmerksam, dass es keine allgemeinverbindlichen Regeln für Literatur gebe.

Das ist jetzt die Frage nach literarischen Kriterien, die man hat und die nicht allgemeinverbindlich sein können. Es sind ja keine Regeln für das Fliegen von Flugzeugen, wo ich eine gewisse Allgemeinverbindlichkeit begrüße. [Heiterkeit] In der Literatur kann ich das, darf ich das leider nicht begrüßen. Zum Glück ist es ja auch nicht so. Ich versuche mir immer vorzustellen: Erzählt mir ein Text eine Geschichte oder ist seine Sprache ein notwendiger Teil dieser Geschichte? Ist da etwas darin, in der Ausdrucksweise, was nicht anders sein könnte, damit es diese Geschichte ist? (2009 Schäfer, 6:17 Spinnen)

Zunächst weist Spinnen also mit sehr viel Nachdruck darauf hin, dass in der Literatur, anders als im Flugverkehr, Abweichungen von Regeln erwünscht sind. Konkret beschreibt er diese Regellosigkeit dann aber so, dass nicht allein der Maßstab Originalität, sondern auch der Maßstab Stimmigkeit als Bezugspunkt angesetzt werden könnte. Hier zeigt sich das bereits erwähnte Ineinandergreifen der Wertmaßstäbe. Er erwartet von einem Text, dass seine sprachliche Gestaltung absolut auf den Inhalt abgestimmt ist („,ist seine Sprache ein notwendiger Teil dieser Geschichte“). Im selben Zuge sollte die sprachliche Gestaltung aber das Alleinstellungsmerkmal der Geschichte sein (,,ist da etwas darin, in der Ausdrucksweise, was nicht anders sein könnte, damit es diese Geschichte ist?“). Die Allgemeingültigkeit, die Spinnen mit seiner Aussage nahelegt, verweist auf den hohen ideellen Wert, der dem Wertmaßstab Originalität zukommt.

Nicht immer wird dieses Ideal geteilt, meistens jedoch wird es trotzdem als Bestandteil einer aktiven Wertungspraxis anerkannt. So etwa in der folgenden Aussage von Robert Schindel in einer Diskussion, in der dem Autor von mehreren Juroren vorgeworfen wird, er kopiere den Stil Thomas Bernhards. Mit dem Hinweis auf den „eigenen Ton“ wäre die Passage eher dem Wert Originalität als Individualität zuzuordnen. Da es allerdings sehr illustrativ für die Bedeutung des Wertmaßstabs Originalität im Allgemeinen ist und den Maßstab explizit anspricht, soll es bereits hier eingeführt werden:

\footnotetext{
Man kann sagen, wenn wir uns der Raserei der Originalität verpflichtet fühlen und meinen, es muss jeder Autor in allem und jedem seinen unverwechselbar eigenen Ton immer und überall haben, dann ist natürlich an diesem Text einiges zu bekritteln. [...] Für hier und für dieses Kabinettstück [...] ist das ausgezeichnet gelungen. [Applaus] (2000 Maier, 9:09 Schindel)
}

Mit der Formulierung „Raserei der Originalität“ weist Schindel die Gültigkeit des Wertmaßstabs Originalität in Schranken. Gleichzeitig macht er implizit deutlich, dass diesem Wertmaßstab im alltäglichen Wertungsvorgehen ein hohes Prestige zukommt. Dass der 
Wertmaßstab, wie in diesem Beispiel, explizit zurückgewiesen wird, ist allerdings selten. In den allermeisten Fällen wird die Eigenschaft Originalität sehr positiv gesehen. Im Fall einer Negativwertung eines originellen Textes wird in aller Regel nicht der Wertmaßstab zurückgewiesen, sondern es wird ein Konflikt mit anderen, möglicherweise höherrangigen Wertmaßstäben postuliert. Diese zwei Argumentationstypen bestimmen die Diskussion, wenn es um Originalität als Innovation geht.

Wie Spinnen stuft auch Elisabeth Bronfen den Wertmaßstab Originalität sehr hoch ein. In der Diskussion zu Susanne Riedels Text (2000) beschreibt sie, warum sie ausgerechnet diesen Text für den Wettbewerb vorgeschlagen hat. Zentrales Kriterium für sie war, so jedenfalls ihr Argument, die neuartige, originelle Sprache des Textes:

Und ich habe ihn aus dem Stapel gefischt, weil ich von der ersten Seite an so hingerissen von der Sprache war. Ich fand, das ist eine ungewöhnliche, neue Sprache, die ich so nicht kenne. Die reine Materialität der Sprache war das Erste, was mich so beeindruckt hat. (2000 Riedel, 2:03 Bronfen)

Ausgangspunkt für das Argument ist ein formales Textmerkmal, nämlich der Stil („hingerissen von der Sprache“) des Textes. Das konkrete Textmerkmal ordnet Bronfen dem Wertmaßstab Originalität zu. Obwohl aus dem Wortlaut nicht zweifelsfrei gesagt werden kann, ob Bronfen „hingerissen“ nicht ausschließlich als starken Wertausdruck benutzt (ähnlich wie „beeindruckt“), soll davon ausgegangen werden, dass sie den auf den Erlebnischarakter hinweisenden Ausdruck „hingerissen“ nicht zufällig verwendet, sondern als Resultat einer Selbstbeobachtung. Die Wahrnehmung der Jurorin wird zunächst unbestimmt auf den Stil des Textes gelenkt. Sie erlebt zunächst einmal die Sprache als etwas Besonderes. Der Wertmaßstab Originalität wird erst in einem sekundären, rationalisierenden Vorgang hinzugefügt. Zu Beginn steht also nicht der Maßstab und auch nicht eine analytische Prüfung des Textes auf bestimmte Eigenschaften hin, sondern die spontane, hedonistische Wahrnehmung des Textes.

Auch Iris Radisch erklärt sprachliche Abweichung zu einem zentralen Merkmal künstlerischer literarischer Texte. Ihre Aussage zum Text von Kathrin Passig spielt mit dem Inhalt des Textes, in dem die Hauptfigur sich denkend vor dem Erfrierungstod zu retten versucht, und entwirft dabei gleichzeitig ein Idealbild von Literatur als einem Medium, in dem der Autor „durchkommt", „der immer wieder alles neu, auch literarisch und sprachlich neu aushandelt":

Und das finde ich ja fast eine Lehre, die man hier aus diesem Wettbewerb mitnehmen kann, dass der Tragiker untergeht. Also der Tragiker, der das Gegebene als gegeben 
nimmt, wurde ja hier auch immer wieder erzählt, der das Gegebene als gegeben nimmt, und sich dann nicht mehr weiterbewegt, weil alles festliegt, der geht unter. Und der, der immer wieder alles neu, auch literarisch und sprachlich neu aushandelt, der kommt durch. (2006 Passig, 10:35 Radisch)

Interessant an dieser Aussage ist die rhetorische Reihung, von „alles neu“, „auch literarisch“ und schließlich „sprachlich neu“. Die generelle Aussage, alles müsse neu ausgehandelt werden, wird zunehmend präzisiert. Das Literarische wird mit dem Sprachlichen parallelisiert, sodass man eine enge gedankliche Verknüpfung zwischen literarisch und sprachlich annehmen kann.

Daniela Strigl macht bewusst, dass eine ungewöhnliche Sprache dem Leser eine große Anstrengung abverlangen kann, sich auf sie einzustellen. Sie hält aber ebenso die Auseinandersetzung mit dieser Sprache für gewinnbringend:

Also man muss sich abstoßen, glaube ich, und auch als Leser etwas riskieren. Es ist natürlich eine ganz andere Sprache. Da hat alles viel mehr Gewicht. Und wenn man sich das aber traut, glaube ich, wird man belohnt. Das ist ein sehr raffinierter Text. Und wahrscheinlich ist er viel raffinierter, als wir hier in einer halben Stunde ausloten können. (2007 Seiler, 8:55 Strigl)

Das Zitat lässt die Vermutung zu, dass der erste Lektüreeindruck Strigls nicht uneingeschränkt positiv war, sondern ein Rationalisierungsprozess, der möglicherweise schon während des Lesens eingesetzt hat, dazu geführt hat, dass der Sprache ein hoher Wert zugemessen wird. Das spiegelt sich auch in der Wortwahl. War Bronfen (s. o.) „hingerissen“ von Riedels Text, findet Strigl den Text Seilers „raffiniert“. Die Raffinesse wird, so darf man annehmen, erst im Prozess der bewussten und genauen Prüfung sichtbar. Dieser Prozess ist Bestandteil der Lektürepraxis geübterer Leser. Möglicherweise spielen dabei auch erlernte Erwartungen an die Sprache der Literatur eine Rolle, die den unmittelbaren Eindruck von Anstrengung bei der Lektüre zugunsten einer Betrachtung des sinnlichen oder sinnstiftenden Potentials der Sprache in den Hintergrund stellt.

Bei weitem nicht alle Aussagen zur Neuartigkeit der sprachlichen Gestaltung sind so emphatisch wie einige der bereits zitierten, der O-Ton bleibt jedoch stets ähnlich. Robert Schindel, der sich an anderer Stelle gegen die „Raserei der Originalität“ (2000 Maier, 9:09; s. o.) gewandt hatte, stellt etwa positiv fest:

Hier sozusagen diese ferne Angst, vielleicht auch diesen fernen Klang des Sterbens dieses Großvaters hier in diesen Sätzen, in dieser puren Sprache sozusagen darzustellen, also das habe ich wirklich noch nirgendwo anders gelesen. (2002 Heisl, 16:27 Schindel)

Was auf den ersten Blick wie eine Beurteilung des Inhalts scheinen kann und ggf. auch teilweise in diesem Sinne zu verstehen ist, wird eindeutig an die sprachliche Gestaltung des 
Textes geknüpft. Zwar geht es wohl auch um das Thema des „Sterbens dieses Großvaters“, allerdings insbesondere um das Thema in „dieser puren Sprache“, die er so noch nirgends gelesen hat.

Burkhard Spinnen erkennt in Passigs Text zunächst einen Genretext. Genretexte sind, darauf deutet diese Aussage neben anderen hin, an sich problematisch, aber es gibt, so Spinnen „auch gutes Genre“, das heißt „Genrebilder, die dem, was in diesem Genre gemacht wird und möglich ist, durchaus noch etwas hinzufügen, nicht nur Virtuosität, sondern auch so etwas wie Zeitgenossenschaft" (2006 Passig, 12:26 Spinnen). Das Originalitätsargument ist in dieser Aussage gleich doppelt verpackt; zum einen in der impliziten Ablehnung von Genreliteratur („es gibt auch gutes Genre“), also einer Literatur, die stark mit festgelegten Themen und Handlungsentwürfen arbeitet, zum anderen in dem Hinweis, dass es möglich ist, „noch etwas hinzuzufügen“, was dem Text laut Spinnen gelingt. Er resümiert: „Hier wird anders erfroren“ (2006 Passig, 12:26 Spinnen) (vgl. auch Kapitel 14 „Detailanalyse Passig“). In negativer Umkehrung, aber in ganz ähnlicher Formulierung, nutzt Spinnen das Argument auch in einer anderen Diskussion, dort nicht in Bezug auf ein Genre, sondern auf ein Thema: „Und er fügt mir, das tut mir leid jetzt, nichts Neues hinzu, außer dem Umstand, dass er eine gut gemachte, eine sehr gut gemachte Variante dieses Themas ist" (2001 Müller, 10:22 Spinnen).

Auch in diesem Beitrag bestätigt sich die Annahme, dass Originalität ein erlernt hochgeachteter Wert ist. Selbst ein insgesamt gut gemachter Text („eine sehr gut gemachte Variante dieses Themas“), dessen Gestaltung explizit als gelungen angesehen wird, kann dem Originalitätsargument zum Opfer fallen.

\subsubsection{Originalität im Konflikt mit Lesegenuss}

Trotz aller Hochwertung des Maßstabs Originalität sind originelle Texte keineswegs ausgenommen von dem Anspruch auf Lesevergnügen. Entsprechend gibt es Diskussionsbeiträge, in denen die Originalität des Textes durchaus anerkannt wird, die Juroren den Text aber dennoch nicht insgesamt positiv bewerten, weil ein Konflikt mit der hedonistischen Wirkung (Lust, Anteilnahme, Unterhaltungswert) entsteht.

Denis Scheck vergleicht die Lesewirkung des als originell anerkannten Texts von Heisl mit der Wirkung einer Inhaltszusammenfassung:

Also Originalität will ich dem Text ja absolut bescheinigen. Mein Problem mit diesem Text ist ja nur, dass er sich in meinen Augen so liest wie eine Inhaltszusammenfassung 
in Kindlers Literaturlexikon eines Fünfhundertseitenromans und/ (2002 Heisl, 18:12 Scheck)

Die Inhaltszusammenfassung im Literaturlexikon dient rein informativen Zwecken und hat in aller Regel keinen Unterhaltungswert und auch nicht den Anspruch, den Leser emotional zu berühren. Insofern kann man darauf schließen, dass Scheck in seiner Aussage den Unterhaltungswert und die mangelnde sinnliche Wirkungskraft des Textes bemängelt. Auch wenn ein origineller Text in seiner Machart vorhersehbar wird, kann er seine Wirkung verfehlen, so im Beispiel Tilman Rammstedt in einer Kritik von Alain Claude Sulzer. Sulzer kritisiert, dass der „sehr originell[e]“ Text, der bei den anderen Juroren viel Zuspruch gefunden hat (Bachmann-Preis 2008), „irgendwann mal leergelaufen [war]“, weil er, so Sulzer, „wie ein Uhrwerk ab[läuft]“ (2008 Rammstedt, 3:54 Sulzer). Hildegard Keller (0:16) argumentiert positiv, der Autor Bönt (2009) habe „ein völlig originelles Ich“ gewählt. Sie fährt dann aber fort, zu erklären, dass dieses Ich ihr nicht wirklich plastisch bleibe bis zum Ende (ebd.). Auch hier steht dem Wert Originalität der Wert Plastizität, der als Ausdruck der Sinnlichkeit des Textes argumentativ immer eng mit Lesegenuss verknüpft ist, gegenüber. Einige sehr eindrückliche Beispiele für die Abwertung von Originalität im Verhältnis zu Lesegenuss bietet die Detailanalyse zu Andrea Winkler (2009) (Kapitel 19).

\subsubsection{Der „eigene Ton“}

Eine besondere Ausprägung des Wertes Originalität in den Jurydiskussionen ist der sogenannte „eigene Ton“ der Autoren bzw. Texte. Der „eigene Ton“ eines Textes ist unter den Wertungen, die dem Maßstab Originalität zugeordnet wurden, sehr eindeutig, sowohl in Bezug auf das, was darunter verstanden wird, als auch in Bezug auf die Tendenz der Wertung. Es handelt sich immer um ein positives Argument. Originalität wird in diesem Fall nicht unbedingt als etwas Neues, sondern viel mehr als etwas Individuelles gesehen. Es wird angenommen, dass es einen Text auszeichnet, wenn man ihn anhand seines sprachlichen Stils einem bestimmten Autor zuordnen kann. Auffällig ist dabei, dass davon ausgegangen wird, dass eine solche Individualität ausschließlich durch die Sprache erreicht werden kann. Neben der Formulierung „eigener Ton“ findet sich auch die Formulierung „eigene Sprache“ und (eigener) „Sound“. Es handelt sich also um einen Wert, der eindeutiger als andere an formale, genauer, sprachliche Aspekte des Textes geknüpft ist. Auffällig ist außerdem, dass eben nicht von "Stil" die Rede ist, sondern von „Ton" und „Sound“. Dem Wert wird damit ein Anstrich des Sinnlichen, nämlich des klanglich Wahrnehmbaren, gegeben. Die Aufmerksamkeit verschiebt sich von einem abstrakten Gestaltungsmittel schriftlicher 
Kommunikation zu etwas vom Leser auditiv Wahrgenommenem. Unter den Juroren, die den „eigenen Ton“ als positives Argument anführen, dominiert mengenmäßig Ilma Rakusa. Sie ist jedoch nicht die Einzige, die das Argument einsetzt. Eines der umfangreichsten Argumente, in dem vertreten wird, dass ein individueller Stil einen Text besonders auszeichnet, stammt von Josef Haslinger. Er macht den „Ton“ des Textes zu einem zentralen Wert innerhalb seiner Argumentation:

\begin{abstract}
Ich sehe in diesem Text einen Ton, einen klaren Ton einer Autorin. Und es ist so. Wir haben gestern die Frage des Tones schon mehrmals erörtert. Es gab Texte, die hatten einen klaren Ton. Der erste zum Beispiel. Das war ein eigenständiger Ton. Es gab Texte, die versuchten sich/ die versuchten ein Spiel mit den Tonarten der Literatur. Ich bin jedes Mal als Leser dankbar, wenn es gelingt, einen Autor zu finden/ wenn ich einen Autor finde, der einen eigenen Ton hat. Und jetzt müssen Sie sehen, diese Autorin ist zwanzig Jahre alt und hat einen eigenen Ton. [...] Natürlich können Sie/ kann man diesen Ton jetzt analysieren. Das ist richtig. Er lebt von kurzen Sätzen. Er lebt von Parataxen. Er lebt von Wortwiederholungen. Er hat eine/ Wenn man diesen Ton analysiert, in Rhythmus und Melodie - denn beides ist ja sozusagen der Sound einer Stimme - Rhythmus und Melodie, dann werden Sie feststellen, dass diese Melodie Elemente hat, die sich wiederholen, ja. Etwas Refrainartiges hat. Dass manche Sätze/ Diese Absätze, die hier drinnen sind, sind natürlich gebaut. Sie können sagen, sie sind designed. Aber ich habe/ Aber für mich vermittelt sich eben nicht der Eindruck eines Designs, sondern ich bin tatsächlich in der Lage, diesem Text zu folgen. (2003 Lewejohann, 5:40 Haslinger)
\end{abstract}

Zunächst fällt auf, dass Haslinger den „eigenständigen Ton“ mit dem „klaren Ton“ gleichsetzt. „Klar“ ist hier offenbar im Sinne von „entschieden“ zu verstehen und lässt sich zu Maßstäben aus dem Komplex Orientierung wie beispielsweise Gestaltetheit, aber auch Kohärenz/Verstehen in Beziehung setzen. ${ }^{61}$ Es wird ein Gegensatz zwischen klar, eindeutig, entschieden, in sich stimmig und unentschieden, gemischt, unstimmig aufgemacht. Das wird auch deutlich, wenn Haslinger nach dem Hinweis darauf, dass es Texte gegeben habe „die hatten einen eigenständigen Ton“ mit Texten kontrastiert, die „ein Spiel mit den Tonarten der Literatur [versuchten]“. Dass Gestaltetheit neben Originalität als Wertmaßstab ebenfalls eine Rolle spielt, verdeutlicht sich in der von Haslinger vorgenommenen Analyse dessen, was seiner Ansicht zufolge den Ton des Textes ausmacht. Zunächst findet sich auch hier wieder der sprachliche Vergleich mit Elementen der Musik: „Rhythmus“, „Melodie“, „Refrainartiges“. Insgesamt ergibt sich daraus für Haslinger der Eindruck, dass der Text absichtsvoll strukturiert und die Sprache bewusst eingesetzt wurde („designed“, „gebaut“). Gerade das Absichtsvolle wird dann auch als positive Eigenschaft des Textes hervorgehoben, weil Haslinger dadurch ,tatsächlich in der Lage ist, diesem Text zu folgen“. Orientierung erweist sich auch hier als wichtiger übergeordneter Wertmaßstab,

$\overline{61}$ Bortulussi et al. (2008) kommen in ihrer Untersuchung zu dem Ergebnis, dass „Clarity“ ein wichtiger Wert ist, der deutlich durch die Beschaffenheit des Textes determiniert wird. 
der mit Werten der Gestaltetheit eng verknüpft ist. Die Argumentation beginnt also mit dem Maßstab Originalität (als Individualität) und geht dann in ein Stimmigkeitsargument über, das sich auf die spezifischen Bauelemente bezieht.

Überwiegend wird Originalität als Individualität jedoch vollkommen eigenwertig verwendet. So zum Beispiel in einem Beitrag von Martin Ebel:

Und es gibt auch keine typisch schweizerische Amtsschimmelsprache. Dieser Sound hier, ob man den nun mag oder nicht, das ist schon echter Zwicky. Das ist nur Zwicky. Das ist nicht zu vergleichen mit Burger oder anderen Schweizer Autoren. (2007 Zwicky, 19:22 Ebel)

Ebel sieht den „Sound“ des Textes als spezielles Charakteristikum des Autors. Er verweigert die Gültigkeit der von anderen Juroren gemachten Vergleiche. Ein individueller Stil wird von Ebel als Beweis der „Echtheit“ des Textes begriffen.

Sehr analog verhält sich die Aussage von Ilma Rakusa zum Text von Stangl:

Ich möchte nur noch zur Sprache sagen: Wir haben es gehört. Diese Sprache entwickelt einen ganz eigenen Sog, einen eigenen Sound. Es gibt auch sehr viel im Detail gearbeitete Sachen: Assonanzen, Alliterationen, aber es liegt vor allem am Satzbau. Es liegt an dieser Syntax, die im Grunde sich immer weiter generiert, zum Teil sehr lange Sätze, auch das hat ein bisschen etwas Nouveau-Roman-artiges. Aber ich will den Vergleich nicht überstrapazieren, weil er auch nicht aufgeht. Bis hin zu diesem offenen Schluss, der auch bewusst aufhört ohne Punkt. Also hier wird etwas offen gelassen und bewusst auch durch die Interpunktion offengelassen. Und dieser Stangl'sche Sound ich kenne ihn aus seinen großen, umfangreichen Büchern - ist natürlich auch in diesem kurzen Text sehr eindrücklich vorgeführt. Ich bin von diesem Text auch sehr angetan. (2007 Stangl, 2:47 Rakusa)

Auch bei Rakusa geht die Argumentation vom wahrgenommenen Höreindruck - „diese Sprache entwickelt einen ganz eigenen Sog, einen eigenen Sound" - aus und kommt über eine kurze stilistische Analyse zum Ergebnis, dass der Stil den Autor als Künstler individuell auszeichnet (Originalität als Individualität). Auch sie weist auf die begrenzte Gültigkeit des Vergleichs mit einer literaturhistorischen Stilrichtung (Nouveau Roman) hin. Die kurze Passage vereint alle Werte und Wertungsargumentationen, die für die Klagenfurter Diskussionen in dieser Arbeit als prägend herausgearbeitet werden konnten: Den Einstieg mit dem Verweis auf die positive Textwirkung beim Lesen („Sog“), den Verweis auf die Gestaltetheit in Verbindung mit einer kurzen stilistischen Analyse, den Hinweis auf die Offenheit des Textes („offener Schluss“, „offen gelassen“) und abschließend das Originalitätsargument, das in diesem Fall möglicherweise auch dazu dient, den Text als Teil eines Werks herauszustellen und ihn so vor dem potentiellen Einwand zu schützen, er sei nur ein zufällig gelungenes Produkt.

Der Verweis auf die Originalität eines Textes findet gerade dann häufig Anwendung, wenn 
der Text aus bekannten Versatzstücken aus Literatur oder Alltagssprache gebaut ist. Gerade dann scheint es notwendig, die stilistische Eigenleistung des Autors zu betonen. Dieses Argument findet sich beispielsweise bei Karl Corino in der Diskussion zu Bodo Hell. Corino stellt dort der Sprache Bodo Hells die Sprache Karl Kraus' als positives Beispiel gegenüber. Kraus entwickle in „Den letzten Tagen der Menschheit“, so Corino „durchaus eine eigene poetische Sprache“, die er der Zitatwelt gegenüberstelle. Dass er das nicht tue, sei „vielleicht das Manko bei Bodo Hell“ (2006 Hell, 22:06 Corino). In derselben Diskussion argumentiert Rakusa, „dass aus all diesen Sprachen und diesen Versatzstücken, diesen montierten Texten, doch was Eigenes entsteht“ (2006 Hell, 18:24 Rakusa).

Neben den bereits zitierten Formulierungen zum „Sound“ und „Ton“ des Textes finden sich einige verwandte Formulierungen, etwa „dass das eine Sprache mit Charakter ist" (2003 Lewejohann, 13:31 Strigl), dass ein Text einen „Stilwille[n]“, eine „Handschrift“ und eine „Eigenart der Stimme“ zeige (2005 Magnusson, 3:59 Rakusa) und dass ein Text „den Blues“, „einen Sound“, „so eine Stimmung“ habe (2000 Alfare, 8:07 Längle).

Der immer positive Wertmaßstab Originalität als Individualität findet überwiegend in defensiven Argumentationen Anwendung. Er verknüpft sich mit Vorstellungen von Echtheit und Einzigartigkeit des sprachlichen Kunstwerks, aber auch mit Beobachtungen der Textwirkung wie etwa der starken Aufmerksamkeitsbindung, die der Autor mittels des Tons erreicht („Sog“), und dem Eindruck von Gestaltetheit. In der Kopplung der Wertmaßstäbe

Originalität und Stimmigkeit bei der Betrachtung eines einzigen Formmerkmals, etwa in den Beiträgen Josef Haslingers zum Text von Sünje Lewejohann und Ilma Rakusas zum Text von Thomas Stangl, ist ein Hinweis auf das Bedürfnis geübter Leser sowohl nach erkennbarer Struktur als auch nach Variation. Letztendlich weisen auch die konkreten Benennungen für die sprachlichen Strukturen, die den Originalitätseffekt ausmachen als „Ton“, „Sound“, „Blues“, „Stimme“ statt - beispielsweise - „Schreibstil“ darauf hin, dass es um die sinnliche Erfahrung von Sprachstrukturen und nicht so sehr um ein rationales Begreifen eines bestimmten Schreibstils geht.

\subsection{4 „Mut" und „Risiko“}

Gelegentlich verbindet sich mit dem Wert Originalität die Vorstellung, der Autor habe Mut aufgebracht, um den Text genau so zu gestalten bzw. er sei ein hohes Risiko eingegangen, indem er eine ungewöhnliche Gestaltungsform gewählt habe. Dass die Rede von Mut bzw. Risiko einer bestimmten formalen Gestaltung ist, bestätigt den Eindruck, dass Originalität kein unbedingter Wert ist. Er fügt sich in ein Netzwerk von Werten ein und 
konkurriert vor allem mit dem Wert Kohärenz.

Dass „Risiko“ überhaupt in entsprechenden Kontexten dem Wert Originalität zugeordnet werden kann, zeigt beispielsweise die Gegenüberstellung von „Konventionalität“ und „Risiko“ im folgenden Beispiel: „Es ist ja sehr konventionell erzählt. Die Sprache geht ja kaum ein Risiko ein“ (2009 Born, 13:51 Jandl). Ähnlich verhält es sich bei Ilma Rakusa. Hier wird der Wert Stimmigkeit mit dem Wert Originalität kontrastiert. Für Rakusa ist, das zeigt die Gesamtheit ihrer Beiträge, Originalität der höhere Wert:

Ich würde der Erzählung auch Stimmigkeit attestieren [...] Die Sprache wird ihrem Gegenstand gerecht. Sie ist in keinster Weise risikofreudig, innovativ oder irgendetwas. Es gibt keinen Satz, den man nicht irgendwie sich vorstellen könnte. (2003 Zaimoglu, 10:23 Rakusa)

Rakusa kann „der Erzählung Stimmigkeit attestieren“, die Sprache werde dem Gegenstand der Erzählung gerecht. Deutlicher kann ein Argument für den Wert Stimmigkeit nicht ausfallen. Sie fügt allerdings kontrastierend hinzu, dass die Sprache „in keinster Weise risikofreudig, innovativ oder irgendetwas" sei. Hier geschieht in der Aufzählung ebenfalls eine Gleichsetzung von „risikofreudig“ und „innovativ“. Eine vergleichbare Gegenüberstellung nimmt auch Corino (10:36) in einem seiner Beiträge vor. Er konstatiert, dass der Text von Claudia Klischat (2006) ,insgesamt [... ] nicht allzu viel wagt“ und schließt dann an, er sei „sprachlich solide, behäbig ein bisschen, manchmal ein bisschen verrutscht“. Es spricht also einiges dafür, „Risiko“ und „Mut“ als Hinweise auf den Wert Originalität zu lesen. Risiko impliziert im Alltagsverständnis wie in den vorgestellten Wertungen die Chance auf Gewinn, aber auch die Möglichkeit des Misserfolgs. Risikofreude und Mut werden zwar grundsätzlich begrüßt, führen aber nicht immer zu einer uneingeschränkt positiven Bewertung. Positive Bewertungen überwiegen jedoch.

In der kontroversen Diskussion zu Artur Becker (2001) wird die Risikobereitschaft des Autors gelobt, obwohl der Text insgesamt nicht als gelungen angesehen wird. Birgit Vanderbeke argumentiert: „Also erstens ist das wunderbar, wenn Texte ein Risiko eingehen. Ich finde Texte entsetzlich, wenn sie keines eingehen“ (2001 Becker, 15:33 Vanderbeke) und Elisabeth Bronfen (2001 Becker, 16:06) schließt sich diesem Lob auf das Risiko an, indem sie „ein Plädoyer fürs Risiko“ ausspricht und für sich in Anspruch nimmt, sie habe „nicht so große Schwierigkeiten mit Texten, die dann manchmal auch scheitern“. Radisch (11:25) lobt in der Diskussion zu Kieninger (2000) die „Wildheit“ des Textes, „sein[en] Mut zu völlig überraschenden Bildern, sein[en] Mut zu irrwitzigen Kombinationen“. Sie lobt in dem Zusammenhang, dass „gerade das, was daran so ungewohnt ist, was einen zunächst überfordert", sie gefreut habe. Auch in diesem Beitrag wird eine ungewohnte 
Textgestaltung gelobt, nicht jedoch, ohne dabei darauf zu verweisen, dass das Abweichende, Neue des Textes auch zu einer Überforderung werden kann. Das Risiko wird also als Überforderung des Lesers benannt.

Ursula März (9:29) kontrastiert das „wahnsinnig hohe[s] kompositorische[], gedankliche[], metaphorische[] Risiko“ des Textes von Ina Strelow (2006) mit anderen Texten des Wettbewerbs von 2006 „die sprachlich sozusagen absolut brav auf Zeitungsniveau vorangehen“. Sie verwendet hier das Risiko-Argument, um den sonst mehrheitlich negativ bewerteten Text Strelows punktuell aufzuwerten. Auch hier bestätigt sich Originalität als grundsätzlich positiver Wert.

Daniela Strigl (2:02) bewundert an Gerhild Steinbuchs Text (2005), dass er „sehr viel riskiert“, denn seine „Sprache hat den Mut, das Pathos im Wortsinn, also das Leiden nicht zu verschleiern“. Sowohl die Einschätzung März' als auch die Radischs und Strigls verweisen, wenn auch in Bezug auf unterschiedliche Texte, auf Elemente der formalen und sprachlichen Gestaltung, um ihr Argument zu stützen. Besonders der Hinweis auf die bildliche bzw. metaphorische Gestaltung ist interessant. Es ist davon auszugehen, dass Metaphern und sprachliche Bilder deswegen als potentiell risikobehaftet gelten, weil sie, gerade dann, wenn sie besonders originell sind, Verständnisschwierigkeiten auslösen können, indem sie entweder das Vorstellungsvermögen des Lesers übersteigen, oder aber, indem sie beim Leser eine abweichende Vorstellung auslösen, die sich nicht in den modellierten Textsinn einpasst (der Bezugswert ist Kohärenz). Umgekehrt kann es passieren dass ein überwiegend als gelungen eingeschätzter Text sich für mangelnde Originalität kritisieren lassen muss:

Hier kann wirklich jemand schreiben. Aber wo ist die Kühnheit? Wo ist der Mut? Wahrhaftigkeit ist nicht unbedingt eine literarische Kategorie. Wo geht dieser Text über die Ästhetik des neunzehnten Jahrhunderts hinaus? Und mir scheint, liebe Kollegen, als wären Sie mit beiden Beinen im neunzehnten Jahrhundert. (2002 Parei, 20:30 Steinfeld)

Vor allem die schon zitierte Strelow-Diskussion enthält Passagen, die die Haltung Steinfelds, ein Text müsse Innovation zeigen, das sei das Risiko, das gute Texte eingehen müssten, stützen. Mit der Behauptung, „Wahrhaftigkeit“ sei nicht unbedingt eine literarische Kategorie, legt Steinfeld nahe, dass die von ihm zuvor genannten Kategorien „Kühnheit“ und „Mut“ dezidiert literarische Kategorien sind. Spinnen weist in dieser Diskussion die Bereitschaft, Neues zu probieren und damit ein Risiko einzugehen, als entscheidende Aufgabe der zeitgenössischen Literatur aus:

Und wenn wir aus dieser breiten/ aus diesem breiten Fluss einer stilistischen Auffas- 
sung, in der wir gewissermaßen nach dem wohltemperierten immer auch verlangen, wenn wir da hinauswollen, was ich mittlerweile für die Sprache in der zeitgenössischen deutschen Literatur für eine immer wichtiger werdende Aufgabe halte, dann werden wir in Kauf nehmen müssen, dass dieses Rauskommen da auch wehtut und dass das mit Versuchen gekoppelt ist, die ein gewaltiges Risiko gehen. (2006 Strelow, 14:25 Spinnen)

Rakusa schließt sich der Meinung Spinnens an, wenn sie sagt, die aktuelle deutsche Literatur sei manchmal zu sehr Mittelstrom. Die Folgerung für sie heißt: „Risiko ist schon einmal, finde ich, etwas sehr Lobenswertes“" (2006 Strelow, 20:34 Rakusa).

Eine ungewöhnliche, originelle Gestaltung wird also nicht selten als Risiko aufgefasst. Dieses Risiko wird prinzipiell positiv gewertet, auch wenn der Text insgesamt nicht positiv gewertet wird. Gleichzeitig erweist sich Risikobereitschaft aber auch als eine positive Beigabe, die zwar bewundert wird, die aber andererseits nicht in der Lage ist, einen Text so aufzuwerten, dass er am Ende als gelungener Text aufgefasst wird. Dafür spricht auch, dass fehlendes Risiko die Bewertung von Texten, die sonst als gelungen eingestuft werden, nur unwesentlich beeinträchtigt. Sprachliche Abweichung erweist sich hier wie auch in anderen Zusammenhängen als ein ideeller Wert (vgl. Kapitel 19 „Detailanalyse Andrea Winkler"). Dass eine ganz besonders ungewöhnliche sprachliche und/oder formale Gestaltung den literarischen Charakter eines Textes, und ganz besonders seinen modernen Charakter, unterstreicht und daher hoch zu bewerten ist, gehört zum Wertungswissen. Sprachlich-formale Abweichung hat ein enormes Prestige, steht aber zur selben Zeit in einem Konkurrenzverhältnis zu dem Wert Kohärenz. Allzu großes sprachliches Foregrounding kann, wie schon mit Bezug auf die negativen Werte Forciertheit (Kapitel 10.3.1) und Überdeterminiertheit (Kapitel 11.2.3) gezeigt wurde, den Lesegenuss stören, weil ein Eintauchen in die Erzählwelt verhindert wird. Gleichzeitig ist dieser Wert eine bloße Spielmarke. Er ändert kaum etwas an der Gesamteinschätzung des Textes.

\subsubsection{Konventionalität}

Konventionalität kann für die Jury ein entscheidendes Manko eines Textes sein. Nur sehr selten wird eine konventionelle Machart positiv beurteilt. Der Kritikpunkt der Konventionalität wird von den Juroren in zwei unterschiedlichen Varianten verwendet. Zum einen kann der Text kritisiert werden, weil in ihm ein bereits bekannter Schreibstil oder ein bekanntes literarisches Muster kopiert wird. Zum anderen kann ihm vorgeworfen werden, dass er sich zu wenig von anderen Texten unterscheidet. Diese Kritik impliziert oft die Forderung nach einem individuellen Stil. Insofern ist Konventionalität einerseits als Ge- 
genwert zu Originalität als Innovation und andererseits zu Originalität als Individualität zu verstehen.

Ein Beispiel für die Kritik an mangelnder sprachlicher Abweichung ist Spinnens Beitrag in der Diskussion zu Kern (2002). Spinnen geht anknüpfend an Robert Schindel von der Sprache des Textes aus. Er urteilt:

Ein weiteres zur Sprache. Robert Schindel sprach vom Sparsamen. Ich muss dem in einem gewissen Grade widersprechen. Es ist ein einfaches wiederkehrendes Muster, das sich unter anderem auf die leicht schräge Manier stützt, im Perfekt zu erzählen. Das gibt da einen seltsam kolloquialen, dann aber auch ein bisschen wieder distanzierten Sound. Innerhalb dieser Sätze aber wird eine Orgie konventioneller Attribuierungen durchgeführt. (2002 Kern, 15:23 Spinnen; Hervorhebung KR)

Im Vordergrund des Ausschnitts steht die sprachliche Gestaltung. Kritisiert wird von Spinnen die „Orgie konventioneller Attribuierungen“, also eine stilistische Eigenschaft. Auch der vorangehende Verweis auf „ein einfaches wiederkehrendes Muster“ im Erzählen ist ein Hinweis darauf, dass Spinnen den Text für eher konventionell hält.

Wesentlich deutlicher als Burkhard Spinnen formuliert Heinrich Detering Konventionalität im Kontrast zu Originalität als Individualität als Negativkriterium:

Als ich diesen Text las, dachte ich, es ist sicher nicht der einzige Text gewesen in diesem Ton unter den vielen Einsendungen, die man so bekommt. Ich habe gedacht: Ach, schau an, das ist wieder dieser gegenwartsdeutsche Durchschnittston: Parataxe, Augenhöhe mit dem Kind. (2004 Hoffmann, 13:35 Detering)

Detering bewertet den Stil des Textes als typisch für Texte der Gegenwart. Diese typische Ausprägung benennt er als „Parataxe“ und „Augenhöhe mit dem Kind“. Gerade die authentisch inszenierte Kinderperspektive ist in den Diskussionen der frühen 2000er Jahre ein häufiger Streitpunkt der Jury, der in jeder Diskussion über entsprechende Texte aufs Neue besprochen wird.

Karl Corino wählt eine andere Formulierung, die ebenfalls darauf abzielt, den Text als sprachlich durchschnittlich einzuordnen. In der Diskussion zu Mingels (2006, 5:22) gibt er zu verstehen, das Ganze sei sprachlich nicht ganz anspruchslos, ,aber doch eher im Bereich der Konfektion“. 2005 urteilt Radisch (15:42) zu Böldl, keine Zeitung würde das Gelesene abdrucken, weil es einfach sprachlich zu konventionell sei. Daniela Strigl (2006 Huonda, 13:44) kritisiert „zu naheliegende Formulierungen“. Wiederum ein anderer Text wird von Radisch (2007 Bernhard, 9:33) als „sprachlich vollkommen ambitionslos“ eingestuft. Und Daniela Strigl (2008 Palzhoff, 11:27) fragt, ob die Sprache eines anderen Textes nicht „allzu erwartbar“ sei. Mit der Erwartbarkeit bringt Strigl indirekt eine Empfindung zum Ausdruck, die allen Aussagen, die die Konventionalität des Textes betreffen, 
unterstellt werden kann, nämlich, dass nicht nur mangelnde inhaltliche Spannung (suspense), sondern auch mangelnder sprachlicher Abwechslungsreichtum - man könnte auch von sprachlicher Spannung (tension) sprechen - zur Abwendung des Lesers vom Text führt (zu Spannungstypen vgl. Langer 2008). Damit wird letztendlich wieder ein Lustargument angeführt. Was „erwartbar“ (Strigl) ist, unterfordert den Leser. Seine Aufmerksamkeit kann nicht gebunden werden. Auch eine Aussage Ijoma Mangolds (2008 Reitzer, 14:45) verweist auf diesen direkten Zusammenhang von sprachlicher Gestaltung und Wirkung auf die Aufmerksamkeit des Lesers: „Ich fand jetzt Ihr Plädoyer sprachlich aufregender als den Text von Frau Reitzer“. Auch wenn selten genau begründet wird, warum einem Text der Wert Originalität zugestanden wird, kann davon ausgegangen werden, dass mangelnde sprachliche Spannung als Grund für die Wahrnehmung von Konventionalität in Frage kommt.

Deutlich wird in allen Textstellen, dass Konventionalität ganz stark an sprachliche Merkmale des Textes gebunden ist. Fast immer ist der Hinweis auf die Sprache direkt, also wörtlich, in der Aussage enthalten.

In seltenen Fällen kann Konventionalität auch positiv gemeint sein. In diesen Fällen, das ist auffällig, muss der jeweilige Juror explizit hervorheben, dass es sich um ein positives Urteil handelt. Auch das weist darauf hin, dass Konventionalität mit großer Selbstverständlichkeit auf der Negativseite des Werterepertoirs rangiert:

Hier wird auch nicht die große ethnographische Entdeckung vorgegaukelt, die es auch nicht mehr gibt. Das heißt, es ist durchaus zeitgenössisch. Aber, und da wäre mein Einwand, es ist ja eine sehr klassische, dramaturgisch auf eine positiv/ wie ich finde, positive Weise konventionell gemachte Geschichte. Das heißt, diese innere Bedrohung zwischen den Geschwistern wird erst einmal überdeckt von der äußeren durch diesen Fahrer, was der/ Der wird im Verlauf des Romans im nächsten Kapitel noch einiges vorhaben, kann ich mir vorstellen. Aber es gibt trotzdem so eine Rückwärtsgewandtheit des ganzen Projektes, etwas zu sehr sich Vertrauendes auf die bewährten Motive. (2003 Lenze, 2:34 März)

Interessant ist neben der besonderen Betonung, sie finde die Geschichte (dramaturgisch) auf „positive Weise konventionell gemacht“ auch die Erklärung, was das Konventionelle ausmacht: Ein psychologisches Problem der Figur tritt für den Leser hinter der Handlung des Textes zurück. Erst auf den zweiten Blick offenbart sich dem Leser, dass die innere Handlung möglicherweise die eigentlich tragende Handlung der Geschichte ist. Die konventionelle Bauform ist also in diesem Falle deswegen akzeptabel, weil sie sich als eine „spannende“ Form etabliert hat. Es bleibt aber auch festzuhalten, dass März zwar behauptet, die Geschichte sei auf „positive Weise konventionell“ gemacht, das Argument der Konventionalität schlussendlich aber gegen den Text verwendet. Offenbar besteht ein Konflikt 
zwischen Textwirkung (tendenziell positiv) und erlerntem Anspruch an einen literarischen Text (Originalität). Letztendlich wird auch hier Konventionalität negativ beurteilt. Eine besonders interessante Ausprägung eines positiven Konventionalitätsarguments formuliert Sulzer:

Es ist eine sehr präzise, sehr klare Sprache. Absolut nicht um Originalität bemüht. Aber das macht vielleicht gerade/ oder macht, finde ich, gerade die Originalität dieses Textes aus. Man hat nie den Eindruck, also hier macht jetzt einer Literatur. Es ist/ Es ist aber Literatur. Das will ich jetzt damit gar nicht gesagt haben, nicht. Es entwickeln sich vor mir eine Fülle von Bildern. Man könnte jetzt vorwerfen, klar, es ist global. Er fliegt da um die Welt und sieht da/ Aber jedes dieser kurzen Bilder, die da aufflackern, wenn er mal da ist, mal hier, tragen alle zu dieser Geschichte bei. (2009 Schäfer, 3:46 Sulzer)

Auch in Sulzers Argumentation zu Schäfer zeigt sich, dass der Wert Originalität ein hohes Prestige hat, das bisweilen mit der subjektiven Textwirkung in Konflikt steht. Sulzer beginnt seine Argumentation mit dem Hinweis, die Sprache sei „sehr präzise“ und „sehr klar“ und „absolut nicht um Originalität bemüht“. Dieses Argument ist positiv gemeint. Der nächste Satz, in dem in einem Anschlussargument nahegelegt wird, dass es möglicherweise eine Originalität der Konventionalität geben kann, bestätigt jedoch grundsätzlich Originalität als Maßstab. Dass ein Text nicht originell sein will, ist offenbar kein schlagkräftiges Argument. Sulzer versucht, sein Argument zu untermauern, indem er das Originelle nicht als das Neue, als das es üblicherweise in den Diskussionen verstanden wird, beschreibt, sondern als das formal Angemessene. Er greift dazu ein Argument auf, das auch in anderen Diskussionen häufiger fällt, nämlich, dass Autoren eine „Literaturimitation“ betreiben. Gemeint ist das Imitieren einer konventionellen Vorstellung von Literatur. „[M]an hat nie den Eindruck, also hier macht jetzt einer Literatur. [... ] Es ist aber Literatur", behauptet Sulzer. Das Angemessenheitsargument geht in ein weiteres Argument über, dass den Text als stimmiges Ganzes beschreibt. Der Beitrag von Sulzer ist ein gutes Beispiel dafür, dass Bewertungen im Rahmen des Ingeborg-Bachmann-Wettbewerbs ad hoc aufgebaut werden (vgl. Kapitel 5) und dass sie auf diese Weise eine Menge an Informationen über das Wertewissen der Juroren offenlegen, das sonst kaum zugänglich wäre. Was Sulzer eigentlich an dem Text gefallen hat, wird in seinen konkreten Aussagen zum Text deutlich. Ihm hat die „Fülle von Bildern“ gefallen, die sich in der Geschichte zu einem Ganzen zusammenfügen („tragen alle zu dieser Geschichte bei“). Ihm hat außerdem die „sehr präzise, sehr klare Sprache“ gefallen. Diese konkreten Aussagen bilden den Rahmen seiner Argumentation. Dazwischen ist er bemüht, sich in einem geteilten Wertesystem zu positionieren. Der Wert Originalität hat in diesem Wertesystem einen hohen Rang. Obwohl Sulzer ihn am Text 
gar nicht nachweisen kann (,absolut nicht um Originalität bemüht“), ist er äußerst bemüht, eine Argumentation zu finden, die die Gültigkeit des Wertmaßstabs für diesen Text bestätigt.

Eine der wenigen Diskussionen, die auffällig stark durch den Negativwert Konventionalität geprägt ist, ist die Diskussion zu Klaus Böldls (2005) Text. Der Text wird von fast allen Juroren hart kritisiert. Hauptkritikpunkt vieler Beiträge ist die als unoriginell empfundene Sprache des Textes. Verteidigt wird der Text von dem vorschlagenden Juror Heinrich Detering, der einen ähnlichen Argumentationsweg einschlägt wie Sulzer in der Diskussion zu Schäfer (s. o.).

Sie ist nach meinem Empfinden vollkommen unprätentiös und unan/ Sie ist sehr angestrengt, aber nicht angestrengt, eine originelle Metapher, ein überraschendes Bild, eine verblüffende Wendung zu finden, sondern im Gegenteil, die Worte zu finden, die schon alle da sind, die schon benutzt sind, um sie/ um mit ihrer Hilfe eine/ eine Momentvergegenwärtigung zu geben, in der die sprachliche Vergegenwärtigung durchsichtig auf diesen Moment hin wird und nicht selbst als artifizieller Vordergrund sich vordrängelt. (2005 Böldl, 7:17 Detering)

Detering weist zunächst zurück, dass der Text originell sein möchte. Interessant ist in diesem Zusammenhang die Parallelisierung von „originelle[r] Metapher“, „überraschende[m] Bild“ und „verblüffende[r] Wendung“. Zum einen gibt sie Aufschluss darüber, wie der Eindruck von Originalität eigentlich zu Stande kommt - der Text muss überraschen bzw. verblüffen - zum anderen schließt genau diese implizite Explikation von Originalität jenes Spannungsmoment mit ein, das schon in anderen besprochenen Beiträgen eine Rolle gespielt hat. Gegenüber anderen, auf eine originelle Gestaltung ausgerichteten Texten sieht Detering den Vorzug von Böldls Text in der Anpassung seiner Mittel an seine Intention. Böldl, so Detering, finde Worte, „die schon da sind [...], um mit ihrer Hilfe [...] eine Momentvergegenwärtigung zu geben“. In einem späteren Beitrag heißt es:

Das ist eine vollkommen andere Art von Attributverwendung, als wir sie in den bisherigen Texten diskutiert haben als gelungen oder nicht gelungen, die/ Nämlich keine piffige Metapher finden und sagen: Hier, schau mal her, wie ich das mache. Sondern wir sollen halt möglichst das Wasser sehen. (2005 Böldl, 16:35 Detering)

Detering setzt statt Originalität die Wertmaßstäbe Angemessenheit und Zweckmäßigkeit. Hinter dem Verweis darauf, dass die verwendeten Sprachbilder den Zweck haben, die Intention des Textes - „wir sollen halt möglichst das Wasser sehen“ - umzusetzen, kann man die Maßstäbe Angemessenheit, aber auch Plastizität vermuten. Die Attribute stehen im Dienste dessen, was dargestellt werden soll und sollen dazu geeignet sein, es möglichst sinnlich fassbar zu machen. Es geht also darum, eine lebendige Textwelt herzustellen. In 
der Gegenüberstellung des von ihm positiv gewerteten Textes von Böldl und „bisherigen Texten“ aus dem Verlauf des Wettbewerbs, die mithilfe ihrer „pfiffigen Metaphern“ die Aufmerksamkeit auf sich zu lenken versuchen, wird deutlich, dass eine originelle Gestaltung an sich keine positive Bewertung erzielt. Die verwendeten sprachlichen Mittel stehen Detering zufolge ausschließlich im Dienste dessen, was der Text vermitteln will, und haben nicht die Funktion, die Jury durch besondere Originalität zu beeindrucken.

Die deutlich häufigere Verwendungsweise des Maßstabs Konventionalität zeigt sich in einer Aussage Iris Radischs in derselben Diskussion. Sie gibt zu verstehen:

Wenn durch die Konventionen dann ein neues Bild entstünde. Aber die Konvention verstellt das neue Bild ja gerade so. (2005 Böldl, 16:28 Radisch)

Hier wird Originalität im üblichen Sinne als etwas Neues verstanden und positiv bewertet.

Die ausgewerteten Textstellen bestätigen Originalität als Maßstab, selbst dann, wenn sie scheinbar Konventionalität als ein positives Merkmal des Textes beschreiben. Konkrete formale Bezugspunkte sind häufig sprachliche Bilder und die stilistische Gestaltung. Insgesamt zeigt sich auch hier eine deutliche Wirkungsbezogenheit der Bewertungen.

\subsubsection{Nachahmung erfolgreicher Muster}

Eine spezielle Form des Nichtoriginellen, die sich allein mit dem Konzept der Konventionalität nicht fassen lässt, ist die Nachahmung von literarischen Erfolgskonzepten. Während Konventionalität lediglich impliziert, dass der Text wenig Anstrengungen unternimmt, sich von anderen Texten abzugrenzen, bedeutet „Nachahmung“ eine bewusste Orientierung an und Imitation von Bekanntem. Wenn die Juroren den Eindruck haben, ein Text ahme erfolgreiche Muster nach, wird er als unauthentisch wahrgenommen, selbst unter der Voraussetzung, dass er unter Verwendung anderer Maßstäbe als gelungen eingestuft werden müsste. Möglicherweise spielen dabei traditionelle Vorstellungen vom Autor als Genie eine Rolle. Von einem künstlerisch ambitionierten Autor wird Individualität in der Gestaltung erwartet. Auch hier ist der „Ton“ oft Bezugspunkt der Wertung. „Musterhaftigkeit“ verhält sich damit auch komplementär zum „eigenen Ton“, der immer wieder gefordert wird (vgl. Kapitel 12.1.3). Die Ablehnung gegenüber Texten, die Stilmuster oder Konstruktionsmuster nachahmen, kann entweder eine neutrale Ablehnung gegenüber allen Texten sein, die sich nicht aktiv als neuartig ausweisen oder sie kann abwertend mit der Unterstellung der Unlauterkeit der literarischen Absichten verbunden sein. Mit der Imitation verbundene 
Formulierungen sind „Klischee“ (u. a. 2009 Preisendörfer, 10:15 Fleischanderl), „Pseudoton“ (2005 Steinbuch, 12:52 März), „Literaturaneignung“ (2005 Steinbuch, 12:52 März), „nachgemachte, erborgte Tonlagen“ und „literarische Kostüme“ (2004 Schönlau, 0:28 Radisch), ,zu traditionell gebaut“ (2002 Zahno, 5:30 Reinacher), „sehr altbacken“ (2003 Ahrens, 29:34 Haslinger) und „sowas Altertümelndes oder Altherrenhaftes“ (2003 de Vries, 8.26 Radisch). Die Skepsis gegenüber traditionelle oder erfolgreiche Muster nachahmenden Texten lässt sich punktuell immer wieder zeigen, sie folgt jedoch keinem bestimmten Muster. Aus den Aussagen der Juroren ist schwer erkennbar, welche Texteigenschaften konkret dazu führen, dass ein Text als musterimitierend eingestuft wird. Man kann vermuten, dass Texte mit Nullfokalisierung sowie Texte im Modus des Telling (vgl. Kapitel 11.2.2), in denen die Handlung breit auserzählt wird, diesen Effekt haben. Beim Autor Preisendörfer etwa kritisiert Karin Fleischanderl den „stilisierten Märchenton“ (2009 Preisendörfer, 10:15 Fleischanderl) und verweist dann auf die Klischeehaftigkeit des Textes. Hier lässt sich vermuten, dass Fleischanderl das Modell des Märchenerzählens als veraltet betrachtet. Letztendlich erleben Erzählformen offenbar eine Abnutzung und verlieren mit allzu großer Verbreitung den Überraschungswert und damit den Zuspruch. So etwa im folgenden Beispiel:

Mich macht dieser Ton in Verbindung mit Familiengeschichten einfach wirklich nervös und ich habe das Gefühl, ich habe in den letzten Jahren unendlich viele Bücher mal gesehen, mal gelesen, mal angeguckt, wo dieser Ton in Verbindung mit Mädchenschwierigkeit, mit Frühlingserwachen, mit sterbenden Großmüttern et cetera zustande gekommen ist. Vielleicht bin ich damit einfach ungerecht aus Übersättigung. (2004 Hoffmann, 10:48 März)

Interessanter sind die Beiträge, die Texten vorwerfen, einen bereits bekannten Stil zu verwenden, um den Eindruck zu erzielen, sie seien Literatur. In diesen Kritiken werden dem Text literarische Qualitäten zugleich anerkennt - indem auf die Ähnlichkeit mit als hochwertig anerkannten Texten verwiesen wird - und aberkannt, indem sie dennoch negativ bewertet werden. Auch in Bezug auf andere Wertmaßstäbe finden sich gelegentlich ähnliche Argumentationen. Immer wird dem Text unterstellt, dass er seine literarischen Mittel nicht dazu einsetze, seinen Inhalt adäquat und „leserfreundlich“ zu transportieren, sondern, dass er mit ihnen ein über den Text hinausgehendes Ziel verfolge, beispielsweise den Leser zu beeindrucken. Das Heteronomie-Argument lässt sich in den dem Maßstab Originalität zugeordneten Diskussionsstellen nicht nachweisen, wohl aber der Vorwurf, die formalen Mittel stünden nicht in einem Ausdrucksverhältnis zum Inhalt des Textes. Einige Beispiele wurden bereits im Abschnitt 12.1.5 („Konventionalität“) zitiert. So sieht 
Iris Radisch (0:28) im Text Schönlaus (2004) „nachgemachte, erborgte Tonlagen“ und „literarische Kostüme, die den Texten [...] eigentlich gar nicht passen“.

Ähnliches kann man in der Diskussion zu Gerhild Steinbuch, in der Originalität eine große Rolle spielt, verfolgen. Auch hier ist Radisch die Stichwortgeberin.

Also, dass da auf sämtliche Kommasetzung verzichtet wird, das ist noch nicht die Garantie dafür, dass ein Text Rhythmus bekommt, das/ Also, ich habe das Gefühl, dass hier ein Geheimnis doch recht wichtigtuerisch umkreist wird. [...] So habe ich das jedenfalls verstanden. Und dass das aber immer nur so umkreist wird und nicht richtig ausgedrückt wird, also dass ich eben in der Tat das vielleicht gar nicht richtig verstehen kann, das ist eben auch, dass dieser Text sich selbst so vernebelt. Und dieses Dunkle eben zum raunenden Stilprinzip erhebt. Dass der Mund eben immer so voll ist, dass man ihn gar nicht richtig aufmachen kann. Das, finde ich, ist eine Schreibtaktik, die nach Literatur aussieht, die ich aber eigentlich inzwischen mehr für Literatursimulation halte. (2005 Steinbuch; 6:50 und 8:00 Radisch; Hervorhebung KR)

Radisch unternimmt mehrere Versuche, zu erklären, warum sie die Gestaltung des Textes für unwirksam, dem Inhalt nicht angemessen hält. Sie kontrastiert (fehlende) Interpunktion mit der von anderen Juroren positiv hervorgehobenen, vielleicht auch dem Text als Intention unterstellten Rhythmik. Sie kontrastiert Bedeutungssuggestion mit dem, was sich ihr als Bedeutung erschließt. Aus diesen punktuellen Beobachtungen der Unverhältnismäßigkeit von vermuteter Intention und literarischer Gestaltungsweise leitet Radisch das Urteil ab, dass der Text Literatur simuliere. Gemeint ist vermutlich, dass der Text Gestaltungsmittel wählt, die als literarische Gestaltungsmittel erprobt und bekannt sind bzw. einen Ton wählt, der als ein Ton für ein bestimmtes Thema bekannt ist, ohne dass das beim Leser auf diese Weise hervorgerufene Schema mit Inhalt gefüllt oder in Hinblick auf das gewählte Thema variiert würde.

Ursula März schließt sich Radischs Meinung explizit an und beurteilt den Text ebenso als literarisch unecht:

Ja, ich kann es relativ kurz sagen. Ich bin sehr einer Meinung mit Iris Radisch. Ich habe den Eindruck, dass wir es hier nicht mit Literatur zu tun haben, sondern mit Literaturaneignung. Und mir scheint einfach der Ton, dieser Pseudoton, dafür zu stehen. Es ist ja ein Ton, der stark sozusagen ins irgendwie Anachronistische, Seelenempfindliche geht und zwar im Rhythmus, in der ganzen Melodie, in der Idiomatik. Also nur ein Satz: „und niemals eine Ruhe in der Nacht“. Oder „Weil ich auf einmal eine Angst krieg“. Ich finde das/ Tut mir leid, Pseudostil und damit Literaturaneignung. (2005 Steinbuch, 12:52 März)

\subsubsection{Originalität als Selbstzweck}

Auch wenn der Wertmaßstab Originalität prinzipiell hohes Ansehen genießt, bleibt die Erwartung von Nachvollziehbarkeit prinzipiell erhalten. Es wird nicht geschätzt, wenn die 
originelle Gestaltung für sich steht und sich daher kein Bezug mehr zur inhaltlichen Aussage des Textes zeigen lässt. Originalität als Selbstzweck wird dabei als Eitelkeit des Autors interpretiert, mitunter auch als Effekthascherei, wie in der bereits erwähnten Passage in Deterings (16:35) Urteil zu Böldls (2005) Text, in der er die „pfiffige[n] Metapher[n]“ in anderen Wettbewerbstexten als ansonsten funktionslose Ausstellungsstücke literarischen Könnens betrachtet (vgl. Kapitel 12.1.5). Das weist darauf hin, dass nicht nur inhaltlich nicht autonome, das heißt belehrende, informierende, appellierende, Texte, sondern auch Texte, die formal ein anderes Ziel als die angemessene Aufbereitung eines Inhalts verfolgen, abgelehnt werden. Auch auf Originalität ausgerichtete Texte unterliegen dem Anspruch auf Kohärenz. Es wird erwartet, dass originelle Gestaltungselemente eine Funktion für den Textzusammenhang behalten (vgl. Kapitel 10). Sogar Ilma Rakusa (2003 Schreuf, 12:13), die eine große Fürsprecherin origineller, neuartiger Gestaltungsmittel ist und dafür bisweilen bereit ist, andere Maßstäbe in den Hintergrund zu stellen, setzt das Selbstzweck-Argument ein, wenn sie urteilt, der Text von Schreuf weise eine Originalitätssucht auf, die sie auch beim zweiten Lesen wirklich sehr gestört habe.

Ein fehlender Bezug der als originell beurteilten Textelemente zur Makroebene (Inhalt, Thema) des Textes als zentrales Argument der Kritik an Überoriginalität findet sich auch bei Paul Jandl. Er spricht von „Zwangsoriginalität“:

Und ich fand diesen Text wahnsinnig anstrengend, auch angestrengt. Es ist eine Zwangsoriginalität, die einen verfolgt mit Redundanzen, Wiederholungen. Ich finde, dass in diesem Text ja mindestens fünf, sechs verschiedene Motive stecken, die gar nicht einmal aufeinander bezogen sind. (2009 Weiss, 8:04 Jandl)

Mit dem Verweis, dass der Text „,anstrengend“ sei, wird wiederum deutlich, dass die neuartige Gestaltung in einem Konflikt mit der Textwirkung während der Lektüre stand. „Zwangsoriginalität“ (2009 Weiss, 8:04 Jandl) und „Originalitätssucht“ (2003 Schreuf, 12:13 Rakusa) sind Ausdrücke, die das Phänomen auf den Punkt bringen sollen. Daniela Strigl spricht in gleicher Absicht vom „gewollt Originelle[n]“, das sie wiederum als „Tageszeitungsartiges, was, glaube ich, der Geschichte nicht gerecht wird“, beschreibt (2008 Mohafez, 2:00 Strigl). Das Funktionsverhältnis von Gestaltung und Inhalt bzw. vermeintlicher Intention des Textes tritt auch in dieser Aussage zu Tage, ebenso die Ablehnung von Originalität um der Originalität willen („gewollt“). Paul Jandl (8:04) formuliert in der Diskussion zu Weiss“ (2009) Text schließlich: „[D]er Text will klüger und auch origineller sein, als er das zu leisten im Stande ist". Es wird in der Aussage deutlich, dass ein Missverhältnis zwischen dem Anspruch, einen originellen Text zu schreiben, und seiner tatsächlichen Originalität besteht. Es wird nicht klar, ob der Text für originell, aber nicht 
wirkungsvoll, für originell, aber nicht angemessen, oder für letztendlich gar nicht originell gehalten wird. Allerdings unterstellt Jandl dem Text einen Willen zur Originalität, der nicht in einem angemessenen Verhältnis zu seinem inhaltlichen Angebot steht.

Bei Juli Zeh (2004) hält es Klaus Nüchtern (19:49) für problematisch, „dass der Text ein bisschen auch zu sehr auch die eigenen Locken schüttelt, dann versucht irgendwie, da ein originelles Bild reinzubringen“. Auch in dieser Aussage geht es um ein zur Schau stellen der eigenen Originalität. Unzufrieden mit der ausgefallenen Bildlichkeit zeigt sich Alain Claude Sulzer (8:05) in der Diskussion zu Clemens J. Setzt (2008): „Es gibt aber einige von diesen etwas übertriebenen Bildern, die mich stören, die ich für überflüssig halte, die so eine Originalität suggerieren“. Wie Nüchtern unterstellt Sulzer, dass die entsprechenden sprachlichen Bilder mit dem Ziel in den Text eingebaut wurden, „Originalität [zu] suggerieren".

In den Argumenten mit dem Bezugspunkt Originalität als Selbstzweck zeigt sich, dass eine originelle Gestaltung dann zu einem Problem werden kann, wenn der Eindruck entsteht, der Text kokettiere mit seiner Originalität. Es liegt nahe, dass gerade die Wettbewerbssituation in Klagenfurt die Juroren sensibel macht für Phänomene, die geeignet wären, die Juroren zu beeindrucken. Zu diesen Phänomenen gehört offenbar eine auffallend originelle Gestaltung. Die gestalterischen Bezugspunkte sind dabei breit gestreut. Die innere Organisation der Motive spielt eine Rolle (2009 Weiss, 8:04 Jandl), die Bildlichkeit (2004 Zeh, 19:49 Nüchtern und 2008 Setz, 8:05 Sulzer), der Titel des Textes (2008 Mohafez, 2:01 Strigl) und auch sein Stil (2003 Schreuf, 12:13 Rakusa). Liest man die Argumentationen gegen den Strich, offenbart sich in ihnen aber auch die Anerkennung des Maßstabs Originalität. Denn gerade die Vorannahme, die Autoren würden eine besonders neue oder individuelle Gestaltung wählen, um zu beeindrucken, impliziert, dass Originalität in der Gestaltung grundsätzlich geeignet ist, Eindruck zu machen. Die Gültigkeit des Wertmaßstabs bestätigt sich indirekt in der Kritik an Originalität als Selbstzweck. Originalität bestätigt sich als tief in den Wertekonventionen verankerter Wert.

\subsubsection{Zusammenfassung}

Originalität ist ein viel genannter Maßstab, mit dem sich die Vorstellung von Literatur als Kunst in besonderem Maße verbindet. Es gibt viele, auch versteckte Hinweise, dass Originalität hoch gehandelt wird. Gleichzeitig ist Originalität als Maßstab jenen Maßstäben nachgeordnet, die in einem unmittelbareren Verhältnis zur Textwirkung während der Lektüre stehen. So wird Originalität dann abgelehnt, wenn sie eine kohärente Lesart 
stört oder so sehr erschwert, dass die Anstrengung, sie herzustellen, Unlust beim Lesen hervorruft. Sie wird aber gelobt, wenn sie eine bewältigbare Herausforderung an den Leser darstellt und die Bereitschaft der Juroren, sich auf den Text zu konzentrieren, fördert.

Besonders interessant ist der Maßstab Originalität dort, wo unterstellt wird, dass die Autoren in ihren Texten aufgrund der Kenntnis des Maßstabs Originalität versuchen, einen Text zu produzieren, der diesem Maßstab entspricht (vgl. Kapitel 12.1.7), also in Argumenten, in denen von „Literatursimulation“, „Zwangsoriginalität“, „Pseudoton“ und „Literaturaneignung“ die Rede ist. Originalität kann also offenbar gezielt produziert werden, sie verliert aber dort ihren Wert, wo deutlich wird, dass sie um ihrer selbst willen produziert wurde. Hier greifen sehr komplexe Vorstellungen ineinander. Einerseits zielen die Argumente darauf ab, dass das nachgeahmte Originelle nicht mehr originell ist. Andererseits wird aber auch darauf verwiesen, dass durch die intendierte Originalität die Zuschreibung von Werten, insbesondere aus dem Komplex Orientierung, gestört wird. Das innere Funktionieren des Textes als Text, das sich zunächst in der Lektürewahrnehmung manifestiert, darf, so kann man folgern, nicht durch die Intention, den Text formal innovativ zu gestalten, gestört werden. Wird die innovative Gestaltung als primäre Funktion von Formmerkmalen wahrgenommen, wird sie abgelehnt. Das enorme Prestige des Wertmaßstabs Originalität vorausgesetzt, lässt sich eine solche Haltung aus der Bedeutung des Lektüre-Erlebnisses erklären. Eine Dominanz der Form, sei sie originell oder nicht, wird in der aktuellen Wertungspraxis nicht honoriert, weil sie den Blick des Lesers von der Textwelt und Figurenhandlung weglenkt. Originelle formale Gestaltungsweisen werden dann gelobt, wenn sie sich beiläufig und unmittelbar erschließen, am ehesten, wenn sie sich als Grund für ein intensives Lektüre-Erlebnis erfassen lassen.

Bei der Einordnung auf der bipolaren Wertskala gelungen/nicht gelungen kann der Wert Originalität verwendetet werden, um Feinjustierungen der Wertung vorzunehmen. Hat die originelle Gestaltung die Wirkung der Aktivierung, indem sie eine Spannung (tension) auslöst, wird sie positiv gewertet. Stört eine originelle Gestaltung dagegen den Lektürefluss, steht der Wert in Konflikt mit dem Wirkungswert Orientierung. Viele Aussagen bestätigen jedoch, dass Originalität als Wert ein sehr hohes Prestige besitzt. 


\section{Teil III}

\section{Detailanalysen}

\section{Ute-Christine Krupp: „Köln-Tokio“ (2001)}

Quelle: http://archiv.bachmannpreis.orf.at/index2001.htm

Eingeladen von: Elisabeth Bronfen

Auszeichnung: keine

\subsection{Transkript der Diskussion}

0:00 Spinnen: [Anfang fehlt] bekleidet zu sein scheint, was er nicht braucht. Das macht ihn manchmal eckig, kantig, kalt, glatt wie einen Eiswürfel, aber ich höre dazwischen Verschiedenes, oder spüre dazwischen Verschiedenes an einer ganz anderen Temperatur. Ich persönlich, Offenlegung der Kriterien, mag Texte, die nach dem Prinzip Saint Exupérys gebaut sind, und das heißt, etwas ist perfekt, nicht, wenn man noch etwas hinzu/ wenn man nichts mehr hinzugeben kann, sondern wenn man nichts mehr wegnehmen kann. Der Text scheint mir auch eine Ästhetik zu vertreten des Nichts-mehr-wegnehmen-könnens. Das macht ihn teilweise auch rätselhaft, ja geradezu verschlossen. Das Zweite, was mir daran gefallen hat, ist, dass aus dieser ungemein, fast doktrinär, streng wirkenden Ästhetik heraus, er am Schluss so etwas tut, wie einen Flugversuch zu unternehmen, wechselt fast, könnte man sagen, die Tonart, das Genre. Erstaunlicherweise ist dann auch noch dieser Genrewechsel als Monolog einer Figur in den Mund gelegt, von der ich bis heute eigentlich nicht weiß, ob es sie gibt, oder ob sie nicht eine Projektion der Figur ist, wie vieles in diesem Text eine Projektion der Figur sein könnte, einer Figur, die als Chemikerin ja gewissermaßen mit der Anlage von Versuchskonstellationen schon berufshalber beschäftigt ist. Das ist ein/ scheint jetzt ein ganz struktureller Eindruck zu sein. Aber etwas, das heute Vormittag schon mal zur Sprache kommt/ gekommen ist - ambivalent behandelt wurde - möchte ich noch einmal aufgreifen, und sagen, wie das eben dann aussieht oder wie das für mich aussieht, wenn mir das gelungen zu sein scheint. Denn dieser Text scheint mir über diese Struktur, über den Rhythmus, der ihr unterliegt, eine sehr bedeutsame Aussage zu machen, ohne zu psychologisieren. Und die Art und Weise, wie das angegangen wird, die hat mir/ die hat mir sehr imponiert.

2:28 Bronfen: Ja, ich habe diesen Text deshalb ausgesucht, weil ich da eine, eigentlich eine Gegenläufigkeit feststellte. Und zwar, es fing für mich eigentlich damit an, dass ganz ähnlich wie Herr Spinnen, mir das Ende so kryptisch und dadurch aber so interessant erschien. Und zwar, weil ich zwar dachte, dass es die Figur gibt, die den Monolog spricht, aber mir zum Schluss nicht mehr klar ist, ob die Frau, also unsere Heldin Carolin, noch ihm gegenüber sitzt oder ob sie schon längst weggegangen ist, weil sie bei diesem Phantasieschwall ihr Interesse verloren hat. Und daran gekoppelt fand ich das eben so gelungen, wie es hier ja einerseits um diese ganze Frage sich dreht, das ist ja auch einer der Sätze im Text, wann sich die Phantasie einschaltet. Und das wird aber, und deswegen habe ich vorher von einer Gegenläufigkeit gesprochen, das wird aber durch, wie ich das empfunden habe, einen wirklich fast klinisch kalten Blick geschafft. Das heißt, verschiedene Figuren, einerseits die Chemikerin in ihrem Interesse für diese Bakterien, die klassifiziert werden sollen, und andererseits ihre Freundin in Tokio, versuchen ja so, ihre Umwelt irgendwie zu klassifizieren, indem sie an Details festhalten. Und das ist dann auch der Gestus, den die Heldin aufgreift, wenn sie ihrem möglicherweise existenten Liebhaber erzählt, wie sie aussieht. Das wird aber alles mit einer unglaublichen Distanz hergestellt. Und fasziniert hat mich an diesem Text eben gerade diese Verknüpfung von einer Distanz, in der es offensichtlich um eine Form von Klassifizieren geht, wo aber gleichzeitig deutlich wird, wie vieles überhaupt nicht gesagt werden kann. Also desto wissenschaftlicher, desto kälter der Blick wird, desto mehr öffnet sich. Und desto 
mehr öffnet sich vor allem auch der Raum der Phantasie. Und das fand ich eine ganz ungewöhnlich/ also für mich ungewöhnliche Mischung von zwei emotionalen Elementen, die in diesem Text für mich so hervorragend zusammenkommen.

4:31 Widmer: Ich glaube, man darf sagen, dass der Text spröde ist. Und ich habe mich eigentlich gefragt, beim Lesen, beim Wiederlesen: Wo wäre ich in dem Text? Oder wo könnte ich mich selber irgendwie finden in dem Text, der mich sehr befremdet hat eigentlich? Und vermutlich wäre ich Gisa, die zwar mit einem Namen ausgestattete, aber ansonsten relativ attributlose Laborkollegin der handelnden Frau. Ich muss sagen, wenn ich Gisa wäre, hätte ich mich vermutlich umgebracht vor Langeweile [Heiterkeit] oder wäre handgreiflich geworden. Ich habe mich/ Ich muss dann vielleicht zum Schluss dieses Votums versuchen, meine Kriterien auch offenzulegen natürlich. Aber zunächst mal ein Sinneseindruck. Ich habe mich entsetzlich gelangweilt beim Zuhören und beim Lesen. Ich fand, dass dieser Text der Horror der reinen Parataxe ist. Die Absenz von Leidenschaften natürlich gewollt. Ich glaube, da würden wir uns wiederfinden, Herr Spinnen, bis zu diesem Abhebeversuch, wo sowas wie Leidenschaft passiert, aber eben nur halluzinierte Leidenschaft, halluziniertes Abheben und dann ist man wieder da bei dieser Sprechblasen/ bei diesem Sprechblasenpaar. Ich sehe auch, dass da Verschiedenes anklingt. Aber was mich auch sehr stört, ist, dass dieser Text eigentlich als Ganzes nirgendwo irgendwie sowas schafft wie also Spitzen oder Sachen, die herausragen. Er ist, ich sage noch mal, entsetzlich, aber entsetzlich gleichförmig, für mich. Das geht sowohl auf die Reiseimpressionen aus Tokio, die ich/ von denen ich finde, dass sie in dieser Art von jedem Reiseführer an Prägnanz übertroffen werden. Es geht hin zu diesen Laborszenen, wo ganz knapp einfach nur das Zubehör eines normalen Labors angetippt wird. Also es gibt nirgendwo eine Tiefe. Es gibt eigentlich nur Oberfläche. Es kann sein, dass das gewollt ist. Ich stelle mir vor, dass sie das gewollt hat. Das finde ich auch plausibel gemacht. Vielleicht ist mein Kriterium halt in dem Fall jetzt/ Also, für mich geht es nicht ohne Leidenschaft. Ich habe mich wirklich/ Also, ich bin froh, war der fertig. [Gemurmel im Saal]

6:46 Schindel: Tja ich/ Dieser Text hat sozusagen einige Verdoppelungen. Ich glaube, er ist einmal/ Er ist mir vorgekommen wie/ zuerst wie eine filmische Erzählung, wie eine Filmerzählung. Es wird sozusagen erzählt in knappen dürren Worten, was man sieht, was immer jeweils gesehen wird. Das geht sogar so weit, dass man auch sagt: Es klingelt das Telefon. Sie hängt/ nimmt den Hörer ab. Also wird genau, minutiös geschildert, als wäre das sozusagen ein größeres Mikroskop, wo man sozusagen jetzt durch die Carolin schaut, was sie macht und dann schaut man/ Dann ist die Begegnung und dann müssen sie sich ebenso wie in einer Filmerzählung gegenseitig immer sagen, was sie anhaben, was sie gerade tun. Es zählt nur das, was man sieht. Es ist ein AugentierText in diesem Zusammenhang, klingt daher auch in dieser klinischen und in dieser Angst vor Berührung/ Ich glaube, das spielt eine große Rolle, hat ja auch sowas Telefonsexartiges, wenn auch jetzt nicht der Telefonsex direkt spielt, sondern er ist ja gar nicht interessiert. Er sagt ja auch einmal: Der nackte Körper hat kein Geheimnis. Er muss sich die Sachen nur vorstellen. Er/ Es darf nichts passieren. Es muss alles nur beschrieben werden. Es muss alles nur sich bewegen wie eine Bakterienkultur. Hier auch diese, wie ich meine, etwas eins zu eins Übersetzung. Und das ist natürlich eine Versuchsanordnung, ein Text in einer Versuchsanordnung. Und jetzt muss ich halt sagen darauf: In DIESEN Text gehört etwas hinein. Da muss was passieren. Dieser Text/ Wenn dieser Text diese Coolness behält und hier einer/ auf einer zweiten Ebene eine Dynamik, eine Spannung, etwas ist, wo ich sage, um was geht es da? Und die kommen dann nicht zusammen. Es geht immer wieder in diese Klinik zurück. Dann hätte er eine Dramaturgie, die mich interessiert. Aber so, glaube ich, bleibt der Text in der Versuchsanordnung stecken und kommt irgendwie nicht auf die Höhe eines Gegenstandes. Er bleibt sozusagen bei sich und das kann man jetzt zwar auch wollen. Nur eine Literatur, die irgendwie sich der Sinnlichkeit vollkommen begibt und das womöglich noch mit Absicht, ist zumindest eine, in die ich sehr schwer hineinkomme.

9:08 Widmer: Ich wollte nur einrufen und einen Satz nachschieben. Wenn das eine Versuchsanordnung ist, womit ich völlig einverstanden bin, dann muss ich sagen, ich bin nicht gern das Meerschweinchen.

9:17 Scheck: Naja, also ich muss schon sagen. Ich finde, Thomas Widmer hat da recht, was das Geschmacksurteil angeht. Auch mich hat das jetzt wieder, zum dritten Mal oder so, gelangweilt. Und Burkhard Spinnen: Wenn die Reduktion der Mittel, die Sie fordern, in Ästhetik, ja, alle Teile präsent halten, sodass man nichts wegnehmen kann, dann muss ich einfach handwerklich an diesem Text sagen: Hier wurde etwas weggenommen, das nie - also war vielleicht auch nie da - das man unmöglich wegnehmen darf, nämlich die Fähigkeit, Dialoge zu schreiben. Wenn ich eine Geschichte 
im Dialog so stark erzähle/ Und jetzt der Einwand, ich ahne ihn schon voraus: Ja, der Mathis ist ja nur phantasiert, ja. Aber hier das ist ein monotoner Text. Alle Figuren dieser/ Die Erzähler/ Die Hauptpersonen und Mathis sprechen alle monoton im gleichen anämischen Sound. Daher rührt meine Langeweile, einfach an dieser unglaublichen sprachlichen Ödheit, die sicherlich gewollt ist, die nicht mal eben so unterläuft. Aber das ist ein, für mich jedenfalls, ein Effekt, der kontraproduktiv wirklich ist. Ich entwickle nirgendwo Interesse, weil ich sprachlich hier nichts finde. Ich möchte/ Ich war diesem Text zunächst sehr zugeneigt, weil ich dachte: Genau! Telefonnummern austauschen, dann der Name. Ja. Das klingt sehr verwandt. Das ist jetzt einfach Zufall. Friedrich Kittler hat gerade einen Essay über Massenmedien und Liebe veröffentlicht, ja, mit kühnen Thesen. Aber, es tut mir leid, diese Massenmedien/ Natürlich, gegenwärtige Literatur misst sich in meinen Augen wirklich an dem Maße, wie sie auf die Massenmedien eingeht, die reflektiert. Die sind hier benannt. Aber die E-Mail aus Tokio liest sich halt genauso wie der erste Satz. Da ist nichts variiert. Dann finde ich es unglaublich handwerklich schlecht, die Art und Weise, wie am Telefon die Frage des imaginierten/ des Mathis wiederholt werden müssen. Das ist einfach langweilig. Also, er muss ja jede Frage wiederholen. Das läuft mir als Dialog durch. Ich finde es einfach/ Von der Konzeption her hätte das vielleicht interessant werden können, aber in der Ausführung schlecht. Und wenn/ Natürlich ist jedes Werk irgendwo, wo man sagt Totenmaske einer Konzeption. Aber das hier ist wirklich tot in meinen Augen.

11:40 Vanderbeke: Mir geht es ähnlich. Ich mache es kurz. Ich war geneigt, den Text sozusagen als Geschichte über Einsamkeit im Zeitalter des Handys und des Internet anzusehen, bin sehr schnell über die parataktische „und dann und dann und dann“-Erzählweise ermüdet worden und habe auch gefunden, dass er natürlich diese Dialoge: „Möchtest du noch ein Glas Wein, Carina?“ [will verbessern] Nein, K/ wie sie nun heißt, ja [im Text wird die Hauptfigur Carolin tatsächlich in diesem Dialog zunächst mit dem Namen Carina angesprochen. KR]. Also diese wörtliche Rede ist ganz, ganz furchtbar. So spricht keiner und so soll auch nicht in Literatur gesprochen werden. Und dann ist mir eben noch aufgefallen, dass er insgesamt auch ein bisschen sorglos ist, selbst in dieser Gewissenhaftigkeit, oder vorgeblichen Gewissenhaftigkeit, die stimmt dann manchmal nicht. An irgendeiner Stelle musste ich dann zurückblättern, weil ich nicht wusste, was das für ein Gelee ist, wo da reingestochert wird. Oder dann frage ich mich: Was soll das, dass sie dann sagt, sie ist glücklich, weil er vorhin auf der Straße gesagt hat, „dass das schön aussehe, wenn ich den Kopf so zur Seite neige“. Das hat er nicht gesagt. Also stolpere ich da drüber und denke: Wird schon eine Bedeutung haben. Und die Bedeutung ist natürlich angelegt darauf, dass das alles nur in ihrer Phantasie stattfindet. Aber in ihrer Phantasie müsste es im Grunde aufregender stattfinden. Das ist das, was die Parataxe dann verhindert. Und da gibt es noch ein paar weitere kleine Ungenauigkeiten. Zum Beispiel, bei aller Ausführlichkeit dieses Textes kommt dann plötzlich lapidar dieses „Sie machte“ / „Sie las das [sic] Mail und antwortete kurz darauf“ [frei zitiert KR]. Das hätte ich ganz gern gewusst, was sie auf die Meldung, vom Erdbeben, glaube ich, war das, geantwortet hat. Dann kürzt er/ macht er es sich dann auch leicht. Also da ist er in sich auch nicht stimmig, der Text.

13:40 Fliedl: Ich kann das auch ganz kurz machen. Also, ich denke, dass man konzedieren muss, dass der Text die Bedingungen, unter/ mit denen er operiert, benennt. Da ist diese in vitro Situation. Aus der wird kein Geheimnis gemacht. Das wird innerhalb dieser Versuchsanordnung exekutiert. Der Text ist sehr versiert in Hinblick auf, was weiß ich, Pseudorealität, Simulationen, Medien, die da ineinandergreifen und funktionieren. Also, das kann ich alles sehen und schätze, dass man fairerweise/ dass ihm sozusagen in/ unter diesen Laborbedingungen beurteilen müsste. Den Schluss erkläre ich mir so, dass sozusagen hier noch mal Präsenz verabschiedet wird. Also im Beisein voneinander wird eine noch mal durch den Rückspiegel gebrochene Phantasie erzählt und sozusagen der gegenseitigen Anwesenheit noch mal ausgewichen in sozusagen einem filmischen oder vorgestellten Ablauf. Das kann ich alles sehen. Was mir so schwer fällt, ist, das zu kombinieren mit dieser allegorischen Ebene des Textes. Die Chemie muss stimmen [paraphrasiert KR]. Und hier: Die Liebe zwischen Partnern funktioniert auf Anziehung [paraphrasiert KR]. Oder: „Vielleicht ist es das Herz, das immer wieder mal anschwillt und sich wieder zusammenzieht“. „Vielleicht ist es ein Hunger, der nicht gestillt werden kann“. Also, das finde ich einen Bruch gegenüber dem Minimalismus des Textes, dass hier dann wirklich so konkrete Anweisungen dafür da sind, wie das Experiment verstanden werden soll.

15:09 Bronfen: Ja, ich kann eben einfach nur sagen: Mich hat so interessiert, dass das gerade um eine Entleerung von Phantasie geht und eine Entleerung von Welt und eine Entleerung von der 
Sprache, die wir normalerweise als eine gefühlte Sprache der Phantasie empfinden. Und ich denke auch, also wenn man das jetzt gleichförmig oder monoton oder langweilig findet, geht das gar nicht so dem Interesse dessen, was der Text machen möchte, entgegen, sondern es geht eben gerade darum, dass diese Phantasiewelten in sich schon/ Ich komme eben nur auf/ Also, die Worte, die ich benutzt hatte, waren ja eben so: distanziert, kalt, entleert. Und da kann/ Ich denke, da ist das eine Konsequenz von dem Text, wenn man solche/ also so eine Vorstellung von, dass die eigenen Vorstellungen - und das wäre jetzt eben diese Vorstellung der Chemikerin, die alles klassifizieren möchte -, wenn diese Vorstellung dann das ganze Leben, das Liebesleben, die ganze Umwelt, die Wahrnehmung in der Welt, in der man sich bewegt, überflutet. Dann kann da eigentlich auch nur so ein/Also, ich hatte für mich auch den Begriff der Austauschbarkeit. Natürlich ist das alles verwoben. Natürlich ist das alles austauschbar. Weil das ist alles Teil von einer auf einer Platte gelegten oder angelegten Phantasiewelt oder Phantasiekultur.

16:27 Spinnen: Noch etwas zu den Dialogen: Also denke bitte keiner, ich würde glauben, das seien lebensnahe, lebenssatte, erznaturalistische Dialoge. Aber man kann einen Text auch nicht, wenn er Dialoge, die möglicherweise sogar fiktive Dialoge sind, darauf verpflichten, dass die alltagsrealistisch sind. Das ist nicht die Konzeption des Textes. Das sind aufgesagte Sätze darin, die schlecht hergesagt sind zum Teil. Das ist so, als wenn ich eigentlich mit einem Sammlerkollegen am Telefon rede und meine Frau kommt rein, und ich tue so, als wenn es ein Redakteur wäre und wiederhole falsche Fragen. Hier macht sich jemand selbst etwas vor. Hier wird selbst diese alte Vorstellung vom erotischen Telefongespräch noch einmal durch eine schüleraufführungshafte Inszenierung noch einmal etwas nach unten abgeleitet. Ich denke schon, dass das in der Konzeption dieses Textes liegt. Wenn man sich davon gelangweilt fühlt, ist natürlich die Frage, wie man von einer, also wie man es zusammenkriegen soll, die Austreibung der Leidenschaft selbst, wieder leidenschaftlich darzustellen. Das ist eine große Herausforderung. Ich glaube aber, dass der Text mit diesem Schluss, mit diesem Verlassen seiner selbst, mit dem Verlassen seiner Konzeption, einen Hinweis darauf macht, wozu mindestens das Material dafür hergenommen werden kann, aus dieser Enge zu entfliehen. Meine persönliche Interpretation dieses Schlusses ist ja so etwas wie ein, ja, gewissermaßen ein Suizid der Figur an ihrer Phantasie. Sie bringt ja ihre eigene Phantasie um. Sie diskreditiert ihren eigenen Widerpart oder lässt den sich im Kontext vollkommen diskreditieren.

18:22 Schindel: Ich glaube, das ist hier ein poetisches Problem oder ein literarisches Problem. Wir kennen es alle und die Schriftsteller vorne weg. Es lässt sich die/ aus der Entleerung der Phantasie nicht durch eine Entleerung der Phantasie darstellen. Es lässt sich nicht die Langeweile durch die Langeweile darstellen. Man muss/ Das poetische Verfahren ist nun eben ein indirektes. Es wird eben in einer Literatur gerade über/ Die handelt ja gerade von dem, was sie nicht schreibt. Das heißt, sie hat dieses indirekte Verfahren und das fehlt hier. Ich glaube, es ist sozusagen eigentlich ein mutiger Text und er ist einfach/ Es klappt/ funktioniert meiner Meinung nach so nicht. Und es kann ja auch nicht sein, dass wir dann zu einer Literatur kommen, die, weil sie strukturell richtig ist, unendlich langweilt, und zwar alle. Nee, nicht. Das ist keine Geschmacksangelegenheit.

19:15 Spinnen: Nicht alle.

19:15 Schindel: [unv.] Ich behaupte, eine Langeweile durch Langweile darstellen/ Da bringt der Leser sozusagen keine Leidenschaft hinein, nicht mehr hoch. Er kann sich sozusagen dafür nicht mehr interessieren. Er kommt nicht mehr in eine/ Er kommt nicht mehr, glaube ich, in eine Kommunikation mit einem Text. Wenn wir eine Literatur/ Wenn wir eine Literatur fördern oder fordern, in der nur Versuchsanordnungen eigentlich interessant sind und die Strukturen interessant sind, aber der Widerpart, die Sinnlichkeit, eben programmatisch auch in der Form ausgetrieben ist und auch nicht im Geheimnis steckt, auch nicht in den Auslassungen steckt. Das, was Sie gefordert haben, das wäre eine große Aufgabe hier sozusagen, dass die Leidenschaft in dieser Leidenschaftslosigkeit irgendwo zu erahnen ist, zu knistern beginnt und dann eine Dynamik entwickelt. Dann ist das ein großer Text. Wenn das aber fehlt, dann fehlt einfach/ dann ist das wie ein Mund ohne Unterkiefer.

20:22 Vanderbeke: Jetzt hat sich das schon fast erübrigt. Ich denke, das einzige, was in diesem Text lebt, sind die Bakterien, die Bazillen. [ganz wenig Heiterkeit] Und das geht mir so, dass wenn ich den Text gelesen habe, mir sozusagen selber eine furchtbare Entleerung wiederfährt und mir erst einmal eine halbe Stunde lang nichts mehr einfällt. Und das ist vielleicht kein gültiges Kriterium, warum man einen Text ablehnt, aber das, was Herr Schindel sagte: Er spricht mit niemandem. Und er will auch mit niemandem sprechen. Und gleichwohl, und da liegt jetzt die Krux, behauptet er, auch wenn das eine Entleerungsgeschichte ist, einen ungestillten Hunger. Und der ist behauptet, 
den sehe ich nicht.

21:07 Scheck: Also jetzt noch ganz kurz. Es geht ja nicht um jetzt mögliche Erektionsprobleme beim Lesen oder so etwas [große Heiterkeit], ob Leidenschaft und Phantasie sich da überträgt. Also, ich glaube, es wird ja in der Diskussion deutlich. Hier ist ein Risiko eingegangen worden, ein Versuch gemacht. Das ist einfach die Regel: Experiment misslungen. Klappt nicht. Trotzdem: Auf eine/ Der Text heißt ja im Untertitel hier, wie wir ihn bekommen haben: „Ein Text für Klagenfurt“. Und nicht nur die Dialoge, sondern, Entschuldigung, der Text selber/ Wenn Burkhard Spinnen sagt, das handelt sich ja um aufgesagte Texte und wenn wir diese Unsicherheit haben, gibt es den Mathis wirklich, der sonst etwas/ Also für mich auch das Kernproblem dieses Textes ist einfach diese unzähligen Absicherungsstrategien, die er enthält, ja. Das Risiko, die Risikobereitschaft ist dann eben doch nicht so groß, um nun zu sagen: Jetzt geht es drum. Und auch in den Argumenten, Frau Bronfen, die ich von Ihnen für den Text höre, die funktionieren doch nur, wenn Sie mir sagen: Also hier wird eine soziale Repräsentanz gebildet in dem Text. Das heißt, das ist die Dokumentation eines Bewusstseins absterbender Phantasie, wie es heute ganz, ganz schlimm zugegen ist. Und das wurde noch nie ausgesprochen oder so etwas. Aber das Problem ist eben: Das ist ausgesprochen. Es ist benannt. Und es findet sich in Bret Easton Ellis „American Psycho“ eben wesentlich besser als ein Versuch wie hier, was für mich auf ähnliches rausläuft, ja.

22:26 Spinnen: Also Mehrdeutigkeit ist keine Absicherungsstrategie. [etwas Heiterkeit]

22:31 Scheck: Ich glaube, ich meine das mit der Absicherungsstrategie auch nicht, um Gottes Willen, als Mehrdeutigkeit. Wir haben mehrdeutige Texte bekommen. Er ist in der [unv., weil Spinnen spricht].

22:41 Spinnen: Mehrdeutigkeit ist keine Absicherungsstrategie. Jetzt machen Sie mir bitte nicht alles, was ich glaube über die Literatur des 20. Jahrhunderts zu wissen, mit einem Satz zunichte. [große Heiterkeit]

22:46 Scheck: Naja, das ist natürlich bei [unv.]/[Heiterkeit]

22:49 Spinnen: Mehrdeutigkeit ist keine Absicherungsstrategie.

22:51 Scheck: Doch.

22:51 Spinnen: Ja, ja, das habe ich auch noch so gemeint. Jo, das könnte ich auch gemeint haben.

22:54 Scheck: Bei nihilistischen Texten, wie das einer ist, kann das schon mal passieren, dass man gewisse, sicher gefühlte Gläubigkeiten verliert. Das will ich Ihnen nicht ganz ersparen [große Heiterkeit]. ,Nicht alles sagen, was man sagen möchte, meint Carolin später zu Gisa, die Spielregeln sind bekannt. Das, worum es geht, wird nicht gesagt". Das ist die Poetik im Grunde dieses Textes oder ein Ansatz dazu. So kann man es nehmen. Das meine ich mit Absicherungsstrategie, ja. Also ich verschweige mein eigentliches Thema. Nun geht mal schön das Osterei suchen, ja. Wir haben ja ein paar Ostereiersucher auch gefunden/ Ostereier gefunden. Soll ja recht sein. Aber es ist unterm Strich halt mir ein bisschen, sorry, zu lau. 


\subsection{Analyse der Diskussion}

\section{Ablauf der Diskussion}

Mit ziemlich genau 24 Minuten ist die Diskussion zu Ute-Christine Krupps Text „KölnTokio“ minimal länger als der Durchschnitt. Die Diskussion ist von relativ großer Einigkeit geprägt. Bis auf die vorschlagende Jurorin Elisabeth Bronfen sowie Burkhard Spinnen findet der Text keine Verteidiger. Auch in der Schlagrichtung der Kritik sind sich die Juroren weitestgehend einig. Der Text wird als langweilig und unsinnlich empfunden, seine Grundidee allerdings als interessant. Damit erweist sich die Diskussion als beispielhaft für einen Text, dessen Thema und Grundidee anerkannt, ja sogar gelobt, dessen sprachliche und formale Umsetzung allerdings als unzulänglich bewertet wird.

\section{Der Text „Köln-Tokio“}

Im Mittelpunkt des Textes „Köln-Tokio“ steht eine Chemikerin, Carolin, die über resistente Bakterien promoviert. In wechselnder Szenenfolge erhält der Leser Einblicke in ihre Arbeit im Labor, Gespräche, die sie mit ihrer Bürokollegin Gisa führt, E-Mails von einer Freundin aus Tokio, die sie liest, und Telefonate, die sie mit ihrem neuen Liebhaber Mathis führt. Dabei bleibt unklar, ob es sich bei den geführten Gesprächen, E-Mails und Telefonaten um reale oder phantasierte Kommunikation handelt. Insbesondere die Frage, ob Mathis real oder Teil von Carolins Phantasie ist, bleibt offen. Alle Nebenfiguren des Textes werden ausschließlich aus der Perspektive der Hauptfigur und zusätzlich medial gebrochen gezeigt. Durch diese medial vermittelte Existenz der Nebenfiguren wird ein Blick von außen auf die Hauptfigur verhindert. Gleichzeitig dienen diese Textpassagen der Charakterisierung Carolins. Indem der Erzähler nur eine Außenperspektive (externe Fokalisierung) auf die Handlung wiedergibt, ist dem Leser nur das zugänglich, was Carolin tut und sagt. Eine Ausnahme bildet die Wiedergabe des Textes einer Postkarte und einer E-Mail, die die Hauptfigur erhält. Hier wird die externe Sicht kurzzeitig zurückgenommen. Ein kurzer Textauszug soll illustrieren, wie der Text in externer Fokalisierung ein Telefongespräch wiedergibt:

Sie sitzt auf dem Sofa, als das Telefon klingelt. Sie nimmt den Hörer ab und lacht und sagt: Die ersten Seiten der Doktorarbeit habe ich geschrieben ... ab und zu auf den Balkon gegangen, eine kurze Pause gemacht ... worüber, über resistente Bakterien ... Ich suche ein Mittel, das den Stoffwechsel stört ... die einzige Möglichkeit, wahrscheinlich...nein, die resistent sind gegen Antibiotika...genau, nein, jetzt habe ich einen Bademantel an, einen roten Bademantel und keine Schuhe, nein, keine...eine helle Decke liegt über dem Sofa... Designerlampen im Zimmer ... und bei dir? ... Ledersessel 
und ... und Bilder von verschiedenen Künstlern an den Wänden?... Den Sommer magst du, ins Schwimmbad gehen, die Frauen...im Schwimmbad beobachten und dir etwas vorstellen dabei...was sie gerade jetzt denken könnten, stumme Fragen und stumme Antworten...und darunter? fragt sie zurück.. aus Seide, schwarzer Seide...Die Frage ist immer, ab wann sich die Phantasie einschaltet? sagst du. (Krupp 2001)

Der Ausschnitt gibt ein (imaginiertes) Telefongespräch zwischen der Hauptfigur Carolin und ihrem (fiktiven) Liebhaber Mathis wieder. Wiedergegeben wird nur, was von außen sichtbar und hörbar wäre. Der Text endet schließlich mit einer Szene, in der Mathis Carolin zum Essen ausführt und in der Carolin sich selbst und den gemeinsamen Abend aus der Perspektive Mathis' als verliebtes Paar imaginiert. Es bleibt dabei für den Leser offen, ob das Rendezvous tatsächlich stattfindet oder ob es eine Phantasie Carolins ist.

\section{Hauptkritikpunkt: Fehlende Sinnlichkeit}

Es gibt nicht viele Diskussionen, in denen die Sinnlichkeit eines Textes so sehr im Vordergrund steht wie in der Diskussion zu Krupps Text. Selten wird so explizit gesagt, dass ein Text langweilig ist wie in dieser Diskussion. Sie ist gerade deswegen so interessant, weil sie deutlich zeigt, dass die formale Gestaltung ganz zentral als dafür verantwortlich gesehen wird, ob ein Text sinnlich und unterhaltsam ist. Beinahe alle Juroren loben die inhaltliche Idee, die „Versuchsanordnung“ (6:46 Schindel; 13:40 Fliedl) bzw. „Versuchskonstellation“ (0:00 Spinnen) des Textes und verweisen darauf, dass diese wenig Wert habe, wenn der Leser „, $[\mathrm{s}$ ]ich entsetzlich gelangweilt [hat] beim Zuhören und beim Lesen“ (4:31 Widmer), „nirgendwo Interesse [entwickelt], weil [er] sprachlich hier nichts finde[t]“ (9:17 Scheck), „über die parataktische [...] Erzählweise ermüdet [wird]“ (11:40 Vanderbeke). Bemerkenswert ist dabei, mit welcher Klarheit und Eindeutigkeit der Wert formuliert wird, dass ein literarischer Text sinnlich ansprechend sein sollte, das heißt, dass er dem Leser erlauben sollte, emotional an ihm teilzunehmen (emotionale Aktivierung). Die Sicherheit, dass der Wert Interessensbindung anerkannt, legitim und anwendbar ist, ist so groß, dass manche Juroren es wagen, sich geradezu polemisch in diesem Sinne zu äußern:

Ich denke, das einzige, was in diesem Text lebt, sind die Bakterien, die Bazillen. [ganz wenig Heiterkeit] Und das geht mir so, dass wenn ich den Text gelesen habe, mir sozusagen selber eine furchtbare Entleerung wiederfährt und mir erst einmal eine halbe Stunde lang nichts mehr einfällt. Und das ist vielleicht kein gültiges Kriterium, warum man einen Text ablehnt, aber das, was Herr Schindel sagte: Er spricht mit niemandem. (20:22 Vanderbeke)

Der Dünkel, dass „Entleerung“ möglicherweise „kein gültiges Kriterium“ ist, entstammt offenbar einem erlernten Wissen, demzufolge Kriterien wie Spannung, Lebendigkeit und 
Anteilnahme auf die sogenannte hohe Literatur nicht anwendbar sind. Vanderbeke zitiert diese Wertungskonvention in ihrem Beitrag lediglich, wendet sie jedoch nicht an. Die Schlagrichtung ihres Argumentes ist aufgrund ihrer Polemik sehr eindeutig: Ein Text kann keine positive Wirkung, und damit auch keine positive Wertung, erreichen, wenn er für seine Leser nicht lebendig wird. Außerdem weiß sie sich an diesem Punkt der Diskussion, die sich bereits dem Ende neigt, in guter Gesellschaft. Einige andere Juroren haben bereits ähnlich drastisch gewertet. Das, was Vanderbeke (ebd.) letztlich als „gültiges Kriterium“ anbietet, nämlich, dass „er [...] zu niemandem [spricht]“ stößt in eine ähnliche Richtung. Die Wertung illustriert, dass der Wert literarischer Texte keineswegs nur in einer kunstvollen Form oder einer stimmigen Umsetzung gesehen wird. Vielmehr wird an literarische Texte die Anforderung gestellt, den Leser durch die Art, wie er gemacht ist, anzusprechen und ihn mitzunehmen.

Thomas Widmer (4:31) gibt zwar zu, dass er davon ausgeht, „dass das gewollt ist" und meint damit, dass der Text „nirgendwo eine Tiefe“ (ebd.) hat und dass er „auch plausibel gemacht“ (ebd.) ist; trotzdem kommt er zu dem Schluss, dass es „für [ihn] nicht ohne Leidenschaft [geht]" (ebd.). In einem zweiten, etwas später nachgeschobenen Statement, das ihm aber - es handelt sich um eine zweite Wortmeldung - offenbar wichtig ist, bringt er seinen Eindruck ähnlich drastisch wie Vanderbeke noch einmal auf den Punkt:

Wenn das eine Versuchsanordnung ist, womit ich völlig einverstanden bin, dann muss ich sagen, ich bin nicht gern das Meerschweinchen. (9:08 Widmer)

Robert Schindel bemüht sich um einen etwas freundlicheren Umgangston. Er formuliert im Zuge seiner Auseinandersetzung mit dem Text einige grundsätzliche Ansichten über die Funktionsweise gelungener Literatur. Mit Blick auf „Köln-Tokio“ stellt er fest:

Ich glaube, es ist sozusagen eigentlich ein mutiger Text und er ist einfach/ Es klappt/ funktioniert meiner Meinung nach so nicht. Und es kann ja auch nicht sein, dass wir dann zu einer Literatur kommen, die, weil sie strukturell richtig ist, unendlich langweilt, und zwar alle. Nee, nicht. Das ist keine Geschmacksangelegenheit. [...] Ich behaupte, eine Langeweile durch Langweile darstellen/ Da bringt der Leser sozusagen keine Leidenschaft hinein, nicht mehr hoch. Er kann sich sozusagen dafür nicht mehr interessieren. [... ] Er kommt nicht mehr, glaube ich, in eine Kommunikation mit einem Text. Wenn wir eine Literatur/ Wenn wir eine Literatur fördern oder fordern, in der nur Versuchsanordnungen eigentlich interessant sind und die Strukturen interessant sind, aber der Widerpart, die Sinnlichkeit, eben programmatisch auch in der Form ausgetrieben ist und auch nicht im Geheimnis steckt, auch nicht in den Auslassungen steckt. Das, was Sie gefordert haben, das wäre eine große Aufgabe hier sozusagen, dass die Leidenschaft in dieser Leidenschaftslosigkeit irgendwo zu erahnen ist, zu knistern beginnt und dann eine Dynamik entwickelt. Dann ist das ein großer Text. Wenn das aber fehlt, dann fehlt einfach/ dann ist das wie ein Mund ohne Unterkiefer. (18:22 und 9:15 Schindel) 
Eine Literatur ohne Sinnlichkeit, die den Leser nicht interessiert, verfehlt ihre Möglichkeiten, ist „ein Mund ohne Unterkiefer" und insofern vielleicht gar keine vollständige Literatur. Damit wird sehr deutlich, wie wichtig Schindel Sinnlichkeit ist. Ganz wie Vanderbeke sich veranlasst sieht, darauf hinzuweisen, dass „das vielleicht kein gültiges Kriterium [ist]“ (Vanderbeke 20:22), sieht sich Schindel veranlasst, darauf hinzuweisen, dass es „keine Geschmacksangelegenheit [ist]“, wenn der Leser sich langweilt. Wie Vanderbeke vertritt er den Wert der Sinnlichkeit mit großem Nachdruck und großer Eindeutigkeit. Gleichzeitig greift er das mögliche Gegenargument, Langeweile sei kein legitimes Kriterium für hohe Literatur, ${ }^{62}$ auf und zeigt damit an, dass seine Position zwar klar ist, er sich auch im Einvernehmen mit dem überwiegenden Teil der Juroren befindet, der Wert, den er einsetzt, jedoch nicht unumstritten ist. Sinnlichkeit, Interesse, Unterhaltung - wie auch immer die Aktivierung des Lesers als Kriterium benannt wird - ist zwar ein Wert, der häufig eine Rolle in der Beurteilung spielt, argumentativ allerdings keine verlässliche Bezugsgröße ist. Ausdrücklich verweist Schindel darauf, dass die Sinnlichkeit in Krupps Text auch „in der Form ausgetrieben ist und auch nicht im Geheimnis steckt".

Auch Scheck begründet seine Langeweile an der sprachlichen Gestaltung des Textes:

Die Hauptpersonen und Mathis sprechen alle monoton im gleichen anämischen Sound. Daher rührt meine Langeweile, einfach an dieser unglaublichen sprachlichen Ödheit, die sicherlich gewollt ist, die nicht mal eben so unterläuft. Aber das ist ein, für mich jedenfalls, ein Effekt, der kontraproduktiv wirklich ist. Ich entwickle nirgendwo Interesse, weil ich sprachlich hier nichts finde. (9:17 Scheck)

Scheck erkennt zwar die Intentionalität und damit die innere Stimmigkeit des Textes an, beurteilt diese aber als unzureichend, weil er kein Interesse für den Text entwickeln kann. Grund dafür ist seiner Meinung nach, dass der Text wenig sprachliche Variation hat und daher keine Lebendigkeit entwickelt.

\section{Die Notwendigkeit textnaher Begründungen}

Die Argumente der Kritiker zeichnen sich außerdem dadurch aus, dass sie geradezu beispielhaft zeigen, dass es üblich ist, jedes Argumente durch die Machart des Textes zu belegen. Immer wird der Versuch unternommen, aus der Machart des Textes heraus zu erklären, warum der Eindruck des Langweiligen und Unsinnlichen zustande kommt. Widmer (4:31) etwa stellt unmittelbar in Anschluss an sein Urteil, dass der Text ihn gelangweilt

62 Dass Langeweile kein gültiges Kriterium sei, vertritt zum Beispiel Dieter Bachmann (22:22) in der Diskussion zu Seidenauer (1999), wenn er sagt, „langweilig“ sei ein Kriterium von Reich-Ranicki und kein Kriterium für Literatur. 
habe, fest, dass er findet „dass dieser Text der Horror der reinen Parataxe [ist]“. Schindel nennt vor seinem Plädoyer für die Sinnlichkeit eine Reihe von Merkmalen des Textes, die für seine Unsinnlichkeit verantwortlich seien: Es werde „in knappen, dürren Worten [erzählt]“, es werde „genau, minutiös geschildert“, es dürfe „alles nur beschrieben werden“ (6:46 Schindel). Schindel rückt Knappheit und Genauigkeit in den Vordergrund. Diese Eigenschaften hätten an sich genauso gut positiv gewertet werden können, denn Dichte und Präzision sind tendenziell positiv gewichtete Wertmaßstäbe (vgl. Kapitel 10.3.2 und 10.3.3). Dass das nicht geschieht, ist offenbar auf die negative Lektürewirkung des Textes zurückzuführen. Denis Scheck (9:17) kritisiert außerdem die seines Erachtens schlechten Dialoge. Er empfindet die Sprache als „monoton“, den „Sound [anämisch]“ und in ihrer "Ödheit" langweilig. Diese „Ödheit" beschreibt er im Verlauf seines Beitrags genauer: „[D]ie E-Mail aus Tokio liest sich halt genauso wie der erste Satz. Da ist nichts variiert. Dann finde ich es unglaublich handwerklich schlecht“ (9:17 Scheck). Vanderbeke (11:40) kritisiert die „Parataxe“ als ermüdend und findet „diese wörtliche Rede [...] ganz, ganz furchtbar“. Die Beurteilungen sind sich äußerst ähnlich. Der konkrete sprachliche Duktus scheint nicht nur für alle genannten Juroren gleich auffällig zu sein, sondern er eignet sich offenbar für alle gleichermaßen gut, um ihr Hauptargument - Langeweile aufgrund fehlender Sinnlichkeit- zu stützen. Keinem der Juroren reicht es, die Langeweile einfach zu konstatieren oder sie auf inhaltliche Aspekte zurückzuführen. Sie alle sehen sich veranlasst, zu klären, wie diese Langeweile in der Machart des Textes verankert ist. Sprachlich-formale Argumente werden dazu bevorzugt eingesetzt.

\section{Die Kriterien der Befürworter: Offenheit und Stimmigkeit}

Der Text wird von drei Juroren verteidig: Burkard Spinnen, Constanze Fliedl und Elisabeth Bronfen, die die Autorin Krupp nach Klagenfurt eingeladen hat. Wie die kritischen Juroren in ihren Urteilen eingestehen, dass der Text stimmig und in seiner Grundidee eigentlich interessant ist, gestehen die befürwortenden Juroren zu, dass der Text durch seine formale Gestaltung Einschnitte in der Lebendigkeit machen muss. Sie weisen allerdings auch darauf hin, dass der Konflikt des Textes, dass etwas Leidenschaftliches vollkommen leidenschaftslos dargestellt wird, an und für sich eine Spannung erzeuge, die ihn interessant mache. Intentionalität und Offenheit wiegen in diesen Argumentationen mehr als Interesse, Anteilnahme und Sinnlichkeit.

Burkard Spinnen betont die Dichte des Textes, die für ihn zu einer Offenheit führt. Als Anerkennung der Offenheit ist wohl auch sein zweites Argument zu verstehen, in dem er 
lobt, dass der Text am Ende sein eigenes Formprinzip durchbreche und auf diese Weise dem Leser einen Ausblick, und damit etwas zu denken, gebe:

Der Text scheint mir auch eine Ästhetik zu vertreten des Nichts-mehr-wegnehmenkönnens. Das macht ihn teilweise auch rätselhaft, ja geradezu verschlossen. Das Zweite, was mir daran gefallen hat, ist, dass aus dieser ungemein, fast doktrinär, streng wirkenden Ästhetik heraus, er am Schluss so etwas tut wie einen Flugversuch zu unternehmen, wechselt fast, könnte man sagen, die Tonart, das Genre. (0:00 Spinnen)

Im weiteren Verlauf seiner Argumentation hebt er außerdem hervor, dass „dieser Text [ihm] über diese Struktur, über den Rhythmus, der ihr [sic] unterliegt, eine sehr bedeutsame Aussage zu machen [scheint], ohne zu psychologisieren“ (ebd.). Form und Sprache des Textes fügen also eine Bedeutungsdimension zum Text hinzu, die andernfalls nicht da wäre, sie haben einen „poetischen Mehrwert“ (2009 Bönt, 4:29 Fleischanderl; 2006 Meyer, 5:50 Rakusa „literarischer Mehrwert“).

Auch Elisabeth Bronfen (2:28) betont die Offenheit, das Rätselhafte, des Textes: „[ihr] [erschien] das Ende so kryptisch und dadurch aber so interessant". Sie fährt fort, dass das Besondere des Textes für sie in der Spannung bestehe, die zwischen wissenschaftlicher Kälte und offenem Raum der Phantasie entstehe (ebd.). Diese Spannung kann wohl als ein Phänomen der Offenheit gedeutet werden. Letztlich geht es um eine Uneindeutigkeit, die dem Leser Deutungsmöglichkeiten eröffnet. In einer späteren Äußerung, die sich an die kritischen Statements vieler Juroren anschließt, betont Bronfen nicht mehr die Offenheit, sondern die Stimmigkeit, die Intentionalität des Textes. Ihrer Meinung nach setzt der Text sein Thema - die Leidenschaftslosigkeit - durch eine leidenschaftslose Sprache adäquat um:

Und ich denke auch, also wenn man das jetzt gleichförmig oder monoton oder langweilig findet, geht das gar nicht so dem Interesse dessen, was der Text machen möchte, entgegen, sondern es geht eben gerade darum, dass diese Phantasiewelten in sich schon/ [...] Also, die Worte, die ich benutzt hatte, waren ja eben so: distanziert, kalt, entleert. (15:09 Bronfen)

In diese Richtung zielt auch Spinnen (16:27) in seinem späteren Beitrag, in dem er zu bedenken gibt, dass es „nicht die Konzeption des Textes [ist]“, alltagsrealistisch zu sein. Um Stimmigkeit geht es auch in der einzigen Äußerung Fliedls (13:40), die der Meinung ist, „dass man konzedieren muss, dass der Text die Bedingungen, mit denen er operiert, benennt" und dass das „innerhalb dieser Versuchsanordnung exekutiert [wird]“. Auch ihre Kritik am Text ist eine Kritik an seiner Stimmigkeit. Der Text zitiert an einigen Stellen Vorstellungen darüber, wie Liebe funktioniert, und zwar keine wissenschaftlichen Vorstellungen, sondern verbreitete Redewendungen wie etwa, dass die Chemie stimmen müsse, 
dass Liebe ein Hunger sei und so weiter. Fliedl liest diese Textstellen nicht als Zitate, die den medialen Charakter des Textes unterstreichen, sondern als Deutungshinweise für den Leser. Da sie den Text insgesamt als „Experiment“ mit dem „Minimalismus“ versteht, fügt sich die, wie Fliedl es nennt, „allegorische Ebene des Textes“ nicht in das Bild ein, dass sie sich von der Form des Textes gemacht hat (ebd.). Auf Stimmigkeit setzt auch Spinnen (16:27) argumentativ, wenn er den Text damit verteidigt, „dass das [die schlechten Dialoge KR] in der Konzeption dieses Textes liegt“. Hatte Schindel die Meinung vertreten, dass ein Text nur dann bestehen könne, wenn er den Leser auch berühre, egal wie gut er sonst gemacht sei, argumentiert Spinnen in diesem Beitrag zunächst, dass die Intention des Textes als Maßtstab für sein Gelingen vom Leser akzeptiert werden muss. Dennoch respektiert er den Einwand seiner Kollegen, der Text sei durch seine Leidenschaftslosigkeit langweilig. Er versucht den Vorwurf zu entkräften, indem er auf den Schluss des Textes verweist, an dem der Text „mit dem Verlassen seiner Konzeption einen Hinweis darauf macht, wozu mindestens das Material dafür hergenommen werden kann, aus dieser Enge zu entfliehen“ (16:27 Spinnen). Obwohl Spinnen also zunächst die Kritik der anderen Jurymitglieder von der Hand gewiesen hatte, weil er der Meinung war, sie widerspreche der Intention des Textes, bemüht er sich, am Text zu zeigen, dass der Vorwurf, der ihm gemacht wird, nicht uneingeschränkt auf den Text zutrifft. Durch sein Argumentationsverhalten erkennt er das Gewicht der Kritik, die geäußert wurde, an.

\subsection{Zusammenfassung}

Die Diskussion zu Ute-Christine Krupps Text illustriert zwei für die Klagenfurter Diskussionen typische Wertungsweisen: Zum einen stehen sich in dieser Diskussion zwei Parteien gegenüber, die sich so auch in vielen anderen Diskussionen wiederfinden: Während die eine Partei unmittelbar aus der Lektürewirkung heraus argumentiert, die in diesem Fall den Eindruck von Langeweile und fehlender Sinnlichkeit hinterlassen hat, bemüht sich die andere Partei, den Text nicht aus der Wirkung heraus, sondern aus ihren Erkenntnissen über die Intention des Textes zu erfassen. Diese letzte Partei bezieht sich vor allem auf das Kriterium Stimmigkeit, aber auch auf Offenheit. Die Bestätigung von Deutungshypothesen über die Länge des Textes und die verschiedenen Ebenen des Textes hinweg, hat für diese Fraktion Vorrang vor sinnlich und emotional stimulierenden Aspekten der Lektüre. Die sinnlichkeitsorientierte Partei gibt diesen Aspekten der Lektüre dagegen Vorrang. Beide Parteien, das ist besonders interessant, erkennen im Verlauf des Gesprächs die Argumente der jeweils anderen an. Beide Wertungsvarianten sind offenbar akzeptiert, welche 
von beiden im konkreten Fall präferiert wird, ist eher eine Frage des Temperaments, der Überzeugung, der Intensität der jeweiligen Lektüreerfahrung oder aber des argumentativen Kontexts.

Darüber hinaus lässt sich in der Diskussion zu Krupps Text der argumentative Stellenwert sprachlich-formaler Eigenschaften gut beobachten. Obwohl die wirkungsorientierten Wertungen nicht notwendigerweise darauf angewiesen wären, den Eindruck durch Formmerkmale intersubjektiv zugänglich zu machen, wird dies immer versucht. Das lässt darauf schließen, dass es die Beweiskraft der Argumentation stärkt, wenn ein Argument durch Texteigenschaften begründet wird. Daneben liegt aber auch die Vermutung nahe, dass die Machart des Textes als Faktor für die Lektürewirkung eine nicht unerhebliche Rolle spielt, allerdings weniger im Sinne von Kunstgriffen als vielmehr im Sinne einer erfolgreichen Strategie, den Leser mental und emotional an den Text zu binden. 


\title{
14 Kathrin Passig: „Sie befinden sich hier“ (2006)
}

\author{
Quelle: http://archiv.bachmannpreis.orf.at/bachmannpreisv2/bachmannpreis/streaming/ \\ stories/117423/index.html \\ Eingeladen von: Daniela Strigl \\ Auszeichnung: Ingeborg-Bachmann-Preis
}

\subsection{Transkript der Diskussion}

0:00 Detering: Ja, „endlich!“, möchte ich sagen. Es ist/ Und ich möchte Iris Radisch zitieren, sinngemäß jedenfalls, die vor zwei Jahren hier aus vergleichbarem Anlass gesagt hat: Ich glaube, wir haben eine sehr gute deutsche Schriftstellerin entdeckt und einen außerordentlichen, bemerkenswerten Text, von dem ich restlos überzeugt bin. Und restlos heißt, dass ich tatsächlich nicht sehe, wo dieser Text irgendwo Fehler oder Makel hätte. Er ist komisch. Das ist schon einmal etwas. Er ist totkomisch. Und er schafft die Balance zwischen Tod und Komik in einer Weise, die ich atemberaubend finde. Er hält/ Dieser Text hält auch das, womit er angefangen hat, auf eine Weise durch, von der ich während des ersten Lesens - ich habe ihn inzwischen einige Male gelesen - nicht gedacht habe, dass er das schaffen kann. Sowohl sprachlich als auch kompositorisch, in der Spannungsregie, im Rhythmus, in der Phrasierung. Es gibt ja nun eine Fülle von Analysekategorien, mit denen Juroren, und das ist ihre Aufgabe, und die sollen sie auch erfüllen, versuchen, Texte analytisch zu erklären, um sie dadurch sozusagen aufzuwerten oder ihre Vorzüge herauszuheben oder so etwas. Man könnte sehr viele dieser Begriffe, in die wir eingeübt sind, auf diesen Text anwenden. Er ist realistisch präzise. Und parabelhaft ist er bis in die letzten Dinge hinein. Er ist auf eine ganz bizarre, komische Weise Rollenprosa, die hält. Er ist perspektivisch sehr übergenau. Er ist kompositorisch in seiner Selbstreflexion noch, in seiner Reflexion über das Schreiben und über die Funktion dessen, was wir alle tun - so reden wir, so reden wir alle Tage - ein Text über Menschheitsfragen und zugleich ein Text über eine einzige Figur. Und ist gerade deshalb das Erste, weil er das Zweite so konsequent ist. „Wir kommen schon zurecht", steht darin, „auch ohne Blendwerk. Hauptsache, man bleibt in Bewegung". Ja, so sind wir irgendwie. Und so kriechen wir durch den Schnee. Und der Text muss das gar nicht sagen. Er muss gar nicht mit einer Beckett-Figur oder mit solchen, an die man denkt, wenn man will, punkten. Der Text/ Ich nenne doch einen Text, nicht um diesen aufzuwerten - das hat er überhaupt nicht nötig -, sondern um einen Vergleichsfall zu nennen. Von William Golding gibt es einen Roman, der heißt „Der Felsen des zweiten Todes“ und schildert die Erlebnisse eines Soldaten, der im Pazifikkrieg auf einem winzigen Felsen allein gestrandet ist, und gibt nur aus dessen Perspektive dessen Beobachtungen und Selbstbeobachtungen wieder. Und wir bemerken schon relativ früh, dass dieser Soldat stirbt, während er noch glaubt, dass er sich auf einer Art Besserungs- und geradezu Siegeszug befindet in den Halluzinationen seines sterbenden Hirns. Und dann kommt der Augenblick, in dem der Soldat einen Hummer an sich vorbeikriechen sieht. Und dieser Hummer ist rot. Und der Soldat weiß mit seinem sterbenden Gehirn noch, dass Hummer nur rot sind, wenn man sie gesotten hat und dass sie so niemals in der freien Natur herumkriechen. Diese Albtraumsekunde ist es, um die dieser Text sich dreht. Und der tut das mit derselben makellosen Präzision, mit der Goldings Text das tut. Ich bin restlos begeistert. [Applaus]

3:07 Nüchtern: Ja, das Humordefizit in Klagefurt ist hiermit behoben. [Heiterkeit] Der Applaus zeigt, dass das auch schon als sehr behebenswert gegolten hat. Ich kann mich dem Urteil des Kollegen Detering nur anschließen. Das ist der Kontrollverlustüberkompensationstext, der je schlimmer es wird umso souveräner wird in den Erklärungen, mit denen er sich selbst souverän zeigen will, mit denen er sich sozusagen Pfeifen im Walde oder Philosophieren im Schnee/ Ein bisschen eine Alice-im-Winterwonderland-Geschichte, wo aber sozusagen die Fläschchen, die dann kommen, um dann rechtzeitig zu groß oder zu klein zu werden/ Also, ich nehme an, das ist ein bisschen auch so eine Anspielung auf den Kaninchen und den Hasen, die ja auch beide durch „Alice in Wonderland“ hoppeln. Diese Todesphantasien oder Nahtoderzählungen/ Ich glaube, es gibt auch von Ambrose Bierce so eine Geschichte von einem Gehenkten. Ja, ich finde sehr schön diese aphoristische, schnoddrige Souveränität eines Zivilisationsapologeten, der weiß, dass man auf Berge nicht gehört. 
Mir ist das sehr nachvollziehbar, [Heiterkeit] denn so gerne ich das tue, habe ich auch schon um zwei am Nachmittag auf irgendwelchen österreichischen Waldstraßen dem Tod ins Auge zu blicken [Heiterkeit] geglaubt. Ja, lassen wir es dabei.

4:48 Ebel: Ich möchte auch nicht widersprechen. Mir ist es ganz ähnlich gegangen wie Ihnen, Herr Detering, und zwar auch, dass der Text mit mehrfacher Lektüre wächst. Das ist ja auch etwas, was nicht allen Texten so eigen ist. Die letzte Dimension, die mir beim Lesen oder beim Wiederlesen dann zugewachsen ist, ist in der Tat die Komik, was auch damit zu tun hat, dass Sie das sehr unterkühlt gelesen haben. Und genau richtig gelesen, finde ich. Die Komik fängt schon an mit dem Titel: „Sie befinden sich hier“. Also nichts ist angemessener für diesen Text als dieser Titel: „Sie befinden sich hier", wobei der Punkt, der das Hier bezeichnet eben weggelassen wird. Dieser Text ist in einer ständigen Bewegung. Aber diese Bewegung führt zu nichts. Denn am Anfang ist die Erzählerin da, wo sie am Schluss auch ist. Sie sagt: „Wenn ich mich umdrehe, kann ich noch Anne sehen" [zitiert frei KR]. Und vorher hat sie die ganze Zeit eben vorwärtsgekrabbelt, gekrabbelt. So, diese Verirrung des Textes, diese Verwirrung der Erzählerin, die wird natürlich dem Leser aufgedrückt. Der Leser muss da mit durch. Der muss mit in den Schnee. Und was ihn eigentlich bei der Stange hält, das ist die ständige Unangemessenheit des Geredes. Also, Sie haben es ja schon auf einen noch schöneren Begriff gebracht als ich. Das ist eine Wissenschaftlerin. Die ist voller Wissen, Halbwissen und vor allem Besserwissen. Und dieses Besserwissen, das müssen wir ertragen. Was ist mit Hasen, was ist mit Kaninchen? Die einen gehören dazu, die anderen gehören dazu. [Heiterkeit] Dann rastet dieses Wissen aber auch dauernd aus. Sie nimmt sich selbst immer wieder beiseite: Nein, so ist es doch nicht. Man sagt „Stein“. Nein, man sagt doch nicht „Stein“, man sagt „Hammer“. Dann kommt die Statistik. Und die Statistik/ Und dann: Nein, die Statistik nützt wieder nichts. Also die dekonstruiert ihr eigenes Wissen in einem fort. Und warum dieses ganze Gerede? Warum dieses ganze Besserwissen? Weil es eigentlich ein Verbergen ist. Dieser ganze Text will etwas verbergen. Und das Verbergen will es durch übergroßes Gerede. Was ist das Verbergen? Das ist diese Anne. Worum geht es? Irgendetwas ist mit Anne passiert. Wir wissen es nicht, wir erfahren es auch nicht. Und sie will eigentlich die Anne auch weghaben. Also nicht nur real, sondern auch aus dem Text. Sie sagt ja dann: Vielleicht war sie gar nicht da und so. Und Anne kommt aber immer wieder. So wie der Mörder immer wieder an seinen Tatort zurückkehrt, so kehrt dieser Text immer wieder zu Anne zurück. Und am Schluss ist sie da und wir können sie sehen. Und wir wissen nicht einmal, ob sie überhaupt jemals existiert hat. Also der Leser ist am Schluss genauso verwirrt wie am Anfang. Aber er hat einen tollen Text gelesen. [Heiterkeit]

7:06 März: Ja, mir hat der Text auch sehr gut gefallen. Das ist, glaube ich, nicht schwer. Da sind wir uns wahrscheinlich auch gar nicht so uneinig. Was ich ihm auch zugutehalte, ist, dass er mit einer vielleicht nicht gerade unabgenutzten symbolischen Fläche in der deutschen Literatur, nämlich dem Schnee, so umzugehen weiß, dass man nicht gleich die Augen nach oben verdreht.

7:32 Detering: Er spielt ja auch drauf an. Fräulein Smilla und der Schnee. Das Zedernfeld. Das ist ja alles da drin.

7:36 März: Genau. Und natürlich, er schafft das auch, weil es ist ja ein Text aus dem Geist des Euphemismus. Also, es fängt ja schon mit dem ersten Satz an. Da heißt es „wenn man im Winter in eine missliche Lage gerät". [Heiterkeit] Missliche Lage im Winter ist, wenn man vergessen hat, irgendwie das Licht am Haus draußen auszumachen, aber hier ist es ja im Grunde sozusagen die letzte Sekunde vor dem Ende. Ich will nicht das wiederholen, was meine Vorredner gesagt haben, gelobt haben. Ich habe eine Überlegung. Ich bin mir da sehr unsicher, ob sozusagen dieses Abstandsverhältnis zwischen dem, was wirklich los ist und dem, was er sich als Euphemist einbildet, ob das nicht sozusagen zu gradlinig durchgehalten wird. Ob sozusagen dieses Nichtdasein der Anne, diese Illusion, ob das nicht ein bisschen zu schematisch ist. Also, es ist jetzt ein Tropfen Wasser in einen wirklich ziemlich guten Wein.

8:36 Detering: Kein Tropfen Wasser in diesen Wein bitte!

8:40 März: Dazu sind wir da, Herr Detering. Ja, es ist/

8:44 Rakusa: Mir hat der Text auch sehr gut gefallen. Ich halte ihn wirklich in seiner Konsequenz für irgendwo fast makellos. Ein gefährliches Wort. Aber hier würde ich es gerne anwenden. Es wurde schon gesagt: Das Wissen wird aufbereitet. Es wird gewissermaßen auch immer wieder relativiert oder dekonstruiert. Ich habe wunderbar gefunden diese Eskimosprachen-Sache, [wenig Heiterkeit] denn da tatsächlich. Das kommt immer wieder vor, und dass man hier sagt, das ist einfach die 
Eigenheit der Sprache. Deswegen gibt es so viele Worte für Schnee. Die polysynthetischen Sprachen, auch die agglutinierenden können das. Und so ein Detail, das aber zeigt, wie gut das eingesetzt ist. Und eine solche Stelle strahlt auch aus. Also der Text oszilliert ja philosophisch, auch poetisch und so weiter, ohne dass er da so gekünstelte Anstrengungen macht, sondern es ergibt sich wirklich durch die Konzeption, durch das viele Wissen, das hier ist, durch die ganze Ausgangssituation und durch die Durchführung. Ich bin sehr angetan.

9:46 Radisch: Ja, es wurde gesagt, dass es sich um ein unangemessenes Sprechen handelt. Dem kann ich als einziges nicht zustimmen, ja. Weil das ist ja das einzig Angemessene, was in dieser Situation überhaupt zu leisten ist/ ist ja sich unangemessen zu verhalten. Und das finde ich die/ also eigentlich sehr schöne Pointe des Textes, dass in Lebensgefahr der Ironiker überlebt, ja. Also der, der das Verhältnis zur/

10:11 Nüchtern: In der Literatur. [Heiterkeit]

10:12 Radisch: Das weiß man nicht genau. Das weiß man nicht genau.

10:16 Nüchtern: Nein, Ironie [rettet?] nicht vor Sterben. Ich kann es Ihnen versprechen. [Heiterkeit] Mögen Sie ein langes Leben haben und wir alle. Aber Ironie wird uns da nicht helfen.

10:24 Radisch: Na, das müssen wir dann erst einmal sehen. Das wollen wir erst einmal sehen. [Heiterkeit] Jedenfalls hier ist es so.

10:29 Nüchtern: Wir werden es wahrscheinlich getrennt erledigen. Außer es stürzt jetzt ein Meteorit herein. Dann würde ich auch noch einen Sekt bestellen. [Heiterkeit]

10:35 Radisch: Also hier ist es jedenfalls so, dass der, der sich alles neu deutet und sich alles neu aushandelt und der eben zu nichts mehr ein stabiles Verhältnis, sondern ein/ eben ein in höchstem Grad bewegliches Verhältnis hat, dass der den angemessenen und auch überlegenen Standpunkt hat. Und das finde ich ja fast eine Lehre, die man hier aus diesem Wettbewerb mitnehmen kann, dass der Tragiker untergeht. Also der Tragiker, der das Gegebene als gegeben nimmt, wurde ja hier auch immer wieder erzählt, der das Gegebene als gegeben nimmt, und sich dann nicht mehr weiterbewegt, weil alles festliegt, der geht unter. Und der, der immer wieder alles neu, auch literarisch und sprachlich neu aushandelt, der kommt durch. Das finde ich eigentlich eine sehr schöne Lehre. Und das ist keine Frage, dass mir der Text sehr gut gefallen hat.

11:23 Spinnen: Aber er kommt durch im Gleichnis. Also die kommt nicht durch. Ich weiß nicht, ob das Lesevarianten sind, was schön ist, wenn ein Text die anbietet. Die Variante hatte sich mir eigentlich nicht angeboten. Mir hatte sich auch nicht die Varianten angeboten, dass es keine Anne gibt, wenn jemand in einer solchen Situation/ Es ist ja übrigens auch ein Genretext - Erfrieren im Eis oder dem Ausgesetztsein in der Unlandschaft. Da gibt es schon/ Das ist ein Motto, ein Topos ja auch, der auch bei Thomas Mann im „Zauberberg“ einer der Wichtigsten/ Und mir ist jedenfalls völlig klar, dass die da liegt. Außerdem: die Protagonistin hat sich nicht bewegt, seitdem sie der Anne erstens die Jacke geklaut hat, zweitens einen übergezogen hat, wobei die sich gewehrt hat und ihr noch einen Kratzer gemacht hat, weswegen da die Bluttropfen etwas parzivalmäßig in den Schnee fallen. Also, so groß sehe ich die Variationsbreite nicht. Was/ Und in Folge dessen: Auch Ironiker sterben, Frau Radisch.

12:24 Radisch: Aber schöner! [Heiterkeit]

12:26 Spinnen: Schöner! [Heiterkeit] Ganz ohne Zweifel. Und humorvoller. Aber nur für die, die zusehen oder zuhören. Mir hat an diesem Text gefallen, dass er meine große Befürchtung, dass etwas, was ich im ersten Satz weiß, und was dann, wenn es eintritt mich/ Naja, wusste ich halt schon. Ich habe schon mehrfach in den Tagen gesagt, also das ist Genre. Aber es gibt auch gutes Genre. Es gibt sehr gutes Genre. Es gibt Genrebilder, die dem, was in diesem Genre gemacht wird und möglich ist, durchaus noch etwas hinzufügen, nicht nur Virtuosität, sondern auch so etwas wie Zeitgenossenschaft. Hier wird anders erfroren. Und ich würde sagen, hier wird extrem zeitgenössisch erfroren. Chapeau davor! Und außerdem noch meinen herzlichen Dank für das von Ihnen gestaltete Portrait, das mich nach dutzenden solcher Portraits auch mit dieser Gattung wieder etwas versöhnen kann. [großer Applaus]

13:37 Nüchtern: Sollten wir vielleicht generell der Regie von Frau Passig überantworten, diese Filmchen. [kurzes Durcheinander] 
13:44 Corino: Ja, das ist ein faszinierender Text. Ein Text, bei dem ich zwischen Ärger und Verwirrung immer wieder hin und hergerissen war. Aber nicht losgelassen wurde, das gebe ich gerne zu. Wir haben einen merkwürdigen Gegensatz. Auf der einen Seite wird uns suggeriert, dass hier jemand in einer absolut lebensbedrohlichen Situation ist. Zwei Tage im Freien. Abgeschnitten von der menschlichen Zivilisation. Und auf der anderen Seite kriegen Sie dauernd den pädagogischen Zeigefinger. So ist ja der eine Satz schon: „wenn man sich im Winter in eine missliche Lage gerät“ und so weiter. Das ist ja kein Ansatz oder keine Schilderung der Situation, sondern das ist abstrakt und abgehoben. Und das geht so weit, dass selbst bei absolut lebensbedrohlicher Situation, nämlich Absterben der Hände und Füße, eigentlich sofort wieder ein Witz kommt: „[S]o steht es bei Epiktet oder Joe Simpson". Das finde ich doch zum Teil etwas makaber. Und da habe ich unter Umständen den Eindruck, da hat sich jemand nicht im Riesengebirge verirrt, sondern in einem Seminarraum, wo dann aber doch immer, Gott sei Dank, noch die richtigen Wörterbücher stehen. In dem Fall Georges Lateinisches Handwörterbuch in zwei dicken schwarzen Bänden, das ich auch zu Hause stehen habe und wo Sie dann nachschlagen können, dass „,cuniculus“ tatsächlich sowohl Kaninchen als auch Kaninchenröhre bedeutet. Also da ist die Philologie dann, glaube ich, doch ein bisschen zu weit getrieben. Aber das Geheimnis der Anne, das uns Herr Spinnen ja gerade schon weitgehend gelöst hat, das ist in der Tat ein Faszinosum. Und so stehe ich am Schluss etwas unentschieden vor diesem Text, habe aber den Eindruck, er wird seinen Weg machen. [Heiterkeit, Applaus]

15:58 Detering: Ich möchte gern Herrn Corinos Entscheidungsschwierigkeiten etwas auf den rechten Weg helfen. [Heiterkeit] Mit dem Hinweis, es ist nicht nur kein Gegensatz, dass die Sprecherin dieses Textes sich nicht im Riesengebirge, sondern im Seminarraum verirrt hat. Es ist eine/ Es hat sich jemand im Riesengebirge verirrt, der die Seminarräume sehr gut kennt. Und ich will das etwas schärfer sagen. Es/ Was mich betrifft: Ich wäre froh, wenn ich in diesem Zustand dieses Reflexionsund Assoziationsniveau halten könnte. [Heiterkeit] Was die hier macht, ist doch/ Das ist ja gerade das Unheimliche, das in der Komik Unheimliche, dass diese Figur nicht im geringsten denunziert wird. Dass wir uns nicht im Geringsten ihr überlegen fühlen können, sondern dass wir so - wir heißt unsereiner, meine ich, jemand wie ich, ich oute mich gerne - auf diese Weise reflektierend sein Leben führt, seine Schmerzpunkte zu überdecken, mit Ängsten umzugehen versucht in einer Situation, von der es hier heißt: „Schließlich scheint auch der Begriff der Orientierung eine gewisse Vorstellung von dem Punkt zu beinhalten, an dem man sich befindet" [zitiert leicht verändert KR]. Und wo man sich befindet, das heißt dann möglicherweise: Hic sunt leonis. Ich hasse es, diesen Satz zu sagen, aber ich sage Ihnen mit dieser Prämisse doch. Diese Erzählerin ist wir. Das sind wir.

17:20 Strigl: Ja, Karl Corino hat gerade den Witz des Textes so beschrieben, dass vom Witz nichts mehr übrig war. [Heiterkeit]

17:25 Nüchtern: Das ist auch nicht so leicht.

17:28 Strigl: Das ist nicht so leicht, ja. [große Heiterkeit] Man kann sich tatsächlich auch in einem Seminarraum verirren. Das erscheint mir jetzt sehr plausibel. Das ist ja klar, dass es hier ein inadäquates Sprechen ist. In jeder Hinsicht. Eine inadäquate Bewältigung der Situation. Interessant ist: Einige von uns haben gesagt „die Erzählerin“ und andere haben gesagt „der Erzähler“. Und beides ist, wenn man den Text anschaut, vollkommen legitim. Man kann sich beides vorstellen. Ich gebe aber zu: Aus geschlechtsspezifischen Vorurteilen heraus war das für mich sofort ein Erzähler. Und offensichtlich habe ich nicht gedacht „Das bin ich!“. Also, diese obergescheite Art, [Heiterkeit, Applaus] wie dieser Erzähler über diese Anne redet etwa, die so dumm ist, immer nur mit einer Panorama Prospektkarte ins Gebirge aufzubrechen. Allerdings, und da nehme ich das wieder zurück: Ich bin auch nicht eine, die hier den ersten Stein werfen darf. Auch ich habe mich schon öfter, wenn auch nicht so dramatisch, verirrt, wo ich nur zu einem kleinen Spaziergang aufbrechen wollte. Vielleicht kommt das noch zu dem Vergnügen dazu, das ich an dem Text habe, dass ich schon weiß, wie man sich da fühlt und wie da die Phantasie arbeitet. Dieser Erzähler sagt also „ich kann mir keine unnützen Gedanken leisten" und leistet sich nichts anderes als unnütze, professorale Gedanken über Gott und die Welt. Die Hälfte von diesen Sachen mag stimmen. Die kann man im Wörterbuch nachlesen. Einiges ist ganz durcheinandergekommen. Und da sagt ja der Erzähler selbst, da bin ich jetzt nicht so sicher, ob jetzt Nansen dort war oder der andere. Also, jemand, der offensichtlich nicht nur Carol gelesen hat und wahrscheinlich auch Thomas Mann, obwohl die Autorin das ja angeblich alles vergessen hat, was sie gelesen hat in der Germanistik. Aber jemand sagt dann auf eine ganz merkwürde Art und Weise/ Es ist diese/ Also, dieses Besserwissen, das geht über den Tod noch hinaus, also über den Tod, den wir jetzt alle erwarten. Der will ja auch noch den Reißverschlusshersteller nachher verklagen. Also sogar da gibt es noch ein Restbedürfnis 
an klüger sein als die anderen. Und, ja, also ich muss eigentlich sonst nicht viel dazu sagen. Ich bin auch froh über die kriminalistische Arbeit, die Burkhard Spinnen erledigt hat, denn es ist, glaube ich, für jeden Krimileser/ Die rostbraunen Flecken sind schon das erste Signal so, dass das nicht ohne Blut abgegangen ist. Und es wird dann eigentlich/ Es gibt mehrere solcher Signale. Und zum Schluss, wo der Blick zurück verweigert ist, da ist die Sache dann eigentlich relativ klar.

20:18 Spinnen: Wir hatten schon eine deutsch-österreichische Auseinandersetzung. Prima, dass der Geschlechterkonflikt auch noch dazukommen kann. [Heiterkeit] Ich denke, wenn man zwei Jacken übereinander an hat, sollten die einem auch passen. Immer einfacher für eine Frau, eine Männerjacke anzuziehen als für einen Mann eine Frauenjacke. [große Heiterkeit, Applaus] 


\subsection{Analyse der Diskussion}

\section{Ablauf der Diskussion}

Die Bachmannpreis-Trägerin des Jahres 2006, Kathrin Passig, ist dafür bekannt geworden, dass sie auf der Grundlage der Kenntnis des Wettbewerbs von 2005 einen Text für den Bachmann Wettbewerb verfasste, wie sie im Interview mit Uwe Ebbinghaus angab (FAZ.NET 26.6.2006). Tatsächlich gewann sie mit ihrem Text „Sie befinden sich hier“ den Hauptpreis. Allein das macht den Text zu einer Besonderheit. Die Diskussion dauert 21 Minuten und 7 Sekunden und ist damit etwas kürzer als eine durchschnittliche Diskussion. Heinrich Detering eröffnet die Diskussion mit einem relativ langen Beitrag von über drei Minuten Dauer, in dem er den Text in den höchsten Tönen lobt. Er fasst den Text thematisch zusammen und benennt relativ ausgedehnt seine Vorzüge. Da sich die Juroren sowohl in ihrem Urteil als auch im Verständnis des Textes einig sind, gibt Detering durch seinen ausführlichen Einstieg die Möglichkeit, sich in der Folge kollegial über den Text auszutauschen. Letztlich kommen alle wichtigen Aspekte der Beurteilung bereits in seinem Beitrag zur Sprache, sodass die anderen Juroren die Möglichkeit haben, auf dieses kommunikative Vorwissen aufzubauen (vgl. auch Kapitel 5). Der einzige Juror, der größere Bedenken gegenüber dem Text äußert, ist Karl Corino, der sich allerdings, vermutlich als Resultat der zum Zeitpunkt seines Beitrags schon umfangreichen Fürsprache für den Text, mit seiner Kritik zurückhält. Aufgrund der großen Einigkeit der Juroren wirken die Diskussionsbeiträge ungezwungener. Die Juroren zeigen Freude an einer detektivischen Auseinandersetzung mit dem Text. Insgesamt lässt sich beobachten, dass sich die Heiterkeit, die während des Textvortrags entstanden ist, auf die Diskussion, während derer sowohl in der Jury als auch im Publikum viel gelacht wird, überträgt.

\section{Der Text „Sie befinden sich hier“}

In ihrem Text spielt Passig mit einem Gegensatz zwischen der objektiven Situation, in der sich die Hauptfigur des Textes befindet, - sie hat sich bei einem Schneesturm im Gebirge verlaufen und befindet sich in einer lebensbedrohlichen Lage - und der als unangemessen empfundenen psychischen und sprachlichen Verarbeitung dieser Situation: Gedanklich ist sie darum bemüht, ihre psychische Integrität durch Rekapitulation logischer Zusammenhänge und erlernter Wissensbestände zu erhalten, während dem Leser klar vor Augen tritt, dass ihre Gedanken allein darauf gerichtet sein müssten, möglichst schnell den Weg zurück zum Auto zu finden. Dieser Gegensatz erzielt einen humoristischen Effekt; gleich- 
zeitig kreist der Text mit der Nahtoderfahrung seiner Hauptfigur um ein existenzielles Thema. Der Text hat ein offenes Ende. Es ist nicht klar, ob die Hauptfigur stirbt, halluziniert oder möglicherweise doch aus dem Schnee gerettet wird. Der folgende Auszug aus dem Text illustriert jene Punkte, die die Juroren immer wieder betonen: die Komik, das Missverhältnis von Verhalten und Reflexionsvermögen der Hauptfigur, die diese Komik hervorruft, aber auch die Offenheit in Kombination mit guter Zugänglichkeit:

\begin{abstract}
Aber ich werde natürlich nicht sterben, und es gibt hier auch gar keinen Gletscher. Nicht zu wissen, wo man sich relativ zu anderen Punkten aufhält, ist keine Todesursache. Verwirrung ist eine Todesursache. Aber ich bin, wenn schon nicht körperlich, so doch geistig orientiert, und ein kleines rotes Dreieck markiert meinen Standort: Sie befinden sich hier. (Passig 2006)
\end{abstract}

Neben diesem Missverhältnis von Situation und psychischer Verarbeitung der Hauptfigur baut der Text eine Rätselspannung auf: Den Ausflug ins Gebirge hat die Hauptfigur mit einer weiteren Figur, Anne, begonnen, die jedoch nicht mehr als handelnde Figur, sondern nur noch als Bezugspunkt der Hauptfigur eine Rolle spielt. Der Text legt verschiedene Fährten aus, was mit Anne geschehen sein könnte. Diese reichen von einer reinen Illusion, über Tod durch Erfrieren bis hin zum Mord der Hauptfigur an Anne, um sich deren Jacke zu sichern. Durch die konsequent interne Fokalisierung ist das Wissen des Lesers auf das der Hauptfigur beschränkt; lediglich die Aktivierung von Weltwissen erlaubt ihm eine Distanzierung von der Figur. Auf diese Weise wird eine starke Spannung zwischen den Wissensständen aufgebaut.

\title{
Das allumfassende Lob Deterings
}

Die Diskussion zu Kathrin Passigs Text eröffnet Heinrich Detering. Nach einem anfänglichen, sehr ausschweifenden Lob des Textes und der Autorin wendet er sich unmittelbar den Gründen für dieses Lob zu. Eine inhaltliche Auseinandersetzung mit dem Text oder eine Rekonstruktion des Plots, wie sie oft zu finden ist, überspringt Detering. Am Anfang seines Beitrags steht dabei das Lob des Unterhaltungswerts, den der Text durch seine Komik hat.

Er ist komisch. Das ist schon einmal etwas. Er ist totkomisch. Und er schafft die Balance zwischen Tod und Komik in einer Weise, die ich atemberaubend finde. (0:00 Detering)

Nicht nur, dass der Text „totkomisch“ ist, darf als eine emotionale Reaktion Deterings auf den Text verstanden werden, sondern auch, dass er ihn - ein sehr starker und emotionaler 
Wertausdruck - ,atemberaubend finde[t]“. Detering räumt seiner emotionalen Reaktion auf den Text relativ viel Raum ein, bevor er dazu übergeht, detailliert zu besprechen, wie dieser Eindruck seines Erachtens zustande kommt. An erster Stelle seiner Explikation steht das Lob der formalen Einheitlichkeit:

Dieser Text hält auch das, womit er angefangen hat, auf eine Weise durch, von der ich [...] nicht gedacht habe, dass er das schaffen kann. Sowohl sprachlich als auch kompositorisch, in der Spannungsregie, im Rhythmus, in der Phrasierung. (ebd.)

Anschließend gibt Detering zu verstehen, dass sich sehr viele mögliche Bewertungskriterien - er selbst spricht von „Analysekategorien“ (ebd.) - positiv auf den Text anwenden lassen. Von besonderem Interesse ist, welche Bewertungskriterien Detering als „Begriffe, die da eingeübt sind“ (ebd.) angibt. An erster Stelle seiner Auflistung steht die Kombination „realistisch, präzise und parabelhaft“ (ebd.). Es geht ihm offenbar zunächst um die Art des Realitätsbezugs, den der Text hat und der im Fall Passigs mehrere Zuordnungen zulässt. Er ist also in diesem Sinne offen und ermöglicht unterschiedliche Lesarten. Anschließend spricht Detering erneut den Unterhaltungswert und die Einheitlichkeit an (,auf eine ganz bizarre, komische Weise Rollenprosa, die hält“). Er findet den Text präzise („perspektivisch übergenau“). Er hebt die Selbstreflexivität des Textes hervor (,in seiner Reflexion über das Schreiben“) und schließlich den Darstellungsmodus des Showing, den der Text verwendet, und der den Text für den Leser zugänglich macht:

[E]in Text über Menschheitsfragen und zugleich ein Text über eine einzige Figur. Und ist gerade deshalb das Erste, weil er das Zweite so konsequent ist. „Wir kommen schon zurecht“, steht darin, ,auch ohne Blendwerk. Hauptsache, man bleibt in Bewegung“. Ja, so sind wir irgendwie. Und so kriechen wir durch den Schnee. Und der Text muss das gar nicht sagen. (ebd.)

Detering lobt, dass es dem Text gelinge, mittels einer einzelnen Figur etwas Allgemeingültiges darzustellen. Dass Detering noch einmal hervorhebt, dass „der Text [...] das gar nicht sagen [muss]" betont die Wichtigkeit des indirekten Darstellungsverfahrens für den Text (Showing). Dass die authentische und angemessene Auseinandersetzung mit Menschheitsfragen tatsächlich ein geteiltes Kriterium ist, zeigt sich später in der Diskussion im Beitrag Corinos. Corino hat als einziger Juror ernsthafte Vorbehalte gegenüber dem Text und distanziert sich von diesem, gerade weil er die Komik des unangemessenen Sprechens als ethisch inadäquat betrachtet, denn Sterben ist für ihn wie für Detering eine „Menschheitsfrage[]" (Detering, ebd.):

So ist ja der eine Satz schon: „wenn man sich im Winter in eine missliche Lage gerät“ und so weiter. Das ist ja kein Ansatz oder keine Schilderung der Situation, sondern das 
ist abstrakt und abgehoben. Und das geht so weit, dass selbst bei absolut lebensbedrohlicher Situation, nämlich Absterben der Hände und Füße, eigentlich sofort wieder ein Witz kommt: „[S]o steht es bei Epiktet oder Joe Simpson“. Das finde ich doch zum Teil etwas makaber. (Corino 13:44)

Das eröffnende Urteil Deterings enthält, das ist deutlich geworden, sehr viele in dieser Arbeit als typisch herausgearbeitete Bewertungskriterien: Neben den zentralen Wertmaßstäben Offenheit und formale Einheitlichkeit, nennt er beispielsweise auch Präzision und nicht zuletzt den Unterhaltungswert des Textes. Mit seinem Eröffnungsbeitrag steckt Detering viele Wertungen ab, die die spätere Diskussion prägen.

\section{Unterhaltungswert durch Empathie mit der Hauptfigur und Anteilnahme an der Handlung}

Nüchtern (3:07) schließt sich Deterings Urteil vorbehaltlos an. Durch seinen Beitrag setzt er lediglich Akzente auf jene Punkte, die ihm besonders wichtig zu sein scheinen. Das ist zum einen der Humor („das Humordefizit in Klagefurt ist hiermit behoben“ (ebd.)), zum anderen das Potenzial des Textes, Empathie zu erzeugen. Er verweist zunächst auf intertextuelle Assoziationen, die er beim Lesen hatte und erzählt abschließend anekdotenhaft, ihm sei die Handlung des Textes sehr nachvollziehbar, weil auch er sich schon einmal verlaufen habe. Sein Beitrag zeigt, was auch einige weitere Beiträge aus dieser Diskussion zeigen werden, dass ein als gelungen eingestufter Text, über dessen Qualität sich die Juroren einig sind, dazu einlädt, literarische Erfahrungen, literarisches Wissen und persönliche Alltagserfahrungen in die Diskussion einzubringen. Auch Strigl knüpft mit einer persönlichen Alltagserfahrung an den Text an:

Vielleicht kommt das noch zu dem Vergnügen dazu, dass ich an dem Text habe, dass ich schon weiß, wie man sich da fühlt und wie da die Phantasie arbeitet. Dieser Erzähler sagt also „ich kann mir keine unnützen Gedanken leisten“ und leistet sich nichts anderes als unnütze, professorale Gedanken über Gott und die Welt. (Strigl $17: 28)$

Strigl betont ausdrücklich, dass es für sie zum „Vergnügen“ beigetragen habe, dass sie sich in die Situation der Hauptfigur hineinversetzen konnte. Ein solches Eingeständnis der Lust an der Identifikation ${ }^{63}$ mit der Hauptfigur gehört nicht zum Standardrepertoire der eingesetzten Argumente. Es fügt sich aber durchaus in das Gesamtbild der Wertungen im Komplex Aktivierung ein und lässt sich auch literaturtheoretisch nachvollziehen. So \begin{tabular}{l}
\hline 3 Identifikation ist hier nicht im Sinne von Eskapismus gemeint, sondern im Sinne von sich selbst wie- \\
dererkennen.
\end{tabular} 
betrachtet Katja Mellmann (2010) beispielsweise die Empathie mit den Figuren des Textes als eine der Grundvoraussetzungen dafür, einen literarischen Text emotional positiv zu erleben. Die Gestaltung von Erzähler und Figur und die spezifische Perspektive und Stimme, mit der die Handlung präsentiert wird, tragen erheblich dazu bei, die Textwelt zugänglich und die Lektüre als Leseprozess goutierbar zu machen (vgl. Kapitel 11.3).

Das hohe identifikatorische Potential des Textes hebt auch Detering (15:58) in seinem späteren Beitrag noch einmal hervor. Der Leser befinde sich, so Detering, mit der Hauptfigur auf Augenhöhe: „[d]ass wir uns nicht im Geringsten überlegen fühlen können“. Die letzten beiden Sätze seines Beitrags lauten: „Diese Erzählerin ist wir. Die sind wir“. Damit macht er unmissverständlich klar, dass es ihm wichtig ist, die Handlung durch die Augen der Hauptfigur nachzuvollziehen und mit dem eigenen Erleben in Beziehung setzen zu können. Er lehnt damit gleichzeitig die Position des (ver-)urteilenden Lesers ab. Obwohl der Text, wie die Wertungen nahelegen, seinen komischen Effekt dadurch erzielt, dass die Juroren als Leser eine ironische Distanz zu ihm einnehmen, legen sie Wert darauf, dass der Effekt durch Nacherleben und nicht etwa durch eine ironisch kommentierende Erzählerstimme zustande kommt (vgl. auch Kapitel 11.2.2).

\section{Die Offenheit und Originalität des Textes}

Ebel (4:48), der Detering ebenfalls „nicht widersprechen [will]“, rekonstruiert, wodurch der Text seine positive Wirkung auf ihn entfalten konnte. Er hebt dabei auch „die Komik“ hervor, die ihm allerdings als „letzte Dimension“ aufgefallen sei. Neben der Komik betont er die Offenheit des Textes, die aus der begrenzten Perspektive resultiere. Zum einen bemerkt er, dass „[d]ieser Text [...] in einer ständigen Bewegung [ist], aber diese Bewegung [...] zu nichts [führt]“. Zum anderen schließt er sein Urteil mit dem Statement ab: „Also der Leser ist am Schluss genauso verwirrt wie am Anfang. Aber er hat einen tollen Text gelesen“. Die Freude an Passigs Text entsteht aus der detektivischen Arbeit, die der Leser während seiner Lektüre animiert wird zu leisten, und aus der daraus resultierenden Rätselspannung. Weil diese Spannung Unterhaltungswert hat, ist sie Selbstzweck. Eine abschließende Auflösung des Rätsels wird nicht erwartet. Nicht die Botschaft des Textes steht im Mittelpunkt des Interesses, sondern die Lektüre selber.

Auch Ursula März (7:06) schließt sich grundsätzlich an. Sie lobt zusätzlich die Originalität der Autorin im Umgang mit dem Bildfeld Schnee:

Was ich ihm auch zugutehalte, ist, dass er mit einer vielleicht nicht gerade unabgenutzten symbolischen Fläche in der deutschen Literatur, nämlich dem Schnee, so 
umzugehen weiß, dass man nicht gleich die Augen nach oben verdreht. (ebd.)

Auch sie unternimmt einen Versuch, das Spannungsverhältnis zwischen Textgeschehen und sprachlicher Bearbeitung zu analysieren und in einer Formel auf den Punkt zu bringen: „[E]s ist ja ein Text aus dem Geist des Euphemismus“. Abschließend gibt sie zu bedenken, ob dieses Muster nicht „sozusagen zu gradlinig durchgehalten wird. Ob sozusagen dieses Nichtdasein der Anne, diese Illusion, ob das nicht ein bisschen zu schematisch ist" (7:36). Der Unterhaltungswert des Textes beruht März zufolge also darauf, dass der Leser das Schema versteht, nach dem der Text seine Pointen produziert. Gleichzeitig betont sie die Gefahr, die solche Schemata bergen, nämlich, langweilig zu werden. Allerdings ist dieser Punkt eher Pseudokritik als Kritik. Ihr Urteil ist durchweg positiv und sie betont das auch zum Abschluss noch einmal („Also es ist jetzt ein Tropfen Wasser in einen wirklich ziemlich guten Wein"). Ihre Kritik muss also vielmehr als die Antizipation einer potentiellen Kritik verstanden werden. Dass März diesen Punkt trotzdem erwähnt, muss als Beweis ihrer Expertise verstanden werden. Statt eine Kritik am Text zu üben, sichert sie sich ab, indem sie zu verstehen gibt, dass sie sich bewusst ist, dass eine Kritik aufgrund zu großer Vorhersehbarkeit möglich wäre.

Um dieselben Werte wie im Beitrag März' kreist auch der Beitrag Spinnens (11:23). Auch er gibt zu verstehen, dass er in der Vorhersehbarkeit des Textes ein potentielles Problem sieht. Außerdem lobt Spinnen wie März die Originalität des Textes, allerdings nicht in Bezug auf die Bilder, sondern in Bezug auf den Umgang mit dem „Genre“:

\footnotetext{
Mir hat an diesem Text gefallen, dass er meine große Befürchtung, dass etwas, was ich im ersten Satz weiß und was dann, wenn es eintritt mich/ Naja, wusste ich halt schon. [...] Hier wird anders erfroren. Und ich würde sagen, hier wird extrem zeitgenössisch erfroren. Chapeau davor! Und außerdem noch meinen herzlichen Dank für das von Ihnen gestaltete Portrait, das mich nach dutzenden solcher Portraits auch mit dieser Gattung wieder etwas versöhnen kann. [großer Applaus] (Spinnen 12:26)
}

Spinnen äußert sich außerdem wie die anderen Juroren grundsätzlich positiv über die Spannbreite von Auslegungsmöglichkeiten, die der Text anbietet, seine Offenheit also. Er sieht diese allerdings weniger stark ausgeprägt als seine Kollegen: „Ich weiß nicht, ob das Lesevarianten sind, was schön ist, wenn ein Text die anbietet“ (11:23). Er verwendet in seinem Beitrag schließlich - auch darin zeigt sich wieder, dass es nicht mehr um eine grundsätzliche Einschätzung des Textes, sondern vielmehr um einen Austausch persönlicherer Auslegungsvarianten geht - einige kriminalistische Energie darauf, die Deutungsvarianten einzuschränken (11:23 und 20:18). 
Originalität sieht auch Radisch (10:35) in dem Text. Sie nimmt ihn sogar zum Anlass, ein

Plädoyer für die Originalität auszusprechen:

Und das finde ich ja fast eine Lehre, die man hier aus diesem Wettbewerb mitnehmen kann, dass der Tragiker untergeht. Also der Tragiker, der das Gegebene als gegeben nimmt, wurde ja hier auch immer wieder erzählt, der das Gegebene als gegeben nimmt, und sich dann nicht mehr weiterbewegt, weil alles festliegt, der geht unter. Und der, der immer wieder alles neu, auch literarisch und sprachlich neu aushandelt, der kommt durch. Das finde ich eigentlich eine sehr schöne Lehre. Und das ist keine Frage, dass mir der Text sehr gut gefallen hat. (ebd.)

Sie parallelisiert in dieser Argumentation die Handlung des Textes mit der literarischen Forderung nach dem Neuem. Anders als die anderen Juroren legt sie das Erzählte allerdings nicht als ein unangemessenes Sprechen aus, sondern als „das einzig Angemessene, was in dieser Situation überhaupt zu leisten ist".

\subsection{Zusammenfassung}

Passigs Text trifft offenbar sehr genau jene Balance von Nachvollziehbarkeit, Offenheit, emotionaler Aktivierung und Originalität, die eine literarische Lektüre für die BachmannPreis-Jury im Idealfall auszeichnet. Der Text erfordert keine grundsätzliche Auseinandersetzung mit dem Inhalt, um etwa die Handlung zu klären. Er ist auf dieser untersten Ebene des Verstehens so kohärent, dass ein Austausch über den Text möglich ist, ohne dass sich die Juroren im Vorfeld in ihrem Verständnis rückversichern müssen, um über den Text diskutieren zu können. Gleichzeitig wirkt sich die Rätselspannung, die der Text aufbaut, positiv auf die Dynamik der Diskussion aus. Sie wird dabei kaum explizit benannt, erweist sich dafür aber durch die diskussionsfördernde Rolle, die ihr zukommt, als positiver Wert. In der Diskussion gibt es einen regen Austausch über Lesevarianten, der ganz offenbar nicht als eine Auseinandersetzung über den „richtigen“ Plot oder den „richtigen“ Textsinn verstanden wird, sondern als eine gegenseitige Ergänzung. Passigs Text ermöglicht also einen leichten Einstieg und gleichzeitig einen Lektüreprozess, der mit Abschluss des Lesens nicht erschöpft ist. Die grundsätzliche Einigkeit über die Wertigkeit des Textes führt dazu, dass die Juroren keine Positionen verteidigen müssen. Die Möglichkeit eines ergänzenden Austauschs wirkt sich positiv auf die Gesamtbewertung aus.

Als zuträglich für die Bewertung, aber auch für die Diskussion, erweist sich die Konstruktion der Hauptfigur, die sowohl Empathie als auch Distanz (Komik) zulässt und auf diese Weise die emotionale Anteilname der Juroren fördert.

Der überwiegende Teil der Wertungen findet, wie in den meisten anderen Diskussionen, 
auf der formalen und sprachlichen Ebene statt.

In der Diskussion zu „Sie befinden sich hier“ spiegelt sich per excellence, in welchem Verhältnis die Werte Kohärenz und Offenheit zueinander stehen sollten, damit ein Text gut bewertet wird: ein unmittelbar nachvollziehbarer Plot mit angelegter (Rätsel-)Spannung und Offenheiten, nachvollziehbaren Konstruktionsprinzipien und einer Hauptfigur, die sowohl Empathie erlaubt als auch eine Distanz, die in diesem Fall Komik möglich macht. 


\section{Katrin de Vries: „Die Lust am Walde“ (2003)}

Quelle: http://archiv.bachmannpreis.orf.at/bp2003/audio_video/start_audio_video.htm Eingeladen von: Thomas Steinfeld

Auszeichnung: keine

\subsection{Transkript der Diskussion}

0:10 Haslinger: Nein, ich kann eigentlich nur konstatieren, dass ich ratlos bin. Absolut ratlos. Das/ Ich weiß nicht, wer spricht hier? Es ist ja ein Ton, ein alter Ton, bewusst veraltet, märchenhaft zum Teil. Dennoch, das ist kein Erzähler im Sinne eines Märchenerzählers. Das ist ein Erzähler im Sinne der Literatur. Aber er scheint sich um alle Kriterien, die literarisches Schreiben ausmacht, Prosaschreiben insbesondere, Geschichtenschreiben, nicht zu kümmern. Und doch, es gibt die Auffälligkeit/ Die größte Auffälligkeit ist vielleicht die Verweigerung aller Satzzeichen mit Ausnahme des Punkts. Das erwartet man nicht in diesem Text. Ich weiß nicht, ob es eine Bedeutung hat. Die Dialoge, die geführt werden, sind so, als wären das nicht direkte Personenreden, also Dialoge, die man sich als realistisch und so geführt ernsthaft vorstellen kann, sondern als wären das Dialoge, die gleichsam ihre Funktion, ihre dramatische Funktion überlaufen. Also zitierte Reden. Figuren, die sich selbst zitieren oder irgendetwas zitieren, aber ich weiß nicht was. Es kommen Assoziationen auf zu Geschichten, wie sie zur Zeit oder zumindest in letzter Zeit das Kino beherrscht haben: „Herr der Ringe" und „Star Wars" und Ähnliches. Also mythologische Assoziationen. Aber ich kann sie nicht wirklich zuordnen. Das ist mein ratloser Anfang.

2:04 Spinnen: Irgendeines meiner Ratlosigkeitssignale ist hier gewertet worden, als würde ich mich melden. [Heiterkeit] So kann das allen gehen. So ersteigert man dann einen van Gogh. [Heiterkeit] Ich habe gedacht, das könnte eine Übersetzung aus einer Literatur sein, deren kulturellen Hintergrund ich absolut nicht kenne. Als wenn es ein Zentralafrika gäbe, das noch nicht durch entsprechende Berichterstattung aufgearbeitet wäre. Und jemand hat das sehr ambitioniert übersetzt und hat versucht, dem einen Tonfall zu geben, der, ja, also in Anlehnung an das, was in Deutschland Märchen genannt wird, klingt. Aber trotzdem ist hinter jedem Satz ein mir unerschlossener kultureller Kontext, der herauszitiert wird. Und in der Übersetzung ist etwas verloren gegangen. Das macht einen gewissen Reiz aus. Das macht irgendwie auch wieder einen gewissen Reiz aus. Obwohl/ Nein, sag ich jetzt nicht. Und dann kommen hineingepickt in den Text Verweise auf jetzt und hier: Notrufsäulen, Fahrmobil, Auto. Und dann natürlich, also wenn ich das einigermaßen richtig verstanden habe, also die Stammzellen. Also da sind Stammzellen in den Zigarettendöschen, nicht. Jaha. [Heiterkeit] Und dann kriegt man doch ein ziemlich wüstes Assortiment von Stilen und kulturellen Versatzstücken. Ein bisschen komme ich mir mit dem Text vor wie eine Art Freitag oder ein Donnerstag, der auf einer Insel angekommen ist, wo die Literatur noch mal erfunden wird. Und nur ein paar der Überlebenden haben so ein paar Erinnerungen an das frühe einundzwanzigste Jahrhundert mitgebracht, die sie jetzt einspeisen. Aber ich muss sagen, das alles ist Tasten im Dunkeln.

4:16 Steinfeld: Ja, ich bin doch ein bisschen verblüfft, weil jetzt gerade doch so getan wird, als hätte es die ästhetische Moderne nie gegeben. Als sei die einzige Bedingung, unter der man erzählen könnte, die realistische. Und verblüfft, weil das einfach hundert Jahre Literaturgeschichte und Kunstgeschichte ausspart. Natürlich ist es möglich, eine solche Geschichte zu schreiben und natürlich gibt es eine solche Geschichte auch mit einer Tradition. Also ich könnte doch jetzt ohne Schwierigkeiten behaupten/ Diese Geschichte ist/ würde uns nicht besonders befremdlich vorkommen, sagen wir mal, wenn wir sie mit dem späten Becket assoziieren würden. Wir würden sagen das ist unglaublich clever, wie der späte Becket da/ Das war sowieso/ Der tendierte so zum Komischen und der hatte etwas Clowneskes. Es wird auch unheimlich clever und so, wie der so mit Versatzstücken aus der deutschen Romantik und gleichzeitig aus der Gegenwart spielt. Das würde uns alles einleuchten.

5:13 Miller: Ich sage es ungern: Mir nicht! Mir nicht. Ich habe auch Assoziationen. Viele. Teile ein bisschen die Ratlosigkeit. Habe dazwischen den Verdacht, dass es die Ziege am besten hat, 
[Heiterkeit] weil sie zwar vielleicht geklont wird, aber das wenigstens nicht weiß. Ich habe zwei Assoziationen nicht. Die eine wäre die zum „Herrn der Ringe“, zu „Star Wars“, zu jener ganzen, vielleicht im weitesten Sinne, Harry-Potter-Umgebung. Ich will es bei dem „Herrn der Ringe“ lassen. Das ist eine sehr ausgetüftelte, über sehr lange Zeit hinweg erfundene, vielleicht prekäre, aber in sich ungeheuer genau ausgearbeitete und in sich völlig kohärent gearbeitete Mythologie. Das ist hier nicht intendiert. Das wollen Sie auch gar nicht. Und deswegen, meine ich, ist hier die Assoziation dahin weniger auffallend als eine andere, die aber nicht zu Becket geht. Ich glaube, dass der ungeheure, in sich geschlossene, auf Aussparungen bedachte, je weiter er fortschritt immer aussparendere Becket, wenn er mythologische Anspielungen macht, und er macht sie sehr selten, dass er sie dann so in den Sog seiner Welt einzieht, dass man sie eigentlich kaum assoziativ verwenden kann. Mir scheint das an andere Richtungen anzuschließen. Auf der einen Seite an das, was einmal vor hundert Jahren das Märchen war, also jene neuromantische Erneuerung, in der Mythologie und Märchen ineinandergreifen und für Modernes verwendet werden sollen. Also von [Peleas?] über Hofmannsthal bis zu etwas schwächeren Autoren hin. Also/ Ich will nicht leugnen, dass auch bei Hofmannsthal es ein bisschen Schwierigkeiten hat. „Und an allem ist Hütchen schuld“ von Siegfried Wagner da näher finde. Es ist von dort aus ein Versuch gemacht aufgrund einer Art von Verkindlichung des Schreibens - es ist eine Zurücknahme des Schreibens - zu Aussagen zu kommen, die [...] mythologische Belange zurückkommen. Also, wenn man an den Schluss denkt, wo eben dann dieses Maria-Stein-Muster, das die jungen Frauen in der Mythologie, wenn sie unfruchtbar sind, über Totenfelsen rittlings herunterrutschen. Das alles greift schon in Mythologisches oder Magisches zurück. Aber ich kann den Sprung, von dem aus der Vater sich über den Sohn hinaus wieder genmanipuliert/ Ich habe da auch meine Schwierigkeiten. Ich muss es gestehen. Ich muss es gestehen.

8:26 Radisch: Ja, also, wo man hier ist? Also man ist im Wald. Das behauptet der Text. Und man sucht ein Geheimnis und das Geheimnis soll sich auf einer Lichtung lichten, also sehr heideggerisch. Ich habe ein bisschen das Gefühl, hier in einem literarischen Antiquitätenladen zu sein, wobei ich nicht so genau weiß, was alles im Angebot ist. Also, es wird in der Tat ganz viel/ Ja, es wird etwas imitiert, aber ich frage mich was. Das ist ein ganz künstliches Gelände, in dem ich bin. Das ist eine künstliche Sprache, eine Kunstsprache. Ja, romantische Motive. Aber ich finde vor allen Dingen sowas Altertümelndes oder Altherrenhaftes darin. Das ist ja alles künstlich hergestellt. Aber ich weiß nicht genau, in welcher Absicht. Und manchmal kommt es mir fast komisch vor. Also wenn es/ Nur mal so eine Passage, die mir so aufgestoßen ist, wo das ganz besonders krass war: „Die kleinen schlanken Hände Thedines die gepuderten Finger Gebkes und die Altmännerhände Heies bemächtigen sich der Pakete und schnell ist fast alles ausgewickelt und zehn stattliche Feldsteine liegen grau und glatt und ähnlich rechts und links und vor Heie auf dem Tisch". Das ist so eine aufgeräumte Erzählwelt so/ Ja, wie in so/ weiß ich nicht, in so einer ganz ordentlichen, geordneten altertümlichen Literatur, die die Moderne eigentlich gar nicht kennt, wo sie auch nicht einbricht. Sie bricht hier dann ein, aber wirklich nur in Form der Genomdebatte. Also als wäre irgendwie das FAZ Feuilleton in diesem Kästchen, was da plötzlich auf der Lichtung entdeckt wird. Das kommt mir alles sehr kostbar vor einerseits. Aber ich habe da meine Zweifel, wo [sic!] das Kostbare nicht auch ins Preziose kippt.

10:16 Rakusa: Ja, wir haben ja den Fernsehfilm gesehen. Und hätte ich ihn nicht gesehen, wäre ich auch trotzdem auf die Idee gekommen: Hier fehlen die Bilder, das heißt die zu ergänzenden Bilder. Das ist eine Art Bilderbuch, das nach Illustrationen fast ruft. Manchmal sind das fast wie Regieanweisungen oder Hinweise für einen Illustrator: So könnte man jetzt diese Szene bebildern und malen. Also, es ist ja manchmal wie ein Theaterstück, dann ist es ein Märchen. Dann ist es eine Parabel. Es ist eine Allegorie. Es ist aber gleichzeitig auch ein Bilderbuch ohne Illustrationen. Die muss man sich quasi dazudenken. Also es sind hier wirklich die Lakunen, die für mich dadurch entstehen, dass es eigentlich nach Bildern quasi ruft. Und dann hätten wir eine Art zeitgenössisches Märchenbuch. Da kann dann die Genmanipulation vorkommen. Für Kinder und fortgeschrittene Erwachsene.

11:10 Steinfeld: Sie vermissen nicht nur den Realismus, Sie vermissen auch die Psychologie.

11:17 Rakusa: Ich nicht, überhaupt nicht.

11:18 Steinfeld: Und ich denke, es geht völlig in Ordnung eine Geschichte ohne Realismus und ohne Psychologie zu schreiben. Und etwas, was ich bewundernswert finde an dieser Geschichte, ist, dass sie von den surrealen Bedingungen aus, von denen sie ausgeht, völlig konsequent geschrieben 
ist mit einer großen Disziplin und mit einer großen Ökonomie. Und natürlich ist es so, dass hier Assoziationen vor allem zum Theater geweckt werden. Also vor allem in der Abwesenheit von Psychologie. Das hat etwas von einem Theaterspiel. Man kann auch nicht in die Köpfe hineingucken.

11:51 Rakusa: Ich habe keine Sekunde die Psychologie vermisst. Aber es ist etwas, was quasi nicht da ist. Und ich denke, das wären wirklich Bilder. Weil manchmal ist es wie so ein Hinweis: So könnte man das jetzt quasi abstrakt oder weniger abstrakt illustrieren. Die Psychologie vermisse ich nicht. Das will ja gar kein psychologischer Text sein. Vom ersten Satz an nicht.

12:12 Steinfeld: Ganz im Gegenteil habe ich den Eindruck.

12:13 Rakusa: Ja, das will er nicht sein. Und das muss ja auch nicht.

12:17 Strigl: Also, Ich muss zugeben, dass ich auf die FAZ nicht gekommen wäre bei dieser Geschichte. Aber die Konsequenz vermag ich schon nachzuvollziehen. Es hat etwas sehr Konsequentes, allerdings auch Rätselhaftes. Da habe ich mich zum Beispiel gewundert, dass im hohen Norden droben auch von Erdäpfeln die Rede ist, so wie hierzulande. Und diese Erdäpfel, die haben wieder was mit den Steinen zu tun. Und die Steine, die liegen ja so auf diesem Grabhügel. Die sind ein Paket. Also, es ist sehr bedeutungsschwanger. Jetzt einmal ohne Werturteil. Was allerdings vielleicht beachtet werden sollte, oder was vielleicht das Problem auch dabei ist: Es sind Auszüge aus einem langen Prosatext. Also, was aus dieser Schwangerschaft nun wird, wissen wir noch nicht so recht. Nämlich ob der Text prägnant im eigentlichen Wortsinn ist, vermag ich noch nicht zu beurteilen.

13:24 März: Also, ich kapituliere ein bisschen vor dem Text. Also geht es mir noch schlechter als den Ratlosen. Und ich habe den Eindruck, das ist Prosa, die erst dann wirklich interessant ist, wenn es einen Aufsatzband dazu gibt. [Heiterkeit] [Gemurmel]

13:48 Steinfeld?: [Das ist das Schlimmste?] Das müssen Sie zurücknehmen, später mal.

13:57 Spinnen: Ratlosigkeit ist ja nun gar nichts Schlechtes, nein. Also da müsste man ja mal gucken, wieso/

14:04 März: Nein, ich meine ja damit/ Das ist ein Text, zu dem man sehr viel denken muss und denken kann aber/ in dem die literarische Luft unheimlich dünn wird. Kann ja sein, dass das wirklich an mir liegt, weil ich im Zwischenlager schlapp mache. [Heiterkeit] Aber es ist so.

14:25 Spinnen: Darf ich was zum Realismus sagen? Also so viel Realismus, Herr Steinfeld, vermisse ich darin eigentlich nicht. Und so surreal erscheint mir der Text eigentlich gar nicht. Das ist ja, wenn man jetzt mal ein bisschen flapsig, entschuldigen Sie Frau de Vries, darüber wegsprechen soll, da würde ich sagen, das ist ein Familientreffen. Das kann ich doch alles hervorragend in meine Alltagserfahrung einbauen. Es gibt so wenige Sätze wie die/ Es sind „glatt und rein“/ die Straße. „Glatt und rein teilt sie die Landschaft unserer Zeit". Das ist ein Satz, der aus dem realistischen Kontext raussticht. Viele andere Sätze fallen gar nicht daraus heraus. Nur der eingezäunte Wald mit den Wegen dadurch oder so. Gut, so genau gibt es den vielleicht nicht mit einem Pförtner oder so, aber das ist nicht das, was meinem Realismus/ meinem Alltagsrealismusempfinden begegnet/ fremd begegnet. Das ist etwas anderes. Das ist in der/ Das ist die sprachliche Aufbereitung dessen. Das ist dieser Versuch, so eine Sprache in einer Art Nullraum anzusiedeln, auf einem Nullstil, der also in keine Richtung historisch oder rhetorisch ausschlägt.

15:46 Radisch: Naja, das stimmt nicht ganz. Also das finde ich nicht/

15:47 Spinnen: Versucht, versucht, versucht/

15:48 Radisch: Weil solche Verschönerungsfiguren wie „er hebt zu sprechen an“. Ich meine, das/ 15:53 Spinnen: Ja, hm, ja, gut.

15:54 Radisch: Dieses etwas/ Also immer ein bisschen so kurz über dem Erdboden. Alles ein bisschen schöner als man es/

15:55 Spinnen: Aber da muss ich sofort gegenkontern. Wenn man diesen Nullwert versucht einzuhalten, indem man überhaupt keine rhetorische Figur macht, dann kriegt man den Polizeibericht. Und dann haben Sie wieder ein stilistische/ Das sind ja Alltagsreportagen, Gebrauchsanweisungen. Das gibt es ja als Stil schon. Und das hier geht immer ein bisschen weg davon und guckt: Wo ist hier ein leerer Fleck, in dem so/ wo so noch gesprochen wird und nicht anders. Spricht sich weg. 
16:30 Haslinger: Also ich sehe auch/ Ich sehe Realismus in diesem Text. Und ich sehe auch Psychologie in diesem Text, wenn Sie sich den Monolog des Pförtners noch einmal vergegenwärtigen. Das ist tatsächlich auch Psychologie. Was nicht da ist, ist das Spiel mit der Psychologie des Lesers. Aber das ist natürlich/ Wenn das wegfällt/ Man hat da Figuren, die mehr oder weniger allerdings verwechselbar sind. Sie werden individuell beschrieben. Ihnen wird ein individuelles Aussehen verliehen. Dennoch sind sie als Individuen nicht fassbar. Fragt man sich: Warum werden sie dann ausgestattet realistisch, ja? Warum werden sie realistisch ausgestattet zu Individualfiguren, wenn sie es dann ja nicht sein wollen? Was ist dann eigentlich das vorantreibende Prinzip dieses Textes? Und das ist so der Grund meiner Ratlosigkeit, dass ich nicht weiß, was der Motor ist. Ich habe/ Ich verweigere keineswegs die Moderne. Also das ist, glaube ich/ Das kann man hier nicht sagen, dass das hier/ jemand, den dieser Text ratlos macht, die gesamte Moderne ratlos machen müsste und mit Becket nichts anfangen könnte. Das geht nicht. Aber es geht darum, um diesen spezifischen Text. Was ist das ästhetische Organisationsprinzip dieses Textes? Und ich habe darauf keine Antwort.

17:55 Radisch: Also vielleicht ist ja doch dieses Kästchenmotiv etwas ernster zu nehmen, weil der ganze Text bewegt sich ja doch auf dieses Kästchen zu, in dem dann dieses Geheimnis, was eben erscheint, in der Weitergabe eines Genoms besteht. Und dieses Kästchenmotiv/ Vielleicht ist dieser ganze Text so eine Art Kästchen, ja. Vielleicht muss man das ja so auch lesen, dass das Geheimnis auch schon eigentlich dieser Text ist. Und der Text ist das Kästchen und ob das nun/ Ich finde, dass es ein ziemliches Schmuckkästchen ist, ja. Aber es ist ein Text, der sich/ oder ein Kästchen, was sich nach außen nicht öffnen will, weder zum Leser hin, noch zur Psychologie, noch zur Sinnlichkeit von Bildern hin. Es ist ein unsinnlicher, unanschaulicher Text und will es sein. Er will luftdicht verschlossen bleiben, ja. Er will sein Geheimnis nicht preisgeben. Das ist, glaube ich, das Äußerste, was man über ihn sagen kann.

18:42 Strigl: Vielleicht sollte man die Ironie der Geschichte nicht ganz unter den Tisch fallen lassen, dass nämlich dieser Mann den Koffer einfach viel zu spät aufmacht. Also, es ist zu spät für diese ganze Transplantation.

\section{8:56 Spinnen: Nein wieso? [Heiterkeit]}

18:59 Strigl: Nein? Vielleicht habe ich es anders verstanden.

19:01 Spinnen: Das sind Stammzellen. Wenn die sich zwei Stunden gehalten haben, dann sind die auch immer noch gut.

19:05 Strigl: Naja gut. Der Mann hätte es eigentlich/ Sein Vater, der hier auch als der Vorgänger bezeichnet wird, der hat ja eigentlich erwartet, dass sein Sohn das spätestens einen Tag nach seinem Tod öffnet. Und er hat es aber sein halbes Leben, und da sind wir wieder beim Symbolischen, mit sich herumgetragen, statt/ Und jetzt ist er alt. Also das ist vielleicht doch ironisch auch, nicht, was die Geschichte betrifft. Und bei den Symbolen, da geht es wieder um diese/ Irgendwo heißt es einmal „Das schwere Nichts“. Das schwere Nichts lastet auf diesem Text, glaube ich. Und es drückt.

19:41 Kretzen: Ja, es ist einfach noch eine Zufügung oder woran ich eigentlich die ganze Zeit gedacht habe. Es gibt so etwas - vielleicht - so etwas wie diesen Text, wie ich ihn auch ein bisschen verstanden habe. Das ist bei Klaus Hoffer „Bei den Bieresch“. Das ist ein Buch, wo er versucht, eine Ethnographie mit den Mitteln der Literatur zu entwickeln, zu schreiben. Und darin kommt genau/ Also die Entfaltung eines Volkes mit seiner Geografie, mit seiner Sprache, mit seinen völlig abstrusen Regeln. Wo es genau um diese Generationenfolge geht. Wo es um die Verweise geht. Wo man etwas findet, wie es im Wald liegt. Wo man auch Diener sein muss. In welche Familie man zurück muss. Das ist eine völlig komplizierte, sehr dichte Geschichte. Das würde ich so die ästhetische Moderne, also in dieser Tradition, sehen. Und vielleicht ist der Text ja so ein Versuch, so etwas Ähnliches zu entwerfen, also so etwas wie eine Landschaft, in der dann diese Symbole, diese Figuren, diese Geschichte, die da angelegt ist/ Und es ist ja durchaus eine Geschichte, in der so etwas versucht wird zu erzählen: Wie erzählt man? Wie gibt man etwas weiter? Wie kommt die Familie/ Also wie inszeniert man den Familienroman, ja? Also das ist ja schon/ So habe ich das gelesen. Und vielleicht ist das schwierig zu Entziffernde ja das, dass es ja vielleicht auch um so etwas wie eine, ja, so eine Art Ethnographie gehen soll. Aber das wäre jetzt so eine Idee vielleicht.

21.10 Miller: Ja, aber nur/ Der Unterschied zwischen den beiden Geschichten ist doch, dass eine solche dichte Beschreibung von Ethnographie ja einen dafür entsprechenden Stil voraussetzt. Das heißt, das muss ich ja auch entsprechend kompliziert machen und kann es nur machen, indem ich 
das fremde Bewusstsein an dem anderen messe und daraus dann etwas herstelle. Die Schwierigkeit, die hier doch drin besteht, wenn wir mal unterstellen, dass dies die Absicht ist, liegt doch darin, dass der Stil, der dafür gewählt ist, der sozusagen etwas überhobene Volksmärchenstil oder Kindermärchenstil ist. Und der Kindermärchenstil so zwischen Brüder Grimm und „Kindern aus Bullerbü“, der ist doch nun dafür sehr schwer geeignet. Das heißt, man weiß gar nicht/ Das war ja Ihr Vorschlag, zu sagen, vielleicht ist es so etwas wie „Herr der Ringe“. Nur das setzt ja einen höheren Komplikationsgrad, wie immer man das dann bewertet, aber es setzt einen höheren Komplikationsgrad voraus. Und ob man das Kästchen, ich weiß ja nicht, vielleicht ist das/ im Fortgang des Textes kann sich das ja öffnen und erweitern. Es ist nur für uns schwer fassbar. Also ich will nichts gegen den Text sagen. Der ist schwer fassbar und man könnte sagen: Vielleicht war Goethe gut damit beraten, dass er im Wilhelm Meister das Kästchen zugelassen hat. [Heiterkeit] 


\subsection{Analyse der Diskussion}

\section{Ablauf der Diskussion}

Die Diskussion zu Katrin de Vries' Text dauert 22 Minuten und 53 Sekunden. Es melden sich alle Juroren zu Wort. Länge und Verteilung der Redebeiträge entsprechen dem Durchschnitt. Die Debatte wird verhältnismäßig unemotional geführt. Nur ein Juror verteidigt den Text von de Vries: Thomas Steinfeld, der die Autorin nach Klagenfurt eingeladen hat. Zwei Jurorinnen, Friederike Kretzen und Daniela Strigl, verhalten sich dem Text gegenüber neutral. Alle anderen Jurymitglieder bringen eindeutig negative Wertungen zum Ausdruck.

Die Jury reagiert, mit Ausnahme von Thomas Steinfeld, mit Desorientierung auf die Lektüre. Der auf der Textoberfläche zunächst leicht verständliche Text verweigert sich einer globaleren Deutung. ${ }^{64}$ Zwar gelingt es leicht, eine grammatisch und auch semantisch kohärente Textwelt zu rekonstruieren, jedoch scheitern die Juroren an der Herstellung kausaler und funktionaler Zusammenhänge. In der Regel führen Schwierigkeiten in der Herstellung von Kohärenz zwar zu eindeutigen Negativwertungen, auf der Textsinn-Ebene jedoch ist die Toleranz größer, sofern der Text ein Spektrum an Zugängen erlaubt. Absolute Hermetik dagegen wird abgelehnt (vgl. Kapitel 19 „Detailsanalyse Andrea Winkler“). In vielen Fällen tritt Hermetik als eine Folge fehlender oder (bewusst) gestörter Kohärenz auf. Im Fall von de Vries, und das ist das Besondere an diesem Text und der dazugehörigen Diskussion, ist die Hermetik nicht durch eine Störung der Kohärenz bedingt. Für die Jury stellt dieses Auseinanderdriften eine besondere Herausforderung dar, weil der Text Zugänglichkeit suggeriert, die Erwartung einer unkomplizierten Deutung jedoch enttäuscht. Die Frustration, die der Text auslöst, ist daher für die Juroren umso schwerer zu begründen.

Die Diskussion teilt sich in drei Abschnitte. Nach vier negativen Bewertungen, die sich im Wesentlichen darin erschöpfen, den Text in literarische Zusammenhänge einzuordnen und zu erfassen, was genau die Abneigung gegen den Text verursacht, erhält die Diskussion durch Thomas Steinfeld einen neuen Impuls. Die darauffolgenden Beiträge reagieren auf die positiven Argumente Steinfelds. War die erste Phase der Diskussion durch explizite Bewertungen gekennzeichnet, spart die Reaktionsphase diese aus. Es kann daher von einem Bewertungskonsens ausgegangen werden (Gesprächsökonomie, vgl. Kapitel 5). In der dritten Phase unternehmen zwei Juroren, Iris Radisch und Friederike Kretzen, noch ein-

$\overline{64}$ Zum Unterschied Textkohärenz vs. Textsinn siehe Schwarz-Friesel (2006). (vgl. auch Kapitel 10.1) 
mal den Versuch, eine umfassende Deutung des Textes zu finden. Diese erneuten Versuche können als ein weiterer deutlicher Hinweis darauf verstanden werden, dass vor allem die Sinnresistenz des Textes als defizitär empfunden wird.

In der ersten und dritten Diskussionsphase sind die Beiträge der Juroren kaum aufeinander bezogen. Lediglich in der Reaktion auf Steinfeld bildet sich kurzzeitig ein gemeinsames Diskussionsthema.

\title{
Der Text „Die Lust am Walde“
}

Um einen Eindruck vom besprochenen Text zu vermitteln, soll wiederum ein kurzes Stück aus ihm zitiert werden. In der Erzählung trifft sich eine Familie, begleitet von einer Ziege, in einem Wald, wo von den Alten auf Drängen der Jungen ein lang gehütetes Geheimnis gelüftet werden soll. Am Anfang werden nacheinander die einzelnen Figuren vorgestellt:

\begin{abstract}
Unter den Kindern ist Thedine die jüngste und schönste. Und von allen wohnt sie am höchsten. In einer der oberen Waben eines Turmes. Nackt steht sie in ihrem Wohnraum vor den Einbauschränken hat die Spiegeltüren hin und her geschoben hat ihre vielen Bekleidungen durchgesehen. Ein Teil nach dem anderen wurde über die Stangen geschoben bedacht und doch hängengelassen. Jetzt ist sie wieder bei dem ganz und gar weissen hochgeschlossenen Kleid angekommen. Nun endlich nimmt sie es aus dem Schrank hält es sich noch am Bügel vom Leibe will es erst einmal auf ihr Bett legen. Aber da liegt schon etwas. Hellbraun und rund. In einer Mulde des rosa Bettüberwurfs ruhen drei große Kartoffeln und ein rostiges Kartoffelschälmesser. Dies war heute morgen gewesen. Und Thedine hat es nicht zu seinem Ende gebracht. (de Vries 2003)
\end{abstract}

Auf den ersten Blick wird hier in musterhafter Weise eine Figur eingeführt. Es wird mitgeteilt, dass sie weiblich ist, das jüngste der Kinder, dass sie schön ist und offenbar viel Wert auf Kleidung legt. Der Duktus erinnert an ein Märchen. Auch einige Elemente der Beschreibung verweisen auf das Märchen: Thedine wohnt in einem Turm. Sie findet auf ihrem Bett drei Kartoffeln. Die erkennbaren Muster von Figureneinführung und Märchen werden jedoch im selben Zuge wieder gebrochen. Thedine wohnt nicht nur in einem Turm, sondern in der Wabe eines Turmes. Turm (Assoziation: Burg, Schloss, Märchen) und Wabe (Assoziation Natur) werden kombiniert mit Einbauschränken, Kleiderbügeln und Spiegeltüren des serienmäßig gefertigten Inventars des 21. Jahrhunderts. Diese Verschränkung von Elementen, die an Natur und Märchen erinnern einerseits, und solchen, die an Technik und Verwaltung des 20./21. Jahrhunderts erinnern, andererseits, nutzt der Text immer wieder: Der Wald wird gemietet und hat einen Pförtner. Er ist mit Maschendrahtzaun eingeschlossen und ausgestattet mit Wegen und Abfalleimern. Dieser Gegensatz zwischen Erwartung und Realität wird auch von den Figuren selbst thematisiert: 
Sie bezwingen einen letzten Hügel und in der Senke sehen sie ihn. So enttäuscht sind die Frauen daß sie stehenbleiben. Sein Grün erscheint ihnen matt seine Wipfel niedrig seine Ausdehnung bescheiden. Vor allem müssen sie ihn abgegrenzt gegen sein Umland erblicken. Auf keiner Abbildung war diese schnöde Umschließung abgelichtet. Ein hoher Maschendrahtzaun zwischen wuchtige Betonpfähle gespannt hält den Wald gefangen.

Sedine: Aber Waschbären sollen dort leben.

Jeicke: Oh nein. Wie häßlich. Habt ihr es gewußt. Ein eingezäunter Wald. Die armen Kinder. Ein eingezäunter Wald kann nicht einmal mehr ihnen ein wilder Wald sein. An einem schönen Ort wollten wir uns treffen. Und nun das.

Heie: Ach ihr Damen. Wie anders ließe sich ein zu mietender Wald gestalten. (de Vries 2003)

Der gesamte Text basiert auf dieser Art von Brechungen. Der Jury gelingt zwar eine Rekonstruktion der intertextuellen Bezüge, sie empfindet aber diese Rekonstruktion als wenig aufschlussreich und daher als ungenügend. Das Ungenügen - typisch für das Kritikerverhalten - wird dem Text bzw. der Autorin angelastet.

\section{Einordnung und explizite Wertung}

Die Diskussion wird von Josef Haslinger eröffnet, der zunächst konstatiert, dass er ratlos sei, ,absolut ratlos“ (0:10 Haslinger). Er nähert sich dem Text, indem er auf die Besonderheiten des Erzählers hinweist. Argumentativ entfaltet sich die Wertung also von einer formal-ästhetischen Beobachtung aus, die als Symptom für die Erfahrung mit dem Text herausgegriffen wird. Über den Erzähler nimmt Haslinger gleichzeitig eine Einordnung in den literarischen Kontext vor und macht auf Defizite des Textes aufmerksam, die sich vorwiegend auf die Erwartungen beziehen, die er als Leser an einen Erzähler hat:

Es ist ja ein Ton, ein alter Ton, bewusst veraltet, märchenhaft zum Teil. Dennoch, das ist kein Erzähler im Sinne eines Märchenerzählers. Das ist ein Erzähler im Sinne der Literatur. Aber er scheint sich um alle Kriterien, die literarisches Schreiben ausmacht, Prosaschreiben insbesondere, Geschichtenschreiben, nicht zu kümmern. (0:10 Haslinger)

Haslinger stellt dem Märchenerzähler einen „Erzähler im Sinne der Literatur“ gegenüber. Worin der Unterschied zwischen beiden Erzählern besteht, wird nicht expliziert, jedoch lässt sich aus der darauffolgenden Aufzählung von Auffälligkeiten des Textes auf die Erwartungen an einen „Erzähler im Sinne der Literatur“ zurückschließen: Der Erzähler verweigert „alle[] Satzzeichen mit Ausnahme des Punkts“. Die Dialoge, die geführt werden, „,[kann] man sich nicht als realistisch und so geführt ernsthaft vorstellen“. Sie „[unterlaufen] ihre dramatische Funktion" (ebd). 
Haslinger sucht nach Auffälligkeiten im Stil des Erzählers. „Und doch“, so beginnt er, „es gibt eine Auffälligkeit“. Im Umkehrschluss ist der Märchenerzähler ein unauffälliger Erzähler, der Geschehnisse ohne individuelle Prägung, ohne einen eigenen „Ton“ erzählt. Man kann also festhalten: Der Erzähler der Literatur ist eine Persönlichkeit; der Erzähler des Märchens ist ein Sprecher. So gilt Haslingers Aufmerksamkeit auch zunächst der fehlenden Interpunktion, die eine Normabweichung ist und somit als Individualisierung interpretiert wird. An zweiter Stelle in Haslingers Argumentation stehen die Dialoge, die nicht dazu geeignet seien, Lebhaftigkeit und Gegenwärtigkeit zu erzeugen („dramatische Funktion“). Am Ende seines Beitrags, nachdem er nochmals sein Nichtverstehen betont hat, kehrt er wieder dazu zurück, eine weitere intertextuelle Assoziation aufzumachen („Geschichten, wie sie zur Zeit oder zumindest in letzter Zeit das Kino beherrscht haben“).

Die Argumentationsschritte lassen sich also wie folgt abstrahieren:

$\begin{array}{ll}\text { Werturteil } & \text { Ratlosigkeit („,absolut ratlos“) } \\ \text { Einordnungsversuch } & \text { Märchen } \\ \text { Gegenargumente } & \text { kein Märchenerzähler wegen Eigenwilligkeiten } \\ & \text { im Erzählstil (Interpunktion, Dialoge) } \\ \text { Urteilswiederholung } & \text { Ratlosigkeit („,aber ich weiß nicht was“) } \\ \text { Einordnungsversuch } & \text { Kino („Herr der Ringe“, „Star Wars“) } \\ \text { Urteilswiederholung } & \text { Ratlosigkeit („Das ist mein ratloser Anfang.“) }\end{array}$

Diese Argumentationsstruktur findet sich so oder ähnlich auch in anderen Beiträgen.

Burkhard Spinnen (2:04), der als Zweiter und offenbar unfreiwillig, aufgefordert wird, seinen Diskussionsbeitrag zu äußern, schlägt eine ähnliche Argumentationsrichtung ein und nutzt auch eine ähnliche Argumentationsstruktur. Er beginnt seinen Beitrag mit dem Hinweis, eines seiner „Ratlosigkeitssignale“ sei als Wortmeldung missverstanden worden. Indirekt bringt er also, in der Wortwahl („Ratlosigkeit“ anknüpfend an Haslinger) seine Wertung zum Ausdruck. Auch er unternimmt einen Einordnungsversuch, indem er schildert, er habe beim Lesen den Eindruck gehabt, er lese eine Übersetzung aus einer ihm völlig fremden Kultur: „Aber trotzdem ist hinter jedem Satz ein mir unerschlossener kultureller Kontext, der herauszitiert wird. Und in der Übersetzung ist etwas verloren gegangen“. Analog zum Märchenerzähler, der kein authentischer Märchenerzähler ist, weil er sich mit einer individuellen Stimme als Figur in die Geschichte einschreibt, ist die (fiktive) Übersetzung bei Spinnen keine gelungene Übersetzung, weil sie, so das Argument, fremde kulturelle Zusammenhänge, in den dem Leser vertrauten kulturellen Kontext „Märchen“ transplantiert und so ein doppeltes Ungenügen produziert, ein Ungenügen dem „über- 
setzten“ Material gegenüber und ein Ungenügen der Gattung Märchen gegenüber. Eine ähnliche Argumentation nutzt später auch Miller (21:10). Die sprachliche Gestaltung verhindert einen authentischen Blick auf die fremde Kultur, die dargestellt werden soll. Das Genre Märchen ist demgemäß gleichermaßen nicht erfüllt, weil das Inventar falsch ist. Das Prinzip der Brechungen, nach dem der Text gearbeitet ist, wird also durchaus erkannt, jedoch sind sich die Juroren uneinig, welches die Ausgangsmuster sind, die gebrochen werden, und vor allem, viel wichtiger, mit welcher Absicht.

Wie Haslinger integriert Spinnen (2:04) in diesen Einordnungsversuch eine Wertung: „Das macht einen gewissen Reiz aus. Das macht irgendwie auch wieder einen gewissen Reiz aus. Obwohl. Nein, das sage ich jetzt nicht" (Hervorhebungen KR). Die Wertung wirkt zunächst positiv, wird dann aber schrittweise zurückgenommen. Das eigentliche Gegenargument gegen den Reiz, den der Text auch habe, wird ausgespart. ${ }^{65}$

Auch bei Spinnen folgt auf die Zwischenbewertung ein zweiter Einordnungsversuch:

Und dann kriegt man doch ein ziemlich wüstes Assortiment von Stilen und kulturellen Versatzstücken. Ein bisschen komme ich mir mit dem Text vor wie eine Art Freitag oder ein Donnerstag, der auf einer Insel angekommen ist, wo die Literatur noch mal erfunden wird. Und nur ein paar der Überlebenden haben so ein paar Erinnerungen an das frühe einundzwanzigste Jahrhundert mitgebracht, die sie jetzt einspeisen. Aber ich muss sagen, das alles ist Tasten im Dunkeln. (2:04 Spinnen)

Die Literatur wird neu erfunden, aber kennt noch alte Versatzstücke. Das ist dasselbe Muster wie in den vorangegangen Beispielen. Es sind Stile erkennbar, aber nur in einem „wüste[n] Assortiment".

Der Schlusssatz des Beitrags fasst wiederum die Ratlosigkeit des Jurors zusammen: „Aber ich muss sagen, das alles ist Tasten im Dunkeln". Wie Haslinger versucht auch Spinnen über „Anker“, dem Text nahezukommen. Diese Anker sind zum Teil formale (Gattungszuordnung, Stile), zum Teil aber auch inhaltliche Auffälligkeiten („Stammzellen“). Das Misslingen des Textes wird allerdings primär auf der formalen Ebene der Stil-und Gattungsbrechungen festgemacht.

Im Anschluss an Spinnen, greift Steinfeld in die Diskussion ein. Läuft die Diskussion gut für den Autor, greifen die vorschlagenden Juroren tendenziell später in die Diskussion ein. In diesem Fall sieht sich Steinfeld offenbar veranlasst, früh einzugreifen, um die Diskussion in eine andere Richtung zu lenken. Er lässt sich dabei auf den bisherigen Argumentationsstrang, der im wesentlichen aus Einordnungsversuchen bestand, ein und versucht das

65 In ähnlichen Fällen wird diese Argumentationsstrategie - die negative Bewertung wird angedeutet, aber nicht ausgeführt - genutzt, um besonders harte, möglicherweise verletzende Werturteile auszusprechen, ohne sie auszuführen. 
Augenmerk von den „literaturhistorischen“ Bezugspunkten, vor allem dem Märchen, weg auf die Modernität des Textes zu lenken. Die Einordnung des Textes in literarische Kontexte des 20. Jahrhunderts, die Herausstellung seiner Modernität, sind in diesem Beitrag der exklusive Maßstab. „Die Lust am Walde“ wird in die Tradition des „späten Samuel Becket“ (4:16 Steinfeld) gestellt. Becket kann sowohl als Epochenindikator als auch als Qualitätssiegel verstanden werden.

Die Beispiele zeigen, dass dieselben Eigenschaften eines Textes, nämlich das Spiel mit literarischen Versatzstücken bzw. die Verweigerung einer eindeutigen Zuordnung zu einer Tradition von den zwei Parteien (befürwortend und ablehnend) vollkommen konträr gedeutet werden.

Da Steinfeld keine wesentlich neuen Herangehensweisen zum Verständnis des Textes in die Diskussion einbringt, nimmt sie keine Wendung. Auch Miller (5:13) führt eine Analyse verschiedener Assoziationen durch und schließt letztendlich damit, dass er „da auch seine Schwierigkeiten [hat]"“.

Iris Radisch (8:26) verpackt ihre Wertung in einem Bild: „Ich habe ein bisschen das Gefühl, hier in einem literarischen Antiquitätenladen zu sein, wobei ich nicht so genau weiß, was alles im Angebot ist". Sie knüpft damit wiederum an die Einordnungsversuche an. Das Antiquarische des Textes drückt sich, so lässt sich schließen, in Aufgeräumtheit und Geordnetheit aus: „Das ist so eine aufgeräumte Erzählwelt so/ Ja, wie in so/ weiß ich nicht, in so einer ganz ordentlichen, geordneten altertümlichen Literatur, die die Moderne eigentlich gar nicht kennt, wo sie auch nicht einbricht“ (ebd.). Der Maßstab, an dem Radisch den Text misst, ist der der Originalität als Innovation (vgl. Kapitel 12.1.1). Dass Novität ein positiv gewerteter Maßstab ist, wird vorausgesetzt. Er wird nicht begründet. Er kann also entweder als allgemein anerkannt vorausgesetzt werden, oder aber die Argumentationsstrategie zielt darauf ab, den Eindruck zu erwecken, dass eine Begründung nicht notwendig ist. Der Beitrag liefert, jenseits der Stimmführung, kaum sprachliche Hinweise darauf, ob die Bewertung positiv oder negativ gemeint ist. Es heißt an einer Stelle, dass eine Passage ihr besonders aufgestoßen sei (ebd.). Dieses Aufstoßen ist ein eindeutiger Hinweis auf ein negatives Urteil auf der Wortebene. Eindeutig ist auch der letzte Satz ihres Beitrags: „Das kommt mir alles sehr kostbar vor einerseits. Aber ich habe da meine Zweifel, wo [sic!] das Kostbare nicht auch ins Preziose [sic] kippt“ (ebd.). Dass „kostbar“ eine positive Bewertung meint, dürfte unumstritten sein. Diesem Kostbaren wird das Preziöse (bei Radisch das „Preziose“) gegenübergestellt. Auch das „Preziöse“ an sich ist ein Wort, das eine negative Bewertung transportiert. Interessant an Radischs Bewertung ist, 
dass sie ein klares Eingeständnis von Ratlosigkeit, das bei den anderen negativ wertenden Juroren vorhanden war, umgeht. Während der Hinweis auf die Ratlosigkeit letztlich auch ein Urteil über den Text beinhaltete, setzt Radischs Bewertungsstrategie im Wesentlichen auf die Selbstverständlichkeit bestimmter Maßstäbe. Nur an sehr wenigen Stellen wird die Bewertung auf der Wortebene fassbar. Radisch immunisiert sich auf diese Weise gegen den Verdacht, den Text nicht verstanden zu haben. Gleichzeitig setzt sie ihre Maßstäbe so ein, als seien sie universelle Maßstäbe, die als Wissen vorausgesetzt werden könnten. Auch diese Strategie ist typisch für viele Klagenfurter Diskussionen.

Ilma Rakusa, die ihrem Selbstverständnis nach eine Befürworterin von Sprachexperimenten ist, sodass von ihr eine Offenheit gegenüber ungewöhnlichen oder innovativen Erzählformen erwartet wird, entzieht sich vollständig einer expliziten Wertung. Mittels des zuvor gezeigten Autorenportraits, in dem darauf hingewiesen wird, dass die Autorin mit der Graphikerin Anne Feuchtenberger zusammenarbeitet, nähert sie sich dem Text. Das heißt, auch Ilma Rakusa greift auf Informationen zurück, die nicht dem Text selber entspringen:

Ja, wir haben ja den Fernsehfilm gesehen. Und hätte ich ihn nicht gesehen, wäre ich auch trotzdem auf die Idee gekommen: Hier fehlen die Bilder, das heißt die zu ergänzenden Bilder. Das ist eine Art Bilderbuch, das nach Illustrationen fast ruft. Manchmal sind das fast wie Regieanweisungen oder Hinweise für einen Illustrator: (10:16 Rakusa)

Ob nun das Fehlen der Bilder als ein Mangel des Textes begriffen wird, wird nicht deutlich. Den folgenden Vorwurf Steinfelds, ihr bzw. den Juroren fehle an dem Text neben dem Realismus auch die Psychologie (11:10 Steinfeld), weist Rakusa scharf zurück. In ihrer Rolle als Fürsprecherin einer experimentellen Literatur kann Rakusa kaum anders. Der Konnex zwischen „herkömmlicher“ Literatur und Realismus/Psychologie auf der einen Seite und Avantgarde und nicht realistisch/nicht psychologisch auf der anderen Seite kann als fester Bestandteil des geteilten Wertesystems gelten. Rakusas Beitrag geht jedoch über den Hinweis auf die zu ergänzenden Bilder nicht hinaus. Sie verweist auf keine positiven Eigenschaften des Textes. Anders verhält es sich beim Verteidiger Steinfeld, der in seinem zweiten kurzen Beitrag zu verstehen gibt, dass gerade die Konsequenz, mit der der Text auf Psychologie verzichtet, ihn beeindruckt:

Und etwas, was ich bewundernswert finde an dieser Geschichte, ist, dass sie von den surrealen Bedingungen aus, von denen sie ausgeht, völlig konsequent geschrieben ist mit einer großen Disziplin und mit einer großen Ökonomie. (11:10 Steinfeld)

An dieser Stelle der Diskussion treten formale Merkmale als Bewertungsmaßstab noch einmal in die Diskussion ein: Ein Text soll, so Steinfeld, in sich konsequent und ökonomisch 
sein. Steinfelds letzter Redebeitrag ruft eine Reihe von Reaktionen hervor und gibt damit der Diskussion doch noch einen spezifischeren Kommunikationsgegenstand, nämlich die Frage, inwieweit der Text psychologisch oder realistisch ist. Gleichzeitig ist die Gesamtbewertung des Textes an dieser Stelle bereits besiegelt. Nach dem Beitrag Steinfelds werden so gut wie keine expliziten Bewertungen mehr ausgesprochen. Es scheint nicht mehr notwendig zu sein, den Text als „gut“, „schlecht“, „beeindruckend“, „verwirrend“ und dergleichen zu kategorisieren.

Die zwei folgenden Bewertungen von Daniela Strigl und Ursula März entziehen sich einer begründenden Bewertung. Für Strigl (12:17) ist der Text zwar konsequent - sie schließt damit zwar scheinbar an Steinfeld an, führt das Argument allerdings nicht aus - und bietet ein großes Bedeutungspotential, das aber ihrer Ansicht nach aus dem vorliegenden Ausschnitt nicht deutbar und damit nicht bewertbar ist. März gesteht dem Text zwar - auf der rhetorischen Ebene - Potential zu, findet ihn aber zu schwierig und ist nicht bemüht, ihr Nichtverstehen durch Einordnungsversuche zu maskieren.

Das ist ein Text, zu dem man sehr viel denken muss und denken kann aber/ in dem die literarische Luft unheimlich dünn wird. Kann ja sein, dass das wirklich an mir liegt, weil ich im Zwischenlager schlapp mache. [Heiterkeit] Aber es ist so. (14:04 März)

Da Textgenuss an das Verstehen bzw. einen Eindruck von Verständlichkeit des Textes gebunden ist (vgl. Kapitel 10.1), geht Nichtverstehen in vielen Fällen mit einer schlechten Bewertung einher. März muss dies nicht ausformulieren. Anders als die anderen „ratlosen“ Juroren verzichtet sie darauf, ihr Nichtverstehen durch Einordnungsversuche zu maskieren. Das Potential, das sie dabei dem Text zugesteht („das ist ein Text, zu dem man sehr viel denken kann"), bleibt ein rhetorischer Kunstgriff. Die Heiterkeit des Publikums ist ein Hinweis darauf, dass die verdeckte Ironie ihrer Aussage, durchaus verstanden wird: „Und ich habe den Eindruck, das ist Prosa, die erst dann wirklich interessant ist, wenn es einen Aufsatzband dazu gibt. [Heiterkeit] [Gemurmel]“ (13:24 März).

In den knappen Aussagen von März kondensiert sich so viel unausgesprochenes Wertewissen wie in kaum einem anderen Beitrag der Diskussion. Die Reaktion des Publikums bestätigt, dass sie eine treffende, wiewohl bissige Aussage gemacht hat. Dass es für Literatur wesentlich ist, dass sie unmittelbar erfasst werden kann, scheint eine weit bekannte Position zu sein. 


\section{Realismus versus Surrealismus. Implizite Wertungen}

Der zweite Teil der Diskussion knüpft an Steinfelds (11:10) verteidigende Aussage an, dass der Text weder Realismus noch Psychologie intendiere, sondern konsequent eine surrealistische Darstellungsweise verfolge. Dabei steht der (Sur-)Realismus des Textes in diesem Abschnitt der Diskussion auf zwei Ebenen zur Debatte: der inhaltlichen und der sprachlichen. Den Beginn dieser kurzen Debatte, in der es schließlich doch zur Auseinandersetzung mit einem spezifisches Problem kommt, macht Spinnen, der den Text nicht als einen surrealen wahrnimmt:

[A]ber das ist nicht das, was meinem Realismus/ meinem Alltagsrealismusempfinden begegnet/ fremd begegnet. Das ist etwas anderes. Das ist in der/ Das ist die sprachliche Aufbereitung dessen. Das ist dieser Versuch, so eine Sprache in einer Art Nullraum anzusiedeln, auf einem Nullstil, der also in keine Richtung historisch oder rhetorisch ausschlägt. (14:25 Spinnen)

Spinnen verweist hier darauf, dass die dargestellte Welt keine für den Leser vollkommen fremde und schwer nachvollziehbare Welt ist. Seine Behauptung, der Text konstruiere einen sprachlichen „Nullraum“, verweist zurück auf das Einordnungsproblem der Jury. Sie verweist gleichzeitig zurück auf Haslingers (0:10) Beobachtung, dass der Erzähler, obwohl er den Märchenton imitiert, „sich um alle Kriterien, die literarisches Schreiben ausmacht, Prosaschreiben insbesondere, Geschichtenschreiben, nicht zu kümmern [scheint]““. Dagegen ist Radisch (15:46) der Meinung, dass das bewusst veraltete Sprechen des Erzählers, das auch Haslinger bereits betont hatte (ebd.) durchaus bekannt ist und daher kein sprachlicher Nullraum sein kann.

Auch Haslinger knüpft an die Schlagwörter Realismus und Psychologie an. Er sieht die Figuren realistisch und psychologisch ausgestattet. Was dagegen fehlt, ist, laut Haslinger (16:30) „das Spiel mit der Psychologie des Lesers“. Da die Psychologie der Figuren und die realistische Beschreibung für den Leser effektlos bleiben, kann er als Leser nicht deuten, warum sie vorgenommen werden. Haslinger fragt nach „dem ästhetischen Organisationsprinzip dieses Textes“ (ebd.). Er sieht, so kann man folgern, die Kohärenz auf der Formebene, die im Rahmen dieser Arbeit als „erweiterte Kohärenz“ beschrieben wurde (vgl. Kapitel 10.1 und 10.2), gestört. Dass er diese Störung der erweiterten Kohärenz argumentativ an das „mangelnde Spiel mit der Psychologie des Lesers“ koppelt, kann wiederum als Kopplung von Textwirkung und ihrer Ursache auf der Textebene (Desorientierung) gesehen werden. 


\section{Zusammenfassende Deutungsversuche}

Die letzten Beiträge sind durch die Absicht gekennzeichnet, dem Text doch noch mit einer abschließenden Interpretation zu begegnen. Iris Radisch (17:55) deutet den Text als Präfiguration des Leserverhaltens. Wie die Figuren in dem Text das Geheimnis um den Inhalt eines vererbten Kästchens lüften wollen, versucht der Leser, bzw. der Juror, das Geheimnis des Textes zu lüften. Wie die Figuren nur Feldsteine in dem Kästchen finden und in ihren Erwartungen getäuscht werden, ist auch die Arbeit des Lesers an dem Text letztlich eine unfruchtbare und enttäuschende. Radisch kommt dabei zu dem Urteil, dass gerade dieses Verschließen des Textes ihn für den Leser unattraktiv („unsinnlicher, unanschaulicher Text“, „will luftdicht verschlossen bleiben“) macht, und zwar auf der sinnlichen Ebene.

Damit kommt Radisch in ihrem abschließenden Urteil zu einem ähnlichen Ergebnis wie Ursula März und auch Josef Haslinger: Indem der Text dem Leser einen unmittelbaren Zugang verweigert, verwehrt er ihm auch die Freude am Lesen. Ganz deutlich wird in Radischs Beitrag auch noch einmal, dass die Juroren keine literarischen Texte wünschen, die einer Präsentation gleichkommen. Dass der Text „sich nach außen hin nicht öffnen will“, das heißt, dass er dem Leser keine Möglichkeit gibt, ihn durch emotionale Anteilnahme („Psychologie“), durch ästhetischen Genuss („Sinnlichkeit von den Bildern her“) oder durch eine intensive Denkanstrengung in ihn einzudringen und zu einem Verständnis zu kommen, wird als unbefriedigend wahrgenommen. Hier wird sehr deutlich, wie sehr nach gelungener Orientierung auch die Aktivierung des Lesers (vgl. Kapitel 11), und zwar zunächst einmal ganz unabhängig von ihrer Ausprägung, erwünscht ist.

Friederike Kretzen kommt in ihrem einzigen, ziemlich späten Beitrag noch einmal auf Spinnens Idee einer fiktiven Übersetzung aus einer völlig fremden Kultur zurück. Jedoch gibt auch sie sich unüberzeugt. Und auch Miller, der noch an ihren Kommentar anschließt, findet, dass der Märchenstil, der eine ganz klare kulturelle Verortung hat, nicht geeignet ist, eine fiktive Ethnographie zu entwerfen.

\subsection{Zusammenfassung}

Der Text von Katrin de Vries suggeriert mit seiner Anlehnung an den Stil des Märchens eine quasi kinderleichte Zugänglichkeit und Deutbarkeit, während er sich gleichzeitig durch, vor allem inhaltliche, Brechungen einer Deutung auf der Textsinnebene entzieht. Da die Juroren in ihrer Rolle als Wertende, von denen eine Begründung erwartet wird, dazu angehalten sind, ihre Unzufriedenheit zu erklären, müssen sie Lösungsvorschläge entwi- 
ckeln. Diese Lösungsvorschläge gehen in zwei Richtungen. Zum einen werden verschiedene Versuche unternommen, den Text intertextuell zu verorten. Es wird danach gefragt, in welche literarische Tradition er sich einordnen lässt und wie er sich von diesen Traditionen unterscheidet. Die konkreten Ankerpunkte, die genutzt werden, um die Einordnung des Textes zu versuchen, sind oft formale Aspekte wie der Erzähler, der sprachliche Stil und bestimmte Gattungskonventionen. Inhaltliche Aspekte müssen schon deswegen in den Hintergrund treten, weil sie ein Verstehen voraussetzen, das offenbar nicht gegeben ist. Es ist davon auszugehen, dass formal-ästhetische, negative Wertungen in dieser Diskussion überwiegen, weil sie im Gegensatz zur inhaltlichen Ebene einen intersubjektiv zugänglichen Diskussionsgegenstand bieten. Die formalen Bezugspunkte Erzähler und Stil gehören dabei in dieser wie in vielen anderen Diskussionen zu den häufigsten Bezugspunkten formal-ästhetischer Wertungen.

Auf der anderen Seite wird der unmittelbare, im weitesten Sinne sinnliche Eindruck auf den Leser bei der Lektüre herangezogen. Denkaufwand und Sinnlichkeit des Textes werden mit einbezogen, oder mit Haslingers (16:30) Worten das „Spiel mit der Psychologie des Lesers". Formale Werteigenschaften des Textes werden vorwiegend als Begründungen für andere Wertmaßstäbe genutzt: Haslinger (0:10) zieht den Erzähler heran, dessen Funktion er als nicht erfüllt begreift, nämlich einen Erzähler, der „sich um alle Kriterien, die literarisches Schreiben ausmacht, Prosaschreiben insbesondere, Geschichtenschreiben nicht zu kümmern [scheint]“. Bezogen wird dies später auf die Leserpsychologie und damit auf einen wirkungsbezogenen Maßstab. Iris Radisch (8:26) kritisiert explizit den bewusst veralteten Ton des Textes. Andere Juroren setzen den Text mit Fantasy-Filmen und anderen literarischen Produkten wie beispielsweise Übersetzungen in Beziehung. Hier werden also relationale Wertmaßstäbe eingesetzt. Ein „alter“ Ton - um nur ein Beispiel herauszugreifen - kann nur dann anerkannt werden, wenn er in einem klaren Funktionszusammenhang mit der (vermuteten) Absicht des Textes steht. Im Fall von Katrin de Vries kann diese Absicht nicht rekonstruiert werden, daher kann auch dem Stil keine Funktion zugewiesen werden. Er wird aus diesem Grund als Selbstzweck verstanden und, mittels des nicht erfüllten Kriterium der Novität, abgelehnt. Einzig Thomas Steinfeld führt in seiner Bewertung Kriterien der Gestaltung als an sich wertvoll an: Konsequenz und Ökonomie. Da er nicht den Versuch unternimmt, dies am Text vorzuführen oder dem Text eine Deutung zu geben - möglicherweise gehört die Verweigerung von Bedeutung und Sinn zu seiner Auffassung von Modernität - laufen seine auf die Form des Textes bezogenen Bewertungen ins Leere. Sie werden von den anderen Juroren in der Diskussion nicht weiter verfolgt und führen so 
zu keiner Veränderung der Stimmung.

Die Diskussion zu „Die Lust am Walde“ illustriert, wie formal-ästhetische Werteigenschaften genutzt werden können, um Defizite auf einer anderen Ebene, grob gesagt der inhaltlichen, zu begründen. Es ist davon auszugehen, dass der Hauptgrund für die Ablehnung des Textes darin liegt, dass kein globaler Textsinn rekonstruiert werden kann, obwohl der Text durchaus kohärent ist, jedenfalls nicht mehr und nicht weniger kohärent als ein Märchen. Die Einordnungsversuche der Jury, die die gesamte Diskussion durchziehen sind ein Hinweis auf diese „Textsinnsuche“. Damit ist die Diskussion auch ein Beispiel für die Annahme, dass eine positive Bewertung Verstehen voraussetzt. Im Regelfall reicht es, wenn Verstehen im Sinne von Kohärenz (Rekonstruktion der Textwelt) möglich ist. Im Idealfall lässt sich jedoch ein globaler Textsinn erkennen. Deutlich wird außerdem, dass Verständnisprobleme durch formal-ästhetische Argumentationen bewertet werden. Dies legt nahe, dass formal-ästhetische Wertungen ein höheres Prestige in der Argumentation haben bzw. dass sie sich besonders gut als Verständigungsgrundlage eignen. 


\section{Nikolai Vogel: „Plug in“ (2005)}

Quelle: http://archiv.bachmannpreis.orf.at/bachmannpreisv2/bachmannpreis/streaming/ stories/42590/index.html

Eingeladen von: vermutlich Norbert Miller

Auszeichnung: keine

\subsection{Transkript der Diskussion}

0:10 Ebel: Ja, der erste Platz ist ja traditionell ein undankbarer Platz für den Autor und vielleicht auch für uns Juroren. Deswegen freue ich mich, dass der erste Text diesmal mir ein starker, ein gehaltvoller Text zu sein scheint. Wir sind ja auch so ein bisschen Fleischfresser in der Jury. Also wir wollen dicke Brocken zu beißen haben und nicht an Knochen herumnagen und so die letzten Fetzen irgendwo an einem schwachen Text noch dann durchkauen und mit unserem eigenen Sekret aufwerten. Also hier ist ordentlich was zu beißen, finde ich. Ich beiße mir einmal einen Brocken raus. Das ist ein Text, der vordergründig ganz im Hier und Heute spielt, aber durch die Assoziation des Helden weite Räume aufreißt. Also Zeiträume vor allem. Er sieht etwas und sofort fällt ihm etwas ein, was also die ganze Evolutionsgeschichte rauf und runter geht. Das fängt an mit einem Wassertropfen, der ihm auf den Kopf fällt. Und es endet eigentlich in seinen Assoziationen bei dem Moment, wo die ersten Lebewesen vom Wasser aufs Land gekommen sind. Das gilt ja gemeinhin als Fortschritt der Evolutionsgeschichte. Für diesen Helden stellt es sich anders dar. Er sieht darin eigentlich einen Abstieg und stellt sich vor, die ganze Geschichte unserer Zivilisation sei nur ein Landausflug, den man auch rückgängig machen könnte. Also, ich habe dabei an Benn gedacht, an diese berühmten Zeilen: „Oh dass wir unsere“. Sie nicken. „Dass wir unsere Ururahnen wären“, wie heißt es genau? „Ein Klümpchen Schleim in einem warmen Moor“. Also es ist viel Regressionslust in diesem Text, aber eigentlich eine sehr angenehme, nachvollziehbare und sympathische. Am Anfang ist er ja noch so ein zivilisierter Mensch. Der möchte alles trockenlegen, was da von oben kommt. Und dann richtet er sich immer mehr ein in diesem Biotop, in diesem nassen Sessel, in diesem Urwald. Und ihm fällt dann auch immer mehr auf: Ein anderer Aspekt neben dem Wasser: Geschwindigkeit. Also dass er in einem beschleunigten Leben ist wie alle und dass es eben einige gibt, die aus dieser beschleunigten Drehung rausfallen. Also die alte Frau über ihm. Und dass für diejenigen, die in dieser Beschleunigung noch mithalten können, das eigentlich wie eine Leere wirkt. Also die Schnelligkeit wird dann immer mehr zu Leere. Wie so Wagenräder, wenn die sich drehen, Wagenräder, die sieht man dann auch als stillstehende. Ja, die Zeitebene wird dann noch weiter geführt. Ich höre jetzt gleich auf mit meinem ersten Brocken. Am Schluss scheint dem Helden doch so etwas erreicht zu sein wie ein Übereinstimmen von äußerer und innerer Zeit. Aber das ist nur im Rausch möglich, nachdem er einige Biere getankt hat. Und er bleibt zurück wie ein begossener Pudel. Aber ich mag eigentlich diesen Gossenpudel sehr.

2:56 Nüchtern: Ja, wir haben ja gestern in der Klagenfurter Rede von Iso Camartin gehört, dass sozusagen der Stil immer mehr zum Lifestyle verkommt. Ich glaube, das ist ein erster, ganz guter Gegenbeweis. Wenn ich es korrekt in Erinnerung habe, das Flaubert-Zitat, heißt es dort, Stil sei der Wille, etwas genau so zu sehen und nicht [anders?]. Und das ist einmal eine klare Perspektive, die vorgegeben wird. Es ist ja ein Text über zu viel, ein Text über zu viel Wasser, zu viel Mails, zu viel Kunden, zu viel Duschgel. Allerdings ein Text, der sich sozusagen dem nicht mimetisch anverwandelt, auch zu fließen beginnt, sondern ein sehr präziser, knapper, pointierter Text. Alles, was man sagen kann, kann man klar sagen. Und er ist ein Text von einer, finde ich, sehr hohen, wenn man so will, ästhetischen Kohäsion. Es gibt sozusagen ein Netz an Motiven, die sich alle um das Thema Wasser gruppieren, das da drüber geworfen ist. Das heißt auch der begossene Pudel weckt dann noch diese Wasserassoziationen. Es ist vielleicht, kleine Kritik, manchmal eine Spur dann schon too much, wenn dann auch der Angelpunkt und Darwinsches Wasserbuch. Da könnte dann eventuell ein bisschen Luft noch durchziehen. Auch solche Sachen wie :,,Die Welt gerät aus den Fugen" [zitiert verkürzt KR]. Das führt der Text ohnedies vor. Das brauche ich dann nicht noch einmal explizit hingeschrieben bekommen. Aber sonst finde ich das eben von der Dramaturgie 
auch sehr fein gemacht mit diesem einen Tropfen. Zuerst gibt es die warmwandige Teetasse. Auch sehr schöne kleine Schocks. Der erste kalte Tropfen auf den Kopf. Das erweitert sich dann immer größer und ist natürlich auch die Bedienung einer, sowas wie einer topografischen, literarischen Urphantasie. Das Zimmer wird die Welt. Also Mikrokosmos und Makrokosmos werden ständig ineinander geblendet. Das Mikroklima. Das Zimmer weitet sich zur Stratosphäre. Und ich denke auch, dass - Herr Ebel hat es ja schon angedeutet - dass sozusagen diese ganze Evolutionsgeschichte da mitschwingt. Ich bin mir eigentlich auch sicher, dass der Typ Fink heißt, weil Darwin mit Finken einige seiner wichtigsten Experimente durchgeführt hat. Kurz und gut, hat mir sehr gut gefallen. Und ich finde auch, dass das ein guter Auftakt war.

5:31 März: Ja, gut, ich muss jetzt ein bisschen die Suppe versalzen. Ich glaube, dass der Text ein Kardinalproblem hat. Ich erlebe das manchmal auch in meinem Privatleben. Meine Tochter hat sich angewöhnt, wenn sie mir einen Witz erzählt, unmittelbar danach ihn zu erklären, weil sie mich vielleicht für zu blöd hält. Und dann ist sie enttäuscht, dass ich nicht lache. Und dann hält sie mich für noch blöder. Und ein bisschen empfinde ich dieses Problem auch hier. Der Text basiert ja auf einem klassischen großen Modell der Komik, nämlich Disproportion. Der Mann kommt irgendwie nach Hause. Wir erfahren, wir ahnen, dass es eine Lebensbedrohung gibt, eine Krankheit, irgendetwas, setzt sich hin und hat dann sozusagen eine kleine Eskalation. Ein paar Flecken an der Decke. Er geht nach oben zu der Frau. Da gibt es die Überschwemmung. Diese Überschwemmung ist dann sozusagen der Urwald, die Vorzivilisation, also alles, was ihr schon ausgeführt habt. Ich frage mich, warum man doch, bei einer so großen komischen Modellbehauptung, relativ wenig lacht. Es ist ein bisschen witzig, aber nicht wirklich witzig anarchisch genug. Und es liegt, glaube ich, daran, dass hier der Fehler meiner Tochter wiederholt wird, dass alles gesagt wird. Anfang und Ende der Welt kommt vor. Der Schlusssatz ist der Anfang des Problems. Die Welt hat sich verändert. Das ist die Geschichte. Das will ich am Ende nun wirklich nicht hören. Und so geht es mit fast allen Motiven. Sie werden ohne Ende ausgeführt. Und das ist ein Todesstoß für Komik.

7:10 Detering: Mir geht es genau umgekehrt eigentlich. Ich habe gedacht, dass bei einem so traurig abgründigen Text so viel gelacht wird, das ist eine Leistung des Textes, denn/ Also, Martin Ebel hat ja schon den dicksten Bissen, glaube ich, an seiner/ den dicksten Fisch an seiner Angel gehabt, aber da ist ja noch etwas mehr dran. Es ist ja nicht nur, dass hier die Welt sich im Wasser auflöst oder ins Wasser zurückkehrt, aus dem sie einmal gekommen ist oder so. Es ist ja auch diese Benn'sche Vorstellung von der Rückkehr ins Urmoor als komische Geschichte und als ein mythologisch aufgefächerter Vorgang. Das will ich/ diese beiden Dinge wollte ich gerne noch einmal etwas auseinanderfieseln. Weil ich finde, der Text ist da noch komplexer, als ihr das bis jetzt gesagt habt. Er hat nicht nur diese Menschheitsurerinnerung. Er hat auch einen ganz hübsch versteckten, aber doch auffallenden Adam drin. Er hat Sindbad, den Seefahrer, und die Quellen des Nils. Er hat die Landeroberung und die Rückkehr in die Höhle. Er hat mit anderen Worten/ Und er hat Noah mit der Arche vor allem. Er hat, mit anderen Worten, eine ganze Reihe von mythologischen Figuren und Geschichten angedeutet, die nicht einfach immer nur dieselbe Grundidee illustrieren, sondern die diese Idee auffächern. Was ist das für eine Idee? Ich glaube, das ist eine Idee von einer Ambivalenz. Einerseits ist es etwas Erlösendes, zurückfallen zu können aus dieser Überanstrengung, der Hetze unserer Alltagszivilisation, zurück so ins warme Moor, ins warme Wasser sich aufzulösen. Andererseits ist genau das aber eine Quälerei. Es ist eine große Anstrengung gewesen, ans Land zu kommen. Die Landeroberung will der Held ja ständig leisten. Und diese beiden Bewegungen, die Auflösungslust und die Auflösungsangst, die gehen fortwährend ineinander über und kommen sich in die Quere. Der Alkohol wird getrunken, damit das System wieder funktioniert, damit es wieder besser geht, damit man flutscht. Und zugleich ist der Alkohol natürlich Teil dieses Bildfeldes Wasser. Und er soll ja irgendwie insgeheim ja auch nicht stabilisieren, sondern er soll destabilisieren. Er soll aufösen. Er soll schwach machen. Und dass eine so komplexe Reflexion über unser Dasein als Menschheitsgattung einerseits und in diesem computergesteuerten Alltag andererseits, dass die dann auch noch komisch ist, das ist so unwahrscheinlich wie ein Buch mit dem Titel „Lachen mit Dr. Benn". Aber das ist hier so.

9:24 März: Ganz kurz: Ich behaupte ja nicht, dass der Text nicht komplex ist. Ich sage nur, das Problem ist, dass er zu seiner Komplexität einen quasi perfekten Kommentar abliefert. Und das ist so unglaublich ordentlich inmitten dieser auseinanderfallenden, überschwemmten Welt. Das ist das Problem. Aber ich bin jetzt zurückhaltend.

9:44 Rakusa: Also, mir haben am Text eben gerade gewisse Ambivalenzen gefallen. Zum Beispiel: Er hat eine hyperbolische, übertreibende Seite. Das zeigt sich in der Duschgel-Episode. Da geht 
es in Richtung Komik, Ursula März, aber es ist trotzdem nicht ein gewollt komischer Text. Er hat auch ganz andere Seiten. Also, ich glaube nicht, dass das das Hauptproblem ist, dass hier ein Witz oder so uns falsch serviert wird. Er hat wirklich beides. Also er spricht zum Beispiel von/ Er hat die Hyperbolik, die Wiederholung. Wird gesagt „Wir sind Wiederholer“ und zwar im ganz negativen Sinn. Gleichzeitig wird gerade zum Beispiel die Wiederholung hier als Stilprinzip vorgeführt. Sehr interessant. Er ist hyperbolisch als Text, er ist stilistisch, wie schon Nüchtern sagte, ist er sehr konzis. Er ist sehr präzise gearbeitet. Er ist cool und er ist schlank. Aber er setzt zum Beispiel sehr musikalisch die Wiederholung als Stilprinzip ein. Und genau das wird eigentlich hier für mich interessant. Also sowohl die inhaltlichen Ambivalenzen als auch die stilistische Durchführung dessen. Mir sind aufgefallen diese sehr schönen Dreierperioden, die er immer wieder hat. Also das ist eine Art eben der musikalischen Gestaltung. Sehr oft sind es Dreierperioden, wo drei Ausdrücke, Substantive zum Beispiel, hintereinander gesetzt: „Der Kaffee wird kalt. Die Kaffeeleiche in der Tasse. Die Tasse ein Grab". Oder auch das mit den Stalaktiten. So wie auch dieses leitmotivische „Eine Nacht. Ein Morgen. Ein verschwommener Tag“. Also man könnte hier sehr viele im Detail solche bewussten Verfahren herausarbeiten. Ein sehr elliptischer Stil, der manchmal eben diese Substantive als Kürzel verwendet, so wie er ja auch die ganze Computerfachsprache, die auch eine reine Formelsprache ist, auch einbaut. Also Thema Kürzel, Verdichtung, elliptischer Stil. Ich finde das sehr schön durchgehalten. Und eben es kontrastiert zum Teil mit diesem hyperbolischen Ansatz, wo alles aus den Fugen gerät, wo die Wiederholung ein Leerlauf wird. Der Text selber reproduziert keinen Leerlauf. Wenn er die Wiederholung einsetzt als Stilprinzip, produziert er eben gerade keinen Leerlauf im Unterschied zu der zu Recht behaupteten Wiederholung im Leben, die uns alle zu langweiligen Wiederholern macht. Also aus diesen Reibungen, Paradoxien, Ambivalenzen wird hier wirklich etwas gemacht, etwas sehr Produktives gemacht.

12:32 Strigl: Ich habe den Text gern gelesen. Ein Text, der zeigt, dass es auch feuchte Apokalypsen gibt und der sich auch in den Dschungel der Nachbarschaft hineinwagt. Denn diese alte Frau ist ja auch eine sehr hübsch gezeichnete Gestalt. Ich bin übrigens der Meinung, dass Niklas Fink, Niklas Fink heißt, weil Nikolai Vogel Nikolai Vogel heißt. Aber [Heiterkeit] das ist ein anderer Aspekt. Ich habe allerdings auch diese Beobachtungen gemacht, die Frau März gemacht hat, und ich sehe sie auch durchaus als strukturelles Problem des Textes und nicht nur als letztliche kleine Sünden. Ich habe das Gefühl, dass es manchmal etwas angestrengt ist, etwas gesucht, dass zu viel erklärt wird und eine überdeutliche Symbolisierung stattfindet. Auch eine überdeutliche Motivkette. Also, das ist natürlich schön, wenn man sieht, ein Text ist durchdacht und ist dicht strukturiert, aber hier tropft es irgendwie an allen Ecken und Enden. Und das hat auch etwas Reizvolles, aber man fühlt sich dann immer wieder zu stark mit der Nase auf etwas gestoßen: „Wir müssen wieder. Alle müssen wir". Also wir wissen, so ist eben das moderne Leben. Aber es wird etwas zu deutlich gesagt. Auch die Welt, die aus den Fugen gerät. Dier Rückverwandlung in die Natur, also dass die Stadt, unsere Zivilisation sich in Natur verwandelt, erscheint mir auch als nicht reiner Wunschtraum hier dargestellt. Also hier ist einerseits ein Angsttraum, andererseits eins Sehnsucht, weil dann das Leben in der Höhle sich irgendwie einfacher gestaltet. Aber das mit dem Schaden/ Also, die zweite biblische Plage hier wäre diese Flut, wieder eine Flut, die Papierflut, die Werbeflut. Und diese/ wieder diese Transponierung auf die Welt an sich muss man, finde ich, nicht noch unbedingt uns unter die Nase reiben. Also Wasserschaden, Wasserweltschaden, Weltschaden. Ich glaube, man versteht es auch, wenn es einfach subtiler wäre.

14:44 Rakusa: Ich wollte nur einen Zwischenruf/ Gerade an dieser Stelle finde ich das überhaupt nicht störend. Es geht nicht nur immer um die Semantik. Das ist doch ganz bewusst. Er weiß ja auch, dass er hier etwas widerholt. Aber das hat für mich auch wieder eine stilistische Qualität. Gerade dass er hier nach/ und Wasserweltschaden. Da kommt doch sogar ein Neologismus ins Spiel. Und die berühmten Dreierperioden. Das stört mich aus dem Grunde nicht, weil ich hier einen stilistischen Willen erkenne und nicht einfach eine plumpe Wiederholung von etwas, was wir eh alle wissen. Es gibt vielleicht ein paar Sätze, die sehr ins Allgemeine stoßen, aber sie sind nicht so zahlreich, dass sie irgendwie den Text überfluten, sagen wir mal so.

15:26 Ebel: Auch ein kurzer Zwischenruf nur. Es hat auch was mit Tempo zu tun, finde ich, diese Wasserschadensreihungen. Also, das ist ja kein langsamer, philosophischer, nachdenklicher Text, sondern ein ganz, ganz schneller Text. Der Held, der leidet ja unter dem Tempo. Aber er hat genau dieses selbe Tempo auch verinnerlicht. Und deswegen/ Seine Assoziationen, die stürzen ja auch übereinander, die sind natürlich vom Autor gesetzt, aber vom Helden nicht.

15:40 Miller: Also, mir ist es mit dem Text so gegangen, und das hat mich an ihm fasziniert - das 
deckt sich mit vielem, was ihr gesagt habt - dass dort auf eine mich völlig überrachende Weise die erzählten Geschichten eine Art von nachklappender Bestätigung für sonderbar für sich laufende Sprachsachverhalte auftauchen. Das heißt, ich bekomme am Anfang/ Das heißt, die Banalität der Geschichte, die Banalität des Wassertropfens, wo man am Anfang zusammenzuckt und sagt: Jetzt macht er auch noch poetische Beschreibungen wie diese Fäden darunter fallen. Die erweisen sich, wenn man weiterliest, als sekundäre Erfindungen von diesen Momenten von Spracherfahrung der Wiederholbarkeit und des Wiederholens, in dem sich alte Schichten, neue Schichten durcheinander[finden?]. Sonst würde man auch diese eingeschobene, lange Passage, über die hier keiner noch was gesagt hat, mit dieser/ in der stereotypierten Computersprache drin haben, in der ja auch jedes einzelne Symbol gewissermaßen aus seiner eigenen Banalität heraustritt und bestimmte Bereiche aufreißt und die dann wieder stilistisch zusammenwirft. Das hat mich wahnsinnig fasziniert, auch an den Stellen, wo ich dazwischen mir gesagt habe: Also, wenn jetzt auch noch der alte Mann, der da gestorben ist und die tief zerfurchten/ und die tief zerfurchten Gesichter, wo man immer wieder dazwischen ihm auf den Leim geht und denkt: jetzt erzählt der einfach eine banale Geschichte. Die Geschichten sind komisch oder nicht komisch. Sie sind banale Ausweisungen von etwas, was auf eine grandiose Weise stilistisch gemacht ist. Das habt ihr ja erzählt.

17:51 Rakusa: Nur ein kleiner Zwischenruf an Sie, Herr Ebel, wegen des Tempos. Das ist hier eigentlich sehr wichtig. Was will der Text sein? Ist er schnell, so wie die Welt angeblich ist oder ist er/ Er ist nicht nur schnell. Er hat eben die retardierenden Elemente. Gerade diese Dreierperioden, die verlangsamen das immer. Das hat man auch beim Lesen gehört. Er hat eben eine Tempovariation drin. Das finde ich sehr schön. Eigentlich ist jemand hier, der sich vielleicht eine Verlangsamung gerade wünscht, weil alles aus den Fugen gerät durch das Tempo. Aber der Text baut das sehr schön ein. Auch die Retardierung. Und auch die unterschiedlichen Tempi.

18:26 Radisch: Ich finde, dass das ein sehr interessanter Text ist, weil alles, was für diesen Text spricht - und es ist, glaube ich, inzwischen fast jedes Detail genannt worden - spricht gleichzeitig gegen ihn. Und das, finde ich, macht diesen Text wirklich auch hier zu einem sehr interessanten Gegenstand. Der fängt natür/ Das ist ja alles wunderbar gesagt worden. Der fängt mit einer tollen Frage an: Was machen wir hier eigentlich? Wenn wir das, was wir machen, einmal durchsichtig machen auf das, wo wir herkommen, ja? Also, wenn wir das wirklich einmal ein paar hunderttausend Jahre zurückrechnen: Was ist das eigentlich, wie wir hier funktionieren? Das finde ich natürlich eine faszinierende Perspektive. Ich glaube, dass es einen/ vielleicht einen Spiegeltext gibt zu diesem Text, den man einfach einmal dagegenhalten muss probeweise. Und das ist von Bachmann „Undine geht“. Was ja auch ein Wassertext ist. Wo es ja auch darum geht, dass jemand diese Welt der Plastiktische und der Männer und der Geldwirtschaft und ich weiß nicht von was allem festen, verlässt. Die Welt verflüssigt sich und die Frau geht ins Wasser. Das ist aber ein Text, der sich in der Tat auch selber verflüssigt, ja. Wo also die Sprecherin sich sozusagen im Sprechen, im Dichten mit auflöst. Also die Welt verflüssigt sich und die Literatur verflüssigt sich. Ist ein ganz radikaler Text. Und ich glaube, was uns hier so stört, ist, dass dieser Text immer nur darüber spricht. Und das tut er - das finde ich schon auch - das tut er mit/ Sie haben von einem Bildfeld gesprochen und Dreiklängen und ich weiß nicht. Es ist ein unglaublich komplizierter Teppich von Signalwörtern, der hier ausgeworfen wird. Und da, finde ich schon, das hat einen Seminartouch. Da höre ich wirklich das Oberseminar, was die Motivketten auseinanderbastelt und/ Der Text macht das nicht. Also er kokettiert damit dann letztlich nur. Er erzählt davon, dass das eine Möglichkeit wäre, die Welt so zu beschreiben, sie so durchsichtig zu machen auf archaische Formen. Aber er geht damit nicht wirklich radikal um. Und deswegen habe ich/ Was für ihn spricht, spricht auch gegen ihn. Er hat einfach diese beiden Seiten.

20:34 Detering: Aber es ist eher, dass/ Ich glaube nicht, dass das Wort Wasser zum Beispiel oder solche Bildfelder oder Mythologien zu viel vorkommen. Das ist nicht overdone oder zu vorgeführt komplex. Es ist das Drüberreden. Das Wort „Welt" kommt zu häufig vor. Allein und in Kombination. Das ist diese Abstraktionsebene, die eigentlich schon auf Seiten des Lesers steht und nicht mehr im Text selbst. Das ist schade.

20:52 Radisch: Nein, Entschuldigung. Auch das, was Sie Bildfeld nennen, und die ganze Bildlichkeit, die ist instrumentell zur Absicht, ja. Also, das, was das Thema ist/

21:00 Detering: Das ist kein Schaden.

21:02 Radisch: Ja, das finde ich schon. Das finde ich schon, weil das hat sowas/ Das hat leider etwas von Bastelecke, also von Handwerksabteilung, wo man sich die verschiedenen Schrauben und 
Drähte und/ [Durcheinander]

21:15 Miller: Also, die Bastelecken, Iris Radisch, die Sie kennen, müssen großartige Bastelecken sein. Denn das ist doch offenbar ja doch nicht das Problem. Da hat ja Ilma nur drauf hingewiesen, dass sozusagen der stilistische Zugriff gelegentlich sozusagen zu rein formalisierenden Mitteln greift. Das ist ein Element des Textes. Das heißt, dieser Text operiert wie ein experimenteller Text an manchen Stellen und schiebt die einzelnen Elemente hinter dieser Geschichtenerzählung zusammen. Darin kann ich keinen Seminartouch erkennen.

22:00 März: Es fehlt ihm nicht an Stil. Es fehlt ihm nicht an Einfällen. Es fehlt ihm nicht am Thema. Es fehlt ihm sozusagen an Charakter, ja. Also, er ist nicht wirklich experimentell, indem er uns an einer Stelle sozusagen die Urbildmalerei zeigt aber drei Sätze später irgendwie vom Dschungel spricht. Er sagt nicht: Das mache ich, weil ich sozusagen Poesie plus Kommentar bin. Das will er nicht sein. Er will Poesie sein und ist dann doch Kommentar. Die Charakterlosigkeit ist das Problem. Das ist ein/

22:30 Miller: Ihr wollt die Pedanterie, indem ihr dem Text die Pedanterie vorwerft. Das ist doch eigentlich das Irritierende, wenn Sie erlauben, dass ich jetzt meinerseits nur einmal einen Zwischenruf mache. Das heißt, eine Geschichte, in der nicht die Geschichte das Entscheidende ist, sondern in der dieses Fortgehen, das ja auch/ Ich meine, das ist ja auch ein dazwischen lockerer Text. Das kommt ja noch dazu. In dem bewegen sich bestimmte, in jeder Wiederholung sich freisetzende Figuren. Das ist ja nicht nur dort so, wo der darauf hinweist. Sondern die Halbsätze, die er macht, laufen ja selber aus dem Ruder und werden ja nur in solchen Dreiergliederungen wieder aufgefangen. Ich glaube, das kann man nicht einfach auf die Geschichte des Helden zurückbeziehen und dann sagen: Daran fehlt es dann ein bisschen am Charakter. Das scheint mir ein bisschen jedenfalls/

23:26 Radisch: Es läuft doch gar nichts aus dem Ruder. Das läuft zwar eine ganze Menge Wasser und es tröpfelt furchtbar viel Post. Aber die Sprache läuft an keiner Stelle aus dem Ruder. Die ist genau strukturiert. Da gibt es genau die richtigen Punkte, genau die richtigen Nachsätze. [Miller widerspricht mehrfach] Die Sprache, die ist fest. Die ist an keiner Stelle/ Die hat keinen Wasserschaden, um es mal so auf den Punkt zu bringen. Von dem Wasserschaden ist immer bloß die Rede.

23:50 Rakusa: Aber das ist ja wichtig. Das gehört eben auch zu diesen Reibungen und Paradoxien. Wenn er genau das mimetisch quasi nachvollziehen würde, wäre es ja wirklich/

23:57 Radisch: Ja, aber das ist nicht mehr Bachmann. Dann müssten Sie sagen, dass Bachmann demgegenüber schwächer ist. Und das kann man ja nun [unv.].

24:02 Rakusa: Nein, nein. Das ist ein ganz anderer Text. Also mir wäre NIE die Assoziation mit Bachmann in den Sinn gekommen. Nie und nimmer. Der hat seine eigene Radikalität. Aber es ist ein vollkommen anderes Unterfangen, als was Vogel macht. Ich würde es nie und nimmer vergleichen.

24:16 Detering: Und der will sich ja auch gar nicht auflösen. Der will ja/ Der träumt ja nie davon zu verflüssigen, anders als Dr. Benn oder als Ingeborg Bachmann. Der will ja das Land unter den Füßen behalten. Der will ja konstruieren und das Leben festhalten. Ein Eingriff steht am Anfang. Der Mann hat ja auch Todesangst. Der hat Angst, sich zu verlieren.

24:33 Rakusa: Da gibt es etwas sehr Cooles und auch Rationales drin, was eben manchmal kontrastiert mit dem Auflösungscharakter. Wenn er genau das täte, ich glaube, dann wäre es ein absolut misslungener Text. Nehme ich mal an.

24:45 Spinnen: Ja, ich habe Ihnen sehr gerne zugehört. Ich kann alles unterschreiben und das jeweilige Gegenteil. Erst wollte ich den Text vor der professoralen Begeisterung in Schutz nehmen. Dann wollte ich ihn vor dem antiprofessoralen Affekt in Schutz nehmen. Ich kann ihn vor allen möglichen Dingen in Schutz nehmen, nur nicht vor einer/ vor einer Lesererfahrung. Ich habe den Satz gelesen: „,Ein kleiner Eingriff“, hatte er gesagt, ,wir bekommen Sie schon wieder hin“". Das ist ein furchtbarer Satz. Das ist ein furchtbar gelungener Satz. Das ist das Schlimmste, was man einem Menschen an Zukunftsperspektive offenbaren kann: Wir bekommen Sie schon wieder hin. Und am Ende des Textes bin ich nicht verstörter gewesen als am Anfang. Es geht ja hier mit allem, worum es geht, um diesen ersten Satz, um diese erste Verstörung. Die ganzen Wasserschäden und die ganzen mythologischen Dinge, die kriegt man ja hin, solange der Blutdruck stimmt und die Blutfettwerte und so weiter. Dann geht die ganze Welt ja prima ab. Ich habe schon hunderte und 
tausende Texte gelesen, in denen die Leute plötzlich einen Schalter umgelegt bekommen und sagen: Oh, scheiße, Existenz. Uh, das ist ja Leben. Kann ja morgen zu Ende sein. Ach du dicke Kacke. Was machen wir jetzt? Wie sieht das überhaupt hier aus? Wie fühlt sich das an? Ist das nass oder trocken? Oh scheiße. Und was macht dieser Text dann? Auf eine hochartifizielle, hochreflektierte Art und Weise arbeitet der an einer Beruhigung des Zustandes, der Überhöhung des Zustandes. Ich bin dem gerne gefolgt. Das ist eine interessante und intelligente Aufgabe. Aber das Existenzielle der ersten Bedrohung ist mir entraten während der Lektüre. Deswegen bin ich hilflos, rettungslos, hoffnungslos und muss mit diesem Bauchurteil schließen.

26:35 Ebel: Ja, das grenzt ja fast an Majestätsbeleidigung nach Herrn Spinnen noch etwas zu sagen, aber [Heiterkeit] ich hätte es sonst vorher gesagt. Ich habe manchmal den Eindruck, wir treten uns selbst ins Knie, um es nicht schlimmer zu sagen. Oder den Text, den wir/ Dieser Text will was. Und das macht er und das gelingt ihm. Und ich finde, das gelingt ihm gut. Und jetzt kommen wir und sagen. Erstens: Wir sind nicht amüsiert, weil es ihm gelingt. Zweitens: weil wir es merken. Drittens: weil wir eigentlich von dem Text was anderes wollen [Nüchtern im Hintergrund unv.] Genau. Und außerdem: Ist der Text jetzt wirklich durcherklärt? Ich weiß es nicht. Also, ich bin nicht so sicher, was es mit diesem kleinen Eingriff ist.

27:13 Spinnen: Denken Sie an die Laokoon-Gruppe. Das ist eines der größten Bildnisse. Wenn man Existenz darstellt, dann zeigt man drei Männer, die mit Schlangen ringen. Es sieht eigentlich schrecklich aus und ist eine peinliche Angelegenheit für den Betrachter. Ist ganz große Kunst. Sind wir jetzt eben mal eine Laokoon-Gruppe.

27:31 Ebel: Das verstehe ich zwar nicht ganz, aber es ist bestimmt ein schöner Schluss. [Heiterkeit]

[März unv.]

27:39 Detering: Ich meine, wir haben einen/

27:41 Nüchtern: Herr Detering, Herr Spinnen wollte die Diskussion beenden. Haben Sie das nicht gemerkt?

27:44 Detering: Ja, ich wollte das eigentlich nicht mit der Laokoon-Gruppe beenden lassen. Ich finde schon, wir haben einen intelligent gemachten Text, einen gut erzählten Text, einen stilistisch raffiniert ausbalancierten, vielleicht zu raffiniert ausbalancierten Text, der Existenzielles berührt oder sogar sehr stark berührt. Und es ist doch relativ viel gelacht worden während der Lesung. Das ist ein ziemlich guter Anfang eigentlich. 


\subsection{Analyse der Diskussion}

\section{Ablauf der Diskussion}

Die Diskussion zu Nikolai Vogels Text „Plug in“ ist auf der Wertungsebene in verschiedener Hinsicht eine Durchschnittsdiskussion. Da der Text mit einigen Vorbehalten positiv bewertet wird, kreisen die Beiträge im Wesentlichen um die Grade an Stimmigkeit und Offenheit und die Frage danach, wie gut diese beiden Werte ausbalanciert sind. Mit 28 Minuten und 23 Sekunden ist die Diskussion etwas länger als der Durschnitt (ca. 23 Minuten). Der Autor wurde vermutlich von Norbert Miller eingeladen. ${ }^{66}$ Alle Juroren beteiligen sich an der Diskussion, die vergleichsweise sachlich - freilich immer noch mit Einsatz von viel Rhetorik - geführt wird. Insgesamt wird der Text positiv bewertet, jedoch nicht vorbehaltlos positiv und auch nicht euphorisch. Er reiht sich damit in die große Menge mittelmäßig bewerteter Texte ein.

Nikolai Vogels Lesung eröffnet den Ingeborg-Bachmann-Wettbewerb 2005. Sein Text ist daher noch nicht in einen konkreten, durch den Wettbewerb 2005 hergestellten kommunikativen Wertungskontext eingebettet und kann auch noch nicht ins Verhältnis zu den anderen Texten gesetzt werden. Wie ein Text eingestuft wird, hängt beim BachmannWettbewerb partiell von der Konkurrenz ab. Diese Konkurrenz ist gesprächslogisch noch nicht aufgebaut. Auch haben sich noch keine Diskussionsgegenstände herausgebildet, die in den einzelnen Diskussionen immer wieder aufgenommen werden. ${ }^{67}$ Obwohl der Text gut bewertet wird und nur vereinzelt konkrete Kritik geäußert wird, erhält er keinen der fünf 2005 vergebenen Preise. Letztendlich wird der Text also wohl als gelungen, aber dennoch unbedeutend, eingestuft.

Vogels Text erschließt sich offenbar mühelos. Es gibt kaum Argumentationsbestandteile, die ausschließlich auf die Klärung von Plot-Fragen ausgerichtet sind. Die Auseinandersetzung mit dem Inhalt erfolgt von Anfang an auf dem abstrakteren Niveau der Interpretation. Auch in Bezug auf die Deutung des Textes entwickelt sich keine Kontroverse. Es kristallisieren sich grob zwei Stoßrichtungen der Kritik heraus, wobei die eine den Grad der Komik betrifft, die andere die mangelnde Offenheit des Textes.

66 Dass Miller der vorschlagende Juror ist, lässt sich nur aus der Wertungskonstellation ableiten.

67 Es kann natürlich nicht ausgeschlossen werden, dass die Juroren im Vorfeld des Wettbewerbs inoffiziell über die Texte sprechen. Dieses diskursive Wissen kann also bereits vorhanden sein. Da es sich allerdings um eine publikumsorientierte Veranstaltung handelt, muss davon ausgegangen werden, dass diskursiv notwendige Bestandteile vor dem Publikum wiederholt werden. 


\title{
Der Text „Plug in“
}

Der Text „Plug in“ erzählt die Entgleisung des Alltags durch eine zufällige Verkettung unglücklicher Ereignisse im Leben des Protagonisten. Niklas Fink steht vor einem chirurgischen Eingriff. Als er, überrumpelt von der Information über die bevorstehende Operation, nach Hause kommt, findet er sein Wohnzimmer durch einen Wasserschaden in ein Feuchtbiotop verwandelt. Am Arbeitsplatz sieht sich der Programmierer Fink Stress und Stumpfsinn zugleich ausgesetzt. Zuguterletzt erhält er auch noch eine Flut von Werbebriefen. Die Situation Finks - im Zentrum das Feuchtbiotop im Wohnzimmer - wird durch die verwendeten Bilder, aber auch durch Gedankenbruchstücke Finks, mit Versatzstücken aus der Evolutionstheorie, Mythen, Redensarten und aufgeschnapptem Allgemeinwissen in Beziehung gesetzt. Angesichts der bevorstehenden Operation sieht Fink alle Ereignisse als Teil größerer Zusammenhänge, entweder der Menschheitsgeschichte oder des menschlichen Zusammenlebens. Strukturell und sprachlich spiegelt der Text den Tagesablauf Finks mit Auszügen aus einer Programmiersprache, lakonischer Auseinandersetzung mit dem, was Fink in seiner Wohnung vorfindet und Reflexion dieser Erlebnisse. Der folgende Textauszug illustriert diese drei Ebenen:

\begin{abstract}
Wir müssen wieder, alle müssen wir. Morgens aufstehen. Tags arbeiten. Abends ins Bett gehen. Wir sind Wiederholer. Ans Telefon gehe ich heute jedenfalls nicht mehr, wie soll man sich überhaupt konzentrieren? my @dirs = grep $\{-\mathrm{d}\} @$ contents; my @files = grep $\{-\mathrm{f}\}$ @contents; Und andauernd Mails. Mails von Kunden, Mails von der Geschäftsleitung, Mails von Newslettern, Mails für Pillen, Potenz, Partner. Jäger und Sammler. Mammon und Macht statt Bären und Beeren. Wunschmaschinen, immer noch. unlink @files; [...] Der Kaffee ist fertig und er beißt achtlos in den Strudel, kaut ein wenig darauf herum, bevor er realisiert, dass er ihn nicht essen kann. Leiche. Ein Apfelstrudel, der wie eine Apfelstrudelleiche schmeckt, tot, verwesend, ranzig. Er spuckt aus und schiebt die Reste mit der Zunge aus dem Mund, entfernt sie umständlich mit den Fingern von der Unterlippe. Der Geschmack verschwindet nicht und er spült sich den Mund im Bad, trinkt ein Glas Valpolicella hinterher. Der Kaffee wird kalt. Die Kaffeeleiche in der Tasse. Die Tasse ein Grab. Sein Zimmer kommt ihm nun neblig vor, kurz vor dem Monsun, kurz vor dem Regen, dräuende Wolken in den Regalen, verklumpende Wortlawinen, verschlammendes Satzgeröll. Vielleicht nur eine Kerze anzünden, denkt er, es sich gemütlich machen. Man lebt nur einmal. Es klingelt das Telefon. Einmal, noch einmal, dreimal, noch mal, noch mal, wieder - Warten - nichts, vorbei. Der graue, nasskalte Himmel von draußen schaut in das Zimmer, die ganze Welt ist nass, denkt er, Rückkehr ins Meer, Beendigung des Landausflugs. (Vogel 2005)
\end{abstract}

Zwar wird der Text intradiegetisch erzählt und hat eine interne Fokalisierung, durch die eingestreuten Wissensversatzstücke („Mammon und Macht statt Bären und Beeren“, „Man lebt nur einmal“, „Rückkehr ins Meer, Beendigung des Landausflugs“) werden dem Leser allerdings laufend durchaus kohärente Deutungsangebote gemacht. Ein komischer Effekt des Textes entsteht aus einem Missverhältnis von Ereignissen und der Reaktion Finks und 
seiner Nachbarn auf diese Ereignisse. Fink fügt sich ähnlich den Helden Kafkas in die absurden Situationen, als gäbe es keine andere Möglichkeit zu reagieren. Seine Nachbarn wundern sich nicht. Während Finks Alltag aus den Fugen gerät, handeln alle, als wäre nichts geschehen.

\section{Inhaltlicher Konsens als Grundlage der Diskussion}

Martin Ebel übernimmt den Einstieg in die Diskussion. Er wertet den Text positiv als „eher [einen] starke[n], [einen] gehaltvolle[n] Text“ (0:10 Ebel). Schon die Kopplung von „stark“ (im Sinne von gut, überzeugend) und „gehaltvoll“ deutet darauf hin, dass diese Wertung vor allem aufgrund von inhaltlichen Kriterien erfolgt. Diese Tendenz setzt sich in der folgenden Einschätzung der Rolle der Juroren fort, die auch als Selbsteinschätzung interessant ist:

Wir sind ja auch so ein bisschen Fleischfresser in der Jury. Also wir wollen dicke Brocken zu beißen haben und nicht an Knochen herumnagen und so die letzten Fetzen irgendwo an einem schwachen Text noch dann durchkauen und mit unserem eigenen Sekret aufwerten. Also hier ist ordentlich was zu beißen, finde ich. (0:10 Ebel)

Schlussfolgern lässt sich: Ein Text sollte zum einen inhaltlich viel anbieten („dicke Brocken") und zum anderen sollte sich diese inhaltliche Vielfalt aus dem Text selbst und ohne intensiven intellektuellen Aufwand („eigenes Sekret“) erschließen. Das ist eine Denkfigur, die aus anderen Diskussionen bekannt ist. Die Argumentation von Ursula März (13:24) in der Diskussion zum Text von Katrin de Vries (2003) (vgl. Kapitel 15 „Detaildiskussion Katrin de Vries“) basiert auf demselben Grundgedanken: Texte sollten nicht erst durch einen dazugehörigen Aufsatzband interessant werden.

Martin Ebel fährt fort, inhaltlich zu zeigen, was ihm an dem Text gefallen hat. Seine Inhaltszusammenfassung und Deutung legt den Grundstein für die weiteren Beiträge. Im Wesentlichen beziehen sich die anderen Juroren auf diese Inhaltszusammenfassung und den Deutungsansatz Ebels. Der Text lässt sich also offenbar inhaltlich gut erschließen, sodass schnell ein Konsens entsteht.

\section{Die Balance zwischen Offenheit und intensiver formaler Umsetzung}

Schon Klaus Nüchtern (2:56) reduziert als zweiter Sprecher seine inhaltlichen Aussagen auf ein Minimum und konzentriert sich statt dessen auf die Frage, was den Text ästhetisch auszeichnet. Er verweist auf „eine klare Perspektive“, nämlich die Perspektive des 
„zu viel“: Es sei ein Text über zu viel (ebd.). Hier wird der Text inhaltlich auf eine einzige prägnante Deutung zusammengeschrumpft. Die „klare Perspektive“ ist im Sinne Isers (1994, 185) als inhaltlich strukturierendes Prinzip zu verstehen, nicht aber, wie in manchen anderen Diskussionen, als Erzählperspektive. Dieser Perspektive des „zu viel“ wird die Form des Textes gegenübergestellt, die gerade nicht mit Redundanz und Verflüssigung arbeite, sich also, wie Nüchtern (ebd.) sagt, mimetisch anverwandle und auch zu fließen beginne, sondern insgesamt einen „konzise[n], knappe[n], pointierte[n] Text“ (ebd.) hervorbringe. Zur „klaren Perspektive“ tritt eine „hohe [...] ästhetische Kohäsion“ (ebd.). Diese insgesamt positive Bewertung wird relativiert durch die Feststellung, dass der Text in seiner formalen Umsetzung an manchen Stellen „too much“ (ebd.) sei. Ausformuliert heißt dieses Argument: „Auch solche Sachen wie ,Die Welt gerät aus den Fugen“ [zitiert verkürzt KR]. Das führt der Text ohnedies vor. Das brauche ich dann nicht noch einmal explizit hingeschrieben bekommen“ (ebd.). In Nüchterns Urteil spiegelt sich die Freude am Erkennen von formalen Strukturen. Gleichzeitig führt es vor, dass der Modus des Showing, in dem der Leser selber die präsentierte Handlung deuten muss, bevorzugt wird. Vom Text wird nicht erwartet, dass er seine eigene Exegese leistet. Nüchtern (ebd.) bringt noch ein drittes Argument in die Diskussion ein, nämlich dass der Text „von der Dramaturgie auch sehr fein gemacht" sei. Dieses Argument expliziert er anschließend an Textbeispielen. „Dramaturgie“ bezieht sich darauf, wie das Wassermotiv variiert und im Laufe des Textes intensiviert wird. Insgesamt erkennt Nüchtern die gelungene Form des Textes an. Die Präzision, die Nüchtern anführt, ist als eine Präzision der gewinnbringenden formalen Umsetzung eines Inhalts (vgl. Kapitel 10.3.2) zu verstehen. Er schränkt sein Lob allerdings ein, indem er anmerkt, dass diese sehr intensive formale Umsetzung auf Kosten der Offenheit (Showing) des Textes gehe.

Die Kritik von Ursula März (5:31) ist grundsätzlicher als die Nüchterns, setzt aber am selben Punkt an. Anders als Nüchtern wertet sie den Text allerdings aufgrund seiner fehlenden Offenheit eindeutig negativ, denn sie hält es für ein „Kardinalproblem“, wenn Texte sich selbst erklären. Ihr gesamter, knapp zweiminütiger Beitrag ist diesem Problem gewidmet:

Es ist ein bisschen witzig, aber nicht wirklich witzig anarchisch genug. Und es liegt, glaube ich, daran, dass hier der Fehler meiner Tochter wiederholt wird, dass alles gesagt wird. Anfang und Ende der Welt kommt vor. Der Schlusssatz ist der Anfang des Problems. Die Welt hat sich verändert. Das ist die Geschichte. Das will ich am Ende nun wirklich nicht hören. Und so geht es mit fast allen Motiven. Sie werden ohne Ende ausgeführt. Und das ist ein Todesstoß für Komik. (5:31 März)

März (9:24) fasst in einem späteren Beitrag pointiert zusammen: „Ich behaupte ja nicht, 
dass der Text nicht komplex ist. Ich sage nur, das Problem ist, dass er zu seiner Komplexität einen quasi perfekten Kommentar abliefert". Deutlicher als in diesen Bewertungen von Ursula März könnte Kritik an fehlender Offenheit kaum formuliert werden. März fordert eine gezielt eingesetzte Vagheit, die ein Mitdenken und Ergänzen von Informationen durch den Leser erfordert, damit dieser den Text verstehen kann. Dass sie bemängelt, der Text liefere einen perfekten Kommentar ab, ist ganz im Sinne des Wertes Showing (vgl. Kapitel 11.2.2) zu verstehen.

Daniela Strigl (12:32) schließt sich in ihrem ambivalenten Urteil der Kritik von Ursula März an:

\begin{abstract}
Ich habe allerdings auch diese Beobachtungen gemacht, die Frau März gemacht hat, und ich sehe sie auch durchaus als strukturelles Problem des Textes und nicht nur als letztliche kleine Sünden. Ich habe das Gefühl, dass es manchmal etwas angestrengt $\overline{\text { ist, etwas gesucht, dass zu viel erklärt wird und eine überdeutliche Symbolisierung }}$ stattfindet. Auch eine überdeutliche Motivkette. Also, das ist natürlich schön, wenn man sieht, ein Text ist durchdacht und ist dicht strukturiert, aber hier tropft es irgendwie an allen Ecken und Enden. Und das hat auch etwas Reizvolles, aber man fühlt sich dann immer wieder zu stark mit der Nase auf etwas gestoßen. (12:32 Strigl, Hervorhebungen KR)
\end{abstract}

Stärker als bei allen ihren Vorrednern wird das Problem der Überkommentierung und daraus resultierenden Überdeutlichkeit, das dem Text angelastet wird, als ein generelles strukturelles Problem eingestuft, das nicht nur als eine „kleine Sünde“ (ebd.) aufgefasst wird. Die Kernannahme dieser Arbeit, dass die positive ästhetische Wirkung von Literatur in der aktuellen Lektüre- und Wertungspraxis in einer Wechselwirkung von Nachvollziehen und Teilnehmen wurzelt, wird von Daniela Strigl in diesem Beitrag mit Bezug auf den konkreten Text beinahe wörtlich ausformuliert: Es ist „natürlich schön, wenn man sieht, ein Text ist durchdacht und ist dicht strukturiert" (Aspekt des Nachvollziehens). Allerdings schränkt sie ein: „[M]an [...] fühlt sich dann immer wieder zu stark mit der Nase auf etwas gestoßen" (Aspekt der Teilnahme). Der Text offeriert das Erkennen von Strukturen. Er verweigert die geistige Partizipation des Lesers aufgrund von mangelnder Offenheit.

Ein zweiter, eng damit zusammenhängender Aspekt wird von Strigl (ebd.) ebenfalls betont: Der Text „erklärt“ zu viel und der Autor nimmt eine „überdeutliche Symbolisierung“ vor. Der Modus des Showing wird also, wie auch in allen anderen Diskussionen beobachtet werden konnte, gegenüber dem Modus des Telling bevorzugt. Strigl nimmt damit eines der häufigsten Argumente überhaupt auf (vgl. Kapitel 11.2.2). Auch beim Showing geht es für den Rezipienten primär darum, dass er sich die Textaussage selber rekonstruieren darf - in diesem Sinne also am Text partizipieren kann - und dass der Text nicht durch den Erzähler auserklärt wird. Der „überdeutliche[n] Symbolisierung“ geht derselbe Anspruch 
auf eine gewissen Polyvalenz voraus. In diesem Beitrag von Daniela Strigl findet sich en nuce eine Argumentation, die für sehr viele Klagenfurter Diskussionen bestimmend ist, obwohl sie keineswegs immer so klar auf den Punkt gebracht wird.

Die zwei zuletzt genannten Aspekte - Übersymbolisierung und Modus des Showing finden sich auch in den Beiträgen von Iris Radisch und Heinrich Detering. Beide Beiträge sind nicht eigentlich negativ, sondern eher wohlwollend kritisch. Bei Detering heißt es:

Das ist nicht overdone oder zu vorgeführt komplex. Es ist das Drüberreden. Das Wort „Welt" kommt zu häufig vor. Allein und in Kombination. Das ist diese Abstraktionsebene, die eigentlich schon auf Seiten des Lesers steht und nicht mehr im Text selbst. Das ist schade. (20:34 Detering)

Detering bezieht sich hier ebenfalls auf den Darstellungsmodus, nämlich das „Drüberreden“. Er würde es vorziehen, wenn die Abstraktion dem Leser überlassen bliebe.

Radisch formuliert ihre Kritik folgendermaßen:

Es ist ein unglaublich komplizierter Teppich von Signalwörtern, der hier ausgeworfen wird. Und da, finde ich schon, das hat einen Seminartouch. Da höre ich wirklich das Oberseminar, was die Motivketten auseinanderbastelt und/ Der Text macht das nicht. Also er kokettiert damit dann letztlich nur. Er erzählt davon, dass das eine Möglichkeit wäre, die Welt so zu beschreiben, sie so durchsichtig zu machen auf archaische Formen. Aber er geht damit nicht wirklich radikal um. Und deswegen habe ich/ Was für ihn spricht, spricht auch gegen ihn. Er hat einfach diese beiden Seiten. (18:26 Radisch)

Die Komplexität und Vielfalt der Deutungsmöglichkeiten, die der Text inhaltlich anbietet, werden durchaus anerkannt. Das ist für Radisch das, was für den Text spricht. Gleichzeitig kritisiert sie, dass der Text diese Bedeutungsangebote ausbuchstabiert, statt sie durch die Darstellung auf der Handlungsebene anzubieten. Verkürzt könnte man sagen: Der Text ist zwar interessant (intellektuelle Ebene) aber nicht ansprechend genug gestaltet (Wahrnehmungsebene/ästhetische Ebene). Er überzeugt auf der Orientierungsebene, aber nicht auf der Wahrnehmungsebene.

\section{Analytiker versus Intuitive}

In eine vollkommen andere Richtung gehen die Beiträge von Ilma Rakusa. Sie bewertet den Text sehr positiv und geht in ihrem Urteil vor allem auf seine Form, ganz speziell auf die sprachliche Ebene ein. Zentral für ihre Argumentation sind die Stilmittel, die Vogel einsetzt. Dabei schließt sie zum Teil an Detering an, geht aber auch darüber hinaus, wenn sie die „hyperbolische“ Seite des Textes und den Einsatz von „Dreierperioden“ (ein Lieblingsstilmittel Rakusas) hinweist: 
Gleichzeitig wird gerade zum Beispiel die Wiederholung hier als Stilprinzip vorgeführt. Sehr interessant. Er ist hyperbolisch als Text, er ist stilistisch, wie schon Nüchtern sagte, ist er sehr konzis. Er ist sehr präzise gearbeitet. Er ist cool und er ist schlank. Aber er setzt zum Beispiel sehr musikalisch die Wiederholung als Stilprinzip ein. Und genau das wird eigentlich hier für mich interessant. Also sowohl die inhaltlichen Ambivalenzen als auch die stilistische Durchführung dessen. Mir sind aufgefallen diese sehr schönen Dreierperioden, die er immer wieder hat. Also das ist eine Art eben der musikalischen Gestaltung. (9:44 Rakusa)

Rakusa stellt der, vor allem von März geäußerten, Kritik gegenüber, dass die vermeintlichen Fehler nicht als Fehler, sondern vielmehr als intendiertes Stilprinzip des Textes zu werten seien. Dass der Text seine eigene Komik zurücknimmt, sieht sie als formalen Schachzug, der dem Text Ambivalenz verleiht. Wie Klaus Nüchtern ist sie beeindruckt von Präzision und Dichte („schlank“) des Textes. Ihr eigentliches Anliegen besteht allerdings darin, auf die Musikalität und das Stilbewusstsein des Textes hinzuweisen. Sie wiederholt dieses Argument wenig später in einem zweiten Beitrag: „Er weiß ja auch, dass er hier etwas wiederholt. Aber das hat für mich auch wieder eine stilistische Qualität" (14:44 Rakusa).

Rakusas Argument, den Text zeichne ein sehr hoher Stilwille aus, wird in der Folge zum zentralen Streitpunkt der Diskussion. Dabei steht zur Debatte, ob das von allen anerkannte stilistische Können des Autors ausreiche, den Text zu einem guten Text zu machen. Es stehen sich grob zwei Gruppen gegenüber, die ich, um einprägsame Kategorien zu finden, die Analytiker und die Intuitiven nennen möchte. Die Analytiker argumentieren, dass der Autor mit einem Text eine bestimmte Absicht verfolgt und zu dieser Absicht bestimmte Mittel einsetzt. Wenn nun der Leser den Stil als intentional eingesetzt und funktional zur Absicht des Textes wahrnimmt, kann das dem Text nicht angelastet werden. An seiner eigenen (von den Juroren natürlich rekonstruierten) Intention gemessen, ist der Text erfolgreich, wenn die Juroren erkennen, dass der Text in einer bestimmten Weise mit Hinblick auf eine bestimmte Intention gestaltet wurde. Der Text wird in diesem Zusammenhang als ein „Versuchsaufbau“ - das Wort fällt auch gelegentlich in anderen Diskussionen (vgl. Kapitel 13 „Detailanalyse Ute-Christine Krupp“) - betrachtet. Die Intentionalität der formalen Mittel spricht für den Text (vgl. Kapitel 10). In diesem Sinne argumentieren Ebel, Rakusa und wohl auch Miller. Zu den Intuitiven zählen März, Radisch und Spinnen. Die anderen Juroren beteiligen sich an diesem Diskussionsabschnitt nicht mehr. Die Intuitiven erkennen die Qualität des Textes auf der Stilebene an, halten ihn auch grundsätzlich für einen gelungenen Text, kritisieren ihn aber trotzdem, und das, zum Teil explizit, zum Teil 
implizit, weil es ihm nicht gelingt, die Juroren zu fesseln. ${ }^{68}$ Das Argumentationsproblem, das sie zu bewältigen haben, besteht darin, dass ihnen ein objektiv guter Text - einer, dessen Schwächen sich nicht ohne weiteres auf der Textebene konkretisieren lassen, - nicht gefällt. Gleichzeitig wird aber eine objektive oder objektorientierte Wertung erwartet (vgl. Kapitel 4).

Pointiert kommt das Problem in der Aussage Spinnens zum Ausdruck:

Ja, ich habe Ihnen sehr gerne zugehört. Ich kann alles unterschreiben und das jeweilige Gegenteil. Erst wollte ich den Text vor der professoralen Begeisterung in Schutz nehmen. Dann wollte ich ihn vor dem antiprofessoralen Affekt in Schutz nehmen. Ich kann ihn vor allen möglichen Dingen in Schutz nehmen, nur nicht vor einer/ vor einer Lesererfahrung. [...] Und am Ende des Textes bin ich nicht verstörter gewesen als am Anfang. [...] Ich bin dem gerne gefolgt. Das ist eine interessante und intelligente Aufgabe. Aber das Existenzielle der ersten Bedrohung ist mir entraten während der Lektüre. Deswegen bin ich hilflos, rettungslos, hoffnungslos und muss mit diesem Bauchurteil schließen. (24:45 Spinnen)

„Ich kann ihn vor allen möglichen Dingen in Schutz nehmen, nur nicht vor einer [...] Leseerfahrung" ist insofern ein bemerkenswerter Satz, als er ganz offen das Problem bezeichnet, das der Text bei einigen Juroren auslöst. Was Spinnen am Ende stört, ist, dass der Text ihn nicht „verstört“. In dieser Formulierung wird ganz eindeutig klar, dass es die fehlende Betroffenheit durch den Text ist, die eine uneingeschränkt positive Rezeption verhindert.

Die Äußerungen von März und Radisch sind bei weitem nicht so pointiert, obwohl ihnen unterstellt werden kann, dass ihrer Rezeption eine ähnliche Erfahrung zugrunde liegt. Beide bemühen sich aber weiter um eine Argumentation, die die Ursachen des Missfallens an der Form des Textes festmacht. Interessant an Radischs Äußerung ist, dass sie zu unmittelbarem Protest in der Jury führt:

20:52 Radisch: Nein, Entschuldigung. Auch das, was Sie Bildfeld nennen, und die ganze Bildlichkeit, die ist instrumentell zur Absicht, ja. Also, das, was das Thema ist/

21:00 Detering: Das ist kein Schaden.

21:02 Radisch: Ja, das finde ich schon. Das finde ich schon, weil das hat sowas/ Das hat leider etwas von Bastelecke, also von Handwerksabteilung, wo man sich die verschiedenen Schrauben und Drähte und/ [Durcheinander]

Letztendlich wird durch diese Äußerung Radischs in ihrem Gesprächskontext ein ganz grundsätzliches ästhetisches Problem sichtbar, das nicht nur in dieser Diskussion Bedeu-

68 Auch hier bietet die Detailanalyse zu Ute-Christine Krupp einen interessanten Vergleich. Die Grundpositionen sind dort dieselben, die Bewertung fällt aber bei Krupp deutlicher zu Ungunsten des Textes aus, weil die Juroren sich weniger unterhalten fühlen. 
tung hat. Verlangt wird von einem Autor immer ein Gestaltungswillen und eine klar erkennbare Form, die in einem nachvollziehbaren Verhältnis zum Inhalt steht. Wenn allerdings das Verhältnis zwischen Form und Inhalt allzu schnell erfasst werden kann, und sich dann für den analysierenden Leser immer wieder bestätigt, führt das zu Kritik. Radischs Rede von der „Bastelecke“ attestiert dem Text handwerkliches Können; gleichzeitig spricht sie diesem Können den Sinn für Originalität, vermutlich aber auch die Fähigkeit, den Leser zu überraschen, ab. „Bastelecke“ und „Handwerksabteilung“ bedeutet für Radisch offenbar, dass bestimmte Werkstoffe (sprachliche Elemente) und Werkzeuge (literarische Kunstgriffe, die eine bestimmte Wirkung erzielen können) nach einen Bauplan eingesetzt werden. Dieses Vorgehen entspricht - hier spielt erlerntes Wissen über Literatur eine große Rolle - nicht ihrer Vorstellung vom Autor als - im Idealfall - Erschaffer neuer Ausdrucksformen (Maßstab Originalität). Auf der anderen Seite geht Radischs Urteil vermutlich aus der Beobachtung hervor, dass sehr genau nachvollziehbar ist, wie Vogel seinen Text gebaut hat („die ganze Bildlichkeit, die ist instrumentell zur Absicht“). Da es an sich in der Regel kein Fehler ist, wenn die Form eingesetzt wird, um eine bestimmte Absicht zu verstärken - Detering weist darauf hin -, muss man davon ausgehen, dass Radischs Argument kein Argument gegen die Abstimmung von Form und Inhalt ist. Es liegt nahe, ihre Aussage mit Bezug auf den Wertmaßstab Überdeterminiertheit (vgl. Kapitel 10.3.1) zu interpretieren. Man kann davon ausgehen, dass die Wahrnehmung der Überdeterminiertheit (d. h. mangelnde Aktivierung) - dass die Machart des Textes bis ins letzte nachvollzogen werden kann -, an erster Stelle steht und das implizite Originalitätsargument ganz im Sinne der Bedeutung von Originalitätsargumenten im Allgemeinen (vgl. Kapitel 12) eingesetzt wird, weil es ein hohes argumentatives Prestige hat.

Die zum Teil empörten Reaktionen einiger anderer Jurymitglieder zeigen, dass die Aussage, die Bildlichkeit verhalte sich instrumentell zur Absicht, nicht prinzipiell ein Problem ist.

Ganz ähnlich wie Iris Radisch argumentiert März:

Es fehlt ihm nicht an Stil. Es fehlt ihm nicht an Einfällen. Es fehlt ihm nicht am Thema. Es fehlt ihm sozusagen an Charakter, ja. Also, er ist nicht wirklich experimentell, indem er uns an einer Stelle sozusagen die Urbildmalerei zeigt aber drei Sätze später irgendwie vom Dschungel spricht. Er sagt nicht: Das mache ich, weil ich sozusagen Poesie plus Kommentar bin. Das will er nicht sein. Er will Poesie sein und ist dann doch Kommentar. Die Charakterlosigkeit ist das Problem. (22:00 März)

März attestiert dem Text in diesem Beitrag erneut, dass sie ihn auf vielen Ebenen (Stil, Einfälle, Thema) für gelungen hält. In Auseinandersetzung mit den Analytikern in der Jury argumentiert März zunächst, dass der Text seinen eigenen Ansprüchen nicht gerecht 
werde: „Er will Poesie sein und ist dann doch Kommentar“. Ihr Schlusskommentar jedoch, der Text leide an „Charakterlosigkeit“, ist ähnlich zu lesen wir Radischs „Bastelecke“. Charakter ist, so kann man erahnen, eine originelle Eigenständigkeit (vgl. Kapitel 12.1 und 12.1.3).

Den Abschluss der Diskussion bilden jedoch eher die Analytiker. Martin Ebel (26:35) etwa stellt noch einmal klar, dass der Text seiner Ansicht nach „[ewas] will“ und dass „[ihm] das gelingt“. Den kritischen Juroren hält er vor, dass sie Maßstäbe an den Text anlegen, die dem Text nicht gerecht werden. Er resümiert schließlich, die anderen Juroren würden den Text nicht gut finden, weil sie einfach etwas anderes von ihm wollen.

Detering bündelt in seinem Schlussplädoyer schließlich noch einmal alles, was er an dem Text für gelungen hält:

Ich finde schon, wir haben einen intelligent gemachten Text, einen gut erzählten Text, einen stilistisch raffiniert ausbalancierten, vielleicht zu raffiniert ausbalancierten Text, der Existenzielles berührt oder sogar sehr stark berührt. Und es ist doch relativ viel gelacht worden während der Lesung. Das ist ein ziemlich guter Anfang eigentlich. (27:44 Detering)

Neben Stil und generellem Bau (,gut gemacht[]“) lobt Detering einen inhaltlichen Aspekt („Existenzielles“) und schließlich die positive Gesamtwirkung auf den Zuhörer (,relativ viel gelacht“). Hatte Ebel den Versuch unternommen, seine Kollegen durch Kritik ihrer Maßstäbe in die Schranken zu weisen, hält Detering an den „objektiven“ Eigenschaften des Textes fest. Es scheint nur logisch, dass er in einem bewusst als Schlussbemerkung formulierten Beitrag noch einmal jene Werteigenschaften hervorhebt, die ihm besonders überzeugend scheinen. Das formale Gelungensein und die positive, in diesem Fall humoristische, Wirkung scheinen von großer Bedeutung zu sein.

\subsection{Zusammenfassung}

In der Diskussion zu Nikolai Vogels Text stehen die (meisten) Jurymitglieder vor dem Problem, einen Text zu bewerten, der formal vielen anerkannten Wertmaßstäben gerecht wird und trotzdem bei der Lektüre keine Begeisterung hervorgerufen hat - allerdings auch keine starke Ablehnung. Sie stehen unter Druck, einen eigentlich gelungenen, aber nicht vollkommen überzeugenden, Text mit Angabe von Gründen, die sich am Text nachvollziehen lassen, zu kritisieren. Sie wählen zu diesem Zweck unterschiedliche Strategien. Eine Strategie besteht darin, die offensichtlich positiven Eigenschaften des Textes, die eigentlich mit den Anforderungen an einen Text konform gehen müssten, gegen ihn zu wenden, 
indem sie als übertrieben dargestellt werden. Der dabei verwendete Maßstab ist Offenheit in verschiedenen Varianten - also ein sehr starker Maßstab. Es wird angenommen, dass die Redundanz der eingesetzten Mittel die aktive Partizipation des Lesers am Text verhindert, weil die überdeutlichen Signale, die der Text formal wie inhaltlich setzt, den Text vorhersehbar machen.

Eine andere Strategie verfolgen die Intuitiven. Sie besteht darin, die Qualitäten des Textes anzuerkennen, den Lesegenuss aber als übergeordnet zu betrachten, sodass mangelnde Lesefreude als höherrangiger Wert die attestierten formalen Qualitäten in den Hintergrund rückt. Dass es möglich ist, die Lesefreude per se in den Vordergrund zu rücken, weist darauf hin, dass dieser Wert keineswegs nebensächlich ist. Sogar die im Code der Literaturkritik grundsätzlich prestigeträchtigen formalen Texteigenschaften können gegenüber dem Unterhaltungswert in den Hintergrund gerückt werden.

Die Gegenstrategie der befürwortenden Analytiker besteht im Wesentlichen in dem Versuch, die kritischen Jurykollegen auf ein Wertungsmuster aufmerksam zu machen, das als Grundlage für die Bewertung allein die (durch Analyse erfasste) Intention des Textes voraussetzt. Ein gelungener Text ist den Analytikern zufolge ein Text, der seine Intention „gelungen" in Sprache umsetzt. Worin genau dieses Gelingen besteht, wird nicht immer klar. Damit wird auch deutlich, dass den Juroren verschiedene Muster zur Verfügung stehen, um Werte einzusetzen. Ob als Bezugsrahmen für das Gelingen - mit Bezug auf dieselben Werteigenschaften - die (vermutete) Intention des Textes angenommen wird oder aber die Wirkung auf den Leser, liegt nicht in der Form des Textes selbst begründet, sondern in der Erfahrung, die die Juroren während des Lesens mit dem Text (und seiner formalen Gestaltung) machen. In Texten wie dem Vogels, in denen die anerkannten Werte als erfüllt angesehen werden müssen, der Text aber trotzdem keine Lektürebegeisterung hervorrufen kann, erlaubt es das Koordinatensystem literarischer Wertung, positive formale Merkmale mittels Werten wie Überdeterminiertheit/Offenheit und Betroffenheit zu negativen Werteigenschaften umzuwandeln. Es gibt keine per se guten formalen Eigenschaften, sondern nur Merkmalskombinationen, die in ihrem Zusammenspiel eine positive Wirkung erzielen können. Ob tatsächlich eine positive Wirkung eintritt, hängt von individuellen, leserseitigen Faktoren ab.

Obwohl die Juroren in der Diskussion zu Nikolai Vogels Text zu unterschiedlichen Einschätzungen derselben Merkmale kommen, ist das Spektrum sowohl der Werteigenschaften als auch der Wertmaßstäbe, die eingesetzt werden, relativ gering. 


\section{Inka Parei (2003)}

Quelle: http://archiv.bachmannpreis.orf.at/bp2003/audio_video/start_audio_video.htm Eingeladen von: Ursula März

Auszeichnung: Ingeborg-Bachmann-Preis

\subsection{Transkript der Diskussion}

0:04 Haslinger: Ich habe in dieser Veranstaltung schon einmal einem Autor für einen Text gedankt, weil er mich sehr angesprochen hat. Und ich möchte das auch diesmal tun. Wir hatten gestern kurz ein Gespräch darüber, ob es denn möglich sei, als Mann aus der Perspektive einer Frau zu schreiben. Mit einigem Abwägen, Köpfe Wägen und Wiegen wurde das eventuell für möglich, aber für sehr schwer befunden. Dieser Text hat mehrere Qualitäten, die mich sehr ansprechen. Die eine Qualität ist, dass er sehr langsam ist, dass er genau ist, dass er sich Zeit lässt, dass er uns in die Welt eines Mannes, alten Mannes, einführt, die wir Schritt für Schritt, Blick für Blick, Gefühl für Gefühl kennenlernen. Wie macht das der Text? Er macht das in der sogenannten, wie Stanzel es einmal genannt hat, personalen Erzählperspektive, eine Perspektive, die uns nicht unvertraut ist. Wir kennen sie aus der Literatur, zum Beispiel von Franz Kafka. Und die kann so weit gehen, dass wir sogar bereit sind, uns in den Kopf eines ungeheuren Ungeziefers, wie es im ersten Satz der „Verwandlung“ heißt, hineinzusteigen. Dieser Text ist allerdings, gemessen an der „Verwandlung“ oder überhaupt an der personalen Perspektive, wie Kafka sie anwendet/ Es ist nicht identisch damit. Er ist sozusagen einen Schritt/ Der Erzähler, die Erzählerin tritt einen Schritt zurück. Sie hat zwischendurch auch eine Außenansicht auf den Mann. Also nicht alles wird gespiegelt durch den Kopf des Mannes. Es gibt zum Beispiel den Satz: „Der alte Mann ließ das Fernglas sinken, seine Hände zitterten. Er hatte grobe Hände, die mit Altersflecken und weißen pigmentlosen Stellen bedeckt waren" und so weiter. Es ist hier nicht gesagt, dass der gerade seine Hände anblickt, aber es könnte sein. Es bleibt alles im Rahmen der Wahrnehmungsmöglichkeiten und des Wissens dieses alten Mannes. Dieser alte Mann möchte etwas/ Vielleicht muss ich etwas kürzer fassen, sonst/ Ich habe jetzt tatsächlich die Neigung, einen Monolog zu halten, um diesen Text in seinen Qualitäten darzustellen. Ich möchte es etwas kürzer fassen. Wir haben eine langsame Einführung. Wir wissen, wo wir sind. Wir sind in Altrödelheim. Wir wissen, wo der Mann herkommt. Wir kennen die Situation. Er hat das/ Es ist ein fremdes Haus. Er sucht die Gegend für sich zu erobern. Er versucht, sich hier eine Heimat zu schaffen, sozusagen in den letzten Jahren vermutlich. Er ist schwer gehbehindert in den letzten Jahren seines Lebens. Er ist alleingelassen. Er versucht, noch einmal für sich ein Zuhause zu finden und es geht um völlig unscheinbare Dinge. Und doch haben sie eine starke Dimension in Bezug auf ein Bekanntwerden mit der Weltwahrnehmung einer Figur.

3:47 Steinfeld: Es gibt, glaube ich, eine ironische Erzählung aus der Zeit der französischen Revolution. Jedenfalls hört man immer wieder Leute lachen über die Idee, eine Karte Frankreichs im Maßstab von 1:1 zu zeichnen. Also eine Karte, in der jedes Ding so abgebildet ist, in der Größe, in dem Ausmaß wie das in der Wirklichkeit auch der Fall ist. Diese Literatur erinnert mich sehr, sehr stark an die Frankreichkarte im Maßstab von 1:1. [jemand lacht] Diese Idee ist lustig im ersten Augenblick, aber auf Dauer hat sie etwas unerträglich Solides, Rechtschaffenes, knochentrocken Braves, Realistisches. [Radisch lacht, Steinfeld grinst]

4:47 Grandits: Noch etwas? [Heiterkeit]

4:49 Steinfeld: Reicht.

4:50 Grandits: Reicht. [erteilt Radisch das Wort]

4:52 Radisch: Also, ich sage das jetzt, obwohl das wirklich, glaube ich, ein bisschen zu frech ist. Wer so etwas sagt, hat kein Herz für Literatur. Das finde ich. Der hört nicht, was literarische Sprache ist. Das ist eine Autorin! [Applaus] Das ist literarische Sprache, ja. [weiterhin Applaus] Also das/ Das muss ich wirklich sagen. Ich habe wirklich das Gefühl, hier fast das erste Mal richtig Literatur miterlebt zu haben, nicht nur Behauptungen über Literatur aufzuschnappen. Also, das ist jetzt zu scharf. Ich lasse mich jetzt ein bisschen anstecken von der Polemik. Natürlich, wir 
hatten wunderbare Texte. Aber das ist ein/ Es ist ein Text, der nicht nur über die Welt etwas behauptet, sondern der es schafft, sie literarisch zu verwandeln. Und das ist, was ich mir von Literatur zuallererst wünsche. Und dieser Text leistet das.

5:40 Steinfeld: Genauso hart zurück. Sie dürfen Sentimentalität und Empfindung nicht verwechseln.

5:43 Radisch: Das ist nicht sentimental. Das ist sowas von unheimlich, was hier passiert. Das ist von einer großen existenziellen, philosophischen Unheimlichkeit, die mit Ihrer Frankreichkarte nun wirklich überhaupt nichts zu tun hat, ja. [Heiterkeit] Das ist auf ganz engem Raum geschrieben. Das stimmt. Wir sind hier in einem Haus. Dieses Haus kommt uns so nahe, dass sich in diesem Rödelheim wirklich der Kosmos öffnet, die Welt öffnet. Das uns dabei verloren geht. Auch das/ Es ist ja nicht nur dieser alte Mann, der sich selbst hier verloren geht und der ja auch am Schluss dann schon den Blick in den Himmel richtet. Und es ist ein großes Thema. Es ist ein alter Mann, der Abschied nimmt von der Welt, der stirbt. Aber nicht nur dieser Mann stirbt. Wir selber werden unserer selbst verlustig und der Welt, so wie wir sie kennen. Das finde ich großartig. Wenn Literatur das leistet, dann/ Alles, was hier an Sinnlichkeit vorkommt: Das trockene Putztuch über dem Eimer. Das Scharren der Fleischwannen auf dem Auto. Der wunderbare Umgang mit den Krücken. Das ist sowas von/ Also mir bleibt wirklich fast der Atem stehen, so genau, präzise und auch für mich überraschend ist das gemacht. Und plötzlich/ Das ist wirklich Kafka, das stimmt schon, obwohl es hier sehr viel weicher und auch lyrischer und poetischer als Kafka ist. Aber plötzlich rückt die Welt ein Stück daneben und man ist auf einer ganz anderen Spur und sieht alles wie verzaubert. Das finde ich eine unglaubliche Leistung.

7:16 Strigl: Ohne auf das Charakterkundliche jetzt näher eingehen zu wollen, muss ich sagen, ganz lustig oder irgendwie lustig finde ich an diesem Text eigentlich gar nichts. Der ist für mich nicht lustig.

7:31 Haslinger?: Wer hat das gesagt?

7:32 Strigl: Steinfeld hat gemeint, das ist ganz lustig.

7:34 Steinfeld: Ich meinte die Frankreichkarte. Also das hat in seiner Kühnheit erst einmal etwas Bizarres.

7:40 Strigl: Gut. Das ist doch ein Text, den man ernst nehmen muss. Die Bewegung, die dieser alte Mann durch den Text trägt, die Langsamkeit des alten Menschen vollzieht der Text nach. Das ist EINE Bewegung. Und dann ist es schlicht und einfach spannend. Denn die Details für sich genommen mögen etwas mühsam sein. Aber manchmal kann man sich dann eben auch für Putztücher interessieren und fürs Putzen. Es sind ja kleine Signale gesetzt, die zeigen, dass aus dem etwas sehr Bedrohliches wächst. Normalerweise passiert in einem Thriller das so, dass der Held eigentlich ein dynamischer Mensch ist, der sich mit dieser Bedrohung auseinandersetzen kann. In diesem Fall ist das auf den Kopf gestellt. Das ist ein hinfälliger Mann und der muss plötzlich offenbar mit einem Verbrechen umgehen. Und dann gibt es noch eine zweite Ebene, die ich nur kurz andeuten will. Da ist von seiner Zeit als Soldat die Rede. Da kommt offenbar noch etwas. Und von Birkenstämmen mit Streifschüssen, die im Traum ihm erscheinen. Also scheint mir, dass, abgesehen von diesem unheimlichen Fremden, der so komisch Nässe verströmt - das ist ja auch alles sehr unangenehm und deutet auf etwas weiteres hin -, dass hier mehrere Ebenen beginnen, ausgebreitet $\mathrm{zu}$ werden.

9:36 Kretzen: Das würde dann auch noch mal das Thema der „Verwandlung“ genau bedeuten. Ich habe mir einfach noch mal dazu so gedacht die ganze Zeit, dass das eigentlich eine Form ist so eines Portraits der Autorin als alter Mann. Und das finde ich das wirklich Tolle daran. Also, das ist wirklich/ Also, man spürt dadurch diese Arbeit der Sprache die ganze Zeit. Das ist ein Text, der immer seine Mittel genau bearbeitet, bei sich behält, Auskunft darüber gibt und in diesem hohen Bewusstsein genau dann Wirklichkeit beschreibt und Wirklichkeit zu fassen bekommt, sodass man sich dem gar nicht entziehen kann. Es ist da. Und ich denke auch noch, weil wir ja immer auch diese großen Themen mit dem Kapitalismus und der Konsumwelt/ Also das braucht es alles nicht und das finde ich so wunderschön, dass der Text eigentlich der Beweis ist dafür, dass man ganz woanders anfangen kann zu erzählen. Es geht darum, wie man erzählt.

10:23 Miller: Ja, ich kann mich eigentlich dem in vieler Hinsicht anschließen. Ich meine, es steckt etwas in der Bemerkung von Steinfeld, was nicht gegen den Text gerichtet ist. Ich glaube auch gar 
nicht, dass es von ihm gegen den Text gerichtet war. Die Vorstellung/ [große Heiterkeit] Ich will es mal annehmen. Die Vorstellung nämlich dabei, dass hier dieses Element des Betrachtens und über dem Betrachten sich Schritt für Schritt der Sache versichern, hat ja als Erzählbewegung, und das deutete Herr Haslinger ja an, an der Stelle, an der man aus dem personalen Erzählen rausgeht/ Es versichert sich doch die Wirklichkeit ihrer selbst. Diese Vorstellung, die am Anfang schon auftaucht, wenn er da mit dem Fernglas diese fragmentierten Teile von Wirklichkeit beschreibt, die alle die gleiche Konsistenz hatten. Ich finde schon, dass die Idee der Parallelisierung von etwas, wo die Literatur und das, was sie darstellen will, sozusagen mit einer leichten Verschiebung sich wechselseitig gewissermaßen in die Pflicht nehmen. Da könnte das Bild von der eins zu eins Karte schon ganz hilfreich sein. Denn es geht ja nicht um ein personales Erzählen des Mannes, sondern wir rekonstruieren ja auch die Welt. Und ich teile in diesem Fall, gestern waren wir uns nicht einig darüber, dass wir dem Vorlesenden gratulieren zu seinem künftigen Buch. Ich möchte das Buch auch gerne lesen. Ich finde das einen ganz wunderbaren Text. Und es ist richtig, was die Iris Radisch gesagt hat. Das ist ein Text, dem man nach zehn Zeilen anmerkt: Da stimmt alles. Und das finde ich schon großartig.

12:15 Rakusa: Mir gefällt der Text auch sehr. Ich mag, wie angedeutet, seine Langsamkeit. Ich mag auch die ganz leisen, leisen Töne und Zwischentöne und Halbtöne und das alles. Ich möchte gerade auf eine so stille Stelle rekurrieren: „Es war eine Stille, in der man die Abwesenheit der Geräusche in all den leblosen Dingen spüren konnte, aus denen Städte bestehen, die Stille des Mörtels, der Mauern und Schienen, der Blechgehäuse, die Stille des Holzes und der behauenen Steine". Es ist sogar eine geradezu poetische Stelle, die aber sehr diskret ist, wie der Text überhaupt ein Maximum an Diskretion aufweist. Und trotzdem eine ganz, ganz große innere Spannung. Hat mir sehr gut gefallen.

13:01 Spinnen: Ja, es ist natürlich immer wieder befruchtend und erregend, nicht der Meinung von Frau Radisch zu sein. [etwas Heiterkeit] Erregend und verstörend ist es dann, Ihre Meinung zu teilen. [große Heiterkeit] Wir haben uns immer/ oder wir tun uns in Klagenfurt immer schwer mit Textauszügen. Und das spricht dann häufig gegen den Text. Das ist hier sehr sauber gemacht, wenn man mal einen Textauszug präsentiert. Es ist einfach der Anfang. Ein Textanfang hat unendlich viel zu leisten. Es gibt die berühmten Dissertationen über Textanfänge. Und der Textanfang leistet ja so etwas wie eine Ouvertüre des Gesamttextes. Das heißt, der schlägt einen Ton an, von dessen Konsistenz wir, ohne zu wissen, ob der konsistent ist, dennoch schon nach fünf Seiten annehmen müssen, dass er es ist, weil er unsere Lesehilfe, unsere Brille, unsere Gehhilfe ist. Und das finde ich ganz großartig gelungen. Haslinger hat es angesprochen. Es wird eine Art der Nähe zu der Figur, Sie sagten „Diskretion“. Vielleicht noch besser. Ich wollte „Takt" sagen, „Diskretion“ ist vielleicht noch besser. Respekt gehört dazu. Interesse gehört dazu. Das alles geht darin zusammen. Der das anschlägt, der eine gewisse Geschwindigkeit anschlägt. Und dabei wird gleichzeitig eins vermocht. Es wird das Unwort Rödelheim, ein absolutes literarisches Unwort, das einen literarischen Unort markiert, aufgenommen und der Text schafft es, dies zu einem Ort zu machen, an dem wir uns für die Dauer eines Buches mit einnisten wollen, um das zu sehen. Alles, was beschrieben wird, gehen Sie die Sachen mal durch, sind Unbeschreibungen. Es ist die Beschreibung des ästhetisch nicht Vorhandenen. Die Plane mit dem Schwein da drüber. Ich kenne sie. Mein Onkel war Metzger. [Heiterkeit] Das ist halt so eine Metzgerplane. Alles andere mit großer Sorgfalt. Die fünfziger Jahre Fassade, die einen Putz hat, der kein Putz ist. Also eine Fassade, die keine Fassade ist. Das ist die ästhetisch anrührende Beschreibung von etwas, das jenseits ästhetischer Kategorien ist. Ein Eckhaus mit einer Metzgerei in Rödelheim. [etwas Heiterkeit] Und dass ich das alles weiterlesen will. Stellen Sie sich das grauenhafte Treatment DIESES Textes vor. Wir würden schreiend weglaufen. Aber der Text, der ist gut.

15:39 Rakusa: Ich wollte nur gerade, weil Sie Rödelheim sagen/ Zu Recht. Es ist wirklich ein Ort. Es ist ein Ortsname. Der Fluss Nidda, alles ist da. Aber, was ich sehr schön finde/

15:50 Miller: Da habe ich mal fast gewohnt. Direkt an der Ecke. [Heiterkeit]

15:54 Rakusa: Aber, was sehr wichtig ist in dem Text. Man muss ja immer auch auf die Namen achten und nicht nur auf die Perspektiven. Auf die Namen. Hier ist es: der alte Mann, der Fremde. Das ist schon ein ganz bestimmter Ton, der allein davon herrührt, dass es nur heißt „der alte Mann“ und „der Fremde“ zu sagen. Keine Namen, keine näheren Erläuterungen. Das ist schon Teil für mich eines, sagen wir mal, eines Geheimnisses. Das heißt, es ist sowohl die Diskretion darin enthalten. Die Diskretion. Aber der Fremde, man muss ja nicht unbedingt an Camus „L'Étranger“ 
denken. Aber allein schon diese Diskretion, es hier einfach dabei zu belassen, ist auch sehr wichtig für den Text. Und es funktioniert. Es geht völlig auf.

16:40 Radisch: Ich würde das nur gerne ergänzen. Es gibt ja noch mehr als dieses Hineingehen in die Bilder, dass dieses Rödelheim einem so auf die Pelle rückt. Es gibt noch mehr. Es gibt schon auch eine Art Spannungspur, die in Richtung Kriminalistik geht. Eigentlich weiß man ja nicht gleich so genau, was da mit diesem Fremden los ist. Man könnte auch eine Weile denken, der alte Mann sammelt Indizien. Man weiß nur gar nicht, für was. Also diese/ Das ist auch schon eine geführte Genauigkeit, was noch mal gegen Ihre Revolutionskarte spricht, in der ja alles den gleichen Stellenwert hat. Hier wird natürlich ausgewählt, wird zugespitzt, wird Spannung erzeugt. Das ist auch eine ganz raffinierte literarische Struktur, mit der wir auf eine Spur gelenkt werden, die natürlich nicht aufgeht. Das ist ja das, was den Text dann/ also, was einen in der Spannung hält.

17:32 März: Es gibt eine Kategorie, die erstens altmodisch anmutet und zweitens sehr schwer in Diskussionen einzuführen ist, weil sie philologisch nicht gut fassbar ist, auch schwer erklärbar ist. Sie lautet „literarische Notwendigkeit“ und deren Emphase. Ich führe sie ein, weil sie in einigen von Ihnen angeklungen ist. Ich denke, dieser Text hat literarische Notwendigkeit und die entsprechende Emphase. Aber woher kommt die eigentlich? Woher kommt diese Empfindung: Hier stimmt es. Hier wird etwas gesagt, was, noch ein altmodisches Wort, was irgendwie Wahrhaftigkeit besitzt, wo es sitzt, wo man den Finger drauflegen kann und sagen kann: Literatur! So wie Frau Radisch es sagt. Und ich habe mich auch bei diesem Text gefragt, nachdem ich ihn gelesen habe: An was erinnert er dich eigentlich? Und dann fielen mir ein solche Modelle, die jeder von uns kennt. Die gibt es in Kinderbüchern und in Schulbüchern, in Biologiebüchern, wo das Leben des Menschen nachgezeichnet wird, also vom Baby zum Kleinkind zum Jugendlichen zum Erwachsenen und dann wird der immer älter. Und dann fängt dieser Text an zu erzählen. Dann kommt diese lange Etappe - die kann länger sein -, wo das letzte Lebensprojekt darin besteht, die Rückenlage des Sterbens einzunehmen. Das ist natürlich dieser große letzte Satz. Man kann den Text auch von diesem Satz her lesen. Eigentlich wird dieser Moment, dieses letzte Lebensprojekt hier geschildert, eben gerade nicht eins zu eins, sondern in einer Parabel. Und die Parabel muss genau sein. In der muss jedes Detail da sein. Das ist es ja. Das ist das Gegenteil, Herr Steinfeld, von eins zu eins. Die Topografie dieses Hauses ist eine Parabel der Lebenszeit. Und wie/ Es wäre furchtbar aufdringlich, wenn man es sofort merken würde. Wenn es eine penetrante, aufdringliche Parabel wäre. Es ist eine ganz, ganz dezente Form und sie ist so ergreifend. Und ich kann es nur noch einmal sagen: Hier ist literarische Notwendigkeit am Werk. Und auch Ihnen verspreche ich: Die letzte Szene, wo ein alter Mann sich zehn Minuten lang an einem Teppich festhält, um zum Bett/ Sie werden sie nicht vergessen. [etwas Heiterkeit]

[Grandits erteilt Steinfeld das Wort]

20:13 Radisch: [an Herrn Steinfeld gerichtet] Das ist jetzt langsam ein bisschen viel, ne? [Heiterkeit]

20:15 Steinfeld: Ich gewöhne mich allmählich an den Gedanken, hier in diesem Fall völlig alleine zu stehen. Aber das ist mir ja schon einmal passiert in dieser Runde.

20:27 Spinnen: Passiert uns allen dauernd. Das ist normal.

20:30 Steinfeld: Aber/ Also ich kann partout nicht einsehen, wieso ich vor einem Eckhaus in Rödelheim und vor einer Metzgerplane in die Knie gehen soll. Ich weiß, wie das Haus aussieht. Ich weiß, wie der Putzlappen aussieht. Ich weiß, wie die Metzgerplane aussieht. Und die Literatur ist nicht dazu da, mir etwas noch einmal zu erzählen, was ich ohnehin schon weiß. Es fehlt hier/ Ich sage, dieser Text ist handwerklich wunderbar gemacht. Hier kann wirklich jemand schreiben. Aber wo ist die Kühnheit? Wo ist der Mut? Wahrhaftigkeit ist nicht unbedingt eine literarische Kategorie. Wo geht dieser Text über die Ästhetik des neunzehnten Jahrhunderts hinaus? Und mir scheint, liebe Kollegen, als wären Sie mit beiden Beinen im neunzehnten Jahrhundert.

21:19 Radisch: Zeigen Sie mir einen Putzlappen, der mit dieser [große Heiterkeit] Poesie, also wirklich mit dieser Feinheit und mit diesem absurd genauen Blick im neunzehnten Jahrhundert beschrieben wurde. Diesen Putzlappen möchte ich wirklich sehen.

21:30 Steinfeld: Also, Sie werden entschuldigen. Ich habe gerade mein Sortiment an Putzlappen nicht dabei. 
21:37 März: Wir kommen jetzt wieder auf den Haushalt von Frau Radisch zu reden. Das finde ich nicht gut.

21:41 Spinnen: Also, was Sie sagen, muss ein Stachel im Fleisch aller bleiben, die sich mit Literatur beschäftigen. Aber, Herr Steinfeld, so lange Sie mir nicht die Literatur des einundzwanzigsten Jahrhunderts zeigen, bleibe ich bei der des neunzehnten unter Umgehung aller Irrtümer des zwanzigsten. Das ist nicht unbedingt eine Rückzugsposition, sondern das ist, gemessen an dem völligen Niedergang des Fortschrittsgedankens, selbst mittlerweile in den Wissenschaften und in der Ökonomie, eine nicht ganz unweise Haltung. Und da nichts wiederkommt, so, wie es war, wir aber im Stande sind, den Formenkanon, den ewigen Formenkanon der Literatur permanent wieder abzurufen auf seine momentanen Möglichkeiten, würde ich sagen, dass so eine Kategorisierung wie „das ist wie neunzehntes Jahrhundert" eigentlich gar nicht möglich ist.

22:34 Radisch: Aber es stimmt nicht, Herr Spinnen, diese Slow Motion, dieses Gucken auf die - das sagten Sie doch auch - auf die völlig unspektakulären aller rödelheimischsten Gegenstände, das hat das neunzehnte Jahrhundert/

22:43 Haslinger: Das gibt es auch bei Adalbert Stifter.

22:45 Spinnen: Das ist Stifter! Danke! Josef!

22:47 Radisch: Aber nicht die Putzlappen. Da müssen es dann schon die Ahornblätter sein oder/ Das ist/ 


\subsection{Analyse der Diskussion}

\section{Ablauf der Diskussion}

Die Diskussion zu Inka Parei im Jahr 2003 verhält sich in vielerlei Hinsicht komplementär zur Diskussion zu de Vries im selben Jahr. Sie ist mit 23 Minuten und 17 Sekunden ähnlich lang wie die zu de Vries (22 Minuten 53). Inka Parei erhielt für diesen Text den Bachmann-Preis. Die Autorin wurde von Ursula März nach Klagenfurt eingeladen. Ursula März tritt allerdings nicht als ihre größte Verteidigerin ein, vielmehr kämpft Iris Radisch mit sehr viel Pathos für den Text. Trotz einer großen Einigkeit der Jurymitglieder über die Qualitäten des Textes, ist die Diskussion im Gegensatz zur Diskussion zu de Vries, die in ihrer großen Einigkeit durch eine große Trägheit gekennzeichnet war, sehr lebhaft. Obwohl sich die Juroren auch in der Diskussion zu Pareis Text sehr einig sind, werden sie nicht müde, sich gegenseitig zu bestätigen. Sie nehmen dabei stärker aufeinander Bezug, beziehungsweise artikulieren ihre Bezugnahme stärker. Dieselbe Tendenz findet sich auch in der Diskussion zu Kathrin Passigs Text, der ebenfalls einen Bachmann-Preis erhielt (vgl. Kapitel 14 „Detailanalyse Kathrin Passig“).

Alle Juroren finden unmittelbar einen Zugang zu dem Text. Inhaltliche Fragen treten völlig in den Hintergrund. Diese Höhergewichtung der ästhetischen Machart gegenüber dem Inhalt, der insgesamt als unbedeutend für die Anerkennung des Textes angesehen wird, wird in diesem Fall deutlich als Argument artikuliert. Immer wieder wird auf die Aufwertung des Inhalts durch die Art der Darstellung verwiesen, auf die spezifisch literarische Qualität, die darin liegt, und die positiven sinnlichen Effekte, die die sprachliche Aufbereitung hat. Trotz, oder vielleicht gerade wegen des großen Pathos, mit dem Argumente vorgetragen und verteidigt werden, bleiben die Bezüge auf formal-ästhetische Eigenschaften des Textes an vielen Stellen eher vage. Die grundsätzliche Einigkeit, die in der Wertung besteht, erlaubt es, den Text als losen Bezugspunkt für grundsätzlichere Aussagen über die Bedingungen des Gelingens von Literatur zu nehmen. Auch in dieser Diskussion vertritt Thomas Steinfeld als Einziger eine abweichende, in diesem Fall negative, Meinung, während alle anderen Juroren sich bis in die Details ihrer Wertung hinein einig sind. Steinfeld muss dabei eingestehen, dass der Text handwerklich gut gemacht sei. Seine polemischen Redebeiträge liefern den anderen Juroren die Möglichkeit, die Qualitäten des Textes umso intensiver hervorzuheben. 


\section{Der Text}

Pareis Text, der in Klagenfurt noch ohne Titel war und später als Teil der Erzählung „Was Dunkelheit war" erschienen ist, beschreibt die Begegnung eines alten, gehbehinderten Mannes mit einem Fremden im nächtlichen Hausflur. Dabei bleibt der Text in der Perspektive des alten Mannes, der in hohem Alter von einem ehemaligen Bekannten, an den er sich nicht erinnern kann, ein Haus geerbt hat, in dem er versucht, heimisch zu werden. Indem der Text das langsame Vergehen der Zeit und die Mühseligkeit aller Verrichtungen ausstellt, wird eine Atmosphäre der Unsicherheit und Resignation hergestellt. Die Orientierungshilfen - Erinnerung und Wahrnehmung - des alten Mannes erweisen sich als unzuverlässig: Als er, nachdem er lange Hausbewohner und Fremde auf den dunklen Hof des Hauses beobachtet hat, ein ungewohntes Geräusch im Hausflur wahrzunehmen glaubt und daraufhin auf einen Fremden trifft, erlebt der Leser diese Situation auf Augenhöhe mit dem seiner selbst und seiner Umwelt nicht sicheren alten Mann. Durch diese eingeschränkte Perspektive und das Wissen um die Wehrlosigkeit des alten Mannes entsteht eine Spannung (suspense). Über weite Strecken ist für den Leser nicht klar, ob die Bedrohung nur eingebildet ist oder ob der Mann tatsächlich im Begriff ist, einem Einbrecher zu begegnen. Erliegt hier ein einsamer alter Mann seinen Angstvorstellungen oder droht er, Zeuge eines Verbrechens zu werden?

Hören Sie mich überhaupt, rief der Fremde, ich komme hier nicht raus. Panik schwang in seiner Stimme mit, es war nur ein kurzes Schwanken, ein Flattern der Tonhöhe, aber der alte Mann war verunsichert, er war sich jetzt nicht mehr sicher, ob er nicht doch für einen kurzen Moment in seinen Gedanken so abwesend gewesen war, daß er den anderen überhaupt nicht mehr gehört hatte. (Parei 2003)

Die Juroren betonen in ihrer Besprechung des Textes immer wieder, wie es der Autorin gelingt, mittels literarischer Techniken aus einem absolut handlungsarmen Plot eine große Spannung zu erzeugen.

\section{Die Rolle von Aufmerksamkeitslenkung und Aufmerksamkeitsbindung}

Die gesamte Diskussion erinnert in ihrer Struktur an ein Gespräch unter Kennern über einen Text, von dem (fast) alle begeistert sind und an dem sich deswegen exemplifizieren lässt, was grundsätzlich von Literatur als Kunst erwartet wird. Damit ist sie vergleichbar mit der Diskussion zum Text Kathrin Passigs (vgl. Kapitel 14), die ebenfalls einen Bachmann-Preis gewann. Beinahe jeder Redebeitrag beginnt mit einem Rückbezug auf einen vorhergehenden Beitrag. Die Diskussion stellt inhaltliche Fragen weitestgehend in 
den Hintergrund; wenn sie in die Beurteilung einfließen, werden sie in ein Verhältnis zu Fragen der Gestaltung gesetzt. So etwa im Beitrag Strigls, in dem sie eine Eigenschaft der Figur (Langsamkeit) mit einer Erzähltechnik (zeitdehnendes Erzählen) parallelisiert:

Die Bewegung, die dieser alte Mann durch den Text trägt, die Langsamkeit des alten Menschen vollzieht der Text nach. Das ist EINE Bewegung. Und dann ist es schlicht und einfach spannend. Denn die Details für sich genommen mögen etwas mühsam sein. Aber manchmal kann man sich dann eben auch für Putztücher interessieren und fürs Putzen. Es sind ja kleine Signale gesetzt, die zeigen, dass aus dem etwas sehr Bedrohliches wächst. Normalerweise passiert in einem Thriller das so, dass der Held eigentlich ein dynamischer Mensch ist, der sich mit dieser Bedrohung auseinandersetzen kann. In diesem Fall ist das auf den Kopf gestellt. Das ist ein hinfälliger Mann und der muss plötzlich offenbar mit einem Verbrechen umgehen. (7:40 Strigl)

Daniela Strigl nimmt in diesem Ausschnitt ihres Beitrags immer wieder Bezug auf inhaltliche Komponenten des Textes, stellt diese dann aber im selben Atemzug wieder in einen Funktionszusammenhang mit seiner formalen Gestaltung: Der Text vollzieht die „Langsamkeit des alten Mannes" nach. Gemeint ist, dass das inhaltliche Moment der motorischen Langsamkeit auch sprachlich nachvollzogen wird. Die Details (Inhalt), die beschrieben werden, sind „mühsam“, aber der Text an sich erzeugt „Spannung“. Putztücher sind, so wird suggeriert, etwas eigentlich Banales, aber im Zusammenhang des Textes sind sie „Signale“ der Bedrohung. Die lustvolle Wirkung „Spannung“ kann entstehen, weil Strigl als Leserin in der Lage ist, zu erkennen, dass bestimmte inhaltliche Elemente ihre bloße Funktion als Referent auf einen Gegenstand (beispielsweise die Putztücher) überschreiten und innerhalb des Textes durch die Art, wie sie arrangiert sind, eine zusätzliche Bedeutung erhalten. Etwas anders gelagert, aber dennoch argumentativ ähnlich eingesetzt, ist der Verweis auf das Muster des Thrillers: Das Genremuster ist erkennbar, aber die Art der Spannungserzeugung wird variiert. ${ }^{69}$ Alle Elemente, die für sich genommen auf Kritik stoßen könnten, haben Strigl zufolge eine Funktion für das Textganze und die Wirkung auf den Leser. Sieht man allerdings vom Langsamkeits-Argument ab, das an die klassische Einheit von Gehalt und Gestalt (Wert Stimmigkeit) erinnert, zielen die anderen Beispiele nicht auf spezifische Formmerkmale im engeren Sinne ab, sondern auf den Eindruck des intentional Gemachten, der entsteht. Als „Signale [...], die zeigen, dass aus dem etwas sehr Bedrohliches wächst“ gehen die Putztücher über die inhaltliche Bedeutung, die sie in der Beschreibung eines Settings hätten, hinaus und werden als intentional gesetztes Element der Aufmerksamkeitslenkung wahrgenommen.

Gerade bei diesem Text wird immer wieder darauf hingewiesen, dass es ihm gelingt, den

69 Genau diese klare Funktionalität in der Abwandlung eines Musters war es, die der Jury bei Katrin de Vries fehlte und die im Text Kathrin Passigs von Burkhard Spinnen als positive Texteigenschaft hervorgehoben wurde (vgl. Kapitel 14 und 15). 
Leser in den Bann zu ziehen. Ganz ähnlich wie bei Strigl sieht die Argumentation bei Spinnen aus:

Und dabei wird gleichzeitig eins vermocht. Es wird das Unwort Rödelheim, ein absolutes literarisches Unwort, das einen literarischen Unort markiert, aufgenommen und der Text schafft es, dies zu einem Ort zu machen, an dem wir uns für die Dauer eines Buches mit einnisten wollen, um das zu sehen. Alles, was beschrieben wird, gehen Sie die Sachen mal durch, sind Unbeschreibungen. Es ist die Beschreibung des ästhetisch nicht Vorhandenen. Die Plane mit dem Schwein da drüber. Ich kenne sie. Mein Onkel war Metzger. [Heiterkeit] Das ist halt so eine Metzgerplane. Alles andere mit großer Sorgfalt. Die fünfziger Jahre Fassade, die einen Putz hat, der kein Putz ist. Also eine Fassade, die keine Fassade ist. Das ist die ästhetisch anrührende Beschreibung von etwas, das jenseits ästhetischer Kategorien ist. Ein Eckhaus mit einer Metzgerei in Rödelheim. [etwas Heiterkeit] Und dass ich das alles weiterlesen will. Stellen Sie sich das grauenhafte Treatment DIESES Textes vor. Wir würden schreiend weglaufen. Aber der Text, der ist gut. (13:01 Spinnen)

Auch Spinnen listet eine Reihe von Aspekten, die seiner Ansicht nach eigentlich kritisiert werden könnten, aber nicht kritisiert werden, weil er sie als in Hinblick auf die Wirkung beim Leser gewinnbringend eingesetzt erachtet: Der Unort Rödelheim werde zu einem Ort, „an dem wir uns für die Dauer eines Buches einnisten wollen“. Dinge, die an sich nicht ästhetisch sein könnten, werden in der Beschreibung der Autorin „ästhetisch anrührend“. Das „Treatment" des Textes wäre furchtbar, aber der Text sei gut. Diese Güte wird eng gekoppelt mit der Aussage, dass er das alles weiterlesen wolle. Wie bei Strigl wird Aufmerksamkeitsbindung als positiver Effekt der ästhetischen Gestaltung hervorgehoben und für die positive Bewertung des Textes eingesetzt. Was genau Spinnen allerdings am geschilderten Setting so ästhetisch grauenhaft findet, bleibt offen. Er setzt in seinem Beitrag auf die suggestive Kraft seiner Worte, dass in dieser Hinsicht nur Einigkeit bestehen könne. Zum einen verweist also auch Spinnen auf die besondere Qualität des Textes, den Leser zum Weiterlesen zu animieren. Zum anderen findet sich erneut die Vorstellung, dass der Inhalt, würde er als Plot nacherzählt, nicht viel hergäbe, dass aber die besondere Verarbeitungsweise den Text herausragend mache.

In der Tat sind sich die Juroren relativ einig darüber, dass die Qualität des Textes, seine Fähigkeit also, den Leser zu fesseln, mit der gewählten Figurenperspektive und der sprachlichen Darstellung zusammenhängt. Schon Haslingers einleitender Diskussionsbeitrag greift verschiedene dieser Eigenschaften auf, die in der Diskussion immer wieder als prägend für den Text genannt werden:

Dieser Text hat mehrere Qualitäten, die mich sehr ansprechen. Die eine Qualität ist, dass er sehr langsam ist, dass er genau ist, dass er sich Zeit lässt, dass er uns in die Welt eines Mannes, alten Mannes, einführt, die wir Schritt für Schritt, Blick für Blick, Gefühl für Gefühl kennenlernen. Wie macht das der Text? Er macht das in der 
sogenannten, wie Stanzel es einmal genannt hat, personalen Erzählperspektive, eine Perspektive, die uns nicht unvertraut ist. Wir kennen sie aus der Literatur, zum Beispiel von Franz Kafka. Und die kann so weit gehen, dass wir sogar bereit sind, uns in den Kopf eines ungeheuren Ungeziefers, wie es im ersten Satz der „Verwandlung“ heißt, hineinzusteigen. Dieser Text ist allerdings, gemessen an der „Verwandlung“ oder überhaupt an der personalen Perspektive, wie Kafka sie anwendet/ Es ist nicht identisch damit. Er ist sozusagen einen Schritt/ Der Erzähler, die Erzählerin tritt einen Schritt zurück. Sie hat zwischendurch auch eine Außenansicht auf den Mann. Also nicht alles wird gespiegelt durch den Kopf des Mannes. [...] Es bleibt alles im Rahmen der Wahrnehmungsmöglichkeiten und des Wissens dieses alten Mannes. (0:04 Haslinger)

Haslinger betrachtet in seinem Urteil, ähnlich wie Strigl, das ruhige Tempo und die (Detail)Genauigkeit der Sprache. Er weist darauf hin, dass der Leser Schritt für Schritt in die Welt des Protagonisten eingeführt wird. Ebenso entscheidend ist, dass die weitestgehend interne Fokalisierung dem Leser die Aufgabe überlässt, die „Welt“ der Figur zu rekonstruieren (Wert Showing). Das Zurücktreten des Erzählers, von dem die Rede ist, wird als Grund für eine Art Schwebezustand der Perspektive gesehen, der dazu führt, dass der Leser nie genau weiß, ob der Erzähler die Figur wahrnimmt und beschreibt oder ob die Figur selbst diese Wahrnehmung hat. Auch dies fordert die aktive Interpretationsleistung des Lesers. Diese Eigenschaften der Machart mit dem Effekt der Aufmerksamkeitslenkung und -bindung prägen die Beiträge: Langsamkeit, Genauigkeit, Erzählperspektive und Erzählhaltung. Sie geben vielfach Raum, einen gut bekannten Wertungs-Topos zu formulieren: Für die Qualität des Textes ist die Präsentation des Inhalts wichtiger als der Inhalt selbst. So beispielsweise auch in folgendem Beitrag:

Und das finde ich das wirklich Tolle daran. Also, das ist wirklich/ Also, man spürt dadurch diese Arbeit der Sprache die ganze Zeit. Das ist ein Text, der immer seine Mittel genau bearbeitet, bei sich behält, Auskunft darüber gibt und in diesem hohen Bewusstsein genau dann Wirklichkeit beschreibt und Wirklichkeit zu fassen bekommt, sodass man sich dem gar nicht entziehen kann. Es ist da. Und ich denke auch noch, weil wir ja immer auch diese großen Themen mit dem Kapitalismus und der Konsumwelt/ Also das braucht es alles nicht und das finde ich so wunderschön, dass der Text eigentlich der Beweis ist dafür, dass man ganz woanders anfangen kann zu erzählen. Es geht darum, wie man erzählt. (9:36 Kretzen)

Auch Friederike Kretzen beginnt bei der (sprachlichen) Gestaltung des Textes („Das ist ein Text, der immer seine Mittel genau bearbeitet, bei sich behält, Auskunft darüber gibt"). ${ }^{70}$ Die folgende Aussage, dem Text gelinge es auf diese Weise, Wirklichkeit zu fassen zu bekommen, erlaubt verschiedene Auslegungen. Stellt man sie in den Kontext des darauf folgenden Hinweises auf die „großen Themen mit Kapitalismus und Konsumwelt“, kann man davon ausgehen, dass Kretzen inhaltlich argumentiert: Die sprachliche Gestaltung

$\overline{70}$ Eine genaue Deutung dieser Wertung fällt schwer. Verstanden wurde sie daher als eine Aussage im Sinne des Wertes Gestaltetheit. Der Text wird als intensiv und intentional gestaltet wahrgenommen. 
ermöglicht einen Erkenntnisgewinn über die außerliterarische Wirklichkeit. Wichtig ist allerdings noch der Hinweis auf den Effekt, den die sprachliche Gestaltung darüber hinaus beim Leser erzielt: Er kann sich „nicht entziehen“.

Iris Radisch stellt die gelungene Aufmerksamkeitsbindung („Spannung“) ins Zentrum ihres zweiten Beitrags:

Es gibt ja noch mehr als dieses Hineingehen in die Bilder, dass dieses Rödelheim einem so auf die Pelle rückt. Es gibt noch mehr. Es gibt schon auch eine Art Spannungspur, die in Richtung Kriminalistik geht. [...] Das ist auch schon eine geführte Genauigkeit, was noch mal gegen Ihre Revolutionskarte spricht, in der ja alles den gleichen Stellenwert hat. Hier wird natürlich ausgewählt, wird zugespitzt, wird Spannung erzeugt. Das ist auch eine ganz raffinierte literarische Struktur, mit der wir auf eine Spur gelenkt werden, die natürlich nicht aufgeht. Das ist ja das, was den Text dann/ also, was einen in der Spannung hält. (16:40 Radisch)

Nicht nur „,[rückt] dieses Rödelheim einem so auf die Pelle“, sondern dem Text gelingt es durch die Setzung von Details („,geführte Genauigkeit“, „raffinierte literarische Struktur“), die die Aufmerksamkeit des Lesers auf sich ziehen, eine Rätselspannung zu erzeugen. Offenheit spielt außerdem als Kriterium eine Rolle, wenn Radisch sagt, dass die Spur, auf die der Leser gelenkt wird, nicht aufgehe. Die Wirkung dieser Offenheit ist Spannung. Damit bestätigt sich, dass die formalen Eigenschaften von Texten von den Juroren besonders dann ins Bewusstsein rücken, wenn sie sich als Ursachen von Wirkungen wie Spannung und Anteilnahme heranziehen lassen.

Insgesamt unterscheiden sich die Diskussionsbeiträge im Spektrum und in der Art der Argumente nur geringfügig. Interessant wird die Diskussion noch einmal auf einer anderen Ebene.

\section{Pathos und Polemik. Die zweite Ebene der Diskussion}

Auffallend an der Diskussion ist, dass sie trotz der überwiegend großen Einigkeit - und damit genau im Gegensatz zur Diskussion zu Kathrin Passigs Siegertext (vgl. Kapitel 14 „Detailsanalyse Kathrin Passig“) mit einem großen Pathos und zum Teil sehr polemisch geführt wird. Gerade die Polemik ist nicht charakteristisch für positive Diskussionen, in denen sich die Jurymitglieder oftmals eher über Lektüreeindrücke austauschen, als sich über Machart oder angemessene Interpretation zu streiten. Die Basis dafür, dass diese Polemik überhaupt stattfinden kann, ist Thomas Steinfelds konträre und stark polemisch vorgetragene Position. Obwohl er an anderer Stelle eingesteht, dass der Text „handwerklich wunderbar gemacht" (20:12 Steinfeld) sei, vertritt er gleich zu Beginn der Diskussion als zweiter Redner die Meinung, der Text habe „etwas unerträglich Solides, Rechtschaffenes, 
knochentrocken Braves, Realistisches“ (3:47 Steinfeld). Seine Mimik und Gestik, gerade am Ende seines Beitrags im Wortwechsel mit dem Moderator deuten an, dass er sich des provokanten Stils seiner Äußerung bewusst ist. Er beginnt seinen Beitrag, indem er den Text mit einer Frankreichkarte im Maßstab 1:1 vergleicht. Diese Idee wird trotz ihrer Abwegigkeit immer wieder aufgenommen. Tatsächlich bemühen sich viele Juroren darum, zu zeigen, dass dieser Vergleich auf den Text nicht zutrifft. Thomas Steinfeld sichert sich mittels seiner Polemik trotz seiner isolierten Position einen strukturierenden Platz in der Diskussion. Er prägt sie, obwohl er das Gesamturteil über den Text nicht beeinflussen kann. Vor allem Iris Radisch gibt er damit aber auch die Möglichkeit, ebenso polemisch zu reagieren und eine Darlegung dessen zu starten, was ihrer Meinung nach Literatur ausmacht: „Wer so etwas [wie Steinfeld KR] sagt“, behauptet Radisch (4:52), „hat kein Herz für Literatur. [...] Der hört nicht, was literarische Sprache ist“. Zusätzlich weist sie darauf hin, dass diese Aussage eigentlich „ein bisschen zu frech“ sei. Dieser Verweis auf die eigene Verwegenheit muss weniger als eine Entschuldigung gegenüber Steinfeld gelesen werden als ein Hinweis darauf, dass sie eine außergewöhnlich zugespitzte (und deswegen möglicherweise nicht den Normen der Höflichkeit entsprechende) Aussage macht. Sie erhöht den Authentizitätsanspruch ihrer Aussage, indem sie behauptet, Grenzen der Höflichkeit in den Hintergrund zu stellen. Auffällig an dieser pathetisch vorgetragenen Aussage ist auch ihre Verknüpfung mit der „literarische[n] Sprache“. Gewichtig ist der Vorwurf, literarische Sprache nicht erkennen zu können, weil sich mit der Sprache eine Vorstellung vom spezifisch Literarischen verbindet. Hier erhält das Argument zusätzlich das Attribut der Kennerschaft. Nur wer eine spezielle Kennerschaft der Sprache besitzt und Steinfeld wird im Rahmen dieser Auseinandersetzung unterstellt, er habe sie nicht -, hat auch den „richtigen Draht“ zur Literatur. Dass sie selbst ein „Herz für Literatur" hat, setzt Radisch mit größter Selbstgewissheit voraus.

Im Anschluss trifft Iris Radisch zwei Aussagen über den Text, die auf die ersten Blick nicht besonders viel miteinander zu tun haben, die sich aber auf den zweiten Blick in ihrer Argumentationslogik auffallend ähnlich verhalten:

Das ist literarische Sprache, ja. [weiterhin Applaus] Also das/ Das muss ich wirklich sagen. Ich habe wirklich das Gefühl, hier fast das erste Mal richtig Literatur miterlebt zu haben, nicht nur Behauptungen über Literatur aufzuschnappen. Also, das ist jetzt zu scharf. Ich lasse mich jetzt ein bisschen anstecken von der Polemik. Natürlich, wir hatten wunderbare Texte. Aber das ist ein/ Es ist ein Text, der nicht nur über die Welt etwas behauptet, sondern der es schafft, sie literarisch zu verwandeln. Und das ist, was ich mir von Literatur zuallererst wünsche. Und dieser Text leistet das. (Radisch 4:52, Hervorhebungen KR]

In beiden Aussagen geht es um ein Echtheitszertifikat für Literatur. Die erste Aussage 
ordnet den Text als „wahre“ Literatur ein. „Wahre“ Literatur versucht aus Radischs Perspektive nicht intentional, Literatur zu sein, indem sie bestimmte Verfahren anwendet, die als literarische bekannt sind. Sie ist darauf ausgerichtet, eine Idee sprachlich adäquat umzusetzen, ohne dabei literarisch sein zu wollen. Sie erschließt sich unmittelbar als Literatur. In der Diskussion zu Steinbuch (2005) bezeichnet Radisch (8:00) diese spezielle Art von Texten, die, ihrer Ansicht nach, eine bestimmte Gestaltungsweise nur deswegen verwenden, weil sie als literarisches Stilmuster bekannt ist, als „Literatursimulation“. Analog dazu verhält sich der zweite hervorgehobene Satz, in dem es um die im Text dargestellte Welt geht. Diese „schafft“ Parei anstatt sie zu „behaupten“. Wieder geht es um die Unmittelbarkeit. Der angelegte Wert ist der des Showing (vgl. Kapitel 11.2.2). In beiden Aussagen geht es darum, dass sich der Text unmittelbar erschließt - als Literatur erschließt und als literarische Welt erschließt.

Ursula März (17:32) muss in ihrem Beitrag keine Überzeugungsarbeit mehr leisten. Sie hat alle Freiheiten, über abstrakte Kategorien literarischer Wertung zu sprechen: „Notwendigkeit“ und „Wahrhaftigkeit“. Sie selbst führt an, dass die Kategorie der literarischen Notwendigkeit „philologisch nicht gut fassbar" sei und dass sowohl Wahrhaftigkeit als auch Notwendigkeit „altmodisch anmute[n]“. Der Beitrag klärt auch nicht, was genau mit den Kategorien gemeint ist. Als reine Wortgewichte unterstreichen sie die positive Wertung:

\begin{abstract}
Es gibt eine Kategorie, die erstens altmodisch anmutet und zweitens sehr schwer in Diskussionen einzuführen ist, weil sie philologisch nicht gut fassbar ist, auch schwer erklärbar ist. Sie lautet „literarische Notwendigkeit“ und deren Emphase. [... ] Aber woher kommt die eigentlich? Woher kommt diese Empfindung: Hier stimmt es. Hier wird etwas gesagt, was, noch ein altmodisches Wort, was irgendwie Wahrhaftigkeit besitzt, wo es sitzt, wo man den Finger drauflegen kann und sagen kann: Literatur! [...] Eigentlich wird dieser Moment, dieses letzte Lebensprojekt hier geschildert, eben gerade nicht eins zu eins, sondern in einer Parabel. [.. . Es wäre furchtbar aufdringlich, wenn man es sofort merken würde. Wenn es eine penetrante, aufdringliche Parabel wäre. Es ist eine ganz, ganz dezente Form und sie ist so ergreifend. Und ich kann es nur noch einmal sagen: Hier ist literarische Notwendigkeit am Werk. Und auch Ihnen verspreche ich: Die letzte Szene, wo ein alter Mann sich zehn Minuten lang an einem Teppich festhält, um zum Bett/ Sie werden sie nicht vergessen. [etwas Heiterkeit] (17:32 März)
\end{abstract}

Bemerkenswert ist außerdem der Hinweis auf die „dezente Form“. Ähnlich wie bei anderen Beiträgen, die auf „Diskretion“ (12:15 Rakusa), „Takt“ und „Respekt“ (13:01 Spinnen) und das Zurücktreten des Erzählers (0:04 Haslinger) eingehen, verweist die „dezente Form“ auf eine Unaufdringlichkeit der Gestaltung. Das von den Juroren bevorzugte Mischverhältnis von Wiedererkennen und Anteilnahme bestätigt sich in diesen Andeutungen über die Unaufdringlichkeit. 
Letztendlich kommt auch ein „wunder Punkt“ der de-Vries-Debatte (vgl. Kapitel 15 „Detailanalyse Katrin de Vries“) noch einmal zurück, nämlich die Frage, in welcher ästhetischen Tradition der Text steht. Wiederum erweist sich Steinfeld als Verfechter einer Ästhetik, die über das 19. Jahrhundert hinausgeht.

Hier kann wirklich jemand schreiben. Aber wo ist die Kühnheit? Wo ist der Mut? Wahrhaftigkeit ist nicht unbedingt eine literarische Kategorie. Wo geht dieser Text über die Ästhetik des neunzehnten Jahrhunderts hinaus? Und mir scheint, liebe Kollegen, als wären Sie mit beiden Beinen im neunzehnten Jahrhundert. (20:30 Steinfeld)

Die „Ästhetik des neunzehnten Jahrhunderts“ wird implizit als konventionell verstanden. Von Literatur wird „Kühnheit“ erwartet. Originalität ist der Maßstab, an dem sich für Steinfeld moderne Literatur bemisst.

Burkhard Spinnen (21:41), der in anderen Diskussionen durchaus eine ähnliche Position vertritt wie Steinfeld, argumentiert im Gegenzug, dass die Literatur immer aus einem Formenkanon (,ewiger Formenkanon der Literatur“) schöpfe und daher aus einem überzeitlichen Pool von Möglichkeiten. Man kann daher, so seine Argumentation en nuce, an Literatur nur die Frage stellen, ob sie gekonnt mit diesem Pool umgeht. Einen literarischen Fortschritt kann es seiner Ansicht nach nicht geben („,ölliger Niedergang des Fortschrittsgedankens“). Er wiederspricht damit der Vorstellung, es könne eine grundsätzliche Höherwertigkeit von Literatur geben, wenn sie besonders originell gemacht ist.

Die große Einigkeit über den Text erlaubt den Juroren, ausgehend vom Text persönliche Standpunkte zur Bewertung von Literatur als Kunst darzulegen. In der Diskussion zu Pareis Text stecken viele Hinweise darauf, wie das Koordinatensystem der literarischen Wertung im Einzelfall bewusst gemacht werden kann. Innerhalb dieses Koordinatensystems ist immer ein Spektrum von Aussagen möglich; die konkrete Aktivierung von Werten hängt unter anderem vom Verlauf der Textrezeption und von kommunikativen Kontext ab. Ruft Steinfeld den Wert Originalität als Leitwert für seine Argumentation ab, nehmen die anderen Juroren die Werte Stimmigkeit, Präzision, Wahrhaftigkeit, Notwendigkeit, Erkenntnisgewinn und Spannung auf. Würde man nur auf diesen Werte-Salat blicken, ergäbe sich ein diffuses Bild literarischer Wertung. Bezieht man aber die Äußerungskontexte der Werte mit ein und die Art, wie sie an den Text Pareis rückgebunden werden, ergibt sich ein klareres Bild: Ausgehend vom Erlebnis der Ergriffenheit, der Spannung, des gebannten Lesens werden Gründe für diese Wirkung postuliert. ${ }^{71}$ Dabei wird immer wieder der Primat der Form gegenüber dem Inhalt formuliert - auf das Wie komme es an -, allerdings nicht

$\overline{71}$ Argumentativ wird die Wirkung jedoch überwiegend nicht als Ursache der Wertung, sondern als Folge der Textgestaltung präsentiert. 
einer Gestaltung, die für sich steht und Bewunderung erweckt, sondern einer Gestaltung, die funktional ist in Bezug auf Inhalt und Wirkung. Sogar in dem am wenigsten konkreten Beitrag von Ursula März, in dem sie die Werte Wahrhaftigkeit und Notwendigkeit formuliert, fällt eine Formulierung, die diese Position nahelegt: „Wenn es eine penetrante, aufdringliche Parabel wäre. Es ist eine ganz, ganz dezente Form und sie ist so ergreifend“.

\subsection{Zusammenfassung}

Die Diskussion zu Pareis Text ist im Vergleich zu anderen Siegertextdiskussionen ungewöhnlich. Die Qualität des Textes scheint so unumstritten bzw. so unbestreitbar, dass die Diskussion sich nur selten im Detail auf den Text einlässt, sondern vielmehr als eine Bühne für die Juroren genutzt wird, ihre literaturkritischen Positionen offenzulegen. Beinahe in jedem Beitrag finden sich Aussagen mit Anspruch auf Allgemeingültigkeit. Dass Thomas Steinfeld als einziger Textgegner polemisch gegen den Text kämpft, erscheint in dieser Diskussion wie ein strategischer Schachzug, um genau diese Offenbarung von literaturkritischen Positionen möglich zu machen.

Die Prestigeträchtigkeit formal-ästhetischen Wertungen bestätigt sich in der Diskussion zu Pareis Text. Nach Möglichkeit wird jedes Argument, auf welchen Wertmaßstab es auch bezogen sei, rückgebunden an Werteigenschaften des Textes: seine Fokalisierung, die Aufmerksamkeitslenkung durch den Einsatz von Bildern und Motiven, die Präzision der Beschreibungen. Obwohl die „Textarbeit“ in dieser Diskussion vergleichsweise vage bleibt, spiegeln die Positionen, die sich herausarbeiten lassen, die drei großen Wertekomplexe, die in dieser Arbeit als kennzeichnend erkannt wurden, eindrücklich. Steinfelds Forderung nach mehr Originalität wird letztlich als zweitrangig zurückgewiesen. Originalität als radikale Erneuerung von literarischen Formen (vgl. Kapitel 12.1.1 und 12.1.7) ist für einen Großteil der Juroren, die in Klagenfurt vertreten sind, kein leitender Wert. ${ }^{72}$ Die Bewunderung der Juroren gilt nicht dem, was der Text macht und wie er es macht, sondern der Frage, was und wie er es mit ihnen macht. Das ist zum einen die Lenkung des „Blickes“, das heißt eine Auswahl und eine Anordnung von Informationen, die sich den Juroren als gewinnbringend für ihr Verständnis des Textes erschließt (Orientierung). Zum anderen ist es die Aktivierung des Leserinteresses durch Rätselspannung, offene Bezüge und Entwicklungen sowie Anteilnahme und Rührung auf der emotionalen Ebene.

\footnotetext{
$\overline{72}$ Allerdings ist es möglich, dass Originalität als Kriterium bei der Vorauswahl der Texte für die Bewertung eine höhere Rolle spielt, sodass die Texte, die im Wettbewerb bewertet werden in der Regel ein Mindestmaß an Originalität aufweisen.
} 


\title{
18 Björn Kern: „Eine halbe Stunde noch“ (2007)
}

\author{
Quelle: http://archiv.bachmannpreis.orf.at/bachmannpreisv2/bachmannpreis/streaming/ \\ stories/203494/ \\ Eingeladen von: Karl Corino \\ Auszeichnung: keine
}

\subsection{Transkript der Diskussion}

0:27 März: Ja, noch einmal kneifen gilt nicht. Das habe ich gestern schon einmal gemacht. Das hat mir auch zu schaffen gemacht im Nachhinein. Beide Male hat es den selben Grund. Es gibt Texte, die sich durch ihren Stoff und durch die Art, wie sie ihn verarbeiten, also durch drastische Stoffe und durch die Art, wie sie ihn verarbeiten auf eine schwierig zu packende Art unangreifbar machen. Da kann Humor eine Rolle spielen. Hier ist es etwas ganz anderes. Es fällt mir sehr schwer, diesen Text zu kritisieren, weil der Soff natürlich sehr packend ist, sehr überzeugend und sehr wichtig. Er ist sehr aktuell. Wir leben in einer Gesellschaft, die immer/ die älter wird. Es ist nicht die reine Theorie, sondern die reine/ die Zukunft, die wahrhaftige Zukunft, dass sich das Alter um ein Alter verlängern wird, dass sozusagen das mit achtzig anfängt. Dass man ein Alter hat, in dem Menschen dement sind, pflegebedürftig sind. Wir haben Pflegekatastrophen. Dieses Thema. Das spielt hier alles eine Rolle. Wir haben es mit einer Frau zu tun, die, ich würde mal sagen, im Grenzbereich der Demenz ist, die dann entmündigt wird, die stirbt, die nicht mehr bei sich ist und viele Sachen tut, die man als gaga bezeichnet. Trotzdem am Anfang noch alleine lebt, einen Pfleger hat, vielleicht einen Zivi, der in Berlin lebt. Mir gefällt die Geschichte gar nicht. Und zwar glaube ich, dass die Entmündigung, die diese alte, über neunzigjährige Frau hier erlebt, eigentlich auch in der Erzählung geschieht, und zwar durch die falsche Erzählperspektive, die falsche Erzählhaltung. Mir ist einfach nicht klar, zumal am Anfang, wenn aus Elsa Lindströms Perspektive ja erzählt wird, was sie erlebt, wer das eigentlich macht. Wer mir, wenn diese Frau, die da allein vor sich ja mehr hinvegetiert als lebt/ Die aus dem Bett fällt und unter diesem Bett sind diese ganzen Fertiggerichte mit der eingeschweißten Folie drüber, die dort alle liegen und eine ergießt sich über sie. Die auf den Herd fasst, weil sie nicht mehr genau weiß, ob sie ihn an hat oder ob sie ihn nicht an hat. Die Frau, die also ein so schlechtes Kurzzeitgedächtnis hat, die also so nahe der Demenz ist, also so gaga, wie die dann sagen kann, oder wer mir sagt: „Elsa Lindström lebte seit einem Vierteljahrhundert alleine“. Das kann man jetzt sagen/ Das ist vielleicht/ Es gibt andere solche Sätze, wo einfach sozusagen die Erzählermitteilung nicht stimmt. Da kann man sagen: gut, das ist ein Versehen. Dann kommt irgendwie ein guter Lektor und macht das raus. In diesem Fall ist es nicht nur ein Versehen. Denn durch diese Falschheit der Perspektive geschieht etwas, was leider bei diesem Stoff das Allerschlimmste ist: Die Frau wird lächerlich. Das ist natürlich am Ende des Textes, wo sie dann stirbt, nicht. Aber am Anfang wird sie meines Erachtens zu einer lächerlichen Figur. Ich finde, dass sie schon lächerlich wird. Ich habe gesagt, es ist nicht ganz einfach, gegen Texte/ Texte zu kritisieren, die sich unangreifbar machen. Es heißt auf der ersten Seite: „Roch da nicht etwas?“. Das dürfte ja Elsa selber merken mit der Nase. Und dann heißt es: „Sie stemmte sich aus dem Stuhl. Ihr Gebiss klapperte“. Das sind sozusagen die prototypischsten, klischeehaftesten Dinge, die man über alte Menschen, die nicht mehr alleine/ die körperlich gebrechlich sind, sagen kann. Dass sie wackeln. Dass sie nicht mehr aus dem Stuhl kommen. Und dass ihr Gebiss klappert.

4:40 Kern: Ich muss da sofort etwas zu sagen: von Erzählperspektive habe ich keine Ahnung, aber von alten Menschen sehr viel/

4:45 März: Aber Sie sollten von Erzählperspektive, wenn Sie über solche Menschen schreiben, Ahnung haben!

4:50 Kern: Aber die sind tatsächlich so.

4:53 März: Ich weiß!

4:48 Kern: Die erzählen an einem Tag: Seit fünfundzwanzig Jahren lebe ich hier. Und am nächsten Tag wissen sie nicht einmal, ob sie den Herd an- oder ausgeschaltet haben. So, das ist wirklich real. Das andere möchte ich überhaupt nicht kommentieren. 
5:06 Ebel: Ja, aber da liegt der Hund begraben, nicht. Also in dem Missverhältnis von Stoff und Bewältigung des Stoffes. Ich finde den Text, anders als Sie, durchaus angreifbar.

5:20 März: Das Sujet. Durch das beeindruckende Sujet.

5:22 Ebel: Der macht sich nicht unangreifbar, sondern er macht die Türen für Angriffe sehr weit auf. Man muss nur aufpassen, dass man da nicht gleich reinläuft mit dem Kritikerpanzer. Ich finde auch nicht, dass es einen Stoffbonus gibt für Texte. Also dass Texte, die jetzt einen Stoff behandeln, deswegen hier höher oder niedriger angesiedelt sein sollten. Wir haben ja hier schon großartige Texte gehabt über alte Menschen, also Inka Parei oder Arne Roß vor zwei Jahren. Mein Problem mit dem Text ist, dass ich ihm nicht so recht glauben kann. Also wir hatten ja PeterLicht gestern, einen Text, der das Glaubenwollen und Glaubenmüssen systematisch subversiv aufhebt und uns dadurch in so eine Art masochistische Lust versetzt, wie immer man das letztlich literarische einschätzen will. Hier habe ich den Eindruck, das macht der Autor nicht bewusst, sondern es passiert ihm. Also ich glaube einfach ganz viel an diesem Text nicht. Und das liegt daran, dass es für mich nicht sprachlich überzeugend gestaltet ist. Und das hat wieder mit der Perspektive zu tun. Ich habe aber auch Bedenken auf der sachlichen Ebene. Und ich bin natürlich sicher, dass Herr Corino das alles gegengecheckt hat. Aber, was da jetzt mit der alten Frau passiert, nachdem sie aus dem Bett gefallen ist/ Gut, werden Sie jetzt auch sagen: So sind Pfleger. So gehen Pfleger mit alten Leuten um. Aber ich meine, die fällt auf den Boden. Die ist offensichtlich verletzt. Das eine Bein ist nach außen, dann ist das Knie noch mal nach außen gedreht. Würde ich als Laie jetzt diagnostizieren: Die Frau hat etwas gebrochen. Kann man sie dann in den Stuhl „zerren“. Und jetzt das Wort „zerren“. Das fällt ja. Was sagt das Wort „zerren“? Ist das jetzt ein kommentierender, bewertender Erzähler oder ist das jetzt die Perspektive von dem Bruno? Solche Geschichten gibt es dauernd. Also, Sie haben ja ein paar Beispiele genannt. Wir haben mal die Elsa-Perspektive. Und dass die Elsa schwankt, das finde ich völlig plausibel. Alte Leute sind mal völlig klar, mal sind sie völlig weg. Mal leben sie vor neunzig Jahren, mal leben sie vor fünf Minuten. Das ist geschenkt. Aber dass ich hier nie weiß, wo ich bin: Bin ich in Elsa? Bin ich im Kopf des Autors, der es kommentiert, der so Erklärungssätze nachschiebt: „Ihr Körper, der nie einen Mann gekannt hatte“ oder „wie Elsa intuitiv erfasste“. Das passt einfach nicht zu der Elsa-Perspektive. Und diese Figur des Pflegers, die finde ich völlig unglaubhaft, nicht nur in dem, was er tut, sondern auch in dem, wie er hier geschildert wird: „Er schmunzelte" und solche Sachen. Also da bin ich ganz misstrauisch.

7:52 Strigl: Also, ich glaube, man kann ganz objektiv feststellen, dass es so etwas gibt wie einen Boom der Altenpflege in der derzeitigen deutschsprachigen Literatur. Also die ganze Literatur schon ein Pflegefall. Aber man sollte es eigentlich nicht gegen/ weder für noch gegen den Text verwenden. Also das kann man dieser Erzählung nicht vorwerfen, dass sie sich damit beschäftigt, notabene, wo der Autor diese Sphäre kennt. Ich glaube aber auch, dass es hier an der Sprache hapert und dass die Sprache in diesem Text, und zwar die Erzählweise, nicht nur die Perspektive, sondern auch die Stilistik, so inkonsistent ist, wie die Gedächtniskraft der Figur. Es gibt Szenen, die sind in sich stimmig, und dann gibt es andere, vor allem dort, wo dann so eine/ der Versuch einer Poetisierung passiert, da geht es dann ganz schief. Und das ist gleich am Anfang diese Bildlichkeit: „Die Lippen brachen auseinander. Ein Luftzug kühlte ihren Gaumen“. Also, es wurde schon etwas zitiert davon. Oder wenn dann die Abendsonne, die Reflektoren aufblinken, die Reflektoren eines Rollstuhls in der Abendsonne sozusagen als geriatrisch verformter Sonnenuntergang. Das geht irgendwie zu weit in Richtung Poesie. Das kann der Text nicht einlösen und es gibt dann immer wieder auch Durchhänger, wo / Das mit dem Lächerlichmachen. Da ist schon etwas dran. Es gibt eine Szene, wo er im Auto fährt. Und die ist für mich ganz unglaubwürdig. Da läuft ein altes Lied und er denkt sich/ Und er denkt an diese Frau: „Fast schon überschwänglich fragte er sich“. Was heißt „fast schon überschwänglich“? Also, das versteht man einfach nicht. Und dass er dann so über diese Frau/ Also es werden lauter/ Die ganze Erzählung schwelgt ja im Schrecklichen. Es werden lauter schreckliche/, die diese alte Frau macht. Und er findet das aber/ schmunzelt darüber und wischt sich sogar die Tränen aus den Augenwinkeln, nämlich vor Lachen offensichtlich. Also „die Frau war wirklich gut" heißt es. Das passt nicht zu der dann sehr empathischen Einfühlung am Ende. Also, es schwankt mir zu stark.

10:19 Mangold: Ja, ich glaube, Björn Kern versteht sein Handwerk, aber was er mit diesem Handwerk macht, das mag ich überhaupt nicht. Er setzt es nämlich ein, wie ich finde, zu rein manipulativen Zwecken. Für mich ist das ein Erpressungstext. Ein moralischer Erpressungstext, der in der Haltung eines Staatsanwaltes gewissermaßen auftritt. Der mir nicht eine Wirklichkeit erzählt, sondern der mich an den Schultern geradezu körperlich packt und sagt: Hier, schau dahin! 
So sieht es aus. Und der nun das gesamte Szenario so entwirft, dass ich quasi als fühlender Mensch gar nicht anders können dürfen soll wie die Geschworenen beim amerikanischen Gerichtsprozess, als den Zustand, der darin sicherlich zu recht beklagt wird, auch in irgendeiner engagierten Weise zu verdammen und gleichzeitig der Erzählung darin ihr moralisches Surplus zuzugestehen. Das kann ich überhaupt nicht. Ich möchte mich nicht in dieser Weise drängen oder erpressen lassen. Ich finde besonders stark oder krass treten diese Mittel dann zutage, wenn, es wurde, glaube ich, schon einmal angedeutet, wenn dieser Perspektivwechsel stattfindet auf Seite sechs, wenn dann aus der Erzählung des Pflegers, aus der Perspektive Brunos erzählt wird. Diese Figur, Bruno, finde ich hanebüchen in ihrer Einseitigkeit, wie er charakterisiert wird. Das ist das Bier. Er kommt nach Hause, dann muss er sich das Bier öffnen. Dann kommt natürlich sofort als nächstes Motiv der Fernseher. Dann nimmt man vom Fernseher aus dem Motivkreis das Wort des Wegzappens, wendet das aber nicht an auf das Programm, sondern natürlich auf die Wirklichkeit, der er überdrüssig ist, der er als kaltherziger Mensch/ die er als kaltherziger Mensch wegzappen will. Und dass so jemand auf die Wirklichkeit des Pflegenotstands nur mit Spritzen reagiert, braucht einen dann ja nicht wundern, wo er sonst nur in die Glotze schaut. Das alles finde ich von so brachialen Mitteln, um den Leser dahin zu führen, dass ich im Grunde, um es hart zu sagen, dass ich dem Erzähler im Grunde auch gar nicht glaube, dass der Mitleid empfindet für diese Figur. Er benutzt diese Figur.

12:23 Heiz: Ich versuche, drei Schritte zurückzutreten und die Frage zu stellen - wir haben hier auch sehr viele Schulklassen, das habe ich mit großer Freude gesehen - zu fragen: Wie kommt es denn eigentlich zu Texten? Und das hat mich bei Männern dieses Jahr wirklich die ganze Zeit umgetrieben. Sie schreiben in Ihrem Buch „Einmal nach Marseille“: „Du erlebst so viel, sagte sie noch, ich könnte dir Stunden lang zuhören. Im Gegensatz zu mir kannte meine Mutter die Dinge, über die ich sprach tatsächlich". Nehmen wir einmal an, man ist virtuos im Tanzen. Dann geht man auf einen Tanzboden. Das haben wir auch gehört. Nehmen wir einmal an, man ist virtuos und unglaublich lebendig im Schreiben, was Sie uns offensichtlich [unv.]. Ich habe überall hier hingeschrieben „Lebendigkeit der Sprache“. Ich beurteile nicht Ihren Metaphernsalat. Was machen Sie dann damit? Warum muss Virtuosität, Lust am Schreiben, Liebe zum Detail, legitimiert werden durch metaphysische Größe? Kranke Leute. Klare Novellen. Ist das Angst vor der Lust am Schreiben? Also es ist so wie die Agonie der Mittel. Und statt mit Mitteln etwas Neues zu erfinden, werden die in etwas eingepackt, wo es dann auch nicht mehr aufgeht. Also hier kann ich zuhören und Ihr Sprachlabor genießen. Aber die Geschichte ist mir vollkommen gleichgültig. Die Sprache macht manchmal auch so, als ob Sie vielleicht Comicstrips schreiben könnten. Also ganz, ganz andere Formen. Und das treibt mich hier schon immer um, warum die Lust am Schreiben, die Lebendigkeit am Schreiben, die vielleicht junge und alte Menschen - es kamen ja auch Leute zu mir, die sagten, sie würden auch immer noch Lust am Schreiben haben -, domestiziert wird durch so ein Referenzsystem, das wieder nicht zu den Menschen und zu den Texten passt. Das ist ein persönliches Unbehagen, das ich hier formuliere. Also in keiner Weise gegen Sie oder gegen den Text. Sondern eine Beobachtung, die ich so einfach menschlich mitgeteilt haben möchte.

14:46 Radisch: Ich sehe überhaupt nicht, liebe Ursula März, wo der Text unangreifbar ist. Ich finde ihn an jeder Stelle angreifbar. Und was mich wirklich umgehauen hat, ist, dass der Autor selber sagt, er habe von Erzählperspektive keine Ahnung. Das ist, finde ich, eigentlich doch die Voraussetzung, wenn man Geschichten schreibt, dass man sich Gedanken über Erzählperspektiven macht. Und wenn hier etwas missglückt ist, ist es meiner Ansicht nach die Erzählperspektive. Und zwar ist es natürlich etwas Ungeheures, was er hier auf den letzten Seiten versucht. Das ist noch nicht angesprochen worden. Hier soll ja Sterben von innen beschrieben werden, ja. Ein UNGEHEUERLICHER Vorgang! Ungeheuerlich, ja! Ein Sterbender soll beim Sterben beschrieben werden. Das ist ja. Dass er sich das zutraut, ist schon mal/ ist schon mal/ ist schon mal fast größenwahnsinnig. Aber, ich muss wirklich sagen, dass es peinlich misslingt. Das Sterben wird als „Feuersturm“ - zunächst einmal - von einem auktorialen Erzähler, den es ja auch noch gibt, der ja ständig alles kommentiert. Also Sterben wird als „Feuersturm“ ja schon angekündigt. Und findet dann auch wirklich als ein lyrisch inszenierter Feuersturm statt. Da frage ich mich wirklich: Wer produziert diese feurigen Lyrismen? Das kann doch nicht die Sterbende sein. Wer ist das? Wie können Sie sich in den Kopf dieser Sterbenden mit/ also wirklich mit solchen/ muss ich schon sagen, mit so einem metaphorischen Quark begeben. Das finde ich eine Grenzüberschreitung, wo ich auch das Gefühl habe: Da sind auch schon diese moralischen Anklänge, die hier kamen, sehr, sehr berechtigt. Da hat man wirklich das Gefühl einer Grenzüberschreitung in einem so heiklen Bereich. Wenn Literatur das wagt, dann muss sie das können. Ich bin noch nicht/ Ich will eins 
noch sagen. Und ich will auch noch etwas dazu sagen, weil Ursula März ja hier im Publikum auch gleich so angegriffen wurde, als sie sagte, da wird auf Kosten der alten Frau erzählt. Dafür gibt es gute Gründe, dass man das sagt, finde ich. Weil, natürlich ist das alles so, wie Sie das beschreiben. Niemand zweifelt Ihre empirische Erfahrung an. Niemand hier. Und wir alle haben sehr alte Eltern und wissen da, glaube ich, auch selber inzwischen schon eine ganze Menge davon. Wichtig ist ja nur, wie das im Text vorkommt, ja. Und das finde ich/ Der Text kokettiert mit diesen gebrauchten Slips und mit den auseinandergerissenen Gesäßbacken, wo dann die Luft entströmt. Er kokettiert damit, ja. Dass das bei alten Leuten so ist - ja, so blöd sind wir nicht, dass wir das anzweifeln. Die Frage ist doch aber, wie man daraus Literatur macht. Und das finde ich auf Kosten/ also wirklich auf Kosten, jetzt in Anführungszeichen, der „Opfer“, dieser Greise. Die werden hier/ die werden hier inszeniert, damit das ein schicker Text ist. [einzelner Applaus]

17:30 Nüchtern: Jetzt mal halblang. Nein, ich habe jetzt wirklich hier ein stark/ zwei Unbehagen. Und eins ist ein völlig außerliterarisches und eins ist literarisch. Jetzt/ Mir geht das jetzt einfach zu weit. Das ist jetzt/ hat jetzt noch nichts mit dem Text/ Man muss bei diesen Manipulationsvorwürfen und Lächerlichmachen und Kokettieren sich zurückhalten. Ich habe einfach einen Grundrespekt vor Zivildienern, die so etwas machen, unter anderem deswegen, weil ich mich davor gedrückt habe. Ich habe auch in einem Altersheim gearbeitet und habe mich/ habe darauf gesehen, dass ich in der Küche beschäftigt bin und nicht auf einer Bettenstation. Und ich finde es absolut unstatthaft da anzudeuten, dass der Autor da irgendjemand ausbeuten möchte. Und man kann auch nicht sagen, er kokettiert mit diesen Dingen, weil die gibt es und man darf darüber auch schreiben.

18:30 Radisch: Ja, aber WIE ist doch trotzdem noch eine Frage.

18:32 Nüchtern: Ja, dazu komme ich. Ich finde, das Problem ist dort, wo er zu sehr auf die Tube drückt, ja. Ich finde das Bild des benutzten Slips, mit dem die Frau das Fenster wischt, völlig legitim und völlig in Ordnung. Aber dann wird einfach etwas zu/ In dieser Schlussapokalypse oder in dem auch schon angesprochen Szene, wo er dann zappt und diese Schreckensbilder dazwischengeflasht werden, da finde ich das dann auch too much. Ich habe auch nichts gegen die von der Kollegin Strigl inkriminierter Stelle: Sie öffnete ihren Mund. „Die Lippen brachen auseinander. Ein Luftzug kühlte ihren Gaumen, und mit der Zunge strich sie über die wunden Striemen“. Ich finde das eine völlig legitime Naheinstellung. Da wird sozusagen auf der/ sozusagen in Slow Motion und in einer Naheinstellung noch einmal auf dieses ganze/ diese Microbereiche gezoomt. Und da können auch Lippen - mein Gott, ja - brechen. Also wenn sie aufeinander kleben, brechen sie auf und dann ist halt das Fleisch wund. Das finde ich schon in Ordnung so. Ich finde auch eine ganz hübsche germanistische - also ganz so blauäugig kann der Autor auch wieder nicht - Passage. Das spielt zum Teil in einer Gegend, da gibt es eine Simon-Dach-Straße und eine Gryphius-Straße. Das sind die großen Barockdichter des Memento Mori, die in ihren Sonetten mit extremen Verfallsbildern der Körper arbeiten. Also so ganz unraffiniert ist der Text/

20:15 Radisch: Ja, der ist super raffiniert. Das wirft ihm ja keiner vor.

20:14 Nüchtern: Das braucht er ja nicht. Man kann es/

20:18 Radisch: Dieses Ausgeklügelte, ja, diese literarische Inszenierung dieser Gebrechlichkeit, das ist doch der Vorwurf.

20:25 Nüchtern: Ja, und noch eines zur Erzählperspektive. Ich glaube auch, dass die stottert und nicht funktioniert, aber es ist durchaus legitim, Erzählperspektiven zu wechseln. Man sollte nur wissen, in welcher/ wo man gerade ist. Und da hapert es. Also man kann ein streng/ ein personales Erzählen mit einem kommentierenden wechseln. Ich finde, es funktioniert dort nicht, wo es zum Beispiel in ihrem Traum, der sozusagen vorgeführt wird/ Und dann heißt es „Elsas Hirn kotzte die Zeitung aus". Das geht nicht. Da muss man auch wirklich auch immanent bleiben.

20:58 März: Nur ganz kurz. Noch was anderes. Man kann ja eine Gegenrechnung aufmachen. Warum ist der Text nicht komisch? Also, hat jemand richtig gelacht? Obwohl eigentlich sehr viel Komisches vorkommt. Unterhosen auf Schirmen, die anschmoren, sind doch eigentlich komische Situationen. Warum ist es aber hier beklemmend, obwohl es komisch ist? Nur, ich kenne von der Dänin [Marie Pettersson?]/ die hat ein Buch geschrieben. Ganz ähnliches Sujet. Eine alte Frau, etwas dement, ein Pflegefall, aber sie kann noch sich ein bisschen bewegen. Und es gibt eine Pflegerin. Und deren beider Geschichte wird erzählt. Und das Buch ist wahnsinnig komisch. Weil diese alte Frau geht dann mal mit so einem Rollwagen in den Supermarkt. Und im Supermarkt legt 
sie sich in die Kühltruhe, weil es ihr so bequem vorkommt und weil es ihrem Bett so ähnlich sieht. Und dieses Buch ist sehr komisch. Und es gibt aber durch die Erzählung keine Entmündigung, weil die beiden sich in der Perspektive auf Augenhöhe bewegen. Diese Augenhöhe, die gibt es hier nicht. Und dann ist es eben nicht egal, wovon erzählt wird. Wir haben es mit einem ohnmächtigen behin/ Menschen zu tun und dann gibt es ein Machtgefälle. Und dann wird er benutzt.

22:51 Rakusa: Ja, wir hatten vorhin gerade diesen leisen, sehr ökonomisch gearbeiteten Text von Jan Böttcher, wo sogar etwas Dramatik vermisst wurde. Spannung hieß es. Hier ist dessen einfach zu viel. Und zwar viel zu viel würde ich sagen. Es gab einmal diesen Roman der jung verstorbenen Katrin Seebacher, auch über alte Menschen, der im Ton dann sehr viel zurückgenommener war. Da ging es nicht nur um eine alte Person und um sterben. Hier ist für mich, abgesehen von der Konfusion der Perspektiven und für mich auch kaum nachvollziehbaren Weise, wie hier tatsächlich über das Innenleben einer Frau berichtet wird, die schon dem Tod nahe ist oder sogar dann stirbt. Also es ist sehr problematisch, um das Mindeste zu sagen. Aber der Text ist irgendwie überinstrumentiert. Er ist auch zu metaphorisch. Ich mache das nur an einer Stelle fest. Auf Seite fünf. Es geht um diesen Aufprall auf den Fliesen: „Ihr Aufprall klang knöchern, etwas knirschte, etwas knackte“. Da wird auch noch nachgeschoben, gut, Alliteration. „Sie hatte die Tüte mit sich heruntergerissen, die Metallschale war aufgeplatzt auf den Fliesen und in Elsas Hand schimmerte püriertes Huhn gelblich im Mondlicht wie eine giftige Substanz". Ja, das kann man vielleicht sogar interessant finden. Aber dann kommt dieses Mondlicht gleich wieder. Und ich sage, da finde ich es dann, vor allem aufs Ganze gesehen sehr, sehr überinstrumentiert. Und ich glaube - das würde aber einen ganz anderen Ansatz bedeuten - dass die Demenz der Frau, auch dieser Wahnsinn, der sich in ihr abspielt, in allem, dass der eigentlich nur dann zum Ausdruck käme, wenn die Erzählung das, was uns einfach berichtet wird, der Erzählbericht an sich, sehr viel sachlicher, unmetaphorischer, undramatischer wäre. Ich glaube, hier ist in jeder Beziehung eine Steigerung und Übersteigerung, die aber das Groteske nicht erreicht. Nicht wahr Frau März? Es ist nicht ins Komische oder Groteske getrieben. Das auch wieder nicht. Das wäre auch eine Möglichkeit, aber das will der Text, glaube ich, wirklich nicht. Aber in der Beziehung ist er dann auch wieder unschlüssig. Weil er das eine nicht tut und das andere aber auch nicht lässt. Nämlich uns durch eine Überdramatik einfach ständig so anzutörnen. Und da wird eben gerade das Berühren/ Diese alte Frau ist eigentlich ja eine zutiefst bemitleidenswerte, auch irgendwo berührende Figur. Aber das kommt für mich gerade dadurch nicht zustande, denn das könnte zustande kommen. Wirklich der Wahnsinn. Auch unter Umständen mit dieser doppelten Perspektive, wenn Sie das richtig lösen. Dann erst/ Aber dann müsste/ Der Grunderzählton müsste ein anderer sein. Und ein sehr viel diskreterer.

25:29 Mangold: Ganz kurz zu der Stelle, die Sie zitiert haben, wenn von dem pürierten Huhn die Rede ist, das in Elsas Haar hängt und dann dieser Nachsatz „wie eine giftige Substanz". Das ist als Vergleich vollkommen überflüssig.

25:41 Rakusa: Ja, mich hat auch dieses Mondlicht gestört. Da kommt irgend so etwas Romantisches. Und das Mondlicht kommt dann nachher gleich wieder: „Direkt vor ihr leuchteten Augen aus dem Dunkeln, eine zitternde Schnauze ragte ins Mondlicht". Wir wissen jetzt auch nicht, wo wir sind. Denn das ist jetzt bereits wieder ihre Imagination, ihr Traum. Dieses Mondlicht. Das Mondlicht davor ist aber das andere Mondlicht, ja. Und also, da geht auch etwas irgendwie nahtlos ineinander über, was nicht nur eine motivische Konstruktion ist, sondern ich glaube, es geht hier einfach nicht auf. Aber mich würde die Figur sehr interessieren, die Elsa, in ihrer Demenz. Und das könnte ruhig eine Spur sogar noch wahnsinniger sein. Aber es kann nicht das Ganze sich auf diesem fast hysterisch dramatischen Niveau bewegen. Und voller Metaphern auch. Es ist wirklich sehr viel Metapher, sehr viel Tube wurde schon gesagt, ja.

26:36 Corino: Ja, ich habe diesen Text eingeladen. Und das hängt vielleicht nicht zuletzt damit zusammen, dass ich selbst zwei Verwandte jenseits der Neunzig habe, die in fernen Heimen der Demenz entgegendämmern oder schon in ihr versunken sind. Ich habe also nichts zu recherchieren brauchen, lieber Herr Ebel. Und es hat mich gefreut, dass ausgerechnet von Klaus Nüchtern ein Rettungsversuch dieses Textes kam. Das ist wahrscheinlich auch nicht von ungefähr, dass er neben Björn Kern der Einzige ist, der offensichtlich in einer solchen Einrichtung Erfahrungen gesammelt hat. Im Unterschied zu uns allen ist Björn Kern der Einzige, der ein Jahr lang, ein Jahr seines Lebens geopfert hat, um solche Menschen zu pflegen. Was er erzählt, ist also von sehr viel Erfahrung grundiert. Und was hätte er für eine Möglichkeit gehabt, diesen Text zu erzählen? Weil ja immer auf der Erzählperspektive beharrt wird. Wir hatten auch Texte, wo die Erzählperspektive fraglich ist. Zum Beispiel bei Jochen Schmidt. Das ist dann aber gar nicht weiter ernst genommen worden. 
Hier ist der Fall natürlich sehr viel dramatischer, weil wir es mit einem Text zu tun haben, der die Ästhetik des Hässlichen, die Rosenkranz, der Hegelbiograf, einst entdeckt hat, natürlich in einer extremen Weise durchexerziert wird, in einer extremen Weise, die natürlich Abwehr und Ekelgefühle hervorruft, die sich dann leicht rationalisieren lassen und die sich dann gar erpresserisch nennen lassen, wie das Herr Mangold getan hat. Björn Kern hätte den Text natürlich total aus der Innenperspektive dieser Frau erzählen können, wie er es dann im Schlussmonolog, inneren Monolog, ja versucht. Ich sehe das unter anderem als Gegenentwurf zu Hermann Brochs „Tod des Vergil“ mit den [März? signalisiert Unglauben]/ Ja! Aber auf einer ganz anderen Ebene und auf einer schmerzlichen Ebene. Da geht es eben nicht so hymnisch-rhapsodisch zu wie bei Broch mit endlosen Partizipialkonstruktionen, sondern hier werden Momenteindrücke und Kindheitseindrücke wie der Brand des Elternhauses, der offensichtlich ja nicht verstanden worden ist, in einen wahnsinnigen Sog zusammengeführt. Und, ja es ist schon klar: Wenn man einerseits das Gaudiburschentum der Apokalypse bei Herrn Licht goutiert/

29:07 Radisch: Ah, jetzt endlich sagen Sie mal etwas zu dem Text. Das freut mich aber, Herr Corino.

29:11 Corino: Jaja. Ich/

29:12 Radisch: Das haben wir gestern schmerzlich vermisst!

29:15 Corino: Ich bin dabei, liebe Frau Radisch.

29:16 Radisch: Und jetzt so ein kleiner Tritt so nebenbei, wo man überhaupt keine Zeit zum Argumentieren mehr hat.

29:20 Corino: Frau März hat auch davon gesprochen gerade. Ja, das ist schon sehr symptomatisch, wie ein solcher Text mit seiner Banalisierung und Bagatellisierung des Todes, wo die Ersoffenen munter wieder aufstehen, als wäre nichts geschehen. Wie der da also in einer Orgie der Akklamation hier begrüßt wird und wie hier ein Text, der sich mit einem gesellschaftlichen und persönlichen Problem von extremer Tragweiter befasst, doch auf eine sehr erstaunliche Weise abgewertet wird. Ich bin nach wie vor überzeugt, dass Björn Kern hier ein sehr wichtiges Experiment unternommen hat - es mag nicht überall gelungen sein - aber das doch großer Ehre wert ist. [Applaus]

30:21 Mangold: Darf ich nur kurz nachfragen: Wofür meinen Sie, dass das symptomatisch ist? Jetzt irgendwie für den Zeitgeist, oder?

30:24 Corino: Ja, eben auch für die Abwertung von Erfahrungen, die sehr extrem sind und die uns alle eines Tages womöglich selber ins Haus stehen. Sie sind da noch von weit weg, aber wenn man das aus nächster Nähe erlebt hat, dann kann man nicht so mit einem ästhetischen Achselzucken über diesen Text hinweggehen.

30:44 Rakusa: Aber ich möchte auch richtigstellen, obwohl das mich weniger betrifft als vielleicht so den/ so insgesamt die Wortmeldungen hier. Ich glaube nicht, dass irgendjemand etwas gegen diesen Stoff hat. Der ist unglaublich wichtig. Das wurde, glaube ich, am Anfang auch schon gesagt. Und ich habe auch Katrin Seebacher erwähnt als ein sehr gelungenes Beispiel der Auseinandersetzung mit alten Menschen.

31:09 Radisch: Parei, die hier einen Preis bekommen hat für einen Text eines alten Mannes, der stirbt, ja! Wir haben nichts gegen dieses Thema!

31:14 Rakusa: Das ist doch gar keine Frage, dass dieses Thema ganz wichtig ist, sondern uns interessiert ja eher, wie es hier angegangen wird, wie es behandelt wird. Und ich überlege ja die ganze Zeit, hätte man den Text/ oder könnte man ihn durch Umschrift - aber das müsste ja ein bisschen anders geschehen - eben doch noch so tarieren, dass gerade vielleicht Ihr Grundanliegen dadurch besser zum Ausdruck kommt. Denn gegen Ihr Anliegen ist ja überhaupt/ Und gegen das Anliegen des Textes ist überhaupt nichts zu sagen. Ich bin eigentlich von dem Anliegen selbst und dass es gemacht wird erst einmal auch beeindruckt. Es ist nur die Frage, wie es hier gelöst wird. Das ist das, wo man sich wirklich streiten kann, nicht. Aber grundsätzlich ist es ein ganz wichtiges Thema.

32:00 Strigl: Eigentlich nur ein Satz: Ich glaube nicht, dass es fruchtbringend ist, den Text, den wir jetzt gehört haben in irgendeiner Weise gegen den von PeterLicht auszuspielen. Das sind Lichtjahre dazwischen, sowohl was das Sujet betrifft als auch was die Form betrifft. Und genauso wenig halte ich es für irgendwie weiterführend, die Biografie des Autors für den Text oder gegen 
den Text einzusetzen. Wir müssen schon die Geschichte betrachten. Und wir haben ja gar keine andere Wahl, als uns mit den ästhetischen Mitteln zu beschäftigen. Und wenn der Autor, was möglich gewesen wäre, drei Jahre gearbeitet hätte in diesem Institut, dann würde das den Text für mich nicht besser und nicht schlechter machen. [Applaus]

32:46 Corino: Die Texte stehen nebeneinander im Raum und dürfen durchaus miteinander verglichen werden, vor allem wenn eben mit dem vorausgehenden Text ein solcher Affenzirkus veranstaltet wird, wie wir das erlebt haben.

33:00 Radisch: Aber dieses Nachtreten, Herr Corino, das finde ich nicht in Ordnung. Das muss ich wirklich sagen. Sie haben gestern zu diesem Text nichts gesagt und jetzt treten Sie in Nebensätzen nach. Das finde ich nicht richtig, ja.

33:10 Corino: Wir haben eine Gesamtdiskussion und wir müssen die Texte auch insgesamt würdigen. Der Wettbewerb ist noch nicht zu Ende. Wir sprechen nicht nur intra muros über solche Texte. Wir sprechen öffentlich. Und wann es geschieht, ist letztlich egal, liebe Frau Radisch. [Applaus]

[Radisch weist die Aussage im Hintergrund zurück.] 


\subsection{Analyse der Diskussion}

\section{Ablauf der Diskussion}

Die Diskussion zu Björn Kerns Text „Eine halbe Stunde noch“ gehört mit knapp 34 Minuten zu den längsten Diskussionen des Korpus. Es melden sich alle Juroren zu Wort. Außer dem vorschlagenden Juror Karl Corino begegnen alle Juroren dem Text mit harter Kritik. Diese Kritik veranlasst den Autor bereits nach der ersten Wortmeldung dazu, einen Verteidigungsversuch einzuleiten, der allerdings nicht gut aufgenommen wird. Karl Corino meldet sich zuletzt zu Wort, macht in seinem Beitrag allerdings unmissverständlich klar, dass er der Bewertung der anderen Jurymitglieder grundsätzlich nicht folgen kann. Dadurch kommt es gegen Ende der Diskussion zu einem Streit zwischen Corino und einigen anderen Juroren, insbesondere Iris Radisch und Ilma Rakusa. Die Diskussion ist sowohl von der Länge her als auch von der Intensität der Kritik und der Auseinandersetzung, letztendlich auch in Hinblick auf die in ihr verwendeten Kriterien, eine eher ungewöhnliche Diskussion. Zentraler Gegenstand der Auseinandersetzung ist ein Konflikt zwischen der Anerkennung des Sujets und dessen sprachlicher Umsetzung, die in erster Linie aus moralischen Gründen abgelehnt wird. Der moralische Vorwurf, der Text mache seine Hauptfigur lächerlich, verknüpft sich in den Argumentationen eng mit einer Kritik an der Verwendung verschiedener Erzählperspektiven. Anders als zu erwarten gewesen wäre, wird der Text allerdings nicht insgesamt in seiner formalen Gestaltung kritisiert. Ganz im Gegenteil attestieren ihm einige Juroren hohe sprachliche und formale Qualitäten. Offenbar reagieren die Juroren spontan mit starker Ablehnung auf den Text, die sie allerdings nur teilweise an seiner formalen Gestaltung festmachen können. Die verschiedenen Jurymitglieder finden verschiedene Wege, damit argumentativ umzugehen.

\section{Der Text „Eine halbe Stunde noch“}

Der Text „Eine halbe Stunde noch“ erzählt die letzten Lebenstage der dementen, siebenundneunzigjährigen Elsa Lindström. Im Zentrum des Textes steht die Verwahrlosung der Frau, zunächst in der eigenen Wohnung, später in einem Pflegeheim. Die Hauptfigur wird sowohl aus der Außenperspektive als auch aus der Innenperspektive dargestellt. Neben Elsas Gedanken werden auch die ihres Pflegers Bruno wiedergegeben, vor allem in einer zentralen Passage, in der Elsa von ihrer Wohnung ins Pflegeheim gebracht wird. Schließlich wird Elsas Tod aus der Innenperspektive erzählt. Im Text werden poetische Passagen und Passagen, die das Alltägliche auch in seiner Hässlichkeit darstellen, nebeneinandergestellt. 
Eine jener Passagen, die in der Diskussion erwähnt wird, weil sie als stereotyp, aber auch als eine unangemessen hässliche Darstellung empfunden wird, führt Elsa als Figur ein:

Sie stemmte sich aus dem Stuhl, ihr Gebiss klapperte. Elsa hasste dieses Geräusch. Sie hasste alle Geräusche, die ihr Körper verursachte, das Knirschen der Nackenwirbel, wenn sie ihren Kopf bewegte, das Knacken der Gelenkkapseln in den Knien, das Schmirgeln der trockenen Haut, wenn sie an ihre Stirn fasste, das stundenlange Rumoren im Bauch. (Kern 2007)

Während hier der Erzähler (interne Fokalisierung) Elsas Perspektive wiedergibt, greift er in anderen Passagen kommentierend in den Text ein und offenbart Wissen, das über das der Hauptfigur hinausgeht (Nullfokalisierung). Dieses kommentierende Eingreifen wird von den Juroren aus verschiedenen Gründen als problematisch empfunden. Auch hierfür eine Beispielpassage:

Elsa Lindström erwachte in einem Zimmer, das mit sechseinhalb Quadratmetern gerade noch der gesetzlichen Mindestgröße für Heimzellen entsprach. An der Decke surrte ein Ventilator, das Zimmer war winzig, aber sauber und hell, rundum gekachelt wie ein Schlachthaus, so ließe sich all das problemlos abspritzen, was bis zu Elsas endgültigem Auszug von ihrem Körper noch an die Wände fand. (Kern 2007)

In dieser Passage wird durch den Erzähler eindeutig eine moralische Bewertung des Geschehens nahegelegt, indem die Funktionalität und Kälte des Sterbezimmers („wie ein Schlachthaus") herausgestellt wird. Es wird mit der Diskrepanz zwischen der emotionalen Betroffenheit des Lesers angesichts der Themen Sterben und Tod und der Funktionalität professioneller Altenpflegeeinrichtungen gespielt.

\section{Der wegweisende Einstieg durch Ursula März}

Ursula März eröffnet die Diskussion und setzt mit ihrem Beitrag bereits die Themen und Werte, die die gesamte Diskussion prägen werden. Sie verweist auf die Wichtigkeit des Sujets, das den Text „auf eine schwierig zu packende Art unangreifbar mach[t]" (0:27 März). Damit nimmt sie die Argumentation Corinos (26:36) vorweg, der in der Tat am Ende der Diskussion darauf hinweisen wird, dass die Erfahrung des Autors mit alten Menschen und die Wichtigkeit und Aktualität des Stoffes die entscheidenden Vorzüge des Textes seien. Sie kritisiert den Text dafür, dass er beim Lesen die falschen Gefühle wecke: Die Figur werde „lächerlich“ und es finde eine „Entmündigung“ der Protagonistin in der Geschichte statt. März legt also nahe, dass es bei einem solchen Thema notwendig ist, dass der Leser der Hauptfigur gegenüber positiv empfindet. Weil in Kerns Text die Hauptfigur ihrer Meinung nach „lächerlich“ wird, verfehlt der Text nicht nur seine Wirkung, sondern 
auch sein Ziel, dass der Leser sein Anliegen ernst nimmt. In dieser Hinsicht ist März' Kritik also eine moralische Kritik: Ihrer Argumentation zufolge ist es nicht richtig, dass der Leser durch den Text verleitet wird, sich über die Protagonistin, die alte Frau, lustig zu machen.

Mir gefällt die Geschichte gar nicht. Und zwar glaube ich, dass die Entmündigung, die diese alte, über neunzigjährige Frau hier erlebt, eigentlich auch in der Erzählung geschieht, und zwar durch die falsche Erzählperspektive, die falsche Erzählhaltung. (0:27 März)

März begnügt sich in ihrer Argumentation nicht damit, die Entmündigung, die sie im Text wahrnimmt, zu beschreiben, sondern bemüht sich auch, diese auf der formalen Ebene des Textes nachzuweisen. Nicht die Einstellung des Autors wird in erster Linie als problematisch eingeschätzt, sondern die „Erzählperspektive, die falsche Erzählhaltung“ des Textes. Auf diese Weise entzieht sich die Jurorin dem Problem, ein Urteil über das Denken des Autors abzugeben. Gleichzeitig wechselt sie von der moralischen auf die formale Ebene und damit auf eine Wertungsebene, die mehr Ansehen genießt und aus diesem Grund mehr Überzeugungskraft hat. Im weiteren Verlauf ihres Beitrags führt März exemplarisch an Textstellen vor, wie der Eindruck der Lächerlichkeit entsteht. Die zentralen Wertkomplexe, die sie damit eingeführt hat und die die Diskussion weitestgehend prägen, sind: 1. die moralische Kritik daran, dass die Hauptfigur lächerlich wird, verbunden mit der Kritik an der Erzählperspektive („falsche Perspektive“); 2. die Frage danach, ob es einen Aktualitätsbonus für bestimmte Stoffe oder Sujets gibt; 3. der Wunsch nach einer Hauptfigur, die dem Leser erlaubt, sich in sie einzufühlen. In anderen Diskussionsbeiträgen kommt noch 4. die Kritik hinzu, dass der Text zu wenig offen lasse („Überinstrumentierung“) und 5. die Kritik an der Unstimmigkeit auf der Ebene der Perspektive, aber auch in Bezug auf die Abstimmung von Sprache und Inhalt.

\section{Das argumentative Prestige der Formebene im Verhältnis zum Plot}

Im Anschluss an März' Beurteilung, die im Vergleich zu einigen anderen Diskussionsbeiträgen, die später folgen, relativ zurückhaltend in der Härte der Äußerung ist, meldet sich der Autor selber zu Wort, um März' Kritik zurückzuweisen. Eine solche Einmischung des Autors ist selten und hat, insbesondere dann, wenn der Autor sich rechtfertigend äußert, in der Regel keine positiven Auswirkungen auf die Diskussion. Björn Kern (4:40) rückt sich in seiner Verteidigung geradezu in ein ungünstiges Licht, wenn er feststellt: „Ich muss da sofort etwas zu sagen: Von Erzählperspektive habe ich keine Ahnung, aber von alten Menschen sehr viel/“. Diese Aussage ist insofern ungünstig, als Kern sich selbst auf der 
prestigeträchtigen Formebene als unbedarft darstellt und dafür seine stoffliche Expertise ins Spiel bringt. März kontert, er sollte aber von Erzählperspektive, wenn er über solche Menschen schreibe, Ahnung haben (4:45 März). Auch Iris Radisch nimmt sehr viel später im Diskussionsverlauf in ihrer aufgebrachten Bewertung die Aussage des Autors noch einmal auf:

Und was mich wirklich umgehauen hat, ist, dass der Autor selber sagt, er habe von Erzählperspektive keine Ahnung. Das ist, finde ich, eigentlich doch die Voraussetzung, wenn man Geschichten schreibt, dass man sich Gedanken über Erzählperspektiven macht. Und wenn hier etwas missglückt ist, ist es meiner Ansicht nach die Erzählperspektive. (14:46 Radisch)

Die Reaktion der beiden Literaturkritikerinnen zeigt deutlich an, welchen argumentativen Stellenwert die Beherrschung literarischer Formen, das „Schreibenkönnen“, gegenüber Absicherung des Plots durch Recherche oder Erfahrungen hat. Lediglich zwei Juroren lassen das Argument, dass die Darstellung der neunzigjährigen Protagonistin wirklichkeitsgetreu sei, gelten. Das ist zum einen Klaus Nüchtern, der sich bemüht, die sehr harte Kritik am Text abzufedern, ohne jedoch grundsätzlich anderer Meinung zu sein:

Mir geht das jetzt einfach zu weit. [...] Man muss bei diesen Manipulationsvorwürfen und Lächerlichmachen und Kokettieren sich zurückhalten. Ich habe einfach einen Grundrespekt vor Zivildienern, die so etwas machen, unter anderem deswegen, weil ich mich davor gedrückt habe. (17:30 Nüchtern)

Nüchtern erkennt, dass die Grundtendenz der Kritik moralisch ist und sich aus diesem Grund auch gegen den Autor als Menschen wendet, weil dieser ihn gedanklich konzipiert hat. Unmoralische Texte können, so muss man im Sinne dieser Annahme folgern, nur von unmoralischen Autoren kommen. Daher wirbt er für Respekt den Erfahrungen gegenüber, die der Autor, der im Altenheim gearbeitet hat, in den Text eingebracht hat. Auch Nüchtern argumentiert anschließend auf der formalen Ebene weiter - ebenfalls kritisch. Karl Corino, zum anderen, setzt als einziger Juror den Inhalt als entscheidendes Argument für den Text ein:

Im Unterschied zu uns allen ist Björn Kern der Einzige, der ein Jahr lang, ein Jahr seines Lebens geopfert hat, um solche Menschen zu pflegen. Was er erzählt, ist also von sehr viel Erfahrung grundiert. (26:36 Corino)

Er wundert sich später, „wie hier ein Text, der sich mit einem gesellschaftlichen und persönlichen Problem von extremer Tragweite befasst, doch auf eine sehr erstaunliche Weise abgewertet wird“ (ebd.). Corino, der allgemein im Rahmen des Ingeborg-BachmannWettbewerbs dafür bekannt ist, dass er in literarischen Texten Wert auf stichhaltige Informationen legt, vertritt in diesem Beitrag eine andere Auffassung von Literatur als die 
anderen Jurymitglieder, in der die Aktualität des Stoffes und das gesellschaftliche Engagement des Autors von größerer Bedeutung sind. Die Verteilung positiver und negativer Bewertungen in der Diskussion zeigt aber deutlich an, dass die Mehrheit der Juroren eine Lektüre bevorzugt, die insofern „einladend“ ist, als sie beispielsweise einen empathischen Zugang zur Figur ermöglicht. Die Aktualität des Themas ist demgegenüber sekundär. Ebel (5:22), der im Anschluss an März spricht, sagt es ganz explizit: „Ich finde auch nicht, dass es einen Stoffbonus gibt für Texte. Also dass Texte, die jetzt einen Stoff behandeln deswegen hier höher oder niedriger angesiedelt sein sollten“. Das Problem des Textes sieht Ebel dann, wie nicht anders zu erwarten, auf der sprachlich-formalen Ebene: „Also ich glaube einfach ganz viel an diesem Text nicht. Und das liegt daran, dass es für mich nicht sprachlich überzeugend gestaltet ist. Und das hat wieder mit der Perspektive zu tun" (5:22 Ebel).

Mit Corinos Verteidigung gegen Ende der Diskussion entstehen, insbesondere weil Corino den anderen Jurymitgliedern zu verstehen gibt, dass er ihre Werte nicht teilt, wiederholt Versuche, bereits geäußerte Wertungen zu legitimieren. Rakusa (30:44) führt an, dass niemand etwas gegen diesen Stoff habe. Der sei unglaublich wichtig. Radisch (31:09) beteuert „Wir haben nichts gegen dieses Thema!“. Indem sie Corinos Meinung ein „Wir“ gegenüberstellt, gibt sie deutlich zu erkennen, dass sie beansprucht, eine Mehrheitsmeinung zu vertreten. Sie gibt zu verstehen, dass für sie, und zwar möglicherweise nicht nur auf der Ebene des Stoffes, sondern auch in der sprachlich-formalen Kritik des Textes ein Konsens besteht. Offenbar aufgemuntert durch diese suggerierte Einigkeit, unterstreicht Rakusa (31:14) unmittelbar nach Radisch noch einmal deren, aber auch ihre eigene Aussage, wobei sie ebenfalls zum „Wir“ wechselt: „Das ist doch gar keine Frage, dass dieses Thema ganz wichtig ist, sondern uns interessiert ja eher, wie es hier angegangen wird, wie es behandelt wird“. Sie greift damit auch einen der stärksten Bewertungstopoi überhaupt auf, dass es nämlich um das Wie (Form) gehe, nicht um das Was (Inhalt). Auch Daniela Strigl sieht sich unter diesem Vorzeichen veranlasst, noch einmal das, was sie für einen sinnvollen Umgang mit einem solchen Text hält, zu formulieren:

Und genauso wenig halte ich es für irgendwie weiterführend, die Biografie des Au-
tors für den Text oder gegen den Text einzusetzen. Wir müssen schon die Geschichte
betrachten. Und wir haben ja gar keine andere Wahl, als uns mit den ästhetischen
Mitteln zu beschäftigen. Und wenn der Autor, was möglich gewesen wäre, drei Jahre
gearbeitet hätte in diesem Institut, dann würde das den Text für mich nicht besser
und nicht schlechter machen. [Applaus] (32:00 Strigl)

Im Anschluss an diese Äußerung gibt es längeren Applaus im Publikum. Strigl bemüht sich an dieser Stelle um eine Rekapitulation dessen, was sie in vorausgesetztem Einver- 
nehmen mit den anderen Jurymitgliedern für die Aufgabe einer Literaturpreisjury hält. Ihre zentrale Annahme besteht darin, dass der Stoff und seine Sicherung durch Erfahrung des Autors wenig Einfluss auf die Bewertung des Textes haben sollte, die „ästhetischen Mittel[]" dagegen viel.

Geradezu prototypisch zeigt sich in dieser Diskussion, dass die Aktualität des Stoffes zwar ein theoretisch bekannter und auch anerkannter Wert ist, der aber gegenüber sprachlichformalen sowie moralischen Bedenken argumentativ in den Hintergrund tritt. So gut wie alle Juroren halten es in ihren Beiträgen für notwendig, zu betonen, dass sie sich bewusst sind, dass die Aktualität des Stoffes bzw. das Sujet ein anerkanntes Kriterium ist. Mit Ausnahme von Corino setzt aber keiner der Juroren den Wert als wichtigsten Wert ein. Die Anerkennung des Sujets hat also in erster Linie einen kommunikativen Wert. Gesellschaftliche Aktualität ist im Wertungswissen der Juroren als möglicher positiver Wert so tief verankert, dass sie in ihren Bewertungen stets zu erkennen geben, dass ihnen die Existenz des Wertes bewusst ist und sie in diesem Fall bewusst anderen Werten wie Offenheit, Nachvollziehbarkeit und Identifikationspotential der Hauptfigur den Vorrang geben.

\section{Die Kohärenz der Erzählperspektive}

In seinen Erläuterungen geht Ebel (5:06) darauf ein, dass der Text wechselnde Erzählperspektiven einnehme, die den Leser verwirren und zudem als nicht authentisch wahrgenommen würden. In der Tat wird ein Authentizitätsproblem, das durch die Fokalisierung bzw. die Erzählhaltung zustande kommt, von mehreren Juroren bemängelt. In diesen Argumentationen geht es um die Kohärenz und Stimmigkeit der Erzählung, und zwar sowohl auf der Ebene der Abstimmung der Textelemente aufeinander als auch auf der Ebene der Nachvollziehbarkeit des Geschehens. So bemerkt Strigl, dass „nicht nur die Perspektive, sondern auch die Stilistik, so inkonsistent ist, wie die Gedächtniskraft der Figur" (7:52 Strigl). Es gebe Szenen, so Strigl, die seien in sich stimmig. Insbesondere dort, wo der Text versuche zu poetisieren, sei er allerdings unstimmig. Strigl stimmt zwar zu, dass ein Effekt dieser Poetisierungen die Lächerlichkeit der Figur sei, macht aber dieses moralische Argument nicht zum Zentrum ihrer Kritik. Um Nachvollziehbarkeit und Einheitlichkeit geht es auch bei Nüchtern, der sich in seiner Argumentation dazu berufen fühlt, wiederum einige der Argumente seiner Jurykollegen zu relativieren:

Ja, und noch eines zur Erzählperspektive. Ich glaube auch, dass die stottert und nicht funktioniert, aber es ist durchaus legitim, Erzählperspektiven zu wechseln. Man sollte nur wissen, in welcher/ wo man gerade ist. Und da hapert es. Also man kann ein streng/ ein personales Erzählen mit einem kommentierenden wechseln. Ich finde, es 
funktioniert dort nicht, wo es zum Beispiel in ihrem Traum, der sozusagen vorgeführt wird/ Und dann heißt es: „Elsas Hirn kotzte die Zeitung aus“. Das geht nicht. Da muss man auch wirklich auch immanent bleiben. (20:25 Nüchtern)

Nüchtern hebt zunächst hervor, dass es durchaus legitim ist, in einem Text verschiedene Erzählperspektiven zu koppeln. Im Text von Björn Kern „funktioniert“ diese Kopplung aber Nüchtern zufolge nicht, weil Textsequenzen, die offenbar vom Leser dem Innenleben der Figur zugeordnet werden - Nüchtern nennt den Traum der Protagonistin - unerwartet durch Kommentare des Erzählers unterbrochen werden. Nüchtern sieht darin eine Inkonsistenz; die Kommentierung scheint ihm nicht plausibel. Argumentativ funktioniert der Wert Kohärenz hier offensichtlich als Absicherung. Nüchtern, der sich, wie bereits erwähnt, bemüht, die Diskussion von der emotionalen auf die sachliche Ebene zurückzuführen, setzt den Wert Kohärenz zu diesem Zweck ein. Zum einen erlaubt dieser Wert es, textnah zu argumentieren, zum anderen ist Kohärenz ein so unstrittiger, anerkannter Wert, dass Nüchtern nicht mit starken, engagierten Reaktionen rechnen muss.

\section{Die moralische Auseinandersetzung mit dem Text}

Schon in März' Einstiegskommentar war deutlich zu erkennen, dass der Argumentation eine moralische Abwehrhaltung zugrunde lag. Nicht in allen, aber doch in mindestens zwei weiteren Beiträgen lässt sich dieses moralische Grundargument sehr deutlich nachvollziehen: bei Ijoma Mangold sowie bei Iris Radisch. Beide tragen ihre Bewertungen mit großem Pathos vor und machen auf diese Weise deutlich, wie intensiv ihre Ablehnung ist, aber auch wie sehr der Bereich der moralischen Bewertung offenbar umkämpft ist. Obwohl beide Juroren letztlich moralisch argumentieren, gehen beide Argumentationen in eine völlig andere Richtung. Iris Radisch stimmt März in der Einschätzung zu dass „da [...] auf Kosten der alten Frau erzählt [wird]“ (14:46 Radisch). Dieses Lächerlichmachen resultiert ihrer Meinung nach daraus, dass der Text „mit diesen gebrauchten Slips und mit den auseinandergerissenen Gesäßbacken, wo dann die Luft entströmt [kokettiert]“ (ebd.). Sie fährt fort zu begründen:

Dass das bei alten Leuten so ist - ja, so blöd sind wir nicht, dass wir das anzweifeln. Die Frage ist doch aber, wie man daraus Literatur macht. Und das finde ich auf Kosten/ also wirklich auf Kosten, jetzt in Anführungszeichen, der „Opfer“, dieser Greise. Die werden hier/ die werden hier inszeniert, damit das ein schicker Text ist. [einzelner Applaus] (14:46 Radisch)

Letztlich liegt Radischs Aussage die Annahme zugrunde, dass Autoren dazu verpflichtet sind, ihre Leser dazu zu bringen, bestimmten Figurentypen - in diesem Fall geht es um 
alte Menschen - mit einer bestimmten Einstellungen zu begegnen. Hilflosen alten Menschen gebührt, das ist die zugrundeliegende Annahme, eine literarische Darstellung, die Lesern eine positive, empathische Grundeinstellung der Figur gegenüber erlaubt. Stünde im Mittelpunkt des Textes eine aufgrund ihrer gesellschaftlichen Position als moralisch problematisch kategorisierten Figur, beispielsweise ein Massenmörder wie im Text von Artur Becker (2004), würde vom Autor verlangt werden, dass er den Leser zu einer entsprechend distanzierten emotionalen Einstellung führt. ${ }^{73}$ Für die Juroren hat der Autor, wenn nicht unbedingt eine erzieherische Funktion, so doch eine moralische Verantwortung. Es wird von ihm erwartet, dass er soziale Normen respektiert und seine Texte entsprechend gestaltet (vgl. Kapitel 11.3.4). Wie stark bei Radisch die moralischen Argumente überwiegen, wird auch deutlich, wenn man die Äußerung im Kontext aller Äußerungen Radischs in dieser Diskussion sieht. Sie bestätigt dem Text nämlich mehrfach, dass er gut gemacht ist, legt das aber, und das ist in der Tat ungewöhnlich, zu seinem Nachteil aus. Sie findet den Text sogar „super raffiniert“ (20:15 Radisch) und bezeichnet die „literarische Inszenierung der Gebrechlichkeit“ als „ausgeklügelt“ (20:18 Radisch). Alle drei Werturteile, in denen sie dem Text zunächst positive Eigenschaften zuspricht („schicker Text“, „super raffiniert“, „ausgeklügelt“) legen in diesem speziellen Kontext eine kritische Haltung nahe. „Schick“ ist der Text offenbar insofern, als er der Skandallust des Lesers entgegenkommt. Die Formulierungen „raffiniert“ und „ausgeklügelt" legen eine besondere Durchdachtheit des Textes nahe, die von Radisch abgelehnt wird, weil sie eine Wirkung beim Leser hat, die Radisch ablehnt, das heißt, anerkannte, hochgewertete Gestaltungselemente werden eingesetzt, um die Figur lächerlich zu machen, ein Effekt, den Radisch offenbar aus menschlichen Gründen nicht annehmbar findet. Die dominante Position, die moralische Werte bei der Beurteilung von literarischen Texten haben können, tritt hier deutlich zu Tage. Unter dem Vorzeichen eines moralischen Defizits kann die gelungene (!) Form eines Textes sogar als Negativargument eingesetzt werden. Gleichzeitig wird wiederum die argumentative Bedeutung von Gestaltungsmerkmalen sichtbar.

Die Kritik an der Wirkungsabsicht des Textes steht auch im Mittelpunkt von Mangolds Wertung:

Ja, ich glaube, Björn Kern versteht sein Handwerk, aber was er mit diesem Handwerk macht, das mag ich überhaupt nicht. Er setzt es nämlich ein, wie ich finde, zu rein manipulativen Zwecken. Für mich ist das ein Erpressungstext. Ein moralischer Erpressungstext, der in der Haltung eines Staatsanwaltes gewissermaßen auftritt. Der mir nicht eine Wirklichkeit erzählt, sondern der mich an den Schultern geradezu körperlich packt und sagt: Hier, schau dahin! So sieht es aus. Und der nun das gesamte Szenario

$\overline{73}$ Sabine Buck $(2011,237)$ spricht für diesen Fall von einem „Distanzierungsgebot“. 
so entwirft, dass ich quasi als fühlender Mensch gar nicht anders können dürfen soll $[\ldots]$, als den Zustand [...] auch in irgendeiner engagierten Weise zu verdammen und gleichzeitig der Erzählung darin ihr moralisches Surplus zuzugestehen. [...] Das alles finde ich von so brachialen Mitteln, um den Leser dahin zu führen, dass ich im Grunde, um es hart zu sagen, dass ich dem Erzähler im Grunde auch gar nicht glaube, dass der Mitleid empfindet für diese Figur. Er benutzt diese Figur. (10:19 Mangold)

Mangolds Argumentation ähnelt in ihren Grundzügen der Radischs. Auch er ist der Meinung, dass der Text formal gut gemacht ist, kritisiert dafür aber die Wirkung, die mit der formalen Gestaltung des Textes auf den Leser ausgeübt wird. Im Hintergrund steht hier der Wert Offenheit, denn Mangolds Kritik bezieht sich letztlich darauf, dass dem Leser nicht die Freiheit gelassen wird, zu entscheiden, ob das Dargestellte "gut" oder "schlecht" ist. ${ }^{74}$ Mangolds Argument ist allerdings nicht nur in jener Hinsicht eine moralische Bewertung, als er nicht damit einverstanden ist, dass der Text offenbar eine didaktische Absicht verfolgt. Vielmehr stellt er das Verfahren als solches als unlauter dar („Erpressungstext“). Unmoralisch ist also das, was der Text mit dem Leser macht. In seiner Schlussaussage kommt aber auch das zum Ausdruck, was Radisch und März bereits betont hatten: Die Figur wird „benutzt“ und das authentische „Mitleid“ des Erzählers/Autors mit seiner Figur wird vermisst.

\section{Überdeterminiertheit}

Nicht alle Juroren interpretieren den Aufbau des Textes, der den Leser ihrer Ansicht nach sehr stark lenkt, wie Mangold und Radisch moralisch. Rakusa, Heiz und Nüchtern argumentieren auf rein formaler Ebene. Sie vertreten die Meinung, dass der Text zu viele formale Mittel einsetze, um seine Botschaft umzusetzen, sodass letztendlich Offenheit fehlt. Nüchtern (17:30) stellt fest, dass zwar einzelne, von anderen Juroren kritisierte Bilder „völlig legitim und völlig in Ordnung“ sind, dagegen „finde[t] [er] das Problem dort, wo er [der Text KR] zu sehr auf die Tube drückt“. Das ist ihm „too much“ (ebd.). Hier geht es offenbar um eine überdeutliche bzw. redundante Umsetzung der vermeintlichen „Botschaft" (vgl. Kapitel 11 und 10.3.1).

Was Nüchtern möglicherweise mit „too much“ meint, lässt sich eher nachvollziehen, wenn man den Beitrag Rakusas hinzuzieht, die auch der Meinung ist, dass der Text an vielen Stellen übertrieben ist:

Ja, wir hatten vorhin gerade diesen leisen, sehr ökonomisch gearbeiteten Text von Jan Böttcher, wo sogar etwas Dramatik vermisst wurde. Spannung hieß es. Hier ist dessen

$\overline{74}$ Sabine Buck $(2011,237)$ hat diese Art der Argumentation als „Belehrungsverbot“ benannt. 
einfach zu viel. Und zwar viel zu viel würde ich sagen. [.. . ] Hier ist für mich, abgesehen von der Konfusion der Perspektiven und für mich auch kaum nachvollziehbaren Weise, wie hier tatsächlich über das Innenleben einer Frau berichtet wird, die schon dem Tod nahe ist oder sogar dann stirbt. Also es ist sehr problematisch, um das Mindeste zu sagen. Aber der Text ist irgendwie überinstrumentiert. Er ist auch zu metaphorisch. [...] Ja, das kann man vielleicht sogar interessant finden. Aber dann kommt dieses Mondlicht gleich wieder. Und ich sage, da finde ich es dann, vor allem aufs Ganze gesehen sehr, sehr überinstrumentiert. Und ich glaube - das würde aber einen ganz anderen Ansatz bedeuten - dass die Demenz der Frau, auch dieser Wahnsinn, der sich in ihr abspielt, in allem, dass der eigentlich nur dann zum Ausdruck käme, wenn die Erzählung das, was uns einfach berichtet wird, der Erzählbericht an sich, sehr viel sachlicher, unmetaphorischer, undramatischer wäre. Ich glaube, hier ist in jeder Beziehung eine Steigerung und Übersteigerung, die aber das Groteske nicht erreicht. (22:51 Rakusa)

Die Wertung Rakusas vermittelt den Eindruck, dass es so viele formale Mängel am Text gibt, dass sie nicht in der Lage ist, diese geordnet wiederzugeben. Obwohl der O-Ton ihrer Wertung, zu dem sie immer wieder zurückkehrt, das Problem ist, dass der Text ihrer Meinung nach „überinstrumentiert“ ist, schiebt sie wiederholt Beobachtungen ein, die andere Aspekte der Form betreffen, so etwa die „Konfusion der Perspektiven“, die dazu führe, dass der Text schwer nachvollziehbar sei und die Metaphorik. Übertrieben findet sie die „Dramatik“ und die Menge und Intensität der sprachlichen Mittel, die eingesetzt werden, um den Eindruck des Dramatischen zu erzeugen. Offenbar sieht sie das Verhältnis von Intention des Textes und den dazu eingesetzten Mitteln gestört, was - Rakusa sagt das allerdings nicht explizit - in mangelnder Offenheit resultiert. Dass sie sich allerdings eine Erzählung wünscht, in der „einfach berichtet wird, der Erzählbericht an sich, sehr viel sachlicher, unmetaphorischer, undramatischer wäre“, weist darauf hin, dass sie es bevorzugen würde, als Leserin selber die Schlüsse aus dem Dargestellten zu ziehen. In einem zweiten Beitrag betont sie noch einmal ihr Gefühl des Zuviel: Der Text dürfe sich nicht „auf diesem fast hysterisch dramatischen Niveau bewegen“ (25:39 Rakusa).

\subsection{Zusammenfassung}

Kerns Text wird in doppelter Hinsicht moralisch bewertet. Zum einen begegnen die Juroren der Darstellung der alten Frau mit großer Skepsis. Die Darstellung eines alten Menschen in einem Zustand, der den Leser dazu veranlasst, sich zu distanzieren, ist offenbar ein gesellschaftliches Tabu. Argumentativ wird dieses moralische Problem benannt und mit formalen und sprachlichen Argumenten gekoppelt, das heißt, eigentlich moralische Argumente werden durch formale und sprachliche Eigenschaften des Textes erklärt. Der Inhalt allein ist, wie man aus diesem typischen Aufbau der Argumente schließen kann, allein kein akzeptiertes Mittel der Kritik. Es gehört nicht zum konventionalisierten Code, rein in- 
haltlich oder moralisch zu werten. Rein inhaltliche Urteile kommen nur äußerst selten vor. Moralisch geprägt ist die Diskussion aber auch auf einer anderen, übertragenen Ebene. Die Kritik der Intensität, mit der der Autor die von den Juroren erkannte Intention seines Textes, auf die verheerende Situation alter Menschen aufmerksam zu machen, umsetzt, stößt bei einigen Juroren auf harte Kritik. Dass der Leser mittels der Drastik der Darstellung zu einer bestimmten Deutung geführt werden soll, wie es einige Juroren auffassen, wird als ein geradezu „moralischer“ Verstoß gegen die Gesetzmäßigkeiten der Literatur ausgelegt. Besonders deutlich wird das bei Mangold, der mit seiner Verurteilung des Textes als „moralischer Erpressungstext" eine pädagogische Funktion unterstellt, die nicht ins Leitbild hochwertiger Literatur gehört. Der Literatur selbst wird hier also eine ethische Aufgabe zuteil. Sie soll nicht durch die Drastik ihrer Mittel zu einer anderen Haltung erziehen, sondern möglicherweise - gesagt wird das allerdings nicht - durch ihre Darstellung dem Leser erlauben, die Situation der Figur nachzuvollziehen, um auf diesem Weg eine Erfahrung zu machen. Im Hintergrund mag dabei, das lässt sich allerdings nicht nachweisen, die Hoffnung stehen, dieser literarischen Erfahrungen könnten auch das Alltagserleben der Leser verändern. Die Juroren fordern eine aktive Mitkonstruktion des Textes durch den Leser ein. Der (ideale) Leser ist dieser Vorstellung zufolge nicht mit dem Dekodieren einer Botschaft befasst, sondern mit dem Konvertieren von Informationen in ein lebendiges, subjektiv gefärbtes Modell eines Textes.

Obwohl in fast allen Diskussionsbeiträgen deutlich wird, dass eigentlich eine gesellschaftliche Frage verhandelt wird, nämlich die Frage danach, wie alte Menschen dargestellt werden dürfen, nehmen die Beiträge häufig Bezug auf die formale Gestaltung des Textes. Die Frage, ob ein Text an seinem Thema bemessen werden darf, wird beinahe einstimmig explizit verneint.

Die Präferenz für formal-ästhetische Begründungen bei Kritik, die im Kern moralisch ist, hat ihre Ursache auf der einen Seite im hohen Prestige formal-ästhetischer Bewertungen. Ein Argument, das durch formale Eigenschaften des Textes belegt werden kann, wiegt mehr. Denkbar ist aber auch ein Konflikt zwischen der Ästhetik des Hässlichen, der der Text nahesteht, und dem Wunsch der Juroren als Leser nach einer Hauptfigur, die empathisches Mitfühlen erlaubt. Eine solche Interpretation lässt sich zwar nur implizit in den Diskussionen erkennen, erweist sich aber im Kontext anderer Diskussionen (vgl. Kapitel 11.3) als plausibel. So begründen die Juroren ihre moralische Kritik mittels einer Haltung der überheblichen Distanz des Erzählers gegenüber der Hauptfigur. 


\section{Andera Winkler: „Aus dem Gras“ (2009)}

Quelle: http://archiv.bachmannpreis.orf.at/bachmannpreis.eu/de/audio_video/ 1928/index.html

Eingeladen von: Paul Jandl

Auszeichnung: keine

\subsection{Transkript der Diskussion}

[Stadler leitet die Diskussion ein.]

0:16 Fleischanderl: Also, ich finde Andrea Winkler dampft die Literatur auf ihr Wesentliches, auf ihr Essentielles ein, nämlich auf die Inszenierung der Sprache und auf radikale Subjektivität. Ein Ich geht über eine Wiese, denkt, schaut, fühlt, hat Erinnerungen, Assoziationen, versichert sich zwischendurch der eigenen Wirklichkeit, der eigenen wirklichen Hand. Ich finde, es ist eine große Wohltat, Andrea Winkler zu hören und zu lesen. Es ist, als ob ihre Literatur Räume für das Ich öffnen würde, Räume, wo plötzlich Stille ist, Ruhe möglich ist, wo das Ich nicht ständig zugeschüttet wird vom medialen Getöse. Und gleichzeitig ist ihre Literatur auch eine Poetik. Sie formuliert die Erkenntnis oder auch die Forderung, dass Literatur letztendlich eine narzisstische Allmachtsphantasie ist. Das Ich möchte sich die Welt einverleiben oder Untertan machen, dass sie aber in dieser Eigenschaft aber auch gezwungen ist, an der Wirklichkeit zu zerschellen, aber genau in dieser Forderung eigentlich die utopischen Glücksmomente der Literatur liegen. Und für mich ist eigentlich der höchste Anspruch, den man an die Literatur formulieren kann, ist, dass Literatur eigentlich nicht Welt abbildet und beschreibt, sondern Welt macht, mit Hilfe von Worten und von Sprache. Und diesen Anspruch sehe ich eigentlich bisher in zwei Texten eingelöst: Das ist der von Andrea Winkler und nach wie vor der von Linda Stift. [wenig Applaus]

1:49 Stadler: Ein Plädoyer für die Literatur. Herr Mangold, sehen Sie Literatur auch so?

1:53 Mangold: Ich hatte so gehofft, dass ich als Letzer drankomme, damit mir meine Kollegen erklären, um was es in diesem Text geht. Damit ich nichts Unsinniges sage.

2:01 Fleischanderl: Habe ich gerade getan! [Applaus]

2:05 Mangold: Ich habe mich immer gefreut, wenn dieser Satz kam: „Meine Hand, meine ausgesprochen wirkliche Hand“. [Heiterkeit] Der war sehr schön. Was dazwischen stand, habe ich dann nicht verstanden. Mir war schon klar, dass abgebrühte Poststrukturalismus sagen würden: Ja, es gibt nur die Spur auf dem Papier und das ist der Text und dem sind wir hier gegenübergestellt. Dieser Text arbeitet mit einer Fülle an Motiven, deren akustisches Wiederauftauchen ich auch immer zur Kenntnis genommen habe. Es gibt den Bahnhof, der sich ins Meer verwandelt, den Zug, der zum Schiff changiert. Es gibt Stimmen. Ich glaube, es gibt auch irgendwie ein Du, ein Gegenüber. Ob dieses Du - vermutlich würde Frau Fleischanderl sagen, jetzt verlasse ich schon wieder die Welt der hohen Literatur und bin auf dem Weg der nur bloßen Psychologie - ob dieses Du das Du einer Beziehung ist oder nur das Du einer Welt, die diesem sprechenden Ich immerzu entgleitet, das weiß ich nicht. Es geht offenbar um Verlust, um Weltverlust, um Weltversicherung, Es gibt ein mich manchmal an Paul Celan erinnerndes, aber nur auf der phonetischen Ebene an Paul Celan erinnerndes Haus in den Lüften. Ob dies eine Form des gewissermaßen das Haus des Seins in der Sprache zu finden/ Ich weiß es alles nicht. Ich vermute, man kann diesen Text mit sehr großen Worten beschreiben, ohne ihm deswegen näher zu kommen. Ich habe ihn leider nicht verstanden.

3:35 Jandl: Macht aber auch nichts, Herr Mangold. [Heiterkeit]

3:36 Mangold: Nein, macht nichts.

3:37 Jandl: Das ist kein Kriterium der Literatur. Also, das würde ja jetzt kein Schaden sein.

3:43 Feßmann: Also, ich habe jetzt gegen diesen Text überhaupt keine handwerklichen Einwände. [Heiterkeit] Ich bin aber/ bin aber auch überhaupt nicht glücklich mit diesem Text. Es ist eindeutig, 
was er macht. Also, das ist ein Text, der in der Bewegung, die er beschreibt, sein Sujet erst erzeugt. Wir haben keinen Referenten. Wir wissen lange nicht, worum es geht, außer/ das einzige Merkmal, das wir von Anfang an kennen, ist: Hier wird es um die Sprache selbst gehen. Sie sind damit glücklich, Frau Fleischanderl. Sie haben ja gesagt, das Wesentliche in der Literatur ist die Inszenierung der Sprache. Das find/ Und narzisstische Allmachtsphantasie. Also eines anderen Menschen narzisstische Allmachtsphantasien zuzuschauen, sehe ich eigentlich keinen Sinn drin. Also, aber erst einmal: Der Text schafft offenbar seinen eigenen Raum. Es gibt offenbar ein Ich, das sehr, sehr skrupulös, nicht einmal wagt, seinen Fuß auf ein Stück Gras zu setzen - das wird ja den ganzen Text über durchgehalten - und sich schon freut, wenn es das Wort „Hand“ ausspricht. Also das Aussprechen des Wortes „Hand“ hat mehr Realität als das Setzen eines Fußes ins Gras. Man kann ja diesen Text gar nicht anders lesen, als dass man ihn einmal durchliest, um sich so ein bisschen zu orientieren und dann noch einmal von vorne anfängt und die paar Marken, die man hat, sich dann zusammensucht. Ich war glücklich, als ich irgendwann gemerkt habe, hier geht es offenbar um eine Liebesverletzung. Es gibt also offenbar so etwas wie ein Thema. Dieses Ich schreibt einer verlorengegangenen Liebe hinterher und stellt sich vor, ob dieser Mann jemals wiederkommt oder für immer verschwunden ist. Also da war ich dankbar, weil ich gemerkt habe, also es geht um irgendetwas, was einen interessieren kann und nicht nur um die Sprache selbst. Das Problematische bei solchen Texten ist, finde ich, dass der Autor fröhlich mit den Worten spielt, aber der Leser wird genötigt, wirklich wie so ein Trüffelschwein jedem Wort hinterherzuschnüffeln. Er tut also so, als wäre er unheimlich distanziert und zwingt den Leser aber zu einer Nähe zu dem Text. Also es ist eine echte Nötigung, die Lektüre.

5:58 Fleischanderl: Also, ich finde, ein Kriterium, was im ganzen Bewerb eigentlich noch nicht gefallen ist, ist Musikalität. Ich finde, Musikalität ist ebenfalls eine große Eigenschaft der Literatur. Ich finde auch, einige Texte, die hier vorgelesen wurden, besaßen Musikalität, aber die Jury versucht immer nur deutsch-deutsche Beziehungen oder politische Beziehungen oder Geschichte oder irgendwie massig Stoff und Inhalt zu suchen, symbolische Überfrachtungen. Dass ein Text Form ist, reine Konzentration, Musikalität, fast auf die Ebene von Musik gehoben wird aufgrund einer sublimierenden Anstrengungen, ist, glaube ich, in diesem Bewerb noch nie gefallen. [Applaus]

6:43 Spinnen: Die Frau Fleischanderl hat zwei Mal vollkommen recht gehabt. [Heiterkeit] Jetzt gerade zwei Mal. Es waren zwei Wortmeldungen. Das reicht. Nicht drei Mal recht haben für zwei Wortmeldungen. Ich habe mir folgendes vorstellt: Es gibt ein Computerprogramm, das im Stande ist, die Wiederkehr von Nomina und Konstruktionen in diesem Text in Akkorde zu übersetzen und dann quasi die Partitur auszuwerfen. Dann wäre das, dessen bin ich wir sicher, eine Musik, die ich verstehen würde beim Hören als MUSIK. Denn die hat den Vorteil, dass Töne und Akkorde und Melodien zwar semantisch sind, aber nicht sprachlich. Wir können bei bestimmter Musik weinen, uns erhaben fühlen oder sonst irgendetwas, ohne dass Worte dabei sind. Und nun hat die Frau Fleischanderl wahnsinnig recht damit, wenn sie sagt, wir vergessen dauernd - und das ist auch etwas, was in der momentanen literarischen Produktion wie in der literarischen Kritik immer wieder zu passieren droht, möglicherweise unter dem Einfluss von Publikumserwartungen, unter dem Einfluss von ökonomischen Erwartungen - wir vergessen dieses Erbe der Moderne, das immer wieder aufs Sprachliche hinweist. Aber, ich denke, das alles ist ein Streit, das ist ein Zweikampf miteinander. Denn in dem Moment, wo ich mit Worten arbeite, wo ich diese ganze Musikalität durch Worte und Sätze/ ausgedrückt wird, habe ich semantisches Material, das mir nicht ausschließlich allein gehört. Das kommt alles aus dem Duden. Das kommt aus der Sprechergemeinschaft. Das kommt aus dem Assoziationsraum von Lesern. Und dann/ da verlange ich von so einem Text/ Was heißt verlange? Da erwarte ich von so einem Text, dass er das austrägt und sich nicht allein auf die eine oder auf die andere Seite schlägt. Weder darf er dieses Element der Musikalität oder dieses Element des Sprachzweifels, dieses Element des Sich-erst-realisieren-als-Mensch in Sprache vergessen, noch darf er, nach meinen Dafürhalten, zu gering achten, dass wir diese Sprache auch als Verständigungsmittel benutzten, dass sie auch etwas historisch gewachsenes ist. Und deswegen würde ich mich über Texte unendlich freuen, die das miteinander austragen. Wenn es erlaubt ist, an Texte zu erinnern: Michael Lenz hat hier einmal mit einem Text gewonnen, der in der Tradition dieser Darstellung stand, der sich selbst gewissermaßen dauernd ins Wort fiel, der die Sagbarkeit von etwas dauernd zum Thema hatte, der aber auch ein Thema hatte, an dem er sich sprachlich abarbeiten ließ. Dieser Text ist sehr, sehr weitgehend auf der Ebene des Musikalischen. Und auch mir ist es nicht vollständig gelungen, ihm die andere Ebene, quasi die allgemeine Ebene, die sprachliche Ebene zur musikalischen wieder hinzuzufügen, sodass ich diese Auseinandersetzung 
spüren könnte.

9:51 Jandl: Wir sind natürlich jetzt schon mitten wieder in einer Realismusdebatte. Und jetzt prozentuell der Anteil an Texten/ der Anteil von Texten, die in diesen diesjährigen Bachmann-PreisTagen nicht explizit realistisch waren, ist gering. Also so gesehen hat dieser Text seine Chance, wie ich finde, seine große Chance, verdient. Es wäre ja traurig, wenn wir in den Texten nur das lesen wollten, was wir schon kennen. Das wäre also wirklich/ Es gibt ein schönes Zitat von Franz Kafka, das heißt: „Die erste Voraussetzung des Schriftstellertums ist nicht die Wachheit, sondern die Selbstvergessenheit“. Das ist ein Text der Selbstvergessenheit, wie ich finde. Das ist ein Text, der eine Poetik liefert, der gleichzeitig auch Poesie ist, der mit Bildern arbeitete, die sich allmählich zu einem Bild fügen. Man kann nicht sagen, dass in dem Text nichts erzählt würde. Es ist nur sehr wenig, was erzählt wird. Es ist das Bild von der Schaukel. Es ist eine Bewegung, die visuell zu sehen ist. Das Grün der Wiese, das Blau des Himmels. Akustisch das Näherkommen des Zuges, das Pfeifen des Zuges, der Nachklang. Wichtig ist das Wort/ der Begriff vom „Nachklang“. Eine Definition von Literatur findet sich, eine Definition von Poesie auch, findet sich gleich auf der zweiten Seite: „Sich an einen Nachklang zu wenden, als ob er dann eine Gestalt zurück bekäme, einen Leib mit klaren Konturen, über den die Hand so wirklich streichen kann wie übers Gras hier! Das wächst mir dann und wann beinah zu Mund und Nase hinein, beinah über die Ohren". In diesem Zitat ist mitreflektiert, wie aus Wirklichkeit Literatur wird und wie aus Literatur Wirklichkeit wird. Das ist keine Beschreibung von Wirklichkeit. Das ist eine Erfindung von Wirklichkeit. Und die Literatur kann eine eigenen Wirklichkeit für sich beanspruchen, die Qualitäten hat, die nicht allein darin liegen, wie gut etwas beschrieben ist, sondern die musikalische Qualitäten hat, die poetische Qualitäten hat, die Bilder zusammenzwingt, die also im Rationalen nicht unbedingt aufgehen. Und ich finde, dass dieser Text das ganz bravourös einlöst. Und der Kritiker freut sich immer, wenn man ihm ein Reh vorbeitreibt, das er möglichst bequem schießen kann. In diesem Fall ist das Reh nicht so einfach zu erkennen. Es steht gewissermaßen in der Dämmerung an so einem Anhang der Schläfrigkeit und vielleicht kann auch gerade dieser Text uns zu Wachheit verführen. [Applaus]

12:38 Stadler: [unv.] kompaktes Statement [unv.].

12:47 Keller: Ich sitze zwischen den beiden Herren und ich fühle mich auch zwischen den beiden Herren. Ich würdige die Virtuosität dieses Gewebes, dieses Geschwebes. Ich teile aber auch die Verwirrung. Und ich musste an die Mönche in St. Paul denken. Die haben vor vielen, vielen hundert Jahren eine großartige Technik entwickelt der Meditation. Sie heißt „Ruminatio“. Das Wiederkäuen wie von Paarhufern, wiederkäuen und wiederkäuen. Und ich/ Vielleicht ist es eine Meditation in der Selbstvergessenheit, die zur Selbstvergessenheit führen kann. Vielleicht ist das eine ästhetische Wirkung von Literatur. Kann ich alles für möglich halten. Ist natürlich wiederum an die Bereitschaft gebunden, dass ich mitgehe. Und ich habe mich auch etwas verloren gefühlt. Hier und beim mehrmaligen Lesen.

13:34 Sulzer: Also, es hat sich auch durch die Lesung bei mir nichts verändert. Also, wenn musikalisch/ oder wenn ein musikalisches Stück, dann, es tut mir jetzt furchtbar leid, dann hat es aber den Klang eines/ oder den Sinn eines Schlafliedes. Sie haben von einer Wohltat gesprochen und von einer Poetik. Also für mich war diesen Text zu lesen auf keinen Fall eine Wohltat. Und zwar nicht/ Ich finde, es wimmelt übrigens von Bildern, die ich/ Also ich möchte nur einmal eins vorlesen, das muss man sich einmal auf der Zunge zergehen lassen: „Wirklich, du warst mir der Zaun und noch mehr die Lücke in ihm". Das ist/ Also und davon wimmelt es. Bei mir war es/ Ich hätte gern gewusst/ Es ist jetzt tatsächlich eine Realismusdebatte, ist mir schon klar.

14:23 Jandl: Wir kommen ja immer wieder aufs selbe Argument. Ich verstehe es nicht. Also, dass/

14:26 Keller: Ja, wir haben mit Sprache zu tun. Wir haben es mit Semantik zu tun.

14:30 Sulzer: Also sagen wir es einmal so: Ich hatte mir überlegt, ob ich mich überhaupt hier zu Wort melden soll. Man hat mir es jetzt erklärt. Ich habe mir auch gedacht, dass die Erklärung so sein wird. Dieser Ton ist ganz hoch und ich bin eben ganz niedrig. Ich verstehe diesen Ton nicht. Ich bin zu blöd oder zu niedrig und ich will nicht auf diesen hohen Ton gehen. Ich würde, um es ganz platt zu sagen - klingt ein bisschen aggressiv - aber ich würde, wenn ich das lesen müsste oder wenn ich das in einer Buchhandlung lesen würde, ich würde nach einer Seite einfach aufhören. Ich überlasse das natürlich den anderen, daran ihr Vergnügen zu haben wie Frau Fleischanderl. Ich habe irgendwie gar kein Vergnügen daran. Ich habe mir jetzt während des Vorlesens, weil ich beim 
Lesen zu Hause wirklich Mühe hatte, mich - also, wie gesagt - dem Schlaf nicht zu ergeben. Ich habe mir so ein bisschen/ Es hat so etwas Geklöppeltes. Es ist so nett. Man denkt auch, es wird bestimmt auch einige Kritiker finden, die das ganz wunderbar finden. Man kann damit bestimmt auch Preise bekommen. Es ist ganz und gar auf sich bezogen und mich - das ist schrecklich subjektiv - geht es überhaupt gar nichts an. Es ist auch schön, das mit den Mönchen. Das sehe ich ein. Es ist vielleicht auch ein mystischer Vorgang. Aber nicht meiner. [Heiterkeit, Applaus]

15:43 Spinnen: Ja, also ich will damit gewissermaßen/ Also es ist jetzt so quasi für die, die mitschreiben und so, [Heiterkeit] dass auf gar keinen Fall der Eindruck entstehen darf, es würde diese literarische Tradition jetzt einfach gewissermaßen weggebürstet. Vor ein paar Jahren hatte mir einmal ein Literaturagent gesagt: Also Gedichte nehme er gar nicht mehr in sein Portfolio auf. Das ginge so gar nicht mehr. Das ist eine schwierigere Literatur, was die Rezeption angeht, ganz ohne Frage. Und in ökonomisierten Kontexten wird Schwierigkeit mit Zeitaufwand identifiziert. Zeit ist Geld und infolgedessen fällt das weg. Wir haben nur noch einen kleinen Anteil dieser Literatur an der aktuellen Produktion. Der war/ Vor zwanzig, dreißig Jahren, sah die Sache umgekehrt aus. Da mussten sich hier Leute rechtfertigen, die erzählerische Texte geschrieben haben. Die mussten sich vor der Moderne rechtfertigen. Es wäre das Grauen, wenn aufgrund all dieser Prozesse solche Anstrengungen um die Erkenntnis des Menschen als sprachlichen Wesens, um die Entstehung unserer Subjektivität aus Sprache, wenn die aus der Literatur verbannt würden. Andererseits aber muss jeder einzelne dieser Texte sich auch immer wieder bewähren. Und genau wie realistische Texte sich zu bewähren haben, müssen es auch diese tun. Ich habe im Vorfeld eine Reihe von weiteren Texten von Frau Winkler gelesen, um den Versuch zu machen, mich selbst darauf einzustimmen, mir selbst diese Sprache näherzubringen. Und ich muss aber dabei bleiben, dass ich den Grad der Hermetik und den Grad der musikalischen Selbstständigkeit für mich letztlich immer etwas zu hoch empfunden habe.

17:39 Mangold: Ich wollte noch sagen. Das kann nicht sein, dass man diesen/ so wie man diesen Text kritisiert, gleich in die dunkle Ecke gewissermaßen eines totalen Avantgardeverweigerers gestellt wird. Das ist die Gefahr, glaube ich, auch in dieser Diskussion. Der Text wird verteidigt nämlich als Repräsentant eines Genres, das wir hochhalten, viel mehr denn als dieser einzelne konkrete Text. Und warum? Weil der Text sich natürlich auch immunisiert gegen seine Kritik, weil er sich in einer Weise verschließt, wo es dann natürlich albern wäre, wenn ich jetzt Herrn Jandl zum Beispiel frage: Was meint dieser Satz „und bitte den Boden unter mir, mich an den Luftzug zu erinnern"? Er lässt sich ganz schwer überprüfen und deswegen verfallen wir bei diesem Text sofort in so eine allgemeine Überbaudiskussion, die aber in Wahrheit keine Auseinandersetzung mit einem einzelnen Text ist.

18:30 Jandl: Ich finde nur, er immunisiert sich gegen bestimmte Formen der Kritik. Und es ist auch Aufgabe der Kritik, Formen zu finden, die möglicherweise solchen Texten adäquat sind. Also/ Und es wäre schade, um den Text noch einmal zu zitieren/

18:42 Stadler: Bitte nicht mehr lange. Wir müssen langsam zur „Kulturzeit“ übergehen.

18:44 Jandl: Kann ich kurz das Zitat? Es ist ein ganz kurzes Zitat. Ich beginne den Satz noch einmal. Entschuldigung. Es wäre schade „wenn sich die versammelte Runde der Befugten über alles blitzschnell einig wird". So steht es im Text.

18:59 Spinnen: Die Gefahr war nicht gegeben.

[Stadler schließt die Diskussion.] 


\subsection{Analyse der Diskussion}

\section{Ablauf der Diskussion}

Die Diskussion zu Andrea Winklers Text „Aus dem Gras“ umfasst 19 Minuten und 36 Sekunden und ist damit relativ kurz. Karin Fleischanderl und Paul Jandl, die beiden aus Österreich stammenden Juroren, verteidigen die ebenfalls aus Österreich stammende und von Paul Jandl eingeladene Autorin. Offenbar neigen die Jurymitglieder nicht nur, wie Doris Moser $(2004,246)$ beobachtet hat, dazu, Autoren der eigenen Nationalität einzuladen, sondern sich für diese auch besonders einzusetzen. Feßmann, Sulzer und Mangold üben sehr deutliche Kritik, Hildegard Keller und Burkhard Spinnen verhalten sich zurückhaltend kritisch. Bei Winklers Text handelt es sich um einen sprachexperimentellen Text, dessen Fokus statt auf einer (realistischen) Handlung auf der Auseinandersetzung mit Sprache im Medium der Sprache liegt. Die Diskussion ist geprägt von zwei sich diametral gegenüberstehenden Positionen: Die Befürworter sehen den Text als Paradebeispiel für Sprachkunst: Die Maßstäbe Musikalität und Dichte stehen dabei im Vordergrund. Die Gegner geben zu bedenken, dass der Text es schwer macht, ihm zu folgen, weil er keine Handlung besitzt und eine Deutung sich allenfalls auf einem sehr hohen Reflexionsniveau erarbeiten lässt. Sie zeigen sich frustriert über den geistigen Aufwand, den sie betreiben müssen, um sich dem Text zu nähern bzw. darüber, dass sie keine Kohärenz herstellen können. Weil der Text selber aufgrund seiner auf ein Minimum reduzierten Handlung schwer zugänglich ist und dadurch die Möglichkeiten, über ihn zu sprechen, eingeschränkt sind, findet die Diskussion teilweise auf einer Meta-Ebene statt, auf der besprochen wird, welchen Rang experimentelle Literatur hat und welche Anforderungen an einen experimentellen Text gestellt werden können.

\section{Der Text „Aus dem Gras“}

In der Tat hat Andrea Winklers Text keine Handlung im engeren Sinne, auch keine innere Handlung im engeren Sinne. Ein Ich geht über eine Wiese auf einen Baum zu. Es streicht mit der Hand über die Grashalme und denkt nach. Der Text variiert verschiedene Bilder, die immer wieder aufgenommen werden, so etwa die Hand, die über das Gras streift, die Schaukel, von der aus das Ich sich die Wiese als Meer vorstellen kann, der Dachboden, der unheimlich ist, der Baum, von dem aus es eine Aussicht gibt, der Zaun, der begrenzt. Diese Elemente werden genutzt, um einen Gegensatz, vielleicht auch ein Zusammenspiel, von Illusion und Wirklichkeit zu illustrieren, das für den Sprecher des Textes von zentraler 
Bedeutung ist. Im Text wird ein undefiniertes Du angesprochen. Es lässt sich erahnen, dass dieses Du ein Geliebter des Sprechers ist und dass eine Trennung stattgefunden hat, weil der Sprecher eine andere Vorstellung von Wirklichkeit und Illusion hatte. Mittels dieser Überlegungen über das Verhältnis von Illusion und Wirklichkeit reflektiert der Text auch das Verhältnis von Literatur und Wirklichkeit. Durch die Wahl der Bilder spielt „Aus dem Gras" auf verschiedene, bekannte Texte der deutschen Literatur an. Mit der Schaukel, dem Zaun und dem Dachboden werden zentrale Bilder aus einem Paradebeispiel realistischen Erzählens, Theodor Fontanes „Effi Briest“, aufgenommen, mit dem „Haus in der Luft“, wird eine vage Assoziation zu Celans „Todesfuge“ („ein Grab in den Lüften) hergestellt, also zu einer nichtrealistischen, stark chiffrierten Literatur.

Auch auf dieser Ebene wird also mit dem Verhältnis von Realismus und der Selbstreferenzialität literarischer Texte gespielt. Prägend für den Text ist, dass er mit Fragen der Referenz, des Realismus und der Illusion spielt, dass er aber keine eindeutigen Hinweise darauf gibt, wie er verstanden werden will.

Wiederum soll ein Textauszug einen Eindruck von der Gestaltung des Textes geben:

Ich werde vielleicht mein Haar hinters Ohr schieben, damit ich mir die Antwort noch besser vorstellen könnte, eine dunkle Stimme aus dem hohen Gras Richtung Himmel, und bei manchen Wörtern stirbt sie beinah. Den ganzen Weg über auf den Baum zu wird die Hand nichts anderes tun, und ich auch nicht. Einen halben Kilometer oder einen ganzen lang, wo der Baum nicht ferner und nicht näher rückt, würde ich meine Hand sagen, meine ausgesprochen wirkliche Hand, und jeden Augenblick das Haar hinters Ohr schieben, in Erwartung der Antwort. Wenn ich, was nicht mehr länger aufgeschoben werden kann, den Fuß auf die Wiese setze, in eine Umgebung von lauter Grün, nichts als Grün, wird das Grün mich an die Zäune und Sträucher des Gartens erinnern, auf die ich zu- und von denen ich auf meiner Schaukel fortschwang, und dabei ausrief: Das Meer, sehen Sie? Und hören Sie den pfeifenden Ton des Schiffes, das gleich vor Anker geht im Hafen? Als ob ich nicht gewusst hätte, dass es sich um einen Zug handelte, der in den Bahnhof fuhr, dass der Bahnhof einer der kleinsten der Welt war, und der Laut, den der Zug in den Garten schickte, sich beinah verfangen musste in den Sträuchern, die ihn begrenzten. (Winkler 2009)

Dass Winklers Text auch dem geübten Leser bei der Modellierung der Textwelt hohe Widerstände entgegensetzt, dürfte aus diesem Abschnitt unmittelbar ersichtlich sein. Der Text eröffnet vielmehr Assoziations- und Reflexionsräume, die es zulassen, Bedeutungsnetzwerke aufzubauen.

\section{Formale Gestaltung und Lesegenuss im Konflikt}

Als experimenteller Text, der inhaltlich schwer fassbar ist, wird in der Diskussion zu Winklers „Aus dem Gras“ in der Tat die Form zu einem der wichtigsten Referenzpunkte für die Auseinandersetzung mit dem Text. Insofern ist diese Diskussion für die Einschätzung der 
Bedeutung formal-ästhetischer Werte von besonderem Interesse. Im Verlauf der Diskussion bilden sich unter den Juroren zwei maßgebliche Positionen heraus: eine idealistische und eine „pragmatische“, wobei die Pragmatiker unter den Juroren sprachliche Qualität gegen geistigen Aufwand und unmittelbare Lesefreude abwägen und die Idealisten bereit sind, den unmittelbaren Unterhaltungswert zugunsten des ihres Erachtens höheren Ziels des sprachlichen Genusses in den Hintergrund zu stellen. Die Verteilung der Parteien zwei Idealisten und fünf Pragmatiker - spiegelt durchaus die im Rahmen des IngeborgBachmann-Wettbewerbs üblichen Verhältnisse der beiden Fraktionen wider.

Der Lesegenuss spielt für beide Parteien eine wichtige Rolle, und zwar deutlich expliziter als in vielen anderen Diskussionen. Karin Fleischanderl, die in ihrer Argumentation sehr grundsätzliche Ansprüche an Literatur formuliert, verankert ihre Einschätzung im Lesegenuss, wenn sie sagt:

Ich finde, es ist eine große Wohltat, Andrea Winkler zu hören und zu lesen. Es ist, als ob ihre Literatur Räume für das Ich öffnen würde, Räume, wo plötzlich Stille ist, Ruhe möglich ist, wo das Ich nicht ständig zugeschüttet wird vom medialen Getöse. (0:16 Fleischanderl, Hervorhebung KR)

Sie begründet also ihre Vorliebe für den Text bzw. alle Texte der Autorin mit einem persönlichen Gewinn, den sie aus der Wirkung der Texte ziehen kann.

Sehr deutliche Worte für die Enttäuschung ihrer Lektüreerwartungen finden die Juroren Feßmann, Sulzer und Keller. Keller ist zwar, wie fast alle anderen kritischen Juroren, bereit, die ästhetische Qualität des Textes in der Theorie anzuerkennen, gibt aber dann zu bedenken, dass der Text auf sie als Leserin keinen Sog ausübt:

Vielleicht ist es eine Meditation in der Selbstvergessenheit, die zur Selbstvergessenheit führen kann. Vielleicht ist das eine ästhetische Wirkung von Literatur. Kann ich alles für möglich halten. Ist natürlich wiederum an die Bereitschaft gebunden, dass ich mitgehe. Und ich habe mich auch etwas verloren gefühlt. Hier und beim mehrmaligen Lesen. (12:47 Keller, Hervorhebungen KR)

Sicherlich spielt in Kellers Argument, wie auch bei einigen anderen der wirkungsbetonten Contra-Argumente, der Wert Kohärenz ebenfalls eine Rolle. Dieselbe Kombination aus grundsätzlicher Bereitschaft, die formale Qualität des Textes zuzugestehen, und großer Ablehnung der Hermetik aufgrund des Lektüreerlebnisses bringt Sulzer in seiner Bewertung zum Ausdruck:

Dieser Ton ist ganz hoch und ich bin eben ganz niedrig. Ich verstehe diesen Ton nicht. Ich bin zu blöd oder zu niedrig und ich will nicht auf $\overline{\text { diesen hohen Ton gehen. Ich }}$ würde, um es ganz platt zu sagen - klingt ein bisschen aggressiv - aber ich würde, 
wenn ich das lesen müsste oder wenn ich das in einer Buchhandlung lesen würde, ich würde nach einer Seite einfach aufhören. Ich überlasse das natürlich den anderen, daran ihr Vergnügen zu haben wie Frau Fleischanderl. Ich habe irgendwie gar kein Vergnügen daran. (13:34 Sulzer)

Dass der Leser die Lektüre abbrechen würde, würde er den Text freiwillig lesen, ist wohl eines der schwerwiegendsten Urteile, die über einen Text ausgesprochen werden können. Deutlich wird aber auch, dass Sulzer seine eigenen Kohärenzbildungsstrategien als unzureichend empfindet („Ich verstehe diesen Ton nicht“; „ich bin zu blöd“). Argumentiert man mit Belke/Leders (2006) kognitionspsychologischem Ansatz, setzt der Eindruck, den Text zu verstehen (Kohärenzbildung) Belohnungsmechanismen im Gehirn in Gang, die dazu führen, dass die Lektüre als lustvoll empfunden wird. Sulzers Bewertung illustriert den gegenteiligen Prozess. Sein Statement verrät aber auch - auch das wird sich im weiteren Verlauf der Diskussion zeigen - dass sprachexperimentellen Texten mit einem hohen Grad an offensichtlicher sprachlicher und formaler Durchgestaltung - ein hoher ideeller Wert zukommt. Die Gegenüberstellung von „hoch“ und „niedrig“ („Dieser Ton ist ganz hoch und ich bin ganz niedrig.") macht deutlich, dass „Aus dem Gras" einer Kategorie von Texten zugeordnet wird, die grundsätzlich als potentiell hochwertig im Wertungswissen verankert sind.

Die härtesten Worte für denselben Wertezusammenhang findet Meike Feßmann:

\begin{abstract}
Also, ich habe jetzt gegen diesen Text überhaupt keine handwerklichen Einwände. [Heiterkeit] Ich bin aber/ bin aber auch überhaupt nicht glücklich mit diesem Text. [...] Also da war ich dankbar, weil ich gemerkt habe, also es geht um irgendetwas, was einen interessieren kann und nicht nur um die Sprache selbst. Das Problematische bei solchen Texten ist, finde ich, dass der Autor fröhlich mit den Worten spielt, aber der Leser wird genötigt, wirklich wie so ein Trüffelschwein jedem Wort hinterherzuschnüffeln. Er tut also so, als wäre er unheimlich distanziert und zwingt den Leser aber zu einer Nähe zu dem Text. Also es ist eine echte Nötigung, die Lektüre. (3:43 Feßmann)
\end{abstract}

Mit dem Hinweis, sie habe „überhaupt keine handwerklichen Einwände“ - sie verweist damit auf ihren Beitrag in der Diskussion zu Sander (2009, 3:01), in dem sie „handwerkliche“ Kritik geäußert hatte -, macht sie zunächst genau wie Sulzer und Keller das Zugeständnis, dass dem Text formal nicht viel vorgeworfen werden könne. Indem sie den Leser als „Trüffelschwein, [das KR] jedem Wort hinterherschnüffelt“, beschreibt, bringt sie pointiert zum Ausdruck, dass sie die Hermetik des Textes als geistige Anforderung wahrnimmt, die für den Leser mit Arbeit, jedoch nicht mit Genuss verbunden ist. Dass sie die Lektüre als „Nötigung“ beschreibt, ist ein klarer Ausdruck, dass sie den Lesevorgang als unangenehm empfindet und die Lektüre, wie Sulzer, vermutlich im Rahmen eines freiwilligen Lektüreprozesses abgebrochen hätte. Wie Keller und Sulzer hat Feßmann Schwierigkeiten, das 
"Textpuzzle“" zusammenzusetzen.

Verständlichkeit (Rekonstruktion der Textwelt) spielt in allen negativen Bewertungen eine Rolle. Mangold (2:05) baut seine gesamte Argumentation darauf auf, dass es ihm nicht gelingt, den Text zu verstehen. Er beendet seinen Beitrag mit den Worten, er vermute, man könne diesen Text mit sehr großen Worten beschreiben, ohne ihm deswegen näher zu kommen. Er habe ihn leider nicht verstanden. Prinzipiell gibt auch Mangold einen Kredit auf die Ehrbarkeit des Anliegens an sich, ohne dass das seine Einstellung ändern würde. Burkhard Spinnen gibt sich dagegen nicht die Blöße, einzugestehen, dass er als Kritiker den Text nicht verstanden hat. Er nimmt die Aussage Fleischanderls auf, sie finde, Musikalität sei ebenfalls eine große Eigenschaft der Literatur (5:58 Fleischanderl) und nähert sich in seinem Beitrag theoretisch dem Problem von Musikalität in der Literatur.

\begin{abstract}
Denn in dem Moment, wo ich mit Worten arbeite, wo ich diese ganze Musikalität durch Worte und Sätze/ ausgedrückt wird, habe ich semantisches Material, das mir nicht ausschließlich allein gehört. Das kommt alles aus dem Duden. Das kommt aus der Sprechergemeinschaft. Das kommt aus dem Assoziationsraum von Lesern. Und dann/ da verlange ich von so einem Text/ Was heißt verlange? Da erwarte ich von so einem Text, dass er das austrägt und sich nicht allein auf die eine oder auf die andere Seite schlägt. (6:43 Spinnen)
\end{abstract}

Am Ende seines Beitrags erklärt Spinnen, dass es ihm nicht gelungen sei, die sprachliche Ebene zur musikalischen wieder hinzuzufügen. Indem er sich darauf stützt, dass Sprache semantisches Material sei, das den Leser dazu veranlasse, nach Bedeutung zu suchen, gibt er zu verstehen, dass er sich der Kritik an der Hermetik des Textes anschließt.

\title{
Die Bewertung des Textes als Beispiel seiner Klasse: Die Bedeutung avantgar- distischer Texte
}

Die Taktik Spinnens, den Text repräsentativ für eine bestimmte Klasse von Texten zu besprechen, anstatt über den konkreten Text zu diskutieren, findet sich in vielen Beiträgen und ist sicherlich der Hermetik des Textes geschuldet. Ijoma Mangold bringt das Problem am Ende der Diskussion selber auf den Punkt:

Das kann nicht sein, dass man diesen/ so wie man diesen Text kritisiert, gleich in die dunkle Ecke gewissermaßen eines totalen Avantgardeverweigerers gestellt wird. Das ist die Gefahr, glaube ich, auch in dieser Diskussion. Der Text wird verteidigt nämlich als Repräsentant eines Genres, das wir hochhalten, viel mehr denn als dieser einzelne konkrete Text. [...] Er lässt sich ganz schwer überprüfen und deswegen verfallen wir bei diesem Text sofort in so eine allgemeine Überbaudiskussion, die aber in Wahrheit keine Auseinandersetzung mit einem einzelnen Text ist (17:39 Mangold) 
Mangold deutet an, dass es einen Konsens darüber gebe, dass avantgardistische Texte als "Genre“ wertvoll seien. ${ }^{75}$ In Andeutungen war diese Annahme auch schon in Sulzers (13:34) Äußerung über den hohen und niedrigen Ton erkennbar. Offenbar gilt die literarische Avantgarde als besonders formverliebt (die vielfach angesprochene Musikalität) und diese Formverliebtheit wiederum als hochwertig. Kurz: Sprachlich besonders intensiv und offensichtlich gestaltete Texte haben im Wertespektrum der Juroren ein hohes Prestige. Wer, so kann man folgern, sprachlich-formal originell gestaltete Texte nicht in ihrer Sprachqualität anerkennt, gilt als unqualifiziert. Diese Grundeinstellung ist im Wertungswissen verankert. Im konkreten Fall kann sie aber mit anderen Faktoren, beispielsweise der Lektürewirkung, in einen Konflikt kommen. Die Diskussion zu Winklers Text ist symptomatisch für diesen Konflikt zwischen einem Wert, der als positiv im Wertungswissen verankert ist, und einer negativen Lektüreerfahrung, die in diesem Fall aus Verständnisproblemen und daraus resultierendem Desinteresse am Text entsteht. Genau diesen Konflikt spricht Spinnen (15:43) in seinem zweiten Beitrag an. Er beginnt mit dem Hinweis für „die, die mitschreiben" - vermutlich sind die Journalisten gemeint, die sich mit dem Preis beschäftigen - „dass auf gar keinen Fall der Eindruck entstehen darf, es würde diese literarische Tradition [Avantgardismus KR) jetzt einfach gewissermaßen weggebürstet". Es ist Spinnen sehr wichtig, dass der Jury nicht der Vorwurf gemacht werden kann, sie würde avantgardistische Texte ablehnen. Die Avantgarde prinzipiell zu begrüßen, ist Teil des Expertencodes. ${ }^{76}$ Wenn von diesem Code abgewichen wird, muss das, wie im Beispiel erkennbar, erklärt werden. Spinnen fährt in seiner Verteidigung erwartungsgemäß auch damit fort, dass er den Text trotzdem ablehne, weil „,jeder einzelne dieser Texte sich auch immer wieder bewähren [muss]. Und genau wie realistische Texte sich zu bewähren haben, müssen es auch diese tun“ (ebd.).

Die Juroren, die den Text positiv bewerten, vertreten ihren Anspruch, dass avantgardistische Texte der Inbegriff guter Literatur seien, beinahe mit Selbstverständlichkeit. Fleischanderl wendet sich gleich in ihrem Eingangsplädoyer explizit gegen realistische Literatur:

Und für mich ist eigentlich der höchste Anspruch, den man an die Literatur formulieren kann, ist, dass Literatur eigentlich nicht Welt abbildet und beschreibt, sondern Welt macht, mit Hilfe von Worten und von Sprache. (Fleischanderl 0:16)

$\overline{75}$ Dass es verschiedenste Ausprägungen „der“ Avantgarde gibt, wird hier aus pragmatischen Gründen nicht weiter beachtet. Aus der Kenntnis des Korpus ist klar, dass es für die Juroren eine prototypische Avantgarde gibt, die sich durch Dominanz von Form und Sprachspiel bei gleichzeitiger Zurückstellung von Handlung und Figurenentwicklung auszeichnet.

76 Diese Beobachtung stimmt mit Bourdieus Annahme überein, dass Experten sich profilieren können, indem sie neue Formen vor anderen erkennen, das heißt, dass das Exklusive das Wertvolle ist. 
Paul Jandl formuliert sogar einen Anspruch, den Text nach Möglichkeit wohlwollend zu betrachten, mit Blick auf seine experimentelle Form:

Wir sind natürlich jetzt schon mitten wieder in einer Realismusdebatte. Und jetzt prozentuell der Anteil an Texten/ der Anteil von Texten, die in diesen diesjährigen Bachmann-Preis-Tagen nicht explizit realistisch waren, ist gering. Also so gesehen hat dieser Text seine Chance, wie ich finde, seine große Chance, verdient. Es wäre ja traurig, wenn wir in den Texten nur das lesen wollten, was wir schon kennen. (9:51 Jandl)

Winklers Text ist für Jandl der Inbegriff des Abweichenden und Originellen, dessen, was der Leser noch nicht kennt. In Hinblick auf die Verstehensprobleme Mangolds hatte er zuvor formuliert, Verstehen sei kein Kriterium der Literatur (2009 Winkler, 3:37 Jandl). Während Jandl und Fleischanderl in ihren Beiträgen mit großer Selbstverständlichkeit darauf bestehen können, dass Winklers Text als Vertreter einer experimentellen Literatur nicht nur eine Daseinsberechtigung, sondern geradezu ein Recht auf gute Bewertung hat, sehen die kritischen Juroren sich offensichtlich unter Druck gesetzt, ihre kritische Haltung einem solchen Text gegenüber zu verteidigen. Der hohe „soziale“ Stellenwert, den experimentelle Texte haben, erlaubt es den Expertenlesern nicht, den Text von Andrea Winkler zu kritisieren, ohne dabei gegenüber der Kategorie experimenteller Texte Stellung zu beziehen. Sie erkennen auf diese Weise den hohen Rang nicht-realistischer bzw. avantgardistischer Texte theoretisch an.

\subsection{Zusammenfassung}

Andrea Winklers Text bleibt dem Großteil der Jury unverständlich und wird deswegen von vielen negativ bewertet. Dem Text wird vorgeworfen, dass der mentale Aufwand, den der Leser betreiben müsste, um eine Kohärenz herzustellen, den Lesegenuss dermaßen schmälert, dass die möglicherweise anerkennenswerte formale Gestaltung in den Hintergrund tritt. Weil der Text aufgrund seiner Hermetik schwer besprechbar ist, weichen die Jurymitglieder, sowohl jene, die positiv werten, als auch jene, die negativ werten, auf eine Prinzipiendiskussion aus, in der es letztlich darum geht, welchen Rang experimentelle, avantgardistische Texte haben. Es wird dabei deutlich, dass avantgardistische Texte ein hohes Prestige besitzen. Auch den kritischen Juroren ist es äußerst wichtig, deutlich zu machen, dass sie experimentelle Texte grundsätzlich befürworten. Dennoch bewerten sie den Text schlussendlich negativ und ziehen als Hauptbegründung ihre unlustvolle Lektüre heran. Ganz wie in den Diskussionen zu Vogel (vgl. Kapitel 16) und Krupp (vgl. Kapitel 13) ist der Wert Lesegenuss insgesamt wichtiger als alle anderen verfügbaren Werte. 
Trotzdem ist nicht von der Hand zu weisen, dass insbesondere bei sprachlich sehr originell gestalteten Texten, die sich damit in eine Tradition stellen, die als „hohe Literatur“ gilt, Kritik an dieser formal intensiven Gestaltung aufgrund von mangelndem Lesegenuss gut begründet werden muss, damit die Juroren ihren Expertenstatus sichern können. Neben der extremen Bedeutung von Textkohärenz als Grundlage einer positiven Bewertung illustriert die Diskussion zu Andrea Winkler auch das hohe Prestige des Maßstabs Originalität. 


\section{Fazit}

\section{Formal-Ästhetische Werte in den Diskussionen des Ingeborg-Bachmann-Wett- bewerbs. Wie oft? Welche? Und warum?}

Die Ausgangsfrage dieser Arbeit war die nach dem Stellenwert formal-ästhetischer Werte in der Bewertung von literarischen Texten am Beispiel der Bachmann-Preis-Diskussionen. Damit verbunden war die Frage danach, welche Rolle die Machart des Textes eigentlich für die Einschätzung der Textqualität spielt. Leitfrage der Analyse war, welches Wertungsverhalten die Juroren des Preises in Bezug auf formal-ästhetische Werte zeigen. Ausgehend von der Annahme, dass Wertungen den greifbarsten Zugang zu Werten bilden (vgl. Bortolussi et al. 2008, 409), wurde in der Arbeit von Wertungen auf Werte zurückgeschlossen. Unterstellt wurde dabei außerdem, dass Wertungen, obzwar sie ein konventionalisiertes Handlungsrepertoire darstellen, nicht in einem willkürlichen Verhältnis zum Text stehen, sondern dass in Texten Anhaltspunkte für die Zuschreibung eines Wertes vorhanden sein müssen. Die Beschaffenheit dieser Zuordnungsvoraussetzungen zwischen Texteigenschaft und Wertzuweisung entwickelte sich im Verlauf der Analysen zu einem weiteren, entscheidenden Erkenntnisziel, wobei es weniger um konkrete Texteigenschaften, sondern vielmehr um abstraktere Textstrategien ging. Impulse für diese Untersuchung waren neben den methodischen Problemen, die hermeneutische und introspektive Zugänge zur Bewertung von Literatur aufwerfen, auch die Einseitigkeit konstruktivistischer und relativistischer Positionen, u. a. in der Kanonforschung. Konstruktivistische Positionen legen nahe, die Rezeption literarischer Texte mit allen dazugehörigen Komponenten wie Textdeutung und Textbewertung sei ein Resultat individueller und/oder kultureller Faktoren, und nur unwesentlich auf ein Angebot des Textes zurückzuführen. Diese hier sehr pauschalisiert dargestellten Positionen boten während der Analyse eine Reibungsfläche und haben die Perspektiven auf das Material beeinflusst.

Das Anliegen dieser Arbeit war daher, ein Set aktuell gültiger formal-ästhetischer Wertungskriterien zu gewinnen, das auf dem Wertungsverhalten einer Gruppe von Expertenlesern aufbaut, die nicht in der Rolle des Literaturwissenschaftlers werten und nicht primär programmatische Ziele verfolgen. Mit „gültigen Werten“ war nicht gemeint, dass es sich bei den beobachteten Werten um „gute“ Werte handelt, sondern vielmehr, dass die Werte Teil der Wertungspraxis sind. Die Ingeborg-Bachmann-Preis-Diskussionen 1999 bis 2009 haben sich als Zusammenstellung von Wertungsäußerungen nicht literaturwissenschaftlich agierender Expertenleser ohne primär programmatischen Anspruch bewährt. 
Einschränkend, auch für die Aussagekraft der Ergebnisse der Arbeit, muss allerdings angemerkt werden, dass in den Analysen nicht gezielt geprüft wurde, ob Wertaussagen nicht auch Auskunft darüber geben, wie die Juroren über Themen in der Gegenwartsgesellschaft sprechen und welche Positionen dabei akzeptiert sind, welche dagegen nicht. Mit Sicherheit gibt es in den Diskussionen, stellenweise lässt sich das sogar ohne großen analytischen Einsatz zeigen, auch eine Auseinandersetzung mit der Frage, wie ein bestimmtes Thema in einem literarischen Text „richtig“ behandelt werden kann oder was behandelt werden darf und was nicht. Als sprachliches Produkt kann Literatur auch nicht anders, als im Sinne der Diskurslinguistik gesellschaftliche Wirklichkeit mit zu konstruieren. Insofern ist es unbestreitbar, dass sowohl die Texte selbst als auch die Diskussionen über sie dazu beitragen, Wirklichkeit zu strukturieren. Diese Ebene der Diskussionen wurde in der Arbeit nicht eingehend analysiert. Vordergründig jedoch spielen inhaltliche Argumente im überwiegenden Teil der Diskussionen auf der Ebene der expliziten, verbalen Äußerung nur selten eine wichtige Rolle. Inhaltliche Auseinandersetzungen finden hauptsächlich im Prozess der Gegenstandskonstitution statt (vgl. Kapitel 5). Die Grundhaltung gegenüber dem Material schloss auch ein, die Wertungszuschreibungen, insbesondere auch die Zuschreibung von Werteigenschaften, nicht in Frage zu stellen. Die Juroren wurden beim Wort genommen und ihr Expertenstatus anerkannt. Es wurde daher auch nicht im Vorfeld der Analysen festgelegt, was unter „formal-ästhetisch“ zu verstehen ist. Stattdessen wurde ein Analyseverfahren gewählt, bei dem relevante Textstellen zunächst durch explizite Hinweise der Juroren darauf, dass sie mit Bezug auf die Form werten, identifiziert wurden. Ausgehend von diesen expliziten Hinweisen wurde eine Gruppe von formal-ästhetischen Wertungskriterien zusammengestellt, die die Analyse leiteten. Auf diese Weise war es möglich, eigene Wertvorstellungen in den Analysen weitgehend im Hintergrund zu halten.

\section{Welchen Stellenwert haben formal-ästhetische Werte in den Diskussionen des Ingeborg-Bachmann-Wettbewerbs?}

Formal-ästhetische Werte spielen für die Argumentationsstruktur eine zentrale Rolle. Dabei sind auf der Oberfläche formal-ästhetische Werteigenschaften bedeutender als formalästhetische Wertmaßstäbe; es werden überwiegend Werteigenschaften benannt, nur selten dagegen Maßstäbe. In der Diskussion erfüllen vor allem formal-ästhetische Werteigenschaften die Funktion, von der Angemessenheit des Urteils zu überzeugen. Die anderen Juroren von der Richtigkeit der eigenen Einschätzung zu überzeugen, darf, neben dem Anliegen, als Kritiker zu brillieren, als primäres Kommunikationsziel in Klagenfurt gel- 
ten. Sowohl Äußerungen der Juroren über ihr eigenes Wertungsverhalten als auch die schiere Menge von Wertaussagen, die auf die Machart von Texten Bezug nehmen, lassen darauf schließen, dass formale Eigenschaften von Texten überzeugender als beispielsweise inhaltliche oder wirtschaftliche Aspekte sind, sodass Argumentationen durch den argumentativen Einsatz formal-ästhetischer Eigenschaften an Beweiskraft gewinnen. Jedoch werden nicht nur den genuin formal-ästhetischen Wertmaßstäben - beispielsweise Stimmigkeit und Mehrdeutigkeit - formal-ästhetische Werteigenschaften zugeordnet, sondern auch Wertmaßstäben, die nicht dem formal-ästhetischen Bereich zuzurechnen sind. So werden beispielsweise auch Urteile, die eindeutig ethischen oder inhaltlichen Kriterien gehorchen, vielfach mit Aspekten der Machart begründet. Die Diskussion zum Text von Björn Kern (vgl. Kapitel 18) stand beispielhaft für diese Beobachtung. Dominiert wird diese Diskussion von einer ganz klaren ethischen Abneigung gegenüber einer Darstellung alter Menschen, die negative Emotionen wie Ekel beim Leser erzeugt. Sie wird von den Juroren durch die Kritik an der Erzählsituation begründet. In einer Argumentation, in der es, wie beim Ingeborg-Bachmann-Wettbewerb, um die nicht näher spezifizierte Qualität von Texten geht, werden also Begründungen, die die Gestaltung des Textes zum Ausgangspunkt haben, als besonders überzeugend eingestuft. Neben der Unterhaltungsfunktion der Diskussionen, die die Juroren durchaus durch Polemik, Spitzfindigkeit und kauziges Verhalten zu erfüllen vermögen, ist „die Arbeit am Text“ zentraler Bestandteil der Diskussionen. Diese Textarbeit ist jedoch nicht gleichzusetzen mit der analytischen und hermeneutischen Arbeit vieler Literaturwissenschaftler. Immerhin muss sie aufgrund der begrenzten Redezeit, aber auch aufgrund ihrer Unterhaltungsfunktion, sehr viel pointierter erfolgen als in typischen wissenschaftlich-hermeneutischen Textanalysen, die auf sachliche, möglichst präzise und umfassende Darstellung abzielen. Dennoch fußt sie auf derselben Grundannahme, dass Behauptungen über einen Text am Text selber nachgewiesen werden müssen. Als argumentatives Material sind formal-ästhetische Werte für die Juroren daher unverzichtbar. Insbesondere formal-ästhetische Werteigenschaften, eng verknüpft mit der „Arbeit am Text“, sind Bestandteil ihres Knowing-How.

Die argumentative Überzeugungskraft formal-ästhetischer Argumentationen lässt sich nicht nur durch ihre Beweisfunktion erklären, sondern auch als Ausdruck der Auffassung begreifen, dass literarische Texte sich durch einen besonderen Umgang mit Sprache auszeichnen. Obwohl die Grenzen zwischen Literatur und Alltagstext fließend sein können, dominiert die Vorstellung, dass Literatur als Kunst typischerweise durch eine besondere sprachliche und formale Gestaltung geprägt ist und sich so von Alltagstexten unterscheidet. 


\section{Wie gewinnt man den Bachmann-Preis?}

In einer Arbeit, die danach fragt, wie die formale Beschaffenheit der Texte die Bewertung durch die Jury beeinflusst, kommt man nicht umhin, die Frage zu beantworten, ob es Eigenschaften gibt, die Texte in der Gunst der Juroren deutlich heben. Die schlechte Nachricht: Es gibt kein Rezept. Die gute Nachricht: Es gibt durchaus einige Strategien, die ehrgeizige Anwärter beachten können.

Grundsätzlich gilt: Auch der professionelle Leser will „auf seinem Niveau“ gut unterhalten werden. Das heißt, es ist bei der Konzeption oder Wahl der Wettbewerbstexte die große Erfahrung mit Literatur in Rechnung zu stellen. Die folgenden Strategien versprechen also nur dann Erfolg, wenn sie auch dem Erfahrungshorizont der Jury gerecht werden.

1. Filmisch erzählen. Gute Aussichten auf Anerkennung haben Texte, die Figuren und eine Handlung zeigen, ohne diese zu bewerten und sie zu kommentieren. Zu diesem Erzählverfahren gehört u. a. auch ein Erzähler, der sich freundlich distanziert zur Hauptfigur verhält, eine Szenenfolge, die sich an der Schnitttechnik des Films orientiert, das heißt, zwischen Figuren und Schauplätzen springt, und der Einsatz einer Figurenpsychologie, die die Handlung motiviert und dem Leser Empathie erlaubt. Der Erzählmodus des Showing bietet die beste Grundlage für das Gelingen.

2. Sinnlich erfahrbar machen. Die sprachliche Gestaltung des Textes spielt für die Juroren dort im Detail eine besondere Rolle, wo es darum geht, dass der Plot sinnlich erfahrbar wird. Was der Film durch die Bildkomposition und die Filmmusik leistet, sollen literarische Texte durch sprachliche Bilder und Rhythmik leisten. Dabei spielen Eindrücklichkeit, Eindringlichkeit und Sinnlichkeit eine besondere Rolle. Durch eindrückliche Bilder und eine eindringliche Rhythmik kann der Text als sprachliches Kunstwerk besonderen Eindruck machen, jedoch nur, wenn beides in einem Funktionsverhältnis zur Handlung steht. Experimentellere Texte, die primär als Sprachspiele gestaltet sind, finden im Untersuchungszeitraum selten Anerkennung.

3. Spannung erzeugen. Spannung ist ein vielschichtiges Phänomen. Viele Facetten spielen für die Klagenfurter Jury eine Rolle, jedoch ist gerade in diesem Punkt der Status der Juroren als Expertenleser bedeutsam. Nicht alles, was einen Durchschnittsleser überrascht, fesselt, neugierig macht, kann einen Berufsleser gleichermaßen in den Bann ziehen. Für die Juroren spielt die Offenheit des Textes mit allen dazugehörigen Facetten - angelegte Unvorhersehbarkeit der Entwicklung des 
Plots, angelegte Vielschichtigkeit des Plots, verschiedene Perspektiven und Ebenen, Leerstellen, Modus des Showing - eine entscheidende Rolle für die Einstufung eines Textes als spannend. Hier ist auch die Originalität des Textes wichtig. Der Text muss jedoch überschaubar bleiben, das heißt, er darf die Juroren nicht überfordern.

Der ideale Text hält, wie die Analyse der Jury-Bewertungen gezeigt hat, insgesamt eine Balance zwischen orientierungsstiftenden und aktivierenden formalen Merkmalen.

\section{Welche formal-ästhetischen Werte lassen sich erkennen und wie verhalten sich diese zu den bisherigen Annahmen der Literaturwissenschaft über das Re- pertoire an formal-ästhetischen Werten, das aktuell bei der Bewertung von} Literatur eingesetzt wird?

Die Juroren des Ingeborg-Bachmann-Wettbewerbs greifen auf dieselben formal-ästhetischen Werte zurück, die Heydebrand/Winko (1996) als charakteristisch für die formal-ästhetische Bewertung von Literatur herausgearbeitet haben. Allerdings koppeln die Juroren diese Werte stark mit der hedonistischen und affektiven Wirkung (vgl. Heydebrand/Winko 1996, 127 ff.), die die Texte während der Lektüre auf sie gehabt haben. Lesegenuss, Langeweile und Betroffenheit sind Wertmaßstäbe, die häufig dazu verwendet werden, formalästhetische Eigenschaften eines Textes als „gute“ oder „schlechte“ Eigenschaften einzustufen und auf diese Weise letztlich den Text als gelungen oder nicht gelungen zu bewerten. Aber auch solche Bewertungen, die zunächst rein formal-ästhetisch anmuten - also formalästhetische Werteigenschaften des Textes mit Bezug auf formal-ästhetische Wertmaßstäbe - stehen häufig in einem hedonistischen oder affektiven Argumentationskontext. Damit stehen die Bewertungen in einem krassen Kontrast zu Aussagen wie etwa Hans Robert Jauß` (1982, 77) kritischer Bemerkung, ästhetischer Genuss gelte „als Inbegriff eines Verhaltens, das schon gegenüber klassischer Kunst als banausisch, gegenüber allen Kunstformen der Moderne aber als die konträr ausgeschlossene Einstellung“ gesehen wird. Ästhetische Erfahrung sei, so Jauß $(1982,79)$ in seiner Auseinandersetzung mit dieser Haltung, erst da legitim, wo sie sich auf die Stufe ästhetischer Reflexion erhoben habe. Terry Eagleton (1997, 184) merkt an, das Wort »Vergnügen« habe einen Beigeschmack von Trivialität. Hakemulder $(2013,173)$, dessen empirische Studien mit Studenten zeigten, dass Schönheit keinen Beitrag zur gebannten Lektüre eines Textes zu leisten scheint, zeigt sich befremdet über diese Absenz des Schönen: „Intuitively, and from own experience, it seems likely that responses to literature go beyond the typical entertainment emotions, that is, suspense, 
surprise, and curiosity“. Die Aussagen sind symptomatisch für die - immerhin zunehmend selbstkritische - Selbstwahrnehmung des Faches. Hedonistisches Lesen wird nicht geleugnet; es ist jedoch kein legitimer Lesemodus weiter Teile der Literaturwissenschaft und kann daher auch nicht Teil ihrer Wertungspraxis sein.

Die Frage, die am Ende dieser Arbeit also beantwortet werden muss, ist die Frage danach, wie sich die Verquickung von Wertmaßstäben, die die Literaturtheorie anerkennt, und von hedonistischen Werten, die aus literaturwissenschaftlicher Sicht eher in den Bereich der Laienwertung gehören, erklären lässt. Es zeigt sich, dass die Trennung von hedonistischem Lesegenuss und „ernsthaftem“ ästhetisch ausgerichtetem Lesen - die Modi werden als typische Rezeptionsformen von Unterhaltungsliteratur bzw. sogenannter ernster Literatur wahrgenommen - auch zu einer Absonderung der Forschungsfelder voneinander geführt hat. Textwirkung wird in der Wertungsforschung kaum betrachtet. Die Textwirkungsforschung versteht sich umgekehrt nicht als Beitrag zur Wertungsforschung. Dabei ist es naheliegend, dass ein Text, der „wirkt“, das heißt, der den Leser zu fesseln vermag, auch das Potential hat, als "guter" Text wahrgenommen zu werden, nicht nur unter Laien. Ein „guter“ Text in diesem Sinne ist vielleicht noch kein wertvoller Text, das heißt ein Text, der Eingang in den Kanon finden kann. Dennoch wird, wenn man Winkos (2002) Theorie des Kanons als invisible-hand-Phänomen voraussetzt, durch die positive Wahrnehmung des Textes durch einzelne Leser ein Grundstein dafür gelegt, dass ein Text zukünftig möglicherweise auch als wertvoll eingestuft wird. Subjektiver Genuss und gesellschaftlicher Wert liegen näher beieinander, als bisher vermutet wurde, und gerade für den Genuss dürften Eigenschaften der Machart durchaus eine Rolle spielen. Bevor dies genauer erläutert wird, soll allerdings das Repertoire an formal-ästhetischen Werten, das in den Analysen herausgearbeitet wurde, vorgestellt werden.

Es lassen sich dabei zwei Wertekomplexe und ein einzelner Wertmaßstab ausmachen, die die Diskussionen maßgeblich bestimmen: Orientierung, Aktivierung und Originalität. Während Originalität zum Standard-Repertoire formal-ästhetischer Wertmaßstäbe gehört, sind Orientierung und Aktivierung wirkungsbezogene Maßstäbe, die im Rahmen der Fragestellung erklärungsbedürftig sind. Sie sind den formal-ästhetischen Wertmaßstäben übergeordnet. Im Analyseprozess wurde deutlich, dass es in der Tat keine Wertmaßstäbe gibt, die per se zu einer positiven Bewertung führen, wenn sie sich im Text bestätigten. Texte wurden zwar häufig, aber keineswegs immer, positiv bewertet, wenn sie Kriterien wie Stimmigkeit, Gestaltetheit oder Offenheit erfüllten. Es stellte sich daher die Frage nach den Zuordnungsvoraussetzungen: Unter welchen Umständen wird ein als 
stimmig eingeschätzter Text positiv oder negativ bewertet? Als Bedingung für die $\mathrm{Zu}-$ ordnung erwiesen sich die Textwirkung auf den Ebenen Orientierung und Aktivierung. Gelungene Texte gewähren Expertenlesern, so das Analyseergebnis, eine Orientierung im Text, ermöglichen aber auch eine emotionale und kognitive Aktivierung. Den jeweiligen Wirkungen werden von den Juroren typischerweise bestimmte Werte zugeordnet, die aus dem formal-ästhetischen Werterepertoire stammen. Eine vollkommen positive Bewertung erfolgt aber nur dann, wenn beide Hauptwirkungen gleichermaßen erzielt werden. Um das am Beispiel Stimmigkeit noch einmal zu veranschaulichen: Stimmigkeit ist ein Wert, der zu einer Gruppe von Werteigenschaften gehört, die eine weitreichende Orientierung im Text ermöglichen. Er wird aber nur so lange goutiert, wie er nicht dazu führt, dass der Leser sich aufgrund von Unterforderung abwendet (mangelnde kognitive Aktivierung). Bei mangelnder Aktivierung - der Text wirkt langweilig - kann Stimmigkeit also ein negativer Maßstab sein. Die folgende Übersicht zeigt, welche formal-ästhetischen Werte in den jeweiligen Komplexen zur Wertungsbegründung herangezogen wurden:

Orientierung: Hierhin gehören Werte wie Kohärenz (gelungene Rekonstruktion einer Textwelt) und Stimmigkeit und Angemessenheit (die Passung von Gehalt und Gestalt), aber auch Gestaltetheit (der Text ist erkennbar kunstvoll geformt), Dichte und Präzision. Letztendlich wurzeln all diese Werte in einer Selbstbestätigung des Lesers im Sinne Belke/Leders (2006), die mit Lust belohnt wird: Weil die Juroren sich im Text orientiert fühlen, weil sie den Eindruck haben, dass ihre Verstehens- und Analysebemühungen erfolgreich sind und in einem guten Verhältnis zu dem Lustempfinden stehen, das sie während der Lektüre hatten, können sie diese Qualitäten honorieren. Die Rekonstruktion einer Textwelt als mentales Modell (Christmann/Groeben 1999) oder Simulation (Oatley 1994) ist dabei eine Basisvoraussetzung und geht allen anderen Auseinandersetzungen mit dem Text voraus. Wenn die Textwelt nicht simuliert werden kann, gehen die Diskussionen kaum über Versuche der Textweltrekonstruktion hinaus. Texte, deren Textwelt nicht rekonstruiert werden kann, können selbst dann nicht positiv bewertet werden, wenn das Strukturprinzip des Textes erkannt wird. Die Werte Stimmigkeit, Gestaltetheit, Dichte und Präzision sind in ihren verschiedenen Facetten Steigerungen der Kohärenz auf formaler Ebene. Nicht nur die Textwelt kann simuliert werden, sondern auch die formal-ästhetische Beschaffenheit des Textes kann, sozusagen als abstrakterer Bauplan, simuliert werden. Die Vorstellung, dass alle inhaltlichen Elemente und formalen Entscheidungen des Autors eine Funktion für den Text haben, spielt auf dieser Ebene eine große Rolle. Wenn eine Funktion für bestimmte Elemente oder Formentscheidungen nicht erkannt werden kann, werden 
Texte kritisiert, vorausgesetzt der Juror wird auf ein solches, vermeintlich funktionsloses Element auch aufmerksam. Maximale Orientierung macht aber noch keinen guten Text. Auch das wird in den Diskussionen schnell klar. Ein Text muss auch die Aktivierung des Lesers erreichen, um wirklich positiv bewertet zu werden.

Aktivierung: Werte aus diesem Komplex bauen auf der Selbstbeobachtung der Juroren auf, dass sie den Text nicht nur als passive Rezipienten, sondern als stumme Teilnehmer wahrgenommen haben. Diese Aktivierung kann auf verschiedenen Ebenen stattfinden. Die emotionale Aktivierung spielt eine große Rolle und offenbart sich vor allem in Werten, die sich auf die Figur beziehen wie Empathie und Lebendigkeit. Gleichermaßen wird Texten aber auch das Vermögen zugeschrieben, Leser mittels ihrer Strukturen mental anzuregen, sodass sie eine kreative Leistung beim Zusammensetzen eines Textverständnisses vollbringen müssen. Die formal-ästhetischen Werte, auf die sich die Juroren dann beziehen, sind Offenheit, Showing, die Distanz des Erzählers zur Figur sowie die Vielschichtigkeit und Mehrdeutigkeit des Plots. Gerade diese mentale Aktivierung ist offenbar ein Balanceakt, denn mentale Aktivierung wurzelt ebenfalls in der Simulation. Der Kipppunkt zwischen gelungener Aktivierung und Verlust der Orientierung ist kaum bestimmbar und hängt auch von der Lesesozialisation und Leseerfahrung sowie von konkreten Text- und Kontextfaktoren ab. Die Werte aus dem Komplex Aktivierung sind gegenüber den Werten aus dem Komplex Orientierung höherrangig, weil sie den Erlebnischarakter des Textes steigern. Sie setzen aber ein Mindestmaß an Orientierung voraus. Dass die Juroren intensiv vom Text in den Bann gezogen werden, ihre Aufmerksamkeit vollständig durch den Text gefesselt ist, dass sie Spannung empfinden, macht den gelungenen Text eigentlich aus. Der Komplex Aktivierung steht damit für viele Phänomene, die alltäglich mit dem Begriff „Spannung“ bezeichnet werden. Alle Facetten, die Spannung im alltäglichen Gebrauch umfasst - rätseln, emotional angespannt sein, Unbekanntes entdecken, einer Entwicklung folgen, bemerkenswerte Formulierungen registrieren -, finden sich im Komplex Aktivierung wieder. In der Wertsprache der Juroren taucht der Begriff „Spannung“ selber allerdings eher selten auf. Drei Gestaltungsstrategien sind vor allem zu nennen, die von den Juroren als Garanten der Aktivierung immer wieder angeführt werden: der Modus des Showing - also eine filmische Erzählweise, die die Hauptfigur in verschiedenen Handlungen/Szenen zeigt, die der Leser selber deuten muss und die, dank der Möglichkeiten sprachlicher Gestaltung, gezielt mehrdeutig gestaltet werden kann. Außerdem die Anlage verschiedener erzählerischer Ebenen im Text, die schließlich auch Deutungsebenen eröffnen können. Und schließlich die neutrale Distanz des Erzählers zur Hauptfigur, die dem Leser erlaubt, 
selbst zu urteilen. Emotionale Betroffenheit fördert eine positive Bewertung, wenn sie über indirekte Darstellungsverfahren erreicht wird.

Ein dritter Wertmaßstab muss in seiner Bedeutung differenziert werden: Originalität. Originalität wird in den Diskussionen des Ingeborg-Bachmann-Wettbewerbs oft als Kriterium genannt. Dennoch spielt dieser Maßstab für die Entscheidungsfindung der Jury keine entscheidende Rolle. Originalitätsargumente werden in den Argumentationen unterstützend oder ergänzend verwendet, selten bilden sie aber den Kern einer Argumentation. Ganz explizit wird Originalität in seiner Ausprägung „Aktualität“ als ein schwieriger Maßstab bezeichnet, wenn beispielsweise Schindel darauf hinweist, „der Begriff zeitgenössisch [kommt ihm manchmal] so wie eine bösartige Drohung vor" [2000 Kieninger; 18:19 Schindel].

Vergleicht man die geringe Bedeutung des Wertes Originalität beim Ingeborg-BachmannWettbewerb mit den Aussagen von Literaturwissenschaftlern, die sich auf theoretischer Ebene mit Werten beschäftigt haben, sieht man eine deutliche Diskrepanz. Andreotti (1983, 406) kommt beispielsweise zu dem Ergebnis, „dass gute literarische Texte stets zeitgemäße, innovative Texte sind, die gängige Formen und Normen immer wieder durchbrechen“. Fricke/van Peer $(1999,151)$ sehen Abweichungen als ein zentrales Moment der Aufbereitung und Präsentation von Stoff, indem durch Abweichungen bestimmte Aussagen erst möglich werden. Der Grund für die geringe Bedeutung von Originalität als Wert in den Diskussionen ist darin zu suchen, dass die Texte, die von den Juroren nach Klagenfurt „eingeladen“ werden, jene sind, die sie unter den ihnen zugesandten als die besten herausgefiltert haben. Sogenannte Genreliteratur - stets das Standardbeispiel für nicht originelle Schemaliteratur - steht in Klagenfurt gar nicht erst zur Disposition. ${ }^{77}$ Man kann also annehmen, dass ein grundlegendes Maß an Originalität für die Auswahl der Texte eine größere Rolle spielt - aber auch hier wahrscheinlich eher implizit als explizit. Dass Literatur als Kunst keinem Muster folgt - in diesem Sinne also originell ist - gehört zum stärker konventionalisierten Wertungswissen. Es besteht kein Anlass, dieses Wertungswissen in Klagenfurt zu verhandeln. Dabei bedarf es allerdings nicht unbedingt einer besonders ausgeprägten Originalität, wie sie typisch für experimentelle Texte ist, um nach Klagenfurt eingeladen zu werden.

Wenn dennoch Originalitäts-Argumente verwendet werden - und es finden sich derer viele -, haben sie eine andere Funktion als Wertungen im Orientierungs- und Aktivierungs-

\footnotetext{
$\overline{77}$ Allerdings stehen gelegentlich Texte zur Debatte, die gut erkennbar an ein bestimmtes Genre anknüpfen und es variieren. In diesen Fällen ist der neuartige Umgang mit dem Genre oft ein positiver Faktor in der Bewertung.
} 
Komplex. Originalität trägt bei den meisten Juroren wenig zur grundsätzlichen Wertungshaltung bei, sondern stützt die Argumentation für eine positive oder negative Entscheidung. Sie ist in den Bewertungen eine Außerdem-Kategorie, die dabei hilft, eine bereits getroffene Werteinschätzung zu stützen. Wieso ist das so? Originalität ist ein Maßstab, der die besondere Expertise eines Kritikers unter Beweis stellt. Die Einschätzung eines Textes auf der Originalitätsskala setzt eine breite Kenntnis literarischer Texte voraus. Auffallend ist, dass der Einsatz von Originalitätsargumenten wenig Effekt auf die Entwicklung der Diskussion hat. Sie werden als bloße Wortgewichte eingebracht, die dazu dienen, die Position des Kritikers, sein Expertenwissen und sein besonderes Gespür für Literatur darzubieten.

Andererseits ordnet sich der Effekt, der durch formale Originalität erzielt wird, auf der Ebene der Texteigenschaften in die Komplexe Orientierung und Aktivierung ein. Der Effekt von Originalität ist der einer Variation oder Abweichung von Bekanntem, die aber nur mit Bezug auf das Bekannte funktionieren kann (Orientierung). Gleichzeitig ist diese Variation des Bekannten durch ihre Unvorhersehbarkeit dazu geeignet, die Aufmerksamkeit des geschulten Lesers zu fesseln (Aktivierung). In der Tat muss man also davon ausgehen, dass Originalität, insofern sie eine Unterscheidung zwischen Schemaliteratur und Literatur als Kunst möglich macht, eine Rolle für die Bewertung spielt, allerdings keine, die entscheidender Bestandteil der Diskussionen ist. Die Beobachtungen legen nahe, dass die Unterscheidung von Schemaliteratur und Literatur als Kunst auf der Grundlage des Maßstabs Originalität eine der grundlegendsten Wertentscheidungen und daher unter Experten nicht verhandlungsbedürftig ist. Dabei zeigt sich zum einen, dass Originalität fester Bestandteil der Wertsprache der Juroren - durchaus auf denselben Effekten aufbaut wie alle anderen Werte auch: Orientierung und Aktivierung. So gehen in den Diskussionen viele Originalitäts-Argumente in Aussagen über die Wirkung und Wertigkeit anderer formaler Eigenschaften über. Im Vordergrund stehen dann Fragen nach der Erkennung, Funktion, Deutung und Wirkung von Formelementen. Wenn Originalitätsargumente ohne Bezug auf die Funktion oder Wirkung der originellen Formelemente verwendet werden, dienen sie der Profilierung der Experten.

Die zwei Komplexe Orientierung und Aktivierung prägen die Diskussionen. Es gibt zwar Diskussionen, die ganz klar nach ethischen Kriterien funktionieren (z. B. 2001 Tingler, 2004 Dieckmann, 2004 Balaka, 2009 Stift). Es gibt auch Diskussionen, in denen die Frage nach der Originalität als Leitfrage der gesamten Bewertung eine entscheidende Rolle spielt (z. B. Maier 2000). Sobald es aber darum geht, die Verwendung dieser Kriterien am Text 
zu begründen, werden Maßstäbe aus den Bereichen Orientierung und Aktivierung hinzugezogen. Ausgehend von den - in der Regel nicht explizit verbalisierten - Fragen, wie gut ein Text verstanden wird (Simulationsvorgänge) und wie sehr er beim Lesen fesselt, wird Bezug genommen auf etablierte formal-ästhetische Wertmaßstäbe. Die Empfindung geht dabei der Wertfindung voraus. Die Struktur der Diskussionen legt insgesamt offen, dass nicht die Wertmaßstäbe vorausgesetzt und auf den Text bezogen werden, sondern umgekehrt, dass zunächst eine Empfindung der Wertigkeit (Gefallen) besteht, von der aus sich die Juroren dann Stück für Stück zu „passenden“ Maßstäben hinarbeiten. Charakteristisch dafür ist auch, dass es für keinen der Juroren Wertmaßstäbe gibt, die in ihrer Umsetzung per se positiv sind. Unter der Voraussetzung, dass ein Text während der Lektüre lustvoll rezipiert wurde, können alle genannten Maßstäbe positiv verwendet werden, unter der Voraussetzung einer negativen Wirkung negativ. Dabei verändert sich die Bedeutung eines Maßstabs im Wertungswissen nicht. Stimmigkeit bleibt beispielsweise auch dann als positiver Maßstab erhalten, wenn Iris Radisch (0:59), nachdem sie die Bildlichkeit des Textes von Ulrike Draesner (2000) analysiert hat, befindet: „Also mit anderen Worten: Ich finde das ein bisschen zu sauber gebaut. [...] Aber im Großen und Ganzen finde ich es selber zu ordentlich in Schachteln aufgehoben, was hier gesagt werden soll“. Dem Statement geht eine ganze Reihe von Beispielen voraus, in denen Radisch zeigt, wie sie die Thematik des Textes in seiner Bildlichkeit umgesetzt sieht (Verhältnis von Gehalt und Gestalt). Sie gibt zu verstehen, dass sie den Inhalt grundsätzlich adäquat (stimmig) in der Form umgesetzt findet, bewertet diese stimmige Umsetzung aber dennoch nicht positiv. Gleichzeitig stellt Radisch aber nicht unbedingt Stimmigkeit als Maßstab in Frage, sondern erwartet, so lässt sich annehmen, eine stärkere Ambivalenz, d.h. eine stärkere Offenheit oder Mehrdeutigkeit. ${ }^{78}$ Dagegen urteilt Radisch in der Diskussion zu Julia Schoch: „Ich finde das so ansteckend [die trockene Traurigkeit des Textes KR]. Und ich denke auch, dass dieser Text wirklich selber sprachlich umsetzt, was ihn umtreibt. Und das ist natürlich das, was Literatur erst zu großer Literatur macht“ (2005 Schoch, Radisch 2:30). Derselbe Maßstab (Stimmigkeit) wird, gekoppelt mit einer klaren Wirkungswertung (,,ansteckend“), eindeutig positiv eingesetzt. Welche Maßstäbe in der verbalen Umsetzung der Wertung überhaupt eingesetzt werden können, bestimmen Konventionen des Literaturbetriebs. Wie genau aber die Maßstäbe eingesetzt werden, das ist die entscheidende Beobachtung aus den Diskussionen des Ingeborg-Bachmann-Wettbewerbs, wird bestimmt durch die (un-)lustvolle Lektürewirkung des Textes. Die Einteilung der verschiedenen Wertmaßstäbe in die beiden Komplexe

78 Heydebrand/Winko (1996, 117. f.) geben zu Stimmigkeit kein Gegenteil an, wie sie das bei vielen anderen Werten - beispielsweise Offenheit mit dem Gegenteil Geschlossenheit - tun. 
Orientierung und Aktivierung ist ein Produkt dieser Beobachtung.

An dieser Stelle können wir auf die Beantwortung der Frage zurückkommen, wie sich diese Verquickung von hedonistischen und formal-ästhetischen Werten erklären lässt. Drei Thesen, die zur Beantwortung der Frage beitragen können, sollen hier vorgestellt werden.

1. Die Vermischung ist bedingt durch die Sozialisation und Funktion der Juroren.

2. Die Vermischung ist bedingt durch die Bewertungsebene „Literaturpreis“. Im Rahmen der Literaturpreiswertungen werden weder rein subjektive Geschmacksurteile noch intentional kanonbildende Wertungen geäußert.

3. Bei den formal-ästhetischen Werten der Literaturwissenschaft handelt es sich um „fachsprachliche“ Ausdrücke für Phänomene der Wirkung, die sich während der Lektüre als Resultat kognitiver Verarbeitungsprozesse einstellt.

Die Thesen sind miteinander verwoben und können gemeinsam eine differenzierte, aber keine abschließende Antwort geben. Eine weitere Erklärungshypothese soll an dieser Stelle nur sehr kurz angerissen werden. Es liegt nahe, dass sich ein größerer gesellschaftlicher Wertewandel auch im Sprechen über Literatur spiegelt. Unter dem Stichwort „Erlebnisgesellschaft" ist das Phänomen beschrieben worden, dass sich gesellschaftliche Gruppen nicht mehr ausschließlich durch ihren sozioökonomischen Status bestimmen lassen, sondern dass es zusätzlich - teilweise überlappend mit sozioökonomischen Faktoren - Erlebnismilieus gibt (Schulze 1993). Welche Erlebnispotentiale und Erlebnisqualitäten an Medienangebote (u. a.) als attraktiv eingeschätzt werden, bildet eine Voraussetzung für die Zugehörigkeit zum entsprechenden Milieu. Es ist wahrscheinlich, dass sich eine solche Aufwertung von „Erlebnissen“ auch in der verbalen Auseinandersetzung mit dem Medium Literatur niederschlägt, sodass es heute im Gegensatz zu Wertungsauseinandersetzungen in den 1950er Jahren legitimer erscheint, die Erlebnisqualität einer Lektüre auch in der Bewertung explizit zu thematisieren.

\section{These: Die Kopplung von formal-ästhetischen und hedonistischen Werten ist durch die Sozialisation und das Rollenverständnis der Juroren bedingt.}

Um die größte Auffälligkeit in den Diskussionen - gleiches formal-ästhetisches Wertespektrum verbunden mit hedonistischen wirkungsbezogenen Werten - zu verstehen, hilft es, die starke Verflechtung und die Unterschiede in der Funktion der beiden Teilbereiche des Literaturbetriebs - Literaturwissenschaft und Literaturkritik - genauer zu betrachten. In 
kaum einem anderen künstlerischen Gebiet dürften die Kunst selbst, die Wissenschaft, die sie beschreibt, und ihre Vermittlung durch Kritiker personell so eng miteinander verwoben sein wie im Bereich der Literatur. „Literaturwissenschaft ist eine Sozialisationsinstanz für Literaturkritiker“ bemerkt Thomas Anz (1990, 203) und: „Der Erwerb von literaturwissenschaftlichen Kenntnissen und Kompetenzen ist für gute Literaturkritiker unabdingbar" (ebd.). Nicht nur die Kritiker, auch die Autoren verfügen häufig über literaturwissenschaftliches Wissen. Der Bachmann-Preis zeigt das geradezu exemplarisch: Acht von elf Bachmann-Preis-Trägern im Zeitraum von 1999 bis 2009 haben Germanistik, Literaturwissenschaft oder eine andere moderne Philologie studiert. Mit Ausnahme von Robert Schindel, Friederike Kretzen, André Vladimir Heiz, Alain Claude Sulzer und Karin Fleischanderl haben alle Juroren der untersuchten Jahrgänge ein philologisches Studium absolviert. ${ }^{79}$ Die Philologien sind nicht nur für jene, die einen wissenschaftlichen Umgang mit Sprache und Literatur anstreben, attraktiv, sondern auch ein Ausgangspunkt für diejenigen, die als Autoren produktiv mit Sprache umgehen, oder diejenigen, die als Vermittler tätig sein wollen. Sie bieten Werkzeuge, um mit Texten umzugehen. Zu diesem Handwerkszeug gehören auch Wertmaßstäbe und Werteigenschaften von Texten. Dass die Wertmaßstäbe, die sich in den Bewertungen der Juroren verbal explizit manifestieren, weitgehend mit denen, die die Literaturwissenschaft - teils normativ, teils deskriptiv bestimmt hat, übereinstimmen, ist bedingt durch die Sozialisation der Juroren in philologischen Studiengängen. Dennoch unterscheidet sich der Zugriff der Juroren auf die Texte von dem vieler Literaturwissenschaftler. Der Unterschied in der Perspektive, die starke Betonung der hedonistischen und affektiven Wirkung bei den Juroren erklärt sich aus den unterschiedlichen Rollen, in denen die Literaturprofis agieren. Wird in der Literaturwissenschaft, je mehr sie sich dem Anspruch der Überprüfbarkeit stellt, ein analytischer, deskriptiver Blick gefordert, so dürfen Kritiker einen subjektiveren Standpunkt einnehmen. Sie dürfen in Fragen der Wirkung die Rolle eines Lesers einnehmen, der nicht danach fragt, beziehungsweise zu fragen braucht, ob die erzielte Wirkung eine gesellschaftlich, moralisch oder ästhetisch wünschenswerte ist. ${ }^{80}$ Die erste Frage in Hinblick auf die hedonistische Wirkung ist die danach, ob der Text gerne gelesen wurde, ob es Spaß gemacht hat, ihn zu lesen. Diese Perspektive, die keineswegs eine zwingende ist, ist unter den Juroren des Ingeborg-Bachmann-Wettbewerbs vielfach vertreten. Leselust scheint in aktuellen literaturkritischen Debatten ein durchaus anerkannter Referenzpunkt zu sein,

\footnotetext{
79 Ich gehe stillschweigend davon aus, dass die Nationalphilologien sich in ihrem Umgang mit literarischen Texten grundsätzlich sehr ähnlich sind.

80 Sie können Texte allerdings nach Wunsch oder aktueller Anforderung auch in Hinblick auf ihre ethische und gesellschaftliche Akzeptabilität hin bewerten.
} 
wenn auch getarnt unter dem Deckmantel einer sachlicheren, auf die formale Gestaltung bezogenen Wertsprache. Die Teilbereiche des literarischen Feldes Literaturkritik, Literaturwissenschaft und Literaturproduktion bilden, aller Rollenspezifika zum Trotz, ein Netz von eng verwobenen Interdependenzen. Dabei ist allerdings die Wirkung der Literaturwissenschaft auf Autoren wie auf Kritiker nicht zu unterschätzen, denn als Ausbildungsstätte für beide Akteursgruppen prägt sie vor allem das Handwerkszeug, das zur Analyse - sei sie auch beiläufig - von literarischen Texten zur Verfügung steht, aber auch die Art und Weise, wie in literarischen Texten präsentierte Informationen gedeutet werden. Gleichzeitig wirken Autoren auf die Literaturwissenschaft zurück, indem sie überhaupt erst die „Herausforderungen" schaffen, die Literaturwissenschaftler zu bewältigen haben. Und Kritiker tragen durch ihre Bewertung dazu bei, dass Texte die Wahrnehmungsschwelle überschreiten und so von der Literaturwissenschaft überhaupt erst wahrgenommen werden können. Die Analyse der Klagenfurter Diskussionen führt diese Vernetzung am Beispiel der Kritikerwertungen konkret vor Augen.

\section{These: Die Vermischung ist bedingt durch die Bewertungsebene „Literatur- preis".}

Die Macht-These der Kanontheorien (vgl. Kapitel 1), die den ersten Impuls für diese Arbeit gegeben hat, geht davon aus, dass literarisch Wertvolles die Funktion hat, gesellschaftlich „Wertvolles“ zu stützen. Das heißt, dass dominante gesellschaftliche Gruppen genau jene Werke für wertvoll halten, die diese Gruppe und ihre Werte positiv darstellen, und somit ihre gesellschaftliche Stellung stützen. Einiges spricht für diese These und auch die Ingeborg-Bachmann-Preis-Diskussionen bieten Hinweise darauf, dass beispielsweise ethische Tabus die Bewertungen erheblich beeinflussen können. Allerdings erweisen sich die Bewertungen als weitaus vielschichtiger, als dass sie sich allein durch die MachtThese erklären ließen. Es handelt sich bei den Bachmann-Preis-Diskussionen auch nicht um Bewertungen, die das Ziel haben, Texte für den Kanon auszuwählen. Vielmehr bilden sie ein Scharnier zwischen den Bewertungsebenen „subjektiv befriedigend“ und „kutlurell bedeutend".

Simone Winko (2002) hat den Kanonisierungsprozess als einen invisible-hand-Prozess beschrieben, in dem zunächst viele Einzelwertungen stattfinden, die nicht das Ziel haben, wertvolle Weke zu küren. Erst anschließend werden aus dieser „Vorauswahl“ Texte für den Kanon „bestimmt“, indem sie intentional in Hinblick darauf bewertet werden, ob sie kulturell wertvoll sind. Die Wertungen im Rahmen des Ingeborg-Bachmann-Wettbewerbs 
stehen im letzten Stadium der „Vorauswahl“ durch nicht intentionale Wertungen. Es geht noch nicht darum, Texte auszuwählen, die einer besonderen Pflege und Verbreitung bedürfen (Kanon). Es geht aber auch nicht mehr darum, was einen beliebigen Laienleser amüsiert.

Die Art der Bewertungen im Rahmen des Wettbewerbs entspricht dieser Schwellenposition des Bachmann-Preises. Der Lektüre-Eindruck, der für Laienbewertungen die entscheidende Grundlage jeder Bewertung sein dürfte, spielt auch in den Literaturpreis-Wertungen noch eine große Rolle. Gleichzeitig ist der Code so gewählt, dass die Bewertungen möglichst intersubjektiv wirkungsvoll sind.

Es wird damit deutlich, wie wichtig es ist, bei der Analyse von Wertungen das „Stadium“ der Bewertung mit zu bedenken. Es mag durchaus möglich sein, dass es bei der Bildung eines Kanons (intentionale Bewertungen) in einem hohem Maße darum geht, gesellschaftlich Gruppen und Werte zu repräsentieren. Diesen intentionalen Bewertungen gehen aber viele unintentionale Bewertungen voraus, an deren Anfang zunächst einmal eine subjektive Leseerfahrung mit einem Text steht. Und auf dieser Ebene, das lassen die Bachmann-Preis-Diskussionen vermuten, spielt die Beschaffenheit des Textes (Sprache und Form) durchaus eine Rolle. Die Expertenwertungen des mittleren Stadiums, die Lektüreerfahrungen in Wertbegriffe wie Stimmigkeit und Offenheit übersetzen (vgl. These 3), illustrieren die Transformation form- und sprachbasierter Lektüreerfahrungen in eine intersubjektiv nachvollziehbare Wertungssprache, die den Weg für eine weitere Auseinandersetzung mit den Texten ebnet.

\section{These: Bei den formal-ästhetischen Werten der Literaturwissenschaft han- delt es sich um „fachsprachliche“ Ausdrücke für Phänomene der Wirkung.}

Diese ersten Erklärungsansätze vermögen zu zeigen, warum überhaupt eine Mischung der beiden Wertungsbereiche stattfindet. Dabei geht es primär, um den „Code“, also um die verbale Umsetzung der Wertung. Es konnte aber nicht erklärt werden, wie es zu dem spezifischen Zusammenwirken von Wirkungswerten und formal-ästhetischen Werten kommt. Betrachtet man nämlich die Beiträge der Juroren als komplexe Wertungsaussagen, dann fällt auf, dass sich formal-ästhetische Argumente wie Illustrationen, Beweise oder Erläuterungen zu den eindeutiger wertenden Aussagen über die Wirkung des Textes verhalten. Wenn Scheck (2002 Kern, 10:30) in Anschluss an seine einleitende Aussage „Unheimlich ist diese Geschichte, aber sie ist vor allem unheimlich langweilig“ dazu übergeht, ein zentrales Bild der Szene zu analysieren, das bei ihm einen „pawlow'schen Interpretationsreflex“ 
augelöst habe, und schließlich zu dem Urteil kommt, der Text sei zu mechanisch, er solle ihm das alles nicht sagen, sondern zeigen, dann muss man davon ausgehen, dass das Wirkungsurteil „langweilig“ und die dann folgende Auseinandersetzung mit der Machart des Textes, die letztlich auf den klassischen formal-ästhetischen Wert Offenheit (Modus des Showing, vgl. Kapitel 11.2.2) hinausläuft, nicht in einem zufälligen Verhältnis zueinander stehen. Die Wirkung eines Textes, die in emotionaleren Ausdrucksweisen wie langweilig, spannend, lässt mich kalt, berührt mich nicht oder Fragen wie Was hat das mit mir zu tun? zur Geltung kommt, hat ihren Ursprung in einer spontaneren Reaktion auf den Text. Sie lässt sich, man kennt es aus eigener Erfahrung, noch während des Leseprozesses fassen oder auch unmittelbar im Anschluss an die Lektüre. Das Festmachen dieses Wirkungseindrucks an Eigenschaften des Textes und die Zuordnung zu Wertmaßstäben dagegen, dürfte ein längerer Prozess sein, in dem der Wertende auch erlerntes Wissen über die Bewertung von Literatur heranzieht (vgl. Belke/Leder 2006, 9). Die entscheidende Frage für das Verständnis von formal-ästhetischen Wertungen ist also die nach den Mechanismen der Zuordnung zwischen Textwirkung (primär auf der Lust-Unlust-Ebene) und der argumentativen Begründung unter Zuhilfenahme des literaturwissenschaftlichen Handwerkszeugs und „Codes". Anders gefragt: Wie funktioniert die Zuordnung zwischen einer Wirkung wie Langeweile zu dem im professionellen Literaturwissen verankerten Wert Offenheit? Dabei war der Blick auf die Leseforschung, in der ein sehr viel engerer Zusammenhang von Beschaffenheit des Textes und seiner Rezeption angenommen wird, äußerst fruchtbar. Textwirkungen sind bisher kaum Gegenstand der Wertungsforschung, sondern vielmehr der Leseforschung, insbesondere auch in ihrer psychologischen Ausrichtung, gewesen. Neben allen Differenzen im Detail ist sich die Lese- und Leseemotionsforschung in vielen Aspekten sehr einig: Einig ist sie sich dahingehend, dass die Kohärenzherstellung für den Leser zunächst das zentrale Anliegen ist und dass dieser Prozess, wenn er gelingt, eine positive Auswirkung auf die Wahrnehmung des Textes hat (Oatley 1994; Kneepken/Zwaan 1994; Pette 2001; Gibson/Levin 1989; Christmann/Groeben 1999). Für die Betrachtung literarischer Texte ist dabei die Vorstellung, Kohärenzbildung erfolge in Form mentaler Modelle (vgl. Christmann/Groeben 1999) bzw. einer Simulation von Welt im Kopf des Lesers (Oatley 1994) besonders fruchtbar, weil auf diese Weise die Lebendigkeit, die die literarische Welt für viele Leser entwickelt, gut nachvollziehbar wird. Diese erste, basale Form der Texterfassung unterscheidet sich bei professionellen Lesern nicht grundsätzlich von der anderer Leser. Allerdings sind sie aufgrund ihrer Ausbildung und entsprechender Übung in der Lage, wesentlich komplexere Texte zu modellieren oder simulieren als 
ungeübtere Leser (vgl. Miall/Kuiken 1998). Außerdem haben sie das Handwerkszeug, um literarische Texte auch strukturell zu verstehen. Neben einer inhaltlichen Simulation des Textes können sie ein strukturelles Modell des Textes entwerfen, das heißt, es gelingt ihnen, formale und sprachliche Elemente als „bedeutsam“ zu identifizieren. Wenn man mit Belke/Leder (2006, 5 und 7) davon ausgeht, dass die Auseinandersetzung mit einem ästhetischen Objekt ein Problemlösungsprozess ist, der im Zuge seiner Bewältigung ein Belohnungssystem - positive Emotionen - in Gang setzt, erklärt das, warum die Zugänglichkeit des Textes auf der Formebene für die Juroren zu einer positiven Wirkungswertung führen kann. Die Artefakt-Emotionen Oatleys (1994) verweisen ebenfalls auf die positiven Emotionen, die literarische Texte beim Leser aufgrund ihrer künstlerischen Form auslösen können. Wenn man also das strukturelle Modellieren des Textes nicht als rein kognitive Aufgabe ansieht, sondern viel mehr als einen Prozess der Selbstbestätigung als kompetenter Leser, der durch positive Emotionen belohnt wird, kann dies den Zusammenhang von emotional geladenen Wirkungsurteilen und auf formal-ästhetische Werte ausgerichteten Wertungen erklären. Die Werte, die sich im Komplex Orientierung finden, sind dann wertsprachliche Umsetzungen einer ästhetischen Emotion, die ihre Entstehung im Lesevorgang selbst hat. Der Lesevorgang selbst ist zwar auf vielen Ebenen mitbedingt durch Erfahrung und Vorwissen des Rezipienten, er ist aber gleichermaßen in den Informationsangeboten des Textes verankert. Die Art, wie die Informationen arrangiert werden, spielt unbestreitbar eine Rolle für ihre Rezeption. Daher kann angenommen werden, dass das Arrangement von Informationen einen direkten Effekt auf den Leseprozess und damit auf die Textwirkung hat. Die Textwirkung wiederum kann als ein bedeutender Faktor für die verbale Bewertung auf formal-ästhetischer Ebene betrachtet werden. Das lässt den Schluss zu, dass die Art, wie Informationen im Text präsentiert und arrangiert werden, mittels ihrer Wirkung auf den Leser eine Grundlage für formal-ästhetische Bewertungen bilden.

Zu einer gelungenen Lektüre gehört aus Sicht der Leseforschung aber nicht nur die Modellierung der Textwelt. Ganz wie die Juroren des Ingeborg-Bachmann-Wettbewerbs „überdeterminierte“, das heißt scheinbar ganz und gar verständliche Texte, ablehnen, ist sich auch die Leseforschung sicher, dass die Aufmerksamkeit des Lesers nur dann vollständig gebunden werden kann, wenn der Text Herausforderungen bereithält. Er darf in Anbetracht der Fähigkeiten des Lesers nicht unterkomplex - allerdings auch nicht überkomplex - sein (Pette 2001, Christmann/Groeben 1999, Nell 1989). Gesteigerte Aufmerksamkeit und damit auch bessere Memorierbarkeit wird zum einen erreicht, wenn Texte geistig herausfordernd (aber bewältigbar) sind, und zum anderen, wenn sie emotional stimulie- 
ren. Aktivierung des Lesers kann also einerseits durch geistige Angebote erreicht werden. Hier ist der Übergang zu Wahrnehmungen der Orientiertheit fließend. Aktivierung kann außerdem erreicht werden, indem der Leser emotional angesprochen und vom Text geführt wird. Dabei spielt es keine Rolle, ob der Leser Glück oder Trauer, Ärger, Sorge oder Freude empfindet (vgl. Vorderer 2004, 391). „Bewegtheit“, „Berührtheit" und „Betroffenheit" eignen sich als neutrale Ausdrücke besonders gut, um starke emotionale Reaktionen auf einen Text zu beschreiben. ${ }^{81}$ Es ist die Ebene der Aktivierung, die Literatur substantiell von anderen Texten unterscheidet (Hakemulder 2013, 159; Kneepken/Zwaan 1994, 125) und die auch beim Ingeborg-Bachmann-Wettbewerb als Wert eine große Rolle spielt. Der Effekt besteht im Erreichen eines Zustands, bei dem im Idealfall die Aufmerksamkeit des Lesers vollständig auf den Text gerichtet ist und er die Textwelt tatsächlich erlebt. Benannt worden ist dieser Zustand als ,involvement, [...] immersion, flow, transportation, [...] absorption, [...] presence" (Vorderer 2004, 396). Vorderer betrachtet das Eintreten des Rezipienten in die narrative Welt als eine der Grundvoraussetzungen für Unterhaltung, die sich bei ihm eng mit Genuss verbindet. Auf der kognitiven Ebene spielt die Informationsvergabe eine große Rolle für die Fesselung der Aufmerksamkeit (vgl. Hillebrandt 2001). Durch das Offenlassen und Zurückhalten von Informationen, durch Mehrdeutigkeiten und das Wechseln der Ebenen, durch Anbieten von Szenen, deren Bedeutung der Leser selber herausfinden muss, kann Spannung erzeugt werden. Auf der emotionalen Ebene hängt der Grad der Aufmerksamkeitsbindung stark von der Entwicklung von Plot und Figuren ab. Inhaltliche und thematische Aspekte, die im Leser Interesse hervorrufen, spielen dabei ebenso eine Rolle wie die Art, wie vor allem die Figuren dargeboten werden. Die Möglichkeit, die Handlungen, Gefühle und Gedanken mindestens einer Hauptfigur nachvollziehen zu können, ist als notwendiges Element von emotionaler Beteiligung und Lesegenuss erkannt worden (Oatley 1994, 71; Vorderer 2004; Steinhauer 2010). Auch diese emotionale „Linie“ findet sich in den Werten des Komplexes Aktivierung, der in den Klagenfurter Diskussionen herausgearbeitet wurde, wieder.

Besonders interessant sind diese Ergebnisse, wenn man sie in den Kontext der Schreibschulen des Creative Writing stellt. Die Creative-Writing-Anleitungen unternehmen immerhin den Versuch, Grundregeln und -kompetenzen für das Schreiben literarischer Texte zu vermitteln und sind somit ein normativer Ansatz, der allerdings jenseits der wissenschaftlichen Wertungsdiskussionen steht. Dabei bedenkt das Creative Writing stets den Effekt, \begin{tabular}{l}
\hline 1 Auch für emotionale Betroffenheit gibt es allerdings ein richtiges Maß. Emotionale Wirkungen werden \\
abgelehnt, wenn sie sich als offensichtliche, primäre Intention des Textes darstellen.
\end{tabular} 
den Texte mit ihrer spezifischen Gestaltung auf den potentiellen Leser haben werden:

In any story you communicate with your reader by building up a rhythm of disclosing or withholding information. By moderating what they know you are inviting you readers to use their imagination, to elaborate on the facts they are given and help create the story. (Creative Writing. A Workbook with Readings 2006, 161)

Im „Creative Writing Guidebook“ $(2008,15)$ heißt es ganz ähnlich „Short fiction uses patterns that take advantage of the reader's own desire to see narrative and ,put it all together"“. Bestimmte Gestaltungsmuster können also, so die Annahme der Anleitungen, spezifische Reaktionen im Leser auslösen. Wenn dieser Auslösemachnismus gelingt, so kann man aus den Ergebnissen der durchgeführten Korpusanalyse annehmen, dann ist auch der Weg für eine positive Bewertung offen. Dabei wird sehr viel Wert auf den Modus des Showing gelegt, der auch in den Bachmann-Preis-Diskussionen vielfach beschworen wird. Die Aufmerksamkeit der Anleitungen gilt außerdem dem Aufbau von Plot und Figur in einer Weise, die geeignet ist, einen Spannungsbogen zu generieren und die Figuren emotional zugänglich zu machen. Die sprachliche Gestaltung wird ebenfalls in Hinblick darauf bewertet, inwiefern sie dazu beiträgt, für den Leser Lebendigkeit und Plastizität zu erzeugen. Ohne darauf Bezug zu nehmen, reflektieren die Schreibanleitungen des Creative Writing sehr genau die Ergebnisse der Leseforschung.

Die Art der Wertungen mit formal-ästhetischem Bezug, die in Klagenfurt vielfach verwendet werden, haben eine Verwandtschaft von Werten, Genusserfahrung, wie sie in der Leseforschung beschrieben wird, und Schreibnormen des Creative Writing zu Tage gefördert. Welche formal-ästhetischen Werte in den Diskussionen explizit eingesetzt werden, erweist sich in den Diskussionen als stark bedingt durch die Wirkung des jeweiligen Textes auf der Ebene der (erweiterten) Textkohärenz und der Ebene der kognitiven und emotionalen Aktivierung.

Welche Schlussfolgerungen lassen sich daraus ziehen?

1. Der konventionalisierte Code der Kritiker beim Besprechen von formal-ästhetischen Textelementen ist autonomieästhetisch geprägt und entspricht in etwa den Ansichten der Literaturwissenschaft über gültige Werte. Um sich als Experten im Umgang mit Literatur auszuweisen, nutzen die Juroren literaturwissenschaftliches Wissen, wie Texte analysiert und besprochen werden können. Entscheidend ist dabei die intensive Arbeit am Text.

2. Die Anwendung dieses Codes wurzelt allerdings nicht in einer Vorstellung des allgemein oder gesellschaftlich Wertvollen, sondern vielmehr im persönlichen Lesegenus- 
ses. Inwieweit diese Verschiebung bewusst wahrgenommen und eingesetzt wird, ist schwer zu ermitteln.

3. Die Korrelation zwischen der Ausprägung verschiedener Wertungen in Form von Arbeit am Text und den Ergebnissen der Lese-und Medienforschung sowie den Anleitungen des Creative Writing, legen nahe, dass die durch die universitäre Sozialisation geprägten formal-ästhetischen Werte eingesetzt werden, um die für die Ausprägung der Wertung (positiv/negativ) bedeutenderen Phänomene des Lesegenusses fassbar zu machen. Werte wie Stimmigkeit, Offenheit, Dichte, Polyvalenz und Musikalität geben die Möglichkeit, wahrgenommene Effekte terminologisch fassbar zu machen, die auch ohnedies vermittels ihrer Wirkung wahrgenommen würden.

4. Das Wertvolle der sogenannten hohen Literatur, von kanonischen Werken beispielsweise, ist also durchaus in der „Form“ des Textes verankert. Es ist darin zu suchen, dass dem geübten Leser durch eine spezifische Balance von Orientierung und Aktivierung die Möglichkeit gegeben wird, den Text zu genießen. Die Mechanismen des Genusses sind dabei nicht grundsätzlich andere als die von Unterhaltungsliteratur, sie greifen jedoch auf einem anderen, der Zielgruppe angemessenen Niveau. Wert ist also etwas im Rahmen eines sprachlichen Wertungsdiskurses Zugewiesenes. Die Zuweisung erfolgt allerdings nicht nur auf der Grundlage von sozialen Mechanismen, sondern auch auf der Grundlage der Textwirkung, die durch formale und ästhetische Eigenschaften des Textes mitbedingt ist.

5. Wenn die formal-ästhetischen Werte des Expertencodes als „Aesthetic Judgment“ (Belke/Leder 2006, 3) ein perzeptives Gegenstück in einer „Aesthetic Emotion“ (Belke/Leder 2006, 3) haben, und wenn gleichzeitig die Leseforschung Textstrategien aufzeigen kann, mit denen solche „ästhetische[n] Emotionen“ erzeugt werden können, die sich auch in den (offenbar durchaus erfolgreichen) Normen des Creative Writing spiegeln, dann kann man davon ausgehen, dass formal-ästhetische Werte weder reine Schimären bildungsbürgerlicher Literaturexperten, noch bloße Konstrukte sind, zu denen es keine lokalisierbaren Entsprechungen auf Textebene gibt, sondern dass es durchaus Textstrategien gibt, mit denen Autoren bestimmte Wirkungen erzielen können und wollen, und dass die gelungene Wirkung dieser Strategien zur Hochwertung des Textes beiträgt.

Literarische Wertung auf der Formebene stellt sich also als ein Prozess dar, der (mindestens) zwei Dimensionen hat: Die unmittelbare Wirkung des Textes auf den Leser, die durch 
die formale und sprachliche Anlage ganz entscheidend mitbestimmt ist, einerseits, und die sprachliche Wertung unter Zuhilfenahme des autonomieästhetischen, durch die Sozialisation in der philologischen Universitätslehre eingeübten Codes andererseits. Trennscharf ist die Unterscheidung der Dimensionen jedoch nicht. Schließlich wirkt die Lesesozialisation zurück auf die Lektüre. Und auf der anderen Seite finden sich im Code Hinweise auf die Bedeutung der Textwirkung.

Die Verklammerung hedonistischer Wirkungswerte mit formal-ästhetischen Argumentationen, die in der Analyse herausgearbeitet werden konnte, wirft qualitativ ein neues Licht auf Wertungsvorgänge. Die formal-ästhetischen Wertmaßstäbe erweisen sich als viel weniger "selbstgenügsam“ als die Überlegungen in der Literaturwissenschaft das zum Teil suggeriert haben. Bezogen auf formal-ästhetische Werte lag das Hauptinteresse literaturwissenschaftlicher Arbeiten stets auf der Frage: Welche formal-ästhetischen Werte (Eigenschaften wie Maßstäbe) sind wann, wie und für wen wichtig? Diese Frage nach dem Was, Wann und Wer wird der Komplexität des Wertungsverhaltens nicht gerecht. Die Analyse der Diskussionen legt nahe, zusätzlich auch eine andere Perspektive auf formal-ästhetische Eigenschaften zu werfen, nämlich die Frage: Wie ist der Zusammenhang zwischen Text, Textwirkung und Textwertung? Anders formuliert: Wie erzielt der Text eine bestimmte Wirkung auf der binären Skala - lustvoll/abstoßend - und wie findet sich diese Wirkung in komplexen sprachlichen Wertungen wieder?

In den Ingeborg-Bachmann-Wettbewerbs-Diskussionen kann der Zusammenhang von Lust und Bewertung ganz eindeutig auch als Bestandteil der Bewertungspraxis hergestellt werden. Mehr noch: Die Frage, ob ein Text beim Lesen Spaß gemacht hat, ob der Kritiker ihn lustvoll rezipieren konnte, kann zentrales Argument der Bewertung werden. Die Detailanalysen der Diskussionen zu Andrea Winkler und Ute-Christine Krupp haben das eindrücklich gezeigt. Beide Texte wurden als von der formalen Anlage her zwar interessant, letztendlich aber als langweilig oder anstrengend zu lesen empfunden und insgesamt abgelehnt. Die Aussage, dass das Lesen von Literatur lustvoll sein sollte, ist also (wieder) salonfähig.

\section{Was verrät die Argumentationsführung darüber hinaus über Zuordnungsre- geln und literarische Letztwerte?}

Nicht Schönheit präsentiert sich in Klagenfurt als Letztwert in der Beurteilung von Literatur, auch nicht Originalität, wie von manchen Vertretern des Faches angenommen (u. a. Andreotti 2008; Fricke 1981; Fricke 2008), sondern der hedonistische Wert Lust. Diese 
Verschiebung entspricht der Beobachtung von Beilein et al. $(2012,11)$, dass „[d]ie Prominenz und der Erfolg von Büchern [...] sich keinem bildungsbürgerlichen Kulturwert mehr [verdanken], sondern einem Kultwert, der charakteristisch ist für eine auf die Steigerung von Erlebnisqualitäten abonnierten Gesellschaft“. „Erlebnisqualität“ ist durchaus etwas, was die Klagenfurter Jury in den Texten sucht und auch in ihren Bewertungen argumentativ einfordert, jedoch bedeutet das nicht, dass gleichzeitig der „bildungsbürgerliche Kulturwert“ aus den Diskussionen verschwindet. Auch darf „Erlebnis“ nicht im Sinne einer möglichst intensiven Sinnesreizung, wie sie Thriller oder Erotikromane möglich machen, verstanden werden. Die Rückbindung an den kulturellen Wert und auch an den formalen und sprachlichen Wert bleibt ein obligatorischer und auch argumentativ bedeutender Bestandteil der Diskussionen. Was in den Klagenfurter Diskussionen der Jahre 1999 bis 2009 abzulesen ist, ist eine Werteverschiebung in der Perspektive von „bildungsbürgerlich bedeutend“ zu „subjektiv ergreifend“. Inwieweit diese Perspektivverschiebung dazu führt, dass andere Texte bevorzugt werden als unter bildungsbürgerlichen Wertungsvoraussetzungen, kann im Rahmen dieser Arbeit nicht beantwortet werden. Es handelt sich zunächst einmal um eine Verschiebung des Blickwinkels, die über die Analyse der Diskussionen nachvollzogen werden kann. Das begriffliche Wertungsinstrumentarium, der begriffliche Bezugsrahmen, beinhaltet dieselben Werte, die auch Heydebrand/Winko (1996) beobachtet haben. Die großen formal-ästhetischen Wertmaßstäbe Stimmigkeit, Polyvalenz, Offenheit, Dichte, Originalität und Komplexität bleiben unangetastet. Das Wertewissen bleibt also gleich, die Zuordnungsvoraussetzungen haben sich jedoch in Richtung einer erlebnisorientierten Literaturbetrachtung verschoben. Die formal-ästhetischen Wertmaßstäbe erweisen sich als Spielmarken, die gewinnbringend in Argumentationen eingesetzt werden, je nach Lustfaktor bei der Lektüre positiv oder negativ. Offenheit, beispielsweise, ist nicht per se gut, sondern genau dann, wenn sie den Juroren als Lesern Lust verschafft. Und dennoch sind die Werte nicht willkürlich, sondern reflektieren Potentiale von literarischen Texten, Lust auszulösen.

So muss diese Arbeit mit einer Frage und einer Aufforderung an die literaturwissenschaftliche Wertungsforschung schließen. Nimmt man an, wie das Ergebnis dieser Arbeit es nahelegt, dass zwar die Zuordnungsregeln und damit die diskursiven Strategien der Wertbegründung sich ändern, seltener aber die Werte; nimmt man also an, dass im Wertungsdiskurs mit unveränderten Maßstäben andere Wertungsschwerpunkte gesetzt werden, ist es unter diesen Umständen nicht möglich, dass Textmerkmalen doch eine Bedeutung zugemessen werden muss, allerdings nicht so sehr als „hohe“ künstlerische Eigenschaften, 
sondern als Vertextungsstrategien, die einen Text in besonderer Weise genussfähig werden lassen? Die Wertungspraxis des beginnenden 21. Jahrhunderts fokussiert - und zwar möglicherweise als Reflex einer gesamtgesellschaftlichen Entwicklung, in der das persönliche Erlebnis als Gegenstand der Kommunikation größere Bedeutung gewinnt als die Repräsentativität einer Handlung für eine bestimmte Gruppe - den subjektiven Erlebnischarakter der Lektüre und operiert mit einem Werterepertoire, das im bildungsbürgerlichen Werterepertoire wurzelt. Die unterschiedliche Fokussierung lässt die Frage immerhin zu, ob nicht auch zu anderen Zeiten Lesegenuss im hedonistischen Sinne eine bedeutendere Rolle gespielt hat, als bisher gedacht. Das Wertungswissen birgt offenbar dieses Potential. Ganz automatisch ergeht damit an die Literaturwissenschaft der Appell, sich mehr damit zu beschäftigen, warum Lesen überhaupt eine geliebte Freizeitbeschäftigung ist. Warum hat das Lesen von Literatur das Potential, lustvoll zu sein? Die evolutionsbiologischen Forschungsansätze von Karl Eibl und Katja Mellmann bieten fruchtbare Ansatzpunkte zur Beantwortung dieser Frage, aber auch die neuere empirische Forschung, etwa zu emotionalen Wirkungspotentialen von Texten beispielsweise in den Arbeiten von David S. Miall. Die Ergebnisse dieser Arbeit werfen aber auch eine andere Frage auf, die zu beantworten eine neue Herausforderung für die literaturwissenschaftliche Wertungsforschung darstellen dürfte: Wie greifen Textwirkung und Textwertung ineinander?

Diese Arbeit hat mit einem Zitat von Robert Schindel begonnen:

Und es kann ja auch nicht sein, dass wir dann zu einer Literatur kommen, die strukturell richtig ist und unendlich langweilt, und zwar alle. Das ist keine Geschmacksangelegenheit. (2001 Krupp, 18:22 Schindel)

„Ist Langeweile nur ein Geschmacksurteil? Ist Langeweile unprofessionell?“ wurde am Anfang dieser Arbeit gefragt. Langeweile ist eine mögliche Textwahrnehmung und damit ein mögliches Bewertungskriterium. Als Wertungskriterium hat sie mehr Aufmerksamkeit verdient, ebenso wie die Spannung und andere emotionale Wirkungen von Literatur. 


\section{Literatur}

\section{Korpus}

Für die Erstellung der Transkripte wurden die Videoaufzeichnungen der Diskussionen verwendet, die auf der Webseite des Ingeborg-Bachmann-Preises zur Verfügung gestellt werden. Die erstellten Transkripte entsprechen dem Stand der Webseiten von 2011. Der letzte Zugriff erfolgte am 6./7.2.2017. Neben den Videos wurden auch diverse andere Informationen abgerufen, darunter Informationen über Juroren, Autoren und Preise. Für diese Informationen werden im Folgenden nur die übergeordneten Seiten zu den jeweiligen Wettbewerbsjahrgängen angegeben.

\section{Jahrgang 1999}

\section{Informationen zum Wettbewerb 1999}

http://archiv. bachmannpreis.orf .at/bachmannpreis.eu/de/archiv/79/

http://archiv. bachmannpreis.orf .at/bp99/index.html

http: //archiv. bachmannpreis.orf .at/bp99/multimedia.htm

\section{Audiodateien für den Jahrgang 1999}

Stefan Beuse:

<mms://apasf.apa.at/nocms-worldwide/kaernten_tddl_1999_beuse_disk.wma>

Ruth Erat:

<mms://apasf .apa.at/nocms-worldwide/kaernten_tddl_1999_erat_disk.wma>

Ursula Fricker:

<mms://apasf .apa.at/nocms-worldwide/kaernten_tddl_1999_fricker_disk.wma>

Patricia Görg:

<mms://apasf.apa.at/nocms-worldwide/kaernten_tddl_1999_goerg_disk.wma>

Katharina Hacker:

<mms://apasf .apa.at/nocms-worldwide/kaernten_tddl_1999_hacker_disk.wma>

Monika Helfer:

<mms://apasf .apa.at/nocms-worldwide/kaernten_tddl_1999_helfer_disk.wma>

Thomas Jonigk:

<mms://apasf .apa.at/nocms-worldwide/kaernten_tddl_1999_jonigk_disk.wma>

Terézia Mora:

<mms://apasf.apa.at/nocms-worldwide/kaernten_tddl_1999_mora_disk.wma>

Thomas Kapielski:

<mms://apasf .apa.at/nocms-worldwide/kaernten_tddl_1999_kapielski_disk.wma>

Thor L. Kunkel:

<mms://apasf .apa.at/nocms-worldwide/kaernten_tddl_1999_kunkel_disk.wma>

Christian Mähr:

<mms://apasf.apa.at/nocms-worldwide/kaernten_tddl_1999_maehr_disk.wma> 
Gudrun Seidenauer:

<mms://apasf .apa.at/nocms-worldwide/kaernten_tddl_1999_seidenauer_disk.wma>

Christian Uetz:

<mms://apasf.apa.at/nocms-worldwide/kaernten_tddl_1999_uetz_disk.wma>

Peter Stamm:

<mms://apasf.apa.at/nocms-worldwide/kaernten_tddl_1999_stamm_disk.wma>

Vladimir Vertlib:

<mms://apasf .apa.at/nocms-worldwide/kaernten_tddl_1999_vertlib_disk.wma>

Aglaya Veteranyi:

<mms://apasf .apa.at/nocms-worldwide/kaernten_tddl_1999_veteranyi_disk.wma>

\section{Jahrgang 2000}

\section{Informationen zum Wettbewerb 2000}

http://archiv. bachmannpreis.orf .at/bachmannpreis.eu/de/archiv/78/

http://archiv.bachmannpreis.orf .at/index2000.htm

http://archiv.bachmannpreis.orf.at/bp_2000/new_media/fs_new_media.htm

\section{Videodateien für den Jahrgang 2000}

Stephan Alphare:

<mms://apasf .apa.at/nocms-worldwide/kaernten_tddl_2000_alphare_disk.wmv>

Martin Amanshausen:

<mms://apasf .apa.at/nocms-worldwide/kaernten_tddl_2000_amanshauser_disk.wmv>

Ulrike Draesner:

<mms://apasf.apa.at/nocms-worldwide/kaernten_tddl_2000_draesner_disk.wmv>

Julia Franck:

<mms://apasf .apa.at/nocms-worldwide/kaernten_tddl_2000_franck_disk.wmv>

Daniel Goetsch:

<mms://apasf .apa.at/nocms-worldwide/kaernten_tddl_2000_goetsch_disk.wmv>

Birgit Kempker:

<mms://apasf .apa.at/nocms-worldwide/kaernten_tddl_2000_kempker_disk.wmv>

Martina Kieninger:

<mms://apasf .apa.at/nocms-worldwide/kaernten_tddl_2000_kieninger_disk.wmv>

Georg Klein:

<mms://apasf .apa.at/nocms-worldwide/kaernten_tddl_2000_klein_disk.wmv>

Patrick Kokontis:

<mms ://apasf .apa.at/nocms-worldwide/kaernten_tddl_2000_kokontis_disk.wmv>

Andreas Maier:

<mms://apasf .apa.at/nocms-worldwide/kaernten_tddl_2000_maier_disk.wmv>

Birgit Müller-Wieland:

<mms://apasf .apa.at/nocms-worldwide/kaernten_tddl_2000_mueller_disk.wmv>

Georg M. Oswald:

<mms://apasf .apa.at/nocms-worldwide/kaernten_tddl_2000_oswald_disk.wmv>

Stephan Reimertz:

<mms : //apasf.apa.at/nocms-worldwide/kaernten_tddl_2000_reimertz_disk.wmv> 
Susanne Riedel:

<mms://apasf.apa.at/nocms-worldwide/kaernten_tddl_2000_riedel_disk.wmv>

Malin Schwerdtfeger:

<mms://apasf .apa.at/nocms-worldwide/kaernten_tddl_2000_schwerdtfeger_disk.wmv>

David Wagner:

<mms://apasf .apa.at/nocms-worldwide/kaernten_tddl_2000_wagner_disk.wmv>

\section{Jahrgang 2001}

\section{Informationen zum Wettbewerb 2001}

http: //archiv.bachmannpreis .orf .at//index2001.htm

http://archiv. bachmannpreis.orf .at/bachmannpreis.eu/de/archiv/77/

\section{Videodateien für den Jahrgang 2001}

Katrin Askan:

<mms://apasf.apa.at/nocms-worldwide/kaernten_tddl_2001_askan_disk.wmv>

Artur Becker:

<mms://apasf.apa.at/nocms-worldwide/kaernten_tddl_2001_becker_disk.wmv>

Robert Fischer:

<mms://apasf .apa.at/nocms-worldwide/kaernten_tddl_2001_fischer_disk.wmv>

Annegret Held:

<mms://apasf.apa.at/nocms-worldwide/kaernten_tddl_2001_held_disk.wmv>

Ute-Christine Krupp:

<mms://apasf .apa.at/nocms-worldwide/kaernten_tddl_2001_krupp_disk.wmv>

Ludwig Laher:

<mms://apasf .apa.at/nocms-worldwide/kaernten_tddl_2001_laher_disk.wmv>

Tanja Langer:

<mms://apasf .apa.at/nocms-worldwide/kaernten_tddl_2001_langer_disk.wmv>

Michael Lentz:

<mms : //apasf .apa.at/nocms-worldwide/kaernten_tddl_2001_lentz_disk.wmv>

Heiner Link:

<mms://apasf .apa.at/nocms-worldwide/kaernten_tddl_2001_link_disk.wmv>

Rainer Merkel:

<mms://apasf .apa.at/nocms-worldwide/kaernten_tddl_2001_merkel_disk.wmv>

Norbert Müller:

<mms ://apasf.apa.at/nocms-worldwide/kaernten_tddl_2001_mueller_disk.wmv>

Antje Rávic Strubel:

<mms : //apasf .apa.at/nocms-worldwide/kaernten_tddl_2001_strubel_disk.wmv>

Brigitte Schär:

<mms://apasf .apa.at/nocms-worldwide/kaernten_tddl_2001_schaer_disk.wmv>

Ulrich Schlotmann:

<mms://apasf .apa.at/nocms-worldwide/kaernten_tddl_2001_schlotmann_disk.wmv>

Philipp Tingler:

<mms://apasf .apa.at/nocms-worldwide/kaernten_tddl_2001_tingler_disk.wmv> 


\section{Jahrgang 2002}

\section{Informationen zum Wettbewerb 2002}

http: //archiv. bachmannpreis.orf .at/bachmannpreis.eu/de/archiv/76/

http: //archiv . bachmannpreis .orf .at/bp2002/

\section{Videodateien für den Jahrgang 2002}

Melanie Arns:

<mms://apasf .apa.at/nocms-worldwide/kaernten_tddl_2002_arns_disk.wmv>

Christoph W. Bauer:

<mms://apasf.apa.at/nocms-worldwide/kaernten_tddl_2002_bauer_disk.wmv>

Lukas Bärfuss:

<mms://apasf.apa.at/nocms-worldwide/kaernten_tddl_2002_baerfuss_disk.wmv>

Mirko Bonné:

<mms://apasf.apa.at/nocms-worldwide/kaernten_tddl_2002_bonne_disk.wmv>

Helga Glantschnig:

<mms://apasf .apa.at/nocms-worldwide/kaernten_tddl_2002_glantschnig_.wmv>

Peter Glaser:

<mms://apasf .apa.at/nocms-worldwide/kaernten_tddl_2002_glaser_disk.wmv>

Heinz D. Heisl:

<mms://apasf.apa.at/nocms-worldwide/kaernten_tddl_2002_heisl_disk.wmv>

Nina Jäckle:

<mms://apasf.apa.at/nocms-worldwide/kaernten_tddl_2002_jaeckle_disk.wmv>

Elfriede Kern:

<mms : //apasf .apa.at/nocms-worldwide/kaernten_tddl_2002_kern_disk.wmv>

Jörg Matheis:

<mms://apasf.apa.at/nocms-worldwide/kaernten_tddl_2002_matheis_disk.wmv>

Roger Monnerat:

<mms: //apasf .apa.at/nocms-worldwide/kaernten_tddl_2002_monnerat_disk.wmv>

Annette Pehnt:

<mms://apasf .apa.at/nocms-worldwide/kaernten_tddl_2002_pehnt_disk.wmv>

Markus Ramseier:

<mms://apasf.apa.at/nocms-worldwide/kaernten_tddl_2002_pehnt_disk.wmv>

Raphael Urweider:

<mms://apasf.apa.at/nocms-worldwide/kaernten_tddl_2002_urweider_disk.wmv>

Daniel Zahno:

<mms://apasf.apa.at/nocms-worldwide/kaernten_tddl_2002_zahno_disk.wmv>

Norbert Zähringer:

<mms://apasf .apa.at/nocms-worldwide/kaernten_tddl_2002_zaehringer_disk.wmv>

\section{Jahrgang 2003}

\section{Informationen zum Wettbewerb 2003}

http: //archiv. bachmannpreis .orf .at/bp2003/ 
http://archiv.bachmannpreis.orf .at/bachmannpreis.eu/de/archiv/74/

\section{Videodateien für den Jahrgang 2003}

Henning Ahrens:

<mms://apasf.apa.at/nocms-worldwide/kaernten_tddl_2003_ahrens_disk.wmv>

Katrin de Vries:

<mms://apasf.apa.at/nocms-worldwide/kaernten_tddl_2003_de_vries_portr.wmv>

Oswald Egger:

<mms://apasf .apa.at/nocms-worldwide/kaernten_tddl_2003_egger_disk.wmv>

Susanne Fischer.

<mms://apasf.apa.at/nocms-worldwide/kaernten_tddl_2003_fischer_disk.wmv>

Olga Flor.

<mms://apasf.apa.at/nocms-worldwide/kaernten_tddl_2003_flor_disk.wmv>

Christian Griebel:

<mms://apasf .apa.at/nocms-worldwide/kaernten_tddl_2003_griebel_disk.wmv>

Christof Hamann:

<mms://apasf .apa.at/nocms-worldwide/kaernten_tddl_2003_hamann_disk.wmv>

Lukas Hammerstein:

<mms://apasf .apa.at/nocms-worldwide/kaernten_tddl_2003_hammerstein_disk.wmv>

Gregor Hens:

<mms://apasf.apa.at/nocms-worldwide/kaernten_tddl_2003_hens_disk.wmv>

Ulla Lenze:

<mms://apasf.apa.at/nocms-worldwide/kaernten_tddl_2003_lenze_disk.wmv>

Sünje Lewejohann:

<mms://apasf .apa.at/nocms-worldwide/kaernten_tddl_2003_lewejohann_disk.wmv>

Norbert Müller:

<mms://apasf .apa.at/nocms-worldwide/kaernten_tddl_2003_mueller_disk.wmv>

Inka Parei:

<mms://apasf.apa.at/nocms-worldwide/kaernten_tddl_2003_parei_disk.wmv>

Christine Rinderknecht:

<mms://apasf.apa.at/nocms-worldwide/kaernten_tddl_2003_rinderknecht_disk.wmv>

Kristof Schreuf:

<mms://apasf.apa.at/nocms-worldwide/kaernten_tddl_2003_schreuf_disk.wmv>

Farhad Showghi:

<mms://apasf .apa.at/nocms-worldwide/kaernten_tddl_2003_showgi_disk.wmv>

Michael Stauffer:

<mms://apasf.apa.at/nocms-worldwide/kaernten_tddl_2003_stauffer_disk.wmv>

Feridun Zaimoglu:

<mms : //apasf .apa.at/nocms-worldwide/kaernten_tddl_2003_zaimoglu_disk.wmv>

\section{Jahrgang 2004}

\section{Informationen zum Wettbewerb 2004}

http://archiv. bachmannpreis.orf .at/bachmannpreisv2/archiv/stories/35116/

http://archiv. bachmannpreis . orf . at/bachmannpreis.eu/de/archiv/73/ 
Videodateien für den Jahrgang 2004

Bettina Balaka:

<mms://apasf .apa.at/nocms-worldwide/kaernten_tddl_2004_balaka_disk.wmv>

Artur Becker:

<mms://apasf.apa.at/nocms-worldwide/kaernten_tddl_2004_becker_disk.wmv>

Dorothea Dieckmann:

<mms://apasf .apa.at/nocms-worldwide/kaernten_tddl_2004_dieckmann_disk.wmv>

Arno Geiger:

<mms://apasf.apa.at/nocms-worldwide/kaernten_tddl_2004_geiger_disk.wmv>

Anna Katharina Hahn:

<mms://apasf .apa.at/nocms-worldwide/kaernten_tddl_2004_hahn_disk.wmv>

Roswitha Haring:

<mms://apasf.apa.at/nocms-worldwide/kaernten_tddl_2004_haring_disk.wmv>

Guy Helminger:

<mms://apasf .apa.at/nocms-worldwide/kaernten_tddl_2004_helminger_disk.wmv>

Wolfgang Herrndorf:

<mms://apasf.apa.at/nocms-worldwide/kaernten_tddl_2004_herrndorf_disk.wmv>

Sansdra Hoffmann:

<mms://apasf .apa.at/nocms-worldwide/kaernten_tddl_2004_hoffmann_disk.wmv>

Andreas Münzner:

<mms://apasf .apa.at/nocms-worldwide/kaernten_tddl_2004_muenzner_disk.wmv>

Melinda Nadj Abonji:

<mms://apasf.apa.at/nocms-worldwide/kaernten_tddl_2004_nadj_disk.wmv>

Richard David Precht:

<mms://apasf.apa.at/nocms-worldwide/kaernten_tddl_2004_precht_disk.wmv>

Thomas Raab:

<mms://apasf.apa.at/nocms-worldwide/kaernten_tddl_2004_raab_disk.wmv>

Arne Roß:

<mms://apasf .apa.at/nocms-worldwide/kaernten_tddl_2004_ross_disk.wmv>

Rolf Schönlau:

<mms://apasf .apa.at/nocms-worldwide/kaernten_tddl_2004_sabato_disk.wmv>

Uwe Tellkamp:

<mms://apasf .apa.at/nocms-worldwide/kaernten_tddl_2004_tellkamp_disk.wmv>

Juli Zeh:

<mms://apasf.apa.at/nocms-worldwide/kaernten_tddl_2004_zeh_disk.wmv>

\section{Jahrgang 2005}

\section{Informationen zum Wettbewerb 2005}

http://archiv.bachmannpreis .orf . at/bachmannpreisv2/bachmannpreis/streaming/ stories/42590/

http://archiv. bachmannpreis.orf .at/bachmannpreis.eu/de/archiv/72/

\section{Videodateien für den Jahrgang 2005}

Natalie Balkow:

$<$ mms://apasf.apa.at/nocms-worldwide/kaernten_tddl_2005_balkow_disk.wmv> 
Klaus Böldl:

$<$ mms://apasf.apa.at/nocms-worldwide/kaernten_tddl_2005_boedl_disk.wmv>

Barbara Bongartz:

$<$ mms://apasf.apa.at/nocms-worldwide/kaernten_tddl_2005_bongartz_disk.wmv>

Martina Hefter:

$<$ mms://apasf.apa.at/nocms-worldwide/kaernten_tddl_2005_hefter_disk.wmv>

Susanne Heinrich:

$<$ mms://apasf.apa.at/nocms-worldwide/kaernten_tddl_2005_heinrich_disk.wmv>

Anna Kim:

$<$ mms://apasf.apa.at/nocms-worldwide/kaernten_tddl_2005_kim_disk.wmv>

Helmut Kuhn:

$<$ mms://apasf.apa.at/nocms-worldwide/kaernten_tddl_2005_kuhn_disk.wmv>

Thomas Lang:

$<$ nms://apasf.apa.at/nocms-worldwide/kaernten_tddl_2005_lang_disk.wmv>

Kristof Magnusson:

$<$ mms://apasf.apa.at/nocms-worldwide/kaernten_tddl_2005_magnusson_disk.wmv>

Sabine Schiffner:

$<$ mms://apasf.apa.at/nocms-worldwide/kaernten_tddl_2005_schiffner_disk.wmv>

Eva von Schirach:

$<$ mms://apasf.apa.at/nocms-worldwide/kaernten_tddl_2005_schirach_disk.wmv>

Julia Schoch:

$<$ mms://apasf.apa.at/nocms-worldwide/kaernten_tddl_2005_schoch_disk.wmv>

Christoph Simon:

$<$ mms://apasf.apa.at/nocms-worldwide/kaernten_tddl_2005_simon_disk.wmv >

Saša Stanišić:

$<$ mms://apasf.apa.at/nocms-worldwide/kaernten_tddl_2005_stanisic_disk.wmv>

Gerhild Steinbuch:

$<$ mms://apasf.apa.at/nocms-worldwide/kaernten_tddl_2005_steinbuch_disk.wmv>

Nikolai Vogel:

$<$ mms://apasf.apa.at/nocms-worldwide/kaernten_tddl_2005_vogel_disk.wmv>

Anne Weber:

$<$ mms://apasf.apa.at/nocms-worldwide/kaernten_tddl_2005_weber_disk.wmv >

\section{Jahrgang 2006}

\section{Informationen zum Wettbewerb 2006}

http://archiv. bachmannpreis.orf .at/bachmannpreisv2/bachmannpreis/streaming/ stories/117423/

http://archiv. bachmannpreis .orf . at/bachmannpreis.eu/de/archiv/70/

\section{Videodateien für den Jahrgang 2006}

Sigrid Behrens:

<mms://apasf .apa.at/nocms-worldwide/kaernten_tddl_2006_behrens_disk. wmv>

Paul Brodowsky:

<mms://apasf .apa.at/nocms-worldwide/kaernten_tddl_2006_brodowsky_disk.wmv>

Bodo E. Hell:

<mms://apasf .apa.at/nocms-worldwide/kaernten_tddl_2006_hell_disk.wmv> 
Katja Huber:

<mms://apasf .apa.at/nocms-worldwide/kaernten_tddl_2006_huber_disk.wmv

Silvio Huonda:

<mms://apasf .apa.at/nocms-worldwide/kaernten_tddl_2006_huonder_disk.wmv>

Claudia Klischat:

<mms://apasf.apa.at/nocms-worldwide/kaernten_tddl_2006_klischat_disk.wmv>

Thomas Melle:

<mms://apasf .apa.at/nocms-worldwide/kaernten_tddl_2006_melle_disk.wmv>

Andreas Merkel:

<mms://apasf .apa.at/nocms-worldwide/kaernten_tddl_2006_merkel_disk.wmv>

Clemens Meyer:

<mms://apasf .apa.at/nocms-worldwide/kaernten_tddl_2006_meyer_disk.wmv>

Hanno Millesi:

<mms://apasf .apa.at/nocms-worldwide/kaernten_tddl_2006_millesi_disk.wmv>

Annette Mingels:

<mms://apasf.apa.at/nocms-worldwide/kaernten_tddl_2006_mingels_disk.wmv>

Angelika Overath:

<mms://apasf .apa.at/nocms-worldwide/kaernten_tddl_2006_overath_disk.wmv>

Kathrin Passig:

<mms://apasf.apa.at/nocms-worldwide/kaernten_tddl_2006_passig_disk.wmv>

Dirk von Petersdorff:

<mms://apasf .apa.at/nocms-worldwide/kaernten_tddl_2006_petersdorff_disk.wmv>

Norbert Scheuer:

<ms://apasf .apa.at/nocms-worldwide/kaernten_tddl_2006_scheuer_disk.wmv>

Ina Strelow:

<mms://apasf.apa.at/nocms-worldwide/kaernten_tddl_2006_strelow_disk.wmv>

Kevin Vennemann:

<mms://apasf.apa.at/nocms-worldwide/kaernten_tddl_2006_vennemann_disk.wmv>

Kai Weyand:

<mms://apasf .apa.at/nocms-worldwide/kaernten_tddl_2006_weyand_disk.wmv>

\section{Jahrgang 2007}

\section{Informationen zum Wettbewerb 2007}

http: //archiv. bachmannpreis .orf . at/bachmannpreisv2/bachmannpreis/streaming/ stories/203494/

http://archiv. bachmannpreis.orf .at/bachmannpreis.eu/de/archiv/69/

\section{Videodateien für den Jahrgang 2007}

Jörg Albrecht:

$<$ mms://apasf.apa.at/nocms-worldwide/kaernten_tddl_2007_albrecht_disk.wmv>

Martin Becker:

$<$ mms://apasf.apa.at/nocms-worldwide/kaernten_tddl_2007_becker_disk.wmv>

Christian Bernhardt:

<mms://apasf.apa.at/nocms-worldwide/kaernten_tddl_2007_bernhardt_disk.wmv>

Jan Böttcher:

$<$ mms://apasf.apa.at/nocms-worldwide/kaernten_tddl_2007_boettcher_disk.wmv> 
Andrea Grill:

$<$ mms://apasf.apa.at/nocms-worldwide/kaernten_tddl_2007_grill_disk.wmv>

Björn Kern:

$<$ mms://apasf.apa.at/nocms-worldwide/kaernten_tddl_2007_kern_disk.wmv>

PeterLicht:

$<$ mms://apasf.apa.at/nocms-worldwide/kaernten_tddl_2007_peterlicht_disk.wmv>

Jagoda Marinić:

$<$ mms://apasf.apa.at/nocms-worldwide/kaernten_tddl_2007_marinic_disk.wmv>

Milena Oda:

$<$ mms://apasf.apa.at/nocms-worldwide/kaernten_tddl_2007_oda_disk.wmv $>$

Kurt Oesterle:

$<$ mms://apasf.apa.at/nocms-worldwide/kaernten_tddl_2007_oesterle_disk.wmv >

Ronald Reng:

$<$ mms://apasf.apa.at/nocms-worldwide/kaernten_tddl_2007_reng_portr.wmv>

Silke Scheuermann:

$<$ mms://apasf.apa.at/nocms-worldwide/kaernten_tddl_2007_scheuermann_disk.wmv >

Fridolin Schley:

$<$ mms://apasf.apa.at/nocms-worldwide/kaernten_tddl_2007_scheuermann_disk.wmv>

Jochen Schmidt:

$<$ mms://apasf.apa.at/nocms-worldwide/kaernten_tddl_2007_schmidt_disk.wmv>

Lutz Seiler:

$<$ mms://apasf.apa.at/nocms-worldwide/kaernten_tddl_2007_seiler_disk.wmv>

Thomas Stangl:

$<$ mms://apasf.apa.at/nocms-worldwide/kaernten_tddl_2007_stangl_disk.wmv >

Michael Stavarič:

$<$ mms://apasf.apa.at/nocms-worldwide/kaernten_tddl_2007_stavaric_disk.wmv>

Dieter Zwicky:

$<$ mms://apasf.apa.at/nocms-worldwide/kaernten_tddl_2007_zwicky_disk.wmv>

\section{Jahrgang 2008}

\section{Informationen zum Wettbewerb 2008}

http://archiv.bachmannpreis .orf .at/bachmannpreis.eu/de/audio_video/

16/index.html

http://archiv.bachmannpreis.orf.at/bachmannpreis.eu/de/archiv/833/

\section{Videodateien für den Jahrgang 2008}

Martin von Arndt:

<mms://apasf .apa.at/nocms-worldwide/kaernten_tddl_2008_arndt_disk.wmv>

Alina Bronsky:

$<\mathrm{mms}$ ://apasf .apa.at/nocms-worldwide/kaernten_tddl_2008_bronsky_disk.wmv>

Patrick Findeis:

<mms://apasf .apa.at/nocms-worldwide/kaernten_tddl_2008_findeis_disk.wmv>

Heike Geißler:

<mms://apasf .apa.at/nocms-worldwide/kaernten_tddl_2008_geissler_disk.wmv>

Dagrun Hintze:

<mms://apasf.apa.at/nocms-worldwide/kaernten_tddl_2008_hintze_disk.wmv> 
Pedro Lenz:

<mms://apasf .apa.at/nocms-worldwide/kaernten_tddl_2008_lenz_disk.wmv>

Sudabeh Mohafez:

<mms://apasf .apa.at/nocms-worldwide/kaernten_tddl_2008_mohafez_disk.wmv>

Markus Orths:

<mms://apasf .apa.at/nocms-worldwide/kaernten_tddl_2008_orths_disk.wmv>

Thorsten Palzhoff:

<mms://apasf .apa.at/nocms-worldwide/kaernten_tddl_2008_palzhoff_disk.wmv>

Tilman Rammstedt:

<mms://apasf .apa.at/nocms-worldwide/kaernten_tddl_2008_rammstedt_disk.wmv>

Angelika Reitzer:

$\langle\mathrm{mms}$ ://apasf .apa.at/nocms-worldwide/kaernten_tddl_2008_reitzer_disk.wmv〉

Anette Selg:

<mms://apasf .apa.at/nocms-worldwide/kaernten_tddl_2008_selg_disk.wmv>

Clemens J. Setz:

<mms://apasf .apa.at/nocms-worldwide/kaernten_tddl_2008_setz_disk.wmv>

Ulf Erdmann Ziegler:

<mms ://apasf .apa.at/nocms-worldwide/kaernten_tddl_2008_ziegler_disk.wmv>

\section{Jahrgang 2009}

\section{Informationen zum Wettbewerb 2009}

http://archiv.bachmannpreis .orf .at/bachmannpreis.eu/de/audio_video/ 1928/index.html

http://archiv . bachmannpreis . orf . at/bachmannpreis.eu/de/archiv/2316/

\section{Videodateien für den Jahrgang 2009}

Ralf Bönt:

<mms://apasf .apa.at/nocms-worldwide/kaernten_tddl_2009_boent_disk.wmv>

Katharina Born:

<mms://apasf .apa.at/nocms-worldwide/kaernten_tddl_2009_born_disk.wmv>

Karsten Kramptitz:

<mms://apasf .apa.at/nocms-worldwide/kaernten_tddl_2009_krampitz_disk.wmv>

Lorenz Langenegger:

<mms://apasf .apa.at/nocms-worldwide/kaernten_tddl_2009_langenegger_disk.wmv>

Christiane Neudecker:

<mms://apasf .apa.at/nocms-worldwide/kaernten_tddl_2009_neudecker_disk.wmv>

Jens Petersen:

<mms://apasf .apa.at/nocms-worldwide/kaernten_tddl_2009_petersen_disk.wmv>

Bruno Preisendörfer:

$<\mathrm{mms}$ ://apasf.apa.at/nocms-worldwide/kaernten_tddl_2009_preisendoerfer_disk.wmv>

Karl-Gustav Ruch:

<mms://apasf .apa.at/nocms-worldwide/kaernten_tddl_2009_ruch_disk.wmv>

Gregor Sander:

<mms://apasf.apa.at/nocms-worldwide/kaernten_tddl_2009_sander_disk.wmv>

Catarina Satamik:

$\langle\mathrm{mms}$ ://apasf .apa.at/nocms-worldwide/kaernten_tddl_2009_satanik_disk.wmv> 
Andreas Schäfer:

<mms://apasf .apa.at/nocms-worldwide/kaernten_tddl_2009_schaefer_disk.wmv>

Linda Stift:

<mms://apasf.apa.at/nocms-worldwide/kaernten_tddl_2009_stift_disk.wmv>

Philipp Weiss:

<mms://apasf .apa.at/nocms-worldwide/kaernten_tddl_2009_weiss_disk.wmv>

Andrea Winkler:

<mms://apasf .apa.at/nocms-worldwide/kaernten_tddl_2009_winkler_disk.wmv> 


\section{Forschungsliteratur}

Allkemper, Alo; Eke, Otto: Literaturwissenschaft. Unveränderter Nachdruck der 2. Auflage. Paderborn: Fink 2007.

Amann, Klaus: Der Ingeborg-Bachmann-Preis. Notizen eines Jurors. In: Wendelin SchmidtDengler/Nicole Katja Streitler (Hg.): Literaturkritik. Theorie und Praxis. [nützliche Handreichungen Zur österreichischen Gegenwartsliteratur; Entfesselt - Literatur - Gefesselt]. Innsbruck, Wien: Studien-Verl., 1999. S. 151-172.

Andreotti, Mario: Die Struktur der modernen Literatur. 4. Auflage. Bern: Haupt 2009.

Anz, Thomas: Literaturkritik und Rezensionskultur in Deutschland. In: Gabriele Rippl/ Simone Winko (Hg.): Handbuch Kanon und Wertung: Theorien, Instanzen, Geschichte. Stuttgart: Metzler 2013. S. 146-152.

Anz, Thomas: Theorien und Analysen zur Literaturkritik und zur Wertung. In: Thomas Anz/Rainer Baasner (Hg.): Literaturkritik. Geschichte - Theorie - Praxis. 4. Auflage. München: Beck 2007. S. 194-219.

Anz, Thomas: Spannung: In: Reallexikon der deutschen Literaturwissenschaft. Band 3. Hg. Jan-Dirk Müller. Berlin, New York: de Gruyter 2003. S. 464-467.

Anz, Thomas: Literatur und Lust. Glück und Unglück beim Lesen. München: dtv 2002.

Anz, Thomas: Theorien und Analysen zur Literaturkritik und zur Wertung. In: Thomas Anz/Rainer Baasner (Hg.): Literaturkritik - Anspruch und Wirklichkeit. DFGSymposion 1989. Stuttgart: Metzler 1990. S. 194-219.

Anz, Thomas: Literaturkritisches Argumentationsverhalten. Ansätze zu einer Analyse am Beispiel des Streits um Peter Handke und Botho Strauß. In: Wilfried Barner (Hg.): Literaturkritik - Anspruch und Wirklichkeit. DFG-Symposion 1989. Stuttgart: Metzler 1990. S. 415-430.

Assmann, Jan: Das kulturelle Gedächtnis. Schrift, Erinnerung und politische Identität in frühen Hochkulturen. 5. Auflage. München: Beck 2005.

Assmann, Aleida; Assmann, Jan: Kanon und Zensur. In: Aleida Assmann/Jan Assmann (Hg.): Kanon und Zensur. Archäologie der literarischen Kommunikation II. München: Wilhelm Fink 1987. S. 7-27.

Baisch, Martin; Degen, Andreas; Lüdtke, Jana: Vorbemerkung. In: Martin Baisch/ Andreas Degen/Jana Lüdtke (Hg.): Wie gebannt. Ästhetische Verfahren der affektiven Bindung von Aufmerksamkeit. Freiburg im Breisgau: Rombach 2013. S. 7-20.

Barney, Tom: Literary evaluation and poetic form. Poetic form and creative tension. In: Willie van Peer (Hg.): The quality of literature. Linguistic studies in literary evaluation. Amsterdam u. a.: Benjaminis 2008. S. 71-82.

Barthes, Roland: Der Tod des Autors. In: Fotis Jannidis/Gerhard Lauer/Matías Martínez/ Simone Winko (Hg.). Texte zur Theorie der Autorschaft. Stuttgart: Reclam 2000. S. 185-197.

Beaugrande, Robert de; Dressler, Wolfgang Ulrich: Einführung in die Textlinguistik. Tübingen: Niemeyer 1981.

Beilein, Matthias: Literatursoziologische, politische und geschichtstheoretische Kanonmodelle (mit Hinweisen zur Terminologie). In: Gabriele Rippl/Simone Winko (Hg.): Handbuch Kanon und Wertung: Theorien, Instanzen, Geschichte. Stuttgart: Metzler 2013. S. 66-75. 
Beilein, Matthias; Stockinger, Claudia; Winko, Simone: Einleitung. Kanonbildung und Literaturvermittlung in der Wissensgesellschaft. In: Matthias Beilein/Claudia Stockinger/ Simone Winko (Hg.): Kanonbildung und Literaturvermittlung in der Wissensgesellschaft. Berlin, Boston Mass. 2012. S. 1-18.

Belke, Benno; Leder, Helmut: Annahmen eines Modells der ästhetischen Erfahrung aus kognitionspsychologischer Perspektive. In: Sonderforschungsbereich 626 (Hrsg.): Ästhetische Erfahrung: Gegenstände, Konzepte, Geschichtlichkeit. < http://edocs.fu-berlin.de/ docs/servlets/MCRFileNodeServlet/FUDOCS_derivate_000000002246/belke_leder. pdf $>$. Berlin 2006. (Zugriff 3.2.2017).

Berlemann, Dominic: Das soziale Gedächtnis und der Nebencode des Literatursystems am Beispiel von Gert Ledigs Luftkriegsroman Vergeltung. In: Matthias Beilein/Claudia Stockinger/Simone Winko (Hg.): Kanon, Wertung und Vermittlung. Literatur in der Wissensgesellschaft. Berlin, Boston Mass.: de Gruyter 2012. S. 77-92.

Bilsky, Wolfgang: Werte. In: Handbuch der Allgemeinen Psychologie - Motivation und Emotion. Hg. Veronika Brandstätter/Jürgen H. Otto. Göttingen u. a.: Hogrefe 2009. S. 46-51.

Blatnik, Meike: Literaturkritik heute. In: Norbert Miller/Dieter Stolz (Hg.): Positionen der Literaturkritik. Köln: SH Verlag 2002. S. 25-38.

Bloom, Harald: The Western Canon. The books and school of the ages. New York u.a.: Harcourt Brace 1994.

Böhler, Michael: „Cross the Border - Close the Gap!”. Die Dekanonisierung der Elitekultur in der Postmoderne und die Rekanonisierung des Amerika-Mythos. Zur Kanondiskussion in den USA. In: Renate von Heydebrand (Hg.): Kanon - Macht - Kultur. Theoretische, historische und soziale Aspekte ästhetischer Kanonbildungen; DFG-Symposion 1996. Stuttgart: Metzler 1998. S. 483-503.

Bortolussi, Marisa; Dixon, Peter; Mullins, Blaine: Literariness and the Process of Evaluation. In: Jan Auracher/Willie van Peer (Hg.): New Beginnings in Literary Studies. Newcastle: Cambridge Scholars Publ. 2008. S. 407-422.

Bourdieu, Pierre: Die Regeln der Kunst. Genese und Struktur des literarischen Feldes. Frankfurt am Main: Suhrkamp 2001.

Brinker, Klaus; Sager, Sven F.: Linguistische Gesprächsanalyse. Eine Einführung. 3. erweiterte und ergänzte Auflage. Berlin: Erich Schmidt 2001.

Buck, Sabine: Philosophische Wertungstheorien. In: Gabriele Rippl/Simone Winko (Hg.): Handbuch Kanon und Wertung: Theorien, Instanzen, Geschichte. Stuttgart: Metzler 2013. S. 6-11.

Buck, Sabine. Literatur als moralfreier Raum. Zur zeitgenössischen Wertungspraxis deutschsprachiger Literaturkritik. Paderborn: Mentis 2011.

Christmann, Ursula; Groeben, Norbert: Psychologie des Lesens. In: Bodo Franzmann/Klaus Hasemann/Dietrich Löffler/Erich Schön (Hg.): Handbuch Lesen. München: Saur 1999. S. 145-223.

Christmann, Ursula; Schreier, Margit: Kognitionspsychologie der Textverarbeitung und Konsequenzen für die Bedeutungskonstitution literarischer Texte. In: Fotis Jannidis/Gerhardt Lauer/Matías Martínez/Simone Winko (Hg.): Regeln der Bedeutung. Zur Theorie der Bedeutung literarischer Texte. Berlin, Boston: de Gruyter 2003. S. 246-285. 
Csikszentmihalyi, Myhalyi: Flow: das Geheimnis des Glücks. 14. Auflage. Stuttgart: Klett Cotta 2008.

Cupchik, Gerald C.: Emotions in aesthetics. Reacitve and reflective models. Poetics 23 (1994). S. 177-188.

Dahnke, Michael: »Wer konkurriert womit worum?«. Ein neues Literaturpreis-Modell. $<$ https://ediss.uni-goettingen.de/bitstream/handle/11858/00-1735-0000-0028-877C-D /Dahnke_Wer-konkurriert-womit-worum_1-neues-Literaturpreis-Modell.pdf?sequence $=9>$ Göttingen 2016. (Zugriff: 8.12.2016).

Deppermann, Arnulf: Gespräche analysieren. Eine Einführung. 4. Auflage. Wiesbaden: VS Verlag für Sozialwissenschaften 2008.

Dresing, Thorsten; Pehl, Thorsten: Praxisbuch Interview, Transkription \& Analyse. Anleitungen und Regelsysteme für qualitativ Forschende. 5. Auflage. Marburg 2013. < http: //www.audiotranskription.de/download/praxisbuch_transkription.pdf?q=PraxisbuchTranskription.pdf $>$. (Zugriff 8.12.2016).

Dücker, Burkhard: Literaturpreise und -wettbewerbe im deutsch- und englischsprachigen Raum. In: Gabriele Rippl/Simone Winko (Hg.): Handbuch Kanon und Wertung: Theorien, Instanzen, Geschichte. Stuttgart: Metzler 2013. S. 215-220.

Dücker, Burkhard: Literaturpreisverleihungen. Von der ritualisierten Ehrung zur Literaturgeschichte. In: Burkhard Dücker/Verena Neumann (Hg.): Literaturpreise. Register mit einer Einführung. Literaturpreise als literaturgeschichtlicher Forschungsgegenstand. Forum Ritualdynamik 12 (2005). S. 4-30. <https://journals.ub.uni-heidelberg.de/ index.php/ritualdynamik/article/view/354/338> (Zugriff 26.9.2016).

Duden online: Wert. <http://www.duden.de/rechtschreibung/Wert>. (Zugriff 4.7.2016).

Eagleton, Terry: Einführung in die Literaturtheorie. 4. erweiterte und aktualisierte Auflage. Stuttgart: Metzler 1997.

Eco, Umberto: Das offene Kunstwerk. Frankfurt am Main: Suhrkamp 1990.

Eder, Jens; Jannidis, Fotis; Schneider, Ralf: Characters in Fictional Worlds. An Introduction. In: Jens Eder/Fotis Jannidis/Ralf Schneider (Hg.): Characters in Fictional Worlds. Understanding Imaginary Beings in Literature, Film, and Other Media. Berlin, Boston: de Gruyter 2010. S. 3-66.

Eibl, Karl: Fiktionalität - bioanthropologisch. In: Gerhard Lauer/Fotis Jannidis/Simone Winko (Hg.): Grenzen der Literatur. Zu Begriff und Phänomen des Literarischen. Berlin, Boston: de Gruyter 2009. S. 267-283.

Emrich, Wilhelm: Zum Problem der literarischen Wertung. In: Peter Gebhardt (Hg.): Literaturkritik und literarische Wertung. Darmstadt: Wissenschaftliche Buchgesellschaft 1980. S. 188-204.

Engel, Manfred: Kanon - pragmatisch. Mit einem Exkurs zur Literaturwissenschaft als moralische Anstalt. In: Nicholas Saul/Ricarda Schmidt: Literarische Wertung und Kanonbildung. Würzburg: Königshausen \& Neumann 2007. S. 23-33.

Erhardt, Walter: Kanonisierungsbedarf und Kanonisierung in der deutschen Literaturwissenschaft (1945-1995). In: Renate von Heydebrand (Hg): Kanon - Macht - Kultur. Theoretische, historische und soziale Aspekte ästhetischer Kanonbildungen; DFGSymposion 1996. Stuttgart: Metzler 1998. S. 97-121.

Ernst, Thomas: Wer hat Angst vor Goethes PageRank? Bewertungsprozesse von Literatur und Aufmerksamkeitsökonomien im Internet. In: Matthias Beilein/Claudia Stockinger/ Simone Winko (Hg.): Kanonbildung und Literaturvermittlung in der Wissensgesellschaft. Berlin, Boston Mass. 2012. S. 306-319. 
FAZ.NET: „Ein ordentliches Metaphernschneegestöber“. <http://www.faz.net/aktuell/ feuilleton/bachmannpreis-ein-ordentliches-metaphernschneegestoeber-1332390.html > . 26.6.2006. (Zugriff 9.11.2016)

Fiehler, Reinhard: Eigenschaften gesprochener Sprache. Tübingen: Narr 2004.

Fish, Stanley: Is there a text in this class? In: Stanley Fish (Hg.): Is there a text in this class? Cambridge Mass. u. a.: Harvard University Press 1980. S. 303-321.

Fix, Ulla: Grammatik des Wortes. Semantik des Textes. Freiräume und Grenzen für die Herstellung von Sinn? In: Fotis Jannidis/Gerhardt Lauer/Matías Martínez/Simone Winko (Hg.): Regeln der Bedeutung. Zur Theorie der Bedeutung literarischer Texte. Berlin, Boston: de Gruyter 2003. S. 80-103.

Freise, Matthias: Literaturwissenschaftliche Kanontheorien und Modelle der Kanonbildung. In: Gabriele Rippl/Simone Winko (Hg.): Handbuch Kanon und Wertung: Theorien, Instanzen, Geschichte. Stuttgart: Metzler 2013. S. 50-58.

Fricke, Harald: Norm und Abweichung. Eine Philosophie der Literatur. München: Beck 1981.

Fricke, Harald: How scientific can literary evaluation be? Arguments and Experiments. In: Willie van Peer (Hg.): The quality of literature. Linguistic studies in literary evaluation. Amsterdam u. a.: Benjaminis 2008. S. 191-208.

Fricke, Harald; Peer, Willie van: How Scientific Can Literary Evaluation Be? Arguments and Experiments. In: Rüdiger Zymner (Hg.): Allgemeine Literaturwissenschaft. Grundfragen einer besonderen Disziplin. Wuppertal: Wuppertaler Schriften zur Allgemeinen Literaturwissenschaft 1999. S. 140-153.

Foucault, Michel: Was ist ein Autor? In: Fotis Jannidis/Gerhard Lauer/Matias Martinez/Simone Winko (Hg.): Texte zur Theorie der Autorschaft. Stuttgart: Reclam 2000. S. 198-233.

Gates, Louis L.: Canon Confidential. A Sam Slade Caper. In: Louis L. Gates (Hg.): Loose Canons. Notes on the Culture Wars. New York u. a.: Oxford University Press 1993. S. 3-16.

Gelfert, Hans-Dieter: Was ist gute Literatur? Wie man gute Bücher von schlechten unterscheidet. 2. überarbeitete Auflage. München: Beck 2006.

Genz, Julia: Diskurse der Wertung. Banalität, Trivialität und Kitsch. München: Fink 2011.

Gerrig, Richard J.; Bernardo, Allan B.I.: Readers as problem-solvers in the experience of suspense. Poetics 22 (1994). S. 459-472.

Gertken, Jan; Köppe, Tilmann: Fiktionalität. In: Gerhard Lauer/Fotis Jannidis/Simone Winko (Hg.): Grenzen der Literatur. Zu Begriff und Phänomen des Literarischen. Berlin, Boston: de Gruyter 2009. S. 228-266.

Gibson, Eleanor J.; Levin, Harry: Die Psychologie des Lesens. Frankfurt am Main: Fischer Taschenbuch 1989.

Graf, Werner: Der Sinn des Lesens. Modi der literarischen Rezeptionskompetenz. Münster: Lit 2004.

Greiner, Ulrich: Ulrich Greiners Leseverführer. Eine Gebrauchsanweisung zum Lesen schöner Literatur. München: dtv 2005.

Grice, Paul: Logic and Conversation. In: Paul Grice: Studies in the Way of Words. Cambridge Mass.: Harvard University Press 1991. S.1-144. 
Groeben, Norbert; Vorderer, Peter: Leserpsychologie. Textverständnis - Textverständlichkeit. Münster: Aschendorf 1982.

Grube, Christoph: Warum werden Autoren vergessen? Mechanismen literarischer Kanonisierung am Beispiel von Paul Heyse und Wilhelm Raabe. Bielefeld: transcript 2014.

Grübel, Rainer; Grüttemeier, Ralf; Lethen, Helmut: Orientierung Literaturwissenschaft. Was sie kann, was sie will. Reinbek bei Hamburg: Rowohlt 2001.

Guillory, John: Cultural Capital. The problem of literary canon formation. Chicago: University of Chicago Press 1995.

Hakemulder, Jèmeljan: Travel Experiences. A typology of transportation and other absorption states in relation to types of aesthetic responses. In: Martin Baisch (Hg.): Wie gebannt. Ästhetische Verfahren der affektiven Bindung von Aufmerksamkeit. Freiburg im Breisgau: Rombach 2013. S. 159-178.

Hassan, Salah D.: Canons after „Postcolonial Studies“. In: Pedagogy: Critical Approaches to Teaching Literature, Language, Composition, and Culture. 1 (2001). S. 297-304.

Haus für Poesie: Statuten des open mike. <http://www.haus-fuer-poesie.org/de/openmike/der-open-mike/die-statuten/> (Zugriff 26.9.2016.).

Heydebrand, Renate von: Kanon Macht Kultur - Versuch einer Zusammenfassung. In: Renate von Heydebrand (Hg.): Kanon - Macht - Kultur. Theoretische, historische und soziale Aspekte ästhetischer Kanonbildungen. DFG-Symposion 1996. Stuttgart: Metzler 1998. S. 612-626.

Heydebrand, Renate von; Winko, Simone: Einführung in die Wertung von Literatur. Systematik - Geschichte - Legitimation. Paderborn: Schöningh 1996.

Heydebrand, Renate von; Winko, Simone: The qualities of literatures. A concept of literary evaluation in pluralistic societies. In: Willie van Peer (Hg.): The Quality of Literature. Linguistic studies in literary evaluation. Amsterdam u. a.: Benjaminis 2008. S. 223-239.

Hillebrandt, Claudia: Das emotionale Wirkungspotenzial von Erzähltexten. Mit Fallstudien zu Kafka, Perutz und Werfel. Berlin: Akademie Verlag 2011.

Hoffstaedter, Petra: Poetizität aus der Sicht des Lesers: Eine empirische Untersuchung der Rolle von Text-, Leser- und Kontexteigenschaften bei der poetischen Verarbeitung von Texten. Hamburg: Buske 1986.

Holt, Nadine van; Groeben, Norbert: Das Konzept des Foregrounding in der modernen Textverarbeitungspsychologie. In: Journal für Psychologie 13 (2005). S. 311-332.

Irsigler, Ingo; Jürgensen, Christoph; Langer, Daniela: Einleitung: Spannung in der Literaturwissenschaft. In: Ingo Irsigler/Christoph Jürgensen/Daniela Langer (Hg.): Zwischen Text und Leser. Studien zu Begriff und Geschichte der Spannung. München: edition text + kritik 2008. S. 7-11.

Iser, Wolfgang: Der Akt des Lesens. Theorie ästhetischer Wirkung. München: Fink 1994.

Janich, Nina: Werbesprache. Ein Arbeitsbuch. 5. vollständig überarbeitete und erweitert Auflage. Tübingen: Narr 2010.

Jannidis, Fotis; Lauer, Gerhard; Winko, Simone: Radikal historisiert. Für einen pragmatischen Literaturbegriff. In: Fotis Jannidis/Gerhard Lauer/Simone Winko (Hg.): Grenzen der Literatur. Zu Begriff und Phänomen des Literarischen. Berlin, New York: de Gruyter 2009. S. 3-40.

Jannidis, Fotis; Lauer, Gerhard; Martínez, Matías; Winko, Simone: Der Bedeutungsbegriff in der Literaturwissenschaft. Eine historische und systematische Skizze. In: Fotis 
Jannidis/Gerhardt Lauer/Matías Martínez/Simone Winko (Hg.): Regeln der Bedeutung. Zur Theorie der Bedeutung literarischer Texte. Berlin, Boston: de Gruyter 2003. S. 3-32.

Jauß, Hans Robert: Ästhetische Erfahrung und literarische Hermeneutik. Frankfurt am Main: Suhrkamp 1982.

Kampmann, Elisabeth: Medien im deutschsprachigen Raum. In: Gabriele Rippl/Simone Winko (Hg.): Handbuch Kanon und Wertung: Theorien, Instanzen, Geschichte. Stuttgart: Metzler 2013. S. 134-139.

Kienecker, Michael: Prinzipien literarischer Wertung. Sprachanalytische und historische Untersuchungen. Göttingen: Vandenhoeck \& Ruprecht 1989.

Kluckhohn, C. K.: Values and Value Orientations in the Theory of Action. In: Talcott Parsons/Edward. A. Shils (Hg.): Toward a General Theory of Action. Cambridge Mass.: Harvard University Press 1951. S. 388-433.

Kneepken, E.W.E.M. Zwaan, Rolf A.: Emotions and Literary Text Comprehension. In: Poetics 23 (1994). S. 125-138.

Köhler, Michaela: Wertung in der Literaturkritik. Bewertungskriterien und sprachliche Ausdrucksmöglichkeiten des Bewertens in journalistischen Rezensionen zeitgenössischer Literatur. Würzburg 2000.

Koppenfels, Martin von; Zumbusch, Cornelia: Einleitung. In: Martin von Koppenfels, Cornelia Zumbusch (Hg.): Handbuch Literatur \& Emotion. Berlin 2016. S. 1-36.

Korte, Hermann: K wie Kanon und Kultur. Kleines Kanonglossar in 25 Stichwörtern. In: Heinz Ludwig Arnold (Hg.): Literarische Kanonbildung. München: Edition Text + Kritik 2002. S. 25-38.

Langer, Daniela: Spannung/en. Spannungsformen in erzählenden Texten und Möglichkeiten ihrer Analyse. In: Ingo Irsigler/Christoph Jürgensen/ Daniela Langer (Hg.): Zwischen Text und Leser. Studien zum Begriff und Geschichte der Spannung. München: edition text + kritik 2008. S. 12-32.

Leinen, Angela: Wie man den Bachmannpreis gewinnt. Gebrauchsanweisung zum Lesen und Schreiben. München: Wilhelm Heyne Verlag 2010.

Leseglück. Eine vergessene Erfahrung? Hg. Alfred Bellebaum/Ludwig Muth. Opladen: Westdeutscher Verlag 1996.

Lerner, Laurence: Poetic value. Poetical value. In: Willie van Peer (Hg.): The quality of literature. Linguistic studies in literary evaluation. Amsterdam u. a.: Benjaminis 2008. S. 83-94.

Limpinsel, Mirco: Angemessenheit und Unangemessenheit. Studien zu einem hermeneutischen Topos. Berlin: Ripperger \& Kremers 2013.

Literarischer März: Wettbewerb. 2014.< https://www.literarischer-maerz.de/wettbewerb/> (Zugriff 26.9.2016).

Madsen, Deborah L.: Beyond the Commonwealth: Post-Colonialism and American Literature. In: Deborah L. Madsen (Hg.). Post-Colonial Literatures. Expanding the Canon. London u. a.: Pluto Press 1999. S. 1-13.

Matlange, Karen; Vorderer, Peter: Fiktionale Texte: evasiv-affirmative Textangebote und ihre Gratifikationseffekte. In: Vorderer, Peter/Groeben, Norbert (Hg.): Textanalyse als Kognitionskritik? Möglichkeiten und Grenzen ideologiekritischer Inhaltsanalyse. Tübingen : Narr, 1987. S. 194-225. 
Martínez, Matías; Scheffel, Michael: Einführung in die Erzähltheorie. 9. erweiterte und aktualisierte Auflage. München: Beck 2012.

Marx, John: Postcolonial literature and the Western literary canon. In: Neil Lazarus (Hg.): The Cambridge Companion to Postcolonial Literary Studies. Cambridge u. a.: Cambridge University Press 2004. S. 83-96.

Mayring, Philipp: Einführung in die Qualitative Sozialforschung. Weinheim: Beltz 2002.

Mellmann, Katja: Empirische Emotionsforschung. In: Martin von Koppenfels/Cornelia Zumbusch (Hg.): Handbuch Literatur \& Emotion. Berlin 2016. S. 158-175.

Mellmann, Katja: Objects of „Empathy”. Characters (and Other Such Things) as PsychoPoetic Effects. In: Jens Eder/Fotis Jannidis/Ralf Schneider (Hg.): Characters in Fictional Worlds. Understanding Imaginary Beings in Literature, Film, and Other Media. Berlin, Boston: de Gruyter 2010. S. 416-441.

Mellmann, Katja: Biologische Ansätze zum Verhältnis von Literatur und Emotionen. In: Journal of Literary Theory 1 (2008). S. 357-375.

Miall, David S.: Feeling from the Perspective of the Empirical Study of Literature. In: Journal of Literary Theory 2 (2007). S. 377-393.

Miall, David S.; Kuiken, Don: The form of reading: Empirical studies of literariness. In: Poetics 25 (1998). S. 327-341.

Moser, Doris: Der Ingeborg-Bachmann-Preis: Börse, Show, Event. Wien u. a.: Böhlau 2004.

Müller-Seidel, Walter: Probleme der literarischen Wertung, Über die Wissenschaftlichkeit eines unwissenschaftlichen Themas. Stuttgart: Metzler 1965.

Muth, Ludwig: Leseglück als Flow Erlebnis. Ein Deutungsversuch. In: Alfred Bellebaum/ Ludwig Muth (Hg.): Leseglück. Eine vergessene Erfahrung?. Opladen: Westdeutscher Verlag 1996. S. 57-81.

Nell, Victor: Lost in a Book. The Psychology of Reading for Pleasure. New Haven, Conn. u. a.: Yale University Press 1988.

Neuhaus, Stefan: Revision des Kanons. Göttingen: Vandenhoeck und Ruprecht 2002.

Neuhaus, Stefan: Literaturkritik - Eine Einführung. Göttingen: Vandenhoeck und Ruprecht 2004.

Oatley, Keith: A taxonomy of the emotions of literary response and a theory of identification in fictional narrative. In: Poetics 23 (1994). S. 53-74.

ORF: Ausschreibung. 17.12.2015. < http://bachmannpreis.orf.at/stories/2746380/> (Zugriff 27.9.2016).

ORF: Richtlinien für die Vergabe des Ingeborg-Bachmann-Preises 2009.

$<$ http://archiv.bachmannpreis.orf.at/bachmannpreis.eu/de/bachmannpreis/65/>. (Zugriff 27.9.2016).

Olsen, Stein Haugom: Why Hugh Maccoll is not, and will never be, part of any literary canon. In: Willie van Peer (Hg.): The quality of literature. Linguistic studies in literary evaluation. Amsterdam u. a.: Benjaminis 2008. S. 31-52.

Peer, Willie van: The evaluation of literary texts. A new perspective. In: Willie van Peer (Hg.): The quality of literature. Linguistic studies in literary evaluation. Amsterdam u. a.: Benjaminis 2008. S. 1-16.

Pfohlbaum, Oliver: Literaturkritik in der Bundesrepublik. In: Thomas Anz/Rainer Baasner (Hg.): Literaturkritik. Geschichte - Theorie - Praxis. München: Beck 2007. S. 160-193. 
Pette, Corinna: Psychologie des Romanlesens. Lesestrategien zur subjektiven Aneignung eines literarischen Textes. Weinheim, München: Juventa 2001.

Porombka, Stephan: Weg von der Substanz. Hin zu den Substanzen Literaturkritik 2.0ff. In: Matthias Beilein/Claudia Stockinger/Simone Winko (Hg.): Kanonbildung und Literaturvermittlung in der Wissensgesellschaft. Berlin, Boston Mass. 2012. S. 293-303.

Reich-Ranicki, Marcel: Die Kanondebatte. In: Marcel Reich-Ranicki (Hg.): Der Kanon. Begleitband. Erzählungen und ihre Autoren. Mit einer Einführung und Kommentaren von Marcel Reich-Ranicki. Frankfurt am Main, Leipzig: Insel 2003. S. 13-15.

Rippl, Gabriele; Winko, Simone. Einleitung. In: Gabriele Rippl/Simone Winko (Hg.): Handbuch Kanon und Wertung: Theorien, Instanzen, Geschichte. Stuttgart: Metzler 2013. S. 1-5.

Roth, Kersten Sven; Spiegel, Carmen: Umrisse einer Angewandten Diskurslinguistik. In: Kersten Sven Roth/Carmen Spiegel (Hg.): Angewandte Diskurslinguistik. Felder, Probleme, Perspektiven. Berlin, Boston: de Gruyter 2013. S. 7-17.

Rückkehr des Autors. Zur Erneuerung eines umstrittenen Begriffs. Fotis Jannidis/Gerhard Lauer/Matías Martínez/Simone Winko (Hg.): Tübingen: Niemeyer 1999.

Ryle, Gilbert: Können und Wissen. In: Gilbert Ryle: Der Begriff des Geistes. Stuttgart: Reclam 1992. S. 26-77.

Schärf, Christian: Duden: Spannend Schreiben. Mannheim, Zürich: Dudenverlag 2013.

Schatzki, Theodore R: Social Practices. A Wittgensteinian Approach to Human Activity and the Social. Cambridge u. a.: Cambridge University Press 1996.

Schildknecht, Christiane: Form. In: Reallexikon der deutschen Literaturwissenschaft. Band 1. 3. neubearbeitete Auflage. Hg. Klaus Weimar. Berlin, New York: de Gruyter 1997. S. $612-615$.

Schmidt, Ricarda: Der literarische Kanon: Ein Organ des Willens zur Macht oder des Gewinns an Kompetenzen? In: Ricarda Schmidt/Nicholas Saul (Hg.): Literarische Wertung und Kanonbildung. Würzburg: Königshausen \& Neumann 2007. S. 9-21.

Schmidt, S. J.: Grundriss der Empirischen Literaturwissenschaft. Der gesellschaftliche Handlungsbereich Literatur. Braunschweig 1980.

Schmidt, S. J.: Literaturkritik als spezielle Form der Teilnahme am LITERATUR-System. In: Schmidt, S. J.: Grundriss der Empirischen Literaturwissenschaft Band 2. Zur Rekonstruktion literaturwissenschaftlicher Fragestellungen in einer Empirischen Theorie der Literatur. Braunschweig, Wiesbanden: Vieweg 1982. S. 151-182.

Schneider, Jost: Die Sozialgeschichte des Lesens und der Begriff „Literatur“. In: Gerhard Lauer/Fotis Jannidis/Simone Winko (Hg.): Grenzen der Literatur. Zu Begriff und Phänomen des Literarischen. Berlin, Boston: de Gruyter 2009. S. 434-454.

Schneider, Jost: Literatur und Text. In: Thomas Anz (Hg.). Handbuch Literaturwissenschaft. 1, Gegenstände und Grundbegriffe. Stuttgart: Metzler 2007. S. 1-24.

Schneider, Ralf: Grundriß zur kognitiven Theorie der Figurenrezeption am Beispiel des viktorianischen Romans. Tübingen: Stauffenberg 2000.

Schober, Rita: Abbild, Sinnbild, Wertung. Berlin: Aufbau 1982.

Schulz, Gerhard: Die Erlebnisgesellschaft. Kultursoziologie der Gegenwart. 3. durchgesehene Auflage. Frankfurt am Main: Campus Verlag 1993.

Schwarz-Friesel, Monika: Kohärenz versus Textsinn: Didaktische Facetten einer linguistischen Theorie der textuellen Kontinuität. In: Maximilian Scherner/Arne Ziegler (Hg.): 
Angewandte Textlinguistik. Perspektiven für den Deutsch- und Fremdsprachenunterricht. Tübingen: Narr 2006. S. 63-75.

Specht, Benjamin: Polyvalenz - Autonomieästhetik - Kanon. Überlegungen zum Zusammenhang von Textstruktur und historischer Ästhetik bei der Herausbildung des deutschsprachigen Literaturkanons. In: Matthias Beilein/Claudia Stockinger/Simone Winko (Hg.): Kanonbildung und Literaturvermittlung in der Wissensgesellschaft. Berlin, Boston Mass. 2012. S. 19-39.

Spitzmüller, Jürgen; Warnke, Ingo H.: Diskurs-Linguistik. Eine Einführung in Theorien und Methoden der transtextuellen Sprachanalyse. Berlin, New York: de Gruyter 2011.

Staiger, Emil: Die Kunst der Interpretation. München: dtv 1971.

Stanzel, Franz K.: Theorie des Erzählens. 8. Auflage. Göttingen: Vandenhoeck \& Ruprecht 2008.

Steinhauer, Lydia: Involviertes Lesen. Eine empirische Studie zum Begriff und seiner Wechselwirkung mit literarästhetischer Urteilskompetenz. Freiburg im Breisgau: Fillibach 2010 .

Strauss, Anselm; Corbin, Juliet M.: Grounded Theory. Grundlagen qualitativer Sozialforschung. Weinheim: Beltz, PsychologieVerlagsUnion 1996.

Strauss, Anselm; Glaser, Barney G.: Grounded Theory. Strategien qualitativer Forschung. 3. Auflage. Bern: Huber 2010.

Texte zur Theorie der Autorschaft. Fotis Jannidis/Gerhard Lauer/Matías Martínez/Simone Winko (Hg.). Stuttgart: Reclam 2000.

Titzmann, Michael: Struktur. In: Reallexikon der deutschen Literaturwissenschaft. Band 3. Hg. Jan-Dirk Müller. Berlin, New York: de Gruyter 2003. S. 532-533.

Tooby, John; Cosmides, Leda: Does Beauty Build Adapted Minds? Toward an evolutionary Theory of Aesthetics, Fiction, and the Arts. SubStance. A Review of the Theory and Literary Criticism 30/1\&2 (2001). S. 6-27.

Vogel, Anke: Der Buchmarkt als Kommunikationsraum. Eine kritische Analyse aus medienwissenschaftlicher Perspektive. Wiesbaden: VS Verlag für Sozialwissenschaften 2011.

Vorderer, Peter; Klimmt, Christoph; Ritterfeld, Ute: Enjoyment. At the Heart of Media Entertainment. In: Communication Theory 14 (2004). S. 388-408.

Wegmann, Thomas: Warentest und Selbstmanagement. Literaturkritik im Web 2.0 als Teil nachbürgerlicher Wissens- und Beurteilungskulturen. In: Matthias Beilein/Claudia Stockinger/Simone Winko (Hg.): Kanonbildung und Literaturvermittlung in der Wissensgesellschaft. Berlin, Boston Mass. 2012. S. 279-291.

Weimar, Klaus: Diegesis. In: Reallexikon der deutschen Literaturwissenschaft. Band 1. 3. neubearbeitete Auflage. Hg. Klaus Weimar. Berlin, New York: de Gruyter 1997. S. 360-362.

Wengeler, Martin: Topos und Diskurs. Begründung einer argumentationsanalytischen Methode und ihre Anwendung auf den Migrationsdiskurs (1960 - 1985). Tübingen: Niemeyer 2003.

Winko, Simone: Literarische Wertung, In: Metzler Lexikon Literatur. 3. völlig neu bearbeitete Auflage. Hg. Dieter Burdorf/Christoph Fassbender/Burkhard Moennighoff. Stuttgart: Metzler 2007. S. 444-445.

Winko, Simone: Textbewertung. In: Thomas Anz (Hg.). Handbuch Literaturwissenschaft. 2, Methoden und Theorien. Stuttgart: Metzler 2007. S. 233-260. 
Winko, Simone: Literarische Wertung und Kanonbildung. In: Heinz Ludwig Arnold/Heinrich Detering (Hg.): Grundzüge der Literaturwissenschaft. 7. Auflage. München: dtv 2005. S. 585-600.

Winko, Simone: Literatur-Kanon als invisible hand-Phänomen. In: Heinz Ludwig Arnold (Hg.): Literarische Kanonbildung. München: Edition Text + Kritik 2002. S. 9-24.

Winko, Simone: Auf der Suche nach der Weltformel. In: Gerhard Lauer/Fotis Jannidis/Simone Winko (Hg.): Grenzen der Literatur. Zu Begriff und Phänomen des Literarischen. Berlin, Boston: de Gruyter 2009. S. 374-398.

Wittstock, Uwe: Leselust. Wie unterhaltsam ist die neue deutsche Literatur? Ein Essay. München: Luchterhand 1995.

Worthmann, Friederike: Literarische Wertungen. Vorschläge für ein deskriptives Modell. Wiesbaden: DUV 2004.

Worthmann, Friederike: Wie analysiert man literarische Wertungen? In: Gabriele Rippl/ Simone Winko (Hg.): Handbuch Kanon und Wertung: Theorien, Instanzen, Geschichte. Stuttgart: Metzler 2013. S. 397-402.

Wehrli, Max: Wert und Unwert in der Dichtung. In: Peter Gebhardt (Hg.): Literaturkritik und literarische Wertung. Darmstadt: Wissenschaftliche Buchgesellschaft 1980. S. 205-222.

Wikipedia: Ingeborg-Bachmann-Preis. $<$ https://de.wikipedia.org/wiki/Ingeborg-BachmannPreis $>$. (Zugriff 26.9.2016).

Wutz, Herbert: Zur Theorie der literarischen Wertung. In: Peter Gebhardt (Hg.): Literaturkritik und literarische Wertung. Darmstadt: Wissenschaftliche Buchgesellschaft 1980. S. $163-187$

Zyngier, Sonia; Peer, Willie van; Hakemulder, Jèmljan: Complexity and Foregrounding. In the Eye of the Beholder? Poetics Today 28 (2007) S. 653-682.

\section{Primärtexte}

Kern, Björn: Eine halbe Stunde noch. <http://archiv.bachmannpreis.orf.at/bachmannpreisv

2/bachmannpreis/texte/stories/200767/index.html>. 2007. (Zugriff 10.11.2016).

Krupp, Ute-Christine: Köln-Tokio. <http://archiv.bachmannpreis.orf.at//bp_2001/auto ren/krupp_text.htm $>$ 2001. (Zugriff 9.11.2016).

Parei, Inka: [ohne Titel]. <http://archiv.bachmannpreis.orf.at/bp2003/downloads/Parei .pdf >. 2003. (Zugriff 12.11.2016).

Passig, Kathrin: Sie befinden sich hier. <http://archiv.bachmannpreis.orf.at/bachmann preisv2/bachmannpreis/texte/stories/117531/index.html> 2006 (Zugriff 9.11.2016).

Uetz, Christian: Hirnhelle Heroine. <http://archiv.bachmannpreis.orf.at/bp99/fs autoren.html>. 1999. (Zugriff 20.3.2017)

Vogel, Nikolai: Plug in. <http://archiv.bachmannpreis.orf.at/bachmannpreisv2/your.orf.at/ downloads/2005/vogel.pdf $>$. 2005. (Zugriff 15.11.2015).

Vries, Katrin de: Die Lust am Walde. <http://archiv.bachmannpreis.orf.at/bp2003/down loads/De_Vries.pdf $>$. 2003. (Zugriff. 13.11.2016). 
Winkler, Andrea: Aus dem Gras. <http://bachmannpreis.eu/de/texte/1168>. 2009. (Zugriff 11.11.2016).

\section{Creative Writing Anleitungen}

Anderson, Linda: Introduction. In: Linda Anderson (Hg.): Creative Writing. A Workbook with Readings. London u. a.: Routledge 2006. S. 11-14.

Creative Writing Guidebook. Graeme Harper (Hg.). London u. a.: Continnum 2008.

Creative Writing. A Workbook with Readings. Hg. Linda Anderson. London u. a.: Routledge 2006.

Creative Writing. Romane und Kurzgeschichten schreiben. Hg. Alexander Steele/Raymond Carver. Berlin: Autorenhaus 2013.

Ebenbach, David Harris: Plot: Eine Frage des Brennpunkts. In: Alexander Steele/Raymond Carver (Hg.): Creative Writing. Romane und Kurzgeschichten schreiben. Berlin: Autorenhaus 2013. S. 75-106.

Egri, Lajos: Literarisches Schreiben. Starke Figuren entwickeln. Originelle Ideen finden. Die Handlung vorantreiben. Berlin: Autorenhaus 2014.

Englert, Sylvia: So lektorieren Sie Ihre Texte selbst. Verbessern durch überarbeiten. Schritt für Schritt von der Erstfassung zum fertigen Manuskript. Berlin: Autorenhaus 2012.

Gesing, Fritz: Kreativ Schreiben. Handwerk und Techniken des Schreibens. Köln: DuMont 1994.

Knut, Detlef: Gute Geschichten schreiben. Düsseldorf: Edition Oberkassel 2012.

Kreatives Schreiben. Vom leeren Blatt zum fertigen Text. Hg. Anni Bürkl/Daniela Kluge. Gütersloh, München: Brockhaus/Wissenmedia in der InmediaONE-GmbH 2013.

Laue, Mara: Von der Idee zum fertigen Text. Reinheim: Sieben Verlag 2014.

Ortheil, Hanns-Josef: Duden: Schreiben dicht am Leben. Mannheim, Zürich: Dudenverlag 2012 .

Reissenweber, Brandi: Figuren: Charaktere, die Schatten werfen. In: Alexander Steele (Hg.): Creative Writing. Romane und Kurzgeschichten schreiben. Berlin: Autorenhaus 2013. S. 41-74.

Pyerin, Brigitte: Kreatives wissenschaftliches Schreiben. Tipps und Tricks gegen Schreibblockaden. Weinheim, Basel: Beltz Juventa 2014.

Steele, Alexander: Literatur: Das Was, das Wie und das Warum. In: Alexander Steele (Hg.): Creative Writing. Romane und Kurzgeschichten schreiben. Berlin: Autorenhaus 2013. S. 11-40.

Stein, Sol: Über das Schreiben. Berlin: Autorenhaus, 2015. 